

\title{
GÉNERO Y EDUCACIÓN: ESCUELA, EDUCACIÓN NO FORMAL, FAMILIA Y MEDIOS DE COMUNICACIÓN.
}

\author{
Coordinadoras: \\ Laura Álvaro Andaluz \\ Carolina Hamodi Galán
}


No está permitida la reproducción total o parcial de este libro, ni su incorporación a un sistema informático, ni su transmisión en cualquier forma o por cualquier medio, sea este electrónico, mecánico, por fotocopia, por grabación u otros métodos, sin el permiso previo y por escrito del editor. La infracción de los derechos mencionados puede ser constitutiva de delito contra la propiedad intelectual (art. 270 y siguientes del Código Penal).

Diríjase a Cedro (Centro Español de Derechos Reprográficos) si necesita fotocopiar o escanear algún fragmento de esta obra. Puede contactar con Cedro a través de la web www.conlicencia.com o por teléfono en el 917021970/932720407

(C) Copyright by

Los autores

Madrid, 2021

Editorial DYKINSON, S.L. Meléndez Valdés, 61 - 28015 Madrid

Teléfono (+34) 915442846 - (+34) 915442869

e-mail:info@dykinson.com

http://www.dykinson.es

http://www.dykinson.com

Consejo Editorial véase www.dykinson.com/quienessomos

ISBN: 978-84-1377-638-5 


\section{ÍNDICE}

\section{INTRODUCCIÓN}

(Laura Álvaro Andaluz y Carolina Hamodi Galán. 7

1. EDUCACIÓN PARA LA IGUALDAD EN LA EDUCACIÓN INFANTIL Y PRIMARIA................... 9

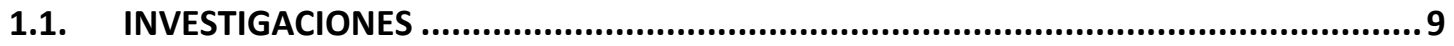

1.1.1. Construcción de Modelos de Género y Sexualidad: la experiencia de niñas y niños de primero básico (Celine Auth Ramírez) 9

1.1.2. Juguetes y estereotipos de género en el alumnado de educación infantil: Un estudio de caso (Javier Callejo Maudes y Ana Pérez Hinojal).

1.1.3. Patios Escolares antes de la Pandemia: Distribución de los espacios y jeraquías de género (Haizea Unda, Nahia Idoiaga y Inge Axpe)...................................... 21

1.1.4. Análisis de las Leyes Educativas Españolas desde una Perspectiva de Género (Paula Pérez Pérez)

1.1.5. Covid-19 ¿Una oportunidad para un uso más equitativo del Patio Escolar? (Haizea Unda, Nahia Idoiaga y Inge Axpe)...

1.1.6. La Brecha Digital de Genero en Educación Primaria y Secundaria en España (Mireia Usart, Carme Grimalt-Álvaro, Vanessa Esteve-González y Mercè Gisbert-Cervera)

1.1.7. Estereotipos en la Imagen de Ciencia y Científico en un Grupo de Niñas y Niños de la Región de Valparaíso-Chile

(Jennifer Venegas-Espinoza)

1.2. EXPERIENCIAS

1.2.1. ¿Puede el arte fomentar la coeducación y la igualdad? Una propuesta basada en el estudio referentes inspiradores y la aplicación del modelo dialógico para fomentar el espíritu crítico y la creatividad en la Educación Primaria (María Ejarque González) .

1.2.2. Mundo Disney y Mito del Amor Romántico: una experiencia con el alumnado del segundo ciclo de educación infantil (Irene Galán Ríos y José Ramón Márquez Díaz)

1.2.3. Acciones en el patio escolar dentro del Plan Coeducativo de Centro del CEIP Federico García Sanchiz (Alzira, Valencia)

(Sandra Molines Borrás y Juan Fernando Lancero Pavía)

2. EDUCACIÓN PARA LA IGUALDAD EN LA EDUCACIÓN SECUNDARIA

2.1. INVESTIGACIONES

2.1.1. El territorio de los silencios: el currículum oculto en los libros de texto del módulo de Formación y Orientación Laboral (María Carmen Alemany Moreno y Helena Aparicio Sanmartín)

2.1.2. Prevención de la Violencia de Género a través de la Educación Física (Carlos Avilés Villarroel, Irene Ramón Otero, Joaquín Piedra de la Cuadra y Elena Ramírez Rico) 
2.1.3. Historia del arte en la LOMCE y la LOMLOE: ¿ hacia una igualdad de género real? ( $D$ a Sandra García-Sinausía y Dra. Ana Valtierra Lacalle) .

2.1.4. Brecha de Género en Matemáticas y Eficacia Escolar en Secundaria (Eider Oregui-González, Ander Azkarate-Morales, Isabel Bartau-Rojas) .76

2.1.5. Modos de ser varón en dos escuelas secundarias. Experiencias de construcción de masculinidades en el partido de La Matanza

(Ezequiel Martín Pannelli)

2.1.6. Memorias escolares de varones gays argentinos: entre acosos, apoyos y amores (Ezequiel Pannelli y Maximiliano Marentes)

2.1.7. Construcción de masculinidades en el espacio escolar: una aproximación a la construcción de masculinidades por parte de estudiantes del primer grado de educación secundaria de un colegio privado de Chimbote - Perú (Samuel Josue Rivero Meza) 92

2.2. EXPERIENCIAS

2.2.1. Análisis de la construcción del género desde la Edad Moderna mediante miniproyectos de Ciencias sociales y Literatura

(Pedro Antonio Amores Bonilla y Laura Victoria Burruezo Hernández) 98

2.2.2. Implantación, Desarrollo y Adaptación Online del Programa de Innovación Educativa por la Igualdad entre Mujeres y Hombres "Educando en Justicia Igualitaria" (Soledad Andrés Gómez)

2.2.3. Salud sexual en jóvenes navarros

(Sofía Blasco Íñiguez y Miren Borja Vitas) 108

2.2.4. "Deportigualízate", una experiencia educativa en educación secundaria (Marina Castro-García y Cristina López-Villar).

2.2.5. Juego coeducativo "Cuidar es otra historia"

(Teresa Pineda Sánchez-Garrido)

3. EDUCACIÓN PARA LA IGUALDAD EN LA EDUCACIÓN TERCIARIA / UNIVERSITARIA. .... 122

3.1. INVESTIGACIONES .

3.1.1. Las trayectorias profesionales de las mujeres científicas: diseño y validación de un cuestionario (María Azcona Sangüesa).

3.1.2. Educación y género: el largo camino de las investigadoras en las ingenierías de Chiapas (Nallely Alonso Gómez, Daniel Hernández Cruz y José Ignacio Rivas Flores).

3.1.3. Un cuerpo que se desborda y (se) afecta

(Eider Chaves Gallastegui y Estibaliz Aberasturi Apraiz) .

3.1.4. Sensibilidad de género en futuros profesionales sanitarios. España y Latinoamérica (M. Teresa Bartual-Figueras, Triny Donoso-Vázquez, Andrés Coco-Prieto, F. Javier Sierra-Martínez, Montserrat Simó-Solsona y Joaquin Turmo-Garuz)

3.1.5. Respetadas y ¿enseñadas? Algunas consideraciones sobre de la perspectiva de género en la Filosofía y la Educación (Vicente de Jesús Hernández Mora y Walter Federico Gadea Aiello) 145 
3.1.6. Los indicios del acoso. Estudio piloto sobre el Acoso Universitario en el Campus María Zambrano de la Universidad de Valladolid

(Sara Fernández Muñoz)... 150

3.1.7. La competencia prosódica de las y los jóvenes bilingües vascos en el relato de un cuento: la importancia del género

(Aitor Iglesias, Naia Eguskiza, Aintzane Etxebarria y Juan Abasolo) 156

3.1.8. Una mirada interseccional sobre el sexismo: buscando sus relaciones con la homofobia internalizada (Miguel Ángel López Sáez)

3.1.9. Análisis de la estructura del Plan de Estudios del grado en Educación Primaria de la Universidad De Huelva respecto a la formación en diversidad afectivosexual (José Ramón Márquez Díaz y Irene Galán Ríos) 164

3.1.10. Motivar la participación en las aulas universitarias desde las pedagogías feministas (Irene Martínez Martín, Carlos Sanz Simón y Ainhoa Resa). 169

3.1.11. La institucionalización de la lucha contra el acoso sexual y la promoción de la igualdad de género en la UACH (Carolina Hamodi Galán, Claudia Contreras Contreras y Belén Andrés Corredor)

3.1.12. Recuperando la memoria de mujeres olvidadas: historia de una Inspectora Soriana, Ma Cruz Gil Febrel (Raquel Vázquez Ramil y Ma Ángeles Guillorme de Miguel) 180

3.1.13. Desarrollo competencias en estudiantes universitarios: el efecto del aprendizaje basado en proyectos y del liderazgo de desarrollo en función del sexo (Andrés Salas Vallina y Manoli Pozo Hidalgo). 185

3.1.14. Sobre violencia de género y crueldad contra los animales: hacia una educación para la paz y la empatían (Angélica Velasco Sesma) 191

3.2. EXPERIENCIAS 196

3.2.1. Los estudiantes de trabajo social frente a la pandemia Covid-19. Resultados de una encuesta desde la perspectiva de género

(María Ángeles Cuadrado Cenzual) 196

3.2.2. Contribuyendo al buen trato, la sexualidad con el SKOLAE

(Elena Bujanda Sainz de Murieta) 200

3.2.3. Un escape para ellas: las que aportaron a los derechos de la infancia. (Elena Bujanda Sáinz de Murieta y María Ángeles Sanmartín Gracia) 206

3.2.4. Satisfacción del alumnado con la metodología evaluativa en la asignatura de Alteraciones de la Salud III del Grado de Enfermería de Valladolid en base al género (Cárdaba García Rosa María).

3.2.5. Movimientos feministas y teoría jurídica feminista: Algunas propuestas innovadoras para el ámbito docente (Fernando Centenera Sánchez-Seco)

3.2.6. Visibilización de la aportación de las mujeres al campo de la psicología mediante una metodología flipped learning (Cristina Díaz Berciano, María Almudena Cabezas González y Susana Barón Vioque). 
3.2.7. Experiencia educativa para estudiantes de enfermería de pregrado en la Patagonia chilena: Género, diversidad y disidencias sexuales en salud. Consideraciones para la gestión del cuidado.

(Renato Gómez Bascuñán y Dave Villafaña Sierra).

3.2.8. Géneros, Educación y Narrativa Transmedia: deconstruyendo mitos y estereotipos; construyendo relaciones afectivas en igualdad en la universidad (Virginia Martagón Vázquez, Piedad Calvo León, Carmen Vaquero Cañestro, María Jesús Márquez García, Laura Triviño Cabrera y Analía Leite Méndez .. 231

3.2.9. La perspectiva feminista en historia de la ciencia y la tecnología (Maria Medina-Vicent).

3.2.10. Campaña \#ViolenciaEs en la Ibero Ciudad de México: apelar a la experiencia (Alejandra Azucena Meza Uscanga).

3.2.11. Estudio piloto sobre el uso de agentes físicos para reducir el dolor en la dismenorrea primaria, en estudiantes da Universidade da Coruña (Zeltia Naia Entonado, Alejandro Quintela del Río, Sandra Martínez Bustelo, Antía Pérez Caramés, Mónica errín Pereira y Olalla Bello Rodríguez) 247

3.2.12. Evitemos la discriminación machista en el trabajo de campo (Zaida Ortega Diago, Laura Contreras Peinado, Ana López Ballesteros, Marga L. Rivas)

3.2.13. Contalles $i$ diàlegs, el storytelling y la tertulia para cuestionar la representación de las mujeres y otros colectivos sociales en los medios de comunicación (Laia Pitarch Centelles, Lucía García Pitarch, Begoña Marqués Ribés y María Tena Moya)

3.2.14. "Rompendo regras": proyecto curricular e interdisciplinar para una alfabetización menstrual crítica (Mar Rodríguez Romero, Alicia Martínez Rodríguez, Ma José Mosquera González, Neves Arza Arza y Carmen Rodríguez Rodríguez)

4. EDUCACIÓN PARA LA IGUALDAD EN LA EDUCACIÓN NO FORMAL (OCIO Y TIEMPO LIBRE, ETC.). 270

4.1. INVESTIGACIONES 270

4.1.1. "Museo y género: el rol de la mujer en la antigüedad. Propuesta de un nuevo recorrido de visita entre el Museo Nazionale de Atestino y el área arqueológica de la ciudad de Este."

(Carolina Ahumada Pizarro)

4.1.2. La educación en los museos madrileños desde la perspectiva de género: retos y propuestas (investigación)

(Irene Barreno García)....

4.2. EXPERIENCIAS

4.2.1. Igualdad de Género y Tiempo Libre en el Campus Hondarribia (Ander Azkarate-Morales, Estibaliz Santamaría-Marcian)

4.2.2. Campaña TOCA IGUALDAD: Coeducar para prevenir las violencias machistas (Clara Urbano Molina). 286 
4.2.3. La perspectiva coeducativa en la intervención con menores infractores (Julia Martínez Del Valle).

4.2.4. Memoria e investigación de la educación en relación: Igualdad, Justicia y Cultura de Paz en las relaciones interpersonales y con la naturaleza. El poder de la imagen (Concha Gaudó Gaudó, Carmen Durán Martínez).

4.2.5. En los caminos del poder: el caso de las mujeres

(Julita Morales Arencibia)

4.2.6. La desigualdad es real

(Meritxell Laborda Montalbán y Fernando Cabeza Garrido) 308

5. EDUCACIÓN PARA LA IGUALDAD EN LAS FAMILIAS.

5.1. INVESTIGACIONES

5.1.1. La Narrativa Autobiográfica y las Relaciones Interpersonales en la Perspectiva del Desarrollo y de Género (Flavia Arantes Hime y Vivian Holovaty Suhorebri)

5.1.2. Manejo de Redes Sociales en la Adolescencia y Juventud LGTB+ durante el Confinamiento (Lucas Platero y Miguel Ángel López-Sáez)

5.2. EXPERIENCIAS

5.2.1. Mapa de la Diversidad (Experiencia Educativa) (Víctor Luqui Plumed)

5.2.2. Prevención de la violencia de género con el Plan Director para la convivencia y mejora de la seguridad en los centros educativos y sus entornos (David Sánchez Hernández y María Luisa Barreda del Olmo) .....

6. EDUCACIÓN PARA LA IGUALDAD DESDE LOS MEDIOS DE COMUNICACIÓN.

6.1. INVESTIGACIONES

6.1.1. Tertulias dialógicas literarias y podcasting (María del Pilar Gómez Mondino) ...

6.2. EXPERIENCIAS

6.2.1. Taller de sensibilización: "Dale la vuelta al Meme" (María Isabel Abril Bernal y María del Pilar Gómez Mondino). 338

6.2.2. Documental, videoactivismo y perspectiva de género (Daniel Aparicio González y Valeria Levratto).

6.2.3. El observatorio ciudadano de la comunicación en Ecuador: un espacio de encuentro para la igualdad de género y para aprender otras formas de ver (Marcela Samudio Granados y Sandra López Astudillo). 


\title{
0. INTRODUCCIÓN
}

\author{
Laura Álvaro Andaluz (Universidad de Valladolid); Carolina Hamodi Galán (Universidad \\ de Valladolid)
}

Decía Malala Yousafzai en su discurso para las Naciones Unidas en el año 2013 que "un niño, un profesor, un lápiz y un libro puede cambiar el mundo". Así, nosotras también creemos en el poder de la educación como motor para el cambio social. Bajo este prisma, nace esta publicación, con el objetivo principal de crear un espacio con contribuciones internacionales para compartir experiencias e investigaciones dentro de diferentes ámbitos (escuela, educación no formal, familias, medios de comunicación, etc.). Todo con el fin de fomentar la educación en igualdad.

Y es que esta, la educación en igualdad, es el pilar fundamental para la erradicación de todo tipo de violencias machistas. Así, en la Ley Orgánica 1/2004, de 28 de diciembre, de Medidas de Protección Integral contra la Violencia de Género, se indica que:

“(...) La violencia de género no es un problema que afecte al ámbito privado. Al contrario, se manifiesta como el símbolo más brutal de la desigualdad existente en nuestra sociedad. Se trata de una violencia que se dirige sobre las mujeres por el hecho mismo de serlo, por ser consideradas, por sus agresores, carentes de los derechos mínimos de libertad, respeto y capacidad de decisión(...)".

Es por tanto que promover la coeducación es la mejor manera de combatir y erradicar esta violencia de género, porque solo gracias a la promoción de la igualdad se logrará acabar con la estructura patriarcal y androcentrista que sostiene, normaliza, perpetúa e incluso en ocasiones hasta justifica las agresiones contra las mujeres.

La teoría del iceberg nos ayuda a comprender el poder transformador de la educación: la violencia de género física se situaría en la punta de dicho iceberg, en la parte visible, la más pequeña. Sin embargo, debajo del agua, oculta, se encuentra la inmensa mayoría del hielo. $Y$ en esa gran masa helada ubicamos todo tipo de desigualdades entre hombres y mujeres que acaban naturalizando la violencia. Hablamos de estereotipos sexistas, roles tradicionales de género, falta de referentes en los materiales didácticos, distribución desigual de los espacios, inequidad en el ámbito laboral, etc. Todos estos comportamientos, comprendidos como lo normativo, y por ello, como imposibles de cambiar, se traducen en una sociedad sexista y jerarquizada en la que lo feminizado se ubica por debajo de lo masculinizado. Interviniendo desde la educación con perspectiva de género sobre lo que no se ve, sobre aquella masa de hielo sumergida en el agua, llegaremos de una manera estructural y perdurable a transformar de manera colectiva creencias y comportamientos machistas.

A lo largo de este libro vamos a encontrar experiencias de éxito e investigaciones que analizan desde diversas perspectivas las posibilidades transformadoras de la educación para la igualdad. Son numerosas las iniciativas y los análisis que aquí se incluyen, tratando de abordar la coeducación de una manera holística y abarcando todos los agentes de socialización. 
Primeramente, se presenta un bloque en el que se recogen experiencias e investigaciones referentes a la educación infantil y primaria. Durante esta etapa educativa, estamos creando los cimientos de la personalidad de cada niña y niño. Es por ello por lo que aquellos valores que se transmitan a lo largo de los primeros años de escolaridad serán la base para aprendizajes posteriores. Poner el foco aquí será clave para un futuro más justo y equitativo.

Después, en un segundo y tercer bloque, se han agrupado las experiencias propias de la educación secundaria y la educación terciaria y universitaria. Damos cabida así a todos los niveles educativos, ya que cada uno de ellos jugará un rol definitivo para la construcción de un pensamiento crítico en el alumnado.

A continuación, en el cuarto bloque encontramos propuestas referentes a la educación no formal, ya que la socialización se plantea más allá de los entornos de la escolarización reglada. De hecho, por ser la educación no formal un contexto más relajado, en el que el interés del alumnado está más agudizado, es fundamental prestar atención a lo que se cuenta y cómo se cuenta, ya que será fácilmente absorbido y naturalizado por los y las aprendices.

Seguimos con un bloque dedicado a la educación para la igualdad en las familias. Este es un eje poco habitual en los contextos académicos, pero que hemos considerado primordial incluirlo en este libro, ya que esta, la familia, es el primer agente de socialización y, por tanto, los conocimientos y los valores que se transmitan en ella serán los primeros con los que niños y niñas empiecen a construir su personalidad.

Para finalizar, incorporamos en el último bloque el eje referente a los medios de comunicación y cómo pueden colaborar en la educación para la igualdad o, por el contrario, contribuir en la perpetuación de las desigualdades. Como último agente de socialización, los medios contribuyen a la creación del imaginario colectivo de la ciudadanía, y por ello marcan tendencias, valores, pautas, costumbres y normas. Analizar su influencia y resaltar las propuestas que aboguen por la equidad es favorecer una actuación conjunta en pro de dicha igualdad.

Con este libro pretendemos aportar una visión en la que una sociedad justa es, no solo viable, sino la mejor opción para todos y todas. Porque solo trabajando de manera colectiva se logrará el verdadero -y necesario- cambio. Una transformación que pone en valor el poder de la educación y la socialización y que deja patente que solo desde la base podremos prevenir la violencia en todas sus formas, conformando personas justas, respetuosas, dialogantes y tolerantes para las que no exista otra opción que la igualdad entre todos los seres humanos. 


\title{
1. EDUCACIÓN PARA LA IGUALDAD EN LA EDUCACIÓN INFANTIL Y PRIMARIA.
}

\subsection{INVESTIGACIONES}

\author{
1.1.1. Construcción de Modelos de Género y Sexualidad: la \\ experiencia de niñas y niños de primero básico \\ Celine Auth Ramírez (Universidad de Chile, Chile).
}

\section{Resumen}

Esta investigación, realizada en el marco de tesis de magíster en Estudios de Género y Cultura de la Universidad de Chile, pretende ser un aporte en la comprensión de los procesos de socialización del género en los primeros años de escolarización, centrándose en la voz de los niños y niñas, con metodologías específicas para la niñez que logren rescatar sus voces.

Este estudio busca comprender la manera mediante las prácticas cotidianas y dinámicas escolares repercuten e influyen en la construcción de modelos de género y sexualidad que realizan los niños y niñas de primero básico. $Y$ también las formas en que dichos modelos de género y sexualidad se reinscriben de manera cotidiana en la escuela, mediante la socialización que realizan con las personas adultas, pero, sobre todo, entre pares.

Palabras clave: modelos de género y sexualidad, prácticas cotidianas, dinámicas escolares, socialización, niños y niñas.

\section{INTRODUCCIÓN Y OBJETIVOS}

Por un lado, la escuela es un espacio de igualdad de oportunidades para las personas, desde una perspectiva de las políticas de acceso universal, sin embargo, tiene un rol fundamental en la profundización de las jerarquías y desigualdades sociales. Asimismo, la niñez es una etapa fundamental en el desarrollo de las personas, en tanto se están modelando sus comportamientos, identidades y representaciones sociales, siendo la escuela uno de los espacios más importantes de socialización del género, que desde sus procesos de enseñanza y aprendizaje moldean y condicionan las construcciones de modelos de género.

En Chile, desde las organizaciones estudiantiles de mujeres en el mayo feminista, que si bien estuvo asociado principalmente a las demandas de acoso y abuso sexual en contexto universitario, apela a una reconfiguración de los roles de género, revisando qué masculinidades y feminidades estamos construyendo, en definitiva nos invita a repensar los modelos de género que estamos produciendo y reproduciendo desde la educación. Sin embargo, esta ola feminista no considera los primeros años de escolaridad, sino que se centra en los contextos universitarios y educación secundaria. Es por esto que esta investigación se centra en el primero básico, primer curso de escolarización formal en Chile, rescatando las voces de las niñas y niños entre 6 y 7 años. 
De esta manera, el objetivo general de esta investigación fue: Describir la construcción de modelos de género y sexualidad que niños y niñas del primero básico del colegio de Maipú (Santiago, Chile) realizan a partir de las prácticas cotidianas y dinámicas escolares que viven en su escuela.

Y los objetivos específicos fueron: 1: Identificar las prácticas cotidianas y dinámicas escolares a partir de la relación adultas/os-niñas/os y entre niñas/os. 2: Caracterizar las respuestas que los niños y las niñas tienen a dichas dinámicas escolares y prácticas cotidianas.

\section{METODOLOGÍA}

Esta investigación fue realizada mediante una metodología cualitativa, y las técnicas utilizadas fueron la observación participante para el registro etnográfico y una modalidad de ejercicios acorde a la edad de las/os niñas/os.

Se realizaron tres ejercicios (de elaboración propia) a todos/as los/as niños/as que se encontraban en sala al momento de su aplicación. Estos fueron aplicados en los últimos días de observación.

- El primer ejercicio aplicado consistía en completar los dibujos de Ana y Pedro vistiéndolos, y asociar los objetos y actividades a cada uno/a:

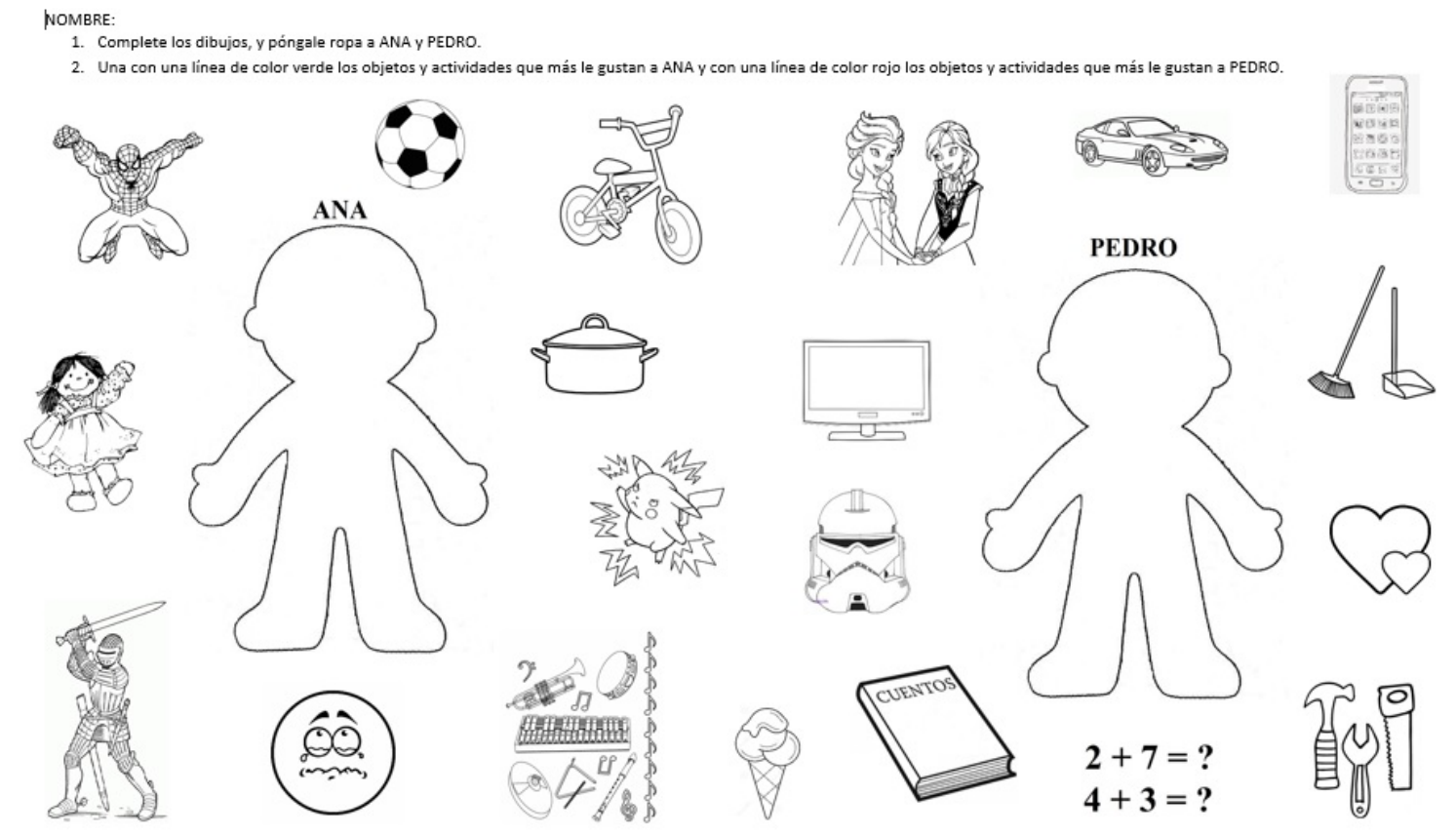

- El segundo ejercicio consistió en dibujar “¿Qué te gustaría ser cuando grande?” $\mathrm{Y}$, por último, el tercer ejercicio consistió en dibujar "¿Qué te gustaría que el viejito pascuero (papa Noel) te regalara?"

\section{RESULTADOS Y DISCUSIÓN}

Un primer elemento importante de mencionar es el carácter cotidiano de la escuela, que mediante la repetición y reiteración de sus prácticas cotidianas, favorecen la internalización del género.

Entre los resultados más relevantes de esta investigación, vemos que el mercado de los juguetes junto con la producción del cine de masas infantil, cumplen un rol importante 
en la niñez y su socialización generizada. Las muñecas y princesas son las más escogidas y deseadas por las niñas, y los superhéroes, el fútbol y Pokémon son los favoritos de los niños. Sin embargo, no solo consiste en el deseo por un juguete, sino que el mercado genera la necesidad de tener las colecciones y accesorios de cada uno. $\mathrm{Y}$ al mismo tiempo, produce opciones generizadas, por ejemplo, los duendes mágicos tienen figuras feminizadas (con tutú) para las niñas y opciones masculinizadas para los niños. Lo mismo ocurre con las bicicletas, patines, videojuegos y superhéroes, estos últimos destinados originalmente a los niños, pero que las niñas pueden serlo en la medida que se feminizan. De esta manera, los juguetes generizados contribuyen al desarrollo de juegos generizados y a la diferencia sexual en la niñez.

Por otro lado, vemos que el fútbol organiza los espacios y las identidades masculinas. Los dibujos de los niños nos hablan de una construcción de masculinidad bastante homogénea y hegemónica. Por un lado, vemos competencia y protagonismo, pero también una validación de esta masculinidad sin resaltar ni individualizarse o diferenciarse, tal como una fraternidad: soy porque somos, es decir, soy niño-hombre en cuanto lo son/somos en colectividad (ver dibujos). Así, el fútbol se erige como un espacio público (o semi-público) de construcción de masculinidad. En este sentido, "Es frecuente que en las instituciones educativas jugar bien al fútbol, por ejemplo, sea un signo de alto estatus dentro de la jerarquía masculina, pues permite poner en juego valores propios de la masculinidad hegemónica tales como la competitividad, la agresividad, la disciplina, la fuerza física, el valor del sufrimiento, la demostración de valor y el riesgo." (Díez, 2015, p.83).
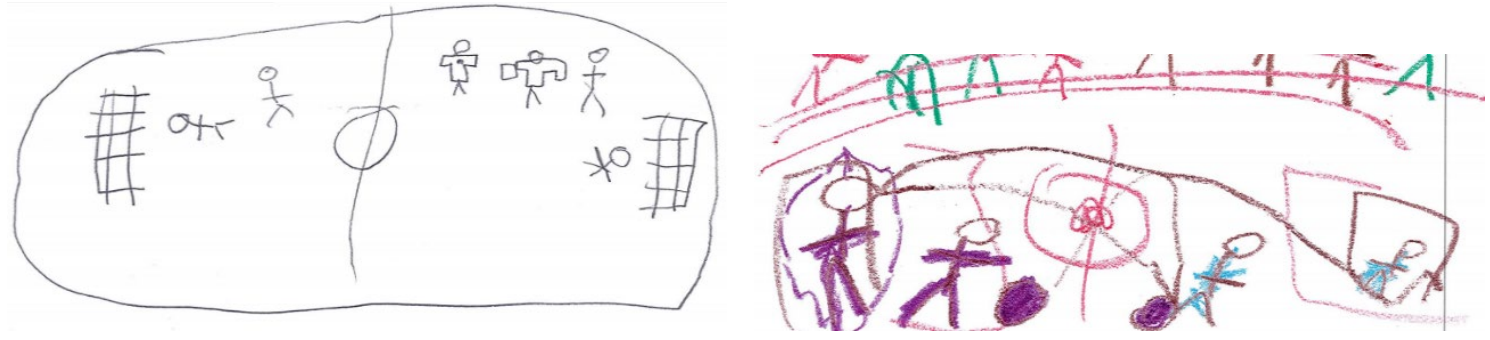

El fútbol se presenta como un espacio de privilegio, y al mismo tiempo, de producción de marginalidad. Es por esto que incluso los niños que no juegan fútbol durante los recreos se dibujan como futuros futbolistas. Por un lado, para pertenecer al grupo de niños de su curso, que desarrollan un modelo de la masculinidad hegemónica, pero, por otro lado, en el trabajo de simular ser parte de este modelo hegemónico, se convencen, incluso a sí mismos, de que también les gusta el futbol, a pesar de no saber jugarlo o no tener interés por éste. "En efecto, en la medida en que los géneros son patrones sociales construidos para que hombres y mujeres se adecuen a determinados comportamientos renunciando a otros, y que existe una coerción fuerte para lograr que así sea, queda claro que limitan las posibilidades de los seres humanos; y las limitan de tal modo que, en general, ni siquiera somos conscientes de ello (...) de modo que facilitan o inhiben el desarrollo de las capacidades, las posibilidades y los deseos de cada individuo." (Subirats, 2010, p.33). En este sentido, el fútbol actúa opacando otros intereses, al esconder otros deseos diferentes -y posibilidades de deseos- de los niños.

No obstante, encontramos una subversión en el deseo de los niños por tener los duendes mágicos, ya que estos peluches se presentan como la posibilidad de tener muñecas, comúnmente negada para los niños. A pesar de estar restringido a los duendes mágicos que no están feminizados, les otorga la posibilidad de tener objetos asociados a juegos de cuidados ma(pa)ternales. Estos últimos siempre vinculados a las niñas, ya que, en la sociedad patriarcal, los cuidados, la maternidad, y el espacio de lo privado, son elementos por excelencia asociados a lo femenino, propio del lugar de las mujeres en la sociedad. En este sentido, también prohibidos para los niños, ya que se 
escapa de la masculinidad patriarcal, que debe diferenciarse constantemente de las niñas y de cualquier otro tipo de masculinidad no hegemónica (Bonino, 2002).

Por su parte, vemos que las niñas son socializadas en los cuidados y para ser las principales encargadas de estos. Las muñecas son los juguetes más escogidos por las niñas y asociadas a un uso exclusivo para ellas, siempre jugando a cuidarlas, siendo madres, alimentándolas y acunándolas. Asimismo, las niñas se dibujaron principalmente en profesiones asociadas a las labores de cuidados de otras personas: profesoras que enseñan y en gran parte de la jornada escolar se encargan también de los cuidados de sus estudiantes, doctoras que sanan y cuidan a sus pacientes, y madres que cuidan a sus hijos/as (ver dibujos). En este sentido, vemos los cautiverios de las mujeres descritos por Lagarde, particularmente la "madresposa": "la condición de las mujeres es opresiva por la dependencia vital, la sujeción, la subalternidad y la servidumbre voluntaria de las mujeres en relación con el mundo (los otros...)" (Lagarde, 1990, p. 35) generando una condición de entrega constante hacia otras personas, renunciando a su propia identidad y a sus deseos, siendo en función de los/as otros/as cuidados/as. Sin embargo, en los márgenes del cautiverio encontramos también maneras de detentar el poder, como la profesora y doctora que se encuentran en una relación jerárquica ante las personas cuidadas, y formas de realización personal de las mujeres, dadas por el cautiverio asignado.
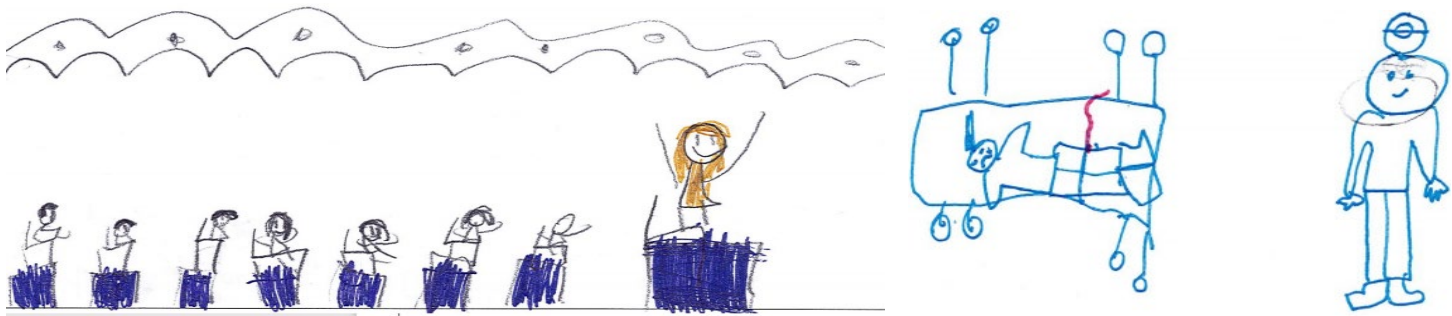

Para la sociedad patriarcal y adulto céntrica, las niñas y niños son considerados como seres asexuados, sin embargo, vemos que desarrollan una sexualidad vinculada al amor romántico. La forma de pensar el amor para los niños y niñas es mediante un amor

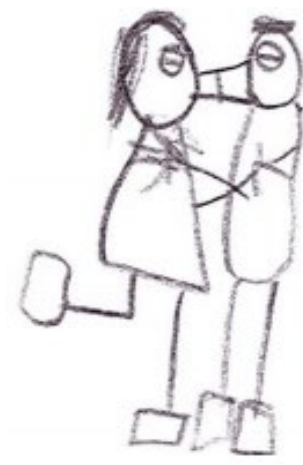
romántico al estilo Disney, acompañada también de una corporalidad particular, los cuerpos feminizados con la "patita levantada" hacia atrás y el cuerpo inclinado hacia el cuerpo masculino entregada para besarlo. Los besos de amor eterno en los finales felices de las películas Disney, las princesas en las películas infantiles y las chicas jóvenes en las películas juveniles, es un contenido característico del amor romántico que se entrega a los niños y niñas. Asimismo, ocurre con la historia de amor de Chocolata y Goldy, personajes protagónicos de los duendes mágicos (juguetes favoritos de niños y niñas), un beso del amor eterno, un amor romántico, un beso con cuerpo, un amor hetero normado.

Se asocia la ternura a las niñas y se espera de ellas que sean tiernas. Así como también sus prácticas de juegos y las imágenes que las rodean están mayormente relacionadas con una característica de ternura, tales como los stickers preferidos, los personajes, las muñecas, los juguetes, etc. Por lo tanto, se espera una conducta rodeada de ternura por parte de las niñas para relacionarse con el resto de sus pares y adultos/as, lo que deriva en que las docentes son más punitivas cuando las niñas se escapan de este carácter de ternura que se espera de ellas. Lo que no ocurre con los niños, ya que de ellos se espera una peor conducta en la sala de clases, por lo tanto, se les llama menos la atención, se les tiene mayor paciencia y se les castiga menos. 
La ternura es para las niñas, lo que las peleas son para los niños. Los niños pelean a combos y empujones entre ellos, mientras que las niñas se acusan, o más bien la mayoría de las veces, se amenazan con acusar, concentrando sus técnicas de pelea en el habla y no en lo físico como los niños. Finalmente vemos que la posibilidad de vivir las emocionalidades y las expresiones de éstas, así como las formas de afecto, están diferenciadas por género, y así también, las maneras de vincularse con las/os adultas/os que les rodean y entre pares. En este mismo sentido, los personajes asociados a los niños están vinculados a la guerra, a la lucha, y a los héroes; la identificación masculina se realiza con alguien que mediante la violencia salva a otras personas. Mientras que los personajes para las niñas son principalmente las princesas, conectadas con el amor, la mayoría debe ser salvada por un príncipe, y las más modernas por amigos/as, pero sin perder el amor y la ternura.

\section{CONCLUSIONES Y LIMITACIONES}

Esta investigación nos invita a reflexionar sobre el currículum oculto y silenciado de la escuela, es decir, a mirar las prácticas que se repiten cotidianamente, algunas ya casi ritualizadas, y muchas totalmente normalizadas, y que hoy producen y reproducen modelos de género y sexualidad hegemónicos, que dan continuidad a las desigualdades de género. En este sentido, esta investigación muestra que la escuela está generizada, así como las relaciones, las estrategias de docentes, los juguetes y accesorios escolares, y los juegos entre niñas y niños. $Y$ es mediante estos que el género se socializa e internaliza en la escuela.

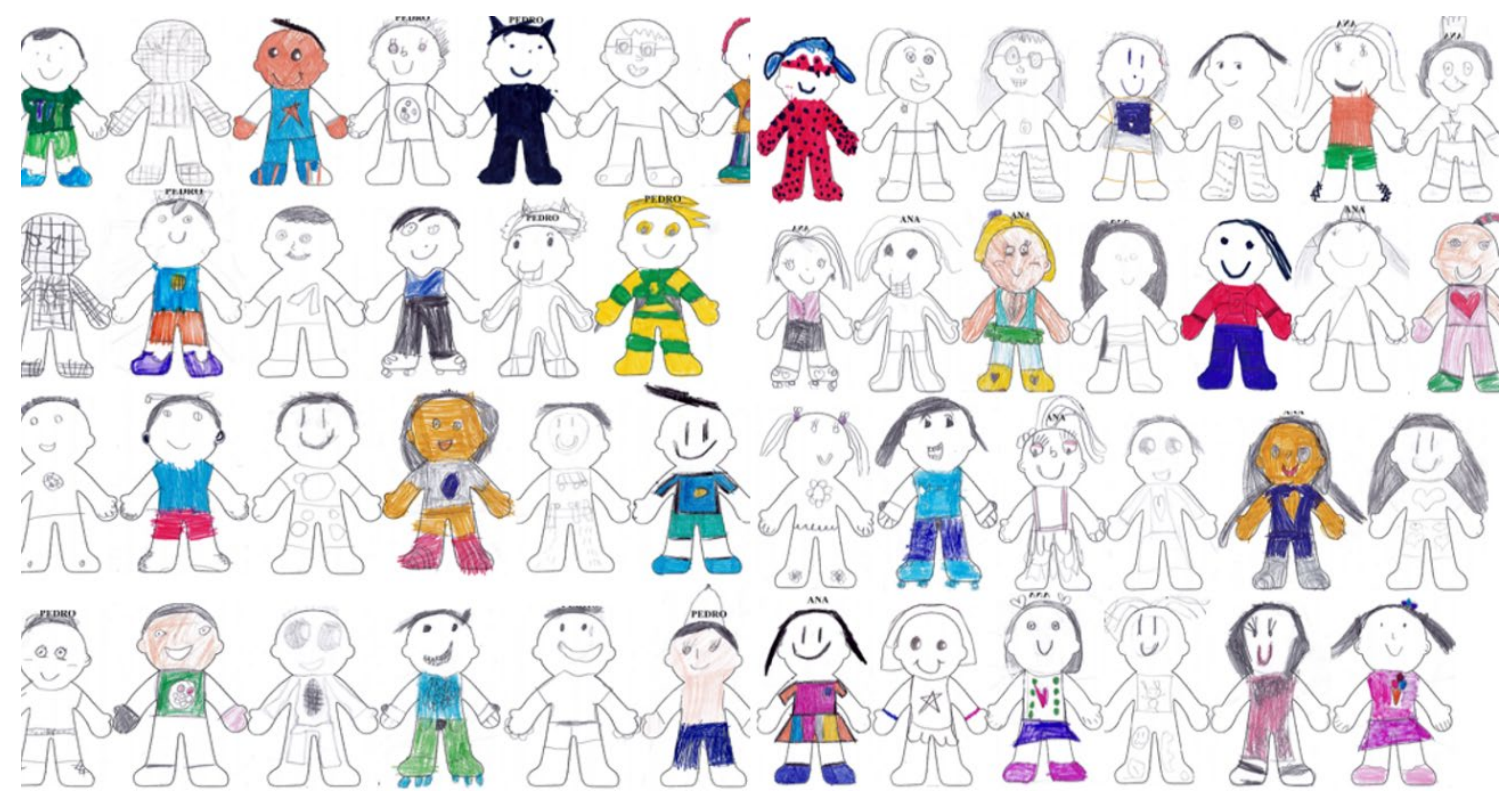

"Los chicos siguen siendo por tradición socializados escolarmente para (...) diferenciarse todo el tiempo de todo aquello que los pueda inscribir como femeninos o como no heterosexuales." (Díez, 2015, p.82). Esto se observa en prácticas cotidianas que refuerzan la masculinidad hegemónica de los niños, entre estas: la transversalidad del fútbol (se imaginan siendo futbolistas, aunque no lo jueguen), mostrarse pa(ma)ternando una muñeca como clásica broma entre pares, y, una mayor comparación y enojo de parte de los niños si sienten que están favoreciendo a las niñas por sobre ellos.

El fútbol ordena el uso espacial del colegio, tal como la masculinidad hegemónica ordena las identidades de género. Es decir, estás dentro o estás fuera de ella: tanto de la cancha como de la masculinidad hegemónica. Si juegas fútbol, ocupas la cancha, y 
si no juegas, estás en los márgenes de ésta. Si bien, las niñas tienen la posibilidad de incursionar en el mundo de lo masculino (por ejemplo, jugando fútbol), solo son aceptadas si se esfuerzan y lo hacen mejor que los mismos niños, pero los niños no entran al mundo feminizado, sino solo para burlarse y reforzar su masculinidad entre pares. En este sentido, incluso la diferencia está generizada.

Un último elemento importante que nos demuestra tanto la importancia de las prácticas cotidianas en la escuela como la posibilidad de introducir transformaciones en la construcción de modelos de género es que niños y niñas asocian la pala y escoba de igual manera para las niñas y los niños, y escogen barrer con una preferencia similar. Lo anterior ha sido logrado por la escuela contando con una pala y una escoba en la sala de clases y dándole un uso cotidiano tanto como una actividad y responsabilidad de las niñas como de los niños. Dicha práctica se refleja en sus percepciones e internalizaciones del género, entregándonos luces del camino a seguir en las escuelas, para contribuir en la equidad de género.

A modo de propuesta, se plantea incluir el género en la escuela, sin embargo, esto supone un trabajo conjunto permanente. En este sentido, sería importante incluir a los niños y niñas, y trabajar con ellos/as, visibilizando, cuestionando y analizando las diferenciaciones de género, viendo, por ejemplo, qué diferenciaciones nos hacen sentir bien y mal, etc. Para así realizar el trabajo involucrando a toda la comunidad educativa y marcar el camino conjunto hacia la eliminación de las desigualdades de género en la escuela.

\section{REFERENCIAS BIBLIOGRÁFICAS}

Bonino, Luis. (2002). Masculinidad hegemónica e identidad masculina. Dossiers Feministes, (2), 7-36.

Díez, Enrique. (2015). Códigos de masculinidad hegemónica en educación. Revista Iberoamericana de Educación (68), 79-98.

Lagarde, Marcela. (1990). Cautiverios de las mujeres: madresposas, monjas, putas, presas y locas. Universidad nacional Autónoma de México.

Subirats, Marina y Amparo Tomé. (2010). Balones fuera. Reconstruir los espacios desde la coeducación. Ediciones Oc

taedro: Barcelona. 


\subsubsection{Juguetes y estereotipos de género en el alumnado de educación infantil: Un estudio de caso. Javier Callejo Maudes (Universidad de Valladolid, España); Ana Pérez Hinojal (Universidad de Valladolid, España)}

\section{Resumen}

El objeto del estudio que aquí se presenta se ha enfocado a indagar en la relación entre la construcción del género y los juguetes utilizados por los niños y niñas.

La metodología elegida ha sido un estudio de caso que se ha llevado a cabo en un aula de infantil. Por un lado, se ha utilizado una técnica cualitativa de observación participante en dos grupos mixtos de alumnos y alumnas y entrevistas personales a niños y niñas en relación a sus preferencias sobre los juguetes. Por otro lado, se han cruzado los datos recopilados con una encuesta realizada a los padres y madres.

El análisis de los datos recogidos ha revelado preferencia por juguetes estereotipados entre niños y niñas ya a estas edades y una clara percepción sobre que juguetes son los apropiados para cada uno ellos según su género.

Palabras clave: Juguetes; Estereotipos; Construcción del Género; Socialización; Roles de Género

\section{INTRODUCCIÓN Y OBJETIVOS}

La relación entre los juguetes y los estereotipos de género ha sido un tema que se ha abordado desde múltiples campos de conocimiento como la Psicología, la Sociología, la Investigación Educativa o los Estudios de Género.

Durante la infancia los niños y niñas reciben multitud de estímulos sobre los juguetes que deben usar y a lo que deben jugar según su género. Desde los libros y cuentos al marketing de juguetes, pasando por la televisión o las películas, se pueden encontrar elementos que retratan representaciones estereotipadas de los intereses de los niños y las niñas (King et al., 2020). Dentro de estos estímulos merecen una mención especial los anuncios de juguetes que tradicionalmente han reproducido roles de género como se ha demostrado en múltiples estudios en nuestro país (Ferrer Lopez, 2007; PérezUgena et al., 2011). Otros estudios denotaban un avance hacia la paridad de la representación de género en los anuncios (Galan Fajardo, 2007) pero todavía queda mucho camino por recorrer (Gasol Tost et al., 2019).

La influencia de los anuncios en la construcción del género es estudiada en profundidad por Pike y Jennings (2005), donde explican, basándose en la Teoría del Cultivo y la Teoría del Aprendizaje Social, que los medios actúan como agentes socializadores que influyen en perpetuación de los constructos de género.

Los estudios actuales sobre internet y las redes sociales, como por ejemplo Facebook denotan que, aunque la reproducción de estereotipos sigue dándose en estas plataformas, las diferencias de género no son tan acusadas como en trabajos anteriores (Díaz-Campo \& Fernández-Gómez, 2017).

Por otro lado, la influencia de los medios, tradicionales o digitales, en la construcción del género a través de los juguetes no es la única, ya que otros elementos como los padres 
y otros familiares, los hermanos y hermanas, la escuela o la imitación de las conductas de amigos y amigas son variables de vital importancia para entender este hecho en su totalidad.

Estudios clásicos como el de Rheingold y Cook (1975) demostraron la influencia de los padres en la construcción del género mediante una observación de las habitaciones que preparaban para sus hijos e hijas y de los juguetes que había en ellas. Otros autores como MacPhee y Prendergast (2019) retomaron este estudio para demostrar que aparte de la influencia de los padres, la existencia de hermanos o hermanas del mismo sexo también influía en la adquisición de roles de género en relación con los juguetes. Por último, también se ha demostrado la influencia de los amigos y amigas dentro y fuera de la escuela en la elección de juguetes estereotipados y la reproducción de roles. Etaugh y Liss (1992) demostraron que los niños y niñas que jugaban en la escuela o en el parque principalmente con amigos de su mismo sexo aumentaban su preferencia por juguetes estereotipados lo que influía en su construcción del género.

En consecuencia, estas influencias desembocan en que los niños y las niñas empiezan a desarrollar preferencias por juguetes diferentes según su género a edades muy tempranas, por debajo de los dos años (Zosuls et al., 2009)

El objetivo de este estudio es el de descubrir, dentro de un aula de educación infantil, si el alumnado ya ha asimilado a estas edades ( 3 y 4 años), roles de género relacionados con los juguetes. Como objetivos específicos se buscó demostrar quien eran los agentes que reproducían dichos roles de género (Padres, hermanos, amigos, medios de comunicación).

\section{METODOLOGÍA}

El estudio que aquí se presenta ha seguido la perspectiva metodológica de estudio de caso de Stake (1999), de carácter intrínseco e instrumental, que se centra en el alumnado de una clase de Educación Infantil.

Las técnicas de investigación utilizadas han sido la observación participante y la entrevista personal a niños y niñas de la clase. La observación participante se realizó en una actividad donde se instaba a los niños, en dos grupos mixtos, a hablar sobre sus preferencias sobre los juguetes, las personas que se los habían regalado y las preferencias de sus amigos, de sus hermanos, etc., o el lugar donde habían conocido los juguetes. En las entrevistas personales se buscaron factores que podrían influir en la elección de los juguetes como los refuerzos o castigos de sus padres, sus amigos o sus compañeros de clase, buscando así la función emotiva del lenguaje que aporta esta técnica.

En concreto los participantes se dividieron en dos grupos, el primero compuesto por 4 niños y 4 niñas y el segundo por 3 niños y 4 niñas. En cuanto a las entrevistas personales estas se aplicaron sobre 2 niños y 2 niñas.

Por otro lado, se pidió a las madres y los padres que completaran un cuestionario al que respondieron 11 de ellos.

La pregunta de investigación principal fue la siguiente: ¿Tienen los niños y las niñas preferencias sobre juguetes estereotipados en el aula de educación infantil?

Las declaraciones temáticas en que se dividió la pregunta de investigación fueron: utilización efectiva de juguetes estereotipados, Agentes que regalan los juguetes, Factores en la elección de juguetes estereotipados y refuerzos a la utilización de juguetes estereotipados. 


\section{RESULTADOS Y DISCUSIÓN}

- Utilización efectiva de juguetes estereotipados

Durante el desarrollo de la actividad en grupo se observó que la mayoría de las niñas jugaba principalmente a juguetes simbólicos, es decir, juguetes donde se asumen roles de otras personas, principalmente muñecas y bebes:

\section{Grupo 1:}

Niña 3: A mí me trajeron los reyes un bebé llorón.

Niña 1: Y yo tengo un bebé llorón.

Niña 3: $Y$ yo tengo tres, uno pequeño y dos grandes.

Niña 4: Yo tengo dos bebés llorones grandes.

Los niños por su parte expresaban que jugaban más con juguetes manipulativos o de construcción en los que para jugar se necesita el control con los dedos, los reflejos, la precisión, como construcciones, legos, puzles, etc., y juguetes simbólicos asociados a roles masculinos como coches, robots o vaqueros:

\section{Grupo 1:}

Niño 2: Los Reyes Magos me lo dejaron en el balcón. Y también a Buddy parlanchín.

Niño 3: A mí me dejaron en el balcón una pista de escorpión de coches.

Niño 4: A mí también y una caja de puzles.

\section{Grupo 2:}

Niño 5: Yo con los legos y coches de robots.

Niño 6: Yo tengo un coche de robots.

Niño 7: A mí un poquito. $Y$ los coches.

Lo más interesante de la observación de los comentarios en los grupos no fue tanto la utilización de juguetes estereotipados sino el rechazo a los juguetes estereotipados del género contrario, lo que demuestra ya una intensa asimilación de los roles en esta etapa de su desarrollo:

\section{Grupo 1:}

Niño 1: Yo el centro de mando.

Profesora: ¿Y no habrías preferido una muñeca de Elsa?

Niña 1: No porque a los chicos no les gustan las muñecas.

\section{Entrevista niña 1}

Profesora: ¿Entonces con qué le gusta jugar a tu hermano?

Niña 1: Pues con unos coches que le regalaron los Reyes Magos.

Profesora: ¿Y tú juegas con él a los coches o prefieres jugar con tu muñeca de Elsa?

Niña 1: Las dos cosas, primero con mi hermano y luego con la muñeca.

Profesora: ¿Te gustan los coches? 
Niña 1: Si, pero son más de los chicos. A mi gustan las muñecas como a las chicas.

\section{Entrevista niño 1}

Profesora: ¿Y compartes algún juguete con tu hermana?

Niño 1: No, porque ella tiene muñecas y a mí no me gustan

- Agentes que regalan los juguetes

Los alumnos mostraban un conocimiento parcial de las personas que les habían regalado los juguetes, mostrando algunos recuerdos de los juguetes que les habían traído los reyes magos y alguno de los que les habían regalado sus padres en su cumpleaños. La única relación que se encontró en los grupos es que los padres habían regalado principalmente juguetes simbólicos a las niñas y juguetes manipulativos o de construcción a los niños, mientras que otros familiares como los abuelos regalaban principalmente juguetes educativos que son los que les ayudan a comprender contenidos escolares.

- Factores en la elección de juguetes estereotipados

Los participantes en los grupos expresaron principalmente dos opciones, juguetes que habían elegido en catálogos o juguetes que habían visto a sus amigos o familiares:

\section{Grupo 1:}

Niña 2: Rodeamos lo que queríamos en la revista.

Niña 3: $Y$ los de mis primas.

\section{Entrevista niño 5:}

Niño 5: Los tíos porque cuando voy a su casa juego con los juguetes de mis primos y tienen un súper parking de coches.

Profesora: $\mathrm{Y}$, si fuera tu cumple ¿qué juguetes te pedirías?

Niño 5: El parking de mis primos para que pueda guardar los coches que tengo porque mamá me los ha metido en una caja y mola más el parking.

- Refuerzos a la utilización de juguetes estereotipados:

Por último, en lo que se refiere a los refuerzos principalmente se han visto dos tipos, por un lado, los padres regalan a sus hijos juguetes estereotipados como premio por portarse bien, por ejemplo, cuando consiguen varias estrellas (niño 5). Por otro lado, se percibe una gran presión del grupo de amigos/as y de los compañeros/as de clase sobre cuáles son los juguetes a los que deben jugar los niños y las niñas, es decir, si juegan a "juguetes de niñas" siendo niños los demás compañeros les cuestionan sobre porque utilizan ese tipo de juguetes. Esto se produce principalmente en dicho sentido, pero también, aunque con menos intensidad en niñas que juegan a "juguetes de niños".

\section{- Percepción de madres y padres}

Las respuestas al cuestionario por parte de las madres y padres corroboran los discursos observados en las niñas y los niños estudiados, por ejemplo, prácticamente el $70 \%$ de sus hijas tienen preferencia por juguetes simbólicos (en casi su totalidad con estereotipos femeninos claros), mientras que el $60 \%$ de sus hijos prefieren juguetes físicos. 
El análisis más interesante de los realizados es el que relaciona el sexo del hijo/a, tipo de juguete favorito, si tiene hermanos/as, los juguetes preferidos de sus amigos/as y lo que quieren ser de mayores (profesión estereotipada o no, mediante un análisis de correspondencias múltiples.

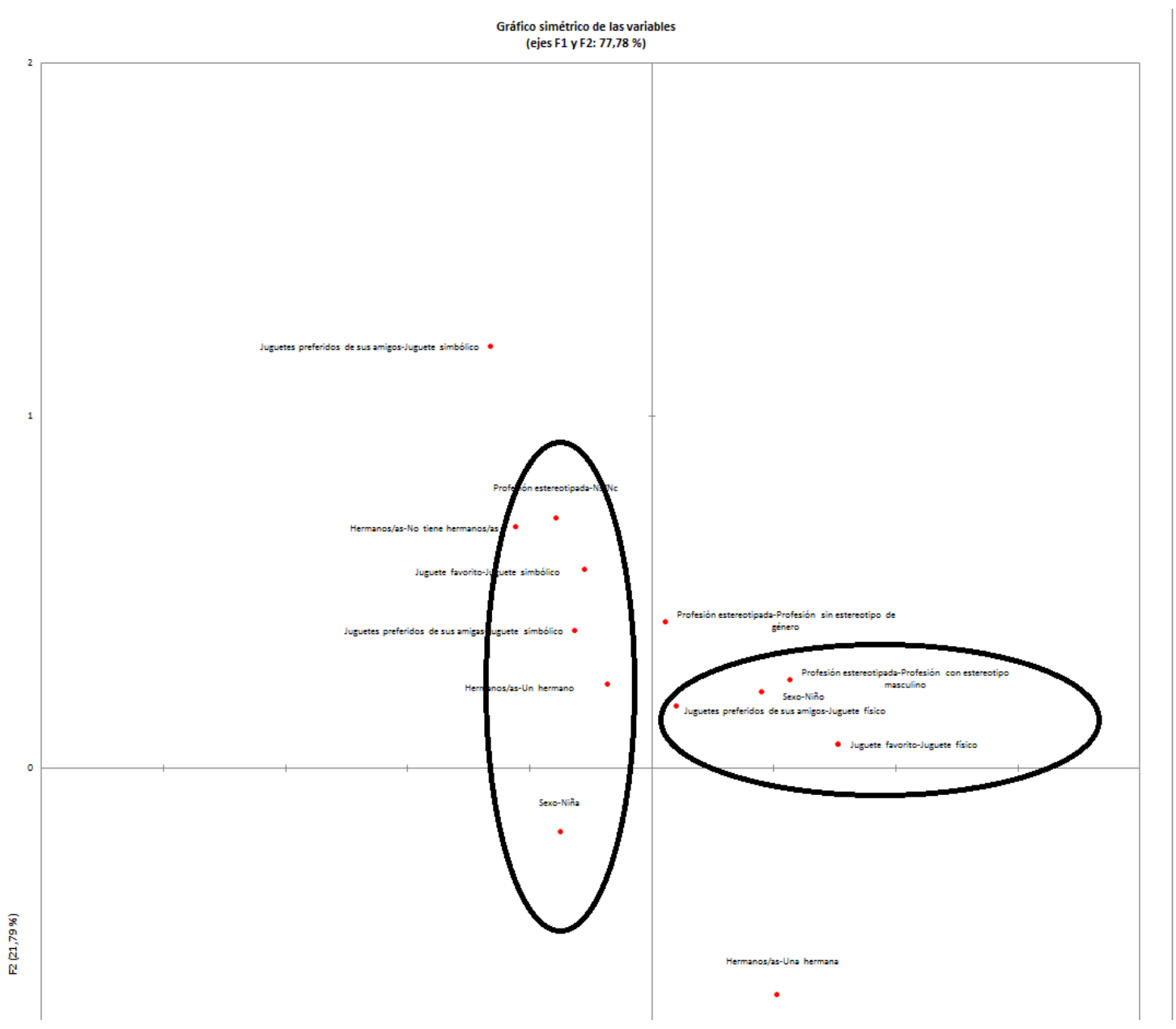

Gráfico 1: Análisis de correspondencias múltiples

En el gráfico se observa una clara relación entre ser niño, la preferencia por juguetes físicos, la preferencia de sus amigos chicos también por juguetes físicos y la preferencia por una profesión estereotipada masculina cuando sea mayor. Por otro lado, las categorías, ser niña, la preferencia por juguetes simbólicos, la preferencia de las amigas por juguetes simbólicos y tener un hermano (chico), parecen estar también relacionadas

\section{CONCLUSIONES Y LIMITACIONES}

La conclusión es que existe una gran diferenciación entre los juguetes utilizados por los niños y por las niñas en la clase, coincidiendo casi en la totalidad de los casos con los estereotipos clásicos. Existe una gran inclinación de las niñas a jugar a juguetes simbólicos donde tienen que asumir la labor de madre o cuidadora, bebes y animales y de los niños a juguetes simbólicos asociados a estereotipos masculinos como los robots, lucha y a los coches. Con respecto a los juguetes manipulativos y de construcción son utilizados principalmente por los niños al igual que los juguetes físicos en los que se desarrolla la velocidad y los reflejos. Esta relación lleva a los niños y niñas a tener 
preferencia por profesiones estereotipadas por género lo que lleva implícita la doble función de los juguetes, por un lado, el ocio y el entretenimiento y por otro el prepararlos para su vida adulta, en la que se reproducirán los mismos roles interiorizados a esas edades.

En las influencias, no se ha encontrado en estos grupos muchas referencias explicitas a los anuncios de la televisión o internet, pero si la influencia de los hermanos y de los amigos. Esta influencia también se percibe en el rechazo como grupo a que los niños jueguen con juguetes que consideran de niñas y viceversa. En el caso de los que tienen hermanos de sexo contrario, se percibe que podría tener importancia en la intensidad en la que se asumen los roles de género.

El estudio tiene serias limitaciones en buscar en profundidad los medios a través de los cuales les llega la información sobre los juguetes mucho más allá de la imitación de los que usan sus hermanos o amigos, así como a las diferencias reales entre los agentes que realizan los regalos.

\section{REFERENCIAS BIBLIOGRÁFICAS}

Díaz-Campo, J., \& Fernández-Gómez, E. (2017). Estereotipos de género y socialización del menor: La publicidad de juguetes a través de Facebook en España. Observatorio (OBS*), 25-43.

Etaugh, C., \& Liss, M. B. (1992). Home, School, and Playroom - Training grounds for adult gender-roles. Sex roles, 26(3-4), 129-147. https://doi.org/10.1007/BF00289754

Ferrer Lopez, M. (2007). Los anuncios de juguetes en la campaña de Navidad. Comunicar, XV(29), 135-142.

Galan Fajardo, E. (2007). Gender construction and spanish fiction TV. Comunicar, 15(28), 229-236. https://doi.org/10.3916/C28-2007-24

Gasol Tost, M., Lopez, C., Puig Sobrevals, C., \& Sanchez, I. (2019). La presencia de estereotipos de género en la publicidad de juguetes. Dos décadas de análisis. Quaderns Del CAC, 45, 37-45.

King, R. A., Scott, K. E., Renno, M. P., \& Shutts, K. (2020). Counterstereotyping can change children's thinking about boys' and girls' toy preferences. Journal of Experimental child psychology, 191. https://doi.org/10.1016/j.jecp.2019.104753

MacPhee, D., \& Prendergast, S. (2019). Room for Improvement: Girls' and Boys' Home Environments are Still Gendered. Sex roles, 80(5-6), 332-346. https://doi.org/10.1007/s11199-018-0936-2

Pérez-Ugena, A., Martínez Pastor, E., \& Salas Martínez, A. (2011). Los estereotipos de género en la publicidad de los juguetes. Ámbitos. Revista Internacional de Comunicación, 20.

Stake, R. E. (1999). Investigación con estudio de casos. Ediciones Morata.

Zosuls, K. M., Ruble, D. N., Tamis-LeMonda, C. S., Shrout, P. E., Bornstein, M. H., \& Greulich, F. K. (2009). The Acquisition of Gender Labels in Infancy: Implications for Gender-Typed Play. Developmental Psychology, 45(3), 688-701. https://doi.org/10.1037/a0014053 


\subsubsection{Patios Escolares antes de la Pandemia: Distribución de los espacios y jeraquías de género}

Haizea Unda (Universidad del País Vasco / Euskal Herriko Unibertsitatea. UPV/EHU, España); Nahia Idoiaga (Universidad del País Vasco / Euskal Herriko Unibertsitatea.

UPV/EHU, España); Inge Axpe (Universidad del País Vasco / Euskal Herriko

Unibertsitatea. UPV/EHU, España).

\section{Resumen}

Este trabajo recoge las respuestas de 14 docentes (12 mujeres y 2 hombres) de la etapa de Educación Primaria en relación a la desigual distribución espacial y uso del patio de recreo de niños y niñas antes de la irrupción de la pandemia causada por la COVID-19. Los resultados muestran que, efectivamente, la estructura habitual de los patios escolares fomentaba el uso no equitativo del espacio, mostrando una clara jerarquía de las actividades "masculinas" (deportes como el fútbol) en detrimento de otras actividades, relegando a los márgenes a las niñas y aquel alumnado no identificado con la masculinidad hegemónica. Se discuten los resultados obtenidos considerando la importancia de la formación inicial del profesorado como herramienta para la concienciación y transformación en pos de una realidad más igualitaria.

Palabras clave: patios escolares; jerarquía; género, Educación Primaria; distribución del espacio.

\section{INTRODUCCIÓN Y OBJETIVOS}

El patio escolar representa, en la mayoría de los casos, un tiempo y espacio que se considera, dentro de unos límites, como propio del alumnado, en el que, a primera vista, tiene libertad de juego y movimiento (Subirats y Tomé, 2007). Sin embargo, en esas interacciones no condicionadas por el profesorado se proyectan roles y relaciones de poder propias del género (Bonal, 2014). "En los movimientos físicos y juegos cotidianos surgen roles sexuales, relaciones de poder y comportamientos que priman las culturas de género" (Subirats y Tomé, 2007, p. 107).

Sin embargo, si se preguntase a los niños y niñas, no mostrarían conciencia de dichas relaciones de poder y dependencia (Tomé y Ruíz, 1996), es decir, no son, en general, capaces de detectar el sexismo o androcentrismo que puede haber en los patios (Ruíz, 2017). Esto demuestra que dichas relaciones de poder y sexistas, así como la distribución desigual del espacio que se produce en los patios se ha naturalizado (Tomé y Ruíz, 1996).

Cabe destacar que la infraestructura escolar contribuye a la existencia de este sexismo, ya que la mayoría de las instituciones de Educación Primaria mantiene la misma infraestructura espacial de hace 50 años (Resa, 2020). Por tanto, el patio es un espacio no neutro, planificado, construido y gestionado desde los valores propios de la sociedad en la que se inserta (Saldaña, 2018). Esta distribución espacial tiene una gran influencia en la creación y mantenimiento de relaciones de poder y en la jerarquía de los juegos. De hecho, normalmente en los patios escolares las canchas deportivas, sobre todo el campo de fútbol, ocupan la mayor superficie de espacio libre y se ubican en el centro (Larramendi, 2016). Así, los chicos ocupan dichos espacios centrales, donde tradicionalmente se dan los juegos más prestigiosos: los deportes (Rodríguez y García, 2009). Mientras que las chicas quedan marginadas ocupando espacios periféricos, 
pequeños e íntimos en los que llevan a cabo actividades "estéticas y no invasivas" como hablar o estar sentadas (Saldaña, 2018).

Como se ha dicho, los juegos de tipo deportivo gozan de mayor prestigio, y cuando la mayor parte del espacio escolar se destina a dicha actividad se transmite un mensaje claro de su superioridad en esta sociedad, otorgando mayor estatus a quienes los practican; generalmente los chicos (Auzmendi et al., 2018). Esto contribuye a que los chicos interioricen dicho estatus y su "derecho" a invadir y dominar el espacio (Resa, 2020). Por el contrario, a las chicas les educa en aceptar las limitaciones espaciales impuestas: en aceptar quedar relegadas a espacios pequeños y protegidos, en los que, además, deben acceder a la periódica invasión que puede producirse si se introduce el balón en su zona (Saldaña. 2018). Por ello, acuden a zonas seguras (soportales, refugios), dejando a los chicos el espacio que desean (Tomé y Ruíz, 1996). Y aunque algunas chicas puedan acceden a la zona de juego central, siempre lo harán con mucha dificultad, y debiendo asumir que solo podrán hacerlo si "son buenas jugando", a pesar que los chicos son aceptados sea cual sea su capacidad (Gobierno Vasco, 2020). Esto demuestra que el espacio limita nuestra libertad de movimiento y desarrollo, contribuyendo a la interiorización de este tipo de relaciones desiguales y jerárquicas.

A pesar de que en el patio se producen estos importantes aprendizajes, en general se considera un tiempo de descanso tanto para el alumnado como para el profesorado, sin considerarlo como un espacio realmente educativo (Resa, 2020). Esto dificulta la detección de las desigualdades de género (Bonal, 2014), y favorece la naturalización del sexismo y androcentrismo en dicho ámbito (Ruíz, 2017). De este modo, en ausencia de la intervención del profesorado, se refleja el mismo control del uso de los recursos que ocurre en la sociedad en general, y que beneficia a un número reducido de alumnos en detrimento del resto (Subirats y Tomé, 2007), perpetuando el silencio que supone tal uso restringido y desequilibrado del espacio en el caso del alumnado que no se incluye dentro de la masculinidad hegemónica (Bonal, 2014).

Teniendo en cuenta la jerarquización de la distribución espacial de los patios escolares y las relaciones de desigualdad que se dan frecuentemente en ellos, el objetivo de este trabajo es analizar si el profesorado es capaz de detectar dichas relaciones en el uso que se hacía del patio antes de la pandemia causada por la COVID-19.

\section{METODOLOGÍA}

Este trabajo forma parte de un proyecto de Campus Bizia Lab de la Universidad del País Vasco / Euskal Herriko Unibertsitatea, en la que se desarrollan distintos trabajos que analizan aspectos relacionados con la igualdad y la coeducación en Educación Infantil, Primaria y Social. Así, dentro de un estudio en relación al uso de los espacios escolares, concretamente del patio de recreo antes y después de la irrupción de la pandemia causada por la COVID-19, se solicitó la participación de 14 docentes de Educación Primaria (2 hombres y 12 mujeres). Se trata de una muestra reducida y no paritaria debido a: 1) su característica de investigación de corte cualitativo y preliminar, a modo de primera aproximación al objeto de estudio a fin de poder desarrollar, posteriormente, una investigación con un diseño mixto y participación más amplia; 2) la feminización de la profesión docente, en la que en los niveles de Infantil y Primaria existe una mayor proporción de mujeres, de la cual es reflejo esta muestra.

El instrumento utilizado ha sido un cuestionario ad hoc compuesto por preguntas abiertas. Se solicitaba la observación durante 2-3 días del patio y posteriormente completar dicha observación respondiendo a una serie de preguntas respecto a los 
juegos, las relaciones entre alumnos y alumnas y el uso del espacio en función del sexo, pidiendo la comparación entre el uso previo a la pandemia y posterior. En este trabajo únicamente se hará referencia a la información relativa a la distribución antes de la pandemia.

\section{RESULTADOS Y DISCUSIÓN}

En la tabla 1 se ofrece un resumen de las respuestas del profesorado respecto a la ocupación del patio antes de la pandemia.

\begin{tabular}{|c|c|c|c|}
\cline { 2 - 4 } \multicolumn{1}{c|}{} & Respuestas & Lugar & Alumnado predominante \\
\hline Campo de fútbol & 8 & Centro & Chicos \\
\hline Zona cubierta & 7 & Periferia & Chicas \\
\hline Frontón & 3 & Centro & Chicos \\
\hline Campo de baloncesto & 1 & Centro & Chicos \\
\hline
\end{tabular}

Tabla 1. Organización del patio y distribución del alumnado.

Como se puede constatar, de las 14 personas participantes más de la mitad han confirmado la predominancia de las canchas deportivas, situadas en el centro y ocupadas generalmente por chicos con juegos de balón (principalmente el fútbol, incluso en la cancha de baloncesto) mientras que las chicas quedaban relegadas a los márgenes del patio o "las esquinas", indicando, además, que eran ellas las que, en los patios en los que existía alguna zona cubierta, más protegida pero considerada "marginal" la ocupaban: "el frontón y la cancha la ocupaban generalmente los chicos, las chicas se quedaban en la zona cubierta de abajo", "generalmente las chicas y unos pocos chicos que no jugaban al fútbol se quedaban en las esquinas o haciendo diferentes juegos en la zona cubierta".

Esta distribución desigual generaba relaciones de jerarquía detectadas claramente por 6 docentes, que señalaban como razón principal el fútbol: "como el balón tenía mucha presencia, fomentaba la hegemonía de los chicos", "como los chicos ocupaban la mayor parte del espacio, las chicas se tenían que conformar con el lugar que les quedaba", "se veía claramente que algunos deportes tenían mucha fuerza y que los que practicaban esos deportes (chicos) ocupaban la mayor parte del espacio, dejando descolgado al resto de alumnado y mostrando una jerarquía de género", "el resto dependía muchas veces de los que jugaban al fútbol". Una docente indica, incluso, que muchas chicas, posiblemente para protegerse, se quedaban en el aula: "muchas chicas no bajaban al patio porque no querían participar en los juegos de 'chicos' ". Otras cinco docentes indican que tales relaciones de poder se producían por la propia estructura del patio: "las relaciones de poder se veían desde el punto de vista espacial, siendo las canchas el espacio más amplio y para actividades específicas", "El centro del patio está dirigido a la práctica de deportes, donde participan más los chicos, obligando a los demás, generalmente chicas, a ocupar el resto, generando una relación de poder muy clara en cuanto al espacio". Es reseñable, sin embargo, que una persona participante manifiesta que "no se veían relaciones de poder", a pesar de reconocer en sus respuestas que "la 
mayoría de las chicas se quedaba estática, los chicos se movían de un lado a otro, acaparando la mayoría de los espacios".

\section{CONCLUSIONES Y LIMITACIONES}

El objetivo de este trabajo era conocer, desde el punto de vista del profesorado de Educación Primaria, la existencia de posibles usos desiguales del patio escolar en función del género antes de la pandemia.

Analizando las respuestas del profesorado queda muy claro que el diseño de la mayoría de los patios sigue siendo muy similar y con la misma infraestructura espacial de hace 50 años (Resa, 2020), ofreciendo así un espacio no neutro (Saldaña, 2018). De hecho, el patio de la mayoría del profesorado que ha participado en este estudio está formado por campos deportivos, siendo el fútbol la cancha que ocupaba el espacio central, en consonancia con la distribución que describe Larramendi (2016). Esta organización del espacio confiere el dominio y prestigio al alumnado que se ubica en ese centro (Rodríguez y García, 2009), principalmente chicos. Se observa así que los chicos mostraban un control territorial muy claro, al mismo tiempo que dificultaban a las chicas y al alumnado no identificado con la masculinidad hegemónica, llevar a cabo otras acciones (Rodríguez y García, 2009). Como señalan muy claramente distintas docentes, las chicas quedaban relegadas a zonas periféricas (Saldaña, 2018), zonas "protegidas" como los espacios cubiertos o la propia aula, mientras que los chicos ocupaban las zonas más amplias (Tomé y Ruíz, 1996).

Esta distribución espacial emitía un mensaje claro: qué alumnos tienen superioridad (Auzmendi et al., 2018). Así pues, los resultados obtenidos han permitido constatar que antes de la pandemia, la distribución espacial de los patios distaba mucho de ser equitativa y de favorecer la igualdad de género.

En cualquier caso, es preciso señalar que los resultados recogidos en este trabajo deben ser interpretados con cautela, y no pueden ser considerados un reflejo de la realidad de los centros de la Comunidad Autónoma Vasca, al haber participado únicamente 14 docentes.

También se puede considerar como limitación el hecho de que no se haya recogido la edad de los participantes, de cara a constatar posibles diferencias en función de tal variable en las respuestas obtenidas.

Por el contrario, sí se recogió el sexo de los participantes, destacando el hecho de que las respuestas dadas por los dos hombres van en la misma línea que las de las mujeres, habiendo sido capaces de percibir el uso o reparto desigual del patio: "En los juegos deportivos (fútbol y baloncesto) se veían sobre todo grandes diferencias de género porque las chicas jugaban muy pocas veces". "Dada la diferencia de ocupación del espacio que se da en función del sexo, la relación de poder era espectacular". Aunque este dato puede considerarse positivo es posible que dichas respuestas se deban a una sensibilidad previa respecto a la temática, que pudo llevar al profesorado a aceptar participar en la investigación.

Para hacer frente a estas limitaciones y avanzar en este tipo de estudios, sería interesante analizar si el alumnado universitario que se está formando para ser docente en un futuro es también consciente de la jerarquía y relación desigual que puede darse en la distribución del espacio de los centros escolares. Si en esta formación universitaria inicial del profesorado se abordase el tema de la desigualdad de género y se potenciasen las observaciones sistemáticas, el futuro profesorado estaría en posición 
de identificar estas situaciones de desigualdad y evitarlas (Tomé y Ruíz, 1996). Esto permitiría asentar las bases de una educación en la que realmente se atendiese a la diversidad propia del alumnado, valorándola y aceptando la diversidad y ofreciendo una verdadera equidad, eliminando las relaciones jerárquicas y permitiendo la implementación de una verdadera coeducación tan necesaria en la escuela actual, fomentando así una educación crítica, transformadora e inclusiva.

\section{REFERENCIAS BIBLIOGRÁFICAS}

Auzmendi, J. M., Azpirotz, A., Gorostitzu, A., Mendizabal, A. y Muñoa, A. (2018). Eskolako patioa. Ikasle guztiei leku egin nahian. Hik Hasi, 224, 11-17.

Bonal, X. (2014). Cambiar la escuela: La coeducación en el patio de juegos. Universitat Autònoma de Barcelona.

Gobierno Vasco (2020). El diseño de los patios escolares desde la perspectiva de género. Gurean berdintasuna, 8.

Larramendi, I. (2016). Eskoletako jolastokiak eta genero-rolak: Diseinuaren eragina genero nortasunaren eraikuntzan. Aldiri. Arkitektura eta Abar, 3(27), 18-21.

Resa, A. (2020). El patio escolar como espacio coeducativo. Diversidade e Educação, 8, 277-293.

Rodríguez, H. y García, A. (2009). Asimilación de códigos de género en las actividades del recreo escolar. Revista Interuniversitaria de Formación del Profesorado, 64(23,1), 59-72.

Ruíz, C. (2017). Estrategias para educar en y para la igualdad: coeducar en los centros. Atlánticas, 2(1), 166-191.

Saldaña, D. (2018). Reorganizar el patio de la escuela, un proceso colectivo para la transformación social. Hábitat y Sociedad, 11, 185-199.

Subirats, M. y Tomé, A. (2007). Balones fuera. Reconstruir los espacios desde la coeducación. Octaedro.

Tomé, A. y Ruíz, R. A. (1996). El espacio de juego: Escenario de relaciones de poder. Aula de innovación educativa, 52-53, 37-41.

NOTA: este trabajo se ha llevado a cabo en el marco del Programa Campus Bizia Lab (el Campus como Laboratorio) con una subvención de la Dirección de Sostenibilidad del Vicerrectorado de Innovación, Compromiso Social y Acción Cultural de la Universidad del País Vasco (UPV/EHU). Este programa cuenta con el apoyo del Gobierno Vasco. 


\subsubsection{Análisis de las Leyes Educativas Españolas desde una Perspectiva de Género \\ Paula Pérez Pérez (Universidad Pablo de Olavide, España)}

\section{Resumen}

Mediante la presente investigación se realiza un recorrido por las leyes educativas españolas bajo una perspectiva de género que permite visibilizar la necesidad de un Sistema Educativo feminista para garantizar el derecho a la educación y el derecho a la igualdad.

La legislación educativa ha planteado a lo largo de la historia avances y retrocesos en materia de igualdad de género. La actual ley educativa, la LOMLOE, manifiesta un fuerte propósito por avanzar hacia la equidad, el respeto a las diferencias, la educación en un mundo global y por garantizar el derecho a la educación; sin embargo, es una ley poco concreta en muchos aspectos, por tanto, los logros dependerán en gran medida de los presupuestos y de la manera en que las administraciones y las propias escuelas la implementen.

Palabras clave: legislación educativa; pedagogía feminista; currículo feminista; LOMLOE; igualdad.

\section{INTRODUCCIÓN Y OBJETIVOS}

El Sistema Educativo español se encuentra atravesado por el impacto directo del Coronavirus en los centros educativos y por los nuevos desafíos sociales, recogidos en la Agenda 2030. Un escenario histórico singular que pone de manifiesto la necesidad de una Educación que garantice la equidad y la justicia social. Por ello, es fundamental analizar los principios y objetivos del Sistema Educativo, así como los enfoques y fines principales de la legislación educativa. Bajo esta lógica, el objetivo de la presente investigación es realizar un análisis crítico de las leyes educativas españolas (especialmente la recién aprobada LOMLOE) desde una perspectiva de género; comparando los avances y/o retrocesos que éstas han representado en materia de equidad e igualdad de oportunidades. Este análisis parte de la premisa de que un currículo educativo feminista promueve, no únicamente el Derecho Humano a la educación -y a una educación de calidad- sino, también, a la igualdad.

Cabe destacar que la presente investigación está vinculada a una tesis doctoral en curso, que tiene como objetivo estudiar el Sistema Educativo formal español y analizar aquellos vacíos que presenta en el abordaje del ecologismo y la equidad de género, a la vez que se visibilizan las potencialidades de fomentar valores ecofeministas en la etapa de Educación Primaria. La hipótesis de dicha tesis es que un currículo educativo encaminado hacia postulados ecofeministas representaría una alternativa pedagógica que promoviera aspectos como la justicia ecológica -basada en una ética socioambiental-, la justicia social -basada en el bien común y el fomento de la solidaridad y la democracia-, la equidad de género -al visibilizar y combatir actitudes androcentristas y sexistas- y un nuevo modelo de consumo -más ético y sustentable-.

\section{METODOLOGÍA}

Para realizar este breve recorrido por la evolución de la legislación reguladora del Sistema Educativo español, se han analizado las leyes educativas desde 1970 
mostrando especial interés en las transformaciones de los últimos 30 años, ya que durante este período se han llevado a cabo ciertas modificaciones legislativas que han influido directamente en la conformación del Sistema Educativo actual. Por tanto, la presente investigación es el resultado de una revisión documental que permite establecer las bases legislativas sobre el Sistema Educativo español y que, a su vez, se nutre de las bases teóricas de la perspectiva de género y los feminismos. Asimismo, se trata de un estudio descriptivo, puesto que pretende dibujar la realidad de la legislación española en materia de educación, aunque se llevará a cabo desde una perspectiva crítica.

\section{RESULTADOS Y DISCUSIÓN}

Al analizar bajo una perspectiva de género las leyes educativas que han estructurado el Sistema Educativo español de las últimas décadas, podemos ver que la LGE (1970) tenía un carácter totalmente sexista: la propia ley establecía que tanto los programas como las orientaciones pedagógicas o los métodos de enseñanza serían matizados en función del sexo del alumnado; diferenciando entre educación femenina y masculina. El hecho de que fuera el Ministerio de Educación quien estableciera dichas líneas de actuación demuestra que el sexismo era algo imperante en el contexto sociopolítico del momento y que el propio sistema legislativo establecía una serie de condiciones estructurales de desigualdad que justificaban la discriminación y la falta de igualdad de oportunidades. No fue hasta 1978, tras el fin de la dictadura franquista y con la entrada en vigor de la Constitución Española, que se estableció que toda la población española tenía los mismos derechos, sin discriminaciones por razón de sexo.

La LODE (1985) mencionaba en varios de sus artículos que no habría, bajo ninguna circunstancia, discriminación por motivos de nacimiento; aun así, en ningún apartado se menciona de forma específica la igualdad de género. Fue la LOGSE (1990) la ley que mencionó por primera vez en la legislación educativa la "igualdad entre sexos" y que estableció ciertos criterios para fomentar la no-discriminación. Sin embargo, la LOCE (2002), aunque estableció como principio básico la transmisión de valores que favorezcan la igualdad entre los sexos, no volvió a nombrar dichos valores en ningún otro apartado de la ley. Asimismo estableció que, en centros educativos confesionales, serían las autoridades religiosas quienes tuvieran la competencia de determinar el currículo educativo y el uso de libros y materiales didácticos; esto podría generar posibles situaciones de discriminación entre el alumnado por diferentes motivos, en primer lugar por razón ideológica y, en segundo lugar, porque -tal y como se ha demostrado a lo largo de la historia- la Iglesia católica puede llegar a perpetuar valores heteropatriarcales mediante sus discursos ${ }^{1}$.

En 2006 entró en vigor la LOE haciendo avances destacables en materia de igualdad: fue la primera ley educativa en incorporar la prevención de la violencia de género como objetivo de la educación; también fue la primera ley educativa en hablar de padres 'y madres', algo que, a pesar de que podría parecer una simple transformación en el lenguaje, no únicamente visibilizó a las madres, sino que abarcó la diversidad familiar existente -por ejemplo, aquellas familias homoparentales o monoparentales en las que no hubiera la figura paterna-. Asimismo, se nombró por primera vez en la legislación educativa el 'acoso escolar' y se estableció la actuación de los poderes públicos para abordarlo; desde una perspectiva de género, este aspecto es destacable ya que, tal y

\footnotetext{
${ }^{1}$ Importante destacar que cada vez existen más voces religiosas disidentes contra las visiones, los discursos y las prácticas más sexistas y homófobos de la religión católica y cada vez son mayores los estudios sobre teologías feministas. Para información sobre la historia de la teología feminista en España, véase Martínez (2018).
} 
como demostró el Colectivo de Lesbianas, Gays, Transexuales y Bisexuales de Madrid (COGAM) en su Informe sobre Cyberbullying LGBT-fóbico (2016, p. 21), la mayoría del alumnado que ha sufrido acoso escolar en los últimos años ha sido por actitudes patriarcales, homófobas o transfóbicas que atentaban contra su orientación afectivo sexual o identidad de género.

Por su parte, la LOMCE (2013), dictó en su artículo 124 una serie de normas de organización, funcionamiento y convivencia mediante las cuales se establecía que los centros educativos debían generar un Plan de Convivencia que tuviera como objetivo lograr comportamientos respetuosos en las escuelas; en él debían quedar reflejados los derechos y deberes del alumnado, las actuaciones de prevención de la violencia de género, igualdad y no discriminación que se llevaran a cabo y las medidas correctoras, cuyo carácter sería educativo y recuperador ${ }^{2}$. Bajo esta lógica, la actual ley educativa, la LOMLOE (2020), recuperando la disposición establecida por la LOE, garantiza la escolarización inmediata, y una especial atención, de aquel alumnado afectado por cambios de centro educativo derivados de actos de violencia de género o acoso escolar.

Asimismo, la LOMLOE recupera otros aspectos clave de la LOE en materia de igualdad de género como, por ejemplo, el principio de coeducación, estableciendo que los centros sostenidos parcial o totalmente con fondos públicos deberán desarrollar el principio de coeducación en todas las etapas educativas. Asimismo, los centros deberán diseñar un proyecto educativo anual que registre todas aquellas medidas acordadas que tengan como objetivo la educación en igualdad, incluyendo la educación para la eliminación de la violencia de género, el respeto por las identidades, culturas, sexualidades y su diversidad, y la participación activa para hacer realidad la igualdad. Dichas medidas deberán ser aplicadas de forma continuada y transversal en todas las etapas educativas; sin embargo, especifica ciertos objetivos concretos para cada una de las etapas educativas:

- Educación infantil: promover, aplicar y desarrollar normas sociales de igualdad de género.

- Educación Primaria y Secundaria: fomentar el respeto a las diferencias personales, la igualdad y la no discriminación desarrollando capacidades afectivas para construir relaciones sociales y vínculos afectivos alejados de la violencia y actitudes sexistas. La nueva asignatura de formación en valores cívicos y éticos trabajará con este objetivo.

- Bachillerato: consolidar una madurez personal, afectivo-sexual y social que permita prever, detectar y resolver posibles situaciones de violencia.

- Formación Profesional: fomentar la presencia de alumnas en ámbitos con menor demanda femenina y la presencia de alumnos en aquéllos con menor demanda masculina.

- Formación de personas adultas: fomentar la igualdad de derechos y oportunidades entre mujeres y hombres analizando de forma crítica las desigualdades existentes entre ellos.

Estas nuevas medidas nacen con la finalidad de garantizar la igualdad de derechos y oportunidades entre el alumnado, de fomentar la convivencia, el respeto y la prevención y resolución pacífica de conflictos y de formar al alumnado para que reconozca toda

\footnotetext{
${ }^{2}$ Las conductas de acoso y discriminación debían considerarse faltas muy graves e implicarían la expulsión, temporal o definitiva. Considerar los ataques a la dignidad humana como faltas graves es fundamental para poder abordar dicha problemática; no obstante, la consecuencia establecida -la expulsión- dificulta o, incluso, impide realizar un trabajo posterior para educar, corregir y reorientar dichas conductas violentas.
} 
forma de maltrato, abuso sexual, violencia, discriminación, etc. para lograr que tenga las competencias y habilidades adecuadas para abordar dichas situaciones. Asimismo, tanto el currículo educativo como los libros de texto y otros materiales didácticos deberán fomentar la igualdad entre hombres y mujeres y eliminar todo indicio de estereotipos sexistas, fomentado el respeto a los principios, valores, libertades, derechos y deberes constitucionales, así como la protección integral contra la violencia de género. Todos estos contenidos serán incluidos también en los programas de formación inicial del profesorado; éste deberá tener formación específica en igualdad y protección contra la violencia de género, en acoso y malos tratos y en prevención, detección y actuación frente a la violencia contra la infancia ${ }^{3}$.

\section{CONCLUSIONES Y LIMITACIONES}

Desde la creación de la Constitución Española (1978), la legislación educativa incluyó la igualdad de oportunidades entre sus objetivos principales y se fueron estableciendo leyes más progresistas o más conservadoras en materia de igualdad de género. Actualmente, se podría afirmar que lo planteado en la LOMLOE cumple con la exigencia básica de las pedagogías feministas -transformar las estructuras educativas y de transmisión de conocimiento tradicionales- al establecer como enfoque principal la igualdad de género y poner los Objetivos de Desarrollo Sostenible en el centro del Sistema Educativo español. No obstante, recuperando lo planteado por Rita Segato en Contra-Pedagogías de la crueldad (2018), existen ciertos aspectos que fomentan la incidencia de la educación en la justicia social y que sería conveniente que el Sistema Educativo español promoviera para lograr una real y verdadera transformación de paradigma, que se oponga a las violencias y desigualdades que el sistema heteropatriarcal impone y, por tanto, pueda apoyar y ayudar a desarrollar procesos coeducativos adecuados y efectivos. Algunos de estos aspectos son:

- La 'contra-pedagogía del poder': mayor cuestionamiento de los mandatos de la masculinidad hegemónica y todo lo que ésta provoca.

- Educación en masculinidades no hegemónicas: la LOMLOE visibiliza y problematiza las desigualdades entre sexos (enfoque, aunque binario, con muchos aspectos positivos e, incluso, necesarios), sin embargo, no hace tanto énfasis en las desigualdades y las violencias ejercidas entre el alumnado del mismo sexo. Es necesario fomentar la ruptura de los mandatos heteropatriarcales visibilizando cómo el machismo victimiza, silencia y oprime las masculinidades y nombrar la violencia en todas sus dimensiones (intra e inter-género).

- Pedagogía de las emociones, sexualidades y vínculos afectivos: fomentar relaciones de igualdad, libertad y respeto, valorizando los cuidados.

Asimismo, tal y como afirma Marina Subirats (2017), es necesario analizar tanto el currículo educativo como los libros de texto, ya que éstos representan para el alumnado verdades indiscutibles, saberes ciertos. Por ello, es fundamental analizarlos desde una perspectiva de género para identificar los sesgos androcéntricos y evitar, así, las consecuencias negativas que representa.

En conclusión, se puede observar que la LOMLOE tiene un fuerte propósito por avanzar hacia la equidad, el respeto a la diversidad, la educación en un mundo global y en

\footnotetext{
${ }^{3}$ La formación permanente del profesorado es entendida como un derecho, una obligación y una responsabilidad; considerándola fundamental para tener un equipo docente capaz de diseñar proyectos educativos adecuados y de dotar al alumnado de herramientas para generar vínculos de igualdad y no discriminación.
} 
garantizar el derecho a la educación. Esto podría ser entendido como una revolucionaria transformación del Sistema Educativo español, sin embargo -aunque todavía es pronto para poder analizar los resultados de los cambios planteados-, los aportes de la ley no suponen una reelaboración estructural del mismo; por tanto, los logros dependerán de la financiación y de la actuación de las administraciones y de las propias escuelas. No obstante, es necesario destacar el reconocimiento que la LOMLOE hace a la diversidad, a la educación como derecho fundamental y a la escuela como bien común; la Administración deberá comprometerse y garantizar que los valores que propone la nueva ley puedan plasmarse en las aulas. Para lograr sociedades más justas y una igualdad de género real, es necesario un cambio cultural, la LOMLOE facilita que el alumnado sea protagonista de dicho cambio; es el momento de aprovecharla en beneficio de toda la sociedad.

\section{REFERENCIAS BIBLIOGRÁFICAS}

COGAM (2016). Ciberbullying LGBT-fóbico: Nuevas formas de intolerancia. https://cogameduca.wordpress.com/ciberacoso-2015/

Constitución Española (1978, 29 de diciembre). Boletín Oficial del Estado, núm. 311.

Jefatura del Estado (1970, 06 de agosto). Ley 14/1970, General de Educación y Financiamiento de la Reforma Educativa. Boletín Oficial del Estado, núm. 187.

Jefatura del Estado (1985, 03 de julio). Ley Orgánica 8/1985, reguladora del Derecho a la Educación. Boletín Oficial del Estado, núm. 159.

Jefatura del Estado (1990, 03 de octubre). Ley Orgánica 1/1990, Ordenación General del Sistema Educativo, Boletín Oficial del Estado, núm. 238.

Jefatura del Estado (2002, 24 de diciembre). Ley Orgánica 10/2002, de Calidad de la Educación, Boletín Oficial del Estado, núm. 307.

Jefatura del Estado (2006, 03 de mayo). Ley Orgánica 2/2006, de Educación, Boletín Oficial del Estado, núm. 106.

Jefatura del Estado (2013, 09 de diciembre). Ley Orgánica 8/2013, para la Mejora de la Calidad Educativa, Boletín Oficial del Estado, núm. 295.

Jefatura del Estado (2020, 29 de diciembre). Ley Orgánica 3/2020, por la que se Modifica la Ley Orgánica 2/2006, de Educación, Boletín Oficial del Estado, núm. 340.

Martínez, S. (2018). 40 años de Teología Feminista en España. Resistencia y Creatividad. Carthaginensia. Vol. 34 (núm. 66), pp. 449-474. Recuperado de https://revistacarthaginensia.com/index.php/CARTHAGINENSIA/issue/view/3

Segato, R. (2018). Contra-pedagogías de la crueldad. Argentina: Prometeo libros.

Subirats, M. (2017). Coeducación, apuesta por la libertad. España: Ediciones Octaedro. 


\subsubsection{Covid-19 ¿Una oportunidad para un uso más equitativo del Patio Escolar?}

Haizea Unda (Universidad del País Vasco/Euskal Herriko Unibertsitatea, España); Nahia Idoiaga (Universidad del País Vasco/Euskal Herriko Unibertsitatea, España); Inge Axpe (Universidad del País Vasco/Euskal Herriko Unibertsitatea, España).

\section{Resumen}

En este trabajo se presenta una investigación preliminar en relación al uso y ocupación de los patios escolares durante la pandemia producida por la COVID-19. Han participado 14 docentes de la etapa de Educación Primaria respondiendo un cuestionario en relación a los juegos y la ocupación del espacio del patio escolar en función del sexo del alumnado. Se observa que, a pesar de que las medidas tomadas para hacer frente a la COVID-19 han favorecido, en parte, mayor interacción entre niños y niñas y un uso menos segregado del patio, todavía prevalece la hegemonía de los chicos, especialmente si se permiten juegos con balón. Estos resultados dan pie a reflexionar sobre los posibles cambios que podrían introducirse a partir de esta situación para fomentar un uso más equitativo de los recursos espaciales.

Palabras clave: COVID-19; patio escolar; juegos, género; uso desigual.

\section{INTRODUCCIÓN Y OBJETIVOS}

Hace unos meses, la pandemia del COVID-19 puso al sistema educativo ante uno de los mayores retos de este siglo (Soria, 2020). Como consecuencia de ello surgió la necesidad de establecer diversas medidas de prevención y control para garantizar la seguridad de la actividad educativa (Gobierno Vasco, 2020). Así, para evitar la transmisión del virus, se estableció un protocolo que ha influido en el día a día de la educación, las aulas y los patios (Gobierno de Navarra, 2020). Dentro de este protocolo se pueden encontrar 29 medidas y 5 recomendaciones para hacer frente a la COVID19, con instrucciones generales (Cobas, 2020). Entre las medidas relacionadas con el patio, se encuentra la de organizar los periodos de recreo de forma que se agrupe simultáneamente el menor número posible de alumnado, solicitando que se intensifiquen los turnos y prevaleciendo el criterio de que los grupos estables, de convivencia o "burbuja" no se encuentren a la misma hora y en el mismo espacio con otros grupos (Gobierno Vasco, 2020). Por tanto, los descansos están escalonados, y se obliga a que cada grupo de convivencia juegue en un lugar previamente delimitado (Gobierno de Navarra, 2020). Estos grupos de convivencia estable han sido denominados "grupos burbuja" y han sido creados con el objetivo de facilitar la actividad relacionada con la trazabilidad de casos y contactos de COVID-19. En estos grupos el alumnado no debe respetar la distancia de 2 metros, pero sí la distancia de 1 metro (Farreras, 2020). Por ello, es necesario organizar el tiempo de recreo, el patio y el comedor, incrementando los turnos y primando el criterio de que salgan al patio de manera simultánea la menor cantidad de grupos de convivencia estables, como se ha dicho, para que el alumnado de los diferentes grupos no se agolpe en una misma hora y espacio (Gobierno Vasco, 2020).

En cuanto a los juegos en los patios, se prohíbe el juego con balón, así como los juegos de contacto o el intercambio de objetos (cromos, discos, cuerdas) que traigan los niños y niñas (Gobierno de Navarra, 2020). El Gobierno Vasco (2020) recomienda evitar los juegos de contacto y los que suponen ejercicio físico. El renunciar a estos juegos supone, de este modo, que el curso 2020/21 sea el primer curso sin balón (Cobas, 2020) de manera generalizada. Así, el alumnado ha tenido que modificar la forma tanto de 
acudir a la escuela y jugar en el patio como el con quién comparte dichas horas de recreo (Franco, 2020). Siguiendo con las delimitaciones, también se explica que las zonas de juego deben estar señalizadas para cada grupo, acotando las mismas y respetando los turnos. Además, se permite adaptar o reducir el tiempo de juego en función de las necesidades de cada centro (Gobierno Vasco, 2020).

Debido a estas medidas, los juegos tradicionales han vuelto a aparecer, alterando totalmente la normalidad conocida hasta ahora (Franco, 2020).

Este nuevo escenario "desconocido" lleva a reflexionar sobre la situación vivida hasta el momento en los patios escolares debido a la socialización diferencial de género recibida. Así, se hace necesario observar si en este nuevo contexto puede seguir existiendo un uso no equitativo del espacio y los recursos disponibles en el patio por parte de niños y niñas. De hecho, este uso sería más notables y visible que nunca ya que cada docente está solo con el alumnado de su grupo, y se dedica por entero a su supervisión (Canelles, 2020). Los y las estudiantes no son personas ajenas a la sociedad, por lo que, aunque esta situación de pandemia parece que supone cambiar de raíz las principales prácticas anteriores a la COVID-19 y las dinámicas de los patios, las desigualdades de género pueden seguir apareciendo, ya que vivimos en una sociedad rodeada de sexismo (STECyL, 2020).

En este sentido, con motivo de la pandemia, se recomienda priorizar las zonas extensas y naturales. En estos espacios se dan más acciones integradoras a diferencia de lo que ocurre en los espacios asfaltados, en los que la mayoría de las prácticas deportivas son realizadas por chicos, ocupando el $70 \%$ de los espacios. Por tanto, además de ser una herramienta anti-covid adecuada, el juego al aire libre en espacios naturales también puede aportar beneficios para combatir la desigualdad (Vázquez, 2020).

Así, el objetivo de este trabajo sería conocer si en la situación actual de pandemia por la COVID-19 el profesorado de Educación Primaria considera que en el uso y ocupación del espacio del patio se reflejan relaciones desiguales o de poder (por razón de género) entre los niños y las niñas.

\section{METODOLOGÍA}

Este trabajo se enmarca dentro de una investigación más amplia incluida en un proyecto de Campus Bizia Lab de la Universidad del País Vasco / Euskal Herriko Unibertsitatea (UPV/EHU). Dentro de dicho proyecto se llevan a cabo, entre otros, distintos trabajos analizando aspectos de Educación Infantil, Educación Primaria y Educación Social.

Ese estudio se incluye dentro de una investigación en relación al uso de los patios escolares antes y después de la pandemia causada por la COVID-19. En este caso se contó con la participación de 14 profesores y profesoras de la etapa de Educación Primaria (12 mujeres y 2 hombres).

La herramienta empleada para obtener las respuestas del profesorado fue un cuestionario ad hoc formado por preguntas abiertas. En dicho documento se pedía al profesorado que observasen el uso del patio escolar por parte del alumnado durante 23 días. Además, se solicitó información complementaria mediante preguntas relativas al tipo de juegos practicados por los niños y las niñas, las relaciones entre alumnos y alumnas y el uso del espacio en función del sexo. Se cuestionó sobre el uso anterior y posterior a la irrupción de la pandemia por la COVID-19. En este trabajo se mostrarán únicamente las respuestas relativas a los juegos y la distribución de espacios durante la pandemia. 


\section{RESULTADOS Y DISCUSIÓN}

En relación a la reorganización del espacio, todo el profesorado participante afirma que se ha tenido que dividir el patio en diferentes zonas para que un solo grupo de convivencia ocupe cada una de ellas: "El espacio del patio ha quedado dividido en 3 zonas, teniendo que adaptarse los grupos al espacio habilitado", "Este año cada curso tiene su zona, por lo que en cada zona hay unos 45 estudiantes". Una docente reconoce que no se respetan del todo esas delimitaciones: "En el patio cada clase tiene su zona, aproximadamente con 21 estudiantes, bastante igualados en cuanto a sexo se refiere. Sin embargo, estos grupos de convivencia no siempre respetan al $100 \%$ la zona delimitada". Cabe destacar que 4 docentes señalan que además del espacio del patio escolar, el ayuntamiento les ha cedido otros lugares, por lo que salen a espacios como el skate-park, la plaza del pueblo o el parque contiguo al colegio. Es destacable también que 4 docentes afirman que se han establecido turnos: "El espacio está dividido en diferentes zonas, teniendo cada clase su zona y saliendo al patio a distintas horas", "Con motivo de la Covid-19, el patio está dividido en dos turnos y tres zonas, con un único grupo en cada espacio".

Respecto al uso en función del sexo de estas zonas delimitadas, 5 docentes han reconocido que sigue existiendo una distribución desigual en función del mismo. De estos, 4 destacan que los chicos ocupan el centro, manteniendo a las chicas en zonas periféricas: "Aunque en el frontón cubierto hay grupos mixtos, los chicos son los que más ocupan el centro, y las chicas los bancos", "Los chicos ocupan el centro del espacio que tienen definido y los juegos que realizan invaden también el espacio alrededor, tanto físicamente como a nivel sonoro", "Como quienes juegan al fútbol en el $90 \%$ de los casos son chicos, ocupan todo el espacio del centro. De esta forma, las chicas se quedan en un lado" o "A pesar de estar en el grupo convivencial del aula, no se da mayor interacción con las chicas, que quedan relegadas generalmente a las esquinas". La quinta figura docente indica que, aunque ha disminuido la segregación por razón de sexo, todavía se mantiene: "Hay menos diferencias en la distribución del espacio, pero todavía los chicos ocupan una parte mayor del mismo".

Dada la situación actual, los juegos practicados por el alumnado se repiten en las diferentes escuelas. De hecho, 13 participantes han destacado la presencia de juegos de movimiento ("carreras", "atrapar" ...): "Destacan las actividades de movimiento, correr, saltar a la cuerda y las coreografías de Tik - Tok". En el mismo sentido 9 personas mencionan juegos y actividades de psicomotricidad (sobre todo bailes) y 8 personas han destacado el juego simbólico. 6 docentes mencionan juegos tranquilos y 3 personas juegos de peleas o lucha. En 6 ocasiones se menciona el fútbol, señalando que lo realizan los chicos (con balón u con cualquier objeto similar): "Los chicos juegan con cualquier objeto redondo que se parezca a un balón", "En general los chicos son más proclives a jugar con el balón o la pelota".

En cuanto al lugar que ocupan estos juegos, 4 de las 6 personas que indican juegos de balón o fútbol no dudan en que este ocupa el centro: "los chicos son los que más participan en deportes, fútbol en la mayoría de los casos, situándose en el centro. Por tanto, se puede decir que estos juegos tienen una 'marca' de género masculina". Una profesora indica que otra actividad a la que juegan los chicos en el centro es el brillet. En cuanto a los juegos de lucha, las 3 personas que los mencionan afirman que los llevan a cabo los chicos: "en el juego de lucha casi todos son chicos, e invaden otros juegos". En el caso de las chicas, sin embargo, 3 docentes indican que ocupan la periferia: "Ellas se quedan en un lado hablando o saltando a la cuerda". Otras tres personas indican que entre las chicas destacan los bailes: "No se mezclan más por sexo ahora, las chicas de dedican a saltar a la cuerda en la esquina, a charlar o a hacer bailes de Tik-Tok". En cualquier caso, hay 3 docentes que no constatan diferencias por razón de género: "Han aumentado las interacciones entre alumnos y alumnas, prevaleciendo los juegos sin distinción de género", "Se ve más juego de grupo" o "los chicos no 
muestran tanta tendencia a ocupar el espacio central, ha aumentado la interacción entre chicas y chicos". En esta línea 2 personas consideran que ahora el juego simbólico se da de una manera más equilibrada entre ambos sexos, al igual que los juegos tranquilos, aumentado la presencia de grupos mixtos: "En los juegos más tranquilos, en cambio, interactúan ambos sexos". Una de las personas participantes señala que cuando salen al parque del municipio no se aprecian diferencias en función del sexo: "Cuando están en el parque, todo el alumnado juega junto".

\section{CONCLUSIONES Y LIMITACIONES}

En primer lugar, hay que señalar que todo el profesorado participante ha hecho referencia a las medidas que se han tenido que tomar para distribuir o turnar el uso del patio escolar, a fin de cumplir las directrices de medidas de seguridad (Gobierno Vasco, 2020). A pesar de que han encontrado testimonios que no coinciden con la renuncia este año al uso del balón (Gobierno de Navarra, 2020).

Esta nueva y desconocida situación de pandemia parece haber alterado en gran medida las dinámicas entre el alumnado, que, limitado a una zona específica y sin posibilidad de uso de material ha retomado juegos más tradicionales (Franco, 2020). Esta nueva distribución espacial, parece haber conseguido acabar, en gran parte, con la hegemonía del fútbol. Sin embargo, aunque se habla de una distribución del espacio más igualitaria, todavía se observa que los chicos siguen tendiendo a ocupar los espacios centrales. Es evidente, por tanto, que, aunque la nueva distribución del patio ha ofrecido la posibilidad de difuminar, en parte, el uso no equitativo que prevalecía antes de la pandemia, al vivir en una sociedad impregnada de sexismo (STECyL, 2020) aún se observa una distribución no igualitaria de los recursos. No obstante, la restricción del uso del balón, así como recurrir (o crear) espacios naturales (Vázquez, 2020) en el patio podría contribuir a un uso más igualitario y equitativo del mismo para todo el alumnado.

\section{REFERENCIAS BIBLIOGRÁFICAS}

Cobas, M. (2020, septiembre, 9). Mariolas, 3 en raya o ajedrez como alternativas al balón en el patio. La voz de Galicia

Canelles, N. (2020). Covid-19 y la diversidad en las escuelas: desigualdades, privilegios y opresiones. Filalagulla.

Gobierno Vasco (2020). Euskal Autonomia Erkidegoko ikastetxeetan koronabirusaren (sars-cov-2) aurrean zer-nola jarduteko protokolo orokorra. 2020-2021 ikasturtea. Eusko Jaurlaritzaren Argitalpen Zerbitzu Nagusia.

Farreras, C. (2020, septiembre, 12). Guía para tener claras las medidas anti Covid en los colegios. La Vanguardia. https://www.lavanguardia.com/vivo/mamas-ypapas/20200912/483402507263/medidas-vuelta-cole.html

Franco, L. (2020, octubre, 6). La rayuela o el pañuelo: la pandemia devuelve a los colegios los juegos de siempre. El País. https://elpais.com/mamas-papas/202010-06/la-rayuela-o-el-panuelo-la-pandemia-devuelve-a-los-colegios-losjuegos-de-siempre.html

Gobierno de Navarra. (2020). Itzultzera goaz. Ikasturte honetan, segurtasuna izango da irakasgai garrantzitsuena. Nafarroako Gobernua.

Soria, L. (2020). La escolarización en tiempos de COVID-19. FEVAS Plena inclusión en Euskadi, 17, 17-30. 
STECyL (2020, mayo, 25). Coeducacion e lgualdad en tiempos del Coronavirus. STECyL-i. Federación de Sindicatos de Trabajadores de la Enseñanza de Castilla y León. https://stecyl.net/coeducacion-e-igualdad-en-tiempos-delcoronavirus/

Vázquez, S. (2020, octubre 30). ¿Educación al aire libre? Sobra cemento y falta verde y supervisión. El Correo. https://www.elcorreo.com/familias-bbkfamily/educacion-aire-libre-20201027185701-nt.html

NOTA: este trabajo se ha llevado a cabo en el marco del Programa Campus Bizia Lab (el Campus como Laboratorio) con una subvención de la Dirección de Sostenibilidad del Vicerrectorado de Innovación, Compromiso Social y Acción Cultural de la Universidad del País Vasco (UPV/EHU). Este programa cuenta con el apoyo del Gobierno Vasco. 


\author{
1.1.6. La Brecha Digital de Genero en Educación Primaria y \\ Secundaria en España \\ Mireia Usart (Universitat Rovira i Virgili, España); Carme Grimalt-Álvaro (Universitat \\ Rovira i Virgili, España); Vanessa Esteve-González (Universitat Rovira i Virgili, \\ España), Mercè Gisbert-Cervera (Universitat Rovira i Virgili, España).
}

\title{
Resumen
}

A pesar de las reformas curriculares en educación, se observa una brecha digital de género que se inicia en la escuela primaria y crece durante la educación secundaria, resultando en una menor elección por parte de las estudiantes, de las áreas de ciencia, tecnología, ingeniería y matemáticas (STEM). El objetivo del proyecto MindGap es medir la brecha digital de género en España, analizando la diferencia en la autopercepción de la competencia digital (CD) de los y las estudiantes. Este artículo presenta los resultados preliminares del proyecto, centrados en el análisis cuantitativo de la CD autopercibida en primaria y secundaria, en relación con la elección de estudios STEM, en una muestra representativa de estudiantes españoles $(n=4936)$. Los resultados confirman la existencia de la brecha digital de género desde primaria, y apunta hacia la autopercepción de la CD como predictor de la elección de estudios STEM en secundaria.

Palabras clave: Educación Primaria, Educación Secundaria; STEM; Competencia Digital, Brecha digital de género.

\section{INTRODUCCIÓN Y OBJETIVOS}

A pesar de los proyectos educativos que pretenden abordar las desigualdades de género en las áreas STEM, las mujeres siguen matriculándose en menor número año tras año, en estudios de las áreas STEM, en concreto en ingenierías y arquitectura (European Schoolnet, 2018). Esta ausencia de mujeres ha propiciado el desaprovechamiento del potencial latente de este género en ámbitos de desarrollo, como la protección del medio ambiente, salud, alimentación; campos donde la innovación, la ciencia y la tecnología son fundamentales (Ferrant \& Kolev, 2016). A estos problemas de desigualdad se le suman los generados por la pandemia del COVID19, en concreto en términos de equidad y calidad de los procesos educativos (UNESCO, 2018; Zhang et al., 2020).

Estudios como el de Wang y Degol (2017) concluyen que hay tres razones responsables de la baja representación de las mujeres en el área STEM: (1) intereses o preferencias ocupacionales; (2) estilo de vida y equilibrio entre el trabajo y la familia; y (3) creencias sobre competencias específicas, estereotipos y sesgos relacionados con el género. Es este último punto el que centra nuestro estudio. La baja representación femenina en estudios STEM se debe, en gran parte, a creencias y autopercepciones sesgadas de las propias capacidades, más que al nivel de desarrollo en sí. Por ende, para reducir el desequilibrio de género en estudios STEM, debemos investigar no solo el nivel de desarrollo de competencias, sino también su autopercepción.

En España se ha identificado una brecha digital de género entendida como la diferencia entre la competencia digital (CD) de hombres y mujeres, determinando el uso efectivo de las Tecnologías Digitales (TD) (Mateos-Sillero \& Gómez-Hernández, 2019). Los datos indican que esta brecha existe en los diferentes niveles educativos. Alrededor de los 6 a 7 años, los estereotipos ya dificultan la percepción de las niñas sobre sus propias habilidades (Bian et al., 2017) aunque éstas tienen un rendimiento similar o superior al 
de los niños (Martínez-Piñeiro et al., 2019). En educación secundaria, la mayoría de los estudios apuntan a la CD como un aspecto clave para que las chicas elijan estudios STEM (González de San Román \& De la Rica, 2013).

Tras esta breve revisión de literatura presentamos las dos primeras fases del proyecto de investigación MindGap (SR0071 2019- 200122), cuyo objetivo es medir la brecha digital de género en primaria y secundaria y discutir los resultados preliminares entorno a la autopercepción de la CD y la elección de estudios STEM en España. Este objetivo general se concreta en dos preguntas de investigación:

PI1: ¿Existe una brecha digital de género entre estudiantes de educación primaria y secundaria en España? y ¿En qué habilidades digitales se observan diferencias significativas?

PI2: ¿Existen diferencias significativas en la autopercepción de la CD, en relación con la elección de estudios STEM / no STEM en secundaria?

\section{METODOLOGÍA}

Este estudio de corte cuantitativo y descriptivo presenta un diseño de encuesta que utiliza tres cuestionarios diferentes adaptados a cada muestra, todos centrados en medir la autopercepción de la CD, con el fin de dar respuesta a las preguntas de investigación en una muestra representativa de estudiantes de primaria i secundaria españoles.

\section{Muestra}

En el proyecto MindGap se está llevando a cabo un muestreo aleatorio estratificado con $p=0,05$. La muestra surge de la población total de estudiantes españoles de educación primaria y secundaria. Se tiene en cuenta el peso relativo de la población, considerando a cada institución educativa como un estrato. En los estratos se realiza una muestra polietápica, en la que se eligen primero los centros y luego los grupos dentro de estos centros. A los y las estudiantes encuestados se les asigna un número en el conjunto de datos, para cumplir con los estándares éticos de registro de datos.

Los datos presentados en este artículo son parte de este proceso de muestreo y se corresponden con la primera toma de datos, llevada a cabo entre diciembre de 2020 y abril de 2021.

\section{Instrumentos}

La CD auto percibida se midió con las tres versiones adaptadas a cada muestra (nivel educativo) del Inventario de Competencias en Tecnologías de la Información y la Comunicación (INCOTIC) (González et al. 2012). El primer cuestionario (etapa inicial de educación primaria) evalúa la autopercepción y el sesgo de género en competencia matemática y CD mediante 9 ítems de respuesta múltiple (No, Sí, Mucho). El segundo, evalúa la CD del alumnado de entre 10 y 17 años en base a las cuatro dimensiones de alfabetización descritas por Larraz (2013) más la dimensión tecno ética (Figura 1) mediante 20 ítems en escala Likert de 5 puntos: Alfabetización informacional $(\alpha=0,71)$, tecnológica $(\alpha=0,62)$, multimedia $(\alpha=0,66)$, comunicativa $(\alpha=0,78)$ y tecnoética $(\alpha$ $=0,69$ ). Para responder a la segunda pregunta, se incorporan a INCOTIC diferentes preguntas que recogen información: elección de estudios STEM y datos demográficos como edad y género. 


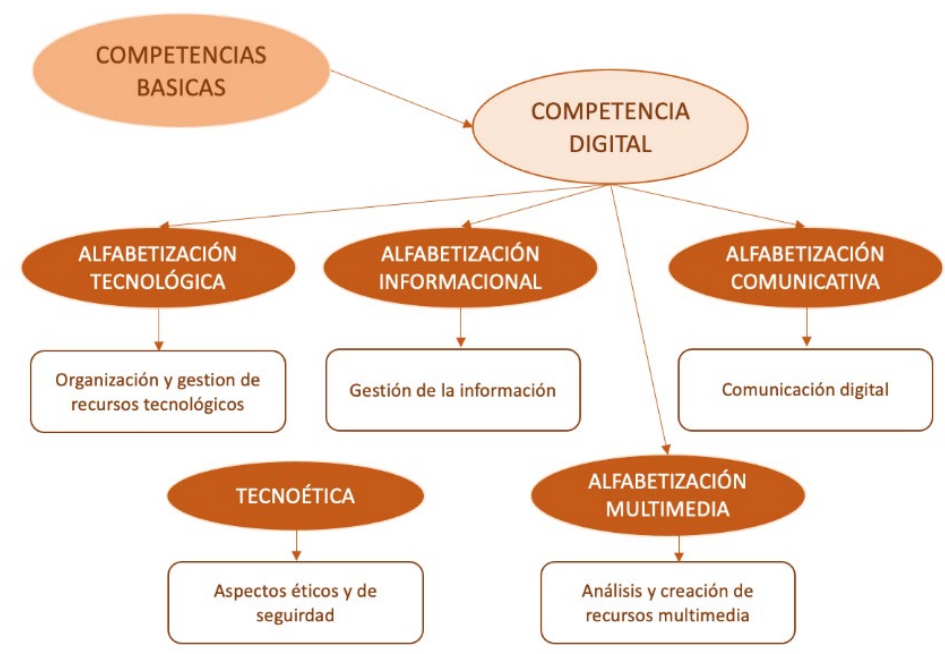

Figura 1. La Competencia Digital y sus dimensiones. Fuente: adaptado de Larraz (2013)

\section{Procedimiento y análisis de datos}

En la Figura 2 se muestran los diferentes cursos en los que se lleva a cabo la toma de datos sobre la CD auto percibida y la elección de estudios STEM, así como los instrumentos anteriormente mencionados, todos ellos implementados y accesibles en línea mediante la aplicación Alchemer. Los centros participantes fueron contactados por diferentes medios, e invitados a participar en el estudio, siendo informados del detalle del proyecto, ofreciendo la elaboración de un informe personalizado sobre el nivel de CD del alumnado para cada grupo-clase como agradecimiento. En color se muestran los niveles concretos de estas dos primeras fases del proyecto que se presentan en este estudio. Los datos se han analizado con el programa JASP $\vee 0.11 .1$. Debido a la naturaleza de las variables, para estudiar las diferencias de género se aplicó la prueba chi-cuadrado $\left(\mathrm{X}^{2}\right)$ a un nivel de significancia de 0.05 (Cohen et al., 2007)

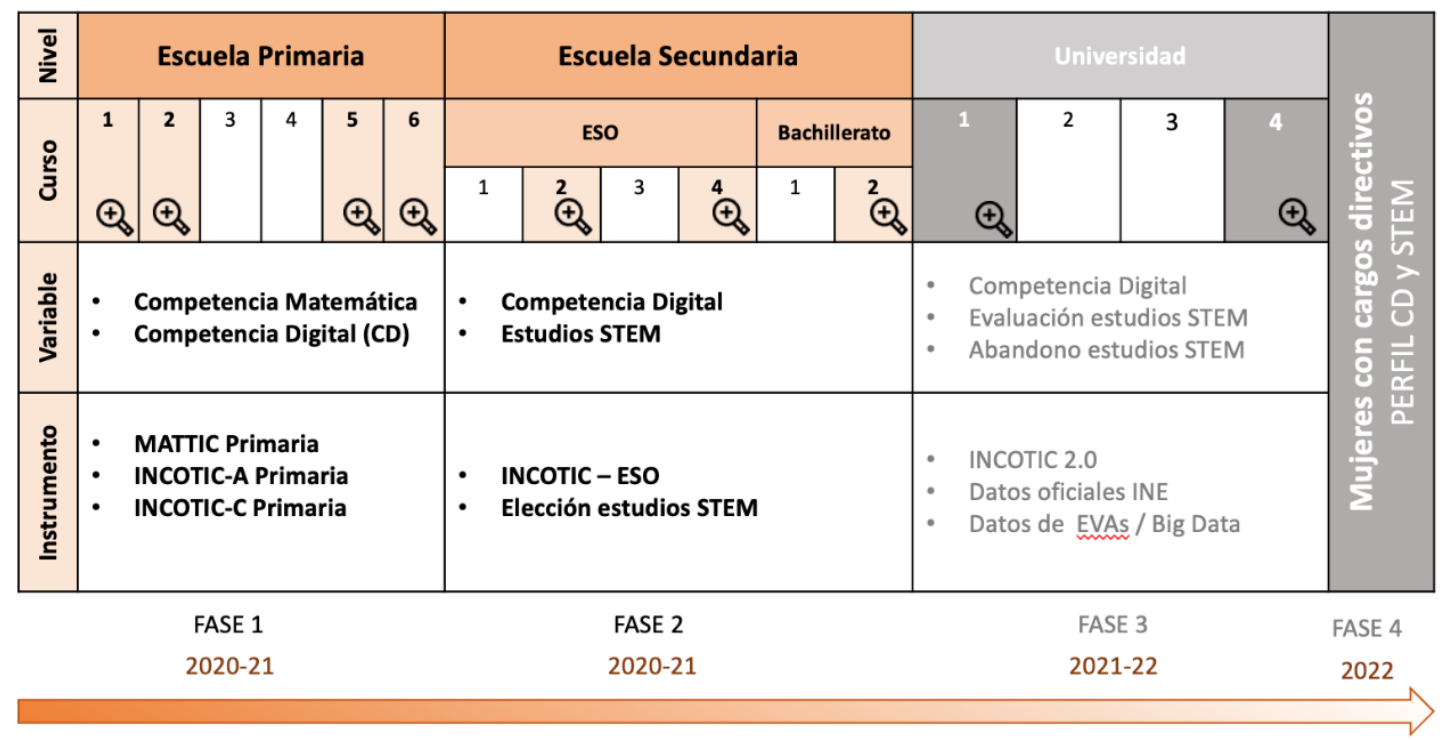

Figura 2. Detalle de las fases del diseño de investigación de MindGAP 
Presentamos en este apartado los resultados principales correspondientes con las preguntas $\mathrm{PI} 1$ y $\mathrm{PI}$.

Muestras. La muestra 1 está compuesta por 284 estudiantes de primer ciclo de primaria (Edad media: 6,38+0,64) años; $52 \%$ niños, $46 \%$ niñas, $2 \%$ no binario), muestra 2: 758 estudiantes de $5^{\circ}$ y $6^{\circ}$ de primaria (Edad media: $11,10 \pm 0,59 ; 47 \%$ niños, $51 \%$ niñas, $2 \%$ no binario); muestra 3: 3894 estudiantes de secundaria (Edad media: 14,84+2,15; 49\% chicos, $48 \%$ chicas, $3 \%$ no binario).

PI1. Para entender dónde se inicia la brecha digital de género nos hemos fijado en la etapa inicial de primaria. Presentamos los resultados del cuestionario sobre género y percepción sobre las TD y las matemáticas como área STEM definida en este nivel (Figura 3):

\section{Y C. MAT. PRIMER CICLO PRIMARIA}

\section{$\mathrm{NO} \otimes \mathrm{SI} \otimes \mathrm{MUCHO}$}

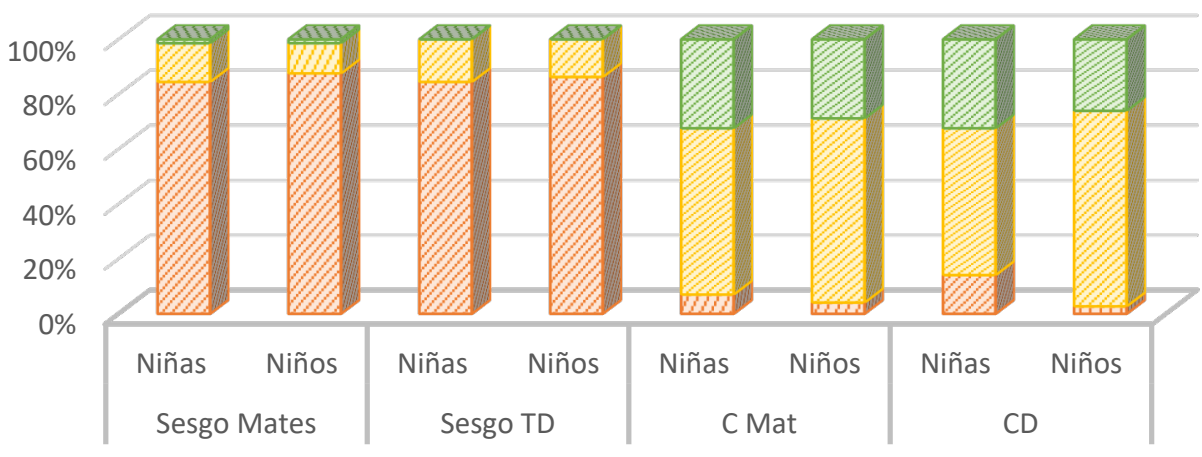

Figura 3. Resultados (en \%) sobre autopercepción competencial en $1^{\circ}$ y $2^{\circ}$ de primaria

Las niñas creen que son menos competentes que sus compañeros $\left(x^{2}=7,87 ; \mathrm{df}=144\right.$; $p=0,02)$. Además, vemos que hay un sesgo de percepción, en concreto en la competencia matemática: un $20 \%$ del alumnado cree que los niños son mejores o mucho mejores que las niñas en matemáticas, algo que hasta ahora no se había medido en nuestro país (Bian et al. 2017). Estos resultados apuntan a la persistencia de la brecha de género digital y también matemática en nuestro país en edades tempranas (6-7 años) y están acorde con estudios previos internacionales sobre la peor percepción de las niñas en CD (Else-Quest et al., 2010).

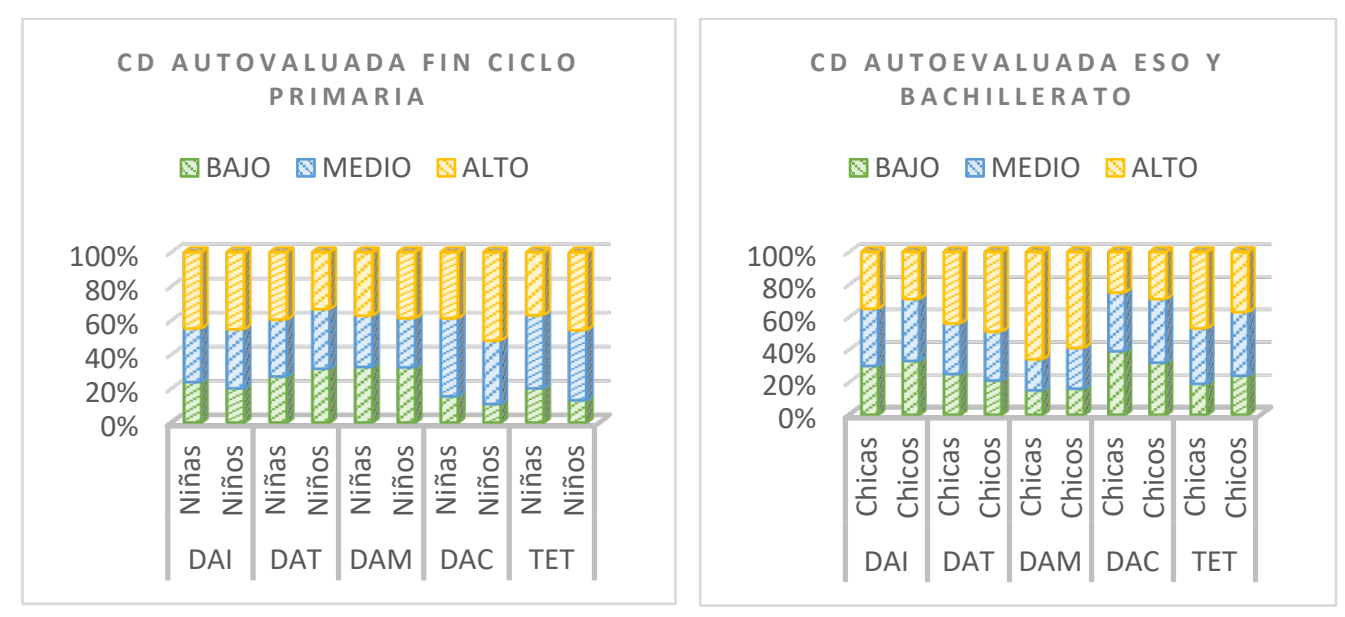


Figura 4. Resultados (en \%) por género de las alfabetizaciones de la CD para la (a) muestra de $5^{\circ}$ y $6^{\circ}$ de primaria; (b) muestra de ESO y bachillerato.

Los resultados de INCOTIC para la muestra 2 nos permiten ver en detalle dónde se encuentran las diferencias de CD al terminar la educación primaria. Observamos que en todas las alfabetizaciones excepto en la tecnológica (Figura 4a) los chicos se perciben más competentes que sus compañeras. Aun así, hay diferencias significativas sólo en la alfabetización comunicativa $\left(X^{2}=16,83 ; \mathrm{df}=6 ; p=0,01\right)$. En secundaria los resultados se mantienen para esta alfabetización, pero mejoran en las dimensiones informacional, multimedia y tecnoética. Estos resultados complementan los estudios que miden que en promedio las chicas obtienen puntuaciones más altas en todas las áreas de la CD evaluada (Martínez-Piñeiro et al., 2019), y confirman la necesidad de trabajar no tanto en el desarrollo competencial, sino en mejorar la autopercepción entre las alumnas, sobre todo de aspectos comunicativos y tecnológicos, estos últimos íntimamente relacionados con las áreas STEM.

PI2. Los resultados sobre autopercepción de la CD según la elección de estudios STEM se muestran en la Figura 5 y muestran que el alumnado que quiere estudiar carreras relacionadas con las ciencias y matemáticas, ingenierías y arquitectura, se percibe más competente digital comparado con aquellos que eligen carreras no STEM (incluyendo las correspondientes con ciencias de la salud), como ya apuntaban Voyer y Voyer (2014). Además, dentro de estos dos grupos, las chicas se perciben como muy competentes en un $70 \%$, mientras los chicos se consideran sólo en un $50 \%$ como muy competentes digitalmente.

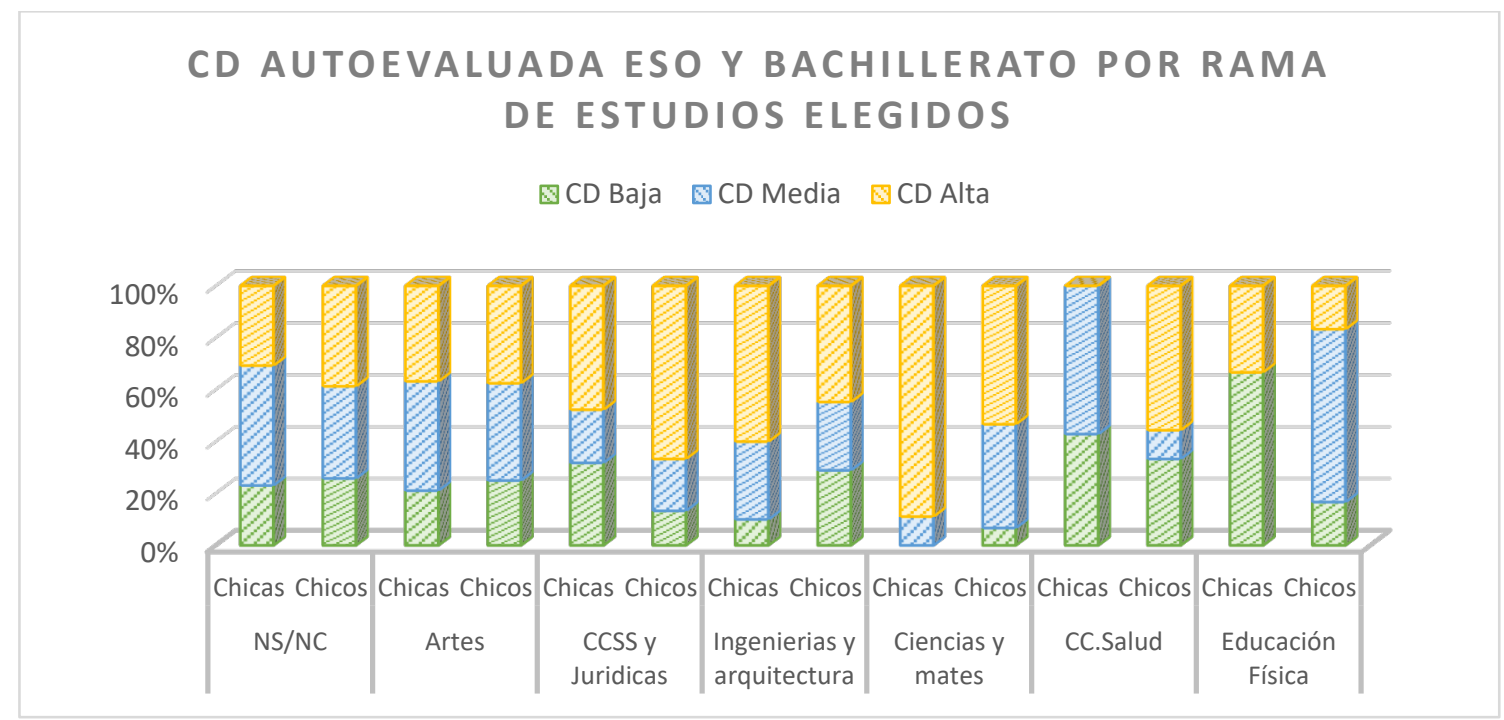

Figura 6. Autopercepción de la CD según elección de área de estudios futuros.

Estos resultados confirman que, como indicábamos en la introducción, y en base a la teoría presentada por Wang y Degol (2017), para lograr que más mujeres accedan a carreras STEM es necesario mejorar las creencias sobre su propia capacidad, para ello, acompañarlas en la mejora de su propia percepción como competentes digitales es un paso clave.

\section{CONCLUSIONES Y LIMITACIONES}

Nuestro estudio pretendía medir la brecha digital de género en primaria y secundaria y discutir los resultados preliminares entorno a la autopercepción de la CD y la elección 
de estudios STEM en España. Como limitaciones cabe indicar los aspectos referidos a la muestra, aun preliminar, junto con el bajo porcentaje de alumnado que se identifica como no binario, razón por la que no se pudo incluir a este grupo en el análisis. Los datos de secundaria se deben analizar más en profundidad incluyendo los datos de asignaturas STEM y el nivel socioeconómico, para entender mejor los factores para tener en cuenta para futuros cambios curriculares que incluyan la perspectiva de género.

Estos hallazgos serán útiles para docentes e investigadoras como un primer paso para entender la autopercepción del alumnado de primaria y secundaria en CD en España. En concreto estos resultados han puesto sobre la mesa un sesgo de género importante entre el alumnado más joven en cuanto a capacidades digitales y matemáticas. Este dato debe ayudar a establecer acciones formativas con perspectiva de género que se inicien en primaria. Proponemos actuar preventivamente desde la acción docente con el uso inclusivo del lenguaje, la presencia y refuerzo de modelos femeninos y el desarrollo de propuestas didácticas que puedan contribuir a mejorar el grado de autopercepción de las alumnas respecto a las habilidades matemáticas y digitales, recomiendan que las actividades divulgativas STEM con perspectiva de género se centren en involucrar sólo a las niñas con percepciones negativas y autopercepción baja hacia STEM, y además recomiendan que estas niñas se enfrenten a desafíos con soluciones fácilmente alcanzables, lo que podría aumentar su autoeficacia en estas ramas. También permitirán ayudar a disminuir la brecha de género mediante acciones preventivas que vayan, no dirigidas a despertar vocaciones STEM, sino a mejorar la autopercepción en habilidades relacionadas, como la digital o la matemática, desde edades tempranas.

El proyecto que condujo a este trabajo ha recibido financiación de la Fundación Bancaria "la Caixa" con el código de proyecto "LCF/PR/SR19/52540001".

\section{REFERENCIAS BIBLIOGRÁFICAS}

Bian, L., Leslie, S. J., \& Cimpian, A. (2017). Gender stereotypes about intellectual ability emerge early and influence children's interests. Science, 355(6323), 389-391 https://doi.org/10.1126/science.aah6524

Cohen, L., Manion, L., \& Morrison, K. (2007). Research methods in education. Routledge.

Comisión Europea (2018). Education and Training Monitor 2018. Country analysis. Publications Office of the European Union: Luxembourg.

González de San Román, A., \& De la Rica, S. (2013). Brechas de género en los resultados de PISA: el impacto de las normas sociales y la transmisión de roles de género de madres a hijas. Estudios de Economía Aplicada, 34, 79-108.

Else-Quest, N.M., Hyde, J.S., \& Linn, M.C. (2010). Cross-national patterns of gender differences in mathematics: A meta-analysis. Psychological Bulletin, 136(1),103127. https://doi.org/10.1037/a0018053

European Schoolnet (2018). Science, Technology, Engineering and Mathematics Education Policies in Europe. Scientix Observatory Report.

Ferrant, G. \& Kolev, A. (2016). Does gender discrimination in social institutions matter for long-term growth?: Cross-country evidence. OECD Development Centre Working Papers, No. 330, OECD Publishing, Paris. https://doi.org/10.1787/5jm2hz8dgls6-en 
Larraz, V. (2013). La competència digital a la Universitat. Tesis doctoral. Universitat d'Andorra.

Martínez-Piñeiro, E., Gewerc, A., \& Rodríguez-Groba, A. (2019). Nivel de competencia digital del alumnado de educación primaria en Galicia. La influencia sociofamiliar. RED. Revista de Educacion a Distancia, 61(1). https://doi.org/10.6018/red/61

González-Martínez, J., Espuny-Vidal, C., de Cid, M. J., \& Gisbert-Cervera, M. (2012). INCOTIC-ESO. Cómo autoevaluar y diagnosticar la competencia digital en la Escuela 2.0. Revista de Investigación Educativa, 30(2), 287-302. https://doi.org/10.6018/rie.30.2.117941

Mateos-Sillero, S., \& Gómez-Hernández, C. (2019). Libro blanco de las mujeres en el ámbito tecnológico. Secretaría del Estado para el avance digital. Ministerio de economía y empresa.

UNESCO (2019). Descifrar el código: La educación de las niñas en ciencias, tecnología, ingeniería y matemáticas (STEM). Francia: UNESCO.

Voyer, D., \& Voyer, S.D. (2014). Gender differences in scholastic achievement: A metaanalysis. Psychological Bulletin, 140(4), 1174-1204. https://psycnet.apa.org/doi/10.1037/a0036620

Wang, M. T., \& Degol, J. L. (2017). Gender Gap in Science, Technology, Engineering, and Mathematics (STEM): Current Knowledge, Implications for Practice, Policy, and Future Directions. Educational Psychology Review, 29(1), 119-140. https://doi.org/10.1007/s10648-015-9355-x

Zhang, W., Wang, Y., Yang, L., \& Wang, C. (2020). Suspending classes without stopping learning: China's education emergency management policy in the COVID-19 Outbreak. Journal of Risk and Financial management, 13, 55. https://doi.org/10.3390/jrfm13030055 


\subsubsection{Estereotipos en la Imagen de Ciencia y Científico en un}

Grupo de Niñas y Niños de la Región de Valparaíso-Chile Jennifer Venegas-Espinoza (Doctoranda Universitat de Barcelona, España).

\section{Resumen}

Esta investigación examina cómo un grupo de niños y niñas chilenos de entre 9 y 13 años matriculados en escuelas financiadas con fondos públicos, perciben la ciencia y a quienes la practican, incorporando la perspectiva de género como eje central del proceso investigativo. A partir del instrumento Draw-a-Scientis Test (versión adaptada), se ha podido observar cómo las niñas son quienes dibujan con mayor frecuencia científicos de género femenino. La presencia de elementos más estereotipados hace alusión al contenido epistémico de los dibujos, esto es, un científico en un laboratorio, rodeado de instrumentos y tecnología y realizando mediciones. Asimismo, el estudio ha permitido observar que son los niños más que las niñas quienes incluyen este tipo de recursos en sus dibujos.

La importancia de investigaciones con perspectiva de género en el ámbito de la educación científica, permite revelar estereotipos respecto de la ciencia, que al ser ésta estereotipada, con cierta supremacía del género masculino, podría perpetuar desigualdades de género en el desarrollo de vocaciones científicas y en el interés por la ciencia en general.

Ante una realidad y datos generalizados alrededor del mundo, se requiere de la implicación de todos los agentes participantes en los procesos educativos (autoridades, centros educativos, profesorado, familias, entre otros) para así poder hacer frente a esta pérdida de vocaciones científicas con la consiguiente pérdida económica y de excelencia científica.

Palabras clave: estereotipos de género; educación primaria; naturaleza de la ciencia; percepción de los estudiantes; Draw-a-Scientist Test (DAST).

\section{INTRODUCCIÓN Y OBJETIVOS}

A lo largo de los años se han evidenciado discursos en torno a una hegemonía masculina en el campo de la ciencia, tanto a nivel práctico como simbólico. Las mujeres son contratadas en menor medida que los hombres en las distintas instituciones científicas (Shaw y Stanton, 2012; Sheltzer y Smith, 2014), reciben un menor número de invitaciones a equipos de investigación o congresos (Nittrouer, Hebl, AshburnNardo, Trump-Steele, Lane, y Valian, 2017), y también es sabido que reciben un menor salario (Moss-Racusin, Dovidio, Brescoli, Graham y Handelsman, 2012; Shen, 2013). Según la Organización de las Naciones Unidas para la Educación, la Ciencia y la Cultura -UNESCO- (2017), en 2017, solo el $28 \%$ de los investigadores del mundo eran mujeres, teniendo además una menor presencia en los puestos de mayor relevancia académica (Montecino y Pemjean, 2011)

Ante este escenario cobra especial importancia el conocer las imágenes y representaciones que las personas tenemos de la ciencia y de quienes la practican. Margaret Mead y Rhoda Metraux (1957), investigaron sobre una muestra de 35.000 estudiantes de secundaria estadounidenses sobre cómo veían éstos a los "científicos", scientist en estricto rigor, logrando describir a un hombre, de mediana o avanza edad, con anteojos y guardapolvos (bata de laboratorio blanca). 
Posteriormente, nuevas investigaciones dan cuenta de la misma situación (Chambers, 1983; Driver, Leach, Millar y Scott, 1996; Finson, 2003; Lee y Kwon, 2018), la imagen sigue bastante estática o con variaciones poco significativas. Se sigue identificando a un hombre blanco (Akcay, 2011; Barman, 1999; Jane, Fleer y Gipps, 2007), solitario (Barman, 1999), en un espacio delimitado (laboratorio) (Akcay, 2011; Erten, Kiray y SenGumus, 2013; Jane et al., 2007) y con materiales que se asocian a las clases de química (matraces, tubos de ensayo, mecheros, etc.).

En este contexto, la siguiente investigación tiene como objetivo explorar los estereotipos asociados a la imagen de ciencia y de científico presente en estudiantes de nacionalidad chilena, pertenecientes a un grupo de escuelas sostenidas con fondos públicos, ubicadas en la región de Valparaíso (zona central y costera de dicho país).

\section{METODOLOGÍA}

Para la recolección de los datos se utilizó el instrumento Draw-a-Scientist Test (DAST), "Dibuja un científico", estrategia desarrollada por Chambers (1983) y aplicada en todo el mundo. El test permite evaluar la representación que hacen los y las estudiantes de la ciencia y de quienes la practican.

Además, para este estudio en particular se tomaron en consideración las recomendaciones de Manzoli, Castelfranchi, Gouthier y Cannata (2006) y Toma, Greca, y Orozco (2018).

A cada grupo participante se le entregó una hoja con la siguiente instrucción "Imagina que vas de viaje a ver cómo se hace ciencia. Dibuja quién hace ciencia, cómo es, dónde trabaja y qué hace" (Toma et al, 2018), esta instrucción basada en Farland-Smith (2012) y adaptada por Toma et al. (2018) permite reducir los sesgos asociados al género de quienes hacen ciencia.

Sumado a lo anterior y tomando en consideración las observaciones de Manzoli et al. (2006) se les brindó la siguiente instrucción "Comenta y describe ¿Qué está/n haciendo la/s persona/s de tu dibujo?", permitiendo así contextualizar y "movilizar" la imagen dibujada.

En este estudio participaron 125 estudiantes de educación primaria, con edades comprendidas entre los 9 y los 13 años. La muestra incluyó 29 personas identificadas con la representación de género femenino, 87, masculino y 3 con la no binaria. Todos los estudiantes participantes estaban matriculados en instituciones financiadas con fondos públicos de carácter municipal o subvencionado/concertado ubicadas en la región de Valparaíso, zona central de Chile.

\section{RESULTADOS Y DISCUSIÓN}

Del total de dibujos analizados, se debe mencionar que tan solo un $23 \%$ representó científicas, mientras que un $57 \%$ representó científicos y en un $20 \%$ de los casos, los dibujos no permitieron identificar una representación clara del género.

El análisis del género de los estudiantes participantes y el del científico dibujado (utilizando solo los dibujos en los que fue posible determinar el género del científico) mostró una relación estadísticamente significativa $\left(x^{2}=16,730, \mathrm{df}=2, p=.000\right)$, lo que evidencia una relación entre el género de la niña o niño que dibuja y el género del científico dibujado.

Respecto a los rasgos físicos descritos a través de los dibujos, cabe mencionar que sólo un $15 \%$ de los científicos aparece con bata de laboratorio, siendo las chicas $(20,7 \%)$ 
quienes con mayor frecuencia que los chicos $(13,8 \%)$ tienden a dibujarlos con esta vestimenta.

En un $18 \%$ de los dibujos, las y los estudiantes representaron la figura del investigador utilizando gafas. No se observan aquí mayores diferencias entre chicas y chicos, así como tampoco con la representación de género no binaria.

En relación con el vello facial, un $7 \%$ de los científicos representados tenía algún tipo de vello en el rostro (barba, bigote), no observándose aquí tampoco variaciones por género.

Un $27 \%$ de los estudiantes participantes dibujó la figura del científico con cabello desordenado, siendo las chicas (31\%) las que tendieron a dibujar esta característica con mayor frecuencia que los chicos $(24,1 \%)$. En relación con la expresión facial, se pudo observar que un $50 \%$ de los estudiantes dibujó un "rostro amigable" y solo un $25 \%$ un "rostro hostil". Las chicas (69\%) más que los chicos (42,5\%) tienden a dibujar rostros amigables y los chicos $(28,7 \%)$ tienden más que las chicas $(17,2 \%)$ a dibujar rostros hostiles.

De la observación de los dibujos sobre la representación de la ciencia se desprende que un $52 \%$ de los casos el científico se localiza en un laboratorio, siendo los chicos $(57,3 \%)$ más que las chicas $(48,3 \%)$ quienes dibujan este espacio. A esta localización le siguen en importancia las aulas de clases, siendo las niñas (31\%) más que los niños $(18 \%)$ quienes tienden a dibujar éstas como el espacio de trabajo de las y los científicos. Las personas identificadas como no binarias mayoritariamente dibujaron las clases como el espacio de trabajo más frecuentes $(83,3 \%)$.

Un $73 \%$ de los dibujos incluyó algún símbolo de investigación (instrumentos y equipamiento de laboratorio, por ejemplo, tubos de ensayo), siendo los chicos $(79,8 \%)$ más que las chicas $(69 \%)$ quienes incluyeron en mayor cantidad estos recursos.

En un $45 \%$ de los dibujos se incluyó algún producto de la ciencia (soluciones en tubos de ensayo, vacunas, maquinaria tecnológica), siendo también aquí los chicos $(50,6 \%)$ más que las chicas $(37,9 \%)$ quienes incluyeron estos recursos en sus dibujos.

Sólo en un $39 \%$ de los dibujos se incluyó algún símbolo de conocimiento (como pizarras, libros o estanterías), siendo las chicas $(48,3 \%)$, así como la representación de género no binaria $(83,3 \%)$ quienes más incluyeron estos recursos (frente al $32,6 \%$ de los chicos)

El tipo de actividad más representado en los dibujos hace alusión a la toma de datos y el muestreo $(69,7 \%)$, siendo de nuevo los chicos $(79,3 \%)$ los que con mayor frecuencia que las chicas $(55,2 \%)$ dibujan a sus científicos en este tipo de actividades.

De acuerdo, a lo dibujado se puede indicar que un $94 \%$ de las actividades representó situaciones y elementos propios de la investigación asociada a las ciencias de la naturaleza (biología, química, física y sus especialidades).

Por último, un $28 \%$ de los dibujos representó a la actividad científica como una práctica grupal, siendo los chicos $(31 \%)$ más que las chicas $(17,2 \%)$ quienes replicaron esta situación.

\section{CONCLUSIONES Y LIMITACIONES}

La presencia del hombre, ya sin gafas y bata de laboratorio, viene acompañada de un rostro más amigable y cercano, manteniéndose de igual forma una baja representación de mujeres científicas. Cobra relevancia que las niñas, aunque en bajo porcentaje, sean quienes incorporan en mayor medida recursos estereotipados en sus dibujos. A ello puede contribuir la falta de referentes o el escaso nivel de reconocimiento que las niñas y jóvenes experimentan con la ciencia (Harding, 2016; Keller, 1991; UNESCO, 2017). 
Sin modelos y con bajas expectativas en el área científica, la probabilidad de aumentar el número de investigadoras en el mundo disminuye.

El contenido epistémico de los dibujos habla de una ciencia hecha en un espacio cerrado, en donde las personas se encuentran realizando mediciones, con materiales e instrumentos típicos de las ciencias más bien de la naturaleza. Esta ciencia tradicional da cuenta de una ciencia aislada, sin conexión con otras áreas del saber y sin relación necesaria, por lo tanto, con la sociedad. Se trata, en consecuencia, de una ciencia limitada por los espacios y por determinados procedimientos (Ziman, 1981).

Para romper con este discurso hegemónico, el primer paso, podría ser entender a la ciencia como una actividad humana, producto de nuestra cultura y cargada con sesgos propios de sus productores humanos. En segundo lugar, cabe visibilizar el trabajo y la aportación de mujeres científicas, así como de otras personas que históricamente se han visto excluidas de los espacios tradicionales de educación y saber y, por último, reflexionar y modificar las prácticas científicas en el aula, prestando atención al contenido epistémico de la ciencia que se enseña, alejándose de esta manera de los estereotipos.

La limitación más importante del estudio aquí presentado tiene que ver con la posibilidad real que otorgan los dibujos de conocer los estereotipos y sus orígenes. Sería importante incorporar en estudios posteriores cuestionarios que permitieran visibilizar el origen de los estereotipos, así como el conocimiento concreto que tienen los y las estudiantes de diferentes científicos y científicas del mundo y de su país.

A su vez, cobra relevancia la ampliación del número de estudiantes participantes, considerando la participación de un mayor número de niñas, y de otras expresiones de género.

Asimismo, el estudio podría aplicarse a profesores y profesoras en formación, evaluando sus estereotipos a lo largo de su carrera académica.

\section{REFERENCIAS BIBLIOGRÁFICAS}

Akcay, B. (2011). Turkish elementary and secondary students' views about science and scientist. Asia-Pacific Forum on Science Learning and Teaching, 12 (1). Article 5,1.

Barman, C. (1999). Students' views about scientists and school science: Engaging K-8 teachers in a national study. Journal of Science Teacher Education, 10(1), 43-54. Doi: https://doi.org/10.1023/A:1009424713416

Chambers, D. (1983). Stereotypic images of the scientist: the draw-a-scientist test. Science Education, 67(2), 255-265.

Dibarboure, M. (2010). La naturaleza de la ciencia como contenido escolar. Quehacer Educativo, 100, 110-120.

Driver, R., Leach, J., Millar, R. y Scott, P. (1996). Young people's images of science. Open University Press.

Erten, S., Kiray, S.A. y Sen-Gumus, B. (2013). Influence of scientific stories on students ideas about science and scientists. International Journal of Education in Mathematics, Science and Technology, 1(2), 122-137.

Farland-Smith, D. (2012). Development and field test of the modified Draw-a-Scientist Test and the Draw-a-Scientist Rubric. School Science and Mathematics, 112(2), 109-116.

Finson, K., Beaver, J. y Cramond, B. (1995). Development of and field-test of a checklist for the draw-a-scientist test. School Science and Mathematics, 95(4), 195-205. 
Harding, S. (2016). Ciencia y Feminismo (Pablo Manzano, trad.). Ed. Morata.

Jane, B., Fleer, M., y Gipps, J. (2007). Changing children's views of science and scientists through school based teaching. Asia-Pacific Forum on Science Learning and Teaching, 8(1), article 11, 1- 21.

Keller, E.F. (1991). Reflexiones sobre género y ciencia. Alfons el Magnànim.

Lee, E., y H. Kwon. (2018). Primary Students' Stereotypic Image of Inventor in Korea. Journal of Baltic Science Education, 17(2), 252-266.

Manzoli, F., Castelfranchi, Y., Gouthier, D. y Cannata, I. (2006). Children's perceptions of science and scientists: A case study based on drawings and story-telling, 9th International Conference on Public Communication of Science and Technology, Seúl.

Mead, M., y Metraux, R. (1957). The image of the scientist among high school students: A pilot study. Science, 126, 384-390.

Montecino, S. y Pemjean, I. (2011). Brechas de igualdad: género, ciencia y academia en el siglo XXI. Colección Cátedra Género de la Unesco, Universidad de Chile, Explora Conycit. Universidad de Chile y Editorial Catalonia.

Moss-Racusin, C.A., Dovidio, J.F., Brescoli, V.L., Graham, M.J. y Handelsman, J. (2012). Science faculty's subtle gender biases favour male students, PNAS, 109(41), 16474-16479.

Newton, D. y Newton, L. (1992). Young children's perceptions of science and the scientist, International Journal of Science Education, 14(3), 331-348.

Nittrouer, C., Hebl, M., Ashburn-Nardo, L., Trump-Steele, R., Lane, D. y Valian, V. (2017). Gender disparities in colloquium speakers at top universities. Proceedings of the National Academy of Sciences of the United $\begin{array}{llll}\text { States of } & 115, & 104\end{array}$ 108. https://doi.org/10.1073/pnas.1708414115.CrossRefPubMedPubMedCentral Google Scholar

Organización de las Naciones Unidas para la Educación, la Ciencia y la Cultura [UNESCO] (2017). Cracking the code: girls' and women's education in STEM. Recuperado de: http://unesdoc.unesco.org/images/0025/002534/253479E.pdf

Shaw, A. y Stanton, D. (2012). Leaks in the pipeline: Separating demographic inertia from ongoing gender differences in academia. Proceedings of the Royal Society B, 279, 3736-3741. doi: 10.1098/rspb.2012.0822.CrossRefPubMedPubMedCentralGoogle Scholar

Sheltzer, J. y Smith J. (2014). Elite male faculty in the life sciences employ fewer women. Proceedings of the National Academy of Sciences of the United States of America, 111(28), 10107-10112.

Shen, H. (2013). Inequality quantified: Mind the gender gap. Nature, 495(7439), 22-24.

Toma, R. B., Greca, I. M. y Orozco Gómez, M. L. (2018) Una revisión del protocolo Drawa-Scientist-Test (DAST). Revista Eureka sobre Enseñanza y Divulgación de las Ciencias, 15(3), $3104 . \quad$ Doi: https://doi.org/10.25267/Rev Eureka ensen divulg cienc.2018.v15.i3.3104

Ziman, J. (1981). ¿Qué es la ciencia? (trad. Eulalia Pérez Sedeño). Alianza Editorial, S.A. 


\title{
1.2. EXPERIENCIAS
}

\author{
1.2.1. ¿Puede el arte fomentar la coeducación y la igualdad? Una \\ propuesta basada en el estudio referentes inspiradores y la \\ aplicación del modelo dialógico para fomentar el espíritu \\ crítico y la creatividad en la Educación Primaria. \\ Ejarque González, María (Universidad de Valencia, España).
}

\section{Resumen}

Esta experiencia educativa tiene la finalidad de utilizar el arte para abordar cuestiones relacionadas con la coeducación e igualdad en el primer ciclo de educación primaria durante un trimestre completo.

La intervención se basa en el uso de la literatura, música y obras plásticas, así como el acercamiento a la vida de artistas relevantes (tanto por su obra como reivindicaciones) El objetivo es dotar al alumnado de referentes que invitan a la reflexión y al desarrollo de la creatividad.

Esta propuesta demuestra que el arte es un instrumento muy valioso para fomentar las habilidades de pensamiento de orden superior siguiendo el modelo de Bloom (1990) tales como el desarrollo del espíritu crítico, despertar su curiosidad y el desarrollo de la creatividad.

Palabras clave: igualdad; arte; primaria, coeducación; creatividad

\section{INTRODUCCIÓN Y OBJETIVOS}

Cada vez somos más conscientes de que vivimos en un mundo androcéntrico en el cual el heteropatriarcado es la única opción válida y que el rol de la mujer todavía no es del todo igualitario, Marañón (2018). Como docentes tenemos una misión muy importante en este aspecto prueba de ello es la reciente modificación de la ley de educación, LOMLOE (2020). En ella el artículo 2 se Oita específicamente este fin: b) La educación en el respeto a los derechos y libertades fundamentales, en la igualdad de derechos y oportunidades entre hombres y mujeres y en la igualdad de trato y no discriminación de las personas por razón de nacimiento, origen racial o étnico, religión, convicción, edad, de discapacidad, orientación o identidad sexual, enfermedad, o cualquier otra condición o circunstancia (LOMLOE, 2020, pp. 65)

Sin embargo, mi experiencia educativa me ha demostrado que estos temas se tratan de una forma muy banal y que los problemas derivados de estas conductas son resueltos por el profesorado, pero en ningún momento se le invita a la reflexión o al diálogo.

El objetivo de este proyecto no es otro que educar en igualdad desde el ejemplo, desarrollar destrezas se pensamientos superiores (Bloom, 1990) y dotar de referentes a las criaturas para que sean libres de expresarse tal y como son. 


\section{CONTEXTUALIZACIÓN}

La experiencia educativa se centra en abordar la igualdad en el primer ciclo de educación primaria en un centro público de la Comunidad Valenciana. La intervención se llevó a cabo en todo el primer ciclo de educación primaria de forma interdisciplinar durante el segundo trimestre.

Este proyecto surge tras una profunda reflexión acerca del tratamiento que se da de la coeducación y la convivencia en esta escuela. Tras una lectura del Proyecto Educativo de Centro y el Plan de Igualdad y Convivencia y mi propia experiencia docente. Me di cuenta de que estos asuntos se trataban únicamente en días conmemorativos de una forma muy superficial.

Por ello vi la necesidad de abordar esta realidad con un proyecto más largo en el tiempo, que invitara a la reflexión y en el que los alumnos y las alumnas fueran los protagonistas, es decir que partiera de sus intereses y vivencias y desarrollara su sentido crítico.

\section{DISEÑO Y DESARROLLO}

Este proyecto se desarrolló a la largo de todo el trimestre con diferentes propuestas tanto en días conmemorativos como en propuestas de aula.

Antes de llevar a cabo esta experiencia realicé una observación sistemática de alumnos y alumnas a lo largo de todo el primer trimestre y detecten carencias a la hora de resolver un conflictos, comportamientos y actitudes machistas y racistas y un rechazo a lo "diferente". Así como un desconocimiento total de referentes femeninos en el arte. De forma paralela a nivel de centro los conflictos se resolvían de una forma muy banal y la igualdad (en todas sus acepciones) se abordaba de una forma muy esporádica y evitando temas comprometidos.

Teniendo en cuenta esta realidad todo el equipo docente del primer ciclo de primaria se planteó llevar a cabo un proyecto conjunto en el que se abordaran estos temas desde el respeto y la igualdad. La finalidad era utilizar el arte para invitar a la reflexión en temas de coeducación e igualdad, mostrar referentes que les inspiren (Marañón, 2017) y que disfrutaran de sus obras.

Brevemente, tal y como señala Nomen (2019), el arte incide en su complejidad puede tratarse de una actividad humana que busca la belleza, la crítica social, emocionarnos o transmitir valores. En cuanto a los beneficios de usar el arte en la escuela Mendívil (2011) señala que el arte tiene el potencial de favorecer la creatividad, la imaginación, el pensamiento crítico, la identidad personal y cultural de los infantes y habilidades que favorecen la convivencia encaminada hacia un cambio social.

En primer lugar, a lo largo de todo el trimestre en las clases de educación plástica y visual los primeros diez minutos de la clase los dedicaba a tratar el proyecto "Women in art" (Mujeres en el arte). Se trataba de una presentación en la cual se mostraban mujeres importantes en el mundo del arte. La elección de las artísticas busco ante todo la variedad tanto de época, estilos, géneros, nacionalidad o reconocimiento. A modo de ejemplo abordé a Camille Claudel, Agatha Ruíz de la Prada, Lola June o Pipilotti Rist. La presentación es muy sencilla constaba de una imagen de la artista y varias de sus obras con el nombre y la fecha. A parte se incluía alguna curiosidad, a modo de ejemplo Lee Krashen (tristemente conocida exclusivamente por ser la mujer de Pollock) decidió 
cambiar su nombre de pila "Lena" al ambiguo "Lee" para evitar la marginación que sufrían las mujeres en aquella época (Levin, 2012)

También en las clases de educación plástica y visual siempre que se abordaban las diferentes actividades utilizando referentes tanto masculinos como femeninos que fueran importantes bien por su obra, originalidad o reivindicación social. Por ejemplo, una propuesta fue a partir del autorretrato y como actividad de motivación se mostraron retratos de Yayoi Kusama, Romero Britto, Frida Kahlo, Pablo Picasso o Artemisa Gentileschi.

El otro motor de este proyecto se centra en días conmemorativos que se celebran en toda la escuela. Por su relevancia abordé día de la Paz y no Violencia (30 de enero) y el día 8 de Mazo (Día de la Mujer). En este caso también se realizaron actividades desde las diferentes tutorías, ya que se trataba de conmemoración que se realizaban a nivel de centro.

En primer lugar, la propuesta para abordar el día de la Paz y No-Violencia se inició a mitades de enero. Para ello se recurrió a la literatura infantil por medio del libro "El club de los valientes" (Ibarrola, 2028) Aunque a ellos y ellas se les presentó como "El club de los valientes y las valientes" en la lectura dramatizada y la tertulia dialógica posterior.

Brevemente, el libro trata sobre un grupo de compañeras y compañeros en una escuela en la que hay un matón que les hace la vida imposible. Para defenderse de las constantes agresiones de este niño crean un club donde su forma de resolver los conflictos es el diálogo no la violencia. A partir de esta historia se ha creado un método para la resolución de conflictos basado en el modelo dialógico (Sancho, 2016) con excelentes resultados, ya que se usa el dialogo (no la violencia) para resolver los conflictos, se rompe con la figura del chivato o la chivata (ahora pasa a ser un o una valiente ya que se atreve a denunciar y defender a quien lo o la necesita) y se crean vínculos de amistad y ayuda mutua que incluso traspasan los límites de la escuela.

Posteriormente, los y las estudiantes tuvieron que crear de forma individual su logo del club de los y las valientes (Como se señala en el libro). Luego todos los logos se expusieron y de forma democrática se eligió el que representaba a la clase.

Pero para ser miembros del club era necesario tener unas normas y comprometerse a cumplirlas. Como actividad de motivación se les puso la canción "Se buscan Valientes" (El Langui). Esta canción es dio alguna idea de qué normas eran necesarias para convivir. En la asamblea se hico una lluvia de ideas y de forma democrática se acordaron las normas. En esta dinámica el rol del docente fue de moderador y acompañante (Harmer, 1998)

Posteriormente, los alumnos y alumnas vieron una pequeña presentación de Keith Haring. Brevemente se trata de un grafitero y activista social americano de la generación Pop y la cultura callejera. La elección de este artista no fue al azar ya que su estilo es muy peculiar $Y$ llamativo. Además, el tipo de ilustraciones son muy sencillas, pero sintetizan muy bien aquello que quieren transmitir. Se dividió a los alumnos y alumnas en grupos heterogéneos para que trabajaran de forma cooperativa y se repartieron las normas de forma equitativa. Al acabar estas normas junto al logo se expusieron y creo el club de los y las valientes. Este club utiliza los principios que se trabajan en el libro para abordar todo lo relacionado con la convivencia. En este proyecto se abordaron destrezas de pensamiento superior (Bloom, 1990) como la creación de sus normas en una representación visual simbólica. 
En segundo lugar, otro día conmemorativo con mucha importancia en toda la sociedad es el 8 de marzo (Día de la Mujer). La finalidad de esta propuesta de actividades era reivindicar las desigualdades que las mujeres hemos experimentado y experimentamos por nuestro sexo biológico.

Las actividades se dividieron en dos bloques una para la materia de educación plástica y visual y otra para lengua extranjera (inglés). Estas se basaron en dotar al alumnado de referentes inspiradores (Marañón, 2017) para ampliar sus horizontes e invitarle a la reflexión.

En educación plástica se presentaron a varias artistas especialmente reivindicativas como Clara Petrees que reivindicó de una forma muy peculiar la prohibición de las mujeres de autorretratarse, las Guerrillera Girls con su provocaciones para reivindicar la prácticamente inexistente presencia de mujeres artistas en las exposiciones, Rihanna creadora de la colección de maquillaje "Fenty Beauty" en la que pone de manifiesto la no existencia de un único "color carne" o Patty Smith (y David Bowie) para hablar del género fluido y los estereotipos vinculados al sexo biológico. Para la clase de inglés se eligieron tres escritoras muy relevantes y datos curiosos de su vida, ellas fueron JK Rowling, Mary Sheller y Jame Austem. A modo de ejemplo de la primera autora se habló de las dificultades para publicar por ser mujer y ello la llevo a firmar con sus siglas ya que resultaba ambiguo su género o la curiosa historia detrás de la creación de Frankenstein.

La finalidad de estas propuestas era dotar de referentes a los alumnos, mostrar al alumnado anécdotas o curiosidades de la vida y obra de estas artísticas que muestran las desigualdades que vivieron o sus reivindicaciones. Por último, enseñarles a disfrutar con el arte, a ser curiosos y curiosas, fomentar su creatividad, pero ante todo tener una actitud crítica.

\section{EVALUACIÓN, CONCLUSIONES Y PROPUESTAS DE MEJORA}

El conjunto de esta propuesta no se reflejó en una nota numérica, ya que se cómo expone el Decreto 108/2014 que establece el currículo de la educación primaria en la Comunidad Valenciana en el artículo 10 donde se desarrollan los elementos trasversales y su importancia se incide en la necesidad de trabajar aspectos como la igualdad y la coeducación de una forma transversal fomentando la reflexión y el diálogo. Además, el punto de partida de la intervención era el respeto por lo que encorsetar las intervenciones de los y las menores a una nota podría condicionar sus respuestas y así se les hizo saber al principio de la intervención.

Sin embargo, no estuvo exenta de evaluación sus intervenciones, opiniones o indignación. Cabe mencionar que la propuesta despertó el interés de la inmensa mayoría de los alumnos y las alumnas, su participación en las actividades fue excelente y mostraron mucha curiosidad por seguir aprendiendo. Respecto a sus intervenciones cabe mencionar notables diferencias entre el alumnado de primero y el de segundo. En las clases de primero los argumentos fueron más vagos y superficiales, además se mostraron más reacios a participar al principio Por ejemplo, "No me parece justo que una mujer tenga que inventarse un nombre de hombre para poder publicar sus obras, todos tendríamos que tener las mismas oportunidades" (Daniel, 6 años) En segundo el alumnado fue muy participativo desde el principio y surgieron reflexiones muy potentes como: "Que triste que una mujer pueda entrar desnuda en un museo pero no se reconozca su trabajo" (Marta, 8 años). Al final de cada tertulia dialógica se llevaba a 
cabo una recapitulación de aquello abordado y en todas ellas se llegaron a conclusiones similares. El alumnado fue consciente en todo momento de la desigualdad por diferentes factores y cómo esta circunstancia nos perjudica a todos y todas. Además, dieron propuestas tales como crear su propio club de los y las valientes que aun hoy aplican en la escuela y fuera de ella. La propuesta despertó su interés y se dicen cuenta de que todavía queda mucho camino para lograr la plena igualdad.

Para futuras intervenciones intentaría adaptar más los recursos al alumnado de manera que la dinámica fuera más atractiva y significativa para ellos. También, sería interesante aplicar propuestas similares en todo el centro educativo y darle continuidad al proyecto.

A modo de conclusión, me gustaría remarcar que estamos formando a la generación del mañana (y del hoy), no podemos pasar por alto cuestiones relacionadas con la convivencia e igualdad ya que son imprescindibles para vivir en sociedad, democrática y plural. El arte, los artistas y las artistas tienen la mágica de introducirnos en estos aspectos de una forma simpática, pero a la vez enriquecedora y profunda.

\section{REFERENCIAS BIBLIOGRÁFICAS}

Bloom, B. (1990). Taxonomía de los objetivos de la educación. Buenos Aires: EI Ateneo.

Ibarrola, B. (2008) El club de los valientes. España: Grupo SM.

Jeremy, H.(1998). How to Teach English: An introduction to the Practice of English Language Teaching. London: Logman.

Levin, G. (2012) Lee Krasner. USA: Harper Collins e-books.

Marañón, I. (2017) Educar en feminismo. España: Plataforma Actual.

Mendivíl, L. (2011). El arte en la educación de la primera infancia: una necesidad impostergable". España: Educación Vol, XX, N³9.

Nomen, J. (2019) El niño filósofo y el arte. España: Arpa.

Sancho, E. (2016) El club de valientes. España: Cuadernos de pedagogía, junio 2016.

Ley Orgánica 3/2020, de 29 de diciembre, por la que s modifica la Ley Orgánica 2/2006, de 3 de mayo de, de Educación.

Decreto 108/2014 del 4 de Julio por el que se establece el currículo y la ordenación de la Educación Primaria en la Comunidad Valenciana. 


\subsubsection{Mundo Disney y Mito del Amor Romántico: una experiencia con el alumnado del segundo ciclo de educación infantil Irene Galán Ríos (Universidad de Huelva, España); José Ramón Márquez Díaz \\ (Universidad de Huelva, España).}

\section{Resumen}

En esta comunicación, nos centramos en cómo influye Disney en la formación del Mito del Amor Romántico, el cual promueve la desigualdad de género, lo que puede derivar en un futuro a la violencia de género. Por ello, a través de este trabajo se insiste en la formación desde una posición coeducativa, con una perspectiva de prevención e intervención. Para ello, se ha revisado la literatura acorde al tema. Seguidamente, se han propuesto los objetivos y se ha descrito el contexto en el cual se ha implementado la propuesta. Para el desarrollo de la misma, se ha creado un taller con sus respectivas actividades y rincones. Por último, se exponen las evaluaciones donde en líneas generales, se han alcanzado la mayor parte de los objetivos propuestos, en este mismo apartado localizamos las limitaciones del estudio, así como las futuras líneas de investigación.

Palabras clave: Mito del Amor Romántico, propuesta educativa, prevención, intervención, Educación Infantil, Mundo Disney.

\section{INTRODUCCIÓN Y OBJETIVOS}

El mito del amor romántico tiene su origen en el mito de andrógino narrado en El Banquete de Platón. Se basa en la historia de unos seres duales que tenían características de diferentes géneros y fueron condenados a estar separados como castigo de Zeus tras intentar invadir el Monte Olimpo. Esta idea, junto con el amor cortés, son las que sustentan actualmente nuestra tradición y mitos del amor (Pascual, 2016).

Este sistema define un tipo de amor caracterizado por la dependencia, subordinación e incompetencia de los individuos (Pascual, 2016). Está formado y preconcebido para crear a personas con unas características uniformadoras (Ferrer y Bosch, 2013). Las falacias que construyen el amor romántico posteriormente se pueden convertir en incentivos para la violencia de género, un problema patente en nuestra sociedad (Jódar, 2019).

El mito del amor romántico lo comenzamos a construir desde bien pequeños/as con la influencia del entorno, por ejemplo, a través del Mundo Disney (Monleón, 2020). A este respecto, en cuarenta y dos de los sesenta clásicos de Disney está presente el mito del amor romántico.

Partiendo de estas premisas, nos hemos centrado en el diseño de una propuesta educativa, la cual va dirigida a la etapa de Educación Infantil, periodo en la que los niños y las niñas están construyendo su personalidad con la interacción de su entorno, así como los medios de comunicación. Si bien es cierto, un gran influyente en estas edades es Disney, por lo tanto, este determina su forma de relacionarse, ya que toman de inspiración a los personajes que visualizan. Por ello, este trabajo se ha diseñado desde una perspectiva de prevención e intervención respecto a la construcción del Mito del Amor Romántico en la infancia, transmitido a su vez por dicha productora, Disney (Alaminos y Martínez Villar, 2017; Monleón, 2020).

Por lo tanto, los objetivos generales que se pretenden alcanzar con esta propuesta educativa son, en primer lugar, analizar el estado actual de la cuestión respecto a la 
prevención e intervención del mito del amor romántico en Disney en la etapa de Educación Infantil para, posteriormente, elaborar una propuesta en torno a las directrices de los últimos estudios.

\section{CONTEXTUALIZACIÓN}

La propuesta educativa se ha llevado a cabo en un centro público situado en el barrio de Santa Marta de Huelva. Es un centro que destaca por su multiculturalidad y por estar formado en su mayoría por familias de un origen sociocultural y económico bajo.

Esta propuesta educativa se ha llevado a cabo en la clase de cuatro y cinco años de infantil que cuentan con un total de nueve niños. Se ha seleccionado este rango de edad con el motivo de que a partir de los cuatro años es cuando se suele comenzar a consumir largometrajes de Disney (Alaminos y Martínez Villar, 2017; Mendoza Rivera, 2018).

Del mismo modo, entre los cuatro y siete años, el juego simbólico característico de estas edades, muestra grandes rasgos relacionados con los roles y los estereotipos de género. Además, atendiendo a la teoría ecológica de Bronfenbrenner, debemos recordar que todo el sistema influye al individuo y viceversa. En este caso, desde el exosistema al individuo y a la inversa (Zufiaurre y Villarreal, 2015).

\section{DISEÑO Y DESARROLLO}

Dentro de la propuesta educativa, se han desarrollo dos escenarios a modo de prevención en caso de confinamiento, debido a la situación de emergencia sanitaria que estamos viviendo. No obstante, la implementación ha sido del escenario A (clases presenciales) compuesto por un taller organizado en; actividades y rincones.

Se han creado cuatro rincones con diferentes objetivos destinado al alumnado, tales como exteriorizar ideas respecto a los roles y los estereotipos de género, las percepciones que tienen acerca del amor, las posibles influencias del mito del amor romántico, entre otros. Todos los rincones vienen acompañados de elementos que fomenten la expresión plástica y artística (será también usada para la evaluación del alumnado), los cuales son los siguientes:

El rincón de la igualdad. Este rincón es el de "las casitas", donde los/as docentes podrán ver las diferentes actuaciones del alumnado de cara a sus comportamientos asociados a roles y estereotipos de género.

El rincón del amor. Este rincón se llevará a cabo en el patio del centro educativo y estará ambientado con fotografías de diferentes expresiones de amor. Además, los niños y las niñas pueden experimentar con piezas de puzle, donde todas encajan acerca de diferentes posibilidades de diversidad de amor (de pareja, de familia o de amistad). Por su parte, dichas piezas representarán a personas de diferente género y etnia.

El rincón de las princesas y los príncipes. Este rincón está pensado para ofrecer la posibilidad al alumnado de convertirse en su personaje de Disney favorito mediante el disfraz correspondiente, mostrando así los mensajes que han aprendido de ellos/as.

El rincón del mundo Disney. Este rincón está pensado para invitar al alumnado a sumergirse en el mundo Disney, esto es, para que conozcan de primera mano desde los clásicos hasta las películas más recientes. Asimismo, podrán contar con cuentos de Disney, tanto clásicos como versionados, acompañados con imágenes que pueden manipular y ver. Además, deberán consensuar qué película quieren visionar.

En relación con las actividades algunos de los objetivos que se pretenden alcanzar para el alumnado son: ideas relativas al amor y mito del amor romántico de las películas Disney. En cuanto a algunos de los objetivos planteados para los docentes son: conocer 
y analizar ideas relativas al amor y mito del amor romántico de las películas Disney, exteriorizadas todas ellas por el alumnado; entre otros. La primera actividad, está pensada a modo de introducción de normas de comportamiento. A continuación, se exponen las actividades:

Actividades de iniciación:

- Actividad 1. ¡Somos una gran clase! Se formarán dos equipos. Un equipo se encargará de crear las normas de comportamiento y sus consecuencias. El otro equipo será el encargado de buscar los saludos y las normas de cortesía típicos de las diferentes culturas de la clase. Los recursos con los que cuentan ambos equipos estarán en el centro del patio y los/as estudiantes deberán negociar qué se queda cada equipo. Posteriormente, se pondrá en común y se completará con la ayuda del profesorado. Por último, se comentará la economía de fichas y el alumnado irá pegando su fotografía en la misma.

- Actividad 2. ¡Descubramos el mundo Disney! Esta actividad está compuesta por diferentes subtareas. En primer lugar, se formarán dos equipos y cada uno tendrá una cesta con imágenes de princesas en una y de príncipes en otra. Después, en forma de carrera de relevo, deberán pegarlas en un mural y unirlas con el príncipe (si es que tiene). Posteriormente, plasmarán en un cuadro sus ideas previas acerca del mundo Disney. Finalmente, en la asamblea se reflexionará acerca de la actividad, y presentarán sus cuadros y lo que reflejan en él.

Actividades de desarrollo:

- Actividad 3. ¡Abramos las puertas del castillo de Disney! Se llevará a cabo un "Scape Room" para poder abrir el castillo de Disney. La misión es superar diferentes pruebas en grupo en torno al mundo Disney y los distintos tipos de amor.

- Actividad 4. ¿Qué es el amor? Esta actividad constará de dos partes. Se visionarán las películas de La Bella y la Bestia, y Frozen, en días diferentes. Cada día, una vez finalizadas las películas, deberán realizar una caja del amor en pequeños grupos, según lo que han entendido en las películas, con imágenes y objetos que ofrecerá el profesorado, y con la posibilidad de crear dibujos. Una vez finalizadas las cajas, estas serán expuestas por el alumnado al resto de la clase. Finalmente, deberán crear una flor como la de La Bella y la Bestia, simbolizando cuál es la idea que entienden ellos/as por amor, donde cada pétalo recoja una característica. Todas las flores serán presentadas por el profesorado en la exposición final (actividad 7). A modo de reflexión, se tratarán algunas consideraciones finales y qué es lo bueno del amor.

- Actividad 5. El gran baile real. Se dividirá la clase en dos grupos, a cada uno de ellos se le asignará una canción. Una será de la película de Frozen y otra de la película de La Bella y la Bestia. Con estas canciones, deberán hacer un baile acorde con la letra. Posteriormente, se votará aquel baile que más les haya gustado y lo representarán todos/as juntos/as. Finalmente, realizarán un dibujo de cada canción, expresando lo que entienden en ellas.

Actividades de síntesis:

- Actividad 6. ¡Creemos nuestra propia historia de Disney! Se dividirá la clase en dos grupos. Cada uno de ellos tendrá un dado formado por villanos de Disney (principalmente, mujeres). Deberán lanzar el dado tres veces y con los/as personajes que les toquen deberán hacer una historia, la cual se inicia de la siguiente manera (explicación del profesorado): "había una vez un príncipe muy 
bueno que vivía con su marido en el castillo de Disney. Un día, se levantó y no encontraba a su marido y entonces le pidió ayuda a...."

- Actividad 7. ¡Somos una gran clase! De forma individual, los/as alumnos/as deberán hacer un cuadro en el que plasmen sus ideas tras la finalización de la presente propuesta educativa. Una vez lo hayan realizado, a modo de exposición, contarán al resto de sus compañeros/as y a través de videollamadas a las familias lo que han aprendido desde que realizaron el primer cuadro (actividad 2) hasta ahora. Una vez finalizada la exposición, en la asamblea se realizará un análisis del diario.

En caso de confinamiento se hubiese aplicado el escenario $B$, el cual está preparado para llevarse a cabo de manera online mediante una página web creada por los autores de la comunicación.

La propuesta se ha realizado durante un total de un mes y medio. En concreto, en el mes de octubre y finalizó en la semana del 25 de noviembre, día de la violencia de género.

Durante esas seis semanas jugaron diariamente en los rincones, intercalando los mismos con otras propuestas educativas del profesorado. La primera actividad se llevó a cabo el primer día de la propuesta. La segunda actividad se llevó a cabo en la misma semana. El resto de las actividades se plantearon una por semana, en las horas correspondientes a la rutina del aula.

\section{EVALUACIÓN, CONCLUSIONES Y PROPUESTAS DE MEJORA}

A lo largo de la implementación del programa se ha aplicado una evaluación procesual y formativa, apoyada principalmente en la técnica de observación. Para ello, se han utilizado diferentes instrumentos relacionados con distintos aspectos a evaluar.

Dentro de la evaluación del alumnado, se ha utilizado una diana, formada por una serie de círculos concéntricos y cada uno de ellos designa un nivel alcanzado. Cuanto más cerca del centro esté, mayor será el logro obtenido (Mosquera, 2020). Esta evaluación del alumnado ha sido completada, con una tabla de análisis para los rincones y una ficha de seguimiento para la expresión artística. Tras esta evaluación, en líneas generales, los resultados que se presentan es que el alumnado se ha percatado de la idea del mito del amor romántico, de los roles y estereotipos de género, se han iniciado en la alfabetización mediática, etc. Todo ello a pesar de su corta edad.

En relación a la evaluación del profesorado, se ha usado una rúbrica, acorde con los objetivos propuestos. Con ello, se sintetizan los resultados en que el rol del docente ha sido de guía y mediador la mayor parte del tiempo, evitando la irrupción en el juego libre. No obstante, se ha podido contemplar dificultades en ciertos momentos a la hora de percatarse de los comportamientos del alumnado en el juego libre.

En cuanto a la evaluación de las familias (las cuales han participado a lo largo del proceso), se ha pasado un cuestionario, donde han expuesto gran parte de ellas que están satisfechos/as con el proyecto, aunque la mayoría muestran poca intervención y colaboración con el mismo desde casa.

En base a la evaluación del proceso, valorada mediante un diario de campo inspirado en el estoicismo, en líneas generales, se puede decir que el proyecto ha sido agradable y bien acogido por el alumnado, el profesorado y la familia.

Con todo esto añadir, que a lo largo de la implementación se han ido haciendo propuestas de mejora, como la simplificación o ampliación de algunas actividades, atendiendo de este modo a intereses y necesidades del alumnado. 
Esto nos permite concluir en que hubiese sido interesante la participación de agentes externos expertos en la temática, sin embargo, la COVID-19 hace que esto no sea posible.

Como futura línea de investigación, se podrían tratar otros aspectos relacionados con el mundo Disney, como los malvados de estas películas asociados principalmente a personajes LGBTQ+ y/o mujeres.

\section{REFERENCIAS BIBLIOGRÁFICAS}

Alaminos, A.F. y Martínez Villar, M. (2017, mayo-junio). ¿Son los clásicos Disney un buen recuso para trabajar la Inclusión Educativa? [Actas del III Congreso Internacional de Educación Mediática y Competencia Digital] Universidad de Valladolid.

Ferrer, P.V. y Bosch, F.E. (2013). Del amor romántico a la violencia de género. Para una coeducación emocional en la agenda educativa. Profesorado. Revista de Currículum y Formación de Profesorado, 17(1), 105-122.

Jódar, R. (2019). Educación de la cultura visual para la vida [Tesis Doctoral, Universidad de Jaén]. Recuperado de https://n9.cl/5blj6

Monleón, V. (2020). La Lucha Cinematográfica entre Oriente y Occidente. Studio Ghibli versus Disney. Cuestiones Pedagógicas, 29, 112-122.

Mosquera, I. (2020). Dianas de aprendizaje: qué son y para qué sirven. UnirUniversidad Internacional de la Rioja 2020. UNIR. Recuperado de https://n9.cl/obzse

Pascual, F.A. (2016). Sobre el mito del amor romántico. Amores cinematográficos y educación. DEDiCA. Revista de Educação e Humanidades, 63, 63-78.

Zufiaurre, B. y Villarreal, M.P. (2015). Positive Educational Actions and Healthy Sustainable Development. Advances in Social Sciences Research Journal, 2(1), 69-86. 


\subsubsection{Acciones en el patio escolar dentro del Plan Coeducativo de Centro del CEIP Federico García Sanchiz (Alzira, Valencia).}

Molines Borrás, Sandra (Florida Universitària, España); Lancero Pavía, Juan Fernando (Estudio Lancero)

\section{Resumen}

Este trabajo refleja, dentro de la redacción del Plan Coeducativo de centro del CEIP Federico García Sanchiz, en la población de Alzira (Valencia), las intervenciones desarrolladas en su patio escolar. Este trabajo ha sido posible tras la capacitación de todo el profesorado en materias tan importantes como: el binomio sexo-género, coeducación, sexismo, androcentrismo, el lenguaje sexista, la diversidad afectiva y sexual etc. Una vez sensibilizado todo el claustro y, junto con las familias, se ha desarrollado esta magnífica propuesta. Fruto de este trabajo, se han podido extraer 27 propuestas (de las 56 acciones totales) encaminadas todas ellas a hacer realidad la coeducación en esta escuela.

Este trabajo se enmarca dentro del diseño de los planes de lgualdad y convivencia de los centros educativos en la Comunidad Valenciana. Gracias a esta formación y acompañamiento, el profesorado ha aprendido la verdadera importancia del trabajo coeducativo.

Palabras clave: patio; coeducación; género, sexismo; educación.

\section{INTRODUCCIÓN Y OBJETIVOS}

Tal como dice la orden de principio de curso de la Comunidad Valenciana de RESOLUCIÓN de 17 de julio de 2020, del secretario autonómico de Educación y Formación Profesional, y por la cual se aprueban las instrucciones para la organización y el funcionamiento de los centros que imparten Educación Infantil de segundo ciclo y Educación Primaria durante el curso 2020-2021, se hace necesario saber qué:

Se tienen que incluir en todo momento los principios coeducativos de manera transversal y por parte de todo el profesorado del centro.

Hay que recordar que estos principios son:

- La eliminación de los prejuicios, estereotipos y roles en función del sexo, construidos según los patrones socioculturales de conducta asignados a mujeres y hombres, para garantizar, tanto para las alumnas como para los alumnos, posibilidades de desarrollo personal integral.

- La prevención de la violencia contra las mujeres, mediante el aprendizaje de métodos no violentos para la resolución de conflictos y de modelos de convivencia basados en la diversidad y en el respecto a la Igualdad.

-La integración de los objetivos coeducativos señalados en los libros de texto y otros materiales didácticos que se utilizan o se proponen en los proyectos de innovación educativa.

- La capacitación del alumnado porque la elección de las opciones académicas se lleve a cabo libre de acondicionamientos basados en el género.

Por todos estos motivos dentro del marco regulador de los centros y también para hacer realidad el Proyecto de Dirección vigente en la actualidad, el profesorado ha recibido una formación encaminada a hacer verdadera coeducación en la escuela. Se ha 
diseñado un Plan coeducativo de centro que plasma el verdadero trabajo con perspectiva de género que está previsto realizarse los próximos 2 cursos académicos.

Del mismo modo, el Plan Director de Coeducación de la Generalitat Valenciana (2018), plantea, en su eje 5 los siguientes puntos:

Conseguir que la ocupación de los espacios sea igualitaria, tanto en los patios como en espacios de estudio, sin predominio de actividades en las que participen específicamente los chicos en momentos en que se comparte el mismo espacio y tiempo (p.18).

A pesar de que la coeducación se debe implementar de forma transversal en los proyectos educativos de los centros, esta comunicación, en consonancia con la normativa actual vigente en la Comunidad Valenciana, se dirige de manera muy especial al abordaje de la situación de los patios escolares. Por este motivo, conviene señalar algunas acciones recogidas en el Plan director de coeducación mencionado con anterioridad:

- Analizar el uso de los patios escolares y de otros espacios del centro en el plan de igualdad y convivencia.

- Revisar si se hace un uso igualitario de los espacios del centro: patios, aulas y otros espacios de estudio, debate o toma de palabra.

- Impulsar acciones dentro del centro en torno al uso de los espacios, especialmente el patio, contando con la participación del alumnado y del resto de la comunidad educativa.

Finalmente, el objetivo general de la presente comunicación es el de compartir los acuerdos alcanzados por parte de todo el profesorado del centro objeto de estudio en el área del patio escolar para hacer realidad lo que viene prescrito en la normativa legal vigente.

Como objetivos secundarios se plantea fomentar buenas prácticas en el patio escolar y sensibilizar a toda la comunidad educativa respecto de la importancia de desarrollar acciones equitativas en estos espacios.

\section{CONTEXTUALIZACIÓN}

El CEIP Federico García Sanchiz es un centro de educación infantil y primaria de la ciudad de Alzira (Valencia). Dicho centro muestra interés en la realización de un Plan Coeducativo de centro que les encamine a trabajar la coeducación de manera transversal. Para todo ello el profesorado recibe formación impartida por Sandra Molines Borrás. En dicha formación, y a través de la toma de decisiones por consenso de todo el profesorado, se elabora un plan coeducativo que comprende acciones en las siguientes áreas:

a) Área de formación permanente del profesorado y del personal educador del comedor

b) Área de Intervención dentro del aula

c) Área del lenguaje

d) Área de revisión del androcentrismo de los materiales escolares

e) Área de Diversidad afectiva y sexual

f) Área de trabajo con las familias

g) Área del patio escolar

Se pretende diseñar un patio en donde todo el alumnado tenga su espacio, en donde se reduce la segregación y se aumentan las propuestas de juegos y actividades más diversas e inclusivas. Como en la mayor parte de patios escolares, se pretende disminuir 
el impacto de futbol centrismo y para ello se hace uso de la Guía de patios coeducativos (Molines, 2020).

Del mismo modo, y en la misma dirección que muestran diferentes estudios al respecto (Camacho, 2013; Muñoz, Rivero y Fondón, 2013), resulta una necesidad preocupante el nivel de sedentarismo y baja actividad física que lleva a cabo la mayor parte del alumnado y en especial las niñas, (Sevil, Abós, Julián, Murillo y García-González, 2015) y que representa índices por debajo de los recomendados por los principales organismos de la salud (Terrón-Pérez, Queralt, Molina-García y Martínez-Bello, 2019).

Dado que la configuración de los espacios nunca es neutra, será necesario saber y reconocer los sesgos de género que puedan estar manifestando las instalaciones del centro educativo y que estén afectando la vida y la convivencia del alumnado del mismo (Saldaña, Gula y Cardona, 2020).

Los patios escolares son lugares idóneos para analizar interesantes procesos socializadores entre el alumnado y para reconocer si existe cierta parte del mismo con determinado uso de poder sobre el espacio, en detrimento como no, de la posibilidad de uso de la otra parte (Equal Saree, 2017).

\section{DISEÑO Y DESARROLLO}

A continuación, se pasarán a describir todas las medidas acordadas para ser desarrolladas en los dos próximos cursos académicos en el patio escolar.

\begin{tabular}{|l|l|}
\hline $\begin{array}{l}\text { Estado de la } \\
\text { situación actual }\end{array}$ & $\begin{array}{l}\text { Actualmente vivimos en tiempos de pandemia. } \\
\text { Los espacios están distribuidos por cursos y clases y se promueve que el } \\
\text { alumnado no interaccione para evitar los contagios. }\end{array}$ \\
\hline $\begin{array}{l}\text { Objetivos a corto } \\
\text { plazo }\end{array}$ & $\begin{array}{l}\text { Revisar si se hace un uso igualitario del patio, de los espacios y de otros } \\
\text { momentos de estudio, debate o toma de la palabra. } \\
\text { Instaurar medidas en el patio conducentes a observar si las mismas disminuyen } \\
\text { la segregación en el juego y en el espacio }\end{array}$ \\
$\begin{array}{l}\text { Promover actitudes igualitarias y de relaciones simétricas entre niños y niñas. } \\
\text { Valorar los aspectos positivos y negativos de la delimitación de los espacios } \\
\text { causada por la pandemia. }\end{array}$ \\
\hline $\begin{array}{l}\text { Objetivos a largo } \\
\text { plazo }\end{array}$ & $\begin{array}{l}\text { Una vez superemos la situación de pandemia, que todo el alumnado del centro } \\
\text { pueda disfrutar de experiencias de juego y descanso conjuntamente, } \\
\text { favoreciendo así una mejor convivencia y una mayor diversidad de propuestas } \\
\text { lúdicas en esos espacios. En definitiva, se pretende educar en el patio. }\end{array}$ \\
\hline Descripción de & $\begin{array}{l}\text { 1. Incorporar un espacio en semicírculo (tipo grada) con disposición para } \\
\text { sentarse, conversar y dar clase. } \\
\text { 2. Recoger, dentro de cada clase, un abanico de materiales de juegos } \\
\text { naturales para poner a disposición del alumnado en una zona para las } \\
\text { construcciones. } \\
\text { Habilitar una zona de escalada en infantil y en primaria. } \\
\text { materiales naturales que posibiliten un circuito por el patio. }\end{array}$ \\
\hline
\end{tabular}




\begin{tabular}{|c|c|}
\hline $\begin{array}{l}\text { la acción a } \\
\text { desarrollar }\end{array}$ & 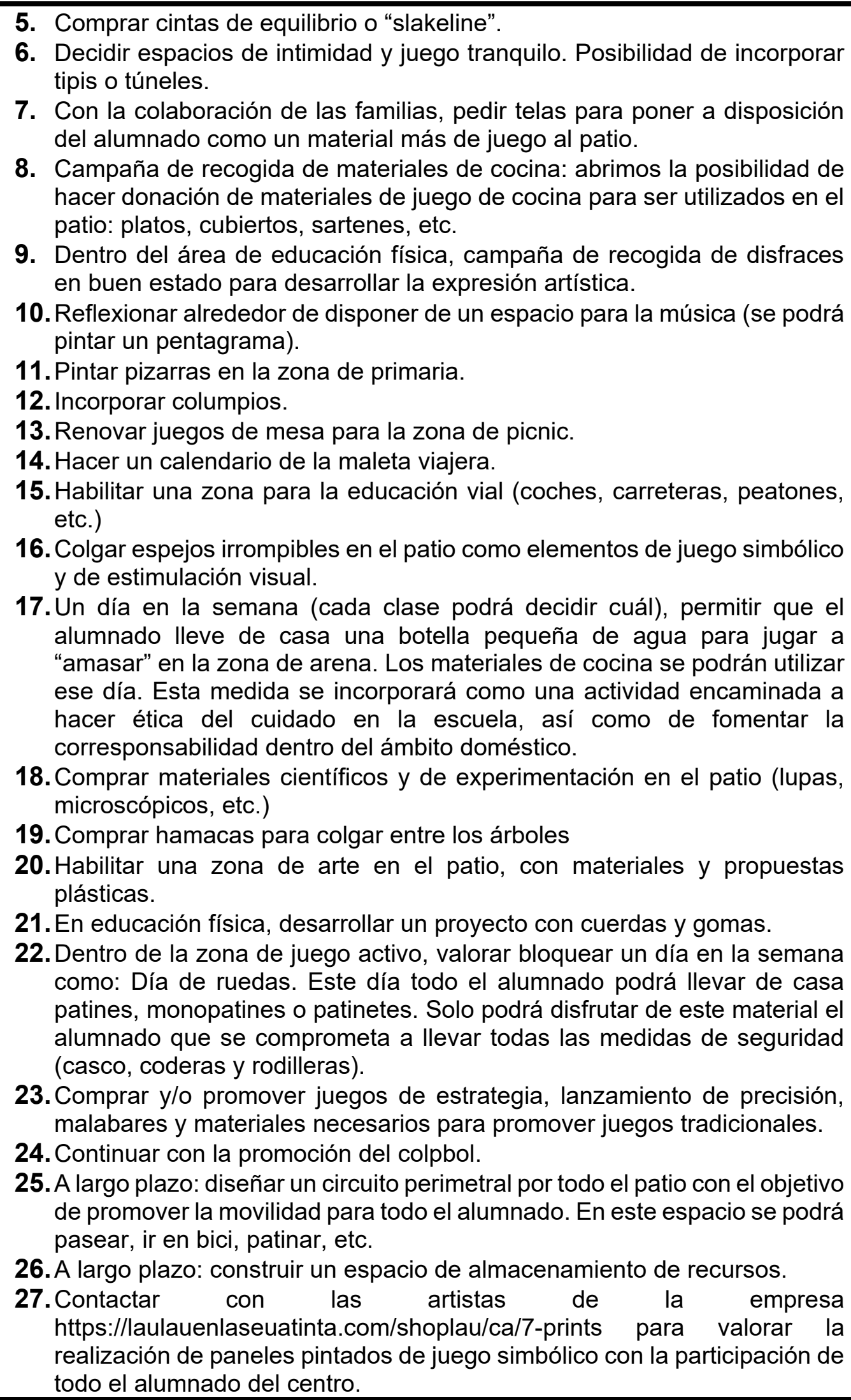 \\
\hline
\end{tabular}

Previa a la toma de decisiones sobre todo este abanico de propuestas, el profesorado, junto con la ponente de la formación, han realizado una detección de necesidades, 
gustos y preferencias por parte de todo el alumnado del centro, así como de todas las familias. De este modo, se han conseguido manifestar y recoger todas estas propuestas.

\section{EVALUACIÓN, CONCLUSIONES Y PROPUESTAS DE MEJORA}

Para el desarrollo de estas propuestas se ha llevado a cabo un diagnóstico de la situación prepandemia utilizando una serie de instrumentos propuestos por Subirats y Tomé (2010). Antes de marzo del año 2019, el colegio llevó a cabo un diagnóstico de la situación recogiendo datos alrededor de los siguientes ítems:

- Presencia de niños y niñas en las diferentes zonas del patio.

- Presencia de niños y niñas en las zonas centrales y periféricas del patio

- Presencia de alumnado en cada una de las áreas del patio escolar

- Encuesta dirigida al alumnado del centro para recoger sus intereses y preferencias

Con toda esta información se llevó a cabo un informe en donde quedaron definidas las necesidades del patio escolar, así como la urgente pertinencia de buscar formación, asesoramiento y acompañamiento en la realización de un nuevo patio escolar.

En todo momento, las familias han sido colaboradoras de la experiencia en el centro, así como han participado aportando propuestas e ideas para incorporar en el Plan coeducativo de centro y en el área del patio escolar.

Como conclusión el proceso ha comportado una elevada motivación tanto por parte del profesorado como del resto de comunidad educativa (familias y alumnado). La formación ha puesto de relieve carencias interesantes que existían el nivel de conocimientos por parte del profesorado en estas materias y ha posibilitado una toma de conciencia respecto de la urgente necesidad de trabajar todos estos temas.

Es interesante apuntar como, en el proceso, se ha conseguido llegar al mismo punto al que apunta Santos (2015) cuando muestra una interesante reflexión y debate de si deseamos que la escuela sea una mera transmisora de la sociedad (y con ella del sexismo), o podemos concebirla desde una perspectiva transformadora, igualitaria y equitativa. La formación claustral consigue esta última mirada una vez capacitado el profesorado en la perspectiva de género.

Por otro lado, se ha conseguido comprometer a las familias en todo el proyecto y ha producido un acercamiento por parte de las mismas al centro.

Las principales propuestas de mejora extraídas son las de la falta de recursos humanos y de tiempo para desarrollar un adecuado seguimiento de todas las medidas iniciadas. Las horas lectivas con el alumnado son una fuerte carga que dificulta el trabajo reflexivo y en comunidad del claustro.

\section{REFERENCIAS BIBLIOGRÁFICAS}

Equal Saree. (2017). El patio de la escuela en igualdad: Guía de diagnóstico y de intervención con perspectiva de género. Barcelona: Ayuntamiento de Santa Coloma de Gramenet. 
Camacho, M.J. (2013). Contradicciones del significado de la actividad físico-deportiva en las identidades corporales de las chicas adolescentes. Feminismo/s 21, 1535

Generalitat Valenciana (2018). Plan director de coeducación. http://www.ceice.gva.es/documents/161634256/165603089/Plan+Director+de+ Coeducaci \%C3\%B3n/a53bc1f6-e22b-4210-89aa-5e34230c4e08

Molines, S. (2020). Guía de Patios Coeducativos. Plataforma REICO Generalitat Valenciana. ISBN: 978-84-482-6507-6 Disponible en: http://www.ceice.gva.es/va/web/inclusioeducativa/guia-de-patis-coeducatius

Muñoz, B., Rivero, B. y Fondón, A. (2013). Feminidad hegemónica y limitación a la práctica deportiva. Feminismo/s 21, 37-50

Saldaña, D., Gula, J. y Cardona, H. (2020). La coeducación como una práctica espacial. Guix. Elements d'Acció Educativa. 468-469, 10-14

Santos, M. A. (2015). Género, poder y convivencia. La escuela como mezcladora social. En Juan José Leiva et al. (Coord.). Género, Educación y Convivencia, 2758. Madrid: Dykinson.

Sevil, J., Abós, A., Julián, J.A., Murillo, B. y García-González, L. (2015). Género y motivación situacional en Educación Física; claves para el desarrollo de estrategias de intervención. RICYDE. Revista internacional de Ciencias del Deporte, 14, 281-296

Subirats, M. y Tomé, A. (2010). Balones fuera ( $\left.2^{a} E d\right)$. Barcelona: Octaedro

Terrón-Pérez, M., Queralt, A., Molina-García, J. y Martínez-Bello, V. E. (2019). Ecological correlates of Spanish preschoolers' physical activity during school recess. European Physical Education Review, vol. 25 (2), 409-423. 


\title{
2. EDUCACIÓN PARA LA IGUALDAD EN LA EDUCACIÓN SECUNDARIA.
}

\subsection{INVESTIGACIONES}

\author{
2.1.1. El territorio de los silencios: el currículum oculto en los libros \\ de texto del módulo de Formación y Orientación Laboral \\ María Carmen Alemany Moreno (IES Jorge Juan, España); Helena Aparicio Sanmartín \\ (IES Jorge Juan, España)
}

\section{Resumen}

La presente investigación pone de manifiesto, cómo se sigue perpetuando el currículum oculto en los libros de texto del módulo de Formación y Orientación Laboral, módulo transversal impartido en los primeros cursos de los ciclos formativos de grado medio y superior, de los Centros Educativos de titularidad pública de la ciudad de Valencia.

Los resultados muestran que, la representación y las aportaciones de las mujeres en los libros de texto, continúa siendo insuficiente, incluso inexistente, salvo cuando se hace referencia a aspectos jurídicos en materia laboral, y siempre referidos al cuidado o la maternidad, incumpliendo así la legislación vigente.

Por ello, es necesario romper con el territorio de los silencios y el currículum oculto. Reforzando la visibilidad y presencia de las mujeres, así como, el planteamiento a la comunidad educativa de la necesidad de llevar a cabo una profunda reflexión sobre el tratamiento otorgado desde la enseñanza.

Palabras clave: Coeducación, territorio de los silencios, currículum oculto, formación y orientación laboral y libros de texto

\section{INTRODUCCIÓN Y OBJETIVOS}

El objetivo principal, es identificar el grado de visibilidad y el tratamiento que las mujeres reciben en las unidades didácticas del bloque de derecho del trabajo, en los libros de texto del módulo de Formación y Orientación Laboral. Operativizado en los siguientes objetivos:

Poner de manifiesto la diferencia de trato entre hombres y mujeres en los libros de FOL

Denunciar la falta de lenguaje inclusivo en dichos libros.

Destacar la ausencia de la figura de la mujer en los temas tratados.

Señalar que las imágenes de las mujeres son pocas y relacionadas, generalmente, con el cuidado y la maternidad.

Revelar que los puestos de trabajo de la mujer en estos temas suelen ser puestos de escasa relevancia.

Expresar la ausencia de logros a nivel laboral del colectivo femenino. 


\section{METODOLOGÍA}

En la presente investigación, se ha utilizado un enfoque metodológico mixto, cuantitativo y cualitativo.

La metodología cuantitativa: en relación con el estudio de la frecuencia en que las mujeres aparecen representadas. Mediante la búsqueda de los datos observados en los libros de texto, de forma objetiva, permitiendo realizar una comparativa entre las distintas editoriales.

La metodología cualitativa, a través del método investigación-acción, con la finalidad de reflexionar y profundizar sobre, la forma y ámbitos en los que se hace alusión a las mujeres, su importancia social y aportaciones, el lenguaje utilizado y los escenarios en los cuales están invisibilizadas.

\section{RESULTADOS Y DISCUSIÓN}

Tras el análisis de las unidades didácticas del bloque de derecho del trabajo, de las 6 editoriales de los libros de texto utilizados en el módulo de Formación y Orientación Laboral, los resultados son los siguientes:

En cuanto al uso del lenguaje, en el texto de las unidades didácticas y en la redacción de las actividades: está prácticamente masculinizado.

Los puestos que desempeñan las mujeres en las actividades: en su mayoría están representadas en puestos de auxiliar administrativa, administrativas, dependientas, limpieza y cocina. $Y$ en actividades sobre flexibilidad horaria y conciliación de la vida personal y familiar, la mujer es referente.

La visibilidad de los logros de la mujer: únicamente en una editorial y en relación a una actividad de cine sobre las trabajadoras de la Ford, que a través de la huelga consiguieron la igualdad de salario.

En relación a las imágenes: la figura de la mujer es escasa en la mayoría de las editoriales. Y cuando aparecen, están representadas como trabajadoras, cuidadoras, madres y no como empresarias.

Las veces que se hace referencia a la mujer en el texto y en las actividades: es en cuestiones de índole estrictamente jurídico como las reducciones de jornada por cuidado de familiares, planes de igualdad, permisos y excedencias por conciliación familiar y personal. Continúan vigentes los patrones culturales androcéntrico y sigue siendo la mujer la protagonista en el ámbito del cuidado.

En todas las presentaciones de los libros se hace constante alusión a autores, cuando han sido elaborados por hombres y mujeres. Además, también hacen referencia a que están dirigidos a profesores y alumnos incluyendo una sola vez, referencia al profesorado.

Destacar, que, en una editorial, en el prólogo del libro se excusan diciendo que hacen uso del masculino genérico para economizar el lenguaje.

\section{CONCLUSIONES Y LIMITACIONES}

Lo que no se nombra no existe. Por ello, se pone de manifiesto la necesidad de una revisión urgente de los libros de texto, cuya finalidad, es poner en práctica la normalización del currículo coeducativo para el cumplimiento de la ley. Siendo la coeducación, un pilar fundamental para prevenir conductas y acciones discriminatorias, y la violencia contra las mujeres. 


\section{REFERENCIAS BIBLIOGRÁFICAS}

Blanco, N. (2000). Mujeres y hombres para el S. XXI: El sexismo en los libros de texto. En: M. A. SANTOS, (Coord.) El Harén pedagógico. Barcelona: Ed. Graó.

Bonal, X. (2014). Cuadernos para la educación. Cambiar la escuela: la coeducación en el patio de juegos. Barcelona: Ed. Institut de Ciències de l'Educació Universitat Autònoma de Barcelona.

De Rougemont, D. (1979). El amor y Occidente. Barcelona: Ed. Kairós.

Ley Orgánica 1/2004, de 28 de diciembre, Ley de Medidas de Protección Integral contra la Violencia de Género. Boletín Oficial del Estado, 29 de diciembre 2004, nº.313, p. 42166-42197.

Ley Orgánica 2/2006, de 3 de mayo, de Educación. Boletín Oficial del Estado, 4 de mayo de 2006, n. ${ }^{\circ} 106$, p. 17158-17207.

Ley Orgánica 3/2007, de 22 de marzo, para la igualdad efectiva entre mujeres y hombres. Boletín Oficial del Estado, 23 de marzo de 2007, n.71, p. 1261112645.

Ley Orgánica 8/2013, de 9 de diciembre, para la mejora de la calidad educativa. Boletín

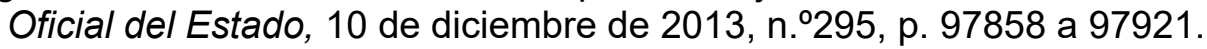

Ley Orgánica 3/2020, de 29 de diciembre, por la que se modifica la Ley Orgánica 2/2006, de 3 de mayo, de Educación. Boletín Oficial del Estado, 30 de diciembre de 2020, n. ${ }^{\circ} 340$, p. 122868 a 122953.

Lorente Acosta, M. (2001). Mi marido me pega lo normal. Barcelona: Ed. Critica.

Méndez Miras, A. y Sasiain Villanueva, I. (2006). En femenino y en masculino. Nombra.en.red. Series Lenguaje $\mathrm{n}^{\circ} 3$. Madrid: Ed. Instituto de la mujer.

Pérez, G. y Pérez, M. V. (2011). Aprender a convivir como oportunidad de conocimiento. Madrid: Ed. Narcea Ediciones.

Petit, M. y Prat, M. (2011). Prevención de la violencia de género en la adolescencia. Barcelona: Ed. Icariaochodemarzo, p.13-55.

Sasiain Villanueva, I. y Mateos Gil, A. (2010). Coeducación en la escuela. Responsables de Coeducación en los centros educativos. Madrid: Ed. CEAPA.

Sau, V. (1986). Ser mujer: El fin de una imagen tradicional. Barcelona: Ed. Icaria.

Simón Rodríguez, E. (2010). La igualdad también se aprende. Cuestión de coeducación. Madrid: Ed. Narcea, p. 54-58.

Valcárcel, A. (2008). Feminismo para un mundo global. Madrid: Ed. Cátedra, Feminismos.

Varela, N. (2013). Feminismo para principiantes. Barcelona: Ed. Ediciones B. 


\subsubsection{Prevención de la Violencia de Género a través de la Educación Física}

Carlos Avilés Villarroel (Universidad Complutense de Madrid, España); Irene Ramón Otero (Universidad Complutense de Madrid, España); Joaquín Piedra de la Cuadra (Universidad de Sevilla, España); Elena Ramírez Rico (Universidad Complutense de Madrid, España).

\section{Resumen}

Este estudio tiene como propósito identificar los trabajos recientes que desarrollan proyectos, programas, estrategias o intervenciones, mediante la Educación Física y sus actividades físicas y deportivas, que permiten interacciones de género entre estudiantes libres de conductas intimidatorias o agresivas, y que promueven la equidad a partir de valores de respeto, aceptación y tolerancia. Para ello, se realizó una búsqueda electrónica a través de palabras clave en las principales bases de datos. Inicialmente, se recuperaron cuarenta y ocho documentos y, posteriormente, se realizó un cribado más exhaustivo para seleccionar solo los documentos que respondían específicamente a nuestra cuestión. Se aplicó un conjunto de criterios de inclusión y/o exclusión lo que permitió seleccionar una muestra final de tres estudios de Educación Primaria y Secundaria. Los resultados reflejan una gran escasez de trabajos publicados, lo que abre todo un mundo de posibilidades para crear e implementar nuevos programas o estrategias de prevención.

Palabras clave: programas; estrategias; educación secundaria, intimidación; equidad

\section{INTRODUCCIÓN Y OBJETIVOS}

En los últimos años, diferentes agentes de la comunidad educativa, y en especial, investigadores en educación, se han preocupado por analizar las múltiples causas que están detrás del aumento de casos de violencia en los centros educativos. Sobre todo, investigadoras e investigadores demandan que, los estudios sobre las intervenciones de prevención de la violencia en escolares se centren en los efectos que producen a largo plazo (Melendez-Torres et al., 2018). Algunas investigaciones recientes indican que cerca del $17 \%$ del alumnado encuestado, ha presenciado acoso escolar siendo testigos de acciones intimidatorias, lo más preocupante es que un $16 \%$ de escolares, declara haber padecido maltrato físico, verbal o relacional (e.g., Chacón-Cuberos et al., 2015). En otras encuestas se han obtenido datos muy alarmantes, al respecto Fuller et al. (2011) destacan que el $50 \%$ de las estudiantes y los estudiantes han respondido que el acoso se produce en sus clases de Educación Física, además, el $77 \%$ del estudiantado, ha declarado que no informaron al profesorado de Educación Física cuando habían sido acosadas o acosados.

Dentro de estos estudios, han surgido diferentes programas y estrategias educativas que intentan reducir la violencia de género y promover conductas más igualitarias entre el alumnado (e.g., Lobejón et al., 2010). Sin embargo, algunos estudios cuestionan la efectividad de estos programas y denuncian importantes lagunas para prevenir la violencia en los grupos de jóvenes más vulnerables (Crooks et al., 2019).

La naturaleza relacional y dinámica de las actividades colectivas en las clases de Educación Física, produce contacto físico entre participantes, a veces, no es fácil distinguir si las acciones deportivas son apropiadas, o si, por el contrario, corresponden a conductas intimidatorias que van generando un daño emocional en quien lo sufre; en este contexto, el papel del profesorado de Educación Física es proactivo, ya que tiene la importante labor de prevenir el acoso escolar utilizando estrategias eficaces de enseñanza, y la creación de un clima positivo en el aula (Fuller et al., 2013, Gibbone \& 
Manson, 2010). En consecuencia, la Educación Física es un medio idóneo para prevenir la violencia de género, crear un ambiente de respeto y promover interacciones positivas entre los estudiantes y las estudiantes. Por ello, surge la necesidad de estudiar y de potenciar las acciones educativas que fomenten igualdad e inclusión en la etapa adolescente (Gallardo \& Gallardo, 2019).

En esta línea, el presente estudio forma parte del Proyecto Nacional I+D+i con referencia RTI2018-095406-A-I00, subvencionado por el Ministerio de Ciencia e Innovación y Universidades de España. El objetivo principal es identificar y analizar los estudios recientes que tratan un conjunto de estrategias o programas de intervención, a través de la Educación Física y sus actividades físico deportivas, que permiten interacciones entre estudiantes libres de intimidación, violencia o agresión, y que promueven la equidad a partir de valores de aceptación y tolerancia. Para lograr este objetivo, el estudio que aquí se aborda consiste en la búsqueda, recopilación y revisión documental sobre trabajos previos existentes en el contexto internacional y nacional que, dirigidos hacia la población escolar y adolescente, hayan tratado la problemática de género que se ha expuesto anteriormente. Esto permitirá conocer el estado de la cuestión y constatar si existe literatura suficiente en esta temática.

\section{METODOLOGÍA}

Inicialmente, los investigadores y los investigadores realizaron una búsqueda electrónica en las siguientes bases de datos y repositorios: Dialnet, Reedalyc, Scopus, SportDiscus, ERIC, PubMED y Web of Sciences. Esta búsqueda se organizó a través de palabras clave en español e inglés con distintos operadores booleanos: Physical Education, Sport, Violence Prevention Program, Violence Prevention Intervention, Sexual Violence, Sexual Abuse, Sexual Harassment; Gender Relation, Gender Interaction, Gender Intimidation, Equity, Equality, Adolescent, Teenager. La finalidad de la búsqueda era seleccionar los estudios recientes, de 2010 a 2020, que hubieran desarrollado programas o estrategias de prevención de la violencia de género en el ámbito escolar, particularmente en Educación Física y sus actividades físico deportivas.

Se revisaron título, resumen, palabras clave y texto completo; concretamente se recuperaron cuarenta y ocho documentos entre artículos, capítulos de libro, informes, guías o manuales. En algunos casos se trataba de programas organizados, desarrollados y con mucha información contrastada para prevenir la violencia de género. En otros casos eran actividades aisladas o estrategias rescatadas de programas más genéricos. Algunos programas utilizaban una muestra de centros, escolares, profesorado de Educación Física, entrenadoras y entrenadores, pero pertenecían más bien a clubes e instituciones del ámbito deportivo. Otros, pertenecían al contexto escolar, pero no tenían como propósito la prevención de la violencia de género como eje central, o bien, se alejaban del objetivo principal de este estudio.

Finalmente, se realizó un cribado más exhaustivo para seleccionar solo los documentos de programas o estrategias más específicas a nuestra cuestión. Los criterios de inclusión y/o exclusión fueron los siguientes:

(i) El programa o la estrategia debía focalizarse en la perspectiva de género: disminución de la violencia y de las conductas discriminatorias, o fomento de la equidad entre las alumnas y los alumnos dentro del centro educativo. Se excluyeron los documentos que trataban problemáticas diferentes como el noviazgo en adolescentes, violaciones en jóvenes, etc.

(ii) El documento, debía explicar el desarrollo o implementación de un programa o estrategias durante un periodo de tiempo. Se excluyeron los artículos de revisión narrativa y sistemática. 
(iii) Debía pertenecer al área de Educación Física e implementarse en el horario lectivo, recreo o en las actividades extraescolares del centro. Se excluyeron los programas que surgían del ámbito deportivo y que eran organizados principalmente por instituciones deportivas.

(iv) El documento debía estar publicado en castellano o en inglés en los últimos años, entre 2010 y 2020.

(v) El programa o la estrategia debía estar aplicada en un ámbito geográfico similar al contexto español (anglosajón-europeo).

\section{RESULTADOS Y DISCUSIÓN}

Los resultados se presentan en la tabla 1. Como se puede ver, solo se han encontrado tres estudios que cumplen todos los criterios de inclusión. Dos de ellos, utilizan una muestra de estudiantes de Educación Primaria y Secundaria.

Tabla 1. Estudios seleccionados que cumplen todos los criterios de inclusión

\begin{tabular}{lll}
\hline Autores, autoras y año & Etapas educativas & Programas o estrategias \\
\hline Pelegrín et al. (2012) & Primaria & Desarrollo actitudinal \\
Rebollo et al. (2012) & Primaria y Secundaria & Prácticas coeducativas \\
Castanedo \& Capllonch (2019) & Primaria y Secundaria & Socialización preventiva \\
\hline
\end{tabular}

Con estos resultados, queda de manifiesto que existe una gran escasez de trabajos sobre programas o estrategias de intervención para prevenir la violencia, y desarrollar actitudes de igualdad de género en la asignatura de Educación Física, o en las otras actividades físico-deportivas desarrolladas dentro del centro educativo.

Aunque el número de estudios es muy limitado, es importante analizar la efectividad de los programas implementados. Queda demostrado que una intervención de un mes (de 8 sesiones) integrada dentro de la programación de la asignatura de Educación Física, aumenta las actitudes de igualdad en niñas y niños de 7 a 12 años; aunque los niños mostraron niveles más altos de conductas discriminatorias que las niñas, antes y después de las actividades realizadas (Pelegrín et al., 2012). También, es interesante el análisis de los proyectos transversales que promueven las buenas prácticas en los centros, y que generan nuevos significados de las acciones coeducativas, sobre todo, cuando estas iniciativas transformadoras surgen de la preocupación de la Asociación de Madres y Padres del Alumnado (AMPA), del profesorado de Educación Física, e implican la colaboración de la Delegación de Deportes del Ayuntamiento (Rebollo et al., 2012).

Dentro de la clase de Educación Física, el diálogo igualitario es una herramienta crucial en el proceso de socialización, a través de la palabra, los estudiantes y las estudiantes toman conciencia, abordan las diferentes problemáticas y reflexionan de manera crítica, lo que contribuye a la prevención de la violencia de género y del acoso escolar dentro de un contexto de apoyo social e inclusivo (Castañedo \& Capllonch, 2019).

Todavía queda mucho camino por recorrer, parece increíble que, a día de hoy, en los centros educativos mixtos, la Educación Física sea la asignatura en la que más se separe las estudiantes y los estudiantes por género durante las clases, sin duda el concepto de "deshacer el género" puede aportar al estudio y a la implementación de nuevas estrategias coeducativas (Hills \& Croston, 2012). Con el objetivo de crear ambientes libres de intimidación en las clases de Educación Física, Hand (2016) 
propone tres pasos para lograr una estrategia efectiva: (i) evaluar y analizar el problema: en cuanto a los tipos de acoso y frecuencia de aparición, (ii) diseñar e implementar actividades específicas para combatir el acoso en las clases de Educación Física y, 3) evaluar el proceso que se ha llevado a cabo para ajustarlo y mejorarlo. A su vez, esta autora, sugiere mantener informados a los padres y las madres sobre cualquier cambio observado en una alumna o en un alumno, ya sea víctima, acosador, acosadora, observador u observadora. Además, recomienda comunicar a las madres y los padres de cualquier modificación del programa que se ha establecido contra el acoso escolar.

Es evidente que todas las personas implicadas en la comunidad tienen mucho que aportar, para que, de este modo, en las clases de Educación Física y en todas las aulas del centro, el clima sea positivo y el alumnado perciba una atmósfera de respeto, confianza y equidad. Las estudiantes y los estudiantes tienen un papel fundamental al observar las conductas agresivas e intimidatorias, necesitan ser informados e instruidos para saber cómo actuar cuando son testigos o padecen maltrato en cualquiera de sus manifestaciones. Las profesoras y los profesores de Educación Física tienen un desafío colosal al incorporar la prevención de las conductas intimidatorias y la perspectiva de género en sus unidades de programación. Al mismo tiempo, la misión del profesorado de Educación Física es un trabajo conjunto y compartido con todo el claustro de docentes y las familias. En cuanto a la creación de nuevos programas, estrategias e intervenciones, el abanico de posibilidades es enorme, más aún con la gran oferta y necesidad que producen las nuevas tecnologías en el alumnado de Educación Primaria y Secundaria.

\section{CONCLUSIONES Y LIMITACIONES}

Una de las dificultades encontradas, fue revisar los documentos para constatar si cumplían todos los criterios de inclusión, ya que algunos trabajos no eran del todo claros y para las investigadoras y los investigadores era complejo discernir, por ejemplo, algunos programas pertenecían al ámbito educativo y de la Educación Física, pero no habían sido elaborados específicamente en una perspectiva de género, por consiguiente, había que descartarlos quedando excluidos de la selección final.

En cuanto a las limitaciones, es posible que algunos estudios, no se hayan detectado mediante la búsqueda electrónica por palabras clave. Nuevos estudios de revisión deberían incluir una búsqueda manual por referencias, con el objetivo de recuperar algunos artículos que se pueden escapar en las búsquedas por palabras clave en las diferentes bases de datos.

Los estudios que responden específicamente a nuestra cuestión son muy escasos. Queda todo un campo abierto de investigación y desarrollo que, mediante la labor de investigadores y del profesorado de Educación Física, podría permitir la disminución de la violencia, de los estereotipos de género y el fomento de contextos más equitativos dentro del horario lectivo y no lectivo del centro. Se requiere más que nunca, nuevos programas o estrategias que surjan de las protagonistas y los protagonistas de los centros e instituciones educativas.

\section{REFERENCIAS BIBLIOGRÁFICAS}

Castanedo, J.M., \& Capllonch, M. (2019). Socialización preventiva de la violencia de género y el bullying en educación física a través de la evaluación dialógica. Infancia, Educación y Aprendizaje, 5(2), 293-299. https://doi.org/10.22370/ieya.2019.5.2.1622 
Chacón-Cuberos, R., Martínez-Martínez, A., Castro-Sánchez, M., Espejo-Garcés, T.,Valdivia-Moral, P.A., \& Zurita-Ortega, F. (2015). Relación entre bullying, género y actividad física: Estudio en escolares de la provincia de Granada. Trances, 7(6):791-810.

Crooks, C. V., Jaffe, P., Dunlop, C., Kerry, A., \& Exner-Cortens, D. (2019). Preventing gender-based violence among adolescents and young adults: Lessons from 25 years of program development and evaluation. Violence Against Women, 25(1), 29-55. https://doi.org/10.1177/1077801218815778

Fuller, B., Gulbrandson, K., \& Herman-Ukasick, B. (2013). Bully prevention in the physical education classroom. Strategies, 26(6), 3-8. https://doi.org/10.1080/08924562.2013.839425

Fuller, B., Herman-Ukasick, B., \& Gulbrandson, K. (2011). Bullying survey middle school/high school. Milwaukee Public Schools.

Gallardo, J. A., \& Gallardo, P. (2019). Educar en igualdad: Prevención de la violencia de género en la adolescencia. Revista Educativa Hekademos, 26, 31-39.

Gibbone, A., \& Manson, M. (2010). Bullying: Proactive physical educators' contribution to school-wide prevention. Journal of Physical Education, Recreation \& Dance, 81(7), 20-24. https://doi.org/10.1080/07303084.2010.10598504

Hand, K. E. (2016). Creating a bully-free environment in physical education. Journal of Physical Education, Recreation \& Dance 87, 55-57. https://doi.org/10.1080/07303084.2016.1203685

Hills, L., \& Croston, A. (2012) 'It should be better all together': exploring strategies for 'undoing' gender in coeducational physical education, Sport, Education and Society, 17(5), 591-605, http://dx.doi.org/10.1080/13573322.2011.553215

Lobejón, M. C., Albillo, M. M., García, M. F., Hermano, E., Ibáñez, M. S., Molina, M. I., \& Antolín, L. (2010). Campaña de prevención de la violencia de género dirigida a jóvenes "contra la violencia, ganas tú". Tabanque Revista pedagógica, 23, 99-126.

Melendez-Torres G.J., Tancred T., Fletcher A., Campbell, R., Thomas, J., \& Bonell, C. (2018). Integration of academic and health education for the prevention of physical aggression and violence in young people: Systematic review, narrative synthesis and intervention components analysis. BMJ Open, 8(9), e020793. http://dx.doi.org/10.1136/bmjopen-2017-020793

Pelegrín, A., León, J., Ortega, E., \& Garcés de los Fayos, E. (2012). Programa para el desarrollo de actitudes de igualdad de género en clases de educación física en escolares. Educación XX1, 15, 271-292. https://doi.org/10.5944/educxx1.15.2.142

Rebollo, M.A., Piedra, J., Sala, A., Sabuco, A., Saavedra, J., \& Bascón, M. (2012). La equidad de género en educación: Descripción de buenas prácticas educativas. Revista de Educación, 358, 129-152.

http://dx.doi.org/10.4438/1988-592X-RE-2012-358-186 


\subsubsection{Historia del arte en la LOMCE y la LOMLOE: ¿hacia una igualdad de género real? \\ $D^{a}$ Sandra García-Sinausía (Universidad Camilo José Cela, España) / Dra. Ana \\ Valtierra Lacalle (Universidad Complutense de Madrid)}

\section{Resumen}

La materia de Historia del arte la podemos encontrar en las leyes educativas españolas desde hace décadas, pero esta materia permanece sin cambios desde hace muchos años. Encontramos mujeres en la legislación relativa a Historia del arte, pero todas las mujeres que aparecen las encontramos en los títulos de las obras de arte, siembre como objetos de las obras, pero nunca como creadoras o sujetos pensantes de las mismas. En ninguna de las leyes se ha modificado el currículo para incluir a las mujeres artistas, este currículo permanece igual en cuestiones de genero desde hace décadas, sin avanzar al mismo ritmo que la sociedad española.

A lo largo de esta investigación hemos indagado si la legislación educativa avanza hacia una igualdad de género real, en especial en las asignaturas de la rama de historia. Con la próxima entrada en vigor de la nueva legislación, la LOMLOE, se espera que se trabajen cuestiones de género en el currículo, y haya una inclusión real de mujeres artistas en las materias de bachillerato.

Palabras clave: Mujeres artistas; Historia del arte; Legislación Educativa, Bachillerato; Igualdad de género.

\section{INTRODUCCIÓN Y OBJETIVOS}

La asignatura de Historia del arte aparece en la legislación educativa española desde hace décadas, se trata de una materia con años de presencia, fundamental para el conocimiento de la cultura y la formación del alumnado. Sin embargo, pese a llevar décadas en los centros educativos, incluso lustros impartiéndose, es una asignatura que no ha evolucionado a la vez que la población española, no se ha ido modificando el currículo en función de nuevas investigaciones y nuevos intereses de la sociedad, y la no inclusión de las mujeres en la Historia del arte de bachillerato es un ejemplo de ello.

Las materias que se imparten en secundaria y bachillerato deben adaptarse a los tiempos, con especial énfasis a las asignaturas relativas a la rama de conocimiento de la historia, donde los acontecimientos siguen sucediendo y los libros de texto y la legislación deben ser un reflejo de ello.

Se han realizado diversos estudios hasta el momento sobre la falta de mujeres en los materiales y la legislación educativa de todas las asignaturas de E.S.O y Bachillerato, entre ellos las investigaciones realizadas por López Navajas (2014), que arrojó información de vital importancia a la hora de tener datos contrastados sobre la presencia de mujeres en los materiales educativos de Educación Secundaria Obligatoria. Sin embargo, actualmente hay muy pocos estudios sobre la situación de las mujeres artistas en las asignaturas relativas a la Historia del Arte que se imparten en Bachillerato. La ausencia de referentes femeninos en todas las ramas de conocimiento es alarmante, en especial en las asignaturas de historia, puesto que el número de nombres propios en estas asignaturas es muy alto, pero si diferenciamos entre hombres y mujeres las proporciones son muy llamativas, en ninguna materia de historia de ESO se supera el $10 \%$ de apariciones femeninas. 
El objetivo principal de este estudio es investigar la ausencia de mujeres artistas y el tratamiento de la figura de la mujer en la asignatura de Historia del arte en los últimos años, además hemos estudiado la inclusión de la mujer y las cuestiones de género en la nueva legislación educativa en España, la LOMLOE. De esta manera, quedará patente la necesidad de la inclusión de las mujeres en el currículo, que sirvan de ejemplo para las generaciones de alumnas y alumnos que estudian estas materias.

\section{METODOLOGÍA}

Para llevar a cabo este estudio hemos revisado la bibliografía existente en cuanto a legislación educativa e igualdad de género, además, hemos analizado cualitativamente la legislación educativa actual, la LOMCE, poniendo el punto de mira en las cuestiones de género y en especial la inclusión de las mujeres en la Historia del arte como creadoras, y no solo como musas o modelos. Posteriormente hemos analizado toda la información disponible actualmente en relación con la LOMLOE, tanto el Boletín Oficial del estado como la información que se encuentra en la página oficial del Ministerio de Educación, para poder ver hacia donde se dirige la legislación y si se prevé una inclusión real de mujeres en las leyes y los materiales educativos.

\section{RESULTADOS Y DISCUSIÓN}

Se ha analizado tanto cuantitativa como cualitativamente el currículo educativo de la materia de Historia del arte incluida en la LOMCE y se puede afirmar con total rotundidad que se trata de una asignatura sexista y nada inclusiva en cuestiones de género, tanto por la ausencia de mujeres como por el tratamiento de estas, las cuales aparecen únicamente como musas o como objeto de las obras de arte, no como sujeto creador. La nueva legislación, la LOMLOE, prevé la inclusión de la perspectiva de género en el currículo educativo, sin embargo, es necesario no solo la inclusión de la perspectiva de género, si no incluir nombres de mujeres reales, ejemplos para el alumnado de secundaria y bachillerato.

Se ha podido comprobar parcialmente que la nueva legislación va en buena dirección en cuanto a la inclusividad y la igualdad, pero aun encontramos ausencias notables de mujeres, es necesaria la publicación de toda la legislación relativa a la LOMLOE para comprobar que la igualdad de género de la que se habla es una igualdad real y no un simple lavado de cara.

\section{CONCLUSIONES Y LIMITACIONES}

La investigación muestra que el currículo educativo que está en vigor a día del envío de este documento, la LOMCE, muestra graves desigualdades de género en las materias de historia del arte de bachillerato. La nueva legislación, la LOMLOE, prevé una inclusión de las mujeres en el currículo educativo, aunque aún no se dispone de la publicación del Boletín Oficial del Estado por el que se establece el currículo de secundaria y bachillerato. Al no disponer actualmente de toda la legislación, esta investigación seguirá avanzando en el tiempo a la vez que se vayan produciendo actualizaciones en el currículo de la LOMLOE.

Es imperativo modificar los contenidos, criterios y estándares incluidos en el currículo educativo de historia del arte para que haya una inclusión real de las mujeres, no solo en un apartado, si no de manera natural y orgánica junto con el resto de artistas. La nueva legislación, la LOMLOE puede ser la legislación en la que, tras muchas leyes 
educativas, se haga justicia a todas las mujeres que han sido olvidadas durante años en los centros escolares.

\section{REFERENCIAS BIBLIOGRÁFICAS}

Bel Martínez, J.C. (2016). El papel de las mujeres en la Historia según las imágenes de los libros de texto Comparación de manuales editados durante la LOE y la LOMCE. AULA. Revista pedagógica de la universidad de Salamanca, 22, 219233.

Bian, L., Leslie, S.J., y Cimpian, A. (2017). Gender stereotypes about intellectual ability emerge early and influence children's interests. Science, 355(6323), 389-391.

Caballero Carrillo, M.R. (1993). La Historia del Arte en la enseñanza secundaria: perspectiva histórica y posibilidades de futuro. Imafronte, (8-9), 51-60.

Colás, P., y Villaciervos, P. (2007). La interiorización de los estereotipos de género en jóvenes y adolescentes. Revista de investigación educativa, 25(1), 35-38.

De Diego, E. (2009). La mujer y la pintura del XIX español: cuatrocientas olvidadas y algunas más. Catedra Ediciones.

Díaz López, M., y Puig Gutiérrez, M. (2020). Análisis de la vigencia de una educación sexista en los libros de textos de Historia de $4^{\circ}$ de la ESO. Social and Education History, 9(1), 38-64.

Hamodi, C. (2014) ¿Transmiten los libros de texto el valor de la igualdad desde la perspectiva de género? Estudio del lenguaje icónico de dos editoriales. Reire: Revista D'Innovació i Recerca en Educació, 7 (1), 30-55

Jiménez Fernández, C. (2011). Educación, género e igualdad de oportunidades. Tendencias Pedagógicas, 18. Universidad Autónoma de Madrid.

Lomas, C. (2002) El sexismo en los libros de texto. En A. González y C. Lomas (coords.). Mujer y educación: educar para la igualdad, educar desde la diferencia. 193-209. Graó.

López-Navajas, A. (2014). Análisis de la ausencia de las mujeres en los manuales de la ESO: una genealogía de conocimiento ocultada. Revista de Educación, (363), 282-308. Ministerio de Educación, Cultura y Deporte de España

López-Navajas, A., López García-Molins, A. et all (2009). La Presencia de las Mujeres en la E.S.O. Mujeres en la E.S.O website: http://meso.uv.es/informe/index.php

Mayayo, P. (2003). Historias de mujeres, historias del arte. Cátedra.

Pollock, G. (1977). What's wrong with "Images of Women"?. Screen Education, (24), 2533.

Real Decreto 1105/2014, de 26 de diciembre, por el que se establece el currículo básico de la Educación Secundaria Obligatoria y del Bachillerato. Ministerio de educación, cultura y deporte. Madrid, España, 3 de enero de 2015.

Rodríguez Martínez, C. (2004). La ausencia de las mujeres en los contenidos escolares. Miño y Dávila Editores. 
Sant Obiols, E y Pagès Blanch, J. (2011). ¿Por qué las mujeres son invisibles en la enseñanza de la historia? Historia y Memortia, (3), 129-146.

Sigal, V. L. (1997). Cómo enseñamos Historia. Los materiales didácticos y su adecuación a maestros y alumnos. Perfiles educativos, (75). Instituto de Investigaciones sobre la Universidad y la Educación de México.

Vega, C. (2002) La mujer en la historia y la historia de las mujeres. En A. González y

C. Lomas (coords.) Mujer y educación: educar para la igualdad, educar desde la diferencia (13-20). Graó. 


\subsubsection{Brecha de Género en Matemáticas y Eficacia Escolar en Secundaria}

Eider Oregui-González (UPV/EHU, España); Ander Azkarate-Morales (UPV/EHU, España); Isabel Bartau-Rojas (UPV/EHU, España).

\section{Resumen}

La finalidad de este trabajo es comparar la brecha de género en la Competencia Matemática entre centros de alta y baja eficacia de Secundaria de la Comunidad Autónoma Vasca (CAV). Se presenta un estudio censal en el que se han analizado las puntuaciones en la Competencia Matemática de alumnas y alumnos de Secundaria en las ediciones 2013, 2015 y 2017 de la Evaluación Diagnóstica en ambos tipos de centros. Los resultados muestran una tendencia a ir superando la brecha de género tanto en los centros de alta como en los de baja eficacia en la edición del 2017. Se analizan las implicaciones para la práctica docente y la política educativa en la CAV.

Palabras clave: Brecha de Género; Competencia Matemática; Educación Secundaria; Eficacia Escolar; Mejora Escolar.

\section{INTRODUCCIÓN Y OBJETIVOS}

Este trabajo se enmarca dentro de una investigación más amplia que pretende explorar la relación entre las dos dimensiones principales de la eficacia escolar, la calidad y la equidad, en concreto abordando la igualdad/brecha de género en la Competencia Matemática del alumnado en los centros de alto y bajo nivel de eficacia de la Comunidad Autónoma Vasca (CAV) 4 .

A pesar del reconocimiento sistemático de la persistente y amplia brecha de género a favor de los chicos en la Competencia Matemática en diversos estudios a nivel internacional (Correa, 2015; Else-Quest et al., 2010; Ibañez y Formichela, 2017; Nosek et al., 2009; OECD, 2019; Quiroz et al., 2020; Riegle-Crumb, 2005), nacional (De la Rica y González, 2013; Fuentes y Renobell, 2020; López et al., 2020) y de la CAV (Angulo et al., 2017), el papel de las escuelas para explicar esta brecha ha sido relativamente poco investigado (Muñoz-Chereau, 2018) y se han realizado escasos trabajos sobre la relación entre la brecha de género y la eficacia de los centros educativos.

Las teorías que explican esta brecha de género remiten a los estereotipos y prácticas de socialización de género que afianzan el dominio masculino y la sumisión femenina (Leaper, 2014; Partridge et al., 2008). Otros estudios muestran que los estereotipos aún hacen creer a las chicas que están poco capacitadas para materias como las matemáticas (Macho et al., 2020; Gunderson et al., 2011). En otros trabajos se ha encontrado que el género influye en las creencias, actitudes y reacciones emocionales del alumnado de secundaria hacia las matemáticas y su aprendizaje, en concreto, las chicas muestran una actitud más negativa y experimentan mayores niveles de ansiedad, desconfianza, inseguridad, falta de perseverancia, sienten menos curiosidad que los

\footnotetext{
${ }^{4}$ Investigación realizada gracias al Proyecto I+D "GESKOLA - Mejora escolar desde la perspectiva de género en centros de la Comunidad Autónoma Vasca (CAV)" financiado por [PGC2018-094124-B-I00] la Agencia Estatal de Investigación (AEI) del Ministerio de Ciencia, Innovación y Universidades (MCIU) del Gobierno de España y cofinanciado por el Fondo Europeo de Desarrollo Regional (FEDER); así como, al Grupo de Investigación "GANDERE - Socialización de Género y Contextos Educativos (www.gandere.eus)" reconocido por [PPGA20/04; GIU19/007; PPGA19/46] la Universidad del País Vasco (UPV/EHU) y por [IT1262-19] el Gobierno Vasco (EJ-GV).
} 
chicos por la solución de problemas, menos sensación de fracaso y de pérdida de tiempo, hacia las matemáticas y su aprendizaje que los chicos (Gil et al., 2006).

La finalidad de este estudio es comparar la brecha de género en la Competencia Matemática entre centros de alta y baja eficacia de Secundaria de la Comunidad Autónoma Vasca.

\section{METODOLOGÍA}

El Instituto Vasco de Evaluación e Investigación Educativa (ISEI-IVEI) realiza Evaluaciones Diagnósticas (ED) cada dos años a los centros escolares de la Comunidad Autónoma Vasca (CAV). La Evaluación Diagnóstica (ED) es una prueba estandarizada similar a PISA que tiene por objetivo evaluar la Competencia Matemática y Lingüística, en Lengua Castellana (o castellano) y Lengua Vasca (o euskara), del alumnado de $4^{\circ}$ de Educación Primaria (EP) y de $2^{\circ}$ de Educación Secundaria Obligatoria (ESO).

En esta comunicación se presentan los resultados relativos a la Competencia Matemática de alumnas y alumnos de Educación Secundaria Obligatoria (ESO) en las últimas aplicaciones de la ED llevadas a cabo en 2013, 2015 y 2017. En total, han participado: en 2013, 19216 estudiantes (9334 alumnas y 9877 alumnos) pertenecientes a 321 centros de Educación Secundaria; en 2015, 19053 estudiantes (9157 alumnas y 9825 alumnos) pertenecientes a 322 centros de Educación Secundaria; y, en 2017, 21436 estudiantes (10310 alumnas y 11121 alumnos) pertenecientes a 326 centros de Educación Secundaria.

Primeramente, se ha realizado un análisis de regresión multinivel (o modelo lineal mixto) por cada año de aplicación de la ED para determinar cuáles de esos centros de Educación Secundaria se pueden considerar de alta (residuo positivo) o baja (residuo negativo) eficacia en la Competencia Matemática una vez controladas las variables contextuales como, por ejemplo: el Índice Socioeconómico y Cultural (ISEC), el tamaño del centro, la tasa de alumnado inmigrante, la tasa de alumnado repetidor, etc. (ver artículo de Lizasoain-Hernández, 2020).

Después, tras agrupar los centros en base a su nivel de eficacia (alta o baja) y comprobar que las puntuaciones en la Competencia Matemática no siguen la distribución normal mediante la prueba de Kolmogorov-Smirnov $(p<.05)$, se ha ejecutado en SPSS la prueba $U$ de Mann-Whitney para contrastar las similitudes y diferencias entre las alumnas y los alumnos de alta eficacia; entre las alumnas y los alumnos de baja eficacia; entre las alumnas de alta y baja eficacia; así como, entre los alumnos de alta y baja eficacia.

\section{RESULTADOS Y DISCUSIÓN}

La diferencia en las puntuaciones medias en la Competencia Matemática tanto de las alumnas como de los alumnos entre centros de alto y bajo nivel de eficacia de secundaria se ha ido incrementando desde 2013 al 2017. Asimismo, los resultados indican que en secundaria las alumnas obtienen una menor puntuación que los alumnos en la Competencia Matemática (ver Tabla 1).

Sin embargo, no se han encontrado diferencias estadísticamente significativas entre las alumnas y los alumnos de alta eficacia en la aplicación de la ED de 2017, ni entre las alumnas y alumnos de baja eficacia en la aplicación de la ED de 2015 y 2017 . Lo que podría indicar una menor brecha de género en las últimas aplicaciones de la ED. 
Tabla 1

Comparativa entre alumnas y alumnos de alta y baja eficacia

\begin{tabular}{|c|c|c|c|c|c|c|c|c|}
\hline \multirow{2}{*}{\multicolumn{3}{|c|}{$\begin{array}{l}\text { Competencia } \\
\text { Matemática }\end{array}$}} & \multicolumn{2}{|c|}{2013} & \multicolumn{2}{|c|}{2015} & \multicolumn{2}{|c|}{2017} \\
\hline & & & Alumnas & Alumnos & Alumnas & Alumnos & Alumnas & Alumnos \\
\hline \multirow{5}{*}{ ESO } & & $\begin{array}{c}M \\
(D T)\end{array}$ & $\begin{array}{l}258.20 \\
(48.36)\end{array}$ & $\begin{array}{l}262.98 \\
(4974)\end{array}$ & 254.23 & $\begin{array}{l}257.70 \\
(48.17)\end{array}$ & $\begin{array}{l}258.76 \\
(4780)\end{array}$ & $\begin{array}{l}259.01 \\
(50.23)\end{array}$ \\
\hline & RSD+ & Z & \multirow{2}{*}{\multicolumn{2}{|c|}{$\begin{array}{l}-4.39 \\
.000\end{array}$}} & \multirow{2}{*}{\multicolumn{2}{|c|}{$\begin{array}{l}-3.36 \\
.001\end{array}$}} & \multirow{2}{*}{\multicolumn{2}{|c|}{$\begin{array}{l}-.24 \\
.813\end{array}$}} \\
\hline & & $p$ & & & & & & \\
\hline & \multirow{2}{*}{ RSD- } & $\begin{array}{c}M \\
(D T)\end{array}$ & $\begin{array}{l}239.61 \\
(49.08)\end{array}$ & $\begin{array}{l}242.23 . \\
(49.38)\end{array}$ & $\begin{array}{l}235.99 \\
(44.65)\end{array}$ & $\begin{array}{l}236.33 \\
(48.13)\end{array}$ & $\begin{array}{l}238.51 \\
(45.81)\end{array}$ & $\begin{array}{l}237.67 \\
(49.35)\end{array}$ \\
\hline & & $z$ & \multicolumn{2}{|c|}{-2.39} & \multicolumn{2}{|c|}{-.271} & \multicolumn{2}{|c|}{-.91} \\
\hline
\end{tabular}

De todas formas, tanto las alumnas como los alumnos de baja eficacia obtienen en la Competencia Matemática puntuaciones más bajas que las alumnas y alumnos de alta eficacia (ver Tabla 2). Por lo que, si realmente existe una menor brecha de género en las últimas aplicaciones de la ED, no podría considerarse como un dato positivo puesto que aún hay alumnado que obtiene puntuaciones inferiores a las que realmente deberían obtener en la Competencia Matemática.

Tabla 2

Comparativa entre alumnas o alumnos de alta y baja eficacia

\begin{tabular}{|c|c|c|c|c|c|c|c|c|}
\hline \multirow{2}{*}{\multicolumn{2}{|c|}{$\begin{array}{l}\text { Competencia } \\
\text { Matemática }\end{array}$}} & & \multicolumn{2}{|c|}{2013} & \multicolumn{2}{|c|}{2015} & \multicolumn{2}{|c|}{2017} \\
\hline & & & RSD+ & RSD- & RSD+ & RSD- & RSD+ & RSD- \\
\hline \multirow{6}{*}{ ESO } & & $\begin{array}{c}M \\
(D T)\end{array}$ & $\begin{array}{l}258.20 \\
(48.36)\end{array}$ & $\begin{array}{l}239.61 \\
(49.08)\end{array}$ & $\begin{array}{l}254.23 \\
(46.84)\end{array}$ & $\begin{array}{l}235.99 \\
(44.65)\end{array}$ & $\begin{array}{l}258.76 \\
(4780)\end{array}$ & $\begin{array}{l}238.51 \\
(4581)\end{array}$ \\
\hline & Alumnas & $Z$ & \multirow{2}{*}{\multicolumn{2}{|c|}{$\begin{array}{c}-16.86 \\
000\end{array}$}} & \multicolumn{2}{|c|}{-17.69} & \multicolumn{2}{|c|}{-19.52} \\
\hline & & $p$ & & & & & & \\
\hline & \multirow{3}{*}{ Alumnos } & $M$ & 265.98 & 242.23 & 257.70 & 236.33 & 259.01 & 237.67 \\
\hline & & $\begin{array}{c}(D T) \\
7\end{array}$ & \multirow{2}{*}{\multicolumn{2}{|c|}{$\begin{array}{r}-18.41 \\
\end{array}$}} & \multicolumn{2}{|c|}{-20.56} & \multicolumn{2}{|c|}{-19.49} \\
\hline & & $\begin{array}{l}2 \\
p\end{array}$ & & & \multicolumn{2}{|c|}{.000} & \multicolumn{2}{|c|}{.000} \\
\hline
\end{tabular}

\section{CONCLUSIONES Y LIMITACIONES}

La principal conclusión de este trabajo es que el análisis de la evolución de la brecha de género en matemáticas en los centros de secundaria de la CAV en función de su eficacia escolar, basado en datos de la Evaluación Diagnóstica de 2013,2015 y 2017, permite concluir que se observa una tendencia a ir superando la brecha de género tanto en los centros de alta como en los de baja eficacia en la edición de 2017.

Si como afirma la OECD (2012) la equidad en la educación se logra cuando todas las personas, independientemente de sus circunstancias personales o sociales, como el género, el origen étnico o los antecedentes familiares, alcanzan al menos un nivel mínimo básico de competencias, estos resultados podrían valorarse positivamente en los centros de alta porque se confirmaría que la igualdad de género podría ir asociada a la equidad de género. No obstante, en el caso de los centros de baja eficacia se valoraría de forma negativa tanto para los chicos como para las chicas que no llegarían a alcanzar este nivel mínimo de competencia en matemáticas, en este caso la equidad de género podría ir vinculada también con la ineficacia.

Estos resultados hay que tomarlos con cautela, ya que son resultados preliminares de una investigación más amplia en la que se van a recabar datos cualitativos para conocer 
cómo se incorpora la perspectiva de género en los centros, así como contrastar y analizar los datos de la Evaluación Diagnóstica del 2019.

\section{REFERENCIAS BIBLIOGRÁFICAS}

Angulo, A., Caño, A., y Elorza, C. (2017). La igualdad de género en la Educación Primaria y ESO en el País Vasco. ISEI-IVEI, Gobierno Vasco. https://iseiivei.hezkuntza.net/documents/635622/1136645/Informe_Igualdad_G\%C3\%A9n ero_ED15.pdf/79fa8bad-3354-4f64-9fd5-678da54afcb1

Correa, J. B. (2015). Desempeño académico y diferencias de género en Colombia: un análisis con base en las pruebas TIMSS 2007. Revista Sociedad y Economía, 30, 15-42. https://www.redalyc.org/articulo.oa? id=99645393002

De la Rica, S., y González, A. (2013). Brechas de Género en los Resultados de PISA: El Impacto de las Normas Sociales y la Transmisión Intergeneracional de las Actitudes de Género. FEDEA. https://documentos.fedea.net/pubs/dt/2013/dt2013-10.pdf

Else-Quest, N. M., Hyde, J. S., y Linn, M. C. (2010). Cross-national patterns of gender differences in mathematics: A meta-analysis. Psychological Bulletin, 136(1), 103127. https://doi.org/10.1037/a0018053

Fuentes-de-Frutos, S., y Renobell-Santaren, V. (2020). La influencia del género en el aprendizaje matemático en España. Evidencias desde PISA. Revista de Sociología de la Educación-RASE, 13(1), 63-80. http://dx.doi.org/10.7203/RASE.13.1.16042

Gil, N., Blanco, L. J., y Guerrero, E. (2006). El papel de la afectividad en la resolución de problemas matemáticos. Revista de Educación, 340, 551-569.

Gunderson, E. A., Ramirez, G., Levine, S. C., y Beilock, S. L. (2011). The role ofparents and teachers in the development of gender related math attitudes. Sex Roles, 66(3), 153-166. https://doi.org/10.1007/s11199-011-9996-2

Ibáñez, M. M., y Formichella, M. M. (2017). Logros Educativos: ¿Es Relevante el Género de los Estudiantes? Education Policy Analysis Archives/Archivos Analíticos de Políticas Educativas, 25, 1-32. https://www.redalyc.org/articulo.oa?id=275050047003

Leaper, C. (2014). Parents' socialization of gender in children. Encyclopedia on Early Childhood Development. https://www.child-encyclopedia.com/gender-earlysocialization/according-experts/parents-socialization-gender-children

Lizasoain-Hernández, L. (2020). Criterios y modelos estadísticos de eficacia escolar. Revista de Investigación Educativa, 38(2), 311-327. https://doi.org/10.6018/rie.417881

López-Rupérez, F., Expósito-Casas, E., y García-García, I. (2020). Educación científica y brecha de género en España en alumnos de 15 años. Análisis secundarios de PISA 2015. Revista Comlutense de Educación, 32(1), 1-14. https://doi.org/10.5209/rced.66090

Macho, M., Padrón, E., Calaza, L., Casanellas, M., Conde, M., Lorenzo, E., y Vázquez, M. E. (2020) Igualdad de género en el ámbito de las matemáticas. En D. Martín de Diego (Ed.), Libro blanco de las matemáticas (pp. 375-420). Fundación Ramón Areces. https://www.fundacionareces.es/fundacionareces/es/publicaciones/libroblanco-de-las-matematicas.html 
Muñoz-Chereau, B. (2018). Exploring gender gap and school differential effects in mathematics in Chilean primary school. School Effectiveness and School Improvement, 30(2), 83-103. https://doi.org/10.1080/09243453.2018.1503604

Nosek, B. A., Smyth, F. L., Sriram, N., Lindner, N. M., Devos, T., Ayala, A., ... y Greenwald, A. G. (2009). National differences in gender-science stereotypes predict national sex differences in science and math achievement. Proceedings of the National Academy of Sciences, 106(26), 10593-10597. https://doi.org/10.1073/pnas.0809921106

OECD (2019). PISA 2018 Results (Volume I): What Students Know and Can Do. OECD Publishing. https://doi.org/10.1787/5f07c754-en

OECD (2012). Equity and quality in education: Supporting disadvantaged students and schools. OECD Publishing. https://www.oecd.org/education/school/50293148.pdf

Partridge, J., Brustad, R., y Stellino, M. B. (2008). Social influence in sport. En T. S. Horn (Ed.), Advances in Sport Psychology (pp. 269-292). Human Kinetics.

Quiroz, S., Dari, N. y Cervini, R. (2020). Desigualdades de género y oportunidad de aprender en la educación secundaria de Argentina, PISA 2018. RELAPAE, 13, 86103. https://revistas.untref.edu.ar/index.php/relapae/article/view/617

Riegle-Crumb, C. (2005). The cross-national context of the gender gap in math and science. En L. Hedges y B. Schneider (Eds.), The social organization of schooling (pp. 227-243). Russell Sage Foundation. https://www.russellsage.org/sites/default/files/Hedges_Schneider_txt.pdf 


\subsubsection{Modos de ser varón en dos escuelas secundarias. Experiencias de construcción de masculinidades en el partido de La Matanza \\ Pannelli, Ezequiel Martín (UBA, Argentina)}

\section{Resumen}

El presente trabajo es un análisis de discusiones y recursos teóricos en el marco de la investigación en curso "Modos de ser varón en dos escuelas secundarias. Experiencias de construcción de masculinidades en el partido de La Matanza". Se analiza la situación del marco socio-político-cultural en el que se desarrolla la investigación y se hace un recuento de trabajos previos. Se revisa cómo las escuelas han impartido educación sexual a lo largo de su historia y cómo la cuarta ola feminista impactó en estas instituciones.

Se desarrollan luego las consideraciones teóricas necesarias para comprender la construcción socio-histórica del género y las masculinidades. Por último, se analizan los aportes conceptuales de la categoría experiencia en tanto operador analítico para el trabajo en cuestión.

Palabras clave: Masculinidades; Escuela; Experiencia; Varones; Género.

\section{INTRODUCCIÓN Y OBJETIVOS}

En la Argentina actual se transita un momento histórico en el que las cuestiones de género y desigualdades ocupan las primeras líneas de debate y se materializaron importantes avances (Faur, 2017). Así, las estructuras y relaciones sociales basadas en el patriarcado y el machismo, y los privilegios resultantes que gozamos los varones, son cuestionadas y reformuladas. Esto conlleva a que la población masculina se vea interpelada de diversas maneras y responda a ello de variadas formas, desde la resistencia hasta la deconstrucción y búsquedas de nuevos modos de ser varón.

Una de las poblaciones masculinas más interpelada es la de los jóvenes y adolescentes, en continuo diálogo con los cuestionamientos a la masculinidad dominante (Chiodi, 2019). En gran medida, estas disputas provienen del activismo llevado a cabo por adolescentes y mujeres jóvenes. A su vez, distintos mandatos acerca de la correcta forma de poner en acto la masculinidad continúan estructurando las subjetividades de adolescentes, quienes, de no adecuarse a las normas esperadas, son objeto de acosos y desplazados por el grupo de pares (Chiodi, 2019).

Esta situación toma relevancia en la escuela dado a que es la institución por excelencia por la que transitan todxs Ixs jóvenes (dictado por su carácter de obligatoriedad) y en la que se plasman sus diversos posicionamientos políticos. Asimismo, como aparato ideológico del estado, es la encargada de impartir conocimientos y producir subjetividades. En este proceso, la escuela y sus actorxs dejan marcas y son importantes protagonistas en la estructuración del género de Ixs alumnxs.

Por ello surge como objetivo de investigación general analizar las experiencias en torno a la construcción de las masculinidades de alumnos varones de escuela secundaria. De manera específica, los objetivos se centran en describir y analizar cómo conciben la masculinidad en general y la suya en particular, cómo la ponen en acto y cómo han influido tanto los dispositivos escolares cómo sus actorxs en dicho proceso. 


\section{METODOLOGÍA}

En virtud de los objetivos de la investigación, se optó por un diseño metodológico cualitativo que analiza una realidad educativa y social específica. Con esta estrategia se busca conocer y describir las experiencias en la construcción de las masculinidades de varones adolescentes en el contexto de escolaridad secundaria.

Las unidades de análisis están conformadas por seis varones de entre 15 y 16 años de dos escuelas secundarias de gestión estatal del partido de La Matanza, provincia de Buenos Aires. En estas edades se produce la primera relación sexual del varón (INDEC, 2013), suponiendo un hito en la constitución subjetiva de su sexualidad y masculinidad. Tres alumnos pertenecen a una institución técnica y los otros tres a un bachillerato.

La técnica de recolección de datos consiste en entrevistas semiestructuradas. Las mismas permiten reconstruir de manera singular y subjetiva las concepciones y sentidos de los sujetos analizados.

\section{RESULTADOS Y DISCUSIÓN}

Numerosxs autorxs estudiaron cómo la escuela imparte educación sexual a través de distintos métodos y dispositivos (Safilios-Rothschild, 1987; Connell, 1997; Morgade, Báez, Zattara y Díaz Villa, 2011; Flores, 2015; Morgade, 2011; 2017). En menor medida se trató cómo estructura la masculinidad (Connell, 2001) y cómo se pone en acto en el ámbito escolar (Scharagrodsky, 2007). De allí surgen interrogantes sobre qué sucede con las experiencias de los varones en la construcción de sus masculinidades en la escuela, qué implica ser varón para ellos, cómo conciben su masculinidad y cómo interactúan dispositivos y actorxs escolares en dicho proceso.

Para ello es preciso tener en cuenta el rol escolar en la estructuración del género y de las masculinidades. Safilios-Rothschild (1987) analiza investigaciones que vislumbran cómo la escuela normaliza y consolida los estereotipos y roles asignados según la diferenciación que realizan las familias en base a la identificación de género que estipulan para sus hijxs. Morgade, Báez, Zattara y Díaz Villa (2011) plantean que la afectividad y la corporeidad han sido omitidas del currículo explícito en pos de la razón. De tal modo, la sexualidad fue abordada exclusivamente desde un paradigma biologicista centrado solo en la genitalidad junto a una perspectiva médica que pretende prevenir conductas riesgosas.

Esta realidad fue puesta en tensión desde la sanción de la Ley Nacional de Educación Sexual Integral ${ }^{5} \mathrm{~N}^{\circ} 26.150$ (2006). Su implementación tuvo desde el principio limitaciones (Morgade, 2017) por la existencia de prácticas y perspectivas que llegan a ser antagónicas y contradictorias (Flores, 2015).

Desde 2015 hasta la actualidad, los feminismos y sus luchas crecieron de manera exponencial en seguidorxs y visibilidad, logrando importantes conquistas (Faur, 2017; Fulco, 2018). Este hecho no fue inerte en la vida escolar: muchxs jóvenes adscribieron a este movimiento y tomaron sus luchas como propias (Fulco, 2018).

El género es entendido como una construcción sociohistórica (Conwey, Bourque y Scott, 2013) en la que femenino y masculino son categorías que no pueden ser pensadas como fijas y cerradas, sino como dinámicas y en constante construcción. Ante este carácter antinatural y antiesencialista del género se configuran alternativas a la normatividad mediante las que se habita la sexualidad cuando ya no puede ser vivida de manera "llevadera" dentro de los parámetros estructurados (Butler, 2010).

\footnotetext{
${ }^{5}$ En adelante ESI
} 
Los estudios de las masculinidades reflexionaron sobre cómo se relacionan las masculinidades en el sistema sexo - género (Schongut Grollmus, 2012) y cómo la cultura patriarcal deja sus marcas en las formas de ser varón (Sharagrodsky y Narodowsky, 2005). Un aporte sustancial a este campo es el concepto de masculinidad hegemónica. Este concepto propone que existen diferentes tipos de masculinidades y no un único modelo (Badinter, 2003). A su vez, el concepto de hegemonía masculina (Connell, 1995) pone de manifiesto la lucha de poder entre los distintos tipos de masculinidad, que da como resultado la concentración de las posiciones superiores de la vida social por parte de un modo de ser varón, la masculinidad hegemónica, que regula y legitima las prácticas que perpetúan la esfera dominante y de opresión.

De Martino Bermúdez (2013) recupera una serie de críticas al concepto de masculinidad hegemónica que refieren a la necesidad de diferenciar el análisis de las masculinidades a nivel estructural y la forma de contemplarlas como un proyecto colectivo vivido individualmente. Partiendo de las categorías de campos y habitus de Bourdieu, la autora propone el concepto de estrategias de masculinización que refiere a aquellas prácticas sociales que articulan lo estructural de la sociedad (la relación de hegemonía) con lo subjetivo del individuo. Las estrategias de masculinización parten desde el seno familiar o individual con el fin de mejorar o mantener la posición social del sujeto. La manera en que se vive el cuerpo sexuado y la orientación sexual se relaciona con las formas o aspiraciones de ascenso social o con las esperanzas frustradas de un futuro mejor.

Para analizar los procesos de construcción de masculinidades, recurro a la categoría de experiencia que sirve de operador analítico. Según de Lauretis (1989), ésta refiere a aquellos efectos de significado, hábitos, disposiciones, asociaciones y percepciones que son la resultante de la acción semiótica del yo en el mundo circundante y que da como resultado la constitución de sujetxs sociales. Scott (2001) aporta que, al ser parte del universo simbólico, la experiencia es un evento lingüístico que no escapa a las contradicciones. Como suceso compartido, es tanto colectiva como individual. Por su carácter lingüístico e histórico, es una interpretación que requiere otra interpretación.

Para profundizar el análisis teórico de esta categoría, se recurre a contribuciones de Butler (2007, 2010). Los aportes de la performatividad de género, la existencia preontológica de ciertas normas de inteligibilidad social, la dinámica relacional del reconocimiento, el acto paródico del género y la capacidad de acción permiten enriquecer la conceptualización de la experiencia para los fines del trabajo.

Por último, surge la interrogante de cómo analizar una experiencia y cuáles son sus alcances y limitaciones. Para ello, se utilizan algunas consideraciones de Butler (2009) cuando plantea que existe tanto una incapacidad de Ixs sujetxs a acceder a ciertos aspectos de su experiencia como una multiplicidad de versiones que pueden dar sobre un mismo hecho sin que sean necesariamente falsas. A esto se suma que toda relatoría no está exenta de marcos de verdad preexistentes en los que Ix sujetx se basa y que forman esa experiencia, generando que se pueda acceder a ésta mediante los límites discursivos que posibilita.

\section{CONCLUSIONES Y LIMITACIONES}

La pertinencia de la investigación que se propone radica en dos cuestiones. La primera se centra en el momento histórico en el que se enmarca: un contexto de alta turbulencia social en cuanto a las cuestiones de identidades y desigualdades de género. De un lado, se encuentran los grupos de mujeres y movimientos feministas y LGTBQ+, del otro una sociedad y un sistema patriarcal y machista. En el medio están miles de jóvenes construyendo su identidad en un ambiente que les dice que para reconocerlos y ser considerados varones deben tener ciertos atributos y actuar de tal modo. Sin embargo, 
una porción de la sociedad les está diciendo cada vez con más vehemencia que esos estereotipos son repudiables y ya no son aceptados. Esta dinámica se condensa en la escuela donde confluyen todxs Ixs jóvenes traccionadxs para uno u otro lado.

La segunda cuestión radica en la vacancia epistemológica al respecto. Se observan pocos trabajos que interseccionen escuela y masculinidad, los cuales suelen centrarse en dispositivos y sentidos escolares que estructuran el género o en cómo este se pone en acto. Por la importancia de recuperar la voz de los implicados, la categoría experiencia cobra relevancia.

En base a las consideraciones teóricas expuestas, se vislumbra una idea de experiencia en la que el género, y por ende el/Ix sujetx, es a la vez producto y causa de ésta. ¿Qué implica sostener esto? Que el/lx sujetx se forma en base a su experiencia en un medio sociocultural histórico, es decir, se constituye una subjetividad gracias a las disposiciones, asociaciones, percepciones, efectos de significados y hábitos resultantes de la acción semiótica del Yo en el mundo circundante. De tal modo, el/lx sujetx transcurre su vida en un contexto no de manera inmutable, sino interactuando con su entorno y apropiándose de los sentidos que circulan, lo que forja su subjetividad. Esto se da en un marco de inteligibilidad pautado socioculturalmente, en el que el/lx sujetx es definido como tal por un otrx y por esas normas socioculturales. Es por ello que se sostiene que el/Ix sujetx es a la vez causa y consecuencia de su experiencia.

Bajo esta perspectiva, se contempla que la experiencia debe ser entendida como un evento lingüístico y discursivo, que es una interpretación del/lx sujetx acerca de sus interacciones con el entorno y, a su vez, requiere una interpretación de quien la analiza. Surge así una nueva limitación: la interpretación que lleva adelante quien analiza la relatoría ajena, ya que ésta solamente puede ser interpretada en aquellos aspectos que guardan relación de inteligibilidad con la propia experiencia.

Más allá de las limitaciones, es propicio puntualizar una cuestión importante para la investigación propuesta. La tarea que aquí se emprende tiene como objetivo comprender y poner en tensión las experiencias en torno a la construcción de las masculinidades de los alumnos.

Se busca, por un lado, dar cuenta de qué aspectos de ese proceso son conscientes para los sujetos: qué se puede recuperar y, si existiesen y manifestasen multiplicidad de versiones, cuáles son los puntos en común que permanecen en los discursos y cuáles se dejan entrever ocasionalmente. Por el otro lado, se pretende analizar qué marcos de verdad son referenciados y por qué, qué efectos han tenido en los sujetos para ser elegidos como tales y cuáles otros y debido a que quedaron descartados

\section{REFERENCIAS BIBLIOGRÁFICAS}

Butler, J. (2007). El género en disputa. El feminismo y la subversión de la identidad. Barcelona: Paidós

- (2009). Dar cuenta de sí mismo. Violencia ética y responsabilidad. Buenos Aires: Amorrortu.

- (2009). Performatividad, precariedad y políticas sexuales. Revista de Antropología Iberoamericana, 4 (3), 321-336. Recuperado de: https://www.redalyc.org/pdf/623/62312914003.pdf

- (2010) Deshacer el género. Barcelona: Paidós. 
Chiodi, A. (coord.) (2019). Varones y masculinidad(es). Herramientas pedagógicas para facilitar talleres con adolescentes y jóvenes. Disponible en: http://www.onu.org.ar/IniciativaSpotlightArgentina/

Connell, R. (1995). "The Social Organization of Masculinity" de Masculinities, del mismo autor, University of California Press, Berkeley. En Valdes, T. y Olavarría, J. (edc.). Masculinidad/es: poder y crisis. ISIS-FLACSO: Ediciones de las Mujeres, 24, 31-48.

- (1997). Escuelas y justicia social. Madrid: Morata.

- (2001). Educando a los muchachos: nuevas investigaciones sobre masculinidad y estrategias de género para las escuelas. Nómadas (Col), 14, 156171. Recuperado de: http://www.redalyc.org/pdf/1051/105115268013.pdf

Conwey, J., Bourque, S., y Scott, J. (2013). El concepto de género. En Lamas, M. (comp.). El género. Construcción cultural de la diferencia sexual. México: Miguel Angel Porrua.

De Lauretis, T. (1989). La tecnología del género. Recuperado de: https://perio.unlp.edu.ar/catedras/system/files/teconologias-del-genero-teresade-lauretis.pdf

De Martino Bermúdez, M. (2013). Connel y el concepto de masculinidades hegemónicas: notas críticas desde la obra de Pierre Bourdieu. Revista Estudos Feministas, $21 \quad(1), \quad 283-300 . \quad$ Recuperado de: http://www.redalyc.org/articulo.oa?id=38126283028

Faur, L. (comp.) (2017). Mujeres y Varones en la Argentina de hoy. Géneros en movimiento. Ciudad Autónoma de Buenos Aires: Siglo veintiuno editores.

Flores, V. (mayo, 2015). ESI: Esa Sexualidad Ingobernable. El reto de desheterosexualizar la pedagogía. Degenerando Buenos Aires. En La escuela como productora de identidad: desafíos de una educación sexual integral no heteronormada. III Jornadas Interdisciplinarias de Géneros y Disidencia Sexual. Escuela Normal Superior no1.

Fulco V. (2018) La Educación Sexual Integral será feminista o no será. En Revista Mora. $25, \mathrm{~s} / \mathrm{d}$.

Morgade, G. (2017). Contra el androcentrismo curricular y por una educación sexuada justa. Revista Internacional de Educación para la Justicia Social (RIEJS), 6(2), 49-62.

Morgade, G; Báez, J; Zattara; S. y Díaz Villa, G (2011). Pedagogias, teorías de género y tradiciones en "educación sexual". En Morgade, G. (coord.). Toda educación es sexual. Buenos Aires: La Crujía (Selección).

Morgade, G. y (comp.) (2011). Toda educación es sexual. Buenos Aires: La Crujía (Selección).

Safilios-Rothschild, C. (1987). Las diferencias según el sexo en la socialización y la educación infantil y sus consecuencias en la elección de los estudios y sus resultados. En Organización Para La Cooperación Y Desarrollo Económico (Ed.) La Educación de lo Femenino: Estudio Internacional sobre las desigualdades entre muchachas y muchachos en la educación. Barcelona: Aliorna. 
Scharagrodsky, P. (2007). Masculinidades valuadas y devaluadas. Tensiones, límites y posibilidades en el ámbito escolar. En Baquero, R. Diker, G. y Frigerio, G.(comps.). Las formas de lo escolar. Buenos Aires: Del Estante.

Scharagrodsky, P. y Narodowski, M. (2005). Investigación educativa y masculinidades: más allá del feminismo, más acá de la testosterona. Revista Colombiana de Educación, Universidad Pedagógica Nacional, 49, 61-80.

Scott, J. (2001) “Experiencia”. La ventana 13, 42-73.

\section{Fuentes}

INDEC, Encuesta Nacional sobre Salud Sexual y Reproductiva, 2013. 


\subsubsection{Memorias escolares de varones gays argentinos: entre acosos, apoyos y amores \\ Ezequiel Pannelli (Universidad de Buenos Aires, Argentina); Maximiliano Marentes \\ (Universidad de San Martín, Argentina)}

\section{Resumen}

El objetivo de este trabajo consiste en reconstruir las memorias escolares de treinta varones gays del Área Metropolitana de Buenos Aires, Argentina. Para ello se utilizan relatos de vida sobre la escolaridad que estos jóvenes dieron en el marco de una investigación sobre amor gay. Proponemos pensar las memorias como un cartón corrugado, en la que la rigidez de la estructura se debe a los acosos sufridos que, como sinécdoque, tiñen la totalidad de la trayectoria escolar. Sin embargo, al estirar los pliegues de las memorias, aparecen tanto los apoyos que recibieron como los amores que experimentaron en esa época. Trabajar con narrativas de escolaridades finalizadas nos permite iluminar aspectos que, cuando se estudian las experiencias de la diversidad sexual en el ámbito educativo, no suelen aparecer.

Palabras clave: Escolaridad; Gays; Argentina; Discriminación; Memorias.

\section{INTRODUCCIÓN Y OBJETIVOS}

A partir de relatos de vida, el trabajo recupera las experiencias escolares de treinta varones gays del Área Metropolitana de Buenos Aires. Estas memorias están tamizadas por el paso del tiempo. Eso supone una diferencia con otros trabajos sobre experiencias de personas sexodiversas que transitan la educación secundaria o recién la terminaron (100\% Diversidad y Derechos, 2017; De Stéfano Bárbero 2017a, 2017b; Jones, 2008; Pichardo y De Stéfano Barbero, 2015). La distancia temporal posibilitó acceder a otros puntos. Los años les permitieron reconocer otras personas que aminoraron los episodios violentos. Al mismo tiempo, es probable que se animaran a describir experiencias homoeróticas y amores platónicos ya asentados en una identidad sexodiversa dado que, como dijeron, ya no les avergonzaba contar que eran gays.

\section{METODOLOGÍA}

Los relatos sobre los que se trabaja provienen de entrevistas realizadas en el marco de una investigación que uno de los autores (Maximiliano) hizo entre 2017 y 2018 sobre amor gay. Con cada entrevistado, se establecieron al menos cuatro encuentros para reconstruir sus trayectorias amorosas. Por su carácter cualitativo, las preguntas exploratorias sobre datos sociodemográficos dieron los primeros indicios acerca de los recuerdos escolares. A su vez, la investigación se realizó con un abordaje sociológico, a partir de las historias de amor que abrieron la puerta a los amores (reales y platónicos) que los entrevistados tuvieron en la secundaria.

\section{RESULTADOS Y DISCUSIÓN}

Las memorias escolares de varones gays suelen tener una estructura, como la del cartón corrugado, ligada a malos tratos, experiencias amargas y situaciones de acoso. Esos malos recuerdos impregnan lo que Williams (2009) denominó estructuras del sentimiento. Al detenernos en los pliegues de esas memorias, aparecen otras personas que sirvieron de puntos de apoyo y amenizaron la experiencia sexodiversa en el tránsito 
escolar y otros varones, como compañeros de clase, que les gustaron y por quienes hicieron cosas impensadas. Es por ello que distinguimos tres dimensiones en las que agrupar dichas memorias: acosos, apoyos y amores.

Para analizar las experiencias de acoso, es decir, la estructura visible del cartón corrugado, propusimos ocho organizadores que agrupan las experiencias relatadas. Las primeras seis - i) detección; ii) tolerancia; iii) chistes, burlas, risas y comentarios; iv) miradas, señalamientos y cargadas; v) insultos gritados; y vi) agresiones físicas-son producto de la clasificación de Jones (2008) y se caracterizan por el creciente grado de violencia.

De los dos restantes, el primero responde a las consecuencias que describe el autor que se producen a raíz de las dinámicas de estigmatización y discriminación. Existen tres tipos que están interrelacionadas entre sí: la discreción de toda actitud considerada como gay a cambio de la no agresión, la invisibilización parcial de las características de los homosexuales y el ocultamiento para no sufrir agravios.

El último organizador de análisis que añadimos al esquema de Jones consiste en prácticas estigmatizantes y discriminatorias que perpetúa la escuela como institución junto a su personal docente, directivo y auxiliar.

Esto nos permitió ver las causas por las cuales las memorias escolares estaban teñidas de un sabor amargo y poco grato. De tal modo, pudimos no solamente analizar esos acosos, sino que también preguntarnos por la realidad actual que viven los adolescentes gays en las escuelas y qué medidas se pueden tomar para que la finalización de la escolaridad no sea un evento que sucede por fortuna como manifestó un entrevistado.

Sin embargo, cuando estiramos los pliegues de ese cartón corrugado, aparecieron, en un primer momento, los apoyos, es decir, aquellas personas que sirvieron de sostén a la hora de transitar la escolaridad. Se distinguieron los apoyos directos efectuados principalmente por compañeras que defendían a los acosados o restaban importancia a las cargadas y, en menor medida, por los facilitadores, compañeros del estigma en términos de Goffman (2006) que servían de consejeros o confidentes para asumir la orientación sexual o contar experiencias.

También el sostén venía a veces de la misma institución, sea por habilitar respetuosos espacios de discusión o porque algún o alguna docente tuvo la palabra que estos entonces adolescentes necesitaban. No todos los apoyos fueron explícitos, muchas veces porque estos varones todavía estaban en el closet. Por eso también existieron apoyos indirectos, los cuales se caracterizaban por la inclusión en dinámicas grupales de la sexodiversidad de estos varones.

Al continuar indagando, surgió una nueva dimensión oculta tras los pliegues de estas memorias: los amores. Al igual que sucede con estudiantes heterosexuales, como demuestran Fernández Rodríguez (2014a, 2014b), Palumbo (2016) y Sustas (2016), el pasaje de varones gays por la escuela también despertó intereses eróticos y afectivos. Las memorias al respecto se ligan con el deseo en tres niveles: en el juego y la experimentación sexual, en el marco de una historia o salir con alguien o en el plano de esos deseos inalcanzables que llamamos amores platónicos. Detenernos en esas fantasías nos permitió trazar un contrapunto con aquellas de las y los estudiantes heterosexuales del estudio de Fernández Rodríguez (2014b). Como muestra la autora, es en relación con el consumo cultural que, especialmente, las jóvenes experimentan fantasías amorosas. En nuestro caso, fue a partir del contacto con otros varones que se movilizan los deseos.

lluminar esos aspectos de las experiencias escolares sexodiversas nos permitió desplegar otras cuestiones. Por ejemplo, qué llegaron a hacer para sentirse más cerca de los chicos que les gustaban. Además, nos permitió ver que les gustaba no sólo que jugaran al fútbol, tuvieran novia, salieran con muchas chicas o fueran más grandes, sino 
también apreciaban que fueran simpáticos, amigables y se llevaran bien con el resto. Tanto los primeros rasgos, más viriles, como los segundos, más sensibilizados, convergían en algo que estos varones añoraban y que a veces llegaron a experimentar: tocar y ser tocados. Tal vez por la cuestión etaria, el contacto corporal era algo añorado y buscado que, cuando se lograba, daba mucho placer. Así, el deseo nos permitió devolver la densidad de las memorias escolares y nos proveyó otra información sobre las experiencias de los varones gays en sus colegios: el espacio donde, como juego, primeros pasos o platónicamente, conocieron los amores.

\section{CONCLUSIONES Y LIMITACIONES}

Si bien el material sobre el que trabajamos no provino de una investigación acerca de la escolaridad de varones adolescentes gays (lo que podemos denominar un primer sesgo), la naturaleza exploratoria de las entrevistas trajo a la luz retazos de recuerdos poco felices sobre el tránsito escolar. Al indagar sobre ellos, surgió toda una estructura del sentimiento (Williams 2009) en base a los acosos sufridos durante esa época y que tiñe todo el recuerdo al respecto. Ello nos permite, en primer lugar, analizar las lógicas abusivas para luego, en segundo lugar, preguntarnos por la realidad actual de varones sexodiversos, con qué soportes cuentan y cuáles se les pueden ofrecer.

No obstante, conforme esos recuerdos fueron aflorando, surgieron dos dimensiones más presentes en la escolaridad. Por un lado, están los apoyos recibidos por pares y no tan pares que alivianaron las cargas soportadas y facilitaron la asunción de la sexodiversidad. Por el otro, están los amores, relaciones, encuentros físicos e idealizaciones que fueron producto de esta etapa y que permitieron conocer las primeras experiencias libidinosas.

Un segundo sesgo del recorte radica en la prioridad por trayectorias en escuelas medias. El sesgo se corresponde con el interés de los mismos varones por describir sus escolarizaciones secundarias. De todos modos, algunos varones trajeron al presente recuerdos de la escuela primaria. Como mostró Sánchez Sáinz (2015), cabe preguntarse qué sucede en este nivel.

El enfoque metodológico nos permitió adentrarnos en las situaciones que recuerdan los protagonistas. Allí radicó un aporte de este trabajo: concentrarse no sólo en las representaciones sobre la diversidad sexual en los colegios, como hacen los estudios de corte estadísticos (100\% Diversidad y Derechos, 2017; Pichardo y De Stéfano Barbero, 2015). Habernos detenido en los pliegues de las memorias se relaciona con una propuesta epistemológica de recuperar, en términos pragmáticos, la definición de la situación en la que se inscribe la acción (Thomas y Znaniecki, 2006). Entendimos esos momentos como pruebas (Lemieux, 2008) que dan cuenta de los quiebres del orden y los esfuerzos por restituirlo. En esa línea, apelamos a la descripción para recuperar lo que nos fue contado sin apresuradas interpretaciones o teorizaciones (Barthe et al., 2017; Baszanger y Dodier, 2004; Bazin, 2017).

Gran parte de las experiencias a las que accedimos están tamizadas por el paso del tiempo. Pero ese mismo sesgo - el tercero- nos permitió alcanzar otros recovecos de las memorias escolares de varones gays. Ya concluido el colegio secundario, habiendo asumido su identidad sexual para con sus íntimos - y no tan íntimos- y con expertise sobre relaciones amorosas, los otrora acosos, apoyos y amores de la escuela hoy se entretejen para conformar sus memorias escolares. 


\section{REFERENCIAS BIBLIOGRÁFICAS}

100\% Diversidad y Derechos. (2017). Encuesta Nacional de Clima Escolar en Argentina Dirigida a Jóvenes LGBT. Buenos Aires.

Barthe, Yannick et al. (2017). Sociología pragmática: manual de uso. Papeles de Trabajo, 11(19), 261-302.

Baszanger, Isabelle y Dodier, Nicolas. (2004). Ethnography: relating the part to the whole. En David Silverman (Ed.), Qualitative research. Theory, method and practice (pp. 9-34). Londres: Sage.

Bazin, Jean. (2017). Interpretar o describir. Notas críticas sobre el conocimiento antropológico. En Mariana Garzón Rogé, (Ed.), Historia pragmática. Una perspectiva sobre la acción, el contexto y las fuentes (pp. 105-124). Buenos Aires: Prometeo Libros.

De Stéfano Barbero, Matías. (2017a). Hacerse hombre en el aula: masculinidad, homofobia y acoso escolar. Cadernos Pagu, 50(0), e175014.

De Stéfano Barbero, Matías. (2017b). ¿"Cosas de niños" o cosas que los niños hacen para hacerse hombres? Reflexiones antropológicas sobre edad, violencia y masculinidad. Hachetepé. Revista Científica de Educación y Comunicación, 15(0), 101-108.

Fernández Rodríguez, Irantzu. (2014a). Etnografiando el amor en la adolescencia: un estudio en tres centros escolares de Bilbao. En Luis Puche Cabezas y Laura Alamillo-Martínez (Eds.). Educación y género. La incorporación de la desigualdad en múltiples contextos de socialización (pp. 19-25). Madrid: Traficantes de Sueños.

Fernández Rodríguez, Irantzu. (2014b). Entre ficciones y fantasías: el aprendizaje amoroso (y de género) a través del consumo cultural en la adolescencia. Revista de Investigaciones Feministas, 8(2), 515-517.

Goffman, Erving. (2006). Estigma: la identidad deteriorada. Buenos Aires: Amorrortu.

Jones, Daniel. (2008). Estigmatización y discriminación a adolescentes varones homosexuales. En Mario Pecheny, Carlos Fígari y Daniel Jones (Eds.). Todo sexo es político: estudios sobre sexualidades en Argentina (pp. 47-71). Buenos Aires: Libros del Zorzal.

Lemieux, Cyril (2008). Scene change in French sociology? When American pragmatism refreshes the French Durkheimian sociological tradition. En L'il sociologique. Site officiel de l'Association pour la Défense des Sciences Sociales, disponible en http://adss.unblog.fr/2008/05/24/scene-change-in-french-sociology/

Palumbo, Mariana. (2016). Noviazgos juveniles. Amor y violencia en las primeras relaciones de noviazgo en jóvenes heterosexuales de clase media del Área Metropolitana de Buenos Aires (2012-2014). Argumentos. Revista de Crítica Social, 18(0), 284-309.

Pichardo, José Ignacio y De Stéfano Barbero, Matías (Eds.). (2015). Diversidad sexual y convivencia: Una oportunidad educativa. Madrid: Universidad Complutense de Madrid.

Sánchez Sáinz, Mercedes. (2015). Las diversidades y la diferencia en educación infantil y primaria. En José Ignacio Pichardo y Matías De Stéfano Barbero (Eds.), 
Diversidad sexual y convivencia: Una oportunidad educativa (pp. 46-62). Madrid: Universidad Complutense de Madrid.

Sustas, Sebastián. (2016). La dimensión erótica en estudiantes de escuelas medias y su relación con la educación sexual. Argumentos. Revista de Crítica Social, 18(0), 310-337.

Thomas, William y Znaniecki, Florian. (2006). El campesino polaco en Europa y en América. Madrid: Centro de Investigaciones Sociológicas y Boletín Oficial del Estado.

Williams, Raymond. (2009). Marxismo y literatura. Buenos Aires, Las Cuarenta. 


\author{
2.1.7. Construcción de masculinidades en el espacio escolar: una \\ aproximación a la construcción de masculinidades por parte de \\ estudiantes del primer grado de educación secundaria de un \\ colegio privado de Chimbote - Perú \\ Samuel Josue Rivero Meza (Pontificia Universidad Católica del Perú, Perú)
}

\title{
Resumen
}

Chimbote se ubica en la región peruana de Áncash donde, durante el 2018, se registró que el $69.8 \%$ de las mujeres habían sufrido alguna vez algún tipo de violencia de género (Instituto Nacional de Estadísticas e Informática, 2019). De esta manera, investigar cómo se desarrollan las identidades violentas desde la etapa escolar es fundamental para comprender las dinámicas en las cuales se encuentran insertos las y los estudiantes. En ese sentido, la presente investigación tiene como objetivo principal analizar la construcción de la masculinidad de adolescentes de educación secundaria de un colegio de la ciudad de Chimbote en Perú durante el año 2019. Para ello, se utilizó una metodología cualitativa basada en entrevistas y grupos focales. De esta manera, el estudio concluye que la masculinidad de los adolescentes se construye en base a características como la corporalidad, el desempeño académico, la disciplina, la sexualidad y la expresión de emociones. Asimismo, que en el aula conviven tres tipos de masculinidad: hegemónica, conservadora y subordinada

Palabras clave: masculinidades; género; comunicación; educación secundaria.

\section{INTRODUCCIÓN Y OBJETIVOS}

Los estudios sobre masculinidades en el espacio escolar han sido desarrollados en distintos países en los diferentes niveles educativos. Así, por ejemplo, existen investigadores como Simon Warren, quien distinguió dos diferentes grupos de estudiantes: los "Princes of the Park", quienes dominan en el aula y los "Working-class Kings" quienes se caracteriza básicamente por los logros físicos y deportivos (Warren, 1997); o como Jill Heinrich, quien concluyó que la influencia de las fuerzas de la jerarquía y la hegemonía afectaba a la vida de los estudiantes al influir en su forma de pensar el comportamiento masculino "apropiado" e "inapropiado" (Heinrich, 2013, p.14).

Continuando con dicha reflexión, la presente investigación abordó la problemática de la construcción de las masculinidades en adolescentes, centrándolo en el entorno educativo peruano. Por ello, el objetivo general que se planteó fue analizar la construcción de la masculinidad por parte de los adolescentes de un salón del primer grado de secundaria de un colegio privado de Chimbote durante el año 2019. Asimismo, se plantearon tres objetivos específicos: (1) caracterizar los grupos de pares existentes en el aula de clases, (2) describir las dimensiones en torno a la construcción de la masculinidad por parte de los adolescentes, e (3) identificar los modelos de masculinidad existentes en el aula de clases.

\section{METODOLOGÍA}

El recojo de información se llevó a cabo durante las dos primeras semanas de marzo del 2020. La investigación se realizó en una institución educativa particular parroquial ubicada en la ciudad de Chimbote. Asimismo, el número de la muestra fue configurada según el número de adolescentes que poseían el consentimiento de sus padres y el 
asentimiento individual para ser parte de la investigación. Así, la muestra fue de 9 estudiantes del primer año de educación secundaria, 6 de los cuales fueron hombres y 3 , mujeres, todos ellos con una edad aproximada de 13 años. Cabe resaltar que la participación de las mujeres fue de suma importancia, puesto que permitió complementar la información brindada por los hombres y confirmar, a su vez, cierta información compartida por los estudiantes.

Por otro lado, el enfoque fue cualitativo, por lo que se utilizaron dos técnicas: grupo focal y entrevistas. De esta manera, las dimensiones establecidas para dichas técnicas estuvieron basadas, en primer lugar, en la concepción del aula como un espacio comunicacional donde se construyen y discuten los significados sobre la masculinidad. Por otro lado, para abordar la construcción de la masculinidad, el análisis se guio por lo expuesto por Luis Bonino sobre las cuatro creencias matrices de la masculinidad: la autosuficiencia prestigiosa, la belicosidad heroica, el respeto a la jerarquía y la superioridad masculina. Asimismo, para identificar los tipos de masculinidad que confluyen en el aula, se utilizó la tipología de masculinidad expuesto por R. Connell: hegemónica, conservadora y subordinada.

\section{RESULTADOS Y DISCUSIÓN}

\section{Caracterización de grupos de pares}

Según los mismos estudiantes, se puede observar la existencia de cinco grupos de pares en el aula de clases del primer año de secundaria, los cuales presentan aproximadamente 4 integrantes cada uno:

- Grupo I: se caracterizan por ser sobresalientes en los deportes, vestir a la moda y ser muy atléticos. Asimismo, en cuanto comportamiento, suelen ser abusivos con sus pares e indisciplinados. Por otro lado, poseen un deficiente rendimiento académico.

- Grupo II: se caracterizan por poseer un buen nivel deportivo, vestir a la moda y ser medianamente atléticos. Además, suelen hostigar a sus pares e incumplir las normas de convivencia. Por otro lado, presentan un deficiente rendimiento académico.

- Grupo III: presentan un nivel deportivo deficiente y se visten con un estilo formal. Asimismo, suelen ser atentos con sus pares, así como educados y respetuosos. En cuanto al rendimiento académico, suelen sobresalir.

- Grupo IV: son medianamente destacados en los deportes, por lo que no son sobresalientes atléticamente. Por otro lado, son atentos con sus pares y disciplinados. Además, su rendimiento académico es sobresaliente.

- Grupo V: se caracterizan por ser moderadamente destacados en los deportes y medianamente atléticos. Asimismo, son atentos con sus pares y poseen un comportamiento medianamente disciplinado. Además, su rendimiento académico es regular.

\section{Dimensiones en torno a la masculinidad}

\section{a. Corporalidad}

En relación a la dimensión corporal, la actividad física es importante entre los adolescentes. Así, poseer una figura atlética, si bien no es deseado por todos, implica ser respetado entre el grupo de pares. De esta manera, quien no presenta dicha figura corporal puede sufrir insultos y ser sujeto de burlas, sobre todo, por parte de los integrantes del grupo I. 
Asimismo, poseer una figura atlética, una estatura alta y demostrar poseer fuerza física constituyen características importantes para poder encajar en el ideal de hombre heroico que posee un cuerpo resistente y los recursos necesarios para poder defenderse 0 hacer uso de la violencia como forma de control sobre los demás. Por otro lado, la práctica de algún deporte, sobre todo fútbol, es fundamental para alcanzar un buen estatus entre los adolescentes.

\section{b. Desempeño académico}

La influencia del desempeño académico en la construcción de la identidad masculina varía de acuerdo a los grupos de pares. De esta manera, para el grupo I, obtener calificaciones bajas o desaprobatorias es un aspecto positivo, puesto que, según su percepción, los convierte en estudiantes populares, rebeldes y autosuficientes.

De manera contraria, para el grupo III las notas son importantes para poder destacar entre sus compañeros, por lo que son admirados por los integrantes de los grupos IV y $\mathrm{V}$, quienes los describen como "privilegiados" por gozar de buenas calificaciones y reconocimiento por parte de los docentes.

\section{c. Disciplina}

Existe una clara diferencia entre los grupos de pares debido a la conducta que presentan. Así, los integrantes del grupo I se perfilan como aquellos que poseen un comportamiento que viola las reglas de convivencia en el aula, ocupando así el liderazgo del salón debido al poder y agresividad que presentan. Por otro lado, los estudiantes del grupo III son aquellos que presentan un comportamiento acorde a lo normado por la institución educativa, lo cual implica ser observados como débiles.

Asimismo, el grupo II aspira a tener el mismo comportamiento violento de aquellos del grupo I, mientras que los grupos IV y V se sienten más cómodos con un comportamiento acorde a las reglas institucionales. Sin embargo, estos dos últimos grupos no siempre presentan un buen comportamiento.

\section{d. Sexualidad}

En cuanto a la vivencia de la sexualidad por parte de los estudiantes, existen comentarios divididos sobre la importancia de contar con una pareja sentimental. Así, para los integrantes del grupo $\mathrm{V}$, este aspecto no es relevante en su vida diaria. Sin embargo, para los adolescentes del grupo I, sí lo es, puesto que considera que reafirma su masculinidad vinculada a la vigorosidad y la potencia sexual.

Ahora bien, en cuanto a temas vinculados a la orientación sexual de los estudiantes, existen prejuicios sobre las personas homosexuales y bisexuales. En efecto, Gabriel, del grupo III, quien se identifica como bisexual, usualmente es agredido por su comportamiento observado como femenino.

\section{e. Expresión de emociones}

En cuanto a la expresión de emociones, se evidencia que los estudiantes tienden a minimizar sus emociones para no ser vistos como débiles frente a sus compañeros. Así, si un adolescente es sensible o expresa sus emociones es probable que sea hostigado por los estudiantes de los grupos I y II. Por el contrario, los integrantes del grupo V afirman ser comprensivos y tener confianza para poder expresar sus sentimientos entre ellos.

De esta manera, si bien existen estudiantes que afirman ser más abiertos a la expresión de sentimientos, aún persiste el ideal de hombre fuerte y duro emocionalmente. Ello debido a que los adolescentes construyen su imagen en oposición a lo considerado femenino, excluyendo de su personalidad características como ser sensible o emotivo frente a sus compañeros de clase. 


\section{Modelos de masculinidad existentes en el aula}

Ahora bien, gracias al análisis de las dimensiones que influyen en la construcción de la masculinidad de los adolescentes, se observa que, sobre todo, los integrantes del grupo I poseen características relacionadas al modelo de masculinidad hegemónica. Es decir, poseen comportamientos y concepciones sobre la masculinidad basados en la oposición a lo femenino.

Ahora bien, en el aula también puede observarse el modelo de masculinidad conservadora, sobre todo, por parte de los integrantes del grupo V. En efecto, según las dimensiones estudiadas, si bien este grupo no presenta los ideales o expresiones consideradas hegemónicas, tampoco posee la motivación para cambiar el sistema hegemónico imperante.

Finalmente, se puede evidenciar el modelo de masculinidad subordinada, sobre todo, personificado en Gabriel, integrante del grupo III. Así, al poseer una expresión de género femenina y al ser bisexual, es el centro de acoso y burlas, sobre todo por aquellos que intentan calzar en el ideal hegemónico de masculinidad.

\section{CONCLUSIONES Y LIMITACIONES}

La construcción de la masculinidad por parte de los adolescentes del primer grado de educación secundaria se formula como un proceso de continuo intercambio de información y sentidos sobre lo que significa ser hombre según los patrones e ideales socialmente implantados. De esta manera, el aula de clases constituye un espacio fundamental para la discusión y construcción de las identidades masculinas, puesto que en él se definen y discuten aquellas características asociadas a lo masculino.

En ese sentido, en el aula se establecen cinco grupos de pares con características, comportamientos e ideales diferentes. Así, son cinco las principales dimensiones que influyen en la construcción de la masculinidad entre dichos grupos: corporalidad, desempeño académico, disciplina, sexualidad y expresión de emociones.

Dichas dimensiones construyen ideales masculinos que siguen, en gran medida, el modelo hegemónico de masculinidad. Por ende, se posiciona un ideal masculino vinculado a poseer fuerza física, una figura atlética, una estatura alta y una habilidad en los deportes.

No obstante, también existen estudiantes que no consideran que sus ideales masculinos se alinean a los anteriormente señalados, sino otros que podrían considerarse saludables y alternativos. Sin embargo, si bien sus concepciones no se responden del todo a una masculinidad hegemónica, colaboran con su imposición por el beneficio que les implica. En efecto, no presentan una actitud propositiva de cambio, sino que conviven con las concepciones hegemónicas perjudiciales.

Finalmente, también existen expresiones de una masculinidad subordinada, puesto que algunos estudiantes son dominados por sus compañeros al no encajar en los ideales hegemónicos de la masculinidad.

Ahora bien, en cuanto a las limitaciones de la investigación, en primer lugar, es necesario señalar que realizar estudios de género en el ámbito educativo en Perú aún es un reto debido al estigma que se ha construido en torno al tema de género en el Currículo Nacional en los últimos años. Por ende, para la presente investigación, el conseguir los permisos parentales para continuar con la investigación fue un proceso complejo. Por ello, en las futuras investigaciones sería recomendable profundizar aún más en los aspectos descritos por la presente investigación y complementarlos con información cuantitativa relevante para la comprensión holística de la problemática en el espacio escolar. 
Sin embargo, en términos generales, gracias a la investigación, se puede afirmar que es imprescindible observar a las escuelas como espacios de comunicación donde se construyen significados sobre lo masculino y femenino y donde se refuerzan los roles de género impuestos por la sociedad. Solo de esta manera se podrán tomar acciones conscientes y efectivas en el futuro para la erradicación de prácticas y actitudes que atenten contra la convivencia segura en las escuelas.

Así, es necesario repensar las normas de convivencia, las prácticas diarias de los docentes, la importancia del seguimiento de casos de hostigamiento, la capacitación en temas de género a la comunidad educativa, entre otras acciones que fomenten una convivencia armónica en el espacio escolar. De esta manera, se podrán formar individuos que acepten y expresen libremente quienes son sin miedo a ser violentados o rechazados por ello.

\section{REFERENCIAS BIBLIOGRÁFICAS}

Bonino, L. (2002). Masculinidad hegemónica e identidad masculina. Dossiers feministes, (6), 7-35. http://www.e-revistes.uji.es/index.php/dossiers/article/view/735

Cáceres, M. (2003). Introducción a la comunicación interpersonal. Síntesis.

Connell, R. W. (1995). Masculinities. Allen \& Unwin.

Connell, R. (2001). Educando a los muchachos: nuevas investigaciones sobre masculinidad y estrategias de género para las escuelas. Nómadas, (14), 156171. https://www.redalyc.org/articulo.oa?id=305024680004

De Martino, M. (2013). Connel y el concepto de masculinidades hegemónicas: notas críticas desde la obra de Pierre Bourdieu. Revista Estudos Feministas, 21 (1), 283-300. https://www.jstor.org/stable/24328046

Durkheim, E. (1976). Educación como socialización. Sígueme.

Fuller, N. (2001). Masculinidades. Cambios y permanencias. Pontificia Universidad Católica de Perú Fondo Editorial.

Geertz, C. (2003). La interpretación de las culturas (12ª ed.). Gedisa.

Guevara, E. (2008). La masculinidad desde una perspectiva sociológica. Una dimensión del orden de género. Sociológica, 23 (66), 71-92. https://www.redalyc.org/articulo.oa?id=305024680004

Heinrich, J. (2013). The making of masculinities: Fighting the forces of hierarchy and hegemony in the high school setting. The High School Journal, 96(2), 101-115. https://www.jstor.org/stable/23351964?seq=1

Instituto Nacional de Estadísticas e Informática. (2019). Perú: indicadores de violencia familiar $y$ sexual, 2012-2019. https://www.inei.gob.pe/media/MenuRecursivo/publicaciones_digitales/Est/Lib1 $686 /$

Lamas, M. (2000). Usos, dificultades y posibilidades de la categoría "género". En Lamas, M. (Ed.). El género. La construcción cultural de la diferencia sexual (pp. 327366). Universidad Nacional Autónoma de México.

Madrid, S. (2011). Masculinidades y equidad de género en la escuela: Consideraciones para la construcción de una política educativa en Chile. En Aguayo, F. y Sadler, 
M. (Eds.), Masculinidades y políticas públicas: Involucrando hombres en la equidad de género. Universidad de Chile.

Warren, S. (1997). Who do these boys think they are? An investigation into the construction of masculinities in a primary classroom. International Journal of Inclusive Education, 1(2),

207-222.

https://www.tandfonline.com/doi/abs/10.1080/1360311970010206 


\subsection{EXPERIENCIAS}

\subsubsection{Análisis de la construcción del género desde la Edad Moderna mediante miniproyectos de Ciencias sociales y Literatura}

Pedro Antonio Amores Bonilla (Universidad Miguel Hernández de Elche-Cefire de Elche, España); Laura Victoria Burruezo Hernández (Cefire de Orihuela, España)

\section{Resumen}

La presente experiencia consiste en un mini proyecto desde el cual comprender el alcance del género dentro del marco del currículo escolar mediante la incidencia en algunas competencias clave, como la competencia lingüística o la competencia social y ciudadana. Esta experiencia se basa en el constructivismo y en el aprendizaje colaborativo como bases pedagógicas $y$, como bases epistemológicas e historiográficas, la Historia Social, la Historia de las mentalidades procedente de la $3^{a}$ generación de los Annales, y todo ello desde la perspectiva de género.

Los resultados han sido sumamente positivos porque se ha conseguido desarrollar un aprendizaje de este período a partir del uso fuentes que facilitaron la utilización de categorías de análisis. Además, se ha generado un aprendizaje significativo desde el punto de vista psicológico. Así ha sido posible generar la empatía histórica y la comprensión del género como constructo social que se ha plasmado en la voz de los sectores marginados, como las mujeres de las clases populares.

Palabras clave: Mentalidades; género; Historia social, competencias clave; aprendizaje significativo.

\section{INTRODUCCIÓN Y OBJETIVOS}

En los últimos años se asiste a la introducción de diferentes métodos pedagógicos y epistemológicos en la Enseñanza Secundaria que tratan de coadyuvar en la formación de una ciudadanía crítica. La presente experiencia es un intento de abordaje de los problemas que se han ido detectando en determinados contextos sociales. Aunque los planteamientos pedagógicos de las Ciencias Sociales han recogido las renovaciones historiográficas de la Escuela de los Annales en sus diferentes generaciones, se hace notar la escasa atención a las mujeres como protagonistas de los procesos de cambio y de permanencia históricas (López Navajas, 2014: 282). Teorías nuevas como las teorías Queer, (Butler, 2006) están adquiriendo suma importancia en esta reivindicación de la igualdad. Aquí sólo se propone el estudio del género como constructo social desde las y en aulas. No obstante, nos parece muy interesante partir, como marco teórico de referencia, de la tercera ola de los feminismos (Gamba, 2008). Este cuestionamiento bebe, en parte, de autoras como Silvia Federici (2010) y de otras como Victoria Camps, para quien sólo desde la educación será factible un cambio en las relaciones sociales de género (Camps, 2019).

Desde una perspectiva pedagógica, la coeducación como herramienta para la construcción de una ciudadanía global es esencial (Sáenz Rosenkranz; Molina Neira; Barriga Ubed; 2018: 106). Además, para conseguir una coeducación significativa se deben utilizar las fuentes y los métodos que apelen a la emotividad del alumnado. Es desde esta emotividad desde la que se consigue una modificación de los sentimientos, 
modificación que es el motor del cambio de las actitudes (Domínguez Almansa; Rivero Rodríguez, 2018: 52) y, por ello, del cambio social. Ello debe plasmarse en metodologías socializadoras y colaborativas que huyen del éxito productivo y ahondan en los procedimientos de desarrollo y de aprendizaje frente a la búsqueda del éxito, propio de entornos masculinizados. Estos enfoques de desarrollo de los aprendizajes de las ciencias sociales, más pausados (Navarro Redondo, 2016) se fundamentan en la pedagogía lenta, pedagogía del caracol o slow education (Pérez Francesch, 2010).

Los objetivos son, en primer lugar, crear de una ciudadanía crítica desde la escuela, partiendo de la necesidad de romper con los estereotipos de género desde la consideración del tiempo presente como referencia (Mora Bleda, 2013) que facilite la empatía histórica (Sáiz Serrano, 2013). Asimismo, como segundo objetivo, se trata de romper con esos estereotipos de género actuales estableciendo la categoría construcción de género como concepto analítico (Scott, 1990) a partir del cual se desarrollen proyectos educativos por parte del alumnado.

\section{CONTEXTUALIZACIÓN}

El contexto en el que se ha desarrollado esta experiencia ha sido una ciudad de unos 200.000 habitantes, ubicada en la costa levantina española y que ejerce importantes funciones en el territorio circundante. Como consecuencia, esta ciudad ha recibido un importante aporte de inmigración procedente del interior del país y del exterior ejemplo de lo cual es la composición del alumnado de los grupos en los que se ha trabajado. La población que vive en los barrios de los que procede el alumnado está muy afectada por procesos de empobrecimiento social general, pero, sobre todo, de empobrecimiento de las mujeres. El alumnado con el que se ha trabajado procede de este contexto.

\section{DISEÑO Y DESARROLLO}

Con este alumnado se ha abordado del siglo de Oro, como indica el decreto de currículo, desde la perspectiva de género. En origen, para conseguir que el aprendizaje fuese significativo desde la perspectiva lógica y psicológica, se han utilizado microproyectos desde la Historia social (Santos Juliá, 2010) mediante el uso de categorías de análisis (Casanova, 2015). Ello implica seleccionar fuentes que sean la manifestación de las voces de los colectivos sociales marginales para generar una forma de empatía histórica. Con esta empatía histórica se pueden movilizar los sentimientos del alumnado. La novela picaresca adaptada, testimonio indirecto de los individuos de los sectores marginales, permite generar en el alumnado simpatía por sectores marginados.

Tras varios años de trabajo sobre Historia social, en un momento dado, varias alumnas, afectadas en sus vidas por situaciones de diferencia de género más o menos radicales, en su proceso de investigación sobre los sectores marginales, encontraron aspectos de género en algunas novelas, como El casamiento engañoso o el coloquio de los perros, o El celoso extremeño. Ello comportó una reorientación del desarrollo de ese proyecto en concreto y de los futuros proyectos que años posteriores fueron poniéndose en práctica. Estos proyectos, con diferencias, ha consistido en lo siguiente: entre finales del segundo trimestre y principios del tercero, dependiendo del desarrollo de la programación, tras el estudio de los elementos estructurales esenciales del período, se ha profundizado en el estudio de la vida cotidiana de las mujeres y la influencia del género en ellas. Las mujeres, en todos los grupos sociales, siempre han sufrido una discriminación de género que ha sido muy similar a lo largo de los siglos, aunque las instituciones de poder, el contexto económico y social, y las manifestaciones artísticas hayan variado formalmente (Ortega López, 2000). Se ha comentado al alumnado que en los siglos XVI y XVII estas diferencias de género se han manifestado en fenómenos como la caza de brujas (Barstow, 1999), fenómeno que, aunque había sido el resultado 
del concepto acumulativo de brujería construido desde antiguo (Caro Baroja, 2005), eclosionó fundamentalmente a principios del XVII y durante toda esa centuria (Fargas García, 2016) y constituyó uno de los elementos esenciales de la mentalidad de la sociedad (Levack, 1997) de la sociedad desde la Edad Media, pero, sobre todo, Moderna (Armengol, 2002). Para ello, como concienciación previa, se han seleccionado algunas secuencias de films como La bruja (Egger, 2015) o como El crisol (Hytner, 1996).

Se ha comentado en el aula, también, que el otro pilar de la construcción del género en el Siglo de Oro iba a ser la honra como elemento esencial del estatus y del prestigio masculino, honra dependía esencialmente del comportamiento sexual de las mujeres (Rivero Rodríguez, 2005). Se indica también que el control de las relaciones sexuales por motivos de prestigio social, y también económicos (Federici, 2010), aparecen en las fuentes. El problema era decidir las fuentes a las que se podía recurrir. No era factible utilizar testimonios directos, dado que las mujeres de este período habían fallecido. Se pensó en utilizar testimonios de procesos judiciales (Howe, 2016), pero su complejidad comportó su sustitución por obras literarias que se pudieran considerar buenas exponentes del esquema de valores del Siglo de Oro. Para ello se decidieron obras literarias, manifestaciones de segundo orden, pero fiables para mostrar el proceso de construcción del género (Vázquez Manassero, 2013). En concreto, fueron algunas novelas ejemplares de Miguel de Cervantes, como las citadas con anterioridad porque son excelentes exponentes de este universo mental en general, y del género en particular (Simón Hernández, 2015).

Con estas fuentes se ha diseñado y puesto en práctica un miniproyecto de cuatro semanas. Este proyecto ha sido ejecutado, con la base de contenidos indicada, por grupos de alumnas y alumnos de $3 / 4$ miembros de competencia lingüística heterogénea. Estos grupos han concretado, en función de sus inclinaciones, el problema nuclear enunciado por la docente, y que era el género, sus características y su comparación con el momento actual.

Para abordar sus proyectos, se han utilizado como fuente El celoso extremeño y El casamiento engañoso o el coloquio de los perros, en versiones adaptadas. Estas novelas se han trabajado a lo largo de varias fases. La primera, de tres sesiones, ha consistido en la extracción de información de las novelas, que se leían en el aula de forma colectiva rotativamente por parte de todos y todas. La idea era la extracción de datos para cubrir una plantilla en la que se cuestionaba la forma de pensamiento y los valores asociados a las diferencias de género en el Siglo de Oro. Edad, extracción social de los personajes, ocupaciones, valores positivos o negativos que manifiestan y de qué forma, etc, han sido los elementos de la rutina de extracción.

En la segunda, de 3 sesiones, se han filtrado y seleccionado esos datos en relación con el problema de género que se hubiera concretado en cada grupo. En esta fase, las emociones salieron a la luz dado que las alumnas y los alumnos pudieron constatar, de forma interna, ahondando en la psicología de los personajes, la artificialidad de esta realidad. Muchas y muchos estaban sufriendo los efectos de micromachismos que han visto plasmados en estas obras de una manera u otra.

En la tercera fase ha tenido lugar la planificación de la producción final, a la que no todos los grupos llegaron, y en la cuarta, esa producción final de un texto que se ha publicado en ocasiones de manera digital, y en otras en forma de exposición o de texto para la revista del centro.

\section{EVALUACIÓN, CONCLUSIONES Y PROPUESTAS DE MEJORA}

Es evidente que este trabajo ha conjugado, de forma sinérgica, contenidos de Ciencias Sociales y de Literatura, lo cual es una orientación sugerida en los artículos 15 (ámbitos), 
y 18 de la LO 3/2020. Además, la evaluación del mini proyecto, desarrollada mediante dianas de evaluación parciales y generales, y rúbricas de evaluación parciales y generales, tanto por la docente como por los grupos de alumnas y alumnos arroja resultados muy positivos porque, tras la publicación de los productos que se ejecutaron finalmente en la revista del centro, se desarrolló un taller-tertulia-coloquio por parte de estos alumnos ante el resto de compañeras y compañeros. Ello comportó un espacio de empatía histórica que ha llevado al cuestionamiento de los roles de género, como se ha visto en gran parte de las conclusiones de estos trabajos.

Por otro lado, sean detectado dificultades en el empleo de categorías de análisis por parte de las alumnas y los alumnos. Estas categorías implican abstracciones a las que no todos ni todas están acostumbradas. Dado que los grupos estaban formados por alumnado cognitivamente heterogéneo, ciertas abstracciones se han podido abordar de forma conjunta entre la docente y los y las miembros de los grupos que han podido comprender términos como género, clase social, brujería, señor, etc. Ahora bien, es pertinente investigar la manera de extender estas categorías de análisis a través del pensamiento histórico porque sin estas categorías sólo se pueden saber hechos y datos, pero no se llegan a conocer. El conocimiento requiere el empleo de categorías. Una vez establecido ese conocimiento, el alumnado ha ido sintiendo emociones de rechazo hacia el género como constructo social artificial a lo largo de los siglos. Aun con esta dificultad, como propuestas de mejora proponemos la asunción de ámbitos que aúnen contenidos de las materias de Lengua y de Ciencias Sociales, de forma integrada, en $1^{\circ}$ de la ESO.

\section{REFERENCIAS BIBLIOGRÁFICAS}

Armengol, A. (2002). "Realidades de la brujería en el siglo XVII: entre la Europa de la caza de brujas y el racionalismo hispánico" Tiempos modernos: Revista de Historia Moderna, vol. 3, (Número 6)

Barstow, A. L. (1999). La caza de brujas en Europa. 200 años de terror misógino. Madrid, Susaeta Tikal

Butler, J, (2007). El género en disputa. El feminismo y la subversión de la identidad. Barcelona, Paidós

Camps, V. (2019). El siglo de las mujeres. Madrid, Cátedra

Caro Baroja, J. (2005) Las brujas y su mundo, Madrid, Alianza Editorial

Casanova, J. (2015). La historia social y los historiadores. Barcelona, Crítica

Domínguez Almansa, A; Rivero Rodríguez, T. (2018). "Lo emocional y lo nacional en la enseñanza de las ciencias sociales". En López Facal, R; Miralles Martínez, P; Prats Cuevas, J. (eds.) Gómez Carrasco, C.J. (coord.) Enseñanza de la historia y competencias educativas. Barcelona, Graó

Fargas García, C. (2016) "El fenómeno de la caza de brujas. El caso de las acusaciones por brujería en la aldea de Salem" (2016). Revista Historia Autónoma, (Número 9), pp. 71-86. e-ISSN: 2254-8726; DOI: http://dx.doi.org/10.15366/rha2016.9.

Federici, S. (2010). Calibán y la bruja. Mujeres, cuerpo y acumulación originaria. Madrid, Traficantes de Sueños-Historia

Gamba. S. (2008). "Feminismos: historia y corrientes". VVAA, Diccionario de estudios de Género y Feminismos, Ciudad Autónoma de Buenos Aires, Editorial Biblos 
Howe, K. (ed.) (2016). El libro de las brujas. Casos de brujería en Inglaterra y en las colonias norteamericanas (1582-1813). Madrid, Alba

Juliá, S. (2010). Historia social/sociología histórica. Madrid, Siglo XXI

Levack, B. (1997). La caza de brujas en la Europa Moderna. Barcelona, Altaya

López Navajas, A. "Análisis de la ausencia de las mujeres en los manuales de la ESO: una genealogía de conocimiento ocultada". Revista de Educación. 363. Eneroabril 2014. pp. 282-308

LÓPEZ NAVAJAS, A. (2019) "Libros de texto y desigualdades: cuando olvidamos a la mitad de la Humanidad". Dossier Graó. Coeducar: poner la vida en el centro de la educación. Barcelona, Graó

Mora Bleda, E. (2013), "El paradigma de género y mujeres en la historia del tiempo presente”. Revista Historia Autónoma, (Número 2), pp. 143-160

Navarro Redondo, I. (2016). Slow education: el poder de la "pedagogía del caracol" en la primera infancia. Universidad de la Rioja, Trabajo de Fin de Grado.

Ortega López, M. (2000). "Género e Historia Moderna: una revisión a sus contenidos". Contrastes: Revista de historia moderna, (Número 11), pp. 9-32

Pérez Francesch, M. J. (2010). "La educación lenta". Jornadas Cefire "Els ritmes del canvi". Pedagogía Magna (Número 5). pp. 125-129

Rivero Rodríguez, M. (2005). La España de Don Quijote. Un viaje al Siglo de Oro. Madrid, Alianza

Sáenz Rosenkranz, I; Molina Neira, J; Barriga Ubed, E. "La enseñanza y el aprendizaje de las ciencias sociales y el desarrollo de la competencia social y ciudadana" (2018). En López Facal, R; Miralles Martínez, P; Prats Cuevas, J. (eds.) Gómez Carrasco, C.J. (coord.) Enseñanza de la historia y competencias educativas. Barcelona, Graó

Sáiz Serrano, J. (2013). "Empatía histórica, historia social e identidades: pensar históricamente la conquista cristiana de la Valencia musulmana con estudiantes de $2^{\circ}$ ESO". Clío, 39

Scott, J. W. (1990), "El género, una categoría para el análisis histórico", AMELANG, JK. y NASH, M. (eds.) (1990). Historia y Género. Las mujeres en la Europa Moderna y Contemporánea, Valencia, Institució Alfons el Magnànim

Simón Hernández, F. (2015). "La feminización del espacio doméstico en la literatura. La obra Trifles de Susan Glaspell". ENSAYOS, Revista de la Facultad de Educación de Albacete, (30- 1) pp. 161-169 Enlace web: http://www.revista.uclm.es/index.php/ensayos - Consultada en (13/09/2019)

Vázquez Manassero, M. A. (2013). "Sobre cuentos e imágenes de brujas en el Siglo de Oro". V Congreso Virtual sobre Historia de las Mujeres 


\subsubsection{Implantación, Desarrollo y Adaptación Online del Programa de Innovación Educativa por la Igualdad entre Mujeres y \\ Hombres "Educando en Justicia Igualitaria" \\ Soledad Andrés Gómez, Universidad de Alcalá (UAH), Madrid, España.}

\section{Resumen}

Se presenta el programa de innovación "Educando en Justicia Igualitaria", implantado en un centro público de Educación Secundaria de la Comunidad de Madrid. Se dirige a estudiantes de $4^{\circ}$ de ESO, con el objetivo de fomentar la educación en igualdad entre mujeres y hombres y desmontar los estereotipos de género. El equipo formador está compuesto por voluntariado del ámbito jurídico, profesorado del centro y otros profesionales educativos. La última fase, en el curso 2019-2020, se suspendió por las necesidades de adaptación de la docencia a la situación de pandemia, finalizándose el programa en el curso actual 2020-2021. Se describen los objetivos del programa, fases de implantación y actividades realizadas presencialmente en el curso 2019-20, así como su posterior adaptación tras la reanudación de las clases.

Se incluye la valoración de su funcionamiento por el equipo formador y las propuestas de desarrollo futuro en otros centros educativos.

Palabras clave: Programa Educando en Justicia igualitaria; adolescentes de secundaria, estereotipos de género, igualdad entre mujeres y hombres; valoración equipo formador

\section{INTRODUCCIÓN Y OBJETIVOS}

No existen antecedentes en España, ni en otros países del entorno europeo, en donde equipos judiciales multidisciplinares accedan a los centros educativos con el objetivo de impartir formación en distintos ámbitos relacionados con la igualdad. El diseño del programa fue realizado por la asociación de juezas AMJE (Asociación de Mujeres Juezas de España), actualmente en proceso de implantación en numerosos centros educativos de toda España.

Los objetivos principales son la promoción de la igualdad entre mujeres y hombres y la sensibilización sobre la violencia de género del alumnado de Educación Secundaria.

Contempla la creación de equipos de trabajo multidisciplinares, dirigidos por una jueza directora del equipo educativo psicojurídico, en el caso que se presenta en coordinación con la Consejería de Educación del municipio en donde tiene lugar la experiencia.

Inserto en los Planes de Acción Tutoriales y/o currículos educativos, consta de tres fases: primera, sensibilización e información; segunda, redacción de un proyecto por el alumnado y visita guiada a edificio judicial, con asistencia a juicio real con perspectiva de género. $Y$ tercera, escenificación de un juicio con perspectiva de género, en donde el alumnado impulsor de los cinco proyectos seleccionados, escenifican públicamente el juicio en una Sala de Vistas del edificio judicial correspondiente.

La especificidad del trabajo que se presenta hace referencia a la adaptación que hubo de realizarse al suspenderse las clases presenciales en el instituto de educación secundaria en donde se estaba desarrollando la experiencia en el curso 2019-22020, así como al diseño de la evaluación que se estaba llevando a cabo en el centro piloto. 
La pervivencia de los estereotipos de género en las jóvenes generaciones, en particular en la adolescencia, es motivo de preocupación en el mundo educativo, así como en el medio social en donde chicos y chicas se relacionan. Las redes sociales, hoy mundos virtuales en donde los y las adolescentes establecen relaciones de amistad, inician o mantienen las primeras relaciones de pareja, se comunican, etc. etc. tienen una influencia clave en la perpetuación de los estereotipos.

La sensibilización de los y las profesionales del ámbito judicial ante el problema, y su preocupación por lo que observan en su medio profesional, ha tenido como resultado su implicación directa en la formación de los y las menores a través de este programa. Al mismo tiempo, los y las profesionales acercan la imagen de la justicia en la intervención frente a los problemas relacionados con la desigualdad entre mujeres y hombres y la violencia de género.

\section{DISEÑO Y DESARROLLO}

El desarrollo del programa parte de la necesidad de informar, concienciar y sensibilizar a la ciudadanía en general y a las/os juezas/es en particular sobre la necesidad de defender los derechos humanos de toda la ciudadanía, con especial énfasis en las mujeres y niñas.

El programa está dirigido al alumnado de primaria (a partir de los 9 años) y secundaria, al personal educativo y a las familias, de manera general. La experiencia que se presenta aquí se ha desarrollado entre alumnado de $4^{\circ}$ de ESO.

Se desarrolla en tres bloques, espaciados a lo largo del curso escolar, ajustándose a la disponibilidad del centro educativo:

\section{Formación del alumnado:}

\subsection{Primer bloque: los equipos judiciales en las escuelas.}

Los equipos judiciales multidisciplinares se desplazan a las escuelas, con objeto de impartir charlas con micro ponencias de 10-12 minutos. Las y los miembros de los distintos estamentos exponen su visión sobre el sentido de la justicia con perspectiva de género desde el punto de vista de su especialización profesional, en coordinación con un/a profesora o profesora del centro que se encarga de la organización y dinamización del debate con el alumnado.

Se utiliza material audiovisual, proyectándose un breve vídeo sobre las discriminaciones y violencias de género en el mundo. Una parte relevante de los contenidos promueve el acercamiento a las diferentes variedades de violencias de género, con especial énfasis en el uso de las nuevas tecnologías, micromachismos, estereotipos y prejuicios sexistas, brechas de género, etc. La sesión finaliza con debate con participación del alumnado.

\subsection{Segundo Bloque: conociendo la Justicia desde dentro.}

Se organiza una visita guiada al Edificio Judicial más próximo al centro educativo en donde se muestra el funcionamiento de las instalaciones, sedes judiciales, forense, fiscalía, abogacía, procuradores/as, decanatos, etc., y las funciones y competencias de los distintos operadores judiciales.

La visita incluye debate del alumnado con el juzgador/a facilitará para aclarar dudas que hayan surgido durante su observación del proceso judicial. 


\subsection{Tercer bloque: el Proyecto Igualitario y escenificación de Juicio con perspectiva de género.}

Este bloque busca la participación directa del alumnado, promoviendo la capacidad de trabajo en equipo, de investigación y sus habilidades comunicativas a través de la realización de un trabajo de contenido igualitario (preferiblemente audiovisual, o en su caso, escrito) sobre un tipo específico de violencia de género.

La segunda parte se centra en la preparación de un juicio con perspectiva de género por los alumnos y alumnas. Se escenifica en una Sala de Vistas de las instalaciones judiciales, con reparto de los papeles de los distintos operadores que participan en juicio. Los chicos y chicas participantes eligen entre una variedad de materias vinculadas a la igualdad entre mujeres y hombres, a partir de las que elaboran el proyecto (escrito o audiovisual) y preparan el juicio.

2. Materiales: espacios educativos en el centro y judiciales para la escenificación del juicio.

3. Duración del programa. se elaboró un cronograma de aplicación de los tres bloques en coordinación con el centro educativo.

4. Convenios de colaboración. Se suscribió un convenio de colaboración con la administración local correspondiente. Asimismo, se informa de que la colaboración por parte de los operadores judiciales y otros participantes en el equipo será voluntaria y altruista.

\section{EVALUACIÓN, CONCLUSIONES Y PROPUESTAS DE MEJORA}

Debido a la situación derivada de la pandemia, que llevó a la suspensión de las clases presenciales, no pudo finalizarse de forma presencial el desarrollo de la última fase del programa, la escenificación del juicio.

Igualmente, hubo que reajustar la evaluación que, prevista inicialmente en dos fases pre-post, por medio de una batería de instrumentos cuantitativos, dejando pendiente la última toma de medidas para el curso próximo 2021-22.

Antes de la suspensión de las clases se recogieron los primeros datos cuantitativos, en este momento en fase de análisis, y se llevaron a cabo la celebración de talleres presenciales, en formato de grupos de discusión con alumnado voluntario del mismo curso objetivo del programa.

Los grupos de discusión con el equipo judicial y las entrevistas en profundidad están teniendo lugar, a pesar de la suspensión de las clases, en los meses de mayo y junio del presente curso 2020-2021.

Debido a los ajustes necesarios por la imposibilidad de celebrar la fase del juicio, esta se sustituyó por ponencias del alumnado, con la realización de vídeos temáticos y micro ponencias de cada miembro del equipo participante, el diseño completo de la evaluación se realizará en el curso 2021-22.

En el curso académico 2020-21 está prevista la implantación del programa en un número representativo de centros de la misma ciudad, en colaboración con la administración local. 


\section{REFERENCIAS BIBLIOGRÁFICAS}

Andrés, S. (2019). Educación feminista: en los colegios y las familias aún queda mucho por hacer. The Conversation. Disponible en: https://theconversation.com/educacion-feminista-en-los-colegios-y-las-familiasaun-queda-mucho-por-hacer-112792

Instituto de la Mujer de Castilla-La Mancha (2020). Igualdad de género entre adolescentes de Castilla La Mancha. Informe 2020. Elaborado por la Cátedra Isabel Muñoz Caravaca (Andrés Gómez, S., Bonilla-Algovia, E., Bruno, L., Carrasco Carpio, C., Checa Romero, M., Hernández-Romero, N., Ibáñez Carrasco, M., De la Osa Escudero, Z., Pascual Gómez, I., Rivas-Rivero, E. y De la Viuda Serrano, A.). Servicio de Publicaciones del Instituto de la Mujer de Castilla-La Mancha.

Andrés, S., Fernández Valentí, A. y Poyatos Matas, G. (2021) O programa educando em justiça igualitária: um modelo de colaboração judicial e educacional para a formação em igualdade e prevenção da violência de gênero na adolescência. https://www.editoraiberoamericana.com/educacaoescolariberoamerica ISBN (Digital): 978-65-86839-04-3 e DOI: 10.47519/EIE.978-65-86839-04-3

Ballarín, P. (2019). ¿Por qué llamamos educación a la que no coeduca?. En R. Cobo (ed.) La imaginación feminista. Debates y transformaciones disciplinares. Madrid: La Catarata.

Bosch, E., Ferrer, M. V., García, M. E., Ramis, M. C.; Mas, M. C.; Navarro, C.; y Torrens, G. (2007). Del mito del amor romántico a la violencia contra las mujeres en la pareja. Madrid: Instituto de la Mujer.

Díaz Aguado, M.J.; Martínez, R. y Martínez, J. (2013). La evolución de la adolescencia española sobre la igualdad y la prevención de la violencia de género. Madrid: Ministerio de Sanidad, Política Social e Igualdad.

Ferrer, V. y Bosch, E. (2013). Del amor romántico a la violencia de género: Para una coeducación emocional en la agenda educativa. Profesorado: Revista de currículum y formación del profesorado, 17 (1), 107-122.

Ley Orgánica 3/2007, de 22 de marzo, para la igualdad efectiva de mujeres y hombres. Madrid: Boletín Oficial del Estado. Disponible en:

https://www.boe.es/buscar/pdf/2007/BOE-A-2007-6115-consolidado.pdf

Ley Orgánica 1/2004, de 28 de diciembre, de Medidas de Protección Integral contra la Violencia de Género. Madrid: Boletín Oficial del Estado. Disponible en:

https://www.boe.es/buscar/act.php?id=BOE-A-2004-21760

OCDE (2012) Cerrando las brechas de género, es hora de actuar (Closing the Gap, Act Now). Publicaciones de la OCDE.

OCDE (2017) La búsqueda de la igualdad de género. Una batalla cuesta arriba. París: OCDE.

De la Osa, Z., Andrés, S. y Pascual, I. (2013) Creencias adolescentes sobre la violencia de género. Sexismo en las relaciones entre adolescentes. European Journal of Investigation in Health, Psychology and Education (EJIHPE), 3, 3, 265-275.

http://www.ejihpe.es/index.php/journal/article/view/49

Reed, L., Tolmanb, R. \& Wardc, M. (2017) Gender matters: Experiences and consequences of digita Idating abuse victimization in adolescent dating relationships. Journal of Adolescence, 59. 79-89. https://doi.org/10.1016/j.adolescence.2017.05.015 
Rodríguez Martínez, C. (2011). Género y cultura escolar. Morata.

Sánchez Jiménez, V., Muñoz-Fernández, N., Lucio López, L. A., \& Ortega-Ruíz, R. (2017). Ciberagresión en parejas adolescentes: Un estudio transcultural EspañaMéxico. Revista Mexicana de Psicología, 34 (1), 46-54.

Subirats, M., Tomé, A. y Solsona, N. (coords.) (2019). Coeducar: poner la vida en el centro de la educación. Barcelona: Dosier Graó. https://www.grao.com/es/producto/coeducar-poner-la-vida-en-el-centro-de-laeducacion-doe04 


\subsubsection{Salud sexual en jóvenes navarros \\ Sofía Blasco Íñiguez (IES Valle del Ebro, España); Miren Borja Vitas (IES Valle del Ebro, España); Celia Jiménez Escudero (IES Valle del Ebro, España).}

\section{Resumen}

Se desarrolla un proyecto de dos cursos de duración sobre la salud sexual en jóvenes navarros mediante tres ejes: diagnóstico, participación y comunicación. En una primera fase se ha desarrollado un cuestionario en base a otros, ya que no existe una versión validada en castellano de ninguno, que permita obtener datos sobre los conocimientos previos y las conductas de riesgo. Se ha aplicado en todos los centros educativos de Navarra con la intención de obtener una muestra suficiente y representativa $(n=380)$. Con los resultados obtenidos se pretende identificar áreas vulnerables y así implementar estrategias efectivas, previamente estudiadas (revisión sistemática y entrevistas), enfocadas a esos temas. La participación está siendo muy elevada y se ha despertado el interés de la población diana.

Palabras clave: salud sexual; adolescentes; educación secundaria, cuestionarios; Navarra.

\section{INTRODUCCIÓN Y OBJETIVOS}

La salud sexual ha sido un tema de interés creciente en los últimos años por sus efectos sobre la salud, tanto en clave de morbilidad como de bienestar, y sobre la sociedad, igualmente, en el sentido de promocionar tanto el desarrollo y autonomía de la sexualidad como de impedir abusos de los derechos humanos relacionados con ella (coerción sexual, violencia, etc.). La salud sexual ha sido incluida, como muestra, en los Objetivos de Desarrollo del Milenio (ODM) 5, «mejorar la salud materna», y 6, «combatir el VIH/SIDA, el paludismo y otras enfermedades».

Para lograr una óptima salud sexual, uno de los pilares esenciales es el acceso a la información y al conocimiento, además del apoyo social, el acceso a los servicios y recursos necesarios para garantizar una salud sexual adecuada (productos, etc.) y un entorno que favorezca la salud sexual. Aún más grave y urgente es que, aunque gran parte del desarrollo sexual de la persona se produce durante la adolescencia, lo hace sin la información adecuada ni el apoyo suficiente; constituye esta etapa una oportunidad crítica para garantizar una transición exitosa hacia la adultez (OMS, 2018).

Tanto la financiación para la investigación como la información existente que se da a los jóvenes en materia de salud sexual en Navarra es insuficiente. El Instituto de Salud Pública y Laboral de Navarra (ISPLN) realizó en 2002 (publicada en 2007) y en 20132014 una encuesta sobre salud dirigida a jóvenes que incluía algunas preguntas sobre conductas sexuales. En 2019 se anunció la realización del nuevo informe, pero no se ha llevado a cabo.

En la realización de este proyecto están colaborando directamente Olga Sanz Asín, Jefa de Ginecología y Obstetricia, y Lorena García Pérez, Jefa de Unidad de Enfermería de cuidados a la Mujer, al Adolescente y Niño, ambas del Hospital Reina Sofía de Tudela; y docentes en el IES Valle del Ebro. Los objetivos son:

1. Conocer el estado de la salud sexual de la población adolescente navarra mediante la recopilación de datos actualizados. Se necesita una muestra de 380 personas (con un nivel de confianza del $95 \%$ y un margen de error del $5 \%$ para un total de 31.453 adolescentes de entre 15 y 19 años que según datos del 
Padrón Continuo actualizados viven en Navarra), utilizando un muestreo aleatorio estratificado según peso poblacional de acuerdo a unidades administrativas (merindades), edades y sexo.

2. Evaluar los conocimientos previos sobre salud sexual en jóvenes para detectar áreas especialmente vulnerables, por ello;

3. Diseñar planes de intervención basados en datos empíricos medibles, como recomienda la bibliografía especializada (Mercer, 2010).

4. Difundir los resultados obtenidos y promover la aplicación del cuestionario periódicamente ya que este factor, la actualización de los datos, es determinante para establecer la evolución en los comportamientos de riesgo (Slaymaker, 2004).

\section{CONTEXTUALIZACIÓN}

Pese a la importancia del tema y al creciente interés que ha generado entre investigadores y público, se han realizado pocos estudios transnacionales para explorar el comportamiento y la salud de los jóvenes, y aún más escasas son las investigaciones que utilizan preguntas, métodos o muestras representativas comparables (Young et al., 2016). Como muestra, en 2009 el Ministerio de Sanidad anunció que iba a realizar una Encuesta Nacional de Salud Sexual, de carácter anual, pero únicamente se llevó a cabo ese año (en 2019 el Ministerio declaró la intención de recuperarla) y en población mayor de 17 años.

Además, la mayoría de los estudios que sí emplean métodos cuantitativos se basan en enfoques epidemiológicos, cuya finalidad es determinar qué factores sociodemográficos se asocian con mayores prevalencias de ITS y de embarazos no deseados; pero pocos se han dirigido a conocer, con estos mismos métodos, las percepciones, conocimientos y experiencias de los adolescentes respecto a la salud sexual (Templeton et al., 2017).

En España la edad media en la que se produce la primera relación sexual es en torno a los 17 años para el grupo de edad comprendido entre los 15 y los 29 años (INJUVE, 2019). Los tres riesgos en salud sexual más habituales que se producen entre los 10 y los 19 años son la maternidad temprana, la interrupción voluntaria del embarazo (IVE) y las ITS, según este mismo estudio. Algunos de estos problemas tienen precisamente mayores tasas de incidencia entre adolescentes y jóvenes, específicamente las ITS y los embarazos no deseados (Kahn y Halpern, 2018). La iniciación sexual temprana, el uso inconsistente de anticonceptivos y las múltiples parejas sexuales son factores de riesgo reconocidos de transmisión de ITS y de embarazo no deseados (Heywood et al., 2015; Vasilenko et al. 2016).

\section{DISEÑO Y DESARROLLO}

Se han establecido tres fases de trabajo: diagnóstico, participación y comunicación. La necesidad inmediata ha sido conocer el estado de la salud sexual de la población adolescente navarra mediante la recopilación de datos procedentes de esta comunidad, así como interpretar estos resultados con la finalidad de detectar áreas particularmente vulnerables que permitan diseñar planes de intervención. No existe actualmente en castellano un cuestionario validado sobre este objeto de estudio y por ello ha sido necesario diseñar uno, proceso que se ha desarrollado entre los meses de diciembre a marzo de 2021.

Una vez elaborado el cuestionario, se promovió la participación enviándolo a todos los centros de educación secundaria de la Comunidad Foral de Navarra (53 en total) desde 
abril de 2021 invitando a su participación para el estudio (hasta junio). Para favorecer esta difusión y animar la participación se tomaron las siguientes medidas:

- Se crearon recursos divulgativos: un cartel científico sobre el proyecto escrito en castellano y en euskera y un breve vídeo de presentación del proyecto.

- Se solicitó el apoyo del Departamento de Educación del Gobierno de Navarra y de organismos específicos como el Observatorio de Salud Comunitaria de Navarra, con quien se mantuvo una reunión en la que se les presentó el proyecto. Se tuvieron en cuenta las consideraciones éticas en los estudios de investigación sobre salud sexual en adolescentes (OMS, 2019a).

- Se facilitó una dirección de correo electrónico a la cual los participantes podían enviar sus dudas y sugerencias respecto al cuestionario. Está previsto contactar con la Comisión Anti-Sida de Navarra, con sede en Pamplona, que tiene un eje de actuación dedicado a resolver dudas.

Paralelamente y en previsión de la fase de comunicación, se pretende identificar una estrategia eficaz de ofrecer información sobre salud sexual a esta población diana, los jóvenes, y para ello se han planificado las siguientes tareas que se desarrollarán entre abril y septiembre de 2021:

- Realizar una revisión bibliográfica sistemática siguiendo los estándares de calidad de la Declaración PRISMA con la finalidad de reunir evidencia sobre programas de intervención y difusión en salud sexual dirigidos a adolescentes.

- Conocer las experiencias y sugerencias de profesionales de diverso ámbito (psicólogos, educadores sexuales, sanitarios, etc.) mediante la técnica de la entrevista semi directiva en base a un mismo guion de preguntas.

- Programar charlas, encuentros y conferencias exponiendo los resultados obtenidos con el cuestionario, en colaboración con el Área de Salud de Tudela y el Departamento de Educación del Gobierno de Navarra.

\section{EVALUACIÓN, CONCLUSIONES Y PROPUESTAS DE MEJORA}

Hasta el momento se ha desarrollado la primera fase prevista. Para diseñar el cuestionario se utilizaron como base las guías de recomendación de la OMS (2019b) y de la National Coalition for Sexual Health (NCSH) de los EEUU. Igualmente, se consultó el cuestionario del estudio Health Behaviour in School-aged Children (HBSC) en su versión española, diseñado para ser autocumplimentado por personas de entre 15 a 18 años. También la National Survey of Sexual Attitudes and Lifestyles (Natsal-4, 2020; es la versión más reciente), que es el mayor estudio consecutivo nacional sobre comportamiento sexual que existe en el mundo (Mirzaei et al., 2016). Asimismo, los 9 ítems sobre conductas sexuales de riesgo del Youth Risk Behavior Surveillance Survey (YRBSS) aplicada cada dos años por el Centers for Disease Control and Prevention de EEUU entre adolescentes. Y, por último, se han tenido en cuenta las reflexiones metodológicas existentes en la bibliografía especializada (Fenton et al., 2001; Mercer, 2010, Cleland et al., 2011) y la revisión reciente sobre instrumentos de Mirzaei et al. (2016).

Se procedió mediante la traducción, adaptación cultural y validación siguiendo criterios comunes señalados en la bibliografía especializada; específicamente: trabajo de doble traducción, una por un miembro del equipo y otra por alguien ajeno a la misma; la retro traducción mediante la simplificación de ítems; y la valoración de un comité de expertos integrado en este caso por tres profesionales del Área de Salud de Tudela - Hospital Reina Sofía. Adicionalmente, se tuvo la oportunidad de discutir sobre las diferentes versiones del cuestionario que se diseñaron, hasta alcanzar la definitiva, con una 
sexóloga, una orientadora educativa y una psicóloga clínica y, posteriormente, con tres profesionales del Observatorio de Salud Comunitaria de Navarra.

La definición del constructo es la salud sexual entre adolescentes y su validez se justifica por el análisis del estado de la cuestión. El propósito de la escala quedaría definido por los siguientes aspectos:

- Población diana: personas de entre 15 y 19 años residentes en Navarra en 2021.

- Dimensiones: conocimientos previos sobre salud sexual, comportamientos sexuales y riesgo (subdivido a su vez en: relaciones sexuales, parejas sexuales, anticonceptivos y atracción e identidad sexual), fuentes de información sobre salud reproductiva (practicadas y preferencias) junto a uso y percepciones de los servicios de salud, y características sociodemográficas.

- Forma de administración: auto cumplimentado a través de ordenador. Es recomendable que cada participante rellene el cuestionario en su casa, es decir, en un lugar privado (Mercer, 2010).

- Formato del cuestionario: versión digital online con acceso cifrado mediante clave.

Debido al elevado número total de las preguntas que plantean las guías consultadas anteriormente citadas se podía comprometer la viabilidad de obtener respuestas, y se procedió a una selección de los ítems, buscando que la comprensión de las preguntas fuese factible para su auto cumplimentación, evitando sesgos tanto de respuesta como en el lenguaje utilizado, procurando que este fuese claro y adaptado a las características de los participantes (a la vez que riguroso).

Finalmente, el cuestionario diseñado fue del tipo multidimensional y quedó integrado por 12 secciones y 83 preguntas en total, incluyendo las específicas para conocer las características sociodemográficas y familiares del encuestado. Se han definido dos escalas, una sobre conocimientos previos (ítems 21-26, 57-68, 70-71, 76-78), que están constituidos por afirmaciones que el participante debe decidir si son verdaderas o falsas, o no responder; y otra sobre conductas de riesgo detectadas $(36,38,39,40,41,46,48$, $49,50,51,53,73,74$ y 75$)$.

Para la validación se aplicarán las siguientes pruebas estadísticas: la consistencia mediante el coeficiente alfa de Cronbach, la estabilidad temporal a través del coeficiente de correlación intraclase $(\mathrm{CCl})$, la concordancia inter observadores calculada mediante porcentaje de acuerdo y el índice Kappa, la validez estimada con el análisis factorial, la matriz multirrasgo-multimétodo, correlaciones de Pearson, cálculos de sensibilidad y especificidad.

Como valoración preliminar, cabe destacar el interés despertado por este proyecto entre el alumnado, de nuestro centro y de otros, visible en que se obtuvieron más de 300 respuestas en los dos primeros días de acceso al cuestionario, así como en la recepción de dudas y sugerencias, en las que se demandan charlas y reuniones. La versión definitiva del cuestionario creemos que va a proporcionar datos cuantificables sobre conocimientos previos y conductas de riesgo, que podrán tratarse estadísticamente para hallar asociaciones entre estos aspectos, así como con las variables sociodemográficas. Pese a su longitud, se cumplimenta en unos 12 minutos. Por todo ello se considera una herramienta adecuada para aplicar periódicamente e incluso en otras poblaciones.

\section{REFERENCIAS BIBLIOGRÁFICAS}

Cleland, J., Ingham, R., y Stone, N. (2011). Asking young people about sexual and reproductive behaviours. Genèva, $\mathrm{CH}$ : Organización Mundial de la Salud.

Fenton, K. A., Mercer, C. H., Johnson, A. M., Byron, C. L., McManus, S., Erens, B., ... Y Wellings, K. (2005). Reported sexually transmitted disease clinic attendance and 
sexually transmitted infections in Britain: prevalence, risk factors, and proportionate population burden. The Journal of infectious diseases, 191(Supplement_1), S127-S138.

Heywood, W., Patrick, K., Smith, A. M., y Pitts, M. K. (2015). Associations between early first sexual intercourse and later sexual and reproductive outcomes: a systematic review of population-based data. Archives of sexual behavior, 44(3), 531-569.

Instituto de la Juventud, INJUVE. (2019). La salud afectivo-sexual de la juventud en España. On-line.

Kahn, N. F., y Halpern, C. T. (2018). Associations between patterns of sexual initiation, sexual partnering, and sexual health outcomes from adolescence to early adulthood. Archives of sexual behavior, 47(6), 1791-1810.

Mercer, C. H. (2010). Measuring sexual behavior and risk. London, UK: Health Protection Agency.

Mirzaei, M., Ahmadi, K., Saadat, S. H., y Ramezani, M. A. (2016). Instruments of high risk sexual behavior assessment: A systematic review. Materia socio-medica, 28(1), 4650 .

Organización Mundial de la Salud, OMS. (2018). Comunicaciones breves relacionadas con la sexualidad. Recomendaciones para un enfoque de salud pública. Washington DC, US: Organización Panamericana de la Salud.

OMS. (2019a). Developing sexual health programmes: a framework for action. Genèva, $\mathrm{CH}$ : Organización Mundial de la Salud.

OMS. (2019b). Directrices para las consideraciones éticas en la planificación y evaluación de estudios de investigación sobre salud sexual y reproductiva en adolescentes. Genèva, $\mathrm{CH}$ : Organización Mundial de la Salud.

Slaymaker, E. (2004). A critique of international indicators of sexual risk behaviour. Sexually transmitted infections, 80(suppl 2), ii13-ii21.

Templeton, M., Lohan, M., Kelly, C., y Lundy, L. (2017). A systematic review and qualitative synthesis of adolescents' views of sexual readiness. Journal of Advanced Nursing, 73(6), 1288-1301.

Vasilenko, S. A., Kugler, K. C., y Rice, C. E. (2016). Timing of first sexual intercourse and young adult health outcomes. Journal of Adolescent Health, 59(3), 291-297.

Young, H., Költő, A., Reis, M., Saewyc, E. M., Moreau, N., Burke, L., ... Y Godeau, E. (2016). Sexual Health questions included in the Health Behaviour in School-aged Children (HBSC) Study: an international methodological pilot investigation. BMC medical research methodology, 16(1), 169. 


\subsection{4. "Deportigualízate", una experiencia educativa en educación secundaria \\ Marina Castro-García (Universidade da Coruña, España); Cristina López-Villar \\ (Universidade da Coruña, España)}

\section{Resumen}

En esta comunicación, se presenta el programa "Deportigualízate", una intervención que tiene como objetivo prevenir las actitudes sexistas en la adolescencia, utilizando la temática deportiva como eje principal. La experiencia se llevó a cabo con alumnado de $4^{\circ}$ curso de educación secundaria obligatoria, dentro de la asignatura de Valores Éticos. Se destinaron 6 sesiones de 50 minutos en el aula, distribuidas en 6 semanas, combinadas con actividades individuales fuera de clase. El programa está basado en los principios de la pedagogía feminista, y se pretende que el alumnado sea el protagonista del aprendizaje, combinando actividades grupales e individuales, y usando diferentes espacios del centro (cafetería, aula, etc.) facilitando así el clima necesario para la reflexión, el debate y el aprendizaje. Durante y tras la intervención, se observan cambios positivos en el alumnado, sobre todo a la hora de identificar situaciones machistas normalizadas.

Palabras clave: coeducación; deporte; adolescencia; pedagogía feminista.

\section{INTRODUCCIÓN Y OBJETIVOS}

A pesar del positivo avance que está habiendo en relación a los estereotipos y creencias sexistas del colectivo adolescente, todavía hay cuestiones que no se han superado (Alemany Arrebola et al., 2019; Martínez-Marín \& Martínez, 2019; Villanueva-Blasco \& Grau-Alberola, 2019). Por ello, la investigación señala que es necesario educar la capacidad de percibir las desigualdades y las violencias de género que operan de forma oculta en el contexto educativo y, más concretamente, en el físico-deportivo (BeltránCarillo \& Devís-Devís, 2019).

Por su parte, el contexto físico-deportivo ofrece un espacio único tanto para examinar la socialización de género (Hannon et al., 2009), como para enfrentarse a ella, permitiendo desarrollar estrategias efectivas a favor de la igualdad (Collison et al., 2017). No obstante, el número de programas que intervienen sobre la problemática de las relaciones de género en este contexto es escaso (Sánchez et al., 2018).

Debido a todo ello, se justifica la necesidad de desarrollar un programa de intervención con el objetivo de prevenir las actitudes sexistas del colectivo adolescente, usando como eje temático el deporte. Más concretamente, se propone que el alumnado mejore sus habilidades a la hora de detectar el sexismo, pueda desarrollar estrategias para enfrentarse a él, y sea capaz de cuestionarse aspectos relacionados con la masculinidad y la feminidad, dentro de la temática deportiva.

\section{CONTEXTUALIZACIÓN}

La intervención se llevó a cabo el curso 2019-2020, en un centro de educación secundaria obligatoria (ESO) de titularidad pública, en Sada (A Coruña). El programa fue enmarcado dentro de la asignatura de Valores Éticos para $4^{\circ}$ curso, participando un total de 8 alumnos y 3 alumnas. Se desarrolló en 6 sesiones de 50' dentro del aula, distribuidas en 6 semanas, combinadas con actividades fuera del aula (cuadernillo de trabajo individual). 
La necesidad de dicha intervención viene dada por los resultados de una investigación previa (curso 2018-2019) financiada con fondos del Pacto de Estado contra la Violencia de Género. Dicho estudio tenía por objetivo conocer las creencias y estereotipos de género en la actividad física y el deporte del alumnado de la ESO de la provincia de A Coruña. Entre las conclusiones, destacaron la falta de rotundidad frente a determinadas afirmaciones sexistas, la persistencia de ideas o actitudes sexistas preconcebidas, y mayor rechazo de los estereotipos de género por parte de las chicas que de los chicos.

Dicha investigación permitió conocer las necesidades específicas del colectivo adolescente en la provincia gallega de A Coruña, así como los aspectos en los que era necesario focalizar la atención.

\section{DISEÑO Y DESARROLLO}

Basándonos en la investigación previamente citada, el diseño del programa fue desarrollado alrededor de cuatro grandes bloques temáticos:

- La problemática de las desigualdades.

- La construcción social del género.

- La construcción social del género en el deporte.

- El alumnado como agente de cambio.

Toda la intervención estuvo basada en los principios de la pedagogía feminista: creación de espacios seguros, desarrollo de relaciones no jerárquicas que favorecen la escucha y empoderamiento del alumnado, promoción de escenarios de análisis crítico, conciencia sobre la interseccionalidad y tener como objetivo la transformación social (Crabtree et al., 2009).

A partir de dichos principios, se procuró desarrollar diferentes tipos de actividades: discursivas, analíticas, reflexivas y motrices. Las dinámicas de trabajo variaron en función del objetivo específico de la actividad, pudiendo ser individuales, en grupo pequeño, o en grupo grande (con la totalidad de la clase).

Asimismo, se emplearon diferentes recursos de enseñanza-aprendizaje como el visionado de imágenes o vídeos, el análisis de periódicos, el debate, un cuadernillo de uso individual, el uso de un perfil de Instagram para difundir contenidos, e incluso la creación de materiales para el centro educativo.

\section{EVALUACIÓN, CONCLUSIONES Y PROPUESTAS DE MEJORA}

Previo a la intervención, se pidió al alumnado que realizara una reflexión escrita sobre la igualdad en la sociedad, en el deporte y en su instituto. Tras la intervención, se pidió que hiciera la misma actividad, para poder comprobar si hubo o no cambios en sus respuestas.

Así mismo, al finalizar la intervención, se pidió tanto al alumnado como al profesor-tutor del grupo (el cual estuvo presente en todas las sesiones), que realizaran una evaluación sobre la propuesta.

Al comparar las reflexiones escritas, vimos una diferencia notable en lo que a especificidad y (des)normalización se refiere. Previo a la intervención, la mayoría de estudiantes identificaba cuestiones como la brecha salarial, pero eran incapaces de detectar sexismo en su realidad más cercana (por ejemplo, en el instituto). Tras la intervención, detectamos que el alumnado había tomado conciencia sobre sus propios estereotipos y violencias normalizadas en su día a día. 
Además, gracias a las evaluaciones, verificamos la idoneidad de la propuesta, destacando el dinamismo de las actividades, alejadas de "charlas chapa que poco escuchamos" (palabras textuales de una alumna). Lo que valoraron de forma más positiva fue el hecho de tener voz en las sesiones, las interacciones creadas y la diversidad de recursos empleados. Lo que valoraron de forma más negativa fue la escasez de tiempo y el hecho de tener que trabajar de forma escrita en el cuadernillo.

Otro aspecto que gustó mucho entre el alumnado y que consideramos que fue positivo, fue la participación del grupo en la creación de pósteres sobre temas libres (como la cosificación de las mujeres deportistas en Instagram, o la invisibilización de ciertos colectivos por parte de la prensa deportiva) que, posteriormente, fueron colgados en los pasillos del centro. De esta manera, se sintieron partícipes y agentes de cambio para el resto de la comunidad. Con la finalidad de mejorar la propuesta, sería interesante poder llegar a más alumnado, de sitios diferentes y con características distintas, y así poder comparar y contrastar las distintas realidades. Asimismo, concordando con lo expresado por el estudiantado, se detecta la duración de la propuesta como una limitación que no permite satisfacer todas las necesidades formativas e intereses del grupo.

\section{REFERENCIAS BIBLIOGRÁFICAS}

Alemany Arrebola, I., Aguilar García, N., Granda Ortells, L., \& Granda Vera, J. (2019). Estereotipos de género y práctica de actividad física. Movimento (ESEFID/UFRGS), 25. https://doi.org/10.22456/1982-8918.93460

Beltrán-Carillo, V. J., \& Devís-Devís, J. (2019). El pensamiento del alumnado inactivo sobre sus experiencias negativas en educación física: los discursos del rendimiento, salutismo y masculinidad hegemónica. RICYDE: Revista Internacional de Ciencias Del Deporte, 15(55), 20-34. https://doi.org/10.5232/ricyde

Collison, H., Darnell, S., Giulianotti, R., \& Howe, P. D. (2017). The inclusion conundrum: A critical account of youth and gender issues within and beyond sport for development and peace interventions. Social Inclusion, 5(2), 223. https://doi.org/10.17645/si.v5i2.888

Crabtree, R., Sapp, D., \& Licona, A. (Eds.). (2009). Feminist Pedagogy: Looking Back to Move Forward. The Johns Hopkins University Press.

Hannon, J., Soohoo, S., Reel, J., \& Ratliffe, T. (2009). Gender Stereotyping and the Influence of Race in Sport Among Adolescents. Research Quarterly for Exercise and Sport, 80(3), 676-684. https://doi.org/10.1080/02701367.2009.10599608

Martínez-Marín, M. D., \& Martínez, C. (2019). Negative and Positive Attributes of Gender Stereotypes and Gender Self-Attributions: A Study with Spanish Adolescents. Child Indicators Research, 12(3), 1043-1063. https://doi.org/10.1007/s12187-018-9569-9

Sánchez, N., Martos, D., Soler, S., \& Flintoff, A. (2018). Challenging gender relations in $\mathrm{PE}$ through cooperative learning and critical reflection. Sport, Education and Society, 23(8), 812-823. https://doi.org/10.1080/13573322.2018.1487836

Villanueva-Blasco, V. J., \& Grau-Alberola, E. (2019). Gender and age differences in the internalization of gender stereotypes in early and mid adolescence. Electronic Journal of Research in Educational Psychology, 17(47), 107-128. https://doi.org/10.25115/ejrep.v17i47.2184 


\author{
2.2.5. Juego coeducativo "Cuidar es otra historia" \\ Teresa Pineda Sánchez-Garrido, ONGD InteRed (España)
}

\title{
Resumen
}

Ante la cada vez mayor preocupación por parte de la sociedad por la falta de corresponsabilidad en los cuidados, y comprobando cómo esta temática resulta eficaz para la sensibilización sobre la desigualdad de género y la sostenibilidad de la vida, InteRed se lanzó a realizar el primer juego basado en la Pedagogía de los Cuidados. Es un juego ideado para los centros educativos, aunque puede utilizarse en otros espacios y grupos grandes. Contiene una guía didáctica, 30 cartas y un Anexo que vincula cada carta a un cuento.

Gracias a su metodología lúdico teatral que permite diferentes formas de expresión artística, a la par que fomenta el aprendizaje vivencial, está permitiendo una alta motivación en las personas que lo han utilizado. Un año después del lanzamiento del juego, podemos afirmar que está fomentando la conciencia personal y ciudadana sobre la necesidad de visibilizar, valorizar y redistribuir los cuidados como eje central de nuestras vidas y sociedades.

Palabras clave: Cuidados 1; Coeducación 2; Corresponsabilidad 3, Innovación 4; Metodología lúdico-teatral 5.

\section{INTRODUCCIÓN Y OBJETIVOS}

Tanto a nivel mundial como en España, las mujeres sufrimos una mayor precariedad laboral, cobramos menos y, especialmente en lo que respecta a los trabajos de cuidados, una preocupante cantidad se encuentra en la economía no formal. Según ONU Mujeres, "en todo el mundo, las mujeres representan el $70 \%$ de quienes trabajan en los sectores sanitarios y sociales, y hacen el triple del trabajo de cuidados no remunerado en comparación con los hombres" (2020).

Frente a ello, InteRed apuesta por un modelo de desarrollo que ponga la vida y su sostenibilidad en el centro y en el que se asuman colectivamente los cuidados. Para ello, es imprescindible que los gobiernos reconozcan los "cuidados" como pilar fundamental del estado de bienestar y, por tanto, desarrollen e implementen políticas públicas que pongan la vida en el centro. Por su lado, los hombres deben comprometerse con los trabajos de los cuidados y dejar de delegarlos en manos de las mujeres.

Desde el año 2012, InteRed promueve procesos de construcción de ciudadanía basados en el derecho universal al cuidado, a través de la campaña Actúa con Cuidados. Transforma la realidad y de iniciativas que han promovido la Pedagogía de los Cuidados en el ámbito formal y no formal, con acciones de sensibilización y movilización juvenil, formación docente, empoderamiento de mujeres, etc.

El eje principal ha sido la Coeducación, fundamento sobre el que se debe sostener la Pedagogía de los Cuidados, ya que la desigualdad en los cuidados proviene del sistema patriarcal, y es necesaria una educación que promueva la equidad y la igualdad de género en este ámbito. Para fomentarlo, desde InteRed hemos generado un recurso coeducativo: El juego "Cuidar es Otra Historia", que tiene como objetivo fortalecer 
la conciencia personal y ciudadana sobre los cuidados como eje central de nuestras vidas y sociedades, cuestionando el modelo capitalista patriarcal que genera injusticias y desigualdad de género por la falta de corresponsabilidad en los cuidados.

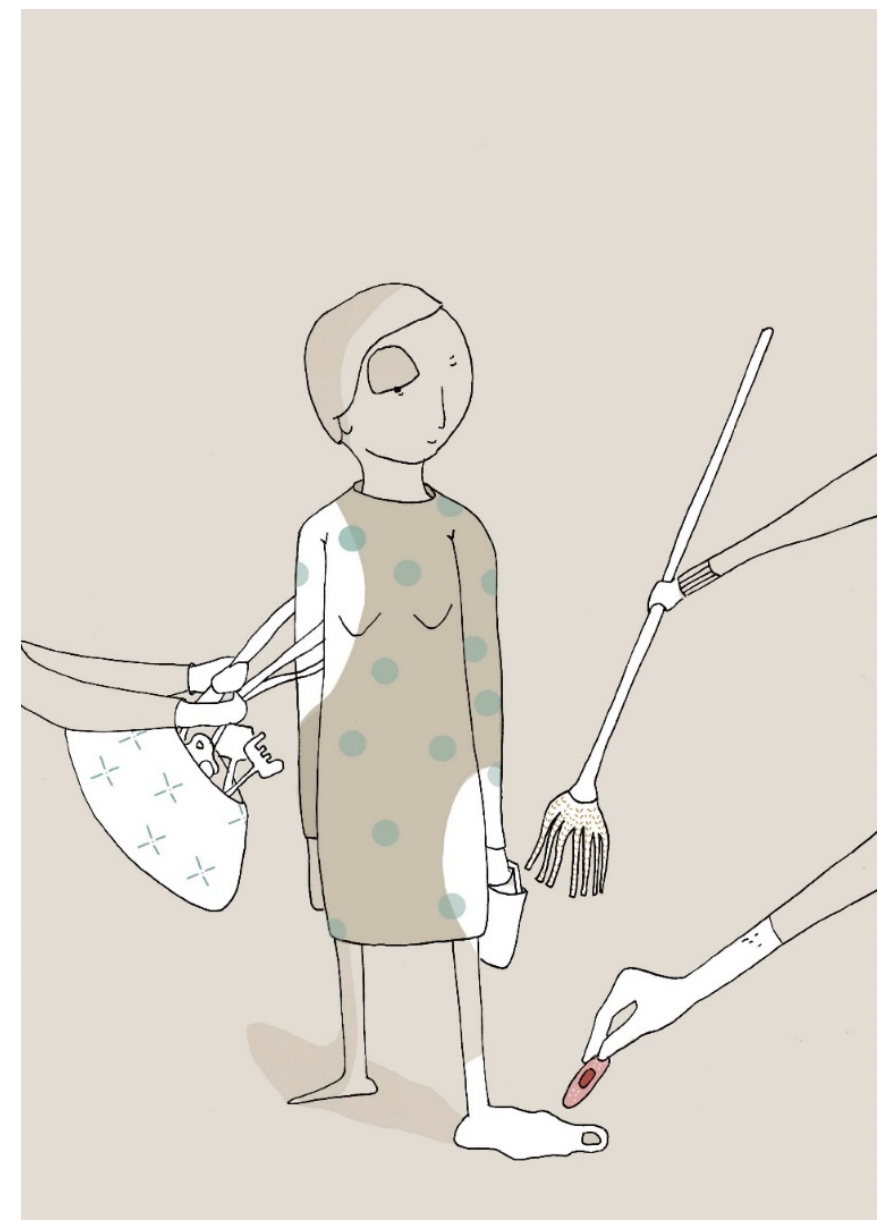

Carta del juego Cuidar es Otra Historia.

\section{CONTEXTUALIZACIÓN}

Frente a la desigualdad de género que en nuestra sociedad se aprende, entre otros, a través de la injusta y desigual distribución de los cuidados entre mujeres y hombres, y, ante la falta de corresponsabilidad de nuestros gobiernos, precisamos de un nuevo modelo social que erradique esta explotación de las mujeres y que priorice los cuidados. Este cambio debe afianzarse a través de un sistema educativo que integre la Pedagogía de los Cuidados con perspectiva de género.

En definitiva, se trata de cuestionar el sistema hegemónico que tiene en su eje el mercado en vez de la vida, y que sigue profundizando en la feminización de la pobreza a través de la división sexual del trabajo.

Para ello, este juego plantea la Pedagogía de los cuidados como modelo coeducativo en el que estas acciones sean prioritarias, $y$, por tanto, la vida y su sostenibilidad están en el centro de todos los contenidos y las acciones educativas. Este modelo incide en la responsabilidad colectiva ante la desigualdad que han sufrido las mujeres por haber sido socializadas, presionadas y obligadas a realizar tareas de cuidados que se asumen como naturales suyas y que deben ser compartidas dentro de las familias y entre éstas, estado y mercado, garantizando el 
derecho a cuidar y ser cuidado de todas las personas, al margen de situación económica.

Gracias a la anteriormente mencionada Campaña Actúa con Cuidados. Transforma la Realidad, hemos comprobado cómo la temática de los cuidados resulta una estupenda puerta de entrada para la toma de conciencia sobre la desigualdad de género, especialmente entre adolescentes y jóvenes. El hecho de que este injusto reparto se pueda ver en casi todos los hogares, facilita la sensibilización y la comprensión del modelo en el que vivimos, y sobre la fuerza que tiene la socialización diferencial en base al género en nuestra identidad y en nuestras vidas. Así lo muestran los resultados de una investigación sobre los efectos de esta Campaña: "podemos afirmar que la reflexión y el análisis de los Cuidados ha dado en la tecla de las preocupaciones y necesidades de la gente, de las mujeres y los hombres desde lo cotidiano, poniendo nombre a emociones y vivencias, necesidades prácticas e intereses estratégicos" (Fundación InteRed, 2019).

Esta afirmación viene reforzada por una creciente preocupación en el imaginario social por la desigualdad en los cuidados, como puede leerse de la histórica Huelga de los Cuidados realizada a nivel internacional el Día de las Mujeres de 2018, día que ha resultado un hito histórico por la alta participación social, y que se ha repetido en los años posteriores.

Ante esta realidad, desde InteRed se decidió apostar por generar un recurso coeducativo basado en la Pedagogía de los Cuidados, pues durante nuestra trayectoria en esta temática no encontramos ningún juego basado en esta Pedagogía.

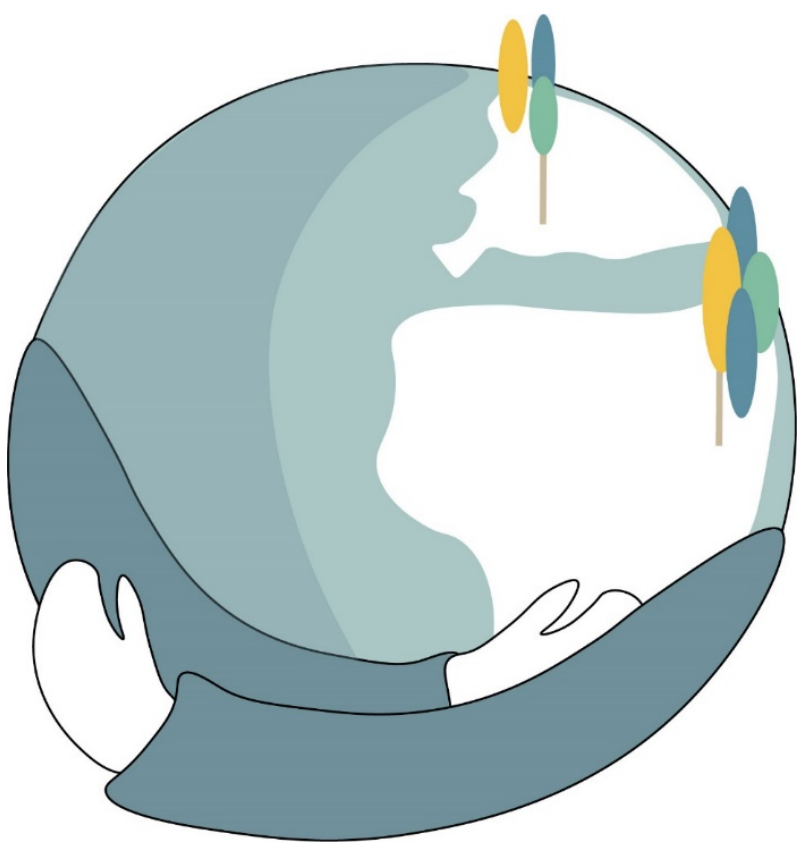

Ilustración de la caja del juego Cuidar es Otra Historia

Para la creación de este recurso, profesorado de varios centros educativo, las ONGDs Mujeres en Zona de Conflicto y ASPA, además de la creadora del juego y voluntariado de InteRed, han colaborado para garantizar la viabilidad y adecuación de este juego. Se validó mediante talleres con 300 estudiantes, donde hemos podido comprobar la fuerte necesidad que estas chicas y estos chicos tienen de poder hablar de las problemáticas personales y sociales que les afectan, y cómo la metodología del juego lo facilita. 


\section{DISEÑO Y DESARROLLO}

La experiencia educativa a través del juego "Cuidar es otra Historia" se ha desarrollado en diferentes centros educativos y otros espacios de educación no formal. Así, se ha mostrado cómo esta práctica lúdica, formalizada y guiada, con un sentido también creativo y pedagógico que pone los cuidados en el centro de la vida y de la sociedad, genera un aprendizaje vivencial con perspectiva de género y de cuidados en las personas que han participado. Para ello, contamos con la puesta en práctica del juego durante el año 2020 y 2021 en diferentes Comunidades Autónomas como Andalucía, Galicia, Cataluña, Comunidad Valenciana, tanto en centros educativos de Educación Primaria, Secundaria, Ciclos Formativos, Universidades y espacios no formales.

También, para la difusión del juego, se ha formado a profesorado, educadoras y educadoras de España y de otros países, como Guatemala, así como a instituciones públicas (personal de ayuntamientos, mancomunidades, Centros de Formación de Profesorado y Equipos de Orientación Educativa) y a agentes sociales de más de 10 ONGDs y asociaciones.

La adaptación metodológica del recurso a las diferentes etapas educativas ha facilitado el éxito del mismo. El juego cuenta con dinámicas de diferente índole que generan un aprendizaje vivencial con perspectiva de género y para la ciudadanía global, basándose principalmente en metodologías lúdico teatrales, artísticas y cuentoterapia.

Comienza con un juego de la silla en el que cada participante nombra un cuidado, para familiarizarse con la temática. Después, gracias al juego simbólico que permiten las 30 cartas con ilustraciones sobre el duelo, la sobrecarga de las mujeres ante la falta de corresponsabilidad y otras muchas temáticas, se permite la conexión emocional del grupo con los cuidados. Esto, comienza realizándose mediante una dinámica de adivinanza de las cartas de las demás personas, lo cual facilita comprobar las múltiples interpretaciones que podemos hacer de una carta, según nuestras vivencias.

En este momento del desarrollo del juego, el grupo pasa a trabajar a nivel corporal todo lo verbalizado con las cartas, realizando estatuas que imitan las emociones y situaciones que les han sugerido las cartas. Para continuar trabajando a través de la expresión corporal, se incluye la realización de escenas mediante rol-playing.

Otra dinámica clave de este recurso se basa en que cada carta está referida a un cuento tradicional sobre los cuidados. La carta que cada grupo ha interpretado en escenas, pasa a tener otro significado, y por tanto, a facilitar otros aprendizajes mediante preguntas que se incluyen en el material.

Por último, el grupo realiza una reflexión mediante preguntas generadoras que permiten que los aprendizajes vivenciales alcancen una mirada de ciudadanía global, indagando en los sistemas que generan las desigualdades de género trabajadas, así como en las posibles alternativas.

El juego, cuenta con una guía didáctica dividida por grupos de edad, 30 cartas y un anexo que vincula cada carta con un cuento. Durante la pandemia, InteRed realizó una nueva guía didáctica que facilitaba el aprendizaje sobre los cuidados según las experiencias vividas en este momento. Todo ello está libre para su uso y descarga en el siguiente enlace: https://www.intered.org/es/recursos/cuidar-es-otra-historia

Contamos con un reportaje sobre esta experiencia educativa en el Programa Solidarios de Canal Sur Televisión: 


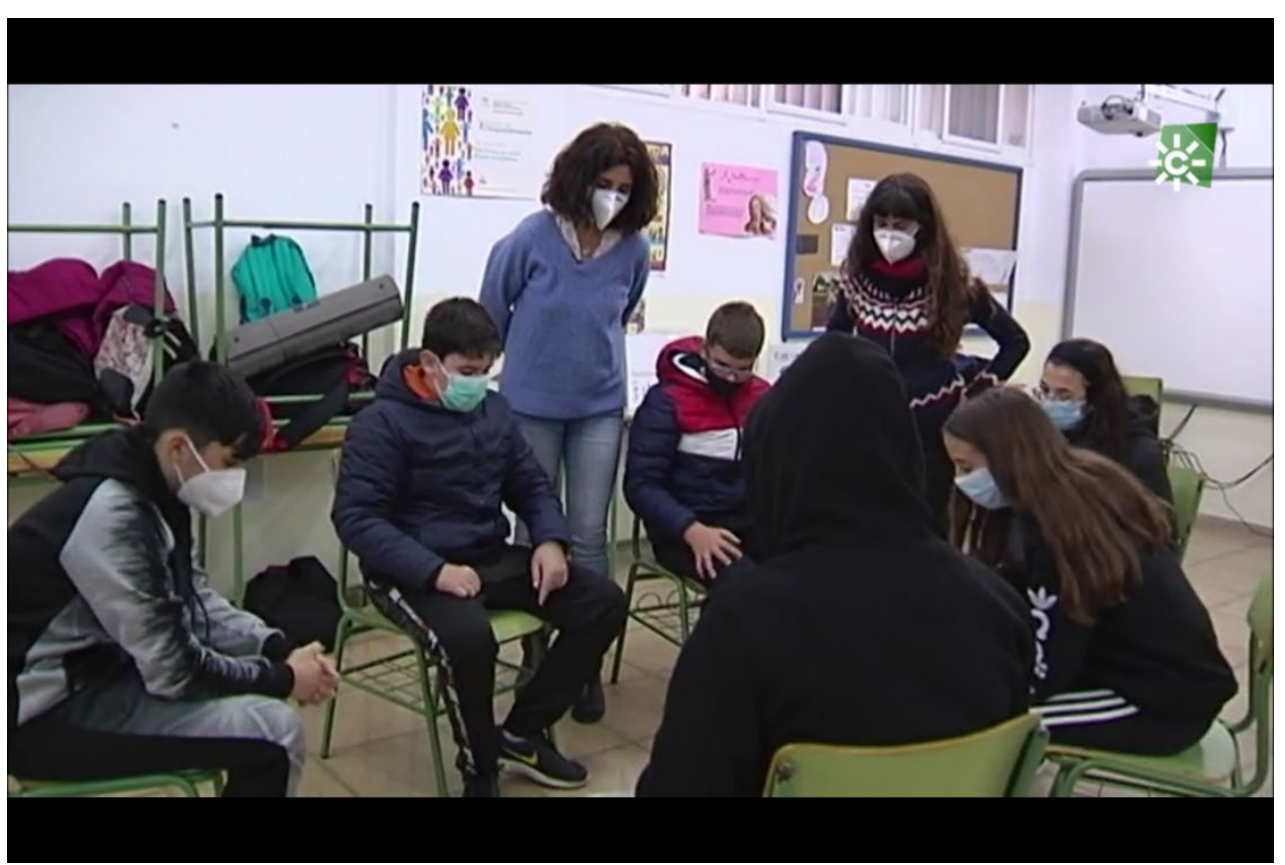

Fotograma del reportaje del juego Cuidar es Otra Historia en el Programa Solidarios de Canal Sur Televisión.

\section{EVALUACIÓN, CONCLUSIONES Y PROPUESTAS DE MEJORA}

Para el proceso creativo, contamos con un Laboratorio de Ideas en el que participaron profesorado, voluntariado de InteRed y agentes sociales que aseguraron la adaptación del recurso a las necesidades del alumnado. Durante ese proceso, se crearon talleres de validación con alumnado, que fueron sistematizados y sus resultados se socializaron en dicho Laboratorio. Esta primera evaluación permitió confirmar que el juego cumplía con los objetivos planteados, ya que fortalecía la conciencia personal y ciudadana sobre los cuidados como eje central de nuestras vidas y sociedades, al mismo tiempo que generaba un cuestionamiento del actual sistema que genera injusticias y desigualdades de género por la falta de corresponsabilidad en los cuidados.

Las siguientes puestas en prácticas del juego fueron evaluadas por el profesorado y personal de InteRed, que concluyó que el juego facilitaba la educación emocional, que los contenidos sobre cuidados, género y ciudadanía global estaban funcionando, así como se valoró positivamente la metodología utilizada.

Este juego se ha mostrado exitoso con respecto a su capacidad transformadora en niños, niñas, adolescentes y jóvenes, entre quienes fomenta una toma de conciencia de género con mirada de ciudadanía global.

Durante este periodo en el que no se han podido llevar a cabo todas las dinámicas del juego por no ser compatibles con las medidas de seguridad reguladas por la pandemia, hemos utilizado parte de las dinámicas y hemos adaptado otras. Sin embargo, aún no disponemos de una versión digitalizada del juego, por lo que resaltamos este aspecto como punto a mejorar. Esta digitalización se está realizando y estará lista en septiembre. 


\section{REFERENCIAS BIBLIOGRÁFICAS}

Almeda, C., de Arriba C., Ortega, M. (2019). Recogida de conclusiones de la investigación sobre el impacto de la campaña "Actúa con Cuidados. Transforma la Realidad" en Andalucía. INTERED https://www.intered.org/sites/default/files/intered_conclusiones_campana_andal ucia_cuidados.pdf

ONU Mujeres (19 de marzo de 2020). Atender las necesidades y el liderazgo de las mujeres fortalecerá la respuesta ante el COVID-19. https://www.unwomen.org/es/news/stories/2020/3/news-womens-needs-andleadership-in-covid-19-response

Pineda, T. (2020). Anexo Cada Carta tiene su historia. INTERED https://www.intered.org/sites/default/files/anexo_cada_carta_tiene_su_historia.p df

Pineda, T. (2020). Guía Didáctica Cuidar es Otra Historia. INTERED https://www.intered.org/sites/default/files/guia_didactica_cuidar_es_otra_histori a.pdf

Pineda, T. (2020). Guía didáctica Las emociones en tiempos de pandemia. Cuidar es Otra Historia. INTERED https://www.intered.org/es/recursos/cuidar-es-otrahistoria 


\title{
3. EDUCACIÓN PARA LA IGUALDAD EN LA EDUCACIÓN TERCIARIA / UNIVERSITARIA.
}

\subsection{INVESTIGACIONES}

\author{
3.1.1. Las trayectorias profesionales de las mujeres científicas: \\ diseño y validación de un cuestionario \\ María Azcona Sangüesa (IES Valle del Ebro, Tudela, España).
}

\begin{abstract}
Resumen
El objetivo ha sido diseñar un cuestionario ad hoc, inédito en castellano, para evaluar la trayectoria profesional en el ámbito científico. Se siguió un proceso de traducción, adaptación cultural y validación de dos instrumentos de referencia del National Research Council de los EEUU, trabajando con una muestra formada por 100 participantes de ambos sexos del área geográfica próxima. El instrumento diseñado consta de 40 ítems y es de tipo multidimensional. Sus propiedades psicométricas fueron óptimas (alfa de Cronbach $\approx 0,8, \quad \mathrm{CCl}>0,7$ y $\mathrm{KMO}>0,5)$ y permitió obtener algunas conclusiones relevantes: las mujeres invierten menos tiempo en titular; estudiar ciencias asegura una rápida inserción en el mercado laboral, y que al pensar en su trabajo ideal las mujeres valoran mayormente aspectos que les proporcionen estabilidad y facilidad en la conciliación familiar.
\end{abstract}

Palabras clave: trayectoria profesional; ciencia; rol social; rol de género; mujeres.

\section{INTRODUCCIÓN Y OBJETIVOS}

Los estereotipos culturales y la escasa conciliación familiar, entre otros, hacen que el sesgo de género siga vigente hoy en día en el ámbito profesional de las ciencias. No basta con conocer este sesgo, pormenorizarlo en cifras. Es necesario ir más allá e investigar por qué se mantienen estas brechas que obstaculizan las trayectorias profesionales de las mujeres, concretamente en la ciencia.

Se han realizado varios estudios, principalmente en EEUU, sobre este tema, pero no así en España, desde esta óptica. El enfoque mayoritario es el de carreras profesionales (Xie y Shauman, 2003) o «life course» (Castaño Collado y Webster, 2011), que permite profundizar en el conocimiento de las normas, valores y estándares implícitos en la ciencia, los efectos derivados de la organización del trabajo y cómo estos factores difieren según se trate de hombres y mujeres (Bailyn, 2003).

Cada dos años el Ministerio de Ciencia publica el informe «Científicas en Cifras», siendo el último disponible el de 2017. El dato más llamativo fue que la proporción de mujeres en el conjunto del personal investigador en España (a jornada completa) no ha mejorado en los últimos 10 años, manteniéndose en el $39 \%$ en 2017. Igualmente, destaca que el $79 \%$ de las cátedras en universidades e instituciones públicas y privadas están ocupadas por hombres; por contra, la proporción de mujeres siempre es mayor en todas las etapas de alumnado hasta la obtención del título de doctor, incluido. La brecha se amplía en los órganos de gobierno, con un $92 \%$ de rectores frente al $8 \%$ de rectoras. 
En el último informe sobre la situación de la mujer en el CSIC la proporción de mujeres en la categoría de Profesores de Investigación era un 26,1\%; mientras que el índice del techo de cristal general mantiene la tendencia descendente de los últimos años situándose en un valor de 1,37 para 2018, por debajo de los correspondientes valores medios europeo y español. Es preocupante, como reconoce la propia presidenta del CSIC en el preámbulo, Rosa Menéndez, la forma de tijeras que adopta la gráfica de evolución en el personal investigador.

El principal objetivo de esta investigación consiste en diseñar un instrumento adecuado para conocer la trayectoria profesional de las mujeres científicas, basado en el enfoque «life course» y que permita evaluar los factores que influyen en su desarrollo.

\section{METODOLOGÍA}

Existen diversos cuestionarios validados para reunir información sobre aspectos muy concretos, como el Career Aspiration Scale (CAS), diseñado por O'Brien et al. (1996) (citado en Donoso et al., 2011), que consta de diez ítems que miden la intención de promocionar y liderar en el campo profesional propio; o la Life Role Salience Scales (Amatea et al., 1986), para analizar roles familiares y profesionales; también Donoso et al. (2011) desarrollaron dos escalas propias llamadas Percepciones de Rol de Género en el Trabajo (PRGT) y Cuestionario de Barreras Percibidas (CBP). Los dos cuestionarios de referencia proceden de EEUU, y son la Survey of Doctorate Recipients, SDR y la Survey of Earned Doctorates, SED; ambos elaborados por la National Research Council. Son estos los que se han utilizado para diseñar nuestro cuestionario.

El proceso de traducción, adaptación cultural y validación (TACV) de un cuestionario no dispone de criterios sistemáticos que normalicen los pasos necesarios, aunque existen revisiones bibliográficas que subrayan rasgos en común y se han tenido en cuenta (Ramada-Rodilla et al., 2013). En la traducción y retro-traducción trabajaron dos profesionales independientemente, una filóloga y un profesor que formaba parte del equipo de investigación (IES Valle del Ebro). Se formó un comité de expertos integrado por tres especialistas procedentes del ámbito sanitario (Hospital Reina Sofía de Tudela) y de los estudios de género (Liga Internacional de Mujeres por la Paz y la Libertad, WILPF).

Para seleccionar a los participantes se siguieron estos criterios de inclusión:

1) Personas mayores de edad.

2) Con estudios universitarios. Áreas de conocimiento observadas: Matemáticas, Física, Ingenierías, Ciencias de la Vida.

3) Realizados en centros españoles o extranjeros.

4) Que trabajen actualmente o lo hayan hecho en el entorno geográfico de la Ribera tudelana de Navarra.

5) Que hayan dado su consentimiento informado.

La muestra quedó finalmente conformada por 100 participantes, con una distribución por sexo de 27 hombres (28,7\%), 67 mujeres $(71,3 \%)$ y 6 sin especificar. Su edad media es de $41,26( \pm 1,973 ; D T=9,671)$. Mayoritariamente (94 participantes) tienen nacionalidad española $(97,9 \%)$, y únicamente 2 personas son extranjeros comunitarios (2,1\%). El $57,3 \%$ de ellos están casados (55 participantes), frente a un 35,4\% que son solteros (34), un 5,2\% que están separados o divorciados (5), y ninguno se encuentra viudo. Un $9,4 \%$ de la muestra tiene a algún familiar enfermo a su cargo (9 respuestas). La media de hijos es $1,15( \pm 0,21 ; D T=1)$. Respecto a la formación académica, el grado ha sido la respuesta mayoritaria con un $46,4 \%$, seguido por la licenciatura, un $22,7 \%$, y, finalmente, por el máster, $13,4 \%$. La mayoría de estos estudios fueron realizados en 
centros públicos nacionales $(69,1 \%)$. Las áreas de conocimiento a las que pertenecían estos estudios se distribuyeron de tal manera: Ciencias de la Vida un 75,0\%, Ingenierías un $17,7 \%$ y Matemáticas un $6,3 \%$.

En el diseño del cuestionario la definición del constructo (aspecto a medir) ha quedado enunciada en el objeto de estudio de este proyecto y consiste en un análisis de la trayectoria profesional en el ámbito de las ciencias. La validez del constructo se justifica por el análisis del estado de la cuestión. El propósito de la escala quedaría definido por los siguientes aspectos:

- Población diana: personas con estudios universitarios (o superiores), entre 25 y 69 años, en el ámbito de las ciencias e ingenierías.

- Dimensiones: se han diseñado mediante el estudio de la bibliografía y se basan en los factores que son estudiados en el análisis de las trayectorias profesionales.

- Forma de administración: auto cumplimentado y a través de entrevista personal.

- Formato del cuestionario: en papel y versión digital online con acceso cifrado mediante clave.

Para la composición de los ítems se partió de los que conforman las dos encuestas citadas (SDR y SED). Debido a la extensión de cada una, 80 y 59 preguntas respectivamente se seleccionaron algunos de ellos. Los criterios considerados para la selección de ítems de los dos cuestionarios de referencia fueron (Martín Arribas, 2004): adaptación al objeto de estudio planteado, intuición de razonabilidad, validez del constructo, obtención de datos generados por los participantes, sensibilidad a circunstancias previstas, comprensión de las respuestas, redacción de las preguntas, ordenación de los ítems.

Las pruebas estadísticas utilizadas para evaluar las propiedades métricas de las dos subescalas (ítem $\mathrm{C} 11$ y C12) han sido: la consistencia mediante el coeficiente alfa de Cronbach, la estabilidad temporal a través del coeficiente de correlación intraclase $(\mathrm{CCl})$, la validez estimada con el análisis factorial, la matriz multirrasgo-multimétodo, correlaciones de Pearson, cálculos de sensibilidad y especificidad. Se han aplicado en fase pre y post test.

Para todas las pruebas se consideraron diferencias significativas aquellas con un valor $p$ inferior a 0,05 y los datos fueron procesados mediante la utilización del programa IBM SPSS Statistics en su versión 25.0.

\section{RESULTADOS Y DISCUSIÓN}

Finalmente, el cuestionario diseñado fue del tipo multidimensional y quedó integrado por cuatro apartados y por 33 preguntas en total, más 7 adicionales para conocer aspectos sobre circunstancias específicas del encuestado.

La pregunta A4 genera problemas al responder por la necesidad de disponer de la lista de códigos. Además, crea una incompatibilidad: al referirse a la respuesta dada en A1 ( Estudios más altos...») y ser una de las posibles respuestas "Doctorado», quien se encuentre en esta situación no podrá responder en A4. La pregunta C13 produce respuestas equívocas: algunos responden de manera numérica y otros, escrita.

Respecto al análisis de fiabilidad y de validez, se obtuvieron unos resultados pre y post test en alfa de Cronbach cercanos a 0,8 ; por lo que el instrumento no requiere reestructurar. El índice de concordancia se considera bueno cuando el valor promedio es superior a 0,7 y excelente si es superior a 0,9. Se ha aplicado un modelo de dos factores con efectos mixtos, el más utilizado. Seguidamente se aplicaron las pruebas de medida de adecuación muestral KMO (debe ser 0,5 o superior) y la prueba de 
esfericidad de Bartlett $(p<0,05)$ para el ítem C11 y el C12 separada y conjuntamente. La siguiente tabla recoge el resumen de estas pruebas.

Tabla 1. Análisis de fiabilidad y validez de los ítems C11 y C12 del cuestionario.

\begin{tabular}{|c|c|c|c|c|}
\hline \multicolumn{2}{|l|}{ Criterio } & \multirow{2}{*}{$\begin{array}{c}\text { Consistencia interna } \\
\text { Alfa de Cronbach }\end{array}$} & \multirow{2}{*}{$\begin{array}{l}\text { Validez del constructo } \\
\text { Prueba KMO y Bartlett }\end{array}$} & \multirow{2}{*}{$\begin{array}{c}\text { Índice de concordancia } \\
\text { Coeficiente de correlación } \\
\text { interclase }\end{array}$} \\
\hline Prueba & & & & \\
\hline $\begin{array}{l}\text { Dimensión } \\
\text { (constructo) }\end{array}$ & $\mathrm{N} .^{0}$ preguntas & & & \\
\hline C11 & 9 & 0,757 & $0,750(p=0,000)$ & 0,757 \\
\hline C12 & 9 & 0,643 & $0,727(p=0,000)$ & 0,643 \\
\hline C11 y C12 & 18 & 0,760 & $0,665(p=0,000)$ & 0,760 \\
\hline
\end{tabular}

Fuente. Elaboración propia.

Se ha tenido además en cuenta el índice de homogeneidad corregido (debe dar un resultado positivo y se considera mejor calidad cuando los resultados se acercan a 1). En la comunalidad de cada pregunta todas superaron el valor de extracción de referencia 0,4 .

Tabla 2. Índices de concordancia y comunalidades de los ítems C11 y C12.

\begin{tabular}{lccc}
\hline Ítem & $\begin{array}{c}\text { Correlación total de } \\
\text { elementos corregida }\end{array}$ & $\begin{array}{c}\text { Alfa de Cronbach si el } \\
\text { elemento se ha suprimido }\end{array}$ & $\begin{array}{c}\text { Comunalidades } \\
\text { (extracción) }\end{array}$ \\
\hline C11.Salario &, 189 &, 779 &, 769 \\
\hline C11.Beneficios &, 556 &, 715 &, 637 \\
\hline C11.Seguridad laboral &, 419 &, 739 &, 584 \\
\hline C11.Localización &, 274 &, 760 &, 600 \\
\hline C11.Ascender &, 503 &, 725 &, 753 \\
\hline C11.Reto intelectual &, 524 &, 725 &, 663 \\
\hline C11.Responsabilidad &, 596 &, 711 &, 696 \\
\hline C11.Independencia &, 621 &, 711 &, 507 \\
\hline C11.Contribución &, 416 &, 742 &, 754 \\
\hline C12.Salario &,- 214 &, 792 &, 749 \\
\hline C12.Beneficios &, 165 &, 646 &, 673 \\
\hline C12.Seguridad laboral &, 224 &, 635 &, 671 \\
\hline C12.Localización &, 379 &, 607 &, 529 \\
\hline C12.Ascender &, 634 &, 522 &, 540 \\
\hline C12.Reto intelectual &, 552 &, 568 &, 683 \\
\hline C12.Responsabilidad &, 608 &, 553 &, 638 \\
\hline C12.Independencia &, 543 &, 579 &, 627 \\
\hline C12.Contribución &, 539 &, 556 &, 640 \\
\hline Fuente. Elaborato & & \\
\hline
\end{tabular}

Fuente. Elaboración propia.

Notas.

a. Método de extracción: análisis de componentes principales. 
Las pruebas de $\mathrm{KMO}$ y Bartlett se aplicaron a los ítems medidos en escala de intervalo (A5, A6, B1, B3, B5, B6, C3, C7) y los resultados fueron 0,795 $(p=0,000)$ en el análisis pre-test, y de 0,811 ( $p=0,000)$ en el post-test.

El cuestionario permite obtener datos sobre variables relacionadas con la trayectoria profesional y aplicar estadísticos deductivos para evaluar la asociación entre las mismas. Se halló significación estadística entre hombres y mujeres de la muestra respecto a los estudios más elevados realizados y el área de conocimiento al que pertenecen. También respecto al tiempo invertido según el sexo utilizando una prueba $\mathrm{U}$ de Mann-Whitney para muestras independientes: los hombres invierten una media de 7 años $(D T=4,169)$ mientras que las mujeres dedican 5,18 años $(D T=2,876)$.

En la subescala del ítem C11 sobre el trabajo ideal se obtuvo significación estadística en la importancia concedida a algunos aspectos según sexo. Las mujeres dan menos importancia al salario: lo consideran «muy» o "bastante importante», únicamente el $8,95 \%$ de las mujeres frente a un $33,33 \%$ de los hombres. También en los «beneficios» (pensión, seguro sanitario, vacaciones pagadas, primas o bonos), donde son las mujeres quienes conceden una mayor importancia con un $70,15 \%$ frente a los varones, que otorgan un $55,56 \%$. Estos resultados pudieron corroborarse mediante el cálculo de Odds Ratio y del test de Wald.

No hubo diferencias significativas según sexo respecto al tiempo transcurrido hasta acceder al primer empleo. Pero sí con el área de conocimiento, ya que se calculó que tiene un peso o influencia del $26 \%$ (coeficiente estandarizado es $-0,262 ; D T=0,114$; $\pm 0,259$ ) en los años transcurridos hasta el primer empleo (adicionalmente: ANOVA $=5,317$ y $p=0,011$ ).

Referente a la situación laboral, ambos sexos utilizan mayoritariamente el contrato a tiempo completo, aunque son las féminas las que hacen un uso mayor del trabajo a tiempo parcial $(23,9 \%)$ respecto al sexo masculino $(7,4 \%)$. Sin embargo, no se demostró asociación entre el tipo de contrato y el número de hijos o responsabilidad de enfermos a su cargo. Algo que contrasta con otros estudios donde la conciliación familiar, la llegada de hijos, o el cuidado de familiares a cargo, puede incidir en la necesidad de una reducción en la jornada laboral para las mujeres (Alberdi y Escario, 2003).

\section{CONCLUSIONES Y LIMITACIONES}

La aplicación del cuestionario tuvo algunas limitaciones. La muestra final de 100 participantes fue inferior a la prevista debido principalmente a la pandemia de COVID19. La composición de esta mostraba un sesgo interno derivado de que la mayor parte de las respuestas se obtuvieron en el Área de Salud de Tudela.

En conclusión, el cuestionario demostró unas características óptimas acompañado de unas propiedades psicométricas adecuadas y permite obtener datos sobre diferentes variables asociadas a la trayectoria profesional que una vez sometidas a tratamiento estadístico ofrecen resultados de gran interés. Por todo ello, se prevé la posibilidad de dar continuidad a este proyecto y extenderlo, considerando que solo una recogida sistemática y amplia de información permitiría conocer los factores que explican la trayectoria profesional de la mujer científica. 


\section{REFERENCIAS BIBLIOGRÁFICAS}

Alberdi, I., y Escario, P. (2003). Flexibilidad, elección y estilos de vida familiar. Madrid: Ministerio de Trabajo y Asuntos Sociales, Subdirección General de Publicaciones.

Amatea, E. S., Cross, E. G., Clark, J. E., y Bobby, C. L. (1986). Assessing the work and family role expectations of career-oriented men and women: The life role salience scales. Journal of Marriage and the Family, 831-838.

Bailyn, L. (2003). Academic careers and gender equity: Lessons learned from MIT 1. Gender, Work \& Organization, 10(2), 137-153.

Castaño Collado, C., y Webster, J. (2011). Understanding women's presence in ICT: The life course perspective. International Journal of Gender, Science and Technology, 3(2), 364-386.

Donoso, T., Figuera, P., y Moreno, M. L. R. (2011). Barreras de género en el desarrollo profesional de la mujer universitaria. Revista de educación, 355, 187-212.

Martín Arribas, M. C. (2004). Diseño y validación de cuestionarios. Matronas profesión, 5(17), 23-29.

Ramada-Rodilla, J. M., Serra-Pujadas, C., y Delclós-Clanchet, G. L. (2013). Adaptación cultural y validación de cuestionarios de salud: revisión y recomendaciones metodológicas. Salud pública de México, 55(1), 57-66.

Xie, Y., y Shauman, K. (2003) Women in Science: Career Processes and Outcomes.

Cambridge MA, US: Harvard University Press 


\author{
3.1.2. Educación y género: el largo camino de las investigadoras en \\ las ingenierías de Chiapas \\ Nallely Alonso Gómez (Universidad Autónoma de Chiapas, México); Daniel Hernández \\ Cruz (Universidad Autónoma de Chiapas, México); José Ignacio Rivas Flores \\ (Universidad de Málaga, España).
}

\title{
Resumen
}

La presente comunicación estudia la desigualdad de género en el ámbito de la investigación científica en el estado de Chiapas, México. Basándose en los resultados del Sistema Nacional de Investigadores (SNI), el objetivo fue: conocer el punto de vista de las investigadoras SNI del área VIII-Ingenierías y desarrollo tecnológico adscritas a universidades públicas de Chiapas, sobre los elementos clave que les permitieron insertarse en un grupo élite de investigación a nivel nacional.

Se empleó una metodología biográfica-narrativa para acercarse a las experiencias de investigadoras en universidades públicas del estado. Así, los resultados muestran que el poseer un capital cultural rico a temprana edad, otorgado principalmente por la familia, impulsa a las niñas a interesarse por las ingenierías y otras ciencias. Se concluye que es importante visibilizar la labor de las mujeres en la ciencia, así como percibir las estrategias y prácticas hegemónicas que imposibilitan la participación de las investigadoras.

Palabras clave: género; equidad; investigación, Sistema Nacional de Investigadores; México.

\section{INTRODUCCIÓN Y OBJETIVOS}

En México, uno de los problemas sociales grandes ha sido la desigualdad de género en los diferentes campos sociales; los factores histórico y cultural han influido en dicha problemática. Es por ello que la presente investigación se centra en la desigualdad de género presente en el grupo élite del Sistema Nacional de Investigadores (SNI), particularmente en el área de conocimiento VIII-Ingenierías y desarrollo tecnológico. El objetivo que se persiguió fue conocer el punto de vista de las investigadoras SNI del área VIII-Ingenierías y desarrollo tecnológico adscritas a universidades públicas de Chiapas, sobre los elementos clave que les permitieron insertarse en un grupo élite de investigación a nivel nacional.

Dentro de las prioridades a nivel mundial que mantiene la Organización de las Naciones Unidas para la Educación, la Ciencia y la Cultura (UNESCO) es la de promover la igualdad de género, ligada a los esfuerzos de la organización por proporcionar el derecho a la educación y lograr los Objetivos de Desarrollo Sostenible (ODS), en donde el ODS 4 tiene como finalidad "garantizar una educación inclusiva, equitativa y de calidad y promover oportunidades de aprendizaje a lo largo de la vida para todos" (ONU, 2015, p.11), y el ODS 5 tiene como finalidad "lograr la igualdad entre los géneros y empoderar a todas las mujeres y las niñas" (ONU, 2015, p. 12).

México tiene una población estimada de 126 millones de habitantes, de los cuales más de 37.7 mil son estudiantes (INEGI, 2021, p. 1). De 2000 a 2020, la población de 15 años y más que no sabe leer o escribir un recado, se ha reducido en casi 1.5 millones de personas. La matrícula en educación superior para el ciclo escolar 2019-2020 de acuerdo a la Secretaría de Educación Pública [SEP] $(2019$, p. 1) fue de 3.7 millones de estudiantes en modalidad escolarizada, de éstos solamente 1.8 millones de estudiantes son mujeres. Si bien la tasa de atención educativa en el nivel superior ha ido 
incrementando, es importante recordar que no sólo se debe analizar la cobertura en términos cuantitativos sino también la calidad de ésta, que realmente posibilite a los estudiantes de habilidades para su vida.

Por su parte, la Asociación Nacional de Universidades e Instituciones de Educación Superior [ANUIES] $(2019$, p. 1) señala que, del total de estudiantes de modalidad escolarizada en instituciones públicas del país, solamente el $45 \%$ pertenece a la matrícula femenina. Así, aunque las mujeres representan el $45 \%$ de los egresados con un primer título de educación superior, más de una de cada cinco no participan en el mercado laboral (Organización para la Cooperación y el Desarrollo Económicos [OECD], 2019, p. 1). En México el nivel de posgrado está compuesto por especialidad, maestría y doctorado, en este nivel, se concentra solamente el $8 \%$ de los estudiantes mexicanos (ANUIES, 2019, p. 1); las especialidades tienen una menor presencia de las mujeres con $40 \%$, y en general, la presencia femenil es evidentemente menor en todo el posgrado (Bonilla, 2015, p. 94).

Por otro lado, en México se creó en 1984 el Sistema Nacional de Investigadores (SNI), sistema que premia la labor en investigación, por medio de un reconocimiento adicional a un estímulo económico, por medio de evaluaciones permanentes a las/los investigadores/as que buscan ingresar a él. El primer requisito para poder ingresar al $\mathrm{SNI}$ es poseer, como último grado de estudios, el doctorado, es por ello que se hace énfasis en los números que refleja el posgrado, ya que, desde ahí, se visualiza un panorama difícil para las mujeres en el campo de la investigación. De acuerdo a Rodríguez (2016, p.11)

En 1984 el SNI estaba compuesto por 1,143 hombres (81.9 por ciento) y 253 mujeres (18.1 por ciento). La diferencia, que entonces era de poco menos de 64 puntos porcentuales, se ha ido acortando con el paso de los años. Sin embargo, la distancia sigue siendo considerable; tan sólo en 2016 era de aproximadamente 28 puntos porcentuales (15,992 hombres contra 9,080 mujeres).

Dentro del SNI, la diferencia de géneros se manifiesta dependiendo del área de conocimiento que se aborde: en el caso de humanidades y ciencias de la conducta, el porcentaje de mujeres y hombres es aproximadamente $50 \%$; le sigue el área de medicina y ciencias de la salud, quedando ligeramente por debajo del $50 \%$ en 2016 . En estas áreas las mujeres tienen mucho peso, en cambio las áreas de fisicomatemáticas y ciencias de la tierra, e ingenierías el porcentaje de mujeres es mucho menor (Rodríguez, 2016, p. 17).

Y también con respecto al nivel o categoría. EI SNI clasifica a los/as investigadores/as en cuatro niveles: candidato, nivel I, nivel II, nivel III e investigador emérito. En este sentido, el mayor número de investigadoras se concentran en el nivel de candidato, seguido por el nivel I, pero muy pocas son las investigadoras en los niveles II, III y emérito. Chiapas, una de las entidades más pobres del país y con el mayor índice de marginación y analfabetismo (INEGI, 2021, p. 1), ofrece un escenario difícil para la investigación.

En la entidad, la presencia de mujeres en la investigación es ínfima. Desde los años 90 's no se ha observado una tendencia clara en el desarrollo de las áreas de conocimiento. No obstante, el área de las ingenierías históricamente se ha visto dominada por hombres. Las estadísticas muestran que, en los últimos cinco años, del total de investigadores SNI en la entidad, solamente el $6 \%$ corresponde al área de ingeniería, lo que significa que se tiene la presencia de 24 investigadores SNI, y de éstos solamente dos son mujeres. Con relación a los niveles del SNI, se sigue la misma tendencia como se muestra en la gráfica 1. 


\section{Gráfica 1}

Categorías y género de los investigadores del área VIII-Ingeniería de Chiapas

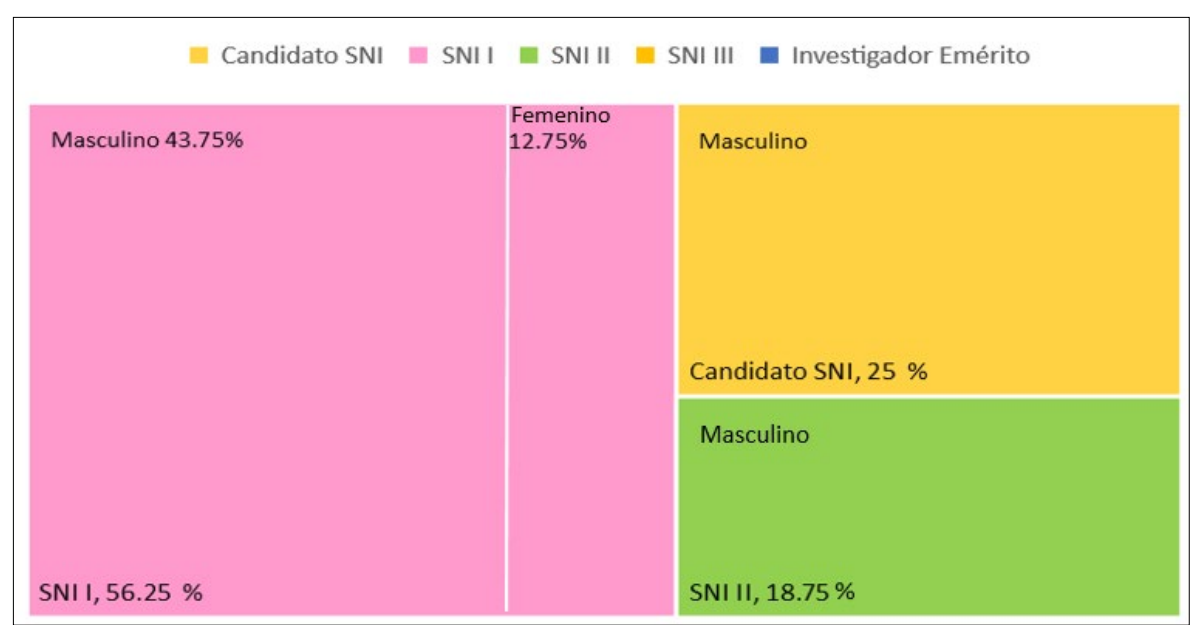

Fuente: Elaboración propia con datos de CONACYT $(2014 ; 2015 ; 2016 ; 2017$; 2018; 2019)

Parecería que el efecto goteo o techo de cristal que marca la literatura respecto a la imposibilidad que tienen las mujeres para acceder a niveles superiores se confirma a cada vez más. El estudio realizado por Cárdenas (2015, p. 64) hace énfasis en los factores y prácticas, de algunos científicos, sobre todo de aquellos en posiciones de poder, que limita la participación de las mujeres en la investigación.

\section{METODOLOGÍA}

Se trata de un estudio cualitativo que se enfocó en las investigadoras del SNI que pertenecen al área VIII-Ingenierías y desarrollo tecnológico del estado de Chiapas, México. La cohorte de estudio corresponde al 2014-2019, enfocándose en universidades de carácter público; cabe señalar, que en la entidad no se cuentan con centros de investigación en el área de estudio. Chiapas cuenta con nueve Instituciones de Educación Superior (IES) de carácter público, pero solamente en cuatro IES se tiene presencia de investigadores/as reconocidos por el SNI, lo anterior se describe en la tabla 1:

\section{Tabla 1}

Académicos e Investigadores SNI por IES Públicas en Chiapas, Cohorte 20142019

\begin{tabular}{lcc}
\hline \multicolumn{1}{c}{ IES en Chiapas } & $\begin{array}{c}\text { Número de } \\
\text { investigadores }\end{array}$ & \multicolumn{1}{c}{ Nivel S.N.I } \\
\hline Universidad Politécnica de Chiapas (UP) & 9 & 6 investigadores Nivel I \\
Universidad de Ciencias y Artes de Chiapas (UNICACH) & 6 & 2 Candidatos \\
Instituto Tecnológico de Tuxtla Gutiérrez (ITTG) & 2 investigadores Nivel I \\
& 6 investigadores Nivel II \\
Universidad Autónoma de Chiapas (UNACH) & 5 investigadores Nivel I \\
& 3 & 1 Candidato \\
\end{tabular}


Fuente: Elaboración propia con datos de CONACYT $(2014 ; 2015 ; 2016 ; 2017$; 2018; 2019).

Posteriormente, se visualizó que la población de estudio estaba compuesta de 24 investigadores/as, pero de éstos, solamente dos eran mujeres. Por lo que se decidió seguir una metodología biográfica-narrativa para rescatar las subjetividades de las investigadoras, dado que, en dicha metodología la parte biográfica prioriza la construcción y reconstrucción de los relatos de los sujetos, tal como señalan Landín, Ramírez y Aréchiga (2015, p. 2), que a partir de este método se genera una develación y comprensión de subjetividades en conjunto.

El marco narrativo sirvió para colocar a las investigadoras como constructoras de sus propias historias, ya que en sus narrativas se entretejen aspectos de la vida social, estructural y mediaciones, así lo señalan Prados y Rivas (2017, p. 81) que a partir de las narrativas de los investigadores se puede conocer la vida de los investigadores y sus condiciones, por lo que cuentan y cómo lo cuentan. Lo anterior, se logró a partir del empleo de entrevistas en profundidad.

\section{RESULTADOS Y DISCUSIÓN}

El análisis de los resultados se realizó a partir del sistema de teorías de Pierre Bourdieu de campo-capital-habitus, así se destaca lo siguiente:

Las investigadoras señalan que los diferentes campos sociales en los que se insertan están estructurados a partir de reglas o condiciones que provocan que muchas mujeres escojan un área de conocimiento diferente a las ingenierías. El aspecto social y cultural permea en la vida de las mujeres, desde que ellas son niñas, ya que, señalan que tienen pocos referentes de mujeres investigadoras en las cuales ellas se pueden ver reflejadas, a diferencia de la existencia de muchos roles socialmente "aceptables" (ama de casa o esposa principalmente). Lo anterior, se traslada a los niveles superiores de educación, al llegar a la universidad las estudiantes tienen pocos o nulos ejemplos de mujeres en la ingeniería, esta situación se agudiza a nivel de posgrado.

También tiene que ver el capital con el que se cuenta en la entidad, ya que como señalaron las investigadoras en Chiapas se carece de recursos suficientes para dar una correcta atención a la población estudiantil, más en los niveles superiores de educación, se sabe que los niveles de escolarización femenina merma a partir del nivel de licenciatura. Además, al ser Chiapas una entidad fuertemente arraigada a sus tradiciones y costumbres, éstas obligan a que muchos estudiantes, hombres y mujeres, opten por dejar sus estudios y prefieran ingresar al mercado laboral para apoyar a sus familias. Las investigadoras señalan que el capital, en sus diferentes especies, brindado principalmente por sus familias, jugó un papel fundamental para el desarrollo de su camino como investigadoras, toda vez que, además del capital económico, el capital cultural al que tuvieron acceso desde niñas las impulsó a desarrollar ciertas habilidades que ellas consideran importantes para la investigación.

Por último, desde la perspectiva de las investigadoras los elementos claves que permitieron que ellas ingresaran al SNI fueron la capacidad de adaptación y flexibilidad ante los cambios que se van suscitando en el campo científico, así como a la responsabilidad y constancia que imprimen en todos y cada uno de sus trabajos. No obstante, también señalaron que, partiendo de una ruptura epistémica sobre la concepción de los roles de las mujeres en la sociedad, instituida por los elementos proporcionados dentro de la familia, han tenido que desarrollar estrategias que les permiten competir a nivel nacional con los demás investigadores, estrategias que tienen que ver con el trabajo multidisciplinario y multifuncional que involucra varios aspectos de su vida, y que inevitablemente implica romper con algunos paradigmas dentro de la investigación. 
En México la participación de la mujer en los distintos niveles educativos ha tenido un fuerte rezago, esta situación se ha logrado reducir en la última década debido al aumento de mujeres en la matrícula en educación superior, y a que se ha avanzado en la alfabetización de la población. Sin embargo, la brecha de género sigue teniendo una fuerte presencia en el campo científico, y particularmente, en el subcampo de las ingenierías. Se hizo evidente que en la sociedad mexicana existen diversas estructuras sociales que priorizan más la participación de los hombres que el de las mujeres.

Lo anterior es relevante, porque esa es la tendencia que se sigue a nivel estatal. En Chiapas, existe una enorme desigualdad de género en los estratos políticos, laborales, y sobre todo, educativos. Si bien el Sistema Nacional de Investigadores (SNI) no hace diferencia por el género, al momento de la evaluación, sí se conduce a partir de criterios o estándares internacionales que son difíciles de cubrir, toda vez que las condiciones nacionales y locales distan mucho de las condiciones presentes en otros países. Así, las investigadoras han tenido que desarrollar reglas por debajo de las reglas establecidas para lograr ser reconocidas por el SNI.

La educación es un factor importante y fundamental, ya que dentro de las propias universidades es el punto de partida hacia ambientes de equidad. Como señala Castañeda (citado en Valdez, Valenzuela y Ochoa, 2016, p. 105) es necesario generar una política institucional que atienda a corto, mediano y largo plazo, la participación equitativa de ambos sexos en los distintos ámbitos universitarios. En definitiva, es importante hablar de equidad social y equidad de género no sólo a través de las leyes, sino buscando concientizar a la sociedad sin olvidar que el desarrollo de investigaciones involucra el ámbito social, familiar y escolar.

\section{REFERENCIAS BIBLIOGRÁFICAS}

ANUIES. (2019). Anuarios estadísticos de educación superior. http://www.anuies.mx/informacion-y-servicios/informacion-estadistica-deeducacion-superior/anuario-estadistico-de-educacion-superior

Bonilla, M. (2015). Diagnóstico del posgrado en México: nacional. Consejo Mexicano de Estudios de Posgrado. https://www.posgrado.unam.mx/sitios_interes/documentos/comepo_regiones.p df

Cárdenas, M. (2015). La participación de las mujeres investigadoras en México. Investigación administrativa, (116), 64-80. https://www.redalyc.org/pdf/4560/456044959004.pdf

CONACYT. (2014). Resultados de la convocatoria 2014 Ingreso o permanencia. http://www.conacyt.gob.mx/images/SNI/RESULTADOS_INGRESO_O_PERMA NENCIA_2014.pdf

CONACYT. (2015). Resultados de la convocatoria 2015 Ingreso o permanencia. http://www.conacyt.gob.mx/images/SNI/2015/INGRESOAG015.pdf

CONACYT. (2016). Resultados de la convocatoria 2016 Ingreso o permanencia. http://www.conacyt.gob.mx/images/SNI/2016/Ingreso_o_Permanencia_SNI_20 16.pdf 
CONACYT. (2017). Resultados de la convocatoria 2017 Ingreso o permanencia. http://www.conacyt.gob.mx/images/SNI/2017/RESULTADOS_INGRESO_O_PE RMANENCIA_2017.pdf

CONACYT. (2018). Resultados de la convocatoria 2018 Ingreso o permanencia. http://www.conacyt.gob.mx/images/SNI/2018/LISTA_INVESTIGADORES_APR OBADOS_2018.pdf

CONACYT. (2019). Resultados de la convocatoria 2019 Ingreso o permanencia. https://www.conacyt.gob.mx/images/SNI/2019/RESULTADOS_SNI_CONVOCA TORIA_2019_INGRESO_O_PERMANENCIA.pdf

INEGI. (2021). Censo 2020 de Población y Vivienda. https://www.inegi.org.mx/contenidos/saladeprensa/boletines/2021/EstSociodem o/ResultCenso2020_Nal.pdf

Landín, M., Ramírez, D. y Aréchiga, K. (2015). El método biográfico narrativo. Aportaciones y obstáculos. Trabajo presentado en VIII Jornadas Nacionales y 1er. Congreso Internacional sobre la Formación del Profesorado, Argentina. https://docplayer.es/75327703-El-metodo-biografico-narrativo-aportaciones-yobstaculos.html

OECD. (2019). Higher Education in Mexico: Labour Market Relevance and Outcomes Higher Education. Organización para la Cooperación y el Desarrollo Económico. https://doi.org/10.1787/9789264309432-en

ONU. (2015). Informe de los Objetivos de Desarrollo Sostenible 2020. Naciones Unidas. https://unstats.un.org/sdgs/report/2020/The-Sustainable-Development-GoalsReport-2020_Spanish.pdf

Prados, M. E. y Rivas, J. I. (2017). Investigar narrativamente en educación física con relatos corporales. Revista del Instituto de Investigaciones en Educación, 8, (10), 1-15. http://revistas.unne.edu.ar/index.php/riie/article/view/3654/3289

Rodríguez, C. (2016). El Sistema Nacional de Investigadores en números. Foro Consultivo Científico y Tecnológico, AC. https://www.researchgate.net/publication/331985104_El_Sistema_Nacional_de Investigadores_SNI_en_Numeros

SEP. (2019). Principales cifras del Sistema Educativo Nacional 2019-2020. https://www.planeacion.sep.gob.mx/Doc/estadistica_e_indicadores/principales_ cifras/principales_cifras_2019_2020_bolsillo.pdf

Valdez, D., Valenzuela, R. y Ochoa, E. (2016). Igualdad de género. Investigaciones. Instituto $\quad$ Tecnológico de
https://www.itson.mx/publicaciones/Documents/cienciaseconomico/equidaddegeneroinvestigaciones.pdf 


\title{
3.1.3. Un cuerpo que se desborda y (se) afecta. Eider Chaves Gallastegui (Universidad del País Vasco, España); Estibaliz Aberasturi Apraiz (Universidad del País Vasco, España)
}

\begin{abstract}
Resumen
La investigación parte de una experiencia educativa llevaba a cabo con alumnado de formación inicial del profesorado. Mediante el proyecto 'Cuerpo limitado', se les propone reflexionar acerca de lo que les desborda, y crear conjuntamente una narrativa visual. Los métodos visuales y el análisis narrativo conforman la metodología del presente trabajo. Los resultados muestran la preocupación de las alumnas respecto a la belleza, los cánones estéticos, la vestimenta, la presión social etc. por un lado, y la relación entre el cuerpo y el afecto, por otro; lo cual implica una reflexión de las instituciones educativas acerca de la presencia del cuerpo, de su relación con los afectos, y las diferencias de género que actualmente se siguen reproduciendo.
\end{abstract}

Palabras clave: cuerpo; giro afectivo; aprendizaje real, género.

\section{INTRODUCCIÓN Y OBJETIVOS}

La tradición platónico-cartesiana, que se define en las concepciones dualistas del ser humano, tiene también implicaciones en el tema del cuerpo y el aprendizaje. La perpetuación de estas dualidades sigue reproduciendo un único modelo hegemónico educativo, lo cual afecta indiscutiblemente a un modelo hegemónico corporal.

En cuanto a la educación, el cuerpo ha permanecido presente pero oculto; se le ha ignorado y marginado, fabricando dinámicas para olvidar-entrenarlo, ha habido una ausencia y un silencio del cuerpo en los discursos y prácticas (Álvarez, 2013; Megías, 2020; Planella, 2006). Además, existe en ello un ejercicio de poder, una política del cuerpo (biopolítica de Foucalt), encaminado a la disciplina, el control y la corrección de los cuerpos escolarizados, reproduciendo un cuerpo obediente, mecanizado, reglado, normativizado, calificado (Megías y Flores, 2017), también en términos estéticos. Así, el significado que adquiere un cuerpo depende de los cánones estéticos, valores, etc. (Martínez, 2001; Butler, 2007), los cuales marcan además diferencias entre hombres y mujeres, marcas de género que responden a patrones sociales de masculinidad y feminidad (Gatens, 2002; Amurrio, Larrinaga, Usategui, Del Valle, 2012), pese a los planteamientos no hegemónicos sobre el cuerpo que se cuestionan hoy en día. Como afirma Han (2015), el imaginario corporal más potente en las sociedades modernas sigue siendo una exaltación o salvación de lo bello, el cual sobrevalora atributos como la delgadez, esbeltez, sensualidad, belleza juvenil, etc., sobre todo en los cuerpos de las mujeres (Gallo, 2007). Así, la feminidad como ideal social se representa y reproduce mediante gestos, vestimentas y comportamientos (Mora, 2019), la alimentación y el cuidado corporal (Martínez, 2004), la delgadez (Carro, 2011) y mucha insatisfacción corporal (Macedo, Machado, Oliveira, Perrout, Silva, 2011).

Esto tiene una implicación directa en la identidad corporal de las mujeres, la cual ha sido definida y relatada por hombres (Prados, García, Padua, 2014; Touraine, 2010). Todo lo anterior contribuye no sólo a reducir el cuerpo a su procedimiento anatómico y fisiológico, sino a despreciar lo afectivo; un desprecio por el cuerpo sensible, expresivo, gestual, artístico (Cadavid, 2007).

En todo este entramado, aparece el giro afectivo, el cual se nutre de posicionamientos posthumanistas y los nuevos materialismos, entre otros. El giro afectivo coloca a los afectos en el centro de las reflexiones (Enciso y Lara, 2013), de tal forma que se 
transciende una dimensión puramente racional y discursiva (Ahmed, 2013). Se entienden los afectos no como emociones individuales, sino en relación con el mundo, con las fuerzas sociales y estructuras" (Lordon, 2018:10). Eso implica, por un lado, profundizar en cierta concepción del cuerpo; los cuerpos existen cuando se ponen en relación (Mayoral y Benavente, 2019). Se acentúa entonces, el cuerpo políticamente implicado, situado con su género, su sexo, etc. que siente, que afecta y es afectada por múltiples agentes (la identidad intersubjetiva). Pero no sólo eso. Es precisamente en ese contacto que surge el afecto, cuando los cuerpos se encuentran.

Haciendo revisión de lo descrito, entonces, ¿existen espacios en las universidades que pongan el afecto y el cuerpo en el centro? ¿Qué tipo de prácticas llevamos a cabo respecto a lo que nos afecta y nos toca?

\section{Objetivos:}

1. Reflexionar acerca de la relación entre el cuerpo y el afecto. Observar las implicaciones del giro afectivo respecto a los modos de entender, concebir y habitar el cuerpo, en las universidades:

\section{- Hipótesis 1.1: lo que nos afecta está relacionado con nuestro cuerpo.}

2. Dar cuenta de una experiencia/ caso llevado a cabo con alumnado de formación inicial del profesorado: fomentar la introspección y la autoobservación en las y los futuros maestros, creando espacios de diálogo y encuentro.

3. Cuestionar y examinar el impacto/influencia del género a la hora de constituir la identidad corporal. Analizar en qué medida y de qué forma la categoría género sigue repercutiendo en las diferencias entre mujeres y hombres, respecto a su cuerpo, su aprendizaje y su afectividad.

\section{METODOLOGÍA}

La investigación parte del proyecto 'Cuerpo limitado' de la asignatura de "Arte y Cultura Visual" del grado de Educación Primaria de la Universidad del País Vasco (UPV/EHU). La experiencia educativa, en la cual han participado 70 alumnas y alumnos de $2^{\circ} \mathrm{curso}$, comienza con la pregunta de “¿Qué me desborda?", como pregunta generadora, y propone la creación colectiva de un video o foto-ensayo, poniendo el cuerpo en el centro, y teniendo como condición que sea una narrativa visual que impulse el cambio social.

Para ello, se han utilizado métodos artísticos y visuales, los cuales nos acercan a experiencias-datos que de otra forma no podríamos acceder, allá de los límites del lenguaje textual o verbal (Banks, 2010; Hernández, 2008). El alumnado, a partir de una reflexión individual acerca de lo que le desborda, ha formado grupos de 2 o 3 personas para pensar y crear conjuntamente una narrativa visual. Durante 3 semanas, se han sumergido en un proceso reflexivo y creativo, explorando otras maneras de representar el conocimiento, planteando nuevas preguntas y abriendo nuevas posiciones (Hernández, Aberasturi, Sancho y Correa, 2020) y movilizando conexiones afectivas que permiten explorar lo desconocido gracias a la comprensión empática (Mannay, 2017) que facilitan las imágenes visuales. En la última sesión, cada grupo compartió su narrativa visual y su "ficha de autor/a", y se hizo un feedback de cada trabajo.

Para el análisis de los datos nos basamos en la Investigación Narrativa, porque permite acercarse a un fenómeno social desde las experiencias de las personas involucradas en el mismo (Aberasturi, Correa y Guerra, 2016). Lo anterior se relaciona con el giro narrativo que propone Clandinin, desde el cual los sujetos de investigación se convierten en individuos biográficos con capacidad de acción y activos constructores de conocimiento. Eso se vincula con el posicionamiento mencionado, ya que el giro afectivo 
supone la superación del "individuo aislado". Respecto a ello, Rivas dice que, en el encuentro mediante las narraciones, se produce una modificación tanto de nuestra propia realidad como la de la otra persona, lo que nos sitúa en el ámbito de las relaciones (citado en Aberasturi, Correa y Guerra, 2016).

\section{RESULTADOS Y DISCUSIÓN}

Para comenzar, sentimos imprescindible subrayar la sorpresa respecto a las narrativas presentadas, ya que ante la situación que estamos viviendo (la docencia semipresencial y con mascarillas), pensábamos que la pregunta les llevaría a establecer relaciones con la pandemia. Sin embargo, en muchos trabajos de mujeres, los trabajos mostraban una gran preocupación por la belleza, la ropa, el maquillaje, la alimentación etc., lo cual corresponde al cuerpo dietético del que hablan Megías y Flores (2017), donde el cuerpo se concibe y habita como espacio para la búsqueda de belleza a través de la higiene, la alimentación y la moda, que se vincula con la idealización de un cuerpo imaginado, sobre todo en el caso de las mujeres. A la pregunta "¿Qué nos desborda?" muchas alumnas eligieron el tema de la presión social y cultural que sufrían respecto a su cuerpo, por el hecho de ser mujeres y sentir la exigencia de cumplir con el ideal femenino. Esa presión se mostraba mediante fotografías como: chicas cambiándose de vestimenta y maquillaje por estar con chicos; cuerpos depilándose con cuchillos y haciendo metáforas con frutas (como elemento asociado a la delgadez), etc. Esto hace referencia a lo que Mora (2019) dice respecto a la propia subjetividad; que se configura a partir de las relaciones con los otros, de manera que el disciplinamiento del cuerpo es un proceso intersubjetivo.

Por otro lado, se confirma la hipótesis de que lo que nos afecta tiene que ver con el cuerpo. Pese a que el cuerpo y el proceso de aprendizaje se han convertido en un elemento más a educar de forma mecánica e invisible (Planella, 2006; Gallo Cadavid, 2009), está dotado y es productor de sentido, lo cual implica su preocupación y ocupación. En todas las propuestas presentadas, el cuerpo ocupa un lugar central, no sólo como instrumento, sino como texto, como elemento que da sentido, como territorio habitado. Cuando el alumnado habla de lo que le desborda, el cuerpo pasa a ser el centro de su relato y también de su obra. En ese sentido, el análisis narrativo ha permitido observar esas concepciones y procesos, ya que como dicen Huber, Caine, Huber y Steeves (2014), los relatos se hallan intrincadamente ligadas a nuestras identidades.

\section{CONCLUSIONES Y LIMITACIONES}

Una de las conclusiones más importantes que emerge pasa por no perder el foco de la cuestión del género dentro de las instituciones educativas. Como muestra un estudio de Amurrio, Larrinaga, Usategui y Del Valle (2012), las vivencias afectivas de la juventud siguen atravesadas por fuertes marcas de género. Se vuelve necesario entonces, atender a esas desigualdades. Además, volviendo a Han (2015), es importante pensar en las nuevas formas de opresión que existen en esta sociedad de la imagen, donde el culto al cuerpo se ha convertido en un valor supremo (Álvarez, 2013).

Por otro lado, la investigación da cuenta de la relación entre el cuerpo y los afectos. Como diría Ahmed (2013), los cuerpos se forman a partir del contacto que tienen con el mundo, y en este contacto, los cuerpos se impresionan y se marcan por el afecto. Las implicaciones que de lo anterior se derivan pasan por poner el cuerpo en el centro, recuperar el cuerpo como centro de gravedad (Planella, 2006). Ello implica cuestionar el papel y presencia que tiene el cuerpo en las universidades. Implica, asimismo, favorecer más prácticas de pedagogía afectiva, donde los afectos y las relaciones 
expandan y fomenten nuevas formas de actuar y pensar (Atkinson, 2017). El alumnado se siente, entonces, emocionalmente retado por una situación particular donde tiene que posicionarse (Hernández, Aberasturi, Sancho y Correa, 2020).

Todo ello se materializa en prácticas específicas en el aula, donde se da valor al cuerpo en tanto que ecosistema informante y territorio de relaciones. Y ello, a su vez, nos lleva a cuestionarnos los espacios educativos actuales, a reflexionar, desde una mirada crítica, las limitaciones de la institución educativa en tanto que generadora de espacios de confianza, de intimidad y diálogo. Nos obliga a pensar en cómo vive y se siente el alumnado en la universidad, si es (o puede ser) un espacio de afección y desplazamiento, y en qué medida lo hace en referencia a la identidad de género.

\section{REFERENCIAS BIBLIOGRÁFICAS}

Aberasturi, E., Correa, J.M, y Guerra, R. (2016). ARTikertuz, ¿qué conocimiento generamos a partir de la relación pedagógica entre profesorado? Educación artística: revista de investigación (EARI), (7), 19-38.

Ahmed, S. (2013). Introduction. Feel Your Way. En The Cultural Politics of Emotion (2a Ed.) (1- 19). Abingdon. Oxon: Routledge.

Álvarez, L.M. (2013). El tratamiento de lo corporal en la formación inicial del profesorado. Revista interuniversitaria de formación del profesorado, 27(3), 161175.

Amurrio, M., Larrinaga, A., Usategui, E., \& Del Valle, A. I. (2012). Los estereotipos de género en los/las jóvenes y adolescentes. Donostia: Eusko Ikaskuntza.

Atkinson, D. (2017). Art, Disobedience and Ethics. The adventure of Pedagogy. Cham (Suiza): Palgrave.

Banks, M. (2010). Los datos visuales en investigación cualitativa. Madrid: Morata.

Butler, J. (2007). El género en disputa: el feminismo y la subversión de la identidad. Barcelona: Paidós.

Carro, F.S. (2011). Deconstruyendo la belleza. En In corpore dominae, cuerpos escritos/cuerpos proscritos. Sevilla: ArCibel Editores.

Enciso, G., \& Lara, A. (2013). El giro afectivo. Athenea Digital: revista de pensamiento e investigación social, 13(3), 101-120.

Gallo Cadavid, L.E. (2007). La educación física y su anclaje en la tradición platónicocartesiana. Lúdica Pedagógica, 2(12), 5-11.

Gallo Cadavid, L.E. (2009). El cuerpo en la educación da qué pensar: perspectivas hacia una educación corporal. Estudios pedagógicos (Valdivia), 35(2), 232-242.

Gatens, M. (2002). El poder, los cuerpos y la diferencia. Desestabilizar la teoría. México: pueg.

Han, B. C. (2015). La salvalción de lo bello. Herder editorial.

Hernández, F., Aberasturi, E., Sancho, J., \& Correa, J. M. (2020). ¿Cómo aprenden los docentes?: tránsitos entre cartografías, experiencias, corporeidades y afectos. Ediciones Octaedro: Barcelona. 
Hernández, F. (2008). La investigación basada en las artes. Propuestas para repensar la investigación en educación. Educatio Siglo XXI, 26: 85-118.

Huber, J., Caine, V., Huber, M., y Steeves, P. (2014). La indagación narrativa como pedagogía en la educación: el potencial extraordinario de vivir, contar, volver a contar y revivir relatos de experiencias. Revista Educación, (7), 33-74.

Lordon, F. (2018). La sociedad de los afectos: por un estructuralismo de las pasiones. Adriana Hidalgo editora: Buenos Aires, Argentina.

Macedo, J., Machado, V; Miguel, H; Oliveira, V; Perrout, J; y Silva, J. (2011). Relationship between anthropometric variables and body image dissatisfaction among fitness center users. Revista De Psicología Del Deporte, 20 (2), 367-382.

Mannay, D. (2017). Métodos visuales, narrativos y creativos. Madrid, Narcea.

Martínez, B.I. (2001). Género, desarrollo psicosocial y trastornos de la imagen corporal. Madrid: Instituto de la Mujer.

Martínez, B.I. (2004). Construcción psicosocial del cuerpo: implicaciones del sistema sexo-género. Seminario Permanente Mujer y deporte: Los modelos corporales dominantes, el ejercicio físico y la salud de las mujeres adolescentes y jóvenes. Memoria de las jornadas. Universidad Politécnica de Madrid, Facultad de Ciencias de la Actividad Física y el Deporte, inef.

Mayoral, S.D.R., y Benavente, B.R. (2019). Hacia una pedagogía afectiva del movimiento. Tercio Creciente, 16, 7-30.

Megías, M.E.P., y Flores, J.I.R. (2017). Investigar narrativamente en educación física con relatos corporales. Revista del Instituto de Investigaciones en Educación, 8(10), 82-99.

Mora, B. L. S. (2019). Disciplinamiento del cuerpo de las mujeres. Revista de Ciencias Sociales, (164), 181-194.

Mora, B.A.M., Megías, M.E.P., y García, M.J.M. (2017). Reescribir el cuerpo educado. De la voz silenciada y la emoción contenida al cuerpo educando. International Journal of Developmental and Educational Psychology, 3(1), 377-386.

Planella, J. (2006). Corpografías: dar la palabra al cuerpo. Artnodes: revista de arte, ciencia y tecnología, (6), 13-23.

Prados, M. E. (2020). Pensar el cuerpo. De la expresión corporal a la conciencia expresivocorporal, un camino creativo narrativo en la formación inicial del profesorado. Revista Retos. Nuevas tendencias en Educación Física, Deporte y Recreación, 37, 703-711.

Prados, M. E., García, M. J. M., \& Padua, D. (2014). Relatando el cuerpo. Una experiencia narrativa con un grupo de mujeres universitarias. In Aprender a ser docente en un mundo en cambio: Simposio Internacional (pp. 334-341). Universitat de Barcelona.

Touraine, A. (2010) El mundo de las mujeres. Barcelona. Paidós. 


\subsubsection{Sensibilidad de género en futuros profesionales sanitarios. España y Latinoamérica}

Bartual-Figueras, M. Teresa; Donoso-Vázquez, Triny; Coco-Prieto, Andrés; SierraMartínez, F. Javier; Simó-Solsona, Montserrat; Turmo-Garuz, Joaquin

\section{Resumen}

El género es un aspecto importante en la salud y la enfermedad. La conciencia de género en las/los profesionales de las Ciencias de la Salud contribuye a la equidad en la salud y la atención sanitaria. Sin embargo, en gran medida, el género no ha sido introducido en los currículos académicos. El objetivo de esta comunicación es estimar la sensibilidad de género de las/los estudiantes de Ciencias de la Salud de España y Latinoamérica. Para ello se realizó una encuesta, de la que se han obtenido 887 respuestas. Los resultados revelan que las/los participantes perciben como insuficiente la implementación de un enfoque de género en sus planes de estudio. También expresaron bajos niveles de estereotipos respecto a temas de salud, con respecto a los pacientes y sobre la transexualidad. Sin embargo, continúan mostrando una prevalencia subyacente del punto de vista biomédico. Además, durante su etapa universitaria, experimentan cierto espejismo de igualdad de género en su futuro profesional, que contrasta con la desigualdad existente en el mercado laboral.

Palabras clave: Sensibilidad de Género; Salud, profesionales de la Salud, Universidad

\section{INTRODUCCIÓN Y OBJETIVOS}

La concepción dominante de la medicina tiene en consideración, fundamentalmente, los factores biológicos, estableciendo como referencia la andronormalidad. Esto se refleja tanto en los estudios clínicos como en los manuales académicos y en las explicaciones docentes. El eje de referencia es el sexo masculino y lo relativo a las mujeres se explica únicamente en base a las especificidades asociadas a determinados aspectos de su biología (Hamberg, 2008; Verdonk, 2009; Raz and Miller, 2013; Parker et al., 2016; Samulowit, 2018). Sin embargo, un mayor conocimiento de la relación que existe entre sexo, género y salud reduce el sesgo de género en la atención sanitaría y contribuye a la equidad asistencial (WHO, 2016). En esta línea, algunas investigaciones muestran las implicaciones del sexo y el género en la prevención, detección, diagnóstico y tratamiento de hombres y mujeres (Jenkins et al., 2016; Morais et al., 2019). No obstante, pese a su importancia, actualmente, existe una amplia discusión sobre el estado real de la implementación de la perspectiva de género en los grados de las Ciencias de la Salud y sobre lo que se necesitaría para que este enfoque tuviera éxito.

Este trabajo forma parte de un proyecto de investigación sobre la conciencia de género en estudiantes universitarios de los grados de Ciencias de Salud, que está financiado por el programa "Ayudas a la Investigación en la Docencia Universitaria REDICE 2020" de la Universidad de Barcelona. Se entiende por conciencia de género de la existencia de una actitud sensible al género, así como el conocimiento y la percepción de los efectos del género en la salud y la enfermedad (Verdonk, 2009). El estudio se centra de las titulaciones de Enfermería, Fisioterapia, Medicina y Odontología de la Universidad de Barcelona (España), la Universidad de Cantabria (España), La Universidad de La Frontera (Chile), La Universidad de Cartagena de Indias (Colombia) y de la Universidad Nacional Autónoma de Nicaragua (Nicaragua).

Nuestros objetivos son: 
Estimar el nivel de conciencia de género de las/los estudiantes de los grados de Ciencias de la Salud

$\checkmark$ Valorar la contribución de la universidad en la asunción de la concienciación de género

$\checkmark$ Valorar la influencia del contexto sociocultural

\section{METODOLOGÍA}

El análisis se basa en una encuesta destinada a las/los estudiantes de los dos últimos de cada uno de los grados analizados. La base teórica en la que sustenta el cuestionario se deriva de la Escala de Conciencia de Género en Medicina de Nijmegen (N-GAMW). La escala fue propuesta por Verdonk y aceptada como una herramienta válida para evaluar las percepciones de la conciencia de género en la educación médica en 2008 (Verdonk et al., 2009).

Siguiendo la escala N-GAMW, en nuestro cuestionario, incluimos ítems sobre sensibilidad de género en temas de salud (5 ítems) (dimensión 1), estereotipos de género sobre los pacientes (5 ítems) (dimensión 2), así como hacia los profesionales de la salud (5 ítems) (dimensión 3). Como aspecto complementario a la escala de referencia, nuestro estudio explora, también, las percepciones de las/los estudiantes sobre los estereotipos de género en general y sobre las personas transexuales (12 ítems) así como los efectos de la implementación de una perspectiva de género en cada universidad (8 ítems). Este último elemento tiene como objetivo ayudar a comprender cómo mejorar la implementación de una perspectiva de género.

La versión inicial del cuestionario incluía 65 preguntas, la mayoría de ellas medidas mediante una escala tipo de Likert de diez puntos, que van desde 0 , Muy en desacuerdo hasta 10, Muy de acuerdo. El cuestionario fue evaluado previamente por 7 personas con experiencia en temas de género y se puso a prueba con 30 estudiantes. Después de la revisión, se eliminaron 6 preguntas, se introdujeron 5 y se revisaron 4 . El cuestionario final estaba compuesto por 55 ítems.

La primera fase de la encuesta se realizó durante los meses de febrero y marzo de 2021. La segunda fase se realizará en septiembre y octubre de 2021. Ello facilita la adaptación a los diferentes ritmos académicos de las universidades participantes. En esta fase de recogida de información, nuestra muestra es de 887 estudiantes.

\section{RESULTADOS Y DISCUSIÓN}

De la muestra de 887 estudiantes, el $73,2 \%$ son mujeres, el $25,7 \%$ hombres y un $0,5 \%$ se identifica como no binario. El $49,2 \%$ pertenecían a universidades españolas y el $50,8 \%$ a universidades latinoamericanas.

Los resultados, que consideramos preliminares dado que falta la segunda fase de la encuesta, revelaron que solo un $29,9 \%$ de las/los estudiantes consideraban suficiente la atención recibida por los temas de género en sus planes de estudio y el $60 \%$ consideraba la necesidad de ampliar la implementar este enfoque de género en sus titulaciones. 
Gráfico 1. Percepción sobre la atención de los temas de género y la necesidad de su implementación. Porcentaje de estudiantes.

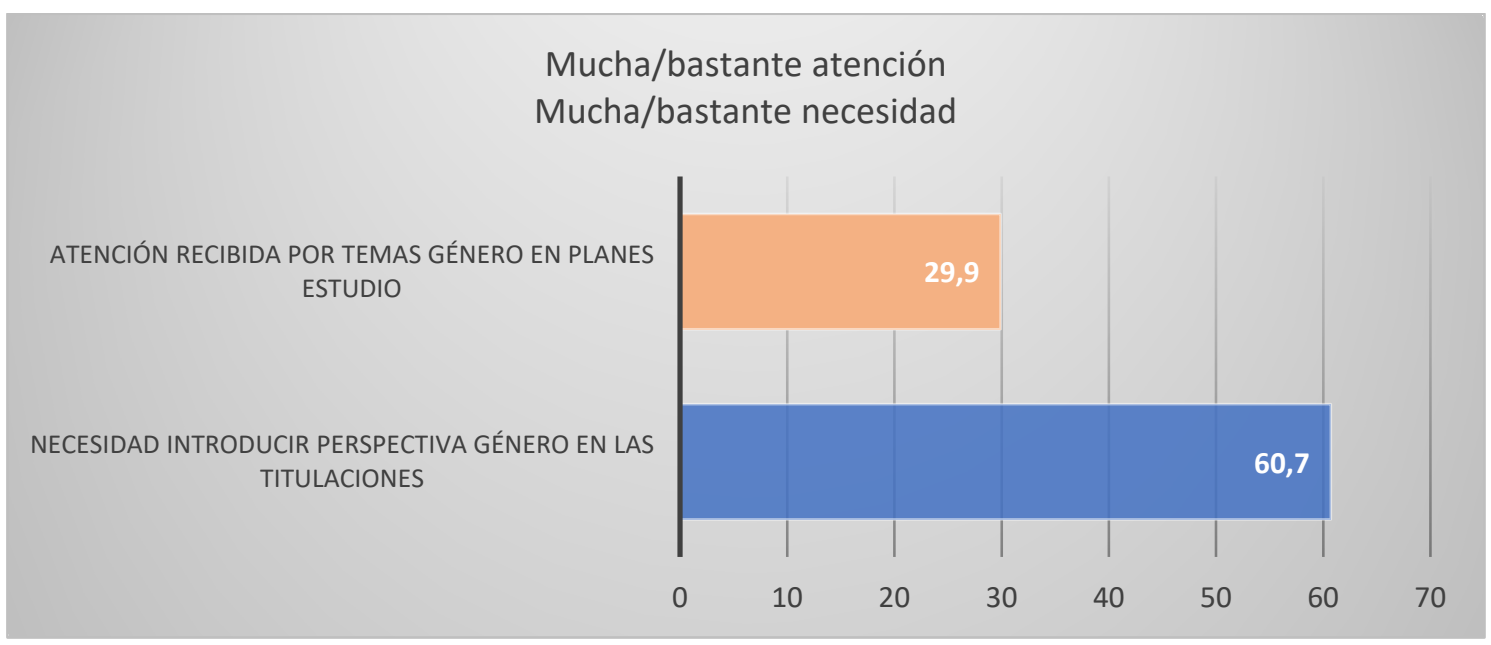

Fuente: Elaboración propia

Las/los estudiantes, también, expresaron niveles relativamente bajos de pensamiento estereotipado sobre el ámbito sanitario en general (tabla 1), sobre las/los pacientes (tabla 2), sobre la transexualidad (tabla 1 y 2 ) y sobre la práctica profesional (tabla 3 ).

No obstante, en la respuesta a los ítems $A$ y $C$ de la dimensión 1, se observa la influencia de la estricta perspectiva biomédica. En general, las/los estudiantes no reconocen la importancia del género al comunicarse y tratar a las/los pacientes. Ello parece reforzar la visión de neutralidad asociada a la profesión sanitaria. Es decir, en la medida en que la socialización profesional produce uniformidad de valores, actitudes y estilos de práctica profesional, se reduce la consideración de la influencia del género en el diagnóstico y el tratamiento. En este sentido, parece que las/los estudiantes han aceptado la idea de que el género no debería se relevante en las interacciones pacienteprofesional sanitario. Estos resultados están en la línea de las investigaciones de Verdonk et al., 2009; Jenkins et al., 2016; Parker, 2016; Morais et al., 2019)

En concordancia con los trabajos de Verdonk et al., 2009 y Morais et al., 2019, en el ítem $\mathrm{E}$ de la tabla 3, relativo a las expectativas profesionales y los logros de las mujeres en el mercado laboral, la existencia de un valor medio de 5,29 nos permite interpretar que hay aspectos todavía no interiorizados respecto a las desigualdades en el ámbito laboral, configurando la falsa idea de que la igualdad de géneros es una meta ya lograda en estas profesiones. El alto porcentaje de mujeres que acceden a estos estudios y el mito aparente de la libre elección contribuyen a este posicionamiento.

Tabla 1. Dimensión 1. Valor medio de los ítems

\begin{tabular}{|l|c}
\hline DIMENSIÓN 1 - AMBITO SANITARIO GENERAL & MEDIA \\
\hline $\begin{array}{l}\text { A. En los trastornos de salud no específicos de cada sexo (como, por ejemplo, las enfermedades de próstata } \\
\text { o de mama), el género de tu paciente es irrelevante }\end{array}$ & 7,26 \\
\hline $\begin{array}{l}\text { B. Ignorar las diferencias de género puede impedir que no se identifiquen adecuadamente los problemas de } \\
\text { salud de tu paciente }\end{array}$ & 6.39 \\
\hline C. Al comunicarte con tu paciente, no te debe importar su sexo ni su orientación sexual & 8.05 \\
\hline $\begin{array}{l}\text { D. El conocimiento de las diferencias de género en la salud y enfermedad aumenta la calidad de la atención } \\
\text { sanitaria }\end{array}$ & 7.91 \\
\hline $\begin{array}{l}\text { E. La atención sanitaria debería considerar mas las experiencieas y necesidades especiales de les personas } \\
\text { transexuales }\end{array}$ & 7.16 \\
\hline
\end{tabular}

Fuente: Elaboración propia 
Tabla 2. Dimensión 2. Valor medio de los ítems

\begin{tabular}{|l|c}
\hline DIMENSION 2 - PERCEPCONES HACA LOS PACENTE & MEDIA \\
\hline A. Los hombres son menos exigentes que las mujeres y se comunican de forma más clara y directa & 4.06 \\
\hline B. Las mujeres piden mayor atención santiaria y se queja mas por su estado de salud que los hombres & 4.34 \\
\hline C. Los hombres solo piden asistencia sanitaria si su problema de salud es importante & 5.52 \\
\hline D. Las mujeres realizan más consultas sanitarias por síntomas inexplicables & 5.91 \\
\hline E. Las personas transexuales demandan más atención sanitaria & 3.29
\end{tabular}

Fuente: Elaboración propia

Tabla 3. Dimensión 3. Valor medio de los ítems

\begin{tabular}{|l|c|}
\hline DIMENSḰN 3 - PERCEPCONES RESPECTO AL PROFESIONAL DE LA SALUD & MEDIA \\
\hline $\begin{array}{l}\text { A. Las profesionales sanitarias prolongan en exceso sus consultas si se las compara con sus compañeros } \\
\text { masculinos }\end{array}$ & 3,13 \\
\hline B. Los profesionales sanitarios son más eficientes que sus compañeras de profesión & 2.17 \\
\hline C. Las profesionales sanitarias son más empáticas que sus compañeros de profesión & 4.09 \\
\hline D. Los profesionales sanitarios pueden afrontar mayor carga de trabajo que sus compañeras de profesión & 2.45 \\
\hline $\begin{array}{l}\text { E. Los profesionales sanitarios acaban teniendo mejores condicione labores que sus compañeras de } \\
\text { profesión }\end{array}$ & 5.29 \\
\hline
\end{tabular}

Fuente: Elaboración propia

No se observa diferencias significativas de género ( $P>.05)$, a diferencia de Verdonk et al., 2009, Morais et al., 2019. No obstante, si se observan diferencias significativas en función del contexto cultural; así, por ejemplo, las diferencias de valoración entre las/los estudiantes de España y Latinoamérica son significativas (Gráficos 2, 3 y 4).

Gráfico 2. Diferencias entre España y Latinoamérica. Dimensión 1 (\% de respuesta)

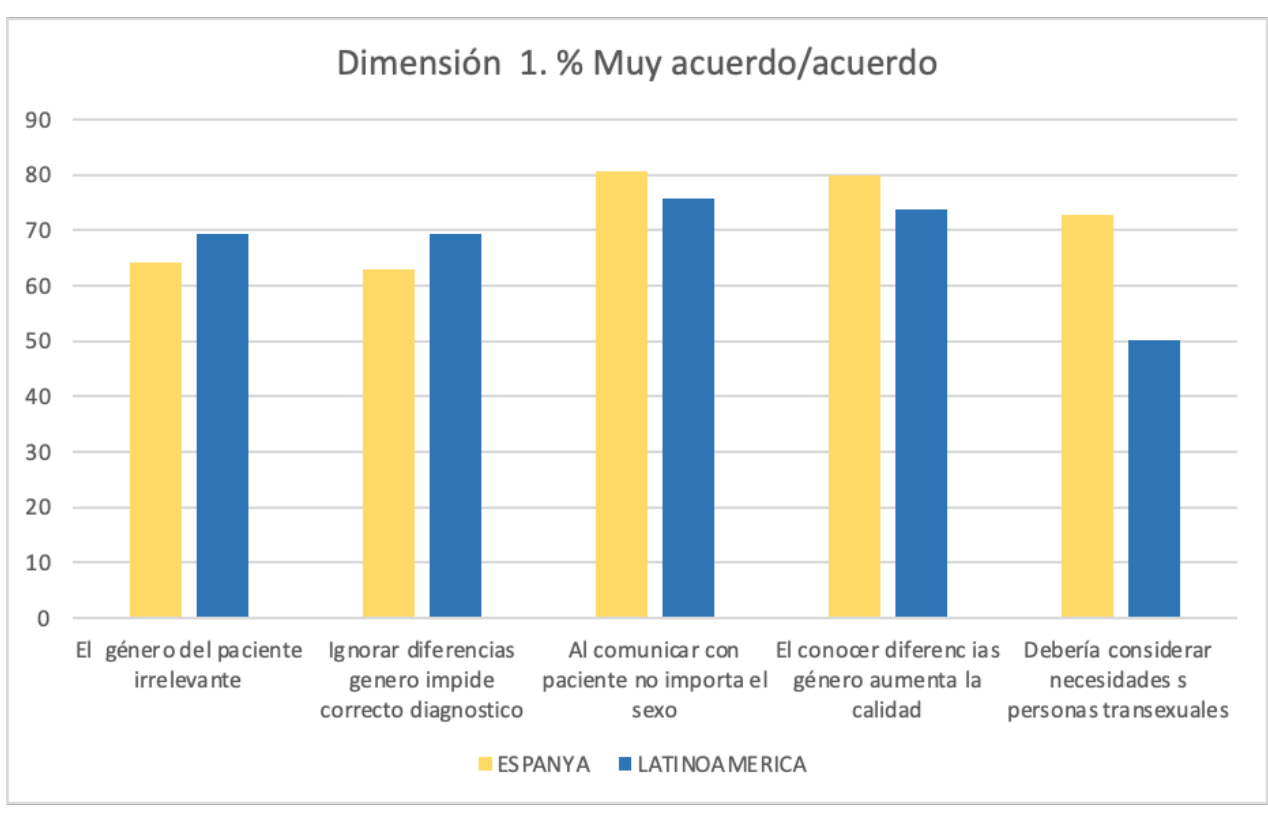

Fuente: Elaboración propia 
Gráfico 3. Diferencias entre España y Latinoamérica. Dimensión 2 (\% de respuesta)

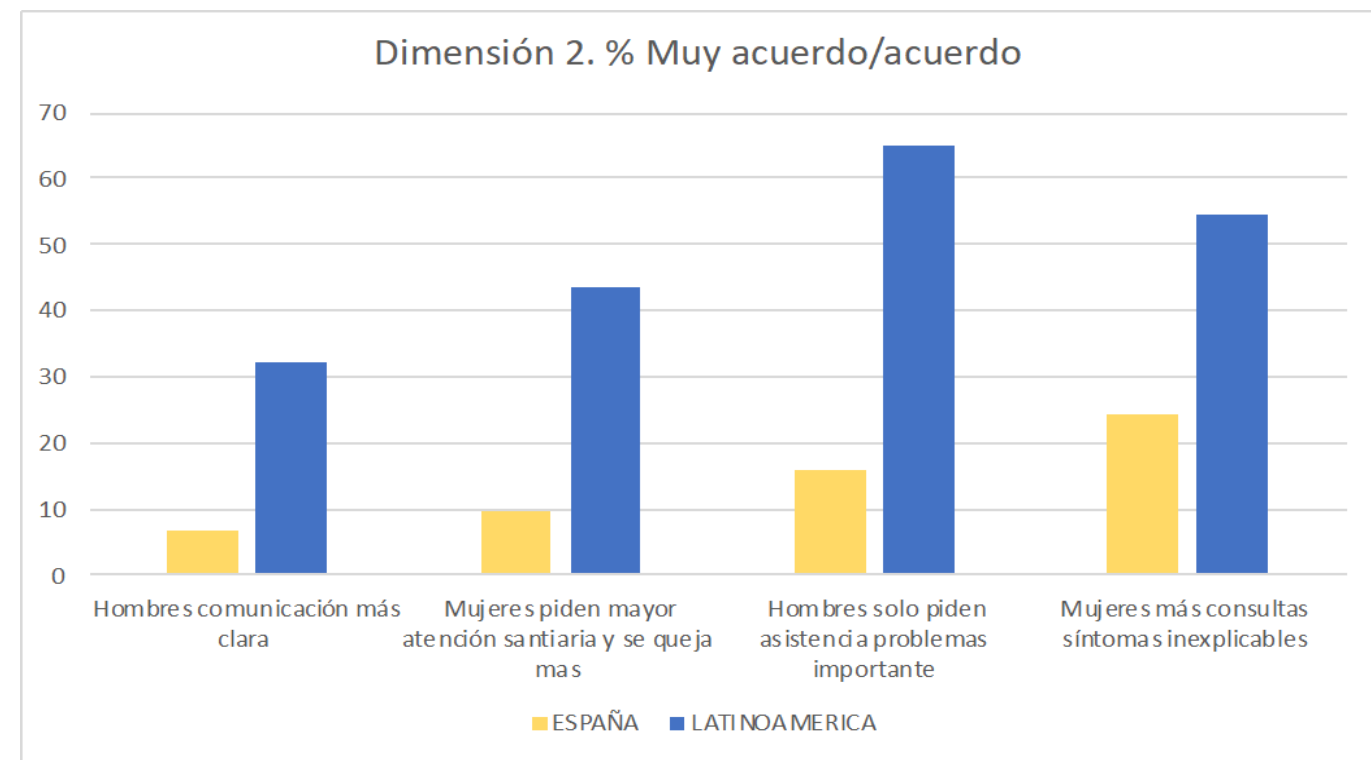

Fuente: Elaboración propia

Gráfico 4. Diferencias entre España y Latinoamérica. Dimensión 3 (\% de respuesta)

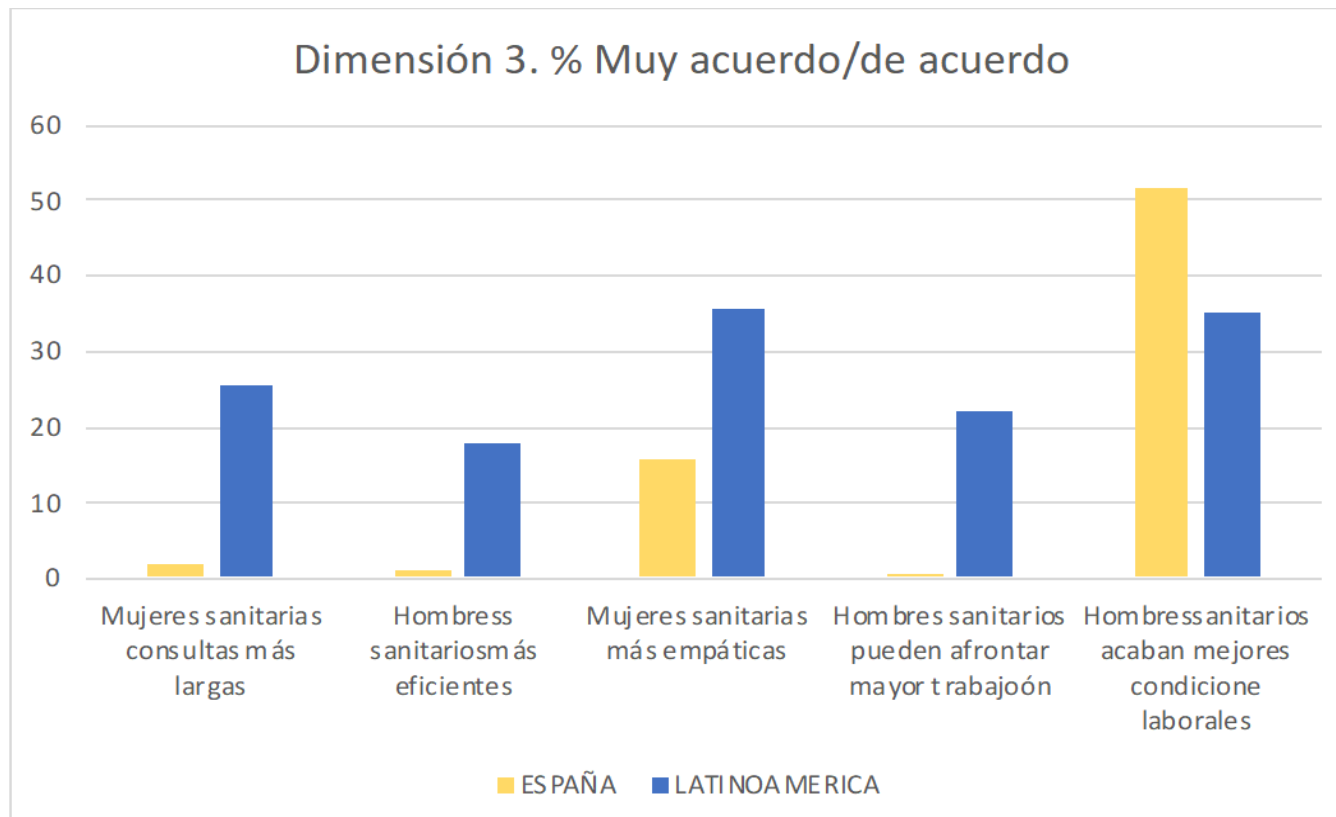

Fuente: Elaboración propia

\section{CONCLUSIONES Y LIMITACIONES}

El estudio muestra un bajo grado de pensamiento estereotipado en las/los estudiantes de Ciencias de la Salud, aunque se observan ciertos aspectos y actitudes que deberían ser tomados en consideración. Estos posicionamientos se refieren al supuesto mantenimiento de la estricta consideración de los aspectos biomédicos en la comunicación y tratamiento con las/los pacientes y que parecen obviar el hecho de que 
el conocimiento de las diferencias biológicas entre mujeres y hombres no reduce los sesgos causados por los estereotipos de género, neutralizando el impacto que los roles de género en los problemas de salud.

No se encuentran diferencias significativas de género, pero si en función del contexto cultural donde se inscriben las universidades. Las/los estudiantes de Latinoamérica muestran posicionamientos más estereotipados.

Estos resultados preliminares confirman la necesidad de integrar la perspectiva de género en la práctica docente, incorporando ejemplos en el aula y en los textos docentes.

La principal limitación es la diferente composición de género de la muestra. No obstante, los grados de ciencias de salud son feminizados y esta composición no deja de ser un reflejo de la realidad.

\section{AGRADECIMIENTOS}

Las y los autores agradecen al Institut de Desenvolupament Professional (IDP-ICE) de la Universidad de Barcelona el soporte financiero a través del proyecto REDICE202400 y REDICE20-2621

\section{REFERENCIAS BIBLIOGRÁFICAS}

Hamberg K. (2008). Gender bias in medicine. Womens Health, 4(3), 237-43

Jenkins, M.R., Herrmann, A., Tashjian, A., Ramineni, T., Ramakrishnan, R., Raef, D., Rokas, T. y Shatzer, J. (2016). Sex and gender in medical education: a national student survey. Biology of Sex Differences, 7, 45

Morais, R., Bernardes, S.F. y Verdonk, P. (2020). Gender awareness in medicine: adaptation and validation of the Nijmegen Gender Awareness in Medicine Scale to the Portuguese population (N-GAMS). Advance in Health Science Education, 25, 457-477.

Parker, R.B., Parker, P.D., Larkin, T. y Cockburn, J. (2016). A psychometric evaluation of the Gender Bias in Medical Education Scale. BMC Medical Education, 16, 251 (2016). https://doi.org/10.1186/s12909-016-0774-2

Raz L. y Miller V.M. (2013). Considerations of Sex and Gender Differences in Preclinical and Clinical Trials. In: Regitz-Zagrosek V. (eds). Sex and Gender Differences in Pharmacology. Handbook of Experimental Pharmacology, vol 214, 127-147. Springer, Berlin, Heidelberg.

Samulowith, A., Ida, G. , Eriksson, E. y Gunnel, H. "Brave Men" and "Emotional Women": A theory-Guided Literature Review on gender bias in Health Care and Gendered Norms towards patients with Chronic Pain. Pain Research and Management. 18, $1-14$

Verdonk, P., Benschop, Y., De Haes, H., y Lagro-Janssen, T. (2008). Medical students' gender awareness construction of the Nijmegen Gender Awareness in Medicine Scale (N-Gams). Sex Roles, 58, 222-234.

World Health Organization (WHO) (2016). Strategy on women's Health and well-being 


\title{
3.1.5. Respetadas y ¿enseñadas? Algunas consideraciones sobre de la perspectiva de género en la Filosofía y la Educación \\ Vicente de Jesús Hernández Mora (Universidad de Huelva, España) \\ Walter Federico Gadea Aiello (Universidad de Huelva, España)
}

\begin{abstract}
Resumen
Presentamos con este trabajo la oportunidad de una investigación de mayor alcance que se cuestione, en términos amplios, la propia posibilidad de la filosofía y su enseñanza desde la perspectiva de género. La toma de conciencia por parte del profesorado de filosofía de la condición patriarcal de la cultura occidental y la naturalización, oculta y subyacente, del sistema de dominación sexo-género en la reproducción institucionalizada de la cultura en las instituciones educativas, suscita problematizaciones para la práctica docente y arroja preguntas como las siguientes, que estructuran este trabajo y sus posibles respuestas: ¿habrían de esperarse cambios y transformaciones radicales en las asunciones vocacionales y profesorales?, ¿pueden asimilarse las disfunciones patriarcales de la Filosofía con modificaciones curriculares coyunturales?, ¿son necesarios replanteamientos fundamentales de la institucionalidad del saber que implica la Universidad y reconceptualizaciones básicas de lo que es Filosofía y lo que polémicamente debería ser la Filosofía y su enseñanza, desde una perspectiva históricamente negada por estas últimas?
\end{abstract}

Palabras clave: palabra 1; palabra 2; palabra 3, palabra 4; palabra 5.

\section{INTRODUCCIÓN Y OBJETIVOS}

La Filosofía, "ciencia de todas las ciencias", "conciencia crítica de todos los saberes" es una de las disciplinas que, posiblemente, por el carácter casi originario de su propia constitución histórica (nos remontarías a los siglos VI-V a. C. y al propio nacimiento de la cultura occidental) más responden al patrón patriarcal, pues, de alguna manera, en tanto equiparable al pensamiento mismo, instituye y legitima el patriarcado. Como sostiene Alicia Puleo, "la Filosofía y el sistema de género-sexo o patriarcado mantienen una relación muy estrecha" (1996, p. 7), pues los conceptos fundamentales que ha acuñado y pensado la filosofía a lo largo de su historia (ser, idea, materia, Dios, alma, tiempo, mundo, verdad, razón,...) se han ofrecido ellos mismos como neutros y universales (más aun, fundantes del pensamiento abstracto y universal), en una operación primaria de desvinculación de las divisiones materiales del trabajo y de la propia vida histórica, en lo que Habermas ha llamado, "una razón idealista y errática, incapacitada para la memoria y el recuerdo histórico" (1994, p. 108). Diferencias culturales en los modelos de producción semiótica y material, diversos modos de configurar la organización social y el control y poder políticos, variedad en la adaptación tecnológica para la transformación de la naturaleza, la lucha contra la escasez y la distribución de la riqueza o, finalmente, "la sexualidad, el sexo, la diferencia hombremujer no contaban en apariencia demasiado para la Filosofía" (Puleo, 1996, p. 7).

Todos los factores materiales y simbólicos que justifican y movilizan la diferencia han sido atravesados por la operación universalizadora (fundamento asimismo de normatividad) de las nociones filosóficas; sin embargo, toda "forma de conocimiento siempre es parcial y 'situada' en un sujeto y una corporalidad" (2010, Posada, p. 86) y en una territorialidad culturizada y, por tanto, han respondido a un práctica social y política concreta y contextualizada. En el caso de la Filosofía, y desde sus orígenes griegos, como bien se sabe, se trata de una actividad especulativa cuyas condiciones de posibilidad han sido las de una élite masculina, blanca y occidental, organizadora y 
reguladora de saber-hacer y de la distribución del bienestar, a partir de la acumulación de la riqueza producida por las clases y grupos humanos tenidos por inferiores, es decir, sostenida por el esfuerzo productivo (material) y reproductivo (biológico) de mujeres, esclavos, colonizados y trabajadores.

Por añadidura, esta "tradición patriarcal que en líneas generales se mantiene bastante homogénea hasta llegar a la llustración" (Reverter, 2003, p 33), se ha constituido con base en intercambios y diálogos cuyo receptor y auditorio ha sido mayoritariamente a lo largo de la historia el de sus pares de género y clase. $Y$ esto ha sido desde el nacimiento de la Filosofía en el siglo $\mathrm{VI}$ a. C., desde sus originarios procedimientos discursivos y sus modelos primarios de transmisión, evolucionando desde prácticas orales de sabiduría-dialéctica a modalidades discursivas de filosofía-retórica, cada vez más apoyadas en la cultura escrita y funcionales a la vida pública ${ }^{6}$ en el seno de la polis (Colli, 1977).

Partiendo de estas nociones primarias, y si el profesor ha tomado conciencia de la perspectiva de género, ¿cómo es posible la enseñanza de la filosofía? Es decir, nos planteamos con este trabajo el objetivo de problematizar la práctica docente de la Filosofía en Educación superior, alentando los cuestionamientos que tanto a profesores, como alumnos y gestores públicos habrían de suscitarles preguntas como las siguientes: ¿cómo persuadir a un auditorio heterogéneo en cuanto a su constitución de clase y género (nuestras aulas habituales), especialmente a las mujeres, de que es legítimo y hasta provechoso que aprendan, se apropien e incluso admiren unos sistemas de pensamiento que han sido en parte constituidos gracias (y para) la negación de su propia condición como ciudadana y hasta como persona?, ¿cómo enseñar unos conceptos que han sido elaborados solo para ser trasladados e interpelar a sus pares hombres y que, por tanto, si son transmitidos acríticamente a un auditorio de mujeres, interpelaría a esta misma mujer alumna para autoconstituirse como un auditoriohombre, pues sería esta la única forma de recibir y legitimar unas ideas que no han sido concebidas para que ellas (las mujeres) las escuche y piense? En definitiva, si la Filosofía es considerada como un ejercicio racional crítico y liberador (y no nos cabe la menor duda de que es legítima y necesaria esta convicción) tomar conciencia de lo anterior, ¿qué implica para nuestra práctica docente y nuestra investigación? Entendemos que este es un reto crucial para el profesor de filosofía (y no solo), pero que es sistemáticamente obviado por el profesor de filosofía (y no solo) y la institución que lo acredita como tal y para la que se desempeña.

\section{METODOLOGÍA}

En un relativamente reciente libro dedicado a reflexionar sobre la conceptualización teórica y la modalidad práctica de la disciplina filosófica, su autor, el conocido filósofo francés André Comte-Sponville, como conclusión de una primera parte introductoria que se propone reflexionar sobre generalidades y conceptos que atañen a la propia definición que habría que contestar a la pregunta ¿qué es la filosofía?, responde del siguiente modo:

Es una práctica teórica (discursiva, razonable, conceptual), aunque no científica; solo se somete a la razón y a la experiencia -con exclusión de toda revelación de origen transcendente o sobrenatural- y aspira menos a conocer que a pensar o poner en cuestión, menos a aumentar nuestro saber que a reflexionar sobre lo que sabernos o ignoramos. Sus objetos preferidos son el Todo y el hombre. Su finalidad, que puede variar en función de las épocas y los individuos, será la

\footnotetext{
${ }^{6}$ Puleo habla de la historia de la Filosofía, como "la historia de una disciplina que, por lo común, ha conceptualizado a «la» mujer para confirmar su exclusión de las luces del conocimiento y de lo que, en términos generales, llamamos ámbito de lo público". (1996, p. 7)
} 
mayoría de las veces la felicidad, la libertad o la verdad, e incluso la conjunción de las tres (2019, p. 26)

Como puede suponerse, el libro, en la sección que sigue a esta definición, no incluye ninguna mención a ninguna filósofa histórica ni al feminismo. De un lado, habríamos de advertir que la tradición de la teoría feminista ya a las alturas del siglo XXI es tan amplia, abigarrada, voluminosa y compleja que su completa omisión es difícil de salvar con las consabidas justificaciones del carácter introductorio o de breve opúsculo del volumen. Obviar a día de hoy la parte que a las mujeres y al feminismo les corresponde en la tarea de debatir en el siglo XXI qué es la filosofía y cómo se practica ya no es una omisión ingenua, inocua y disculpable. Pero más aún, las primeras palabras con la que el autor interpela al lector: "¿Qué es la filosofía? La pregunta ya es filosófica o, en cualquier caso, puede llegar al serlo" (7), buscan ubicarse a sí mismas como parte de un movimiento autorreflexivo que, desde la situación del pensamiento universitario de élite del siglo XXI, heredero necesario de las sospechas críticas que conmovieron las convicciones básicas de humanismo occidental, renombra o redefine la filosofía con la legitimidad que otorga la etapa terminal de un "competo" recorrido histórico y, entendemos, también desde la superación dialéctica de dicha sospecha. Así, el amplio público lector potencial del volumen asume, como precondición cognitiva o metodología implícita para el entendimiento del resto del texto, la definición que el mismo le propone de lo que la filosofía es y de cómo ha superado y asimilado su propio y tortuoso camino histórico para ser eso mismo. Pero el olvido de la perspectiva de género y de las impugnaciones que esta precisamente ha lanzado contra las definiciones "oficiales" o la asunción "espontánea" de lo que es filosofía, quizá vuelva a ejecutar la operación tradicionalmente patriarcal de ofrecerse desde una auto evidencia "neutra" y auto legitimadora, pero forjada por la práctica, definiciones (y autodefiniciones) mayoritarias - por no decir exclusivas- de pensadores hombres.

Es por esto que una propuesta que se pregunta por la filosofía desde el género o el feminismo ha de conllevar una revisión crítica de bibliografía inspirada por "el reto conceptual que supone desvelar el sesgo androcéntrico que se oculta tras un conocimiento aparentemente neutral" (Nuño y Álvarez, 2016, p. 295), y cómo este sesgo permea en los contenidos, normas y estándares académicos y en el conjunto de la "organización y el funcionamiento del sistema universitario, percibiéndose como si fuera un enfoque objetivo", tanto en el diseño de los currículos y de la investigación, como en la concepción y funcionamiento de la institucionalidad toda de enseñanza superior. Preguntas como las que se hace Alicia Puleo:

¿cómo ha conceptualizado la filosofía a varones y a mujeres? ¿Es neutral o puede percibirse en ella un sesgo de género? ¿Se evidencian contradicciones en las teorías filosóficas cuando aparece la temática de "la Mujer"? ¿Tuvo alguna influencia la filosofía en el cuestionamiento contemporáneo de los roles femenino y masculino? Y, a su vez, ¿tienen los movimientos de mujeres y el moderno concepto de género alguna influencia en las polémicas filosóficas actuales? (2012, pp. 91-92)

han de plantearse el imperativo, tanto epistemológico como ético-político, de tomar distancia crítica de las metodologías tradicionales. Pensemos entonces que una perspectiva metodológica hermenéutica, de revisión crítica de textos y de prácticas docentes, como la que aquí se propone, y si quiere tomarse en serio la perspectiva de género, debe superarse a sí misma e incorporar las relaciones de poder y el conflicto en el análisis de la producción de conceptos y subjetividades, con todas la realizaciones institucionales y dispositivos que los generan y perpetúan. $Y$ entre estos no es el menor, sino al contrario, la institución educativa que canoniza y reproduce lo que hay que enseñar, a quién hay que enseñarlo y para qué hay que enseñarlo de la forma en que hay que hacerlo. La metodología así concebida ha de vincularse a las prácticas sociales y políticas y no solamente limitarse a una perspectiva contemplativa y autorreflexiva. En 
el aspecto metodológico vale pena sugerir asimismo la posibilidad de concebir el método también -o sobre todo- como una teoría-praxis de autoconstitución metodológica, en la línea de lo que Chela Sandoval denomina "metodologías de las oprimidas"

«flexible», «móvil», «diaspórica», «esquizofrénica», «nómada» por naturaleza. Estas formas de movilidad, sin embargo, se alinean en torno a un campo de fuerzas que las inspira, concentra e impulsa como formas opositivas de praxis. De hecho, esta forma de conciencia-en-oposición queda mejor imaginada como el particular campo de fuerza que posibilita las prácticas y procedimientos de la «metodología de las oprimidas». (2004, p. 85)

\section{RESULTADOS Y DISCUSIÓN}

En un artículo publicado en diciembre de 2018 en el diario El País, el también muy conocido filósofo español Daniel Innerarity apostaba por decantar el espinoso asunto de la perspectiva de género sobre la historia de la filosofía en la forma de un examen crítico del "modo como sus verdaderos protagonistas describieron un mundo incompleto y proporcionaron el marco conceptual que justificaba esa empobrecedora exclusión" (énfasis nuestro). Como estrategia de compensación por la ausencia de la presencia de mujeres en el pensamiento filosófico y su enseñanza institucionalizada tenemos que cuestionarnos si esta "solución" no viene a suponer un relegamiento (en el mejor de los casos) de la ingente investigación feminista que trabaja desde hace tiempo por rescatar filósofas desconocidas o nuevos textos de filósofas ya conocidas, a los ámbitos de la inocua investigación académica. $Y$ debemos preguntaron entonces si esta propuesta no deja a la investigación feminista sin posibilidad alguna de trastocar fundamentalmente el canon, reorganizar la clasificación del saber y actuar ética o políticamente a través de los currículos educativos. Como bien apunta Fina Birulés, "el proceso de exclusión de las mujeres o su histórica discriminación [...] no sólo ha determinado la escasez de obra filosófica femenina, en comparación con la masculina, sino también y fundamentalmente su falta de transmisión" (2011, p. 9). Por ello, esta revisión de la historia de la filosofía volvería de nuevo, y paradójicamente "para tener una mirada más inclusiva sobre nuestro pasado", en palabras de Innenarity, a sus protagonistas (hombres), pero ahora, eso sí, con (cierta) perspectiva de género. A nuestro entender, desde su aparente contestación a la tradición, esta modalidad de "asimilación" pedagógica e investigativa de la perspectiva de género, estaría de nuevo ubicada dentro de ese sistema de excusas, del que habla Femenías, que "mantiene una eficacia contundente tanto en círculos 'cultos' como en los medios masivos de comunicación, muchos libros de texto, conversaciones cotidianas, etcétera, precisamente por su carácter de tópico" (2012, pp. 31-32). La labor constructiva que la perspectiva de género exige no solo la reconfortante imagen de nuevos cánones que incluyen a mujeres, a decir otra vez Innerarity, sino como apunta Puleo (2012, pp. 93-97), una tarea de genealogía y deconstrucción y la constitución de un corpus filosófico no sexista como base firme establecida para completar y desestabilizar, desde la justicia histórica y epistémica, la imagen canonizada de una historia de la filosofía como solipsismo monológico masculino. Sin este movimiento desestabilizador y radical, el retorno a los verdaderos protagonistas sea desde posiciones convencionales o progresistas, efectúa una doble operación patriarcal totalizante: tanto la exclusión tradicional como su hermenéutica de la sospecha, pero ambas, solo y siempre, desde la voz sus protagonistas autorizados: hombres filósofos y textos escritos por ellos.

\section{CONCLUSIONES Y LIMITACIONES}

La historia de la filosofía, tal y como ha sido construida por la mirada patriarcal y por las ansiedades y tensiones del diálogo entre sus "protagonistas" hombres, quedaría así 
blindada de injerencias subversivas que arriesgaran a redefinir lo que es filosofía y los que es razón, desde las experiencias otras del pensar y del dialogar.

El somero análisis realizado por el momento en esta investigación en curso, tanto de la bibliográfica crítica en el ámbito de la filosofía de la educación y la teoría feminista, y su contraste con planes y programas de estudios y oferta educativa de nuestras instituciones, induce, como resultado preliminar, a advertir la escasa asunción, y en algunos casos nula, por parte de la institucionalidad universitaria de algunas de las conexiones problemáticas entre género y docencia de la filosofía que se quieren apuntar en este texto. $Y$ en concreto, en lo referente a oferta académica de estudias de género, independientes o transversales, a la reestructuración de los contenidos y currículos de grados y asignaturas y, muy especialmente, en toma de conciencia de la perspectiva de género y consecuente revisión autocrítica de la vocación y función social del docente.

Dice Alicia Puleo que "una de las tareas de la filosofía con enfoque de género será recuperar la memoria histórica para evitar el "eterno retorno de lo mismo»" (1996, p. 18). Si la vía para para construir otra filosofía no es el acontecimiento de pensarla desde la "imposibilidad" sociohistórica de esta memoria negada en las mujeres, pensarla entonces desde la crítica de su canon masculino, institucionalizado y enseñado -que al parecer es a lo más a lo que podemos aspirar- es otra vez evitar que no sea el retorno de siempre lo mismo el paradójico resultado de pensar y enseñar filosofía desde el género.

\section{REFERENCIAS BIBLIOGRÁFICAS}

Birulés, F. (2011). Introducción. Notas sobre tradición y pensamiento filosófico femenino.

En F. Birulés y R. Rius Gatell (Eds.), Pensadoras del Siglo XX. Aportaciones al pensamiento filosófico femenino (pp. 7-11). Instituto de la Mujer.

Colli, G. (1977). El nacimiento de la filosofía. Barcelona: Tusquets.

Comte-Sponville, A. (2012). La filosofía. Qué es y cómo se practica. Barcelona: Paidós.

Femenías, M. L. (2012). Introducción: Cuestiones preliminares. En M. C. Spadaro y M. L. Femenías (Eds.), Enseñar filosofía, hoy (pp. 19-47). Editorial de la Universidad Nacional de La Plata (Edulp)

Habermas, J. (1994). Israel y Atenas o ¿a quién pertenece la razón anamnética? Sobre la unidad en la diversidad multicultural. Isegoría, 10, 7-16.

Innenarity, D. (21 de diciembre de 2018). El género de la filosofía. El País. Babelia. https://elpais.com/cultura/2018/12/17/babelia/1545063946_645737.html

Nuño Gómez, L; Álvarez Conde, E. (2017). Androcentrismo académico: la ficción de un conocimiento neutral. Feminismo/s, 29, 279-297.

Posada Kubissa, L. (2010). Igualdad, epistemología y género: desde un horizonte éticopolítico. Quaderns de Psicologia, 12(2), 81-91.

Puleo, A. (2012). La filosofía como cuestionamiento de la vida cotidiana. En M. C. Spadaro y M. L. Femenías (Eds.), Enseñar filosofía, hoy (pp. 91-107). Editorial de la Universidad Nacional de La Plata (Edulp)

Reverter Bañón, S. (2003). La perspectiva de género en la filosofía. Feminismo/s, 1, 3350.

Sandoval, Ch. (2004). Nuevas ciencias. Feminismo cyborg y metodología de los oprimidos. En Otras inapropiables Feminismos desde las fronteras (pp. 81-106). Traficante de sueños. 


\title{
3.1.6. Los indicios del acoso. Estudio piloto sobre el Acoso Universitario en el Campus María Zambrano de la Universidad de Valladolid \\ Sara Fernández Muñoz (Estudiante Universidad de Valladolid)
}

\begin{abstract}
Resumen
El presente trabajo de investigación analiza la existencia de indicios de acoso entre el alumnado del Campus María Zambrano (Segovia) de la Universidad de Valladolid (UVa) mediante las formas de intimidación interpersonal y digital, las repuestas del mismo ante diversas situaciones, su medio de desarrollo y ámbito de repercusión principal. Igualmente, se indaga acerca de la existencia de discriminaciones de género entre el estudiantado. Para este estudio se diseñó y llevó a cabo un procedimiento cuantitativo por encuesta basado en la realización de un cuestionario online autoadministrado. Los resultados obtenidos permiten hacer una reflexión acerca de los usos y desusos que el alumnado realiza en redes, su comportamiento entre grupos, la percepción sobre el acoso, así como un acercamiento a la realidad que envuelve a esta población objeto de estudio.
\end{abstract}

Palabras clave: Acoso; Universidad; Discriminación, Género; Estudiantado.

\section{INTRODUCCIÓN Y OBJETIVOS}

El acoso en todos los niveles de enseñanza es una problemática a tratar. Desde la primaria y secundaria hasta los estudios universitarios se pueden desarrollar comportamientos que deriven en situaciones de este tipo. Tal y como recogen Méndez, Ruiz-Esteban, Ramón y Cerezo (2019) en su investigación, en el ámbito universitario se dan situaciones de conflicto donde predomina el acoso relacional y verbal. La normalización de estas conductas es una amenaza, y tal y como reflejan Conde Vélez, y Delgado-García (2020) existe un proceso de asimilación de conductas violentas y nocivas entre estudiantes. De igual manera y en esta línea, Romero y Plata (2015) concluyeron que se potencia la falta de respeto y prejuicios entre el estudiantado universitario.

La Organización de las Naciones Unidas para la Educación, la Ciencia y la Cultura (UNESCO, 2019) se hizo eco de esta situación realizando un informe donde reflejaba datos sobre la incidencia del acoso escolar desde edades muy tempranas. Detectar estas manifestaciones puede ser una tarea ardua dada la complejidad que subyace a las mismas. Por ello, han de elaborarse mecanismos de detección y contención desde un punto de vista interdisciplinar como El Cuestionario sobre Acoso entre Estudiantes Universitarios (QAEU) que promueve una triple óptica en relación a los roles asumidos por el estudiantado (Ramón, Méndez, Ruiz- Esteban y Cerezo, 2020).

Atendiendo a la tipología expuesta por el Equipo de Expertos de la Universidad Internacional de Valencia (2014) en este estudio se diferencia entre acoso sexual o por razón de sexo (comportamiento de naturaleza sexual que atenta contra una persona), verbal (acción comunicativa que discrimina, difama, etc.),físico (comportamiento que provoca el daño físico y/o de objetos de la persona en cuestión), psicológico (conductas abusivas de intimidación, manipulación, etc., para fomentar miedo y vulnerabilidad) y social/relacional (acción de aislar, ignorar y excluir a una persona del resto del grupo). 
De igual manera, esta investigación se desarrollada en una colaboración en prácticas con el Área de Asuntos Sociales de la UVa ${ }^{7}$, tutorizada por César Vega. A continuación, se señalan los objetivos planteados:

-Objetivo general:

1.Averiguar si existen signos de acoso interpersonal y/o digital entre el estudiantado del Campus María Zambrano (UVa).

-Objetivos específicos:

1.1. Consultar al alumnado sobre las formas de intimidación interpersonal y digital que identifican en las relaciones de convivencia y que pueden definirse como acoso.

1.2. Estudiar las respuestas del estudiantado ante diversas manifestaciones de acoso, su medio de desarrollo y ámbito de repercusión.

1.3. Indagar acerca de la existencia de discriminaciones de género en el Campus.

\section{METODOLOGÍA}

En la presente investigación se ha desarrollado un proceso cuantitativo por encuesta con la implementación de un cuestionario online autoadministrado, cuya población objeto de estudio está compuesta por el alumnado del Campus María Zambrano de la Universidad de Valladolid (UVa). Los mecanismos de difusión de la misma han sido el correo electrónico universitario con el apoyo del Vicerrectorado del Campus y la creación de un perfil en la red social Instagram ${ }^{8}$, activos del 6 al 20 de abril.

Atendiendo a los datos publicados en el Portal de Transparencia de la propia Universidad en el curso 2020-2021, N=2292. La participación total del cuestionario ha sido de 371 personas, de las cuales 334 han superado el filtro "estudios" que delimitaba dicha participación al ámbito universitario de Segovia en concreto $(N=2292 ; n=334)$. En relación a las condiciones de aplicación del muestreo, al no poder controlar los estratos del mismo, no se puede aplicar un error absoluto produciéndose así una máxima indeterminación. Por lo tanto, entiendo la muestra como intencional en tanto su medio de captación (online) y tomando como referencia a González García, Sosa Hernández y Fierro Martínez (2018), se aplicó un muestreo virtual online.

Como punto de partida y haciendo alusión a las categorías de análisis planteadas por Romero y Plata (2015) en su investigación sobre el acoso universitario, se elabora un total de 3 dimensiones con 4 subdimensiones subyacentes y 12 indicadores que componen la estructuración del cuestionario. En cuanto a la primera de las dimensiones creadas, la sociodemográfica, conociendo y respetando la pluralidad existente dentro de las corrientes de género, así como asumiendo las limitaciones de la presente investigación, se procedió a hacer uso del indicador "sexo" con 3 categorías de respuesta: hombre, mujer y otros. Está última opción solo fue marcada por 2 personas del total de $n$, por lo que se ha desestimado al carecer de representatividad. A continuación, se puede ver la relación existente entre la metodología y objetivos

creados.

\footnotetext{
${ }^{7}$ De igual manera, este estudio tiene vinculación con el I+D+i Internética MCINN (PID 2019104689RB-I00).

${ }^{8}$ Véase la cuenta de Instagram: @sisoycompa_uva
} 
Fuente: Elaboración propia.

\begin{tabular}{|c|c|c|c|c|}
\hline DIMENSIONES & SUBDIMENSIONES & INDICADORES & $\begin{array}{c}\text { PREGUNTAS } \\
\text { CUESTIONARIO }\end{array}$ & $\begin{array}{l}\text { OBJETIVOS } \\
\text { ESPECÍFICOS }\end{array}$ \\
\hline \multirow{3}{*}{\multicolumn{2}{|c|}{ Sociodemográficas }} & Sexo & P.1 & \\
\hline & & Edad & P.2 & \\
\hline & & Estudios & P.3 & \\
\hline \multirow{8}{*}{$\begin{array}{l}\text { Acoso: } \\
\text { características y } \\
\text { forma }\end{array}$} & Presencia & Existencia/ Ausencia & p.1, p.10 & Obj.1.2. \\
\hline & \multirow{5}{*}{ Tipo de agresión } & Manifestaciones & p.2, p.8.2 & $\begin{array}{l}\text { Obj.1.2; } \\
\text { Obj.1.3 }\end{array}$ \\
\hline & & Medio & p.3, p.3.1, p.3.2 & Obj.1.2y \\
\hline & & Motivo acoso & p.6 & $\begin{array}{l}\text { Obj.1.2; } \\
\text { Obj.1.3 }\end{array}$ \\
\hline & & $\begin{array}{l}\text { Ámbito de } \\
\text { repercusión }\end{array}$ & p.4, p.4.1 & Obj.1.2 \\
\hline & & Tipo & p.8, p.8.1 & $\begin{array}{l}\text { Obj.1.2; } \\
\text { Obj.1.3 }\end{array}$ \\
\hline & Abuso de poder & Estructura jerárquica & p.7 & Obj.1.1 \\
\hline & Intencionalidad & Conciencia & p.5 & Obj.1.2 \\
\hline Información & \multicolumn{2}{|l|}{$\begin{array}{l}\text { Información y } \\
\text { contacto }\end{array}$} & \multicolumn{2}{|l|}{ p.9. p.11, p.11.1 } \\
\hline
\end{tabular}

Para el análisis de datos se lleva a cabo, mediante el programa estadístico SPSS, una recodificación de las variables. De esta manera, se procedió a realizar un análisis bivariado descriptivo según las dimensiones creadas y pruebas Chi-Cuadrado para observar la significación estadística existente.

\section{RESULTADOS Y DISCUSIÓN}

Los resultados obtenidos manifiestan una clara tendencia hacia la normalización de comportamientos que denotan indicios de acoso universitario en el entorno del Campus. Mediante el análisis descriptivo señalado y las pruebas Chi-Cuadrado realizadas, en la siguiente tabla se muestra una síntesis de las asociaciones resultantes entre el cruce de variables realizado:

Tabla 2: Síntesis de asociaciones de variables.

\begin{tabular}{|c|c|c|c|}
\hline CRUCE DE VARIABLES & $\begin{array}{c}\text { Chi- } \\
\text { Cuadrada }\end{array}$ & $\mathrm{GL}$ & Valor $p$ \\
\hline Presencia (conocedor/a acoso) *sexo & 1,603 & 1 &, $205^{\star *}$ \\
\hline Estructura jerárquica (quién produce el acoso) * sexo & 1,413 & 3 &, $702^{* *}$ \\
\hline Conciencia*sexo & ,414 & 2 &, $813^{\star \star}$ \\
\hline Medio*sexo & 1,238 & 1 & $266^{* *}$ \\
\hline $\begin{array}{l}\text { Manifestaciones (online-recepción mensajes no } \\
\text { deseados) *sexo }\end{array}$ & ,264 & 1 &, $608^{* *}$ \\
\hline $\begin{array}{l}\text { Manifestaciones (online-divulgación de información } \\
\text { personal sin consentimiento) *sexo }\end{array}$ & , 155 & 1 & $694^{* *}$ \\
\hline $\begin{array}{l}\text { Manifestaciones (online-difusión de bulos entre } \\
\text { compañeros/as) *sexo }\end{array}$ & ,780 & 1 & $377^{* *}$ \\
\hline $\begin{array}{l}\text { Manifestaciones (online-ridiculización de personas } \\
\text { mediante chats de grupo/redes sociales) *sexo }\end{array}$ & 0,10 & 1 &, $919^{* *}$ \\
\hline Medio (espacio concreto) *sexo & 7,087 & 1 & 008 \\
\hline Manifestaciones (marginar socialmente) ${ }^{*}$ sexo & 6,624 & 1 & 010 \\
\hline
\end{tabular}




\begin{tabular}{|c|c|c|c|}
\hline Manifestaciones (marginar socialmente) ${ }^{*}$ edad & 12,031 & 3 & 007 \\
\hline $\begin{array}{l}\text { Presencia (conocedor/a acoso) * presencia (medida } \\
\text { manifestación) }\end{array}$ & 12,664 & 4 & 013 \\
\hline Tipo de acoso (principalmente) ${ }^{\star}$ sexo & 13,938 & 6 & 030 \\
\hline Tipo de acoso (secundario) ${ }^{*}$ sexo & 8,461 & 6 &, $206^{* *}$ \\
\hline Ámbito de repercusión (principal)* sexo & 1,548 & 3 &, $671^{\text {** }}$ \\
\hline Ámbito de repercusión (secundario)*sexo & ,992 & 3 &, $803^{* *}$ \\
\hline
\end{tabular}

Fuente: Elaboración propia a partir de los datos generados en SPSS.

Para comenzar el estudio, se preguntó al estudiantado si era conocedor o ha presenciado acoso, donde la mayor parte del mismo niega este hecho $(81,4 \%)$, representando las mujeres el $80,1 \%$ y los hombres el $86,8 \%$. Pero, atendiendo al objetivo específico 1, cabe destacar que el $95,5 \%$ de los estudiantes afirman que el acoso se produce en mayor medida entre los grupos de pares, donde el $68,3 \%$ asume que se da de forma consciente e inconsciente pero nunca únicamente desde una acción involuntaria. Asimismo, 75,7\% manifiesta que es en el medio online donde se materializa más el acoso en general, y en la red social Instagram en particular $(92,9 \%)$.

Esta tendencia se corrobora al contrastar los datos, en relación al objetivo específico 2 y 3 , aludiendo al acoso digital, el $52,5 \%$ del estudiantado ratifica que ha presenciado 0 es conocedor de la recepción de mensajes reiterados no deseados. Concretamente, el $54 \%$ de las alumnas confirma esta situación frente al $45,5 \%$ de los alumnos. En esta línea, se expone que el 50,8\% confirma el hecho de divulgar información personal sin consentimiento existiendo una diferencia del $7 \%$ entre hombres y mujeres, siendo estas últimas las que más destacan esta situación. En concreto, cuando se habla de la difusión de bulos entre el alumnado, el $57,4 \%$ reitera este escenario, donde las participantes tienen un peso del $60 \%$ y los alumnos un $45,5 \%$. Además, el $62 \%$ de los estudiantes es conocedor o ha presenciado la ridiculización de terceras personas mediante chats de grupo y redes sociales.

Estas actitudes son también reflejadas en el ámbito offline y de sociabilización del estudiantado dentro y fuera del Campus ${ }^{9}$ : el $42,6 \%$ de las mujeres cree que tienen mayor presencia dentro de la Universidad frente al $10 \%$ de los hombres que niegan este hecho. En contraste, el $65,4 \%$ del alumnado sin aplicar una distinción por sexo, cree que es fuera de la sede UVa donde se desenvuelven situaciones de acoso.

Independientemente del medio de acción concreto, se ve una clara inclinación a la marginación social entre e intragrupos ya que el $53,6 \%{ }^{10}$ del conjunto de participantes confirma que ha presenciado como se margina a alguna persona de ese mismo entorno. Las mujeres vuelven a manifestar más estas situaciones teniendo un peso del $57,1 \%$ en el promedio total del cálculo porcentual. Además, sin distinción de sexo, el segmento de edad de 20 a 24 es el que más ha presenciado dicha marginación $(59,1 \%)^{11}$.

Por último y como eje central que rige el objetivo general planteado, asumiendo la significación estadística mostrada al comienzo de dicho análisis, este estudio ha esclarecido que el estudiantado no tiene una conciencia clara desde un prisma abstracto, en tanto a lo que el acoso se refiere; pero que, tras una aproximación y ejemplificación del mismo sí manifiestan su presencia en el entorno universitario. Esto pudo ser contrastado mediante las preguntas de contingencia formuladas para conocer en qué grado se materializa el acoso y si se es conocedor u observador del mismo como. El $81,4 \%$ del alumnado (promedio desagregado al comienzo del apartado mediante la variable sexo) afirma no haber presenciado o ser conocedor de diferentes situaciones

\footnotetext{
${ }^{9}$ Valor $\mathrm{p}(, 008) \leq \alpha(0,05)$

${ }^{10}$ Valor $\mathrm{p}(, 010) \leq \alpha(0,05)$

${ }^{11}$ Valor $\mathrm{p}(, 007) \leq \alpha(0,05)$
} 
de acoso; pero en contraste con los datos anteriormente aportados, preguntando al alumnado nuevamente sobre esta problemática, aquel que negó su presencia en un principio concluye diciendo que entre muchas y bastantes veces se materializan este tipo de situaciones con un peso del $21,4 \%$. Del mismo modo, el $35,7 \%$ sostiene su existencia desde un punto de vista (a veces). Por lo tanto, más de la mitad de la muestra $(57,1 \%)^{12}$ que afirmó previamente no ser conocedora de un contexto con indicios de acoso, manifestó posteriormente un giro discursivo.

De igual manera, el acoso social/relacional es el más destacado $(38,3 \%)^{13}$ por parte del estudiantado, seguido del psicológico secundariamente $(31,4 \%)$. Esto contrasta con el ámbito de repercusión al que afecta principalmente y secundariamente en mayor medida: el psicológico $(94,3 \%)$ y relacional $(73,7 \%)$ respectivamente.

\section{CONCLUSIONES Y LIMITACIONES}

Este estudio piloto de índole descriptivo manifiesta una situación preocupante en el Campus María Zambrano y sirve de precedente para futuras investigaciones en relación al eje temático del acoso en el ámbito universitario, donde se manifiesta la relevancia que implica invertir en este tipo de investigaciones. De igual manera, justifica y legitima la necesidad de aplicar acciones de prevención, así como la reconceptualización y concienciación sobre el imaginario social que envuelve a esta materia. El entorno escolar debe ser entendido a todos los niveles como un lugar de crecimiento, seguridad y apoyo, donde se promueva la igualdad y el respeto, desde un punto de vista teórico pero también práctico. Por lo tanto, proseguir con estos trabajos supone un paso hacia la identificación del problema y su fin.

La importancia manifiesta de las redes en el entorno universitario es clara, pero debe ser fundamental su uso responsable dentro del grupo de pares. Gracias a esta primera aproximación a la realidad vivida en el Campus, se pueden observar unas tendencias de padecimiento en relación a conductas de acoso en los medios.

Por otro lado, la mayor dificultad comprendida en este contexto hace alusión a la muestra obtenida ( $n=334 ; N=2292)$. La obtención de una muestra más grande , y por ende, más representativa del universo de estudio fijado, proporcionaría una visión y unos datos mucho más ricos a los conseguidos en este primer estudio. De igual manera, la dimensión elaborada en el cuestionario entorno al abuso de poder no ha podido ser observada en profundidad, dejando un primer resulto descriptivo sobre indicios de acoso principalmente entre grupos de estudiantes. Por ello, se reitera la asunción de este estudio como base para el desarrollo de próximas investigaciones, donde mediante la implementación de un método secuencial mixto (Creswell, 2009) se profundice en mayor medida sobre los motivos que desencadenan este tipo de actitudes, la normalización de las mismas y el papel activo del estudiantado en cuanto al freno de la tendencia recogida en los resultados.

\footnotetext{
${ }^{12}$ Valor $\mathrm{p}(, 013) \leq \alpha(0,05)$

${ }^{13}$ Valor $\mathrm{p}(, 030) \leq \alpha(0,05)$.
} 


\section{REFERENCIAS BIBLIOGRÁFICAS}

Conde Vélez, S. y Delgado-García, M. (2020). Percepciones del alumnado sobre diferentes tipos de violencia. Adaptación y validación del CUVE3-ESO al contexto Universitario. Revista de Investigación Educativa, 38(2), pp.567581.DOI: http://dx.doi.org/10.6018/rie.364431

Creswell, J, W. (2009).RESEARCH DESIGN Qualitative. Quantitative, and Mixed Methods Approaches. SAGE.

Equipo de Expertos Universidad Internacional de Valencia. (2014). EDUCACION. Las diversas formas de bullying: físico, psicológico, verbal, sexual, social y ciberbullying. Universidad Internacional de Valencia. En https://www.universidadviu.com/es/actualidad/nuestros-expertos/las-diversasformas-de-bullying-fisico-psicologico-verbal-sexual

González García, L. M., Sosa Hernández, J. D. J., y Fierro Martínez, S. D. (2018). Muestreo virtual online basado en redes sociales para localización de teletrabajadores como participantes de un estudio realizado en Victoria de Durango, México. PAAKAT: revista de tecnología y sociedad, 8(15), pp. 21-38.

Martínez Ramón, J. P., Méndez, I., Ruiz-Esteban, C., y Cerezo, F. (2020). Validación y fiabilidad del Cuestionario sobre Acoso entre Estudiantes Universitarios (QAEU). Revista Fuentes, 22(1), pp. 88-104.

Méndez, I., Ruiz-Esteban, C., Martínez Ramón, J. P., y Cerezo, F.(2019). ACOSO ESCOLAR EN EL ÁMBITO UNIVERSITARIO. Behavioral Psychology/Psicologia Conductual, 27(1).

Romero, A. y Plata, J. V. (2015). Acoso escolar en universidades. Enseñanza e Investigación en Psicología, 20(3), pp.266-274.

UNESCO (2019). Behind the numbers: Ending school violence and bullying. United Nations Educational, Scientific and Cultural Organization, Paris, France. 


\subsubsection{La competencia prosódica de las y los jóvenes bilingües}

vascos en el relato de un cuento: la importancia del género

Aitor Iglesias (UPV/EHU, España); Naia Eguskiza (UPV/EHU, España); Aintzane

Etxebarria (UPV/EHU, España); Juan Abasolo (UPV/EHU, España)

\section{Resumen}

Este trabajo tiene como objetivo especificar si existen diferencias en el relato del cuento tradicional de "Caperucita Roja" según el género de la o el informante analizando aspectos suprasegmentales de la competencia prosódica. Para realizar este estudio se han recogido 4539 textos de los que se han analizado los aspectos suprasegmentales de 40 grupos prosódicos. Los grupos prosódicos están compuestos por 5, 6, 7, 8, 9 y 10 sílabas, varias muestras por cada uno de los grupos. Han tomado parte 101 jóvenes bilingües del País Vasco de entre 18 y 25 años. Tras analizar los relatos se ha visto que no existen diferencias estadísticamente significativas en los aspectos suprasegmentales de la competencia prosódica según el género. Este hallazgo es subrayable y se debería tener en cuenta en los futuros trabajos en esta dirección.

Palabras clave: género; euskera; prosodia, competencia prosódica; bilingüismo.

\section{INTRODUCCIÓN Y OBJETIVOS}

En este trabajo primeramente se define el marco conceptual haciendo un breve acercamiento al estado actual del término del género y uniéndolo con la pragmática y con la competencia prosódica. El género ha recibido diferentes definiciones, enfoques y abordajes a través de los años y los estudios realizados (García Leiva, 2005; De Juan \& Pérez, 2007, entre otros). En lo que respecta a la prosodia, la RAE define la prosodia como "parte de la gramática que enseña la correcta pronunciación y acentuación. Estudio fonético y fonológico de los elementos que se refieren a unidades superiores al fonema, como las sílabas u otras secuencias de la palabra u oración". Además, en este trabajo se hace un acercamiento al género desde la competencia prosódica (Lakoff, 1975). Creando así un puente entre los dos ejes principales de la investigación: el género y la competencia prosódica. Una vez definido el marco teórico y conceptual se explica la metodología empleada para alcanzar el objetivo principal y los resultados obtenidos. El objetivo principal de este trabajo, teniendo en cuenta la clasificación clásica del género (femenino o masculino), es explicar si existen diferencias estadísticamente significativas en el relato espontáneo en voz alta de 101 jóvenes bilingües del País Vaco, analizando algunas características suprasegmentales según el género.

Por lo tanto, en este trabajo se definirá qué es el género, ya que ha sido definido desde diferentes puntos de vista en diferentes épocas y se acercará a la pragmática y a la competencia prosódica a través de la investigación propuesta para alcanzar el objetivo principal de la investigación.

\section{METODOLOGÍA}

Para la elaboración del corpus objeto de estudio han participado 101 jóvenes bilingües del País Vasco de los cuales 10 hablan euskera y francés y 91 euskera y castellano. En cuanto al género, se les pidió que especificaran el género, como no se reportaron casos de clasificación no binaria son 55 mujeres y 46 hombres de entre 18 y 25 años. En cuanto al euskera, poco más de la mitad lo aprendieron en casa (grupo A: 56) y el resto en la escuela (grupo B: 45), por lo que se distinguen dos grupos: A y B. Para la recogida del corpus, se les solicitó que contaran en voz alta y de manera espontánea el cuento 
"Caperucita Roja" en un entorno silencioso para poder realizar las grabaciones para su posterior análisis.

Las grabaciones se realizaron con dos grabadoras: Marantz PMD620 y ZOOMH4 junto con un micrófono externo de solapa. En total se recogieron 4539 muestras con significado comprendido entre dos pausas. De entre las muestras, se escogieron 40 grupos prosódicos, que han sido analizados atendiendo a los aspectos suprasegmentales (cumbres tonales y tonos de frontera) de la competencia prosódica y cuyos resultados se muestran en esta investigación según el género de las y los informantes. Esos grupos prosódicos están compuestos por estructuras de 5 sílabas ( 5 muestras), 6 sílabas (10 muestras), 7 sílabas ( 7 muestras), 9 sílabas (5 muestras), 10 sílabas (4 muestras) y 8 sílabas (dos estructuras cada una de 5 muestras).

Para el etiquetado y anotado de los grupos prosódicos se ha utilizado el programa Praat (Boersma \& Weenink, 2021) basándonos en la teoría de la jerarquía prosódica (Selkirk, 1995; Nespor \& Vogel, 1986) y en la notación métrica autosegmental (Pierrehumbert, 1980; Beckman \& Pierrehumbert, 1986; Pierrehumbert \& Beckman, 1988; Sag \& Liberman, 1975), la cual se basa en el análisis fonético de la curva f0 dentro del grupo prosódico.

\section{RESULTADOS Y DISCUSIÓN}

En este apartado se expondrán los resultados según el género, el número de sílabas y el tipo de estructura. Se han analizado las estructuras de 5 sílabas (5 muestras), 6 sílabas (10 muestras), 7 sílabas (7 muestras), 9 sílabas (5 muestras), 10 sílabas (4 muestras) y 8 sílabas (dos estructuras cada una de 5 muestras) y se determinará si existen diferencias según el género.

Dentro de los grupos prosódicos se han definido el primer sintagma y el segundo sintagma. Ambos están formados por elementos léxicos (L1 cuando sólo hay un componente y L2 si hay un segundo componente lexical) y sílabas (sílaba 1, sílaba 2, etc.). Los grupos prosódicos de 8 sílabas tienen dos estructuras.

Para analizar la influencia del género en las estructuras ya mencionadas, se ha realizado el test de normalidad y posterior se ha procedido a los análisis ANOVA o Ji cuadrado. En las variables cantidad de sílabas, la cumbre del segundo sintagma y la cumbre del grupo prosódico se ha procedido a aplicar la prueba ANOVA y hemos comprobado que no existen diferencias estadísticamente significativas entre estos tres rasgos y el género de las y los informantes.

En los otros dos casos restantes, en la cumbre del primer sintagma y en la posición de la cumbre según el sintagma se ha procedido al análisis de Ji cuadrado para ver si existe relación según el género. Se ha comprobado que no existe relación estadísticamente significativa entre la cumbre del primer sintagma y la posición de la cumbre según el sintagma en base al género de las y los jóvenes.

\section{CONCLUSIONES Y LIMITACIONES}

Por medio de las características suprasegmentales, conseguimos la función pragmática que nos proponemos, puesto que damos sentido a lo que decimos, contamos, explicamos, mantenemos una conversación, y, además, expresamos emociones y actitudes. Pese a que en los resultados no se han hallado diferencias significativas estadísticamente ni relaciones entre el género y los distintos aspectos suprasegmentales de la competencia prosódica analizados, se considera importante y se pretende subrayar este hallazgo; ya que, aunque en otras ocasiones sí hemos encontrado este tipo de diferencias según el género (Gaminde et al., 2016; Etxebarria et al., 2018; Eguskiza et al., 2018), en este caso no se corroboran a un nivel de confianza del $95 \%$, como se estila en los estudios de ámbito social. Esta ausencia de diferencias 
estadísticamente significativas es un hecho subrayable y así queremos mostrar en este trabajo, siendo esa la conclusión principal y más importante de esta investigación. Además, partiendo de estas conclusiones el siguiente paso es de cara a futuros trabajos seguir indagando en este enfoque, por ejemplo, analizando la influencia del género en la competencia prosódica de los textos leídos en voz alta.

\section{REFERENCIAS BIBLIOGRÁFICAS}

Beckman, M., \& Pierrehumbert, J. (1986). Intonational structure in Japanese and English. Phonology Yearbook, 3, pp. 15-70.

Boersma, P. \& Weenink, D. (2021). Praat: doing phonetics by computer. https://www.fon.hum.uva.nl/praat/

De Juan, J. \& Pérez, R. M. (2007). Sexo, género y biología. Feminismo-s, 10, pp.163.

Eguskiza, N., Gaminde, I., Romero, A. \& Etxebarria, A. (2018). Influencia de factores externos en la duración silábica. Dialectologia, 21, pp. 61-82.

Etxebarria, A., Eguskiza, N., Gaminde, I. \& Romero, A. (2018). Ahots seduzitzaileen ezaugarriak generoaren ikuspegitik. En L. Unamuno, A. Romero, A. Etxebarria \& A. Iglesias (Eds.), Linguistic variation in the basque language and education - III. Euskararen bariazioa eta bariazioaren irakaskuntza - III. (pp. 43-59). Servicio Editorial de la Universidad del País Vasco.

Gaminde, I., Garay, U., Etxebarria, A. \& Romero, A. (2016). Generoaren eragina oinarrizko emozioetan. Anuari de Filologia. Estudis de Lingüística, 6, pp.1-26.

García-Leiva, P. (2005). Identidad de género: modelos explicativos. Escritos de Psicología-Psychological Writings, (7), pp. 71-81.

Lakoff, R. (1975). Women's language. Women's Language and Style, pp. 139-58.

Pierrehumbert, J. B. (1980). The phonology and phonetics of English intonation. [Tesis doctoral]. Massachusetts Institute of Technoloy.

Pierrehumbert, J., \& Beckman, M. (1988). Japanese Tone Structure. MIT.

Sag, I., \& Liberman, M. (1975). The intonational disambiguation of indirect speech acts. Proceedings of the Chicago Linguistics Society, 11, pp. 487-497.

Selkirk, E. (1995). The prosodic structure of function words. Papers in optimality theory, 18, pp. 439-469. 


\subsubsection{Una mirada interseccional sobre el sexismo: buscando sus relaciones con la homofobia internalizada \\ Miguel Ángel López Sáez (Universidad Rey Juan Carlos)}

\section{Resumen}

En el trabajo se exploran las conexiones del constructo de sexismo con otras variables sociodemográficas y actitudinales (como la negatividad internalizada y las resistencias heteronormativas) entre alumnado de psicología. Se usaron análisis no refinados e inferenciales. Método: se seleccionó una muestra representativa de 841 estudiantes de psicología de las universidades públicas madrileñas de entre 17-60 años (Asimetría = 6,09, Mdn = 20, MD = 1). Resultados: existen mayores niveles de sexismo, negatividad internalizada y bajas resistencias a la heteronorma entre hombres, personas heterosexuales y conservadoras; las correlaciones varían en función de la orientación sexual; la afiliación política fue el predictor más frecuente. Conclusiones: se hace necesaria una óptica interseccional para comprender el fenómeno del sexismo.

Palabras clave: Sexismo ambivalente; Negatividad internalizada; Resistencias heteronormativas; Estudio ex post facto.

\section{INTRODUCCIÓN Y OBJETIVOS}

Casi cinco lustros después de que la Association of American Colleges and Universities indicara que el acoso sufrido por las mujeres en la universidad suponía una merma invisibilizada de la equidad de género, los datos reiteran que la desigualdad sigue siendo una materia pendiente. En 2018 las denuncias o quejas de acoso presentadas en las universidades españolas ascendían a 236 (Jara, 2018). Sin embargo, diferentes estudios señalan que son muchas más las estudiantes que sufren acoso y no denuncian (Blahopoulou et al., 2018).

Otro sector de la población que sufre un acoso en la universidad son las personas lesbianas $(L)$, gays $(G)$, bisexuales $(B)$ y trans $(T)$, como indican las investigaciones nacionales e internacionales (Biglia y Cagliero, 2019; Hughes, 2018; Rebollo et al., 2018). La literatura confirma una alianza entre actitudes sexistas y LGBTfóbicas (LópezSáez et al., 2020), y también sobre las violencias derivadas (Biglia y Cagliero, 2019).

Por ello, es importante reflexionar sobre las creencias y discursos que articulan esas conductas de acoso contra las mujeres, que son claves en la normalización del mismo. Además, así lo indica la legislación y los compromisos adquiridos en materia educativa y de investigación, tanto a nivel internacional, europeo, como nacional. Todo esto es de especial relevancia en algunos colectivos como los futuros graduados en psicología para su futuro ejercicio profesional, tal como se recoge en el Libro Blanco de la Psicología.

El sexismo permite una jerarquización del privilegio, donde los hombres heterosexuales y cisgénero se encuentran en la cúspide y el resto por debajo (Connell, 2014). La existencia de actitudes negativas hacia las personas LGBT está mediada por muchos factores. Algunos ejemplos son: la identidad de género, el conocimiento y contacto con la comunidad, la ideología política, la edad, la religiosidad o el sexismo. El sexismo, parece ser uno de los predictores más determinantes del grado de LGBTfobia y en particular de la homofobia (Warriner et al.,2013). El sexismo no parece influir únicamente en la percepción en contra de personas no heterosexuales, sino en el autoconcepto negativo que las propias personas heterodisidentes desarrollan de sí mismas. Por tanto, el sexismo contribuye a garantizar la prevalencia de las esferas 
tradicionales de feminidad y masculinidad mediante la interiorización de un rechazo a la propia orientación no heterosexual.

El presente trabajo tiene como objetivo investigar las relaciones entre el constructo de sexismo y la negatividad internalizada. En ese sentido observa las diferencias según orientación sexual e identidad de género y la relevancia de diferentes variables como la resistencia a las normas heterosexuales, la afiliación política y el contacto con personas LGB.

\section{METODOLOGÍA}

\section{Procedimiento}

Se realizó un muestreo aleatorio estratificado con afijación proporcional para las 3 universidades.

\section{Instrumentos}

- Cuestionario sociodemográfico.

- Ambivalent Sexism Inventory (ASI). Usamos la versión corta de Rollero el tal. (2014).

- Scale of Homonegativity Internalized (SIHS). Su versión corta española de Morell-Mengual et al. (2016)

- Heteronormative Expectations Resistance Subscale (PPS-RHE). Se usó la subescala de la Escala de Prejuicios Polimorfos de Badenes-Ribera et al. (2016).

- Marlowe-Crowne Social Desirability Scale (MCSDS). A modo de control, se aplicó la versión corta española de Gutiérrez et al. (2016).

\section{RESULTADOS Y DISCUSIÓN}

El presente estudio permite explorar las diferencias con respecto al grado de sexismo entre heterosexuales y LGB. Además, facilita la comprensión de otras variables que pueden influir en los niveles de sexismo.

Los resultados de los análisis de covarianza reafirman la importancia que tiene la identidad de género (el hecho de ser mujer u hombre) para marcar diferencias en ambos sexismos. Estas diferencias, también, se dan en base a la orientación sexual (heterosexuales y LGB), siendo más claras dentro de la muestra de mujeres y hombres heterosexuales. La afiliación política, es otra de las variables que resulta un buen indicador del grado de sexismo. En general, los resultados mostraron un menor grado de sexismo entre mujeres, personas LGB y personas de izquierdas.

Esos mismos grupos suelen ser los que a su vez mantienen mayores resistencias a la adhesión a normas conservadoras con los roles y la moralidad sexual (PPS-RHE). Lo que concuerda con lo expuesto por las teorías del sistema sexo/género/sexualidad (Westbrook y Schilt, 2014). Estas teorías vinculan al hombre heterosexual como un sujeto privilegiado en detrimento del resto. Según esta teoría, existe una pirámide con diferentes estamentos que disfrutan más o menos de un marco de privilegios. El disfrute varía en función de la cercanía a la cúspide. En esa cúspide estaría el cishombre con una masculinidad tradicional y heterosexual.

Por ejemplo, en nuestro estudio, en algún nivel de esa pirámide estarían los hombres GB, que mostraron niveles de ASI-BS más altos que todos los grupos de mujeres. También, las diferencias entre grupos (a pesar de no resultar significativas) en cuanto a afiliación política denotan una cierta tendencia. Incluso entre las personas que 
pertenecen a "grupos oprimidos", las personas del espectro de derechas tienen niveles tan altos de sexismo como los que se situarían en la cúspide piramidal. Por tanto, parece que a pesar de las represalias por perturbar el status quo, las personas LGB pueden exhibir actitudes sexistas cuando los parámetros conservadores entran en juego.

Nuestros resultados nos dicen que ser LGB y tener actitudes sexistas se correlaciona con los componentes de la negatividad internalizada, especialmente con SIHS-SEXC. De esta manera, la asunción de cánones sexistas podría asociarse a la consideración de que lo adecuado es una sexualidad con unos roles y una moralidad acordes a lo establecido por el modelo heterosexual (Warriner et al., 2013). Además, hay que considerar que al menos en términos teóricos, los componentes del sexismo referidos a la intimidad heterosexual y la diferenciación de género prescriben un auto LGBnegatividad. Ese sexismo promueve la no identificación y la negación de interacciones sexuales y sociales con personas LGB.

La intersección de la variable identidad de género, influye en la intensidad de las correlaciones entre SIHS y sexismos. Así, entre hombres GB, las correlaciones fueron más altas y con mayor significación. Lo que podría tener que ver con la relación que se puede establecer entre la consideración de lo femenino como amenaza para el papel social de los hombres GB (ASI) y el miedo a ser asociado con aspectos de la feminidad vinculados a lo homoerótico (SIHS). Entrarían aquí aquellos que participan de la lógica homonormativa, por ejemplo: "soy gay, pero soy masculino y me gusta lo masculino". Ese miedo a la pérdida del privilegio masculino que implicaría la feminidad evidencia una vez más la pirámide de jerarquías sociales (Johnson y Samdahl, 2005;).

En la muestra heterosexual tanto PPS-RHE como la falta de contacto con personas bisexuales, fueron las que mejores correlaciones mostraron con el sexismo.

Con respecto a PPS-RHE, esa mayor correlación y significación dentro de la muestra heterosexual podría ser debido a las diferentes implicaciones que tiene la ruptura de las heteronormas. Para las personas heterosexuales, la ruptura puede suponer un cuestionamiento de las esferas tradicionales de masculinidad y feminidad (en las que se basan los componentes del sexismo). Mientras que para las personas LGB no tiene porqué, ya que la baja correlación parece indicar una convivencia separada entre las resistencias a la heternorma separada de las creencias sexistas. Sin embargo, entre personas LGB, la convivencia es asociada entre creencias que generan auto estigmatización hacia la propia orientación en diferentes planos y las creencias sexistas.

Con respecto a la correlación entre la falta de contacto de heterosexuales con $B$ y los sexismos, parece que el contacto podría influir en la protección frente al sexismo (al menos entre heterosexuales). Sin embargo, las menores correlaciones de la falta de contacto con personas LG y las ambivalencias en las correlaciones existentes en la muestra LGB plantean cierta cautela en tal afirmación. El contacto con personas LGB (que transgreden los roles y expresiones de género tradicionales) podría ser un factor de protección al concienciar sobre violencias basadas en el sexismo. Sin embargo, en sociedades como la española donde la gran aceptación social de personas LGB posibilita el conocerlas, el simple contacto no siempre va relacionado a esas protecciones (Badenes-Ribera et al., 2016).

De nuevo, hay que destacar que la variable afiliación política con respecto a los análisis de correlación. La afiliación política resultó significativa en casi todos los grupos de la muestra tanto en hombres como mujeres heterosexuales y LGB. Lo que denota la importante influencia de esta variable. Son multitud los estudios que han venido viendo la asociación entre sexismo y tener una afiliación política escorada a la derecha (Warriner et al., 2013). 
En ese sentido, los análisis predictivos permitieron completar una visión más integral sobre el grado de influencia de esa variable y otras. La variable con mayor potencial predictivo para ambos sexismos en el conjunto de la muestra fue la afiliación política, seguida de la identidad de género. La orientación sexual añadió un ínfimo nivel de la varianza sólo en el caso de ASI-HS. También en la muestra heterosexual, PPS-RHE añadió un ínfimo nivel de varianza, que para ASI-BS y entre hombres resultó nulo.

En la muestra LGB, SIHS-SEXC fue la variable que con más frecuencia mejoró el nivel de varianza explicada por la afiliación política. Aunque para el grupo de hombres GB no ocurrió así, ya que sólo SIHS-SOOC resultó un adecuado predictor para ASI-BS. La ausencia de predicción de ASI-BS por parte de la afiliación política entre hombres GB podría resultar relevante, ya que indicaría que el cambio de afiliación política en ese grupo y para ese sexismo no es tan relevante como lo es SIHS-SOOC.

\section{CONCLUSIONES Y LIMITACIONES}

La necesidad de la inclusión de una perspectiva interseccional en la investigación empírica resulta imprescindible para una visión integral del sexismo. La interseccionalidad facilita un análisis que visibiliza diferentes variables mediadoras y predictoras que se chocan o forman parte de los "ladrillos del muro de la opresión" (Ahmed, 2018).

Los análisis han permitido desvelar, contrariando la lógica razonable, cómo un grupo que sufre la opresión puede a su vez mantener actitudes negativas hacia otros grupos e incluso hacia sí mismo. Es decir, parece que las personas LGB aprenden las actitudes hegemónicas.

También, el estudio del sexismo con personas LGB ha generado algunas dudas sobre las que sería interesante reflexionar. EI ASI para medir el ASI-BS considera la dimensión de intimidad heterosexual para una población que no practica tal intimidad. Si bien es cierto que la población LGB podría asumir la internalización sexista como propia y considerar adecuada tal intimidad, podría darse la posibilidad de no considerarla y aceptar otros parámetros del ASI-BS como son el cuidado y la protección de las mujeres y lo femenino. Sin embargo, en el caso que exponemos (de no considerar la intimidad heterosexual), aunque los hombres homosexuales tengan ciertos niveles de ASI-BS, siempre tendrán menores puntuaciones que los heterosexuales.

Además, los resultados indicaron cómo ser estudiantes de la psicología no es garantía de estar libre de actitudes sexistas, de reconocer las presiones de la normatividad sexual dominante o de tener menor autoestima (cuando se es LGB).

Todos estos descubrimientos y dudas necesitan más investigación para comprender mejor las complejas relaciones y mecanismos relacionados con el sexismo y la LGBnegatividad internalizada. 


\section{REFERENCIAS BIBLIOGRÁFICAS}

Ahmed, S. (2018). Vivir una vida feminista. Bellaterra.

Badenes-Ribera, L., Frias-Navarro, D., Monterde-i-Bort, H., \& Pascual-Soler, M. (2016). Spanish validation of the polymorphous prejudice scale in a sample of university students. Journal of homosexuality, 63(11), 1517-1536. https://doi.org/10.1080/00918369.2016.1223349

Biglia, B., \& Cagliero, S. (2019). Abordajes y 'respuestas' de las universidades catalanas frente a las violencias LGTBIQ+ fóbicas. Quaderns de psicologia. International journal of psychology, 21(2), 1-19. https://doi.org/10.5565/rev/qpsicologia.1532

Blahopoulou, J., Ferrer Pérez, V. A., and Bosch Fiol, E. (2012). "El acoso sexual en el ámbito universitario: estudio comparativo de la percepción diferencial entre alumnos y alumnas," in Actas del IV Congreso Universitario Nacional Investigación y Género: Investigación y género, inseparables en el presente y en el futuro, ed. I. Vázquez (Sevilla: Universidad de Sevilla), 191-214.

Connell, R. (2014). Margin becoming centre: For a world-centred rethinking of masculinities. NORMA: International Journal for Masculinity Studies, 9(4), 217231. https://doi.org/10.1080/18902138.2014.934078

Gutiérrez, S., Sanz, J., Espinosa, R., Gesteira, C., \& García-Vera, M. P. (2016). La Escala de Deseabilidad Social de Marlowe-Crowne: baremos para la población general española y desarrollo de una versión breve. Anales de Psicología/Annals of Psychology, 32(1), 206-217.

Jara, Y. (2018). Más de la mitad de las universidades públicas españolas registran casos de acoso. Píkara Magazine

Johnson, C. W., \& Samdahl, D. M. (2005). "The night they took over": Misogyny in a country-western gay bar. Leisure Sciences, 27(4), 331-348. https://doi.org/10.1080/01490400590962443

López-Sáez, M. Á., García-Dauder, D., \& Montero, I. (2020). Correlate Attitudes Toward LGBT and Sexism in Spanish Psychology Students. Frontiers in Psychology, 11. e2063, 1-11. https://doi.org/10.3389/fpsyg.2020.02063

Morell-Mengual, V., Gil-Llario, M. D., Ballester-Arnal, R., \& Salmerón-Sanchéz, P. (2017). Spanish Adaptation and Validation of the Short Internalized Homonegativity Scale (SIHS). Journal of sex \& marital therapy, 43(4), 298-305. https://doi.org/10.1080/0092623X.2016.1149128

Warriner, K., Nagoshi, C. T., \& Nagoshi, J. L. (2013). Correlates of homophobia, transphobia, and internalized homophobia in gay or lesbian and heterosexual samples. Journal of homosexuality, 60(9), 1297-1314. https://doi.org/10.1080/00918369.2013.806177

Westbrook, L., \& Schilt, K. (2014). Doing gender, determining gender: Transgender people, gender panics, and the maintenance of the sex/gender/sexuality system. Gender \& Society, 28(1), 32-57.https://doi.org/10.1177/0891243213503203 


\subsubsection{Análisis de la estructura del Plan de Estudios del grado en Educación Primaria de la Universidad De Huelva respecto a la formación en diversidad afectivo-sexual \\ José Ramón Márquez Díaz (Universidad de Huelva, España); Irene Galán Ríos (Universidad de Huelva, España)}

\section{Resumen}

En la actualidad, la formación de los/as docentes y, más concretamente, de los/as futuros/as docentes en diversidad afectivo-sexual es muy importante. No obstante, se han llevado a cabo estudios que concluyen en la idea de que la formación que se ofrece en las universidades respecto a esta temática, la diversidad afectivo-sexual, no es la más adecuada. Partiendo de esta premisa, el objetivo del presente estudio es analizar la estructura del plan de estudios del Grado en Educación Primaria de la Universidad de Huelva respecto a la formación en diversidad afectivo-sexual. Los resultados arrojados evidencian que nos encontramos ante un plan de estudios que, en líneas generales, apuesta por la diversidad afectivo-sexual, si bien es cierto que se deberían incorporar más elementos relacionados con dicha temática en el mismo.

Palabras clave: plan de estudios; Grado en Educación Primaria; universidad; diversidad afectivo-sexual; investigación educativa.

\section{INTRODUCCIÓN Y OBJETIVOS}

En la actualidad, en la escuela vemos un reflejo de la sociedad, un reflejo en el que predomina un sistema patriarcal y androcéntrico, donde lo aceptado es la heteronormatividad, por lo que todos aquellos y todas aquellas que se encuentran fuera de la misma, pueden ser considerados/as como un colectivo vulnerable (Maldonado, 2018). Ante esto, los/as docentes, entre otros agentes sociales, deberían contar con la formación necesaria en esta temática, la diversidad afectivo-sexual, con el objetivo de crear instituciones de enseñanza cada vez más inclusivas; esto es, instituciones de enseñanza que acojan a todas las personas, independientemente de las características individuales de cada una de ellas (Salas Guzmán y Salas Guzmán, 2016).

Siguiendo la línea anterior, De Jesús, Cantera, Pereira y Santos Federal (2016) sostienen que la formación de los/as docentes en diversidad afectivo-sexual es fundamental; sin embargo, a veces, este colectivo no sabe cómo actuar frente a esta temática debido, entre otros aspectos, a la escasa formación que reciben en las universidades respecto a la diversidad afectivo-sexual, así como todos aquellos elementos que giran en tono a la misma.

En esta tónica, Rodríguez Pareja (2020) destaca que la formación que se ofrece en las instituciones de educación superior en cuanto a la diversidad afectivo-sexual no es la más adecuada, a lo que añade que sería necesario implementar una metodología eficaz, a través de la cual los/as futuros/as docentes tengan la oportunidad de reflexionar y ser conscientes de sus propios estereotipos. Por este motivo, Salas Guzmán y Salas Guzmán (2016) defienden la idea de que se debe apostar por una perspectiva de reflexión en la práctica para la reconstrucción social, en la cual se promueva el pensamiento crítico del alumnado, entre otros aspectos.

En base a todo lo expuesto a lo largo del presente apartado, es necesario destacar que distintos países se han centrado en generar políticas educativas, con el propósito principal de erradicar esta situación en todas sus manifestaciones, mediante la creación 
y puesta en marcha de legislaciones y planes de estudios que así lo establecen. Un claro ejemplo de ello es España que, a través de la Ley Orgánica 2/2006, de 3 de mayo, de Educación (LOE), vino a disponer por primera vez en una legislación educativa, como uno de los fines de la educación, el pleno desarrollo de la personalidad y de las capacidades afectivas del alumnado, la formación en el respeto de los derechos y libertades fundamentales y de la igualdad efectiva de oportunidades entre hombres y mujeres, el reconocimiento de la diversidad afectivo-sexual, así como la valoración crítica de las desigualdades, que permita superar los comportamientos sexistas. Posteriormente, la Ley Orgánica 8/2013, de 9 de diciembre, para la Mejora de la Calidad Educativa (LOMCE), mantuvo dicho fin. En consecuencia, todo ello ha incidido en la necesidad de formar a las nuevas generaciones de docentes en perspectiva de género, potenciando así, en la medida de lo posible, la igualdad de oportunidades a todas las personas.

Precisamente, el objetivo general de este trabajo es analizar la estructura del plan de estudios del Grado en Educación Primaria de la Universidad de Huelva respecto a la formación en diversidad afectivo-sexual. Ante esto, Roldán Santamaría (2005) sostiene que debemos abogar por analizar los planes de estudios de los/as futuros/as docentes para integrar de una manera más adecuada en los mismos aspectos relacionados con la diversidad afectivo-sexual. En este sentido, esta autora hace alusión a ciertos elementos que se deben tener en cuenta en todo análisis de un plan de estudios: objetivos, contenidos, competencias, metodologías docentes y sistemas de evaluación.

\section{METODOLOGÍA}

La presente investigación se ampara en una metodología de corte cualitativo. Para ello, a través de una rejilla creada para tal fin (compuesta por diferentes apartados: nombre de la asignatura, curso, semestre, objetivos, contenidos, competencias, metodologías docentes y sistemas de evaluación), se han analizado las 66 guías docentes que forman parte del Grado en Educación Primaria de la Universidad de Huelva. El procedimiento consistió en descargar todas las guías docentes de la página web de la Facultad de Educación, Psicología y Ciencias del Deporte de la Onubense, y, posteriormente, analizar las mismas. Este proceso tuvo una duración de dos meses.

\section{RESULTADOS Y DISCUSIÓN}

En primer lugar, respecto a los objetivos que están relacionados con la diversidad afectivo-sexual y que aparecen en las guías académicas de algunas de las asignaturas, encontramos los siguientes: favorecer la espontaneidad y la comunicación interpersonal; potenciar la adquisición de actitudes y hábitos de reflexión, observación e indagación ante los problemas que plantean las diversas situaciones de inclusión en las aulas y centros escolares; conocer diferentes aspectos en torno a las relaciones que se dan entre la familia y la escuela; analizar la escuela inclusiva, modalidades de escolarización y medidas de atención a la diversidad; conocer y analizar las distintas NEAE, así como las diversas estrategias de apoyo; conocer y analizar el papel de la familia en el desarrollo del alumnado; conocer las orientaciones básicas de la Didáctica de Ciencias Experimentales para adecuar las propuestas de enseñanza a la Educación Primaria, y promover el desarrollo personal del alumnado y la sostenibilidad del planeta Tierra, así como la igualdad de género, la equidad y el respeto de los derechos humanos.

Partiendo de la información expuesta en el párrafo anterior, aunque las guías académicas de algunas de las asignaturas de la titulación cuentan con objetivos que, en un principio, podrían estar relacionados con la atención a la diversidad, deberíamos 
tener en cuenta la aportación de Gimeno (1999), autor que sostiene que hay que considerar las limitaciones y posibilidades de cada persona; esto es, no podemos establecer unos mismos criterios curriculares (objetivos, contenidos, competencias etc.) para todos/as. En este sentido, es conveniente que la respuesta educativa sea personalizada; es decir, en función de las características individuales de cada sujeto.

En segundo lugar, respecto a los contenidos que están relacionados con la diversidad afectivo-sexual y que aparecen en las guías académicas de algunas asignaturas, encontramos los siguientes: construcción del esquema corporal; desarrollo social, de la personalidad y de los vínculos afectivos; autoconcepto; autoestima; interacciones en el aula; nuevas perspectivas de intervención; atención a la diversidad, etc. A este respecto, además de los contenidos descritos en este párrafo, contenidos que están insertos en asignaturas específicas del plan de estudios, García et al. (2013) destacan la importancia de introducir contenidos transversales relacionados con la diversidad afectivo-sexual en el currículum de la titulación de magisterio, para potenciar la inclusión educativa de todo el alumnado.

En tercer lugar, respecto a las competencias que están relacionadas con la diversidad afectivo-sexual y que aparecen en las guías académicas de algunas asignaturas, encontramos las siguientes: G5 - trabajar de forma colaborativa; G6 - comportarse con ética y responsabilidad social como ciudadano y como profesional; G18 - compromiso ético para el ejercicio de las tareas docentes; G19 - capacidad de adaptarse a nuevas situaciones en una sociedad cambiante y plural; G20 - relación con diversos interlocutores sociales; E2 - conocer las características de estos estudiantes, así como las características de sus contextos motivacionales y sociales; E3 - dominar los conocimientos necesarios para comprender el desarrollo de la personalidad de estos estudiantes e identificar disfunciones; E6 - identificar y planificar la resolución de situaciones educativas que afectan a estudiantes con diferentes capacidades y distintos ritmos de aprendizaje; E11 - conocer los procesos de interacción y comunicación en el aula; E12 - abordar y resolver problemas de disciplina; E13 - promover el trabajo cooperativo y el trabajo y esfuerzo individuales; E14 - promover acciones de educación en valores orientadas a la preparación de una ciudadanía activa y democrática; E22 relacionar la educación con el medio, y cooperar con las familias y la comunidad.

En base a lo expuesto en el párrafo anterior, Gimeno (1999) sostiene que hay que tener en cuenta las limitaciones y posibilidades de cada persona, esto es, no podemos establecer unos mismos criterios curriculares (objetivos, contenidos, competencias etc.) para todos/as. En esta línea, es conveniente que la respuesta educativa sea personalizada, es decir, en función de las características individuales de cada sujeto.

En cuarto lugar, respecto a las metodologías docentes relacionadas con la diversidad afectivo-sexual, encontramos las siguientes: trabajos de grupo; aprendizaje colaborativo; role-playing; salida de campo. Estas metodologías docentes son similares a las que se reflejan en otros estudios, donde, por ejemplo, Domínguez y Vázquez (2015) expresaron que, para el desarrollo de una comunidad educativa inclusiva, se debe trabajar de forma cooperativa y en grupos heterogéneos.

Por último, en quinto lugar, respecto a los sistemas de evaluación que están relacionados con la diversidad afectivo-sexual y que aparecen en las guías académicas de la titulación seleccionada para este estudio, encontramos los siguientes: realización de trabajos colaborativos y puesta en común de lo trabajado; trabajos en grupo. Además de ello, De Stéfano et al. (2015) manifestaron la importancia de crear técnicas cualitativas para fomentar actitudes positivas en el alumnado hacia el fenómeno de la diversidad afectivo-sexual. Inicialmente, se debe utilizar la técnica de la observación participante para conocer y analizar las particularidades de las personas. Posteriormente, se pone en marcha un conjunto de talleres sobre diversidad corporal, afectivo-sexual y familiar. En los talleres se deberían registrar los comportamientos, los 
discursos y las actitudes, con el fin de seguir generando nuevas estrategias, las cuales permitan seguir trabajando el fenómeno de la diversidad afectivo-sexual desde diferentes enfoques.

\section{CONCLUSIONES Y LIMITACIONES}

En conclusión, la humilde aportación de esta investigación permite albergar evidencias empíricas sobre la posibilidad de introducir en los procesos de enseñanza aprendizaje puestos en marcha en las carreras universitarias la formación en diversidad afectivosexual, bien sea a través del currículum oficial de las titulaciones universitarias de grado o a través del currículum oficial de las titulaciones universitarias de posgrado, titulaciones universitarias todas ellas relacionadas, por ejemplo, con el ámbito educativo.

Y como queda plasmado a lo largo de todo el trabajo de investigación, es importante insistir a las personas encargadas de crear las políticas educativas sobre el hecho de considerar la formación en diversidad afectivo-sexual como algo inseparable de la formación integral, en todas las dimensiones, de todas las personas.

\section{REFERENCIAS BIBLIOGRÁFICAS}

De Stéfano, M., Puche, L. y Pichardo, J. (2015). El compromiso de la investigación social en la construcción de otra escuela posible. Revista Interuniversitaria de Formación del Profesorado, 82(29), 50-54.

De Jesús, E., Cantera, E.L.M., Pereira, D.S.J. y Santos Federal, C. (2016). Multidisciplinary Journal of Educational Research, 6(2), 152-175.

Domínguez, J. y Vázquez, E. (2015). Medidas de atención a la diversidad: perspectiva del equipo de orientación específico. Revista de Estudios e Investigación en Psicología y Educación, 11, 1-4.

García, R., Sala, A., Rodríguez, E. y Sabuco, A. (2013). Formación inicial del profesorado sobre género y coeducación: impactos metacognitivos de la inclusión curricular transversal sobre sexismo y homofobia. Profesorado: Revista de Curriculum y Formación del Profesorado, 17(1), 269-287.

Gimeno, J. (1999). La construcción del discurso acerca de la diversidad y sus prácticas (I). Aula de Innovación Educativa, 81, 67-72.

Ley Orgánica 2/2006, de 3 de mayo, de Educación, Boletín Oficial del Estado núm. 106 (2006).

Ley Orgánica 8/2013, de 9 de diciembre, para la mejora de la calidad educativa, Boletín Oficial del Estado núm. 295 (2013).

Maldonado, E.P. (2018). Competencias del profesorado universitario para la atención a la diversidad en la educación superior. Revista latinoamericana de educación inclusiva, 12(2), 115-131.

Rodríguez Pareja, M.D.M. (2020). Análisis de la formación inicial del profesorado de secundaria en la atención a la diversidad afectivo-sexual. [Trabajo Fin de Máster, Universidad de Almería]. Ual. http://repositorio.ual.es/bitstream/handle/10835/3309/Trabajo.pdf?sequence= 
Roldán Santamaría, L.M. (2005). Elementos para evaluar planes de estudio en la Educación superior. Revista Educación, 29(1), 111-123.

Salas Guzmán, N. y Salas Guzmán, M. (2016). Tiza de Colores: Hacia la Enseñanza de la Inclusión sobre Diversidad Sexual en la Formación Inicial Docente. Revista Latinoamericana de Educación Inclusiva, 10(2). https://scielo.conicyt.cl/scielo.php?pid=S071873782016000200006\&script=sci_arttext 


\subsubsection{Motivar la participación en las aulas universitas desde las pedagogías feministas \\ Martínez Martín, Irene (UCM, España); Sanz Simón, Carlos (UCM, España); Resa, Ainhoa (UCM, España).}

\section{Resumen}

Este escrito recoge los interrogantes planteados en el proyecto de innovación docente titulado "Motivar la participación activa e igualitaria en las metodologías docentes online desde un enfoque de género" en la UCM.

Se pone de relieve la necesidad de repensar las dinámicas y metodologías de participación que suceden en las aulas universitarias, siempre desde un enfoque feminista. Además, debido a las circunstancias COVID, se incluye una mirada de género en las metodologías online.

Se presenta un diseño de investigación basado en la investigación-acción-participativa, haciendo hincapié en la observación participante, la toma de conciencia sobre la propia participación a partir de un cuestionario orientado al alumnado.

Los principales elementos de discusión que se destacan son: la desigualdad en las dinámicas de participación desde un enfoque de género; metodologías docentes poco participativas y sin perspectiva de género; cuestionamiento del marco teórico de la participación universitaria y sus resultados académicos formales.

Palabras clave: pedagogía feminista; participación; formación profesorado, género; docencia online.

\section{INTRODUCCIÓN Y OBJETIVOS}

Pensar la educación como una práctica de libertades (Freire, 1979; Giroux, 1998) supone cuestionar los roles y metodologías tradicionales buscando una participación activa, responsable y horizontal como elemento central del proceso educativo. Por ello y desde las pedagogías feministas, existen actualmente propuestas que ponen en el centro la necesidad de transformar las estructuras de la educación (currículum, metodologías, contenidos, lenguajes, espacios...), las relaciones de poder hegemónicas y las redes de transmisión del conocimiento patriarcales. A través de estas pedagogías feministas se elaboran propuestas educativas que reconocen el derecho a la igualdad real, la inclusión y la participación democrática de todas las personas.

Partiendo de este contexto epistemológico, en el curso 2019-2020 se inició en la Facultad de Educación de la Universidad Complutense de Madrid el proyecto de Innovación "Metodologías participativas e innovadoras en la docencia universitaria desde un enfoque de género". Con el objetivo de mejorar la formación del profesorado, se sitúa en el marco de la investigación SUPERA (Supporting the Promotion of Equality in Research and Academia, EU H2020) liderada por la Unidad de Igualdad de esta institución.

La idoneidad de este proyecto de innovación docente queda enmarcada en una investigación en curso impulsada por la unidad de igualdad de la UCM, el citado proyecto SUPERA, que realiza un diagnóstico de género desde diferentes ejes (igualdad de género en la carrera universitaria, en liderazgos y toma de decisiones, en investigación, docencia y vida universitaria, y estereotipos, sesgos de género, acoso sexual y sexista) que visibiliza una realidad de desigualdad en los diversos espacios universitarios. Como parte de dicho diagnóstico (en el que el equipo de este proyecto 
de innovación participa de manera activa liderado por Dña. Dra. María Bustelo) se ponen de manifiesto una serie de carencias, entre ellas, la falta de metodologías docentes que favorezcan dinámicas de género, inclusivas y participativas en la cotidianidad del aula, así como la formación del profesorado universitario y la difusión de buenas prácticas que se realizan en esta materia y, que en muchas ocasiones, quedan relegadas al espacio privado de cada docente.

Desde el primer proyecto de innovación desarrollado (curso 2019-20) se cuestionaron las metodologías empleadas en las prácticas docentes desde una perspectiva de género. Basándose en los principios de la investigación acción participativa, se emplearon técnicas cualitativas para la toma de conciencia crítica (Martínez, Rabazas, Sanz, Resa, 2020).

\section{METODOLOGÍA}

Se propone una metodología cualitativa dentro de un paradigma de investigación crítico y emancipador que busca el cuestionamiento de una realidad concreta para su transformación y mejora desde la práctica. El diseño metodológico se basa en técnicas de investigación-acción-participativa y se estructura en 4 fases (independientemente de si la asignatura se celebra en el $1^{\circ} \circ 2^{\circ}$ cuatrimestre).

Además, se ha tenido en cuenta los principios de una investigación post crítica y feminista (Sancho et al., 2020) en la que no se busca la generalización de realidades heterogéneas. Más bien, se pretende cuestionar epistemologías hegemónicas desde la reflexión crítica, el cuestionamiento y la búsqueda de múltiples respuestas desde un posicionamiento de diálogo, aprendizaje permanente y ruptura. Un desaprender para volver a aprender. Cuya finalidad es, además del cuestionamiento crítico, la búsqueda de caminos y estrategias enfocadas a una acción transformadora de nuestros contextos sociales.

Las preguntas de investigación que han guiado el proceso expuesto son: ¿Se detectan diferencias entre la participación online y la participación presencial? ¿Siguen siendo evidentes las desigualdades de género en la participación, tanto online como presencial? ¿Quiénes participan, cómo participan y quiénes no participan? ¿influye la participación activa en el rendimiento posterior de la asignatura, es decir, quién más participa tiene mejores calificaciones? ¿Entendemos la participación por igual, profesorado y estudiantado? ¿Somos conscientes de las desigualdades de género presentes en las aulas universitarias?

\section{Muestra}

Las asignaturas que han formado parte de este proyecto son todas aquellas en las que el profesorado participante tiene presencia, en todos los Grados y cursos y que se imparten en la Facultad de Educación (Educación Social, Magisterio Infantil y Primaria y Pedagogía), así como de las otras Facultades colaboradoras (Enfermería, Químicas, Físicas y Políticas), de la Universidad Complutense de Madrid y en la Universidad de Castilla León. Asimismo, esta propuesta se ha llevado a cabo en las asignaturas de los Másteres que se imparten en la Facultad de Educación, como el Máster de Investigación en Educación.

La muestra es feminizada en un $90 \%$ son mujeres, ya sean estudiantes o profesoras. Esto es debido a las circunstancias particulares del estudiantado de la Facultad que lidera este proyecto. La facultad de educación está formada en su mayoría por mujeres (estudiantes, PDI y PAS), siendo un campo de estudio (el magisterio y la pedagogía) feminizado (derivado de los aprendizajes patriarcales y la división sexual del trabajo). 


\section{Objetivos del proyecto}

- Analizar las dinámicas de participación (online y presencial) del alumnado y el papel que juega el profesorado en éstas.

- Visibilizar dichas dinámicas de participación desde un enfoque de género en las aulas universitarias

- Poner en cuestión los componentes de desigualdad de género que intervienen en la cotidianidad de las aulas y que frenan la participación activa de las mujeres y/o impulsan la participación activa de los hombres.

- Tomar conciencia crítica individual y colectiva acerca de los componentes que favorecen o dificultan la participación desde un enfoque de género.

- Comparar las dinámicas de participación en el aula desde un enfoque de género e inclusión, atendiendo a: dinámicas de participación presencial vs. online.

\section{Fases y plan de investigación-acción:}

1) Formación e inclusión de metodologías participativas en el aula (Webinar): Durante la programación de la asignatura y su impartición se incluirán diversas estrategias de fomento de la participación en la metodología cotidiana del aula.

Se realiza un Taller de formación con el profesorado participante con un doble objetivo: 1) poner en común diversas técnicas del fomento de la participación online y 2) consensuar las estrategias de participación con enfoque de género a partir de los resultados del primer proyecto de innovación.

2) Cuestionario percepciones del alumnado, de las dinámicas de participación propias y ajenas durante las clases, con el objetivo de tomar conciencia. Este autoanálisis se basa en un registro previo de las propias intervenciones que se realizará de forma individual a través de un formulario online. Este registro recoge los elementos clave en torno a la percepción que se tiene de la propia participación, así como de la participación del grupo: ¿cuántas veces participo?, ¿cómo es mi participación?, ¿por qué no participo, ¿qué me lo impide?, ¿quién participa más?, ¿cómo son mis intervenciones? y ¿las intervenciones ajenas?, ¿favorece el profesorado la participación?, ¿cómo me siento más interpelada/o a participar?

3) Observación y valoración del profesorado: Esta observación se hace en 2 sesiones aleatorias de cada una de las asignaturas implicadas. Se evalúan los patrones de participación desde un enfoque de género, siguiendo los mismos indicadores del proyecto inicial y teniendo en cuenta el componente online. Se busca un registro cuantitativo de las sesiones observadas (qué personas participan más, cómo es esta participación, etc.) y un registro cualitativo (calidad de la participación, tipo, etc.)

\section{RESULTADOS Y DISCUSIÓN}

Entre los resultados generales (Martínez, Rabazas, Sanz, Resa, 2020) cabe destacar: una mayor participación de los chicos sobre las chicas; distintos estilos de comunicación y participación entre chicos y chicas; autoanálisis diferentes de chicos y chicas sobre su propia participación (los chicos alegan a motivos relacionados con el control del conocimiento de la asignatura y las chicas a motivos vinculados con lo emocional, la autoestima y la inseguridad); diferentes propuestas para la mejora de la participación (chicas más centradas en los grupos pequeños de seguridad entre iguales; chicos proponen incentivos para la mejora de la nota, entre otras). 


\section{Resultados de los cuestionarios, desde un enfoque cualitativo}

Los resultados, vistos con mayor detalle, destacan: del total de las personas participantes, un $86 \%$ asiste a un $75 \%$ o más de las clases presenciales, mientras que este dato aumenta a un $94 \%$ de clases online. Desde su autopercepción, consideran que participan regularmente un $28,4 \%$, a veces un $62,7 \%$ y nunca un $9 \%$ del alumnado. A este respecto, el $59,7 \%$ afirma que no cree que existan diferencias en la participación en función del género de las personas. Su participación, en las clases presenciales, se ve condicionada por factores como el interés que les suscita la temática tratada, el uso de dinámicas en grupos pequeños y el clima de clase. En el caso de la participación virtual, observamos que la participación se da, principalmente, a través del chat escrito y en pequeños grupos. Otro elemento que también fomenta la participación en este formato lo representa el hecho de que todas las personas tengan la cámara y el micrófono activados a lo largo de la clase —un hecho que ocurre con poca frecuencia-

El alumnado considera que la participación se define no solo por la mera asistencia a las clases en cualquier formato. A este respecto, considera que otras variables, como el feedback, la respuesta y realización de preguntas, la colaboración, la reflexión, la escucha activa, la generación de debates e incluso el interés, la mirada hacia él o la docente y la integración en el grupo, determinan su participación en las clases.

\section{Reflexiones registros observación profesorado}

De manera complementaria a las percepciones del estudiantado sobre su participación, se encuentran los registros de observación que, desde la perspectiva del profesorado, pretende complementar los resultados hallados hasta la fecha.

Existe una diferencia destacable entre la participación presencial y virtual. La participación es menor entre el alumnado que sigue las clases a distancia, algo que el profesorado identifica con un clima más distante y una mayor dificultad para establecer un entorno de confianza, debido en parte a este modelo rotatorio entre la presencialidad y lo telemático. Por otro lado, también parece existir un condicionante de género en este formato online, pues las chicas tienden a intervenir a través del chat, escribiendo y sin conectar el micrófono o la cámara. El alumnado, sin embargo, muestran menor reparo a encender el vídeo y el micrófono y comparten sus aportaciones a través de estos medios. Estas diferencias en el modo de participar permiten realizar aportaciones de diferente tipo. Los chicos realizan intervenciones más abiertas, en las que ofrecen su opinión personal a pesar de que este contenido, en ocasiones, no sea necesariamente tan ajustado al contenido y el contexto tratados. Las chicas, por su parte, utilizan el chat para realizar preguntas y aclarar dudas, tendiendo a comunicar sus preguntas de manera concreta.

Del mismo modo que sucede en las clases, en la entrega de trabajos escritos, las alumnas aportan escritos más reflexivos y fundamentados. Aunque su participación a lo largo de la asignatura sea menor, sus entregas muestran una mayor madurez y análisis de la materia. También los ensayos de los alumnos incluyen observaciones más superficiales basadas en la opinión. Esto puede suscitar la necesidad de repensar las concepciones existentes en torno a la relación entre la participación y el rendimiento académico.

En los grados mayoritariamente femeninos, se observa una participación desigual, ya que las alumnas que más participan y se muestran líderes, son aquellas que cuentan con estudios previos relacionados, y que, por tanto, son mayores en edad al resto de sus compañeras. No sucede lo mismo con los alumnos, quienes toman el rol de líderes independientemente de su bagaje y edad. 
Estos resultados generales ponen de relevancia tres ejes fundamentales sobre los que seguir indagando: 1) la desigual participación en las aulas universitarias; 2) una baja percepción de los roles y estereotipos de género en relación con la participación; 3) metodologías docentes que no fomentan la participación teniendo en cuenta una perspectiva de género.

No se puede olvidar la perspectiva de género en el análisis de todo el proceso. Y, a pesar de la feminización de la muestra siguen apareciendo sesgos importantes en los modelos de participación, siendo principalmente masculinos- hegemónicos.

En esta comunicación se buscan respuestas y estrategias de acción desde las pedagogías feministas e interseccionales que ayuden a construir modelos de participación desde lo colectivo, lo crítico y lo transformador (Ramos, Martínez y Blanco, 2020; Bejarano, Martínez y Blanco, 2019). Un importante reto será la toma de conciencia acerca de aquellas personas, lugares e intereses que quedan fuera de los procesos de participación; supone mirar con ojos de diversidad los espacios, perfiles, canales, lenguajes y culturas que conforman la participación en los contextos universitarios.

\section{REFERENCIAS BIBLIOGRÁFICAS}

Bejarano Franco, M. T., Martínez Martín, I., y Blanco García, M. (2019). Coeducar hoy. Reflexiones desde las pedagogías feministas para la despatriarcalización del currículum. Tendencias Pedagógicas, 34, 37-50. https://doi.org/10.15366/tp2019.34.004

Hipólito, N. Martínez, I. y Fernández, S. (2019). Participación social de las mujeres. Síntesis.

Freire, P. (1979). La educación como práctica de la libertad. Ed. Siglo XXI: México.

Giroux, H. (2016). La pedagogía crítica en tiempos oscuros. Praxis educativa, 17(2), 1326.

Martínez Martín, I., Rabazas Romero, T., Sanz Simón, C., y Resa Ocio, A. (2020) La Investigación-acción participativa en la metodología docente universitaria. Una experiencia de innovación desde la perspectiva de género. Tendencias Sociales. Revista de Sociología (6), 111-132. ISSN 2603-8366

Ramos, F. J., Martínez, I. y Blanco, M. (2020). Sentido de la educación para la ciudadanía desde pedagogías feministas, críticas y decoloniales. Una propuesta para la formación del profesorado. Revista Izquierdas, 49, 2103-2116.

Sancho, J. et. al (2020). Cominos y derivas para otra investigación educativa y social. Octaedro. 


\subsubsection{La institucionalización de la lucha contra el acoso}

sexual y la promoción de la igualdad de género en la UACH Hamodi Galán, Carolina (Universidad de Valladolid, España); Claudia Contreras Contreras (Universidad Austral de Chile, Chile); Belén Andrés Corredor (Universidad de Valladolid, España).

\section{Resumen}

Son escasos los estudios realizados en universidades latinoamericanas, que revisen las políticas institucionales que abordan la violencia hacia las mujeres, ya sea desde lo normativo o preventivo. Frente a este complejo escenario, resulta importante lograr diagnósticos que permitan avanzar y mejorar las estrategias que cada institución pueda desarrollar para hacer frente a esta problemática. Ante las desigualdades de género que pone de manifiesto el Diagnóstico de Género y Diversidad en la UACh (Comité Paritario de Género y Diversidad UACh, 2016), consideramos relevante realizar un estudio abordando el siguiente objetivo general: analizar la institucionalización de la lucha contra el acoso sexual y la promoción de la igualdad de género en la Universidad Austral de Chile (UACh).

Este estudio se llevó a cabo mediante una metodología cualitativa, con la realización de diversas entrevistas en profundidad, a informantes clave seleccionados con cargos influyentes, personal docente y a personal participante de colectivos activos en los movimientos por la igualdad de género en el ámbito universitario.

Los resultados evidenciaron que la conjugación de elementos como, las manifestaciones y acciones aisladas, y colectivas, la denuncia de casos y la instalación de normativas, resulta fundamental para la institucionalización de la lucha contra el acoso sexual y la promoción de la igualdad de género en el contexto universitario estudiado. Entre las conclusiones se puede plantear que la promoción de una mayor igualdad de género, así como la lucha contra el acoso sexual tiene su comienzo en las iniciativas individuales, y que, en el impulso de avanzar respecto a las normativas y prácticas, es importante denunciar y visibilizar casos de imponen la necesidad de contar mecanismos reguladores.

Palabras clave: Igualdad de género, política institucional; Universidad; acoso sexual.

\section{INTRODUCCIÓN Y OBJETIVOS}

La universidad, lugar de reflexión y de desarrollo de conocimientos, ha reproducido y reproduce, condiciones de la sociedad patriarcal en la que se encuentra inmersa (Martínez y Ballarín, 2005). Aunque no es algo socialmente conocido, son diversos los estudios que exponen antecedentes que demuestran la veracidad de estos hechos. En concreto, los realizados en la Universidad Austral de Chile, que evidencian las desigualdades de género presentes: menor participación femenina en dirigencias estudiantiles, menor presencia de las mujeres entre los docentes y mucho menor en puestos titulares, baja representación en puestos directivos superiores y brechas salariales.

Ante las desigualdades manifestadas, se busca sistematizar información a partir de un estudio que plantea el siguiente objetivo general:

- Analizar la institucionalización de la lucha contra el acoso sexual y la promoción por la igualdad de género en la UACh. 
Que, a su vez, los siguientes objetivos específicos:

- Identificar el punto de partida desde el cual se comienza a plantear la lucha contra el acoso sexual y la promoción de la igualdad de género.

- Reflejar los avances en la lucha contra el acoso sexual y la igualdad de género

- Analizar las dificultades encontradas en el proceso de implementación de políticas vinculadas a la lucha contra el acoso sexual y la promoción de la igualdad de género

- Plantear los retos a los que debe enfrentarse la UACh a corto y medio plazo, para luchar contra el acoso sexual y fomentar la igualdad de género, de manera que puedan ser tenidos en cuenta en la toma de decisiones y en la instauración de políticas con perspectiva de género.

\section{METODOLOGÍA}

Se llevó a cabo un estudio de caso de corte cualitativo, definido por Stake (2007, p. 11) como "el estudio de la particularidad y la complejidad de un caso singular, para llegar a comprender su actividad en circunstancias importantes" y que, a pesar del marcado carácter contextual en el que esta investigación se desarrolla, pueden ofrecer propuestas que se pueden extrapolan a otras universidades latinoamericanas para poder avanzar en políticas de igualdad de género, así como la lucha contra la discriminación y el acoso sexual.

Para alcanzar el objetivo general propuesto, se llevó a cabo una metodología cualitativa donde se realizaron dieciséis entrevistas en la Universidad Austral de Chile (UACh) a diferentes cargos directivos o miembros de la comunidad universitaria (Prorectoría, Vicerrectorías y Secretaría general, personal docente, investigador y personas pertenecientes a colectivos funcionarios, docentes 0 estudiantes con acciones relevantes en la temática.

Las entrevistas respondieron a los siguientes cuatro ejes temáticos:

1. Cómo, cuándo y porqué se comenzó a abordar la temática del género en la Universidad.

2. Avances.

3. Dificultades encontradas en el proceso.

4. Retos pendientes.

Para el análisis se utilizó el programa Atlas.ti.6.

\section{RESULTADOS Y DISCUSIÓN}

El transcurso de la investigación planteó la necesidad de crear subcategorías analíticas, vinculando a ello la discusión de los resultados. A continuación, se presenta una visión panorámica de las categorías y subcategorías emergentes (Tabla 1):

Tabla 1. Categorías analíticas desarrolladas

\begin{tabular}{|l|l|}
\hline $\begin{array}{l}\text { Categorías } \\
\text { iniciales }\end{array}$ & Subcategorías emergentes \\
\hline Avances & Normativa Institucional \\
\cline { 2 - 2 } & Cambios en el contexto relacional \\
\cline { 2 - 2 } & Transformación cultural \\
\hline
\end{tabular}




\begin{tabular}{|l|l|}
\hline \multirow{3}{*}{ Comienzo } & Decisiones Institucionales \\
\cline { 2 - 2 } & Micro acciones \\
\cline { 2 - 2 } & Reconocimiento de casos \\
\cline { 2 - 2 } & Dificultades al inicio \\
\cline { 2 - 2 } Sucesos & Iniciativas aisladas \\
\cline { 2 - 2 } & Ocurrencia de casos \\
\hline Dificultades & Dificultades para establecer políticas de igualdad \\
\hline Retos & \\
\hline UACh pionera \\
\hline
\end{tabular}

La primera categoría desarrollada se denomina, Avances. Esta conceptualización reúne contenido asociado a los logros, introducción de normativas, cambios en la cultura institucional y fenómenos que implican mejoras en la estructura institucional, teniendo distintas consecuencias o impactos. Los avances se reconocen o evidencian desde la normativa interna, los cambios en el contexto de relaciones, en las visibilización de la violencia simbólica o explícita, entre otros aspectos.

Larena y Molina (2010) reconocen cómo la implementación de medidas como las campañas sensibilizadoras o los proyectos y planteamientos desde las diferentes estructuras (social y cultural) son importantes y necesarios para impedir la normalización de situaciones de violencia de género, el acoso sexual, etc.

De la misma forma, en el relato de las personas entrevistadas se recogen apreciaciones en torno a la nueva normativa institucional, pequeñas acciones implementadas, cambios en las relaciones o transformaciones en la cultura institucional. A continuación, se expone un par de citas que reflejan apreciaciones en torno a estas temáticas:

Para mí la existencia de normativa es una herramienta muy poderosa para empezar a tratar este tipo de cuestiones. No lo resuelve obviamente, pero está ahí y quienes tenemos responsabilidad en gestión ya sabemos que podemos utilizarla para abordar esto. (Entrevista-1, subcategoría: Normativa institucional)

Si yo pudiera identificar un hito decidor desde el punto de vista institucional, fue la negociación colectiva con el sindicato de docentes del 2014, se incluye por primera vez, como parte de los acuerdos con el sindicato, la conformación de un comité paritario de género y diversidad, que institucionalmente se encargue de abordar estos temas. (Entrevista-4, subcategoría: Cambios en el contexto relacional).

Una segunda red conceptual se denomina Comienzo. Esta categoría reúne contenido asociado a las primeras inquietudes e iniciativas que desafiaron o incentivaron la voluntad política.

En este sentido, Gamboa (2019), refleja la incertidumbre de los primeros momentos confusos en una institución tras aprobar un protocolo:

"Por un momento aumentó nuestra confianza en la institución, pero fue sólo una ilusión que muy pronto comenzó a disiparse entre inquietudes que fueron surgiendo a partir de darnos cuenta de que, en el transcurso de dos años desde su aprobación, el Protocolo seguía siendo, un perfecto desconocido entre la comunidad universitaria" (p. 214).

De los relatos se rescatan las experiencias asociadas un primero momento donde avanzar en modificaciones de las prácticas, normativas y políticas institucionales que permitieran luchar contra la violencia de género, y favorecer la equidad e integración de 
la perspectiva de género, se veía como un tema muy complicado o imposible. Como una forma de ejemplificar el contenido emergente de esta categoría, se seleccionaron dos trozos de entrevista incluidos en distintas subcategorías:

Afortunadamente hubo chicas que se animaron a contarle a otras compañeras $u$ organizaciones estudiantiles que levantaron un poquito todo este tema con profesionales de la universidad, con profesoras, sobre todo mujeres, que fueron poniendo en alerta y solicitando que hubiera algo más formal, que la universidad. (Entrevista-10, subcategoría: Reconocimiento de casos)

Entonces es como un poco difícil por lo que había que tener equipo, ya, porque uno no saca nada hacer algo en el año, la idea es tener un programa, evaluarlo, pensar hacia donde avanzamos el próximo año, alianzas, buscaba apoyo en el centro de salud, pero en ese tiempo había media jornada de psicóloga entonces claro que estaba para clínica, obvio. Después había una jornada y media, pero seguía siendo poco. (Entrevista-8, subcategoría: Dificultades al inicio)

La tercera categoría analítica que emerge desde los datos se ha denominado Sucesos. Aglomera contenido asociado con situaciones o hechos particulares, y que resultan significativos en la trayectoria de implementación de normativas o cambios institucionales relacionados a la incorporación en la perspectiva de género en la Universidad. A continuación, se expone una cita que lo expresa:

Nosotras nos empezamos a dar cuenta del índice de chicas que empezaron a acudir a nosotras pero que empezaron a irse de la universidad, que si bien manteníamos contacto empezaban a dejar la carrera o a congelar o simplemente se iban, entonces a nosotras eso nos pareció súper grave, además de que llegó un momento, el 2014 o 15, no recuerdo bien, donde ya fue el mes de octubre recuerdo donde teníamos hasta 10 denuncias por semana y hubo un mes donde tuvimos 3 casos de violación. (Entrevista 15, subcategoría: Ocurrencia de casos)

Ante esta temática, sobre las barreras encontradas con en las denuncias, es una situación extendida y bastante común. Por ejemplo, Larena y Molina (2010) comentan que en las políticas institucionales sobre la violencia de género y sus medidas disciplinares, valoran que hay instituciones universitarias que no responden debido, en muchos casos, a los espacios de poder y de jerarquía existentes; y entienden la poca confianza depositada en la propia institución por no tomar las medidas necesarias y por la tendencia hacia la culpabilización de las víctimas.

La cuarta categoría se ha denominado como Dificultades. Contiene, de esta manera, aquellos sucesos que han supuesto que estaban aconteciendo en dicha universidad y en la vida cotidiana de toda mujer que suponían y suponen, de alguna manera, impedimentos y frenos para llegar a la igualdad en todos los aspectos de mujeres y hombres, más en concreto aquellas que se ven relacionadas con las cuestiones de género en el ámbito educativo. A continuación, se exponen un par de citar que expresan dichas apreciaciones en torno a esta temática:

Yo creo que las barreras culturales, tiene que ver con el cotidiano, con el machismo implícito, con la discriminación implícita. Siempre ha sido así, que se da no solo con el tema de género, sino en otros temas. (Entrevista-1).

En nuestro país, en el sistema universitario no se trabaja con enfoque de género. Es lo primero. $Y$ en nuestra universidad tampoco. Quiero ser bien directo en decirlo. No se está incorporado ni en modelos formativos ni en enfoques educativos (Entrevista-4).

La quinta categoría analítica que se encuentra es la denominada Retos. En esta, se pueden encontrar, los distintos desafíos y futuras cosas que quieren conseguir en 
cuanto al ámbito de género en educación para ir avanzando hacia una sociedad más igualitaria. A continuación, se presentan un par de citas que aclaran esta categoría y la ejemplifican bien:

Desde el 2016 se están haciendo charlas, por ejemplo, para decanos, para los directores de escuela, secretarias de escuela. Sin embargo, aún hay un gran déficit: un solo taller no basta o que se les dé a conocer que esto existe no basta. Tienen que entenderlo para poder aplicarlo (Entrevista-7).

Flores-Bernal, R. (2019) apunta como retos fundamentales a la necesidad de hacer política pública universitaria con perspectiva de género, y seguir buscando mejoras en este ámbito para avanzar hacia una sociedad más igualitaria, como indican Ferrer et al. (2009).

En sexto, en consonancia con lo indicado por Fernández Cruz (2020), se sitúa la categoria "UACh como pionera", al conseguir la aprobación de un reglamento que regule expresamente los asuntos de Acoso, Violencia y Discriminación (AVD) entre estudiantes. A continuación, se presenta una cita que lo ejemplifica:

Me acuerdo que en el consejo que fue... bueno en el 2015/2016 nos pedían el insumo de cómo lo habíamos hecho y eso era darse cuenta de que estábamos avanzando en relación a otras universidades [...] A mí me llamaron varias veces como del Mercurio a raíz de otros casos de violencia o de acoso en otras universidades y me preguntaban que cómo lo hacíamos acá, entonces [...] el sentir con mayor razón, que estábamos como avanzando un poco más (Entrevista-8).

\section{CONCLUSIONES Y LIMITACIONES}

En respuesta a los objetivos planteados, se describen someramente las principales conclusiones derivadas del estudio:

La promoción por una mayor igualdad de género y la lucha contra el acoso sexual en la Universidad que forma parte del estudio comienza a partir de iniciativas individuales y aisladas. No obstante, determinante en ello resulta el liderazgo de ciertas docentes y estudiantes.

En el impulso de avances relacionados con normativas y prácticas, resulta relevante la denuncia y visibilización de casos que instalan la necesidad de contar con mecanismos reguladores.

Entre las dificultades encontradas para implementar políticas vinculadas a la lucha contra el acoso sexual y la promoción de la igualdad de género destacan las barreras culturales, ancladas en un sistema patriarcal.

Se plantea como reto lograr mayor sensibilizar a la comunidad y alcanzar una permanente sistematización de datos que permita tener diagnósticos oportunos

Como limitaciones, se hace necesario evidenciar mediante datos cuantitativos (por ejemplo, mediante un diagnóstico) las desigualdades existentes, las brechas de género y el techo de cristal (salarios, puestos de poder, etc.), para posteriormente poder tomar decisiones políticas en aras de avanzar hacia instituciones más igualitarias. 


\section{REFERENCIAS BIBLIOGRÁFICAS}

Ferrer, V.A, Navarro C., Ferreiro V., Ramis M.C., y Escarrer C. (2009). El acoso sexual en el ámbito universitario. Elementos para mejorar la implementación de medidas de prevención, detección e intervención. Universidad de Balerares. https://www.inmujer.gob.es/areasTematicas/estudios/estudioslinea2014/docs/El _acoso_sexual_ambito_universitario.pdf

Fernández Cruz, J. A. (2020). Los protocolos universitarios para la prevención y sanción de la violencia, acoso y discriminación entre estudiantes: una mirada criminológica y político-criminal. Revista de Derecho (Valdivia), 33(2), 297-317. https://dx.doi.org/10.4067/S0718-09502020000200297

Flores-Bernal, R. (2019). Políticas de educación superior sobre acoso sexual en Chile. Educación y Educadores, 22(3), 343-358. DOI: https://doi.org/10.5294/edu.2019.22.3.1

Gamboa, F.M. (2019). Acoso sexual en la universidad: de protocolos y protocolos. Nómadas, 51, 211-221.

Larena, R., y Molina, S. (2010). Violencia de género en las universidades: Investigaciones y medidas para prevenirla. Trabajo Social Global, 1(2), 202-219

Martínez, C., y Ballarín, P. (2005). Women and higher education. En Elisabeth de Sotelo (ed.), New women of Spain. Social political and philosophical studies of feminist. Thought. Münster: Lit Verlag (pp. 429-441).

Stake, R. E. (2007). Investigación con estudio de casos (4º ed.). Madrid: Morata. 


\subsubsection{Recuperando la memoria de mujeres olvidadas: historia de una Inspectora Soriana, $\mathrm{M}^{\mathrm{a}}$ Cruz Gil Febrel Raquel Vázquez Ramil (Universidad de Valladolid, España) y $M^{a}$ Ángeles Guillorme de Miguel (Universidad de Valladolid, España)}

La Maestra era alegre. ¡Pobre mujer herida! Su sonrisa fue un modo de llorar con bondad.

Gabriela Mistral (1916).

\section{Resumen}

Presentamos un modelo de Trabajo de Fin de Grado del Grado de Educación Infantil en el que se pretende dar visibilidad a una mujer olvidada, $\mathrm{M}^{\mathrm{a}}$ Cruz Gil Febrel, que desarrolló en el primer tercio del siglo XX una notable carrera como pedagoga en la provincia de Soria, contribuyendo a la expansión de la educación primaria, a la mejora de las condiciones de las escuelas de niñas y a la educación de la mujer rural.

Hemos utilizado documentación primaria de archivo, fuentes hemerográficas y bibliografía sobre la educación de la mujer en España a principios del siglo XX. Más allá de la investigación rigurosa, queremos abrir en la Facultad de Educación de Soria una línea de trabajos de investigación que recuperen la memoria de mujeres olvidadas y postergadas.

Palabras clave: Memoria histórica; Visibilidad de las mujeres; Educación en Soria; Educadoras; Pedagogas.

\section{INTRODUCCIÓN Y OBJETIVOS}

La atención a la perspectiva de género en la docencia universitaria ha sido señalada en numerosas ocasiones (Pérez Sedeño 2008) y se han propuesto modelos de trabajos de investigación en el ámbito universitario para visibilizar el papel de las mujeres en diferentes actividades (Aguayo et al. 2017). Por otro lado, casi todas las Universidades públicas españolas conceden anualmente premios a los mejores Trabajos de Fin de Grado y de Fin de Máster con perspectiva de género a través de las respectivas Comisiones u Oficinas de Igualdad.

Sin embargo, apreciamos aún poco arraigo en los trabajos de investigación que se ocupan de temáticas de género en la Universidad de Valladolid, y mucho menos en los que tratan de recuperar la memoria de mujeres o colectivos de mujeres olvidados o postergados.

Nuestro objetivo principal es:

- Visibilizar la trayectoria vital y profesional de una mujer que contribuyó a la renovación pedagógica de la provincia de Soria en el primer tercio del siglo XX.

Los objetivos específicos son:

- Contribuir a recuperar la memoria histórica de mujeres que se implicaron en la mejora social en España antes de la guerra civil.

- Aportar un modelo de trabajo de fin de grado que trata la biografía histórica como recuperación del pasado y ejemplo para el futuro. 
- Reflexionar sobre la escasez relativa de trabajos de investigación sobre feminismo y género en la Universidad española, a pesar de los incentivos económicos y académicos que se ofrecen.

\section{METODOLOGÍA}

Utilizamos el método biográfico para reconstruir la trayectoria vital de una persona, en este caso de $M^{a}$ Cruz Gil Febrel, pedagoga e inspectora de enseñanza primaria en la provincia de Soria durante los años 20 y la Segunda República española. Se trata de una metodología cualitativa que resalta los acontecimientos de la vida de una persona, partiendo de documentos de archivo (partidas de nacimiento y defunción, expedientes académicos, nombramientos, etc.), referencias en la prensa de la época, y noticias o artículos que aluden directa o indirectamente al sujeto de la biografía.

Existe una corriente historiográfica, la Historia de las mujeres, que desde los años 70 del siglo pasado ha abordado la labor de estudiar vidas y actividades femeninas. Como señala Bolufer (2014, p. 88): "El poderoso impulso de recuperar las vidas «robadas» del pasado, sistemáticamente silenciadas u olvidadas por la historia oficial, mediante un ejercicio de reescritura de la historia continúa siendo una motivación presente y productiva en la historia de las mujeres".

Algunas iniciativas producen un curioso efecto "telón", al divulgar una serie de nombres a costa de silenciar otros muchos (Sánchez de Madariaga 2012). Nuestro interés es visibilizar a todas, de ahí la reconstrucción biográfica que hemos emprendido en un Trabajo de Fin de Grado de la titulación de Educación Infantil, con el ánimo de continuar una línea de investigación consistente.

\section{RESULTADOS Y DISCUSIÓN}

Siguiendo el objetivo inicial que expresamos en la Introducción, nos propusimos reconstruir la vida y carrera profesional de una mujer olvidada y elegimos a $\mathrm{M}^{\mathrm{a}} \mathrm{Cruz}$ Gil Febrel (Soria 1895-1943).

La elección obedece a estudios previos sobre mujeres que habían vivido en la Residencia de Estudiantes de Madrid, rama Femenina, entre 1915 y 1936 (Vázquez Ramil 2012). Buscamos a las relacionadas con Soria y nos encontramos con $\mathrm{M}^{\mathrm{a}} \mathrm{Cruz}$ Gil, de la que sabíamos que había estudiado en la Escuela de Estudios Superiores del Magisterio de Madrid entre 1916 y 1919, siendo nombrada en 1920 inspectora de las escuelas de niñas de la provincia de Soria. Sin más.

Podía tratarse de una funcionaria cumplidora, una madre de familia, una hija atenta... No teníamos otros datos y decidimos buscarlos. Para ello utilizamos las hemerotecas virtuales de la Biblioteca Nacional de España y del Ministerio de Cultura y rastreamos noticias sobre $\mathrm{M}^{\mathrm{a}}$ Cruz Gil en la prensa local y en periódicos y revistas educativas. Encontramos muchas y variadas referencias que nos animaron a emprender el trabajo.

$M^{a}$ Cruz Gil Febrel nació en Soria el 28 de febrero de 1895; sus padres eran Pedro Gil Lozano, empleado y contratista de obras públicas, y Raimunda Febrel Esteras, dedicada a sus labores. Tenía dos hermanas mayores: Julia y Antonia; esta última también estudiará en la Escuela de Estudios Superiores del Magisterio y será profesora de Ciencias en las Escuelas Normales de Maestras de Teruel y Soria (Jiménez Laseca 2020). 
$M^{a}$ Cruz estudió Magisterio elemental y dos cursos de Bachillerato en el Instituto General y Técnico de Soria, obteniendo brillantes calificaciones. Fue alumna destacada de Antonio Machado en las clases de francés.

Tras aprobar el difícil ingreso en la sección de Letras de la Escuela de Estudios Superiores del Magisterio de Madrid en 1916, se alojó en la Residencia de Señoritas y colaboró en 1919-20 en las clases prácticas del recién creado Instituto-Escuela (2019). En julio de 1920 es nombrada inspectora de las escuelas de niñas de la provincia de Soria y va a realizar una incansable labor de visita a los centros escolares de zonas rurales, en cuya mejora puso gran empeño (Calvo Villar 2002). Se interesó también por la mejora de la formación permanente de los maestros y maestras, dando conferencias pedagógicas y promoviendo viajes culturales, como el realizado en 1927 con un grupo de profesores y profesoras a Bilbao, Santander y Santiago de Compostela.

Con una clara inclinación social, promovió la cantina escolar del Cuartel de Santa Clara, donde se ofrecía comida en 1929 a casi cien niños y niñas de las escuelas públicas de la capital soriana; y se ocupó, asimismo, de proporcionar ropa de abrigo y juguetes a los más necesitados.

En plena Dictadura de Primo de Rivera, fue nombrada concejala del Ayuntamiento de Soria (sesión municipal de 31 de octubre de 1927); sólo había otra mujer en el consistorio, Victoriana Asenjo, profesora de la Escuela Normal de Maestras. M ${ }^{\text {a }}$ Cruz Gil promovió desde el Ayuntamiento las excursiones y colonias escolares.

Durante la Segunda República continuó, como inspectora-jefe de la provincia de Soria, impulsando la construcción de escuelas y la educación de adultos. En 1935 disfrutó de una pensión concedida por la Junta para Ampliación de Estudios e Investigaciones Científicas, y durante tres meses visitó centros educativos de Francia, Bélgica, Suiza e Italia. A su regreso a España presenta una memoria justificativa sobre "La función social que la maestra rural puede realizar en el medio en que se encuentra", de gran interés.

El golpe militar de 18 de julio de 1936 sorprendió a Ma Cruz Gil en los cursos de verano de la Universidad Internacional de Santander. No pudo regresar a Soria y pasó a la zona republicana. En 1937 fue nombrada inspectora de primera enseñanza de Cuenca por el gobierno de la República; en el mismo año fue apartada del servicio en la zona nacional (Gómez San Miguel 2017, p. 395). En 1940 su expediente fue revisado por la Dirección General de Primera Enseñanza, imponiéndosele la sanción de suspensión de empleo y sueldo por un año e inhabilitación para cargos directivos y de confianza (Hernández García 2015, p. 818). Fue repuesta en su cargo en agosto de 1940, pero ya no era la misma; con una salud muy quebrantada, no podía visitar las escuelas ni realizar convenientemente su trabajo. Falleció en Soria el 13 de enero de 1943, a los 47 años. Está enterrada en el cementerio de El Espino, en una tumba anónima y tan olvidada como ella, que visitamos a veces y nos llena de tristeza.

\section{CONCLUSIONES Y LIMITACIONES}

Adelantamos en esta comunicación el Trabajo de Fin de Grado que estamos realizando, como tutora y tutorizada, sobre una mujer olvidada, $\mathrm{M}^{\mathrm{a}}$ Cruz Gil Febrel, que como inspectora de primera enseñanza realizó una labor muy activa en la extensión de la instrucción primaria en la provincia de Soria, en la mejora de las condiciones de las escuelas, en la capacitación de los maestros y maestras, y en la educación de las mujeres rurales.

Con una excelente formación académica, había sido alumna de Antonio Machado en el Instituto de Soria, y había vivido en la Residencia de Señoritas de Madrid, bajo la tutela 
de María de Maeztu. Sus inquietudes la llevaron a viajar al extranjero, pensionada por la Junta para Ampliación de Estudios, para visitar centros educativos en Francia, Bélgica, Italia y Suiza, países al frente de la vanguardia pedagógica; en Italia tomó contacto directo con el método Montessori y en Bélgica con las escuelas de Decroly.

El estallido de la guerra civil la convirtió en víctima de las dos Españas. Se mantuvo leal al gobierno de la República, desempeñando su puesto de inspectora en Cuenca; lo cual la condenó a ser apartada del servicio por el nuevo régimen. Tras cumplir sanción, se incorporó a su puesto en Soria a finales de 1940, con la salud muy deteriorada. Murió poco después. Merece algo más que nuestro recuerdo como avanzada en la labor de educación de las mujeres sorianas.

Este tipo de Trabajo de Fin de Grado, muy poco frecuente, nos parece útil en los Grados de Educación Primaria y Educación Infantil, como es este caso. Las futuras maestras deben conocer y respetar la vida y obra de quienes trabajaron por una educación para todos y todas y sufrieron castigos, represalias y desprecios.

Terminamos con las palabras de la propia Ma Cruz Gil Febrel (1935): "La escuela tiende a ser educadora más que instructiva y es concepto moderno el conceder igual valor a todos los oficios y profesiones en la vida y, concretamente en la enseñanza, igual valor puede tener la profesión de una maestra maternal que la de un catedrático de Universidad".

\section{REFERENCIAS BIBLIOGRÁFICAS}

Aguayo, E., Freire, M.P., Lamelas, N. (2017). Incorporación de la perspectiva de género en el TFG: una experiencia en el Grado en Economía de la USC. Revista Complutense de Educación, 28(1), 11-28. http://dx.doi.org/10.5209/rev_RCED.2017.v28.n1.48588

Bolufer Peruga, M. (2014). Multitudes del yo: biografía e historias de mujeres. Ayer 93 (1), pp. 85-116.

Calvo Villar, M.C. (2002). Más de cien años de Historia de las Escuelas de Soria, 18121936. Soria: Gráficas Ochoa.

Gómez San Miguel, E. (2017). Inspectoras de primera enseñanza en el segundo tercio del siglo XX. (Tesis doctoral). Universidad Complutense de Madrid, Madrid.

Hernández García, A. (2015). La purga de Franco en el Magisterio soriano. 2 vols. Soria: autor-editor.

Jiménez Laseca, J.M. (2020). La pedagoga María Cruz Gil Febrel (1895-1943). En: https://almajano14.blogspot.com/2020/03/la-pedagoga-soriana-maria-cruzgil_12.html

Mistral, G. (2000). Desolación. Barcelona: Andrés Bello.

Pérez Sedeño, E. (2008). Innovación educativa, xénero e innovación oculta, en I Xornada de innovación en xénero. Docencia e investigación, 7-26. Vigo: Unidade de Igualdade, Universidade de Vigo.

Porto Ucha, A.S. y Vázquez Ramil, R. (2019). En el centenario del Instituto-Escuela. Obra educativa de los institucionistas. Soria: Ceasga. 
Sánchez de Madariaga, E. (Coord.) (2012). Las maestras de la República. Madrid: Los Libros de la Catarata.

Vázquez Ramil, R. (2012). Mujeres y educación en la España contemporánea. La Institución Libre de Enseñanza y la Residencia de Señoritas de Madrid (19151936). Madrid: Akal.

\section{DOCUMENTACIÓN PRIMARIA}

Archivo de la Edad de Plata: Gil Febrel, $M^{a}$ Cruz. Expediente JAE/67-484. Accesible en: http://archivojae.edaddeplata.org/jae_app/JaeMain.html

Archivo de la Edad de Plata: Gil Febrel, Ma Cruz. Trabajos. "Función social que la maestra rural puede realizar en el medio en que se encuentra". Accesible en: http://archivojae.edaddeplata.org/jae_app/JaeMain.html

Archivo Histórico del Instituto Antonio Machado: Gil Febrel, doña M" Cruz. Expte. 235. 


\subsubsection{Desarrollo competencias en estudiantes universitarios: el efecto del aprendizaje basado en proyectos y del liderazgo de desarrollo en función del sexo \\ Andrés Salas Vallina (Universitat de València, España); Manoli Pozo Hidalgo \\ (Valencian International Univeristy, España)}

\section{Resumen}

El aprendizaje basado en proyectos es una metodología docente que organiza el aprendizaje en base a tareas especialmente exigentes, y a la vez estimulantes para los estudiantes. Sin embargo, las circunstancias sobrevenidas con la pandemia generada por la Covid-19, obligan a redefinir las formas de enseñanza-aprendizaje. Con el fin de no sólo mantener, sino también tratar de enriquecer y mejorar las metodologías de enseñanza-aprendizaje existentes, este proyecto pretende desarrollar una metodología no presencial de aprendizaje basado en proyectos, con una nueva forma de interacción entre los grupos de trabajo, y con el objetivo de que los estudiantes adquieran competencias clave que les permitan mejorar su empleabilidad en el mercado laboral, así como su capacidad de cooperar y tener una actitud crítica y reflexiva ante los retos a los que tendrán que enfrentarse. Los resultados muestran que las diferencias de sexo tienen un efecto significativo en el modelo planteado.

Palabras clave: Aprendizaje basado en proyectos; Docencia no presencial; Cooperación; Reflexión; Sexo

\section{INTRODUCCIÓN Y OBJETIVOS}

Ante la situación de restricción de movilidad y de contacto social producida por la Covid19 , las instituciones educativas tienen que enfrentarse al reto de mantener la calidad de la enseñanza en entornos de enseñanza-aprendizaje a distancia. Las nuevas tecnologías permiten que los docentes mantengan contacto con los estudiantes a través de diferentes herramientas. Sin embargo, hay un reto fundamental que requiere de especial atención. Se trata de lograr el trabajo en grupo para el desarrollo de proyectos en entornos no presenciales. El trabajo en grupo es más que la mera unión de acciones individuales de forma coordinada. Es necesario que, además todos los miembros decidan hacer algo juntos y en la misma dirección. En este escenario, hemos diseñado una metodología innovadora, con el fin de que los estudiantes desarrollen tres competencias básicas del Consejo de la Unión Europea: la capacidad de cooperar, la capacidad de reflexionar de forma crítica, y la capacidad de tomar decisiones de forma autónoma. Nos preguntamos si, al tomar una perspectiva de sexo, el modelo que planteamos a continuación puede mostrar resultados significativamente distintos.

A través del aprendizaje basado en proyectos, y de la herramienta informática KanbanFlow, proponemos un diseño innovador y centrado en el trabajo en equipo, que permita un flujo constante de información entre los miembros de cada grupo de trabajo. Esta aplicación permite secuenciar de forma colaborativa una serie de actividades definidas para la realización de proyectos de trabajo, con la constante interacción tanto del profesor como del resto de miembros del equipo. Este modelo de enseñanzaaprendizaje se enmarca en la metodología del aprendizaje basado en proyectos, la cual permite aportar un marco teórico para su diseño y estudio. 
El aprendizaje basado en proyectos es una metodología activa de enseñanzaaprendizaje, que surge como una concepción docente que promueve la crítica y la reflexión, con el apoyo del docente (Membrillo-Hernández et al., 2019).Las metodologías activas se refieren al conjunto de actividades que llevan al estudiante identificar un problema, y a tratar de resolverlo a través de la reflexión y de la interpretación de los resultados, y en las que el profesor ejerce un rol de orientador, supervisor y facilitador (Silberman, 1996).

Pero el rol del docente no se puede limitar al diseño de herramientas y a la evaluación de los resultados de aprendizaje (Duyar et al., 2019). Por ello, el modelo propone que el estilo docente se identifique con el estilo de liderazgo de desarrollo, o developmental leadership. Este estilo de liderazgo incluye comportamientos orientados hacia el desarrollo de los estudiantes, incluyendo mentoring, coaching, identificando las necesidades formativas de los estudiantes, y motivando a que los estudiantes desarrollen sus habilidades y competencias (Rafferty y Griffin, 2006).

La interacción del docente incluye sesiones de videoconferencia de grupos reducidos, con el fin de que la interacción sea más efectiva, y un feedback continuo durante el proceso de elaboración del proyecto.

Los objetivos específicos son los siguientes, todos ellos conectados con las siguientes líneas estratégicas de la convocatoria: 1 ("Elaboración de material y diseño de estrategias para la docencia virtual y evaluación en línea), 2 ("Diseño, desarrollo y evaluación de la docencia"), 6 ("Metodologías activas para el aprendizaje), y 8 ("Acciones para el fomento de la empleabilidad y el emprendimiento).

- Objetivo 1: conocer el impacto de la metodología de aprendizaje basado en proyectos en la mejora de la competencia "reflexión" en los alumnos.

- Objetivo 2: conocer el impacto de la metodología de aprendizaje basado en proyectos en la mejora de la competencia "cooperación" en los alumnos.

- Objetivo 3: conocer el impacto de la metodología de aprendizaje basado en proyectos en la mejora de la competencia "toma de decisiones" en los alumnos.

- Objetivo 4: conocer el efecto moderador del estilo de liderazgo de desarrollo del docente, developmental leadership, en la relación entre el aprendizaje basado en proyectos y las competencias "reflexión", "cooperación" y "toma de decisiones".

- Objetivo 5: conocer si existen diferencias significativas en el modelo de relaciones propuesto (gráfico 1), bajo una perspectiva de sexo. 


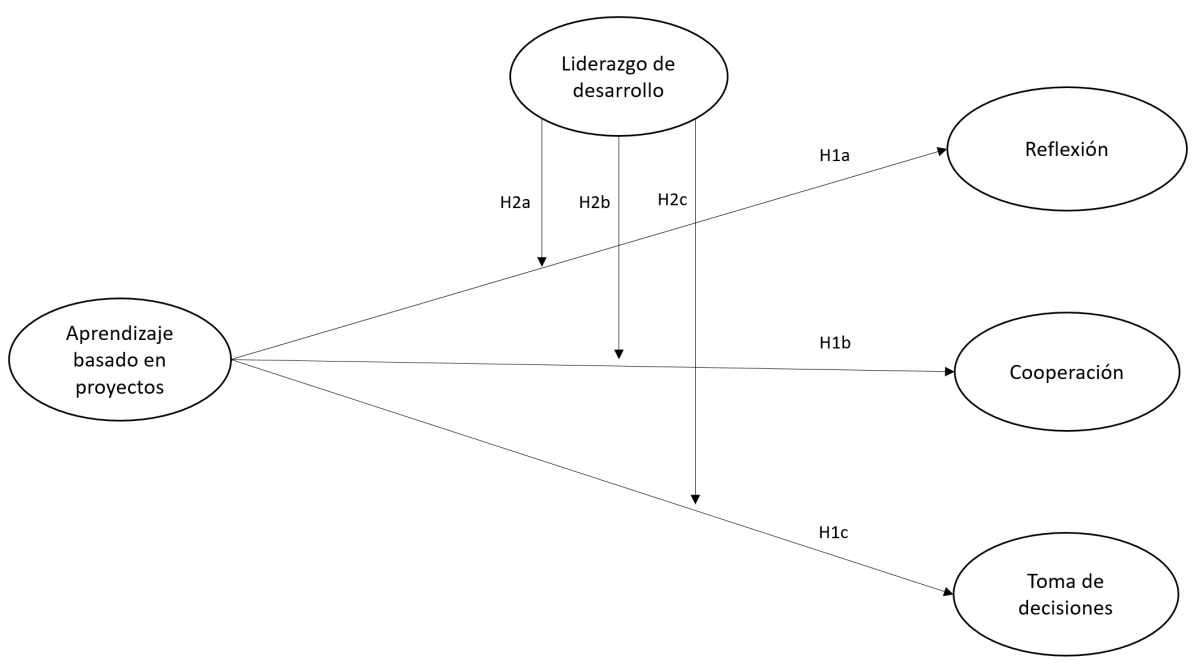

\section{METODOLOGÍA}

En este estudio han participado 144 estudiantes de los grados en Administración y Dirección de Empresas y Relaciones Laborales y Gestión de Recursos Humanos. Los docentes desarrollaron su asignatura utilizando la metodología del aprendizaje basado en proyectos durante todo un semestre, al final del cual se preguntó a los estudiantes por el grado en el que percibían el desarrollo de sus competencias.

La metodología utilizada en este trabajo es cuantitativa, basada en la recogida de datos a partir de cuestionarios cumplimentados por los estudiantes. Para analizar la información, se utilizaron Modelos de Ecuaciones Estructurales, los cuales permiten analizar relaciones de dependencia múltiples y cruzadas, considerando el error de medida (Hair et al., 2006).

Las variables se midieron a través de una escala Likert 1 (nada de acuerdo) a 7 (totalmente de acuerdo). Para reducir el sesgo en las respuestas, los resultados se midieron en tres momentos temporales distintos ( $\mathrm{t} 1$ a las tres semanas del inicio de la asignatura, $\mathrm{t} 2$ a los dos meses del inicio de la asignatura, y $\mathrm{t} 3$ al finalizar la asignatura). La recogida de datos se realizó entre los meses de septiembre y diciembre de 2020.

La variable "aprendizaje basado en proyectos" se midió en t1 a través de un cuestionario Likert, donde 1 se corresponde con nada de acuerdo, y 7 con totalmente de acuerdo. Se realizaron 5 preguntas acerca del grado de uso de esta metodología en la clase (p.e. "En esta asignatura trabajamos a través de una tarea específica, que permite adquirir conocimiento para aplicarlo a un proyecto". El análisis de componentes principales confirmó que los 7 ítems de la escala cargaron de forma satisfactoria en un único factor. El valor a fue de .899 .

Para medir el liderazgo de desarrollo, se utilizó la escala de Podsakoff et al. (1990) en el momento t2, a través de un cuestionario Likert de 3 ítems, donde 1 se corresponde con nada de acuerdo, y 7 con totalmente de acuerdo (p.e. "el profesor promueve que los estudiantes vean en los entornos cambiantes situaciones llenas de oportunidades"). 
El análisis de componentes principales confirmó que los 3 ítems de la escala cargaron de forma satisfactoria en un único factor. El valor a fue de .898 .

Para medir la cooperación, se adaptó la escala de Simsek et al. (2005), a través de un cuestionario Likert de 3 preguntas, realizado en el momento temporal $t 3$, donde 1 se corresponde con nada de acuerdo, y 7 con totalmente de acuerdo (p.e. "los miembros del equipo se ayudan entre ellos para la realización de las tareas". El análisis de componentes principales confirmó que los 3 ítems de la escala cargaron de forma satisfactoria en un único factor. El valor a fue de .812 .

Para medir la reflexión, se realizaron 3 preguntas en el momento temporal $\mathrm{t} 3$, a través de un cuestionario Likert, donde 1 se corresponde con nada de acuerdo, y 7 con totalmente de acuerdo (p.e. "¿Estoy analizando todas las posibles soluciones al problema identificado?"). El análisis de componentes principales confirmó que los 3 ítems de la escala cargaron de forma satisfactoria en un único factor. El valor a fue de .823 .

Para medir la toma de decisiones, se realizaron 3 preguntas en el momento temporal 13 , a través de un cuestionario Likert, donde 1 se corresponde con nada de acuerdo, y 7 con totalmente de acuerdo (p.e. "Cuando se toman decisiones en el grupo, se tiene en cuenta la opinión de todos los miembros"). El análisis de componentes principales confirmó que los 3 ítems de la escala cargaron de forma satisfactoria en un único factor. El valor a fue de .868.

\section{RESULTADOS Y DISCUSIÓN}

El porcentaje de mujeres fue del $61 \%$, con una medad media de toda la muestra de ambos sexos de 21,8 años. Las propiedades psicométricas de las escalas de medida revelaron valores dentro de los límites recomendados, y por tanto mostrando un buen ajuste.

Los resultados del modelo estructural se calcularon utilizando el software EQS. Los resultados muestran que la hipótesis 1a se confirma para ambos sexos, al observar un buen ajuste del modelo y un efecto significativo del aprendizaje basado en problemas y la reflexión. Sin embargo, las hipótesis $1 \mathrm{~b}$ y $1 \mathrm{c}$ no pueden confirmarse para el sexo masculino, ya que el efecto del aprendizaje basado en problemas no es significativo en las variables reflexión y toma de decisiones, en oposición a los resultados para el sexo femenino, donde se confirman ambas hipótesis.

Para las hipótesis $2 a, 2 b$ y $2 c$, encontramos tres interacciones significativas del liderazgo de desarrollo para ambos sexos. El liderazgo de desarrollo incrementa la varianza explicada de la cooperación desde 12,1 a 17,5, la de la reflexión desde 21,8 hasta 26,4, y la de la toma de decisiones desde 39,4 hasta 44,8 para el sexo femenino. En el caso del sexo masculino, liderazgo de desarrollo incrementa la varianza explicada de la cooperación desde 11,1 a 19,8, la de la reflexión desde 19,4 hasta 29,1, y la de la toma de decisiones desde 31,3 hasta 48,1. De esta forma, el aprendizaje basado en proyectos pasa de no ser significativo en la cooperación y la toma de decisiones participativa para el sexo masculino, a serlo cuando existe liderazgo de desarrollo $(\beta=0,39 ; p<0.01$ y $\beta$ $=0.28 ; p<0.01$, respectivamente) . 
Este estudio aporta dos contribuciones teóricas fundamentales. En primer lugar, se pretende ampliar el desarrollo de la teoría de aprendizaje basado en proyectos, al conectarla con resultados concretos en las competencias de los estudiantes. La cooperación, la reflexión y la toma de decisiones son competencias clave para abordar problemas complejos en el área de Organización de Empresas, y este trabajo propone un modelo de relación directa que además confirma con datos obtenidos del estudio experimental. Resulta especialmente interesante poder haber controlado el estudio de forma que se garantizaba su realización en clases basadas en la metodología del aprendizaje basado en proyectos.

En segundo lugar, este estudio avanza en la teoría del aprendizaje basado en proyectos desde una perspectiva de sexo, al conectarlo con la literatura de liderazgo, con gran tradición en la investigación en Organización de Empresas, proponiendo un efecto moderador del liderazgo de desarrollo, en la relación entre el aprendizaje basado en proyectos y las variables dependientes (cooperación, reflexión y toma de decisiones), en función de si la muestra estaba compuesta por estudiantes hombres o mujeres.

El modelo teórico propuesto aporta una perspectiva bajo la cual la figura del docente resulta clave para lograr el éxito en la metodología basada en proyectos, especialmente para el sexo masculino. Además, este estudio aporta evidencia empírica de los efectos del aprendizaje basado en problemas sobre la cooperación, la capacidad de reflexión y la capacidad de toma de decisiones. Los resultados confirman un efecto directo y positivo del aprendizaje basado en problemas, salvo en las variables cooperación y toma de decisiones participativa para el caso del sexo masculino, situación que cambia al analizar el efecto moderador del liderazgo de desarrollo. Es decir, que el liderazgo de desarrollo del docente facilita la cooperación y la toma de decisiones participativa, especialmente para el sexo masculino, y sin él el aprendizaje basado en problemas no es suficiente para fomentarla. Pero, además, el liderazgo de desarrollo refuerza el efecto del aprendizaje basado en problemas en todas las competencias para ambos sexos.

Podemos concluir que los resultados revelan que las mujeres estudiantes universitarias objeto de estudio demuestran un desarrollo más efectivo de las competencias de cooperación y toma de decisiones participativas, ya que no requieren de la intervención del liderazgo de desarrollo, pero igualmente son capaces de aprovechas este estilo de liderazgo del docente para potenciar las tres competencias clave analizadas. Proponemos que futuros estudios analicen diferentes proporciones de hombres y mujeres en los grupos de trabajo para conocer su efecto en el desarrollo de comptencias clave.

\section{AGRADECIMIENTOS}

Quisiéramos agradecer a la Universitat de València el apoyo a esta investigación, realizada dentro del Proyecto de Innovación Docente UV-SFPIE_PID20-1347777. 


\section{REFERENCIAS BIBLIOGRÁFICAS}

Barron, B. J., Schwartz, D. L., Vye, N. J., Moore, A., Petrosino, A., Zech, L., \& Bransford, J. D. (1998). Doing with understanding: Lessons from research on problem-and project-based learning. Journal of the learning sciences, 7(3-4), 271-311.

Bereiter, C., \& Scardamalia, M. (1999). Process and product in PBL research. Toronto: Ontario Institutes for Studies in Education/University of Toronto.

Cohen, P. R., \& Levesque, H. J. (1991). Teamwork. Nous, 25(4), 487-512.

Duyar, I., Mina, K. D., \& Owoh, J. S. (2019). Promoting Student Creative ProblemSolving Skills: Do Principal Instructional Leadership and Teacher Creative Practices Matter?. In Vocational Identity and Career Construction in Education (pp. 78-99). IGI Global.

Hair, J. F., Black, W. C., Babin, B. J., Anderson, R. E., \& Tatham, R. L. (2006). Multivariate data analysis. Uppersaddle River.

Membrillo-Hernández, J., Ramírez-Cadena, M. J., Martínez-Acosta, M., Cruz-Gómez, Muñoz-Díaz, E., \& Elizalde, H. (2019). Challenge based learning: the importance of world-leading companies as training partners. International Journal on Interactive Design and Manufacturing (IJIDeM), 1-11.

Rafferty, A. E., \& Griffin, M. A. (2006). Refining individualized consideration: Distinguishing developmental leadershipand supportive leadership. Journal of occupational and organizational psychology, 79(1), 37-61.

Silberman, M. (1996). Active Learning: 101 Strategies To Teach Any Subject. PrenticeHall, PO Box 11071, Des Moines, IA 50336-1071.

Simsek, Z., Veiga, J. F., Lubatkin, M. H., \& Dino, R. N. (2005). Modeling the multilevel determinants of top management team behavioral integration. Academy of Management Journal, 48(1), 69-84. 


\subsubsection{Sobre violencia de género y crueldad contra los animales: hacia una educación para la paz y la empatía Angélica Velasco Sesma (Universidad de Valladolid, España).}

\section{Resumen}

El presente trabajo constituye una defensa de la educación para la empatía partiendo del análisis bibliográfico de los estudios filosóficos, psicológicos y criminológicos que han señalado los riesgos que tiene para las personas y, especialmente, para las mujeres, el abuso y la crueldad hacia los animales. Se parte de la filosofía ecofeminista para establecer la interconexión entre el sistema de dominación sexista y el sistema de dominación de la naturaleza y los animales y, desde estos planteamientos teóricos y desde la Ética del cuidado, se apuesta por la necesidad de educar en los valores del cuidado, la empatía y la compasión. La relación entre la violencia de género y la violencia contra los animales invita a repensar nuestras conductas hacia los no humanos y a proponer una educación ecofeminista para la no violencia.

Palabras clave: violencia; mujeres; animales, ecofeminismo; empatía.

\section{INTRODUCCIÓN Y OBJETIVOS}

Las relaciones entre la violencia contra las mujeres y la violencia contra los animales son bastante desconocidas e, incluso, negadas. No obstante, es un hecho que la animalización de las mujeres ha mantenido su infravaloración y sometimiento. Es más, en las culturas en las que existe mucha crueldad hacia los animales, es más probable que las mujeres sufran violencia o sean asesinadas (Flynn, 2000). Además, la violencia contra los animales es un mecanismo común que emplean los maltratadores de mujeres en un acto flagrante de violencia psicológica (Adams, 2006, Ascione, 1998, Upadhaya 2014). Por estos motivos, es necesario conocer las conexiones entre la dominación de las mujeres y la crueldad contra los animales con el fin de lograr una educación igualitaria basada en la empatía, que rechace los valores androcéntricos y reivindique las virtudes de la Ética del cuidado.

Si bien la mayoría de las personas excluye de su círculo de consideración moral a los animales no humanos, históricamente, algunos pensadores y pensadoras han señalado la peligrosidad de la crueldad contra los animales en tanto que favorece la violencia contra las personas. Así, por ejemplo, en el Siglo de las Luces, caracterizado por la defensa de la razón, de la crítica al prejuicio y de la educación como motor de cambio social, el filósofo Immanuel Kant señala lo siguiente: "El hombre ha de ejercitar su compasión para los animales, pues aquel que se comporta cruelmente con ellos posee asimismo un corazón endurecido para sus congéneres" (Kant, 1988: 287). En esta misma línea, la filósofa feminista Mary Wollstonecraft sostiene que "la justicia, o incluso la benevolencia, no serán una fuente poderosa de acción si no se extienden a toda la creación; más aún, creo que puede considerarse un axioma que aquellos que pueden ver el dolor sin sentirse conmovidos, pronto aprenderán a causarlo" (Wollstonecraft, 1994: 361). Wollstonecraft une este rechazo hacia la crueldad con los animales con sus reflexiones feministas, mostrando que los niños que atormentan a los animales para divertirse serán, en el futuro, maridos tiránicos. La feminista ilustrada Olympe de Gouges reflexiona de forma similar. Un siglo más tarde, numerosas sufragistas como Frances Power Cobbe unirán su lucha por los derechos de las mujeres y por la igualdad entre los sexos con la defensa de los animales, ya que observaban que los experimentos que los hombres realizaban sobre animales se asemejaban a los abusos que las mujeres sufrían como pacientes en ginecología o como objetos de la pornografía (Munro, 2001). 
Desde el siglo XX hasta la actualidad, han proliferado los estudios y ensayos que muestran los puntos de contacto entre la violencia contra las mujeres y la crueldad contra los animales. Algunas de las propuestas más vanguardistas se han desarrollado desde el eco feminismo, que analiza las conexiones entre la dominación de las mujeres y la dominación de la naturaleza y los animales y propone una educación igualitaria basada en los valores de la Ética del cuidado (Adams, 2017, Puleo, 2011, Shiva, 1995, Velasco, 2017). El presente trabajo aspira a evidenciar la importancia de la educación para la empatía como herramienta que favorece la construcción de una cultura de paz, igualdad y justicia. Persigue, por un lado, mostrar cómo se vinculan los diferentes sistemas de dominación analizando reflexiones ecofeministas; por otro, exponer las vinculaciones entre la violencia de género y la violencia contra los animales; y, finalmente, rescatar los valores de la Ética del cuidado como tradicionalmente despreciados por la educación patriarcal por considerarlos femeninos cuando, en realidad, son valores humanos que deben ser asumidos también por los hombres.

Como señala la ecofeminista Petra Kelly: "La educación para la paz analiza las causas de la guerra, la violencia y la opresión sistemática, e investiga los procesos por los que el conflicto y el cambio puedan desarrollarse para lograr el máximo de justicia y el mínimo de violencia" (Kelly, 1997: 73). Una educación para la paz, la empatía y la compasión favorece la deconstrucción de los valores androcéntricos en tanto que causantes de la mayor cantidad de violencia y sufrimiento.

\section{METODOLOGÍA}

En el presente texto, aporto una investigación filosófica desde el análisis bibliográfico, por un lado, de la filosofía ecofeminista que evidencia las profundas conexiones entre la dominación de las mujeres y la dominación de la naturaleza y los animales y que apuesta por educar contra la opresión; por otro, de investigaciones que han corroborado estas formulaciones teóricas ecofeministas, constatando que la violencia contra los animales favorece la violencia contra las personas y se relaciona estrechamente con la violencia de género; y, finalmente, de la Ética del cuidado, una Ética vinculada a la educación que apuesta por universalizar virtudes como el respeto, la compasión o la empatía y que es una de las bases del ecofeminismo. Mediante el análisis filosófico-conceptual, se clarificarán nociones básicas que evidencian la importancia de la educación para la paz en sentido universal, es decir, paz para humanos y no humanos.

\section{RESULTADOS Y DISCUSIÓN}

El ecofeminismo nos permite evidenciar los puntos de contacto que existen entre la dominación de las mujeres y la dominación de la naturaleza y los animales, con el objetivo de educar en valores igualitarios de sostenibilidad y empatía. Tenemos que partir de la constatación de que el pensamiento occidental se estructura de acuerdo a pares de opuestos en los que una de las partes aparece como superior a la otra: el hombre es superior a la mujer, la cultura a la naturaleza, los humanos a los animales, la razón a la emoción y así sucesivamente (Plumwood, 1993). Esta manera de conceptualizar de forma jerárquica conduce a la inferiorización de las mujeres, los animales, las emociones, el cuidado, la empatía. Desde el ecofeminismo, se ha establecido que todos los sistemas de dominación se encuentran vinculados a nivel conceptual por estar fundados en la misma argumentación lógica: la lógica de la dominación (Warren, 1997). Esta lógica establece que es justo dominar a aquellos que son considerados inferiores. Así, se legitima el sexismo porque las mujeres son entendidas como inferiores a los hombres. También se legitima el racismo, el clasismo, el heterosexismo y el resto de los sistemas de dominación, incluido el sistema de dominación de la naturaleza y de los animales. Ante esta situación injusta, se propone 
eliminar este razonamiento lógico, de forma que dejemos de entender que podemos dominar al que, por ser diferente, es entendido como inferior. Educar contra esta lógica es uno de los objetivos fundamentales del ecofeminismo. Por lo tanto, entendemos que una educación ecofeminista que potencie el respeto hacia las diferencias y hacia el mundo no humano contribuye a redefinirnos de forma más humilde y a trabajar por la igualdad, la justicia y la sostenibilidad (Puleo, 2011).

La ideología patriarcal ha creado la ontología de las mujeres como objetos sexuales a disposición de los hombres y la de los animales como objetos comestibles a disposición de los humanos (Adams, 2016). Esta conceptualización y cosificación ha justificado la violencia de género y la violencia contra los animales creando, de este modo, un mundo violento e injusto en el que las violencias se entrelazan. ¿Podemos considerar que una educación para la paz y la igualdad es completa si no busca también la paz para con los animales? Si, como están mostrando cada vez más estudios psicológicos y criminológicos, la violencia contra los animales aumenta el riesgo de violencia contra las personas (Ascione, 1999, DeGue, DiLillo, 2009, Flynn, 2000, Onyskiw, 2007) y se relaciona con la violencia contra las mujeres, en tanto que muchas de las víctimas de violencia de género en las relaciones afectivas de pareja sufren el abuso hacia los animales con los que conviven y a los que consideran su familia (Strand, Faver, 2005, Loring et al, 2007), será necesario entender que también los animales son víctimas (Bernuz, 2015, Loring et al, 2007) y educar en la empatía también hacia el mundo no humano. Así, se favorece una educación igualitaria y se trabaja, al mismo tiempo, por la eliminación de la violencia contra las mujeres, tal y como proponen las teóricas ecofeministas.

La educación patriarcal ensalza los valores androcéntricos de la competitividad, la violencia, el individualismo y el desprecio por las emociones. Frente a esta educación que desvaloriza las virtudes tradicionalmente asociadas a las mujeres, reivindicamos una educación ecofeminista que enseñe a entender la necesidad de enfrentarnos a la situación de extrema violencia (interpersonal, interespecífica y violencia contra la naturaleza) en la que nos encontramos como consecuencia del andro-antropocentrismo (Puleo, 2019). La Ética del cuidado (Gilligan, 1985) entiende que, además de la justicia, es necesario revalorizar y universalizar virtudes como el afecto, la no violencia, la atención a las relaciones, el cuidado y el amor. Sólo potenciando estas virtudes y enseñándolas también a los varones podremos educar a una nueva generación que ya no aspirará a la autonomía desvinculada y violenta, sino que asumirá el cuidado y la empatía como parte constitutiva del ser humano. Una Ética del cuidado ecofeminista enseña, además, a respetar a la naturaleza y a los otros animales.

\section{CONCLUSIONES Y LIMITACIONES}

Las propuestas ecofeministas continúan siendo desconocidas en gran medida. A este desconocimiento se debe el rechazo que algunas veces genera. A menudo nos cuesta entender que la opresión de las mujeres se relaciona directamente con la explotación de la naturaleza y que la violencia contra las mujeres está vinculada a la violencia contra los animales. Por este motivo, aunque desde el feminismo se apueste por la universalización de los valores del cuidado, demasiado a menudo nos encontramos con un rechazo a aplicarlos también en nuestras relaciones con los no humanos. Como hemos visto, la animalización de las mujeres ha sido un mecanismo empleado tradicionalmente para justificar su inferiorización, exclusión y opresión. Debemos educar en el rechazo a la lógica de la dominación que legitima el sometimiento de mujeres, animales y otros individuos oprimidos. Además, desde la educación en los valores de la violencia propios del androcentrismo, se potencia la violencia contra los animales domésticos con los que convive la víctima de violencia de género. Violencia de género 
y violencia contra los animales están, pues, relacionadas. Entendemos que solamente una educación basada en la empatía y en el cuidado del otro, humano y no humano, puede contrarrestar la socialización violenta patriarcal. Tanto desde la educación formal como desde la no formal es imprescindible inculcar estos valores tradicionalmente despreciados pero indispensables ante el aumento de la violencia y la situación de colapso ambiental actual. Esta investigación se presenta como una defensa de una educación en valores ecofeministas del cuidado que deberán ser enseñados desde todos los ámbitos de la sociedad para evitar que se entienda que se puede dominar a aquel que ha sido considerado inferior. Este razonamiento que entiende que se puede dominar al diferente ha justificado y justifica la violencia machista, la violencia contra los animales y todo tipo de violencia. ¿No es momento ya de desprendernos de esta lógica y educar en la empatía por todos los individuos que son afectados por nuestras acciones? Todos los individuos inferiorizados (mujeres, animales, personas LGTBI, etc.) ganarán en esta nueva educación. Y la sociedad en su conjunto se encaminará, ahora sí, hacia la justicia, la igualdad y la paz.

\section{REFERENCIAS BIBLIOGRÁFICAS}

Adams, C. J. (2006). Woman-Battering and Harm to Animals. En Adams, C., Donovan, J. (eds.), Animals and Women. Feminist Theoretical Explorations. (55-84). USA: Duke University Press.

- (2016). La política sexual de la carne. Madrid: Ochodoscuatro ediciones.

- (2017). Proteína feminizada: significado, representaciones e implicancias. En Andreatta, M. M., Pezzetta, S., Rincón, E. (Eds.), Crítica y animalidad: cuando el otro aúlla. (72-97). Editorial Latinoamericana Especializada en Estudios Críticos Animales.

Ascione, F.R. (1998). Battered Women's Reports of their Partners' and Their Children's Cruelty to Animals. Journal of Emotional Abuse, 1(1), 119-133.

- (1999). The abuse of animals and human interpersonal violence. Making the connection. En F. Ascione y Ph. Arkow (eds.), Child abuse, domestic violence, and animal abuse. Linking the circles of compassion for prevention and intervention. (50-61). West Lafayette: Purdue University Press.

Bernuz, M. J. (2015). El maltrato animal como violencia doméstica y de género. Un análisis sobre las víctimas. Revista de Victimología, 2, 97-123.

DeGue, S., DiLillo, D. (2009). Is animal cruelty a 'red flag' for family violence? investigating Co-ocurring violence toward children, partners, and pets. Journal of Interpersonal Violence, 24, 6, 1036-1056.

Flynn, C. P. (2000). Why Family Professionals Can No Longer Ignore Violence Toward Animals. Family Relations, 49, 87-95.

Gilligan, C. (1985). La moral y la teoría. Psicología del desarrollo femenino. México: Fondo de Cultura Económica.

Kant. I. (1988). Lecciones de ética. Barcelona: Crítica.

Kelly, P. (1997). Por un futuro alternativo. Barcelona: Paidós. 
Loring, M.T., Marsh, J., Geffner, R. (2007). Introduction: Animal Abuse and Family violence. Journal of Emotional Abuse, 7, 3, 1-6.

Munro, L. (2001). Caring about Blood, Flesh, and Pain: Womens Standing in the Animal Protection Movement. Society and Animals, vol. 9, 1, 43-61.

Onyskiw, J. E. (2007). The link between family violence and cruelty to family pets. Journal of Emotional Abuse, 7, 3.

Plumwood, V. (1993). Feminism and the Mastery of Nature. London-New York: Routledge.

Puleo, A. (2011). Ecofeminismo para otro mundo posible. Madrid: Cátedra.

- (2019). Claves ecofeministas. Para rebeldes que aman a la tierra y a los animales. Madrid: Plaza y Valdés.

Querol, N. (2008). Violencia hacia animales por menores... ¿cosas de niños?. Revista de Bioética y Derecho, 13, 12-28.

Shiva, V. (1995). Abrazar la vida. Mujer, ecología y desarrollo. Madrid: Horas y Horas.

Strand, E. B., Faver, C. A. (2005). Battered women's concern for their pets: a closer look. Journal of Family Social Work, 9, 4, 39-58.

Upadhya, V. (2014). The abuse of animals as a method of domestic violence: the need for criminalization. Emory Law Journal, 63, 1163-1209.

Velasco, A. (2017). La Ética Animal. ¿Una cuestión feminista?. Madrid: Cátedra.

Warren, K. (1997). El poder y la promesa de un Feminismo ecológico. En Agra, M. X. (comp.). Ecología y feminismo. (117-146). Granada: Comares.

Wollstonecraft, M. (1994). Vindicación de los derechos de la mujer. Madrid: Cátedra. 


\subsection{EXPERIENCIAS}

\subsubsection{Los estudiantes de trabajo social frente a la pandemia Covid- 19. Resultados de una encuesta desde la perspectiva de género}

Cuadrado Cenzual María Ángeles (UCM, Departamento Medicina, Facultad Trabajo Social. España).

\section{Resumen}

La Pandemia COVID-19 está suponiendo una carga abrumadora a nivel económico sanitario y social. El papel que van a desempeñar el alumnado como profesionales de Trabajo Social (TS) será crucial en la extinción de esta pandemia y en la recuperación de sus consecuencias.

El objetivo es poner de manifiesto actitudes, emociones y conocimientos del alumnado de TS frente a la situación que estamos viviendo desde una perspectiva de género.

Se realizó en los estudiantes de TS un cuestionario anónimo y voluntario diseñado para este estudio. La encuesta incluye, datos demográficos preguntas cuyas respuestas utilizan la escala de 5 puntos de Likert y preguntas de respuesta libre

Contestaron a la encuesta 174 alumnas/os de TS, siendo hombres un $18 \%$. Se observan diferencias en algunas respuestas especialmente sobre el mecanismo de contagio de la enfermedad COVD-19, percepciones y sentimientos, fuentes de información entre otros.

Existen respuestas muy similares en todas/os las/los encuestadas/os pero si hay temas clave en los que se presentan diferencias. Como limitación hay escaso porcentaje de hombre en las respuestas.

Palabras clave: covid19; encuesta; trabajo social, estudiantes;

\section{INTRODUCCIÓN Y OBJETIVOS}

El año 2020 ha sido caracterizado por la aparición de una situación sin precedentes. La pandemia Covid-19 ha afectado gravemente a todos los niveles, económicos, sanitarios y sociales. Dentro de esta extremadamente compleja situación, la población ha tenido que irse adaptando a nuevas y excepcionales medidas que afectan de forma relevante a su forma de vida.

En el ámbito Universitario, la mayoría del alumnado se ha visto afectado, teniendo que adaptarse a la virtualidad de sus estudios y además siendo jóvenes, su relación social ha cambiado drásticamente.

De manera específica, ¿cómo se ha visto afectado el alumnado de Trabajo Social (TS)?

Hemos de ser conscientes de que la población de jóvenes es esencial en las medidas estratégicas encaminadas a reducir la transmisión del virus SARS Cov-2. Por otro lado, 
los/as jóvenes estudiantes de TS son cruciales ya que como futuros/as profesionales en el ámbito de trabajo social constituyen una masa crítica para ayudar al resto de la población en la situación de pandemia.

Debido a lo anteriormente expuesto, el objetivo de este trabajo ha sido evaluar en el alumnado de la Facultad de trabajo social de la UCM, el impacto de la pandemia en las emociones, actitudes y su vida universitaria y social durante casi el primer año de pandemia desde una perspectiva de género.

\section{METODOLOGÍA}

Se realizó en el estudiantado de TS un cuestionario estructurado, anónimo y voluntario diseñado para este estudio. La encuesta incluye, datos demográficos preguntas cuyas respuestas utilizan la escala de 5 puntos de Likert y preguntas de respuesta abierta, son la intención de recoger datos tanto desde el aspecto cuantitativo como cualitativo. Los aspectos que se han incluido al realizar el diseño de la encuesta han sido los conocimientos, percepciones, sentimientos, actitudes y los cambios en general en la forma de vida durante el período de pandemia de marzo 2020 hasta enero 2021.

\section{RESULTADOS Y DISCUSIÓN}

Contestaron a la encuesta 174 alumnas/os de TS, siendo mujeres un $88,6 \%$ hombres un $10,3 \%$, otros un $0,6 \%$ y un $0,6 \%$ prefirió no contestar.

\section{Conocimientos}

Cabe señalar que el alumnado de TS, son conscientes de algunos síntomas comunes del COVID-19. Sin embargo, no conocen la diferencia entre SARS-COV-2 y COVID-19, porque como se muestra en el siguiente gráfico, observando una clara disparidad en la escala (totalmente en desacuerdo-totalmente de acuerdo). En relación al mecanismo de transmisión un $82 \%$ de las personas encuestadas, coinciden en que la vía aérea es claramente una forma de transmisión. Sin embargo, en el resto de los mecanismos de transmisión de la infección existe una gran variabilidad de respuestas.

\section{Percepciones}

En relación con sus percepciones, el $76 \%$ de los encuestados/as valora que el acceso a la atención pública es más deficiente y difícil que antes de la Pandemia y el $78 \%$ considera que la capacidad para continuar con los estudios ha empeorado.

\section{Sentimientos}

En relación con los sentimientos, 118 de las 174 personas encuestadas, están preocupadas por poder contagiar a alguno de sus familiares mientras que únicamente 24 están extremadamente preocupadas.

\section{Actitudes}

Aunque todos los estudiantes conocen algunos de los medios de transmisión más comunes, no todos mantienen una higiene adecuada. Como ejemplo, $71 \%$ refieren que no mantienen una limpieza regular del teléfono móvil.

En relación a los hábitos relacionados con sus estudios, podemos observar claramente que los/as estudiantes cumplen con las medidas establecidas, ya que todo se ha 
realizado a través de recursos en línea, Se observa un aumento considerable de uso por parte de los estudiantes de "recursos en línea" (91\%) y una disminución en uso de biblioteca presencial (51\%) sin embargo el uso de la biblioteca virtual presentó un ligero aumento del $4,6 \%$.

En relación con los cambios generales y su adaptación a la nueva normalidad, se ha observado una gran transición en el uso del transporte. Se ha producido un aumento de la movilidad por medios privados. Sin embargo, se han producido muy pocos cambios con solo una media de 32 personas que han sustituido el transporte público por privado, y solo 3 personas han utilizado otro tipo de transporte.

En cuanto al ámbito social, muchos de los encuestados han indicado que su círculo de amistades se ha visto afectado. Aun así, se puede observar que se siguen realizando actividades de ocio, es cierto que el $79,3 \%$ lo hace en terrazas, pero solo el $2,9 \%$ ha restringido estas salidas

Se observan diferencias en algunas respuestas especialmente sobre el mecanismo de contagio de la enfermedad COVD-19, percepciones y sentimientos, fuentes de información entre otros.

\section{CONCLUSIONES Y LIMITACIONES}

Los resultados de esta investigación han mostrado que, durante el período de realización de la encuesta, existía una falta de conocimiento o conceptos muy confusos sobre la pandemia, la enfermedad y el virus. Si hay desinformación, el problema de la pandemia no podrá ser tratado de la misma manera y se abordará de forma ineficaz. Es estrictamente necesario que la población esté bien informada.

En relación con el mecanismo de transmisión, si bien es cierto que conocían algunos de ellos con total convicción, otros no parecen estar claros. Este es un ejemplo más de la necesidad de informar y ser informado sobre un virus que ha tenido tanto impacto en la vida de la población mundial.

Es de destacar la gran disminución del uso del transporte público. El estudiantado sobre todo en un inicio y debido al desconocimiento y confusión en relación con los mecanismos de contagio, la mayoría del alumnado tenía miedo de ser infectado en el transporte público,

En el ámbito universitario, las clases se estaban impartiendo de forma mayoritaria vía on-line y los trabajos se llevaban a cabo también mediante reuniones on-line.

Se ha puesto de manifiesto un gran descenso en el nivel de socialización de la población estudiada, incluso a pesar de las facilidades de acceso a internet y redes sociales. El círculo de amigos en muchos casos se ha visto afectado por la pandemia, ya que no se reúnen con la misma frecuencia que antes del estado de alarma y cuando se reúnen controlan cómo y con quién lo hacen. Este es uno de los ámbitos que más se ha visto alterado porque se han presentado una serie de medidas restrictivas.

La vida cotidiana ha dado un giro de casi 180 grados, la máscara se ha incorporado como una prenda más en nuestro día a día. La población realiza una mejor higiene de las manos tanto en el lavado como en el uso de gel hidroalcohólico y mantiene medidas de distanciamiento. De esta forma, las relaciones sociales se han visto afectadas, pues debido a la fácil propagación del virus en muchos casos, ha surgido el pánico en continuar con la vida social que antes se realizaba. También se ha alterado la vida 
laboral y de estudio, se ha informatizado completamente, la mayoría de la gente lo hace desde casa para evitar infecciones y no sobrepasar la capacidad permitida de personas en espacios cerrados de aulas y oficinas.

Por otro lado, el ocio también se ha visto afectado, el número de personas en espacios cerrados se ha limitado al 30 y $50 \%$ dependiendo del estado de la pandemia y se han establecido confinamientos por áreas básicas de salud y restricciones perimetrales para evitar la circulación entre algunas ciudades y otros, teniendo así un mayor control sobre el virus. Se han establecido una serie de excepciones que permiten la movilidad de los ciudadanos de una comunidad a otra (Ministerio de Sanidad, Consumo y Bienestar Social - Profesionales - Desarrollo del Estado de Alarma en las Comunidades Autónomas, 2021). Junto a estas restricciones de movilidad, también se han visto afectadas la patrona y las fiestas patrias, que de ser eventos multitudinarios han pasado a no celebrarse, creando así sentimientos de disgusto y tristeza en muchos ciudadanos, y con ello, repercutiendo desfavorablemente en la economía de cada comunidad o país.

Existen respuestas muy similares en todas/os las/los encuestadas/os pero si hay temas clave en los que parecen existir diferencias desde una perspectiva de género, pero debido a que la gran mayoría de las respuestas han sido de las estudiantes femeninas, es difícil establecer diferencias significativas.

\section{REFERENCIAS BIBLIOGRÁFICAS}

1. Alocución de apertura del Director General de la OMS en la rueda de prensa sobre la COVID-19. Organización Mundial de la salud. [Declaración en internet] 2020. 11 de marzo. [acceso 2020 Abr 15] Disponible en: https://www.who.int/es/dg/speeches/ detail/who-director-general-s-openingremarks-at- the-media-briefing-on-covid-19---11-march-2020

2. World Health Organization (WHO). Gender and Health in Natural Disasters. Adapted from: Gender and Health in Disasters. Geneva: WHO; 2002.

3. Social Distancing. Quarantine, and Isolation. cited 2020 May 5. Available from: https://www.cdc.gov/coronavirus/ 2019-ncov/prevent-getting-sick/socialdistancing.html

4. Lim ECH, Oh VM, Koh DR, et al. The challenges of "continuing medical education" in a pandemic era. Ann Acad Med Singapore. 2009;38(8):724-726.

5. Workbook: NYS-COVID19-Tracker. New York State Department of Health. cited 2020 May 9. Available from: https://covid19tracker.health.ny.gov/views/NYSCOVID19-Tracker/NYSDOHCOVID-

19Tracker-Map?

$\% 3$ Aembed $=y e s \& 3$ Atoolbar $=$ no\&\%3Atabs $=n$ 


\subsubsection{Contribuyendo al buen trato, la sexualidad con el SKOLAE}

Elena Bujanda Sainz de Murieta (Profesora de Intervención Sociocomunitaria-FP, Navarra, España)

\section{Resumen}

La presente comunicación muestra una experiencia educativa que ha trabajado la sexualidad y el buen trato con jóvenes de un grupo del ciclo formativo de Grado Superior de Integración Social.

El objetivo general es facilitar un espacio de escucha, diálogo, reflexión y aprendizaje sobre ética de las relaciones y salud, la salud sexual y la desestigmatización de VIH y otras enfermedades de transmisión sexual.

La propuesta se ha realizado implementando fichas seleccionadas del eje 4. "Sexualidad y buen trato" del programa SKOLAE, que trabajan los ámbitos personal, relacional y contextual.

La satisfacción del alumnado ha sido muy alta, puesto que son temas cercanos e interesantes para las y los jóvenes, de los cuales no tienen oportunidad de hablar habitualmente en un entorno educativo.

El programa SKOLAE sirve de mediador para trabajar con el alumnado relaciones respetuosas y de coeducación.

Palabras clave: coeducación; sexualidad; formación profesional; SKOLAE.

\section{INTRODUCCIÓN Y OBJETIVOS}

El programa SKOLAE-Creciendo en igualdad es un programa de educación afectivosexual del Departamento de Educación del Gobierno de Navarra que se desarrolla desde 2017 y está dirigido al alumnado de todos los centros escolares de la Comunidad Foral de Navarra.

SKOLAE desarrolla el modelo de escuela coeducativa, se estructura en torno a numerosos valores y a un derecho fundamental: el derecho a la igualdad.

SKOLAE propone a lo largo de todas las etapas educativas, analizar, corregir y compensar actitudes y comportamientos que no conducen a la igualdad, además de mostrar e identificar aquellas actitudes y comportamientos que nos ayudarán a conseguirla.

El programa ofrece un amplio abanico de recursos didácticos dirigidos a alumnos y alumnas de todas las edades, para que adquieran las competencias necesarias para "aprender a vivir en igualdad".

El trabajo que se presenta se enmarca dentro del eje 4 de este programa, "Sexualidad y buen trato" y se contextualiza en los ámbitos personal, relacional y contextual.

Se diseñó una intervención que consistía en tres sesiones, procurando aportar una globalidad a la intervención. En cada una de ellas, se trabajó una ficha seleccionada previamente del programa SKOLAE con diferentes objetivos:

Ficha "Ética y salud en las relaciones".- Con esta actividad queremos conseguir los siguientes objetivos específicos:

1. Conocer los principios éticos universales con contenido sexual y amoroso. 
2. Desarrollar actitudes que favorezcan la aceptación del compromiso, la responsabilidad y la honestidad como base de las relaciones.

3. Cultivar la sensibilidad para atender las propias necesidades y las necesidades de las personas que nos acompañan en nuestra vida sexual-amorosa.

4. Facilitar que el alumnado descubra en los comportamientos cotidianos el reflejo de la desigualdad de género que impregna muchas relaciones.

5. Generar un espacio de reflexión sobre la ética en las relaciones sexuales y amorosas.

Ficha "Salud sexual".- Nos permite trabajar en:

1. Fomentar conciencia ante la salud sexual y reproductiva.

2. Facilitar que el alumnado conozca los comportamientos sanos para la prevención de ITS y embarazos.

3. Generar un espacio de reflexión sobre las consecuencias de utilizar o no utilizar métodos anticonceptivos.

4. Desarrollar actitudes que favorezcan la salud sexual.

Ficha "STOP al Estigma".- Tiene como objetivos específicos:

1. Fomentar la toma de conciencia ante la salud sexual y reproductiva.

2. Facilitar una serie de conocimientos sobre las ITS para que el alumnado sepa cómo prevenir enfermedades y cómo relacionarse con las personas que ya están infectadas.

3. Generar un espacio de reflexión sobre las consecuencias para la salud individual y social de utilizar o no métodos anticonceptivos.

4. Desarrollar actitudes que favorezcan la salud sexual.

5. Desarrollar actitudes para eliminar el estigma social o rechazo de personas con VIH y otras ITS.

\section{CONTEXTUALIZACIÓN}

La experiencia educativa se llevó a cabo en el Centro Integrado de Formación Profesional Escuela de Educadoras y Educadores-Hezitzaile Eskola I.I., de PamplonaIruña. Es un centro de la familia profesional de Servicios Socioculturales y a la Comunidad, cuyos ciclos formativos están eminentemente feminizados.

El alumnado participante pertenecía al segundo curso del Grado Superior en Integración Social, estaba formado por un grupo de 20 alumnas y 3 alumnos, con una edad media de 20 años, con intereses y motivaciones muy diversas.

\section{DISEÑO Y DESARROLLO}

La intervención se diseñó utilizando tres fichas previamente seleccionadas del eje 4 del programa SKOLAE: "Ética y salud en las relaciones", "Salud sexual" y "STOP al Estigma". Con ellas, se trabaja este eje de forma globalizada, abarcando los ámbitos personal, relacional y contextual. Se trabajaron en tres sesiones diferentes de dos horas de duración cada una. 
Utilizamos una metodología activa y participativa, favoreciendo las interacciones entre el alumnado tanto en pequeño grupo como en gran grupo. Realizaron actividades variadas como trabajos de reflexión en pequeños grupos, análisis de vídeos, reflexiones a partir de cuestiones planteadas, debates o puesta en común en grupo grande.

Puesto que la metodología utilizada en el aula es un aspecto importante que nos puede ayudar en la coeducación, dentro de los grupos pequeños se rotaron las funciones y responsabilidades de las tareas con el fin de evitar roles estereotipados y se establecieron normas para garantizar una participación igualitaria de todas las personas del grupo y poner así en valor todas las funciones y roles asignados. En grupo grande, se tuvieron en cuenta los turnos de palabra para equilibrar y ajustar la participación de todo el alumnado.

La metodología ha sido participativa en todo momento. El diálogo y la puesta en común fueron las estrategias más utilizadas para resolver las dudas del alumnado y fomentar el aprendizaje entre iguales.

\section{Sesión 1. Ética y salud en las relaciones}

Comenzamos con la primera sesión, en la que reflexionamos sobre la ética en las relaciones, a partir de los principios éticos universales con contenido sexual y amoroso. La profesora explicó estos principios: ética del consentimiento, ética del placer y el bienestar compartidos, ética de la igualdad, ética de la honestidad, ética de la salud, ética de los cuidados y ética de la diversidad. A continuación, se trabajó cada principio en grupos de tres personas. El alumnado imaginó diversas situaciones, inspirándose en las relaciones de pareja que ven o viven en su entorno. Por último, pusieron en común las diferentes situaciones, analizaron cada una de ellas, explicando si cumplía ese principio ético o iba en contra. En caso de que fuese en contra, describieron cómo sería la conducta adecuada.

Para trabajar la ética del consentimiento pusieron un ejemplo en el que el marido quiere mantener relaciones sexuales cuando llega a casa, a su mujer no le apetece y él le dice enfadado que nunca tiene en cuenta sus necesidades. Finalmente, ella accede.

En la ética del placer y el bienestar compartidos exponen como situaciones habituales aquellas en las que sólo un miembro de la pareja, habitualmente el hombre, busca placer sin mirar demasiado el placer y bienestar de la mujer.

Se refirieron a la ética de la igualdad a través de un caso de una chica joven que quería controlar a su pareja, no le dejaba tener amigas porque era muy celosa.

La ética de la honestidad se trabajó a través de un caso en el que la pareja no compartía con sinceridad sus sentimientos, lo que daba lugar a malos entendidos. Es el único caso en el que el alumnado ha incluido una pareja homosexual.

El uso de anticonceptivos fue la situación que compartieron las alumnas para referirse al incumplimiento en la ética de la salud. Refirieron el que los chicos jóvenes no quieran usar preservativo como una práctica relativamente habitual.

La conciliación familiar y laboral fue el tema elegido para trabajar la ética de los cuidados, pusieron un caso real y buscaron datos para reafirmar su convicción de que las madres cogen muchas más excedencias laborales que los padres.

En la ética de la diversidad surgieron muchas dudas y comentarios. El grupo que lo trabajaba no veía tan claro el principio de la ética de la diversidad dentro de la pareja. Entendían que hay que respetar esa diversidad existente, pero no que sea un principio dentro de una relación. Se da un pequeño debate en torno al tema, al final asumen esa diversidad como una posibilidad en función de la orientación sexual de la pareja. 
En la mayoría de las situaciones descritas por el alumnado en las que no se cumplía el principio ético en la relación, este incumplimiento estaba motivado por el hombre. Se describen como prácticas presentes todavía en nuestra sociedad el acceder a los deseos del hombre sin mirar los propios de las mujeres y su bienestar, tanto en el consentimiento para mantener relaciones sexuales como en el uso de preservativos. Además, sigue existiendo una brecha importante en cuanto a la conciliación familiar y laboral.

No hubo diferencias entre las propuestas de casos y las opiniones entre los grupos formados solo por chicas o aquellos en los que había chicos.

\section{Sesión 2. Salud sexual}

Una vez enmarcada la actividad en el eje 4 del programa SKOLAE y visionado un vídeo sobre embarazos no deseados, se dejó un espacio para favorecer la reflexión en el que en grupos pequeños las alumnas y alumnos iban contestando a una serie de afirmaciones sobre las actitudes que favorecen o perjudican la salud sexual, los anticonceptivos, embarazos no deseados o prevención de infecciones de transmisión sexual (ITS). Debían contestar si creían que eran verdaderas o falsas razonando su respuesta. Posteriormente, realizamos un debate para compartir y contrastar dichas opiniones.

Como conclusiones, podemos destacar la utilidad de la actividad para hacerse conscientes de que hay jóvenes a las que les preocupan más los embarazos que las ITS. Pusieron sobre la mesa la desigualdad de género que existe en este sentido: los embarazos suponen mayor problema para las mujeres que para los hombres, los anticonceptivos masculinos apenas se conocen, siempre son ellas las que tienen tomar anticonceptivos, la facilidad con la que se les prescriben anticonceptivos orales sin tener en cuenta los efectos adversos...

\section{Sesión 3. Stop al estigma}

En esta última sesión, se trabajó el ámbito contextual, con la ficha "Stop al estigma". Contextualizamos la actividad y visionamos el capítulo 5 "In the wall", de la serie Indetectables. Tras el visionado, se formaron grupos de seis personas para poner en común su reflexión individual y responder a las cuestiones que se planteaban en la ficha SKOLAE, como ¿Tenemos suficiente información sobre el VIH y las ITS? ¿Por qué creemos que el VIH y las ITS están asociadas al estigma social? ¿Cómo podemos reducir el estigma social y la discriminación? ¿Cómo prevenir el VIH y las ITS?

Posteriormente, se puso en común en gran grupo.

Los alumnos y alumnas fueron críticas con la estigmatización social de las personas afectadas. Creen que se produce porque realmente nos falta información sobre qué es y cómo se transmite; les gustaría que se visibilizase desde los medios de comunicación desde otra perspectiva más positiva y real y sin asociarlo a ningún colectivo. Por último, hablamos sobre prevención y aportan diferentes propuestas, como realizar campañas para visibilizar el tema, referentes positivos en los medios o personajes que muestren las repercusiones negativas de estas infecciones para concienciar de la importancia de evitar conductas de riesgo. 
Las actividades realizadas, llevaron al alumnado a las siguientes reflexiones:

- La primera actividad, "Ética y salud en las relaciones", puso de relieve las desigualdades que siguen existiendo en nuestra sociedad, tanto en las relaciones sexuales como en los cuidados y la conciliación familiar. Además, comentaron que lo trabajado en ella les sirvió para reflexionar sobre los principios básicos para una relación sana pero que, en su día a día, veían que en muchas parejas no se cumplen estos principios. Les resultó interesante el tratamiento de este el tema y concluyeron dando ejemplos de buen trato, porque "se habla mucho de lo que no se debe hacer y muy poco de lo que si".

- La segunda actividad, "Salud sexual", les permitió debatir sobre las relaciones sexuales saludables y satisfactorias, sobre diferentes prácticas sexuales, los embarazos no deseados y las ITS. Valoraron muy positivamente el tener un espacio donde poder hablar con libertad sobre estos temas.

- Y, la última actividad que formaba parte de la propuesta "Stop al estigma", les sirvió para hacerse conscientes de que no tienen información suficiente sobre VIH e ITS.

Al finalizar cada actividad, se realizó una valoración cualitativa de la respuesta del alumnado ante la actividad y una valoración de la actividad realizada por el propio grupoclase.

En todas las sesiones comentan que les resultó muy satisfactorio poder hablar, compartir, aprender y reflexionar sobre estos temas, la sexualidad sigue siendo un tema tabú en nuestra sociedad y agradecieron la posibilidad que se les dio en el centro educativo. Por tanto, podemos afirmar que la propuesta "Contribuyendo al buen trato, la sexualidad con el SKOLAE" fue muy bien acogida por el alumnado: la valoraron muy positivamente, hubo un elevado interés en las diferentes sesiones y el grado de motivación al realizar las actividades fue muy alto.

Probablemente, el hecho de pertenecer a la familia profesional Servicios Socioculturales y a la Comunidad influye notablemente en el modo en el que se involucra el alumnado en este tipo de actividades.

Desde mi experiencia, el ciclo de Integración Social contribuye a modelar y fortalecer la mirada feminista tanto en ellos como en ellas. Tanto chicos como chicas coincidieron en sus opiniones y comentaron su deseo de seguir luchando por la igualdad. Ellos son conscientes de que tienen determinados privilegios por el hecho de ser hombres, tanto en la sociedad en general como a nivel profesional.

Como propuesta de mejora, me planteo sistematizarlo dentro de la programación anual dedicándole una sesión mensual al programa SKOLAE. De esta manera, conseguiríamos dar más tiempo a cada actividad, puesto que a partir de la propuesta surgían temas relacionados que no tuvimos tiempo de trabajar en algunas ocasiones.

En conclusión, es muy importante y necesario trabajar el tema de la sexualidad y los buenos tratos en el aula. Les permite hablar con naturalidad del tema, resolver dudas, inquietudes, falsos mitos y desarrollar hábitos saludables respecto a su salud sexual, a la vez que favorece su competencia lingüística, social y cívica. En una palabra, fortalecer su postura y criterio ante la sexualidad como hecho social y necesidad primaria.

Esta propuesta se ha realizado gracias al programa SKOLAE, que ofrece actividades, herramientas y recursos de gran valor educativo. Asimismo, el programa ayuda al profesorado a sistematizar estas intervenciones que tienen como finalidad "facilitar a todo el alumnado la posibilidad de aprender a vivir en igualdad". 


\section{REFERENCIAS BIBLIOGRÁFICAS}

Departamento de Educación (2019). El programa SKOLAE, un itinerario para aprender a vivir en igualdad. Gobierno de Navarra. https://www.educacion.navarra.es/documents/27590/1325202/Libro+SKOLAE+ CAST+web.pdf/1ba58d8b-d13b-4f2d-0fc1-9c5e99d5946e 


\subsubsection{Un escape para ellas: las que aportaron a los derechos de la infancia.}

Elena Bujanda Sáinz de Murieta (Profesora de Intervención SociocomunitariaFormación Profesional, Navarra, España); María Ángeles Sanmartín Gracia (Profesora de Intervención Sociocomunitaria-Formación Profesional, Aragón, España).

\section{Resumen}

Se trata de una experiencia educativa innovadora basada en una sesión de Escape Room con asamblea posterior, dirigida al alumnado de $2^{\circ}$ curso del Grado Superior de Educación Infantil.

Los objetivos son afianzar y evaluar conocimientos del módulo Intervención con Familias y Atención a Menores en riesgo Social (IFAM), aumentar la motivación del alumnado y el trabajo en equipo y, visibilizar el papel de la mujer en la historia de los derechos de la infancia, a través de metodologías activas y cooperativas.

Escape IFAM gira en torno a la figura de Eglantyne Jebb, que desarrolló una gran labor en la protección de la infancia, aportando muchísimo a la promulgación de la Declaración de Ginebra y la fundación de la ONG Save the Children.

La satisfacción del alumnado con la metodología fue muy alta y pudimos comprobar cómo mejoran sus competencias y su motivación.

Palabras clave: innovación; coeducación; formación profesional; infancia; género.

\section{INTRODUCCIÓN Y OBJETIVOS}

Esta experiencia educativa se contextualiza en la interrelación de cuatro factores principales:

- El estudio de los Derechos de la Infancia por parte del alumnado como futuros Técnico y Técnica Superior en Educación Infantil. En este sentido, señalar la necesidad de reflexionar junto al alumnado, desde una visión crítica sobre los logros que ha supuesto la Convención de los Derechos de los Niños y Niñas como verdaderos Derechos Humanos.

- En segundo lugar, la formación profesional comprende el conjunto de acciones formativas que capacitan para el desempeño cualificado de las diversas profesiones, el acceso al empleo y la participación activa en la vida social, cultural y económica.

- En tercer lugar, los centros de formación profesional específica cuentan con planes propios de igualdad.

- Por último, entre los objetivos de innovación de la Formación Profesional se encuentra el de promover la inclusión de la igualdad de género como categoría transversal en la innovación en las empresas y en los centros de FP.

El Grado Superior de Educación Infantil tiene como competencia general diseñar, implementar y evaluar proyectos y programas educativos de atención a la infancia en el primer ciclo de educación infantil en el ámbito formal y en toda la etapa en el ámbito no formal, generando entornos seguros y en colaboración con otros profesionales y con las familias.

Se deriva de esta competencia general que, el Técnico/Técnica Superior en Educación Infantil es un profesional que trabaja con la infancia y con sus familias por lo que necesita 
disponer de una amplia visión de los derechos infantiles como base legal para su intervención educativa y/o socioeducativa. Este profesional será consciente de que, en las sociedades avanzadas como la nuestra, el contexto normativo creado desde la Declaración y la Convención de los Derechos del Niño ha tenido un avanzado grado de concreción, garantizando la atención y protección desde el interés superior del menor. Sin embargo, para aquellos territorios y países que no existen estos marcos normativos son las Organizaciones No Gubernamentales y los Organismos Internacionales quienes la proporcionan. La necesidad de incorporar la visión de género a los derechos de los niños y niñas se convierte en una cuestión de justicia social para los y las más pequeños. Por ello, es importante que trabajemos los derechos de los niños y niñas con perspectiva de género: una de las maneras puede ser a través de la visibilización, el reconocimiento del papel de las mujeres en la construcción de estos marcos de garantías para la atención a la infancia, tan habitualmente, ignoradas o relegadas a un segundo plano en nuestra sociedad.

Por otro lado, en todos los niveles educativos, hay una clara apuesta por la utilización de metodologías educativas activas e innovadoras que motiven más al alumnado y se ajusten a nuestra sociedad.

En este campo de la innovación educativa, destaca la gamificación. La gamificación es definida por muchos como una forma de usar los principios del juego (es decir, desafíos, retroalimentación, interactividad) en contextos no comunes (Attali, 2015). Aunque el juego y la diversión a menudo no están asociados con el aprendizaje, el juego en sí mismo resulta propicio para el aprendizaje. Por ello, las educadoras y educadores han visto un aumento en el compromiso y la retención de conocimientos cuando se utilizan juegos (Bruder, 2015).

La gamificación se concentra más en satisfacer las necesidades intrínsecas de los estudiantes, proporcionando un feedback inmediato, el control sobre el material y una curiosidad inspiradora (Kapp, 2012). De esta forma, debido a que los estudiantes quieren participar, el conocimiento mejora, al igual que el aprendizaje y el desarrollo. Además, la gamificación ayuda a las personas a aprender haciendo, lo que en última instancia mejora tanto los procesos como los resultados (Shute, 2013) pudiéndose hablar por tanto de un aprendizaje activo.

Gracias a esta metodología, no sólo se movilizan conocimientos en un contexto muy motivador, sino que además trabajan competencias necesarias para el futuro profesional de las educadoras y educadores: comunicación, escucha activa, trabajo en equipo, resolución de problemas, perseverancia, creatividad, transversalidad de género, gestión del tiempo...

Esta actividad también comprende los "motores naturales del aprendizaje": el juego, la exploración del entorno, y las interacciones entre pares (Álvarez, Djaouti, y Rampnoux, 2016) y posee pues todas las ventajas para favorecer la adquisición de conocimientos y de competencias.

El objetivo general es afianzar y evaluar conocimientos del módulo Intervención con Familias y Atención a Menores en riesgo social a la vez que disfrutan jugando de forma cooperativa y trabajando las competencias profesionales, personales y sociales.

Objetivos específicos:

1. Aumentar la motivación del alumnado por el aprendizaje y el trabajo en equipo.

2. Visibilizar el papel de la mujer en la historia de los derechos de la infancia.

3. Trabajar su competencia digital.

4. Posibilitar la recuperación de un resultado de aprendizaje del módulo IFAM. 


\section{CONTEXTUALIZACIÓN}

La intervención educativa está dirigida al Ciclo de Grado Superior de Educación Infantil, concretamente al módulo Intervención con Familias y Atención a Menores en riesgo social.

Esta innovadora intervención educativa consiste en la realización de una sesión de Escape Room y una asamblea posterior.

La prueba piloto se realizó en Pamplona y la puesta en práctica en el Instituto de Enseñanza Secundaria Luis Buñuel de Zaragoza.

El grupo de alumnado estaba compuesto por 20 personas, 19 alumnas y 1 alumno del IES Buñuel.

Se realizó al final del segundo trimestre, previo al inicio de la Formación en Centros de Trabajo con una doble finalidad: afianzar contenidos en el alumnado que ya había superado el módulo y dar la posibilidad de recuperar en el caso de que tuvieran pendiente el resultado de aprendizaje.

\section{DISEÑO Y DESARROLLO}

Se diseñó un Escape Room, en el que las personas participantes debían resolver ocho enigmas, con el objetivo de trabajar contenidos y actitudes del módulo Intervención con familias y atención a menores en riesgo social, con perspectiva de género.

Antes de llevarlo al aula, hicimos una prueba piloto, con cuatro grupos de cincos personas de edades similares al alumnado de Formación Profesional. Estas pruebas sirvieron para ajustar el tiempo y la dificultad de las pruebas.

Previamente, se ambientó el salón de actos, lugar en el que se realizó la sesión, con carteles e imágenes de mujeres importantes en la historia de la infancia y de la educación: Eglantyne Jebb, Dorothy Buxton, Concepción Arenal, Clara Campoamor y Malala Yousafzai.

Para comenzar la sesión de Escape, había una entrada en la que se encontraban diversos carteles con las normas del juego: trabajar en equipo, rellenar todos los ejercicios, las contraseñas en mayúsculas sin tildes, el candado sólo se lee por un lado y disfrutar con la actividad.

Una vez dentro del aula, la sesión de Escape Room comenzó con el visionado de un vídeo motivacional en el que aparece la noticia "Desaparece una niña mientras jugaba en el desván de su casa". A partir de ella, se construye una narrativa en la que el alumnado trabaja la historia de la infancia, la Declaración de Ginebra en relación con el papel Eglantyne Jebb y otras mujeres importantes en la historia, la evolución de los derechos de la infancia y las diferentes figuras de protección.

Todo ello, con pruebas muy variadas como la realización de un puzzle de la historia de la infancia, la utilización de criptogramas, códigos $Q R$, visionado de pequeños vídeos, audios, la realización de un test o la búsqueda de información en posters de mujeres importantes en la historia de la infancia y de la educación.

Finalmente, se realizó una pequeña asamblea en la que se recogió todo lo aprendido, se resolvieron las dudas y se valoró la satisfacción del alumnado con la intervención realizada. 
Al finalizar la intervención, pudimos comprobar los aprendizajes adquiridos por el alumnado mediante una asamblea. Las dudas que resolvimos giraban en torno a las figuras de protección de la infancia básicamente.

Se les pasó un cuestionario en Google Formularios, una vez finalizada la asamblea, para evaluar el grado de satisfacción con la experiencia educativa y los resultados obtenidos fueron los siguientes:

\begin{tabular}{|c|c|c|c|}
\hline Aspectos evaluados & $\begin{array}{c}\text { Sí } \\
\text { N (\%) }\end{array}$ & $\begin{array}{c}\text { No } \\
\text { N (\%) }\end{array}$ & Observaciones \\
\hline $\begin{array}{l}\text { 1. La historia del Escape Room es } \\
\text { original, divertida y con sentido. }\end{array}$ & $\begin{array}{c}20 \\
(100 \%)\end{array}$ & $0(0 \%)$ & \\
\hline $\begin{array}{l}\text { 2. Los acertijos tienen un buen nivel de } \\
\text { dificultad. }\end{array}$ & $\begin{array}{c}20 \\
(100 \%)\end{array}$ & $0(0 \%)$ & $\begin{array}{l}\text { Es asequible si tienes idea de } \\
\text { tema, sino sí que tiene } \\
\text { dificultad. } \\
\text { Si eres avispado y observador } \\
\text { puedes encontrarlo fácilmente. }\end{array}$ \\
\hline $\begin{array}{l}\text { 3. El grado de dificultad ha sido } \\
\text { adecuado }\end{array}$ & $\begin{array}{c}20 \\
(100 \%)\end{array}$ & & \\
\hline $\begin{array}{l}\text { 4. Existe coherencia entre las } \\
\text { diferentes pruebas del Escape Room }\end{array}$ & $\begin{array}{c}19 \\
(95 \%)\end{array}$ & $1(5 \%)$ & $\begin{array}{l}\text { No he llegado a entender para } \\
\text { que teníamos algunas } \\
\text { imágenes. }\end{array}$ \\
\hline $\begin{array}{l}\text { 5. ¿Te parece una buena metodología } \\
\text { para aprender, reforzar y evaluar } \\
\text { conocimientos? }\end{array}$ & $\begin{array}{c}20 \\
(100 \%)\end{array}$ & $0(0 \%)$ & $\begin{array}{l}\text { Es divertido, original y ayuda al } \\
\text { aprendizaje ya que jugando } \\
\text { también se aprende. } \\
\text { Me parece una metodología } \\
\text { diferente y atractiva en la que } \\
\text { pueden aprender divirtiéndose }\end{array}$ \\
\hline
\end{tabular}

El $80 \%$ definen la experiencia como muy divertida y el $20 \%$ bastante divertida.

Respecto a la valoración global de la experiencia, en una escala $0-10$, el $60 \%$ de las personas que participaron la valoraron con un 9 y el $40 \%$ con un 10 .

Como se observa en los datos anteriores, el grado de satisfacción general es muy alto.

También se les preguntó qué mejorarían del Escape Room, a lo que la mayoría del alumnado respondió que nada, las pocas propuestas de mejora fueron: "El orden de las pruebas quizá llegaban a confundirse", "Lo único la ambientación, por decir algo", "El uso del móvil" y "Es la primera vez que participo en uno, me ha parecido fascinante, sin duda repetiria".

Respecto a la última pregunta del cuestionario en la que podían decir lo que más les había gustado, obtuvimos respuestas relacionadas sobre todo con la variedad y originalidad de las pruebas, el trabajo en equipo, que fuera una actividad cooperativa o el ir aportando cada persona en función de sus necesidades.

La medición cuantitativa de los conocimientos adquiridos se realizó sólo para el alumnado que cumplimentó el test como instrumento de recuperación de esta parte del módulo. Las tres personas aprobaron dicho test. 
Aunque para el resto no se realizó una medición cuantitativa de los conocimientos adquiridos, sí se pudo constatar cualitativamente que la experiencia vivencial les sirvió para afianzar los conocimientos trabajados en el módulo y para valorar el papel de las mujeres en la historia de la infancia. El grado de motivación coincide con una mejora en los conocimientos adquiridos, puesto que el alumnado necesita una motivación intrínseca para aprender. El deseo propio de conocer cosas nuevas hace que se active la emoción y la alumna o alumno aprenda, tal como revelan los estudios de neuroeducación.

Debemos tener en cuenta que, en esta experiencia, además el alumnado trabaja también otras habilidades muy importantes para su formación como el trabajo en equipo, las habilidades comunicativas, la perspectiva de género, la toma de decisiones para la resolución de problemas en un tiempo determinado, el aprender a aprender y la perseverancia.

La realización de un Escape Room requiere mucho tiempo por parte del profesorado en planificar y diseñar la intervención en comparación con otras metodologías de enseñanza-aprendizaje. Además, a la hora de realizarla, requiere una preparación previa de 15-20 minutos. Por otra parte, se deben crear varios sets de juegos, ya que se realiza en grupos de 4-5 estudiantes y en el aula nos encontramos con 25 estudiantes normalmente. Sin embargo, es una inversión, puesto que una vez creado se puede usar en cursos posteriores.

Como aspectos mejorables, debido a la situación COVID en la que nos encontramos, nos planteamos transformar el Escape Room físico a formato digital.

También, los días previos a la sesión, incluir en el aula la reflexión a través de actividades de evaluación inicial, como agentes y futuras agentes educativas, sobre la necesidad de explicitar historias de mujeres que han aportado a lo largo de nuestra civilización haciendo un mundo mejor.

En el cuestionario incluir preguntas específicas sobre el desconocimiento que se tenía de las aportaciones de estas mujeres.

Como resumen, y a pesar de las propuestas de mejora encontradas, podemos afirmar que esta intervención ha conseguido mejoras en las competencias del alumnado participante, a la vez que sensibilizamos sobre la importancia del papel de las mujeres en la historia. Fue muy bien valorado y aporta una experiencia más para apoyar la utilización de metodologías innovadoras en el aula.

\section{REFERENCIAS BIBLIOGRÁFICAS}

Alvarez, J., Djaouti, D., y Rampnoux, O. (2016). Apprendre avec les Serious Games? Réseau Canopé.

Guigon, G., Humeau, J., y Vermeulen, M. (Jun 2017). Escape Classroom: un escape game pour l'enseignement. 9ème Colloque Questions de Pédagogie dans l'Enseignement Supérieur, Grenoble, France.

Jiménez, C., Lafuente, R., Ortiz, M., Brutonc, L., Millán, V. (2017). Room Escape: Propuesta de Gamificación en el Grado de Fisioterapia. Universitat Politècnica de València Congreso In-Red.

Kapp, K. M. (2012). The Gamification of Learning and Instruction: Game-based Methods and Strategies for Training and Education. San Francisco, CA: Pfeiffer. 


\subsubsection{Satisfacción del alumnado con la metodología evaluativa en la asignatura de Alteraciones de la Salud III del Grado de Enfermería de Valladolid en base al género \\ Cárdaba García Rosa María (Facultad de Enfermería de Valladolid, España)}

\section{Resumen}

La Evaluación clínica objetiva y estructurada (ECOE) es una metodología docente de evaluación que es considerada un procedimiento que incorpora diferentes instrumentos evaluativos por medio de simulación de casos en estaciones clínicas coordinadas, para alcanzar una completa evaluación de competencias. En la Facultad de Enfermería de Valladolid se ha llevado a cabo como método de evaluación y con este estudio se quiere determinar el grado de satisfacción del alumnado con las misma teniendo en cuenta el género. Se emplea para ello un estudio cuantitativo con una encuesta ad hoc de 112 participantes. Se encuentra que en todos los casos la satisfacción es mayor en el colectivo femenino, lo que nos lleva a sacar a la luz la necesidad de fomentar el pensamiento crítico en este grupo.

Palabras clave: género, docencia, evaluación, enfermería, ECOE.

\section{INTRODUCCIÓN Y OBJETIVOS}

El programa de Grado en Enfermería por la Universidad de Valladolid, está diseñado para que, a lo largo de cinco semestres (primero, segundo y tercero cursos académicos), los estudiantes adquieran las competencias que les permitan, de forma progresiva, ir fundamentando la disciplina enfermera tanto desde el punto de vista teórico y conceptual como metodológico, a la vez que van adquiriendo conocimientos que les faciliten la toma de decisiones, la capacidad de utilizar el juicio crítico, la empatía y la responsabilidad. La asignatura de Cuidados de Enfermería en Alteraciones de la Salud III de la Facultad de Enfermería de Valladolid en la Universidad de Valladolid (UVa), se imparte en el tercer curso del Grado, cuando el alumnado ha adquirido muchas de las competencias necesarias en Enfermería para llevar a cabo una evaluación objetiva de los conocimientos adquiridos, sabe integrar dichos conocimientos y da respuesta a los problemas se plantean en la simulación clínica, pero aún no lo hace en la práctica clínica. Estos aspectos se reflejan en la Guía docente de la asignatura (Facultad de Enfermería de Valladolid, 2020).

A pesar de que en actualidad cada vez son más los grados de Ciencias de la salud que emplean esta metodología evaluativa, en muchos casos no se mide en profundidad la satisfacción del alumnado con esta técnica y menos aún se tiene en cuenta el género como factor clave (Kronfly, Ricarte, Juncosa \& Martínez, 2007).

El objetivo de la investigación es determinar el grado de satisfacción del alumnado de tercero del Grado de Enfermería en Alteraciones de la Salud III de la UVa con la metodología de evaluación clínica objetiva estructurada (ECOE) y determinar si existen diferencias por género en el nivel de satisfacción.

\section{METODOLOGÍA}

Estudio cuantitativo descriptivo correlacional, en el que participan el total de alumnos del tercer año del Grado de Enfermería de Valladolid del curso académico 2019/2020 
(112 alumnos). El muestreo es por tanto no aleatorio, de conveniencia. Se emplea para medir la satisfacción un cuestionario diseñado ad hoc por dos de las investigadoras del equipo y que posteriormente fue analizado por el resto del equipo como grupo de expertos, hasta que se definieron las preguntas de modo que no indujeran a error. Dicho cuestionario era autoadministrado, empleando en su cumplimentación no más de 5 minutos y realizándose tras la evaluación ECOE en las salas de simulación. Consta de una pregunta relativa al género y ocho preguntas sobre satisfacción, siendo estas últimas definidas como escala Likert, con valores de 1 a 5 (1 el valor mínimo y 5 el valor máximo). En todo momento se tuvieron en cuenta los principios éticos en investigación y se contaba con la conformidad del Director de Departamento para llevar a cabo el estudio. Las variables empleadas fueron: satisfacción general, mejora de la reflexión, satisfacción con la información previa, ajuste a los contenidos de la asignatura, trato recibido, trabajo en equipo, tiempo disponible y objetividad de la evaluación. El análisis de datos se realiza con el software SPSS ${ }^{\circledR}$ en su versión 24.0 y con licencia de la UVa. Se realiza una descripción de variables en cuanto a frecuencias, porcentajes, media y desviación estándar. Además, se correlacionan las variables con las pruebas $t$ de Student y el coeficiente de correlación de Pearson, según el tipo de variable a analizar. E nivel estadístico empleado para determinar que existe significación estadística es de 0,05 .

\section{RESULTADOS Y DISCUSIÓN}

Se calcula inicialmente el valor Alfa de Crombach de la escala en la muestra, que es de 0.77 , lo cual determina que el instrumento es adecuado para el estudio.

La muestra como era de esperar está formada mayoritariamente por mujeres $(73,4 \%)$, ya que el Grado de Enfermería está fuertemente feminizado.

El análisis descriptivo de las respuestas a la encuesta de satisfacción nos aporta en cuanto a medidas de centralidad y dispersión, que la media y la desviación típica están en: 3.88 en satisfacción general $(\sigma=0.94), 3.58$ para capacidad de reflexión y razonamiento $(\sigma=1.13), 3.38$ en información previa suministrada $(\sigma=1.24)$, en ajuste a los contenidos de la asignatura $4.02(\sigma=1.04), 4.60$ para trato recibido $(\sigma=, 56), 4.43$ para trabajo en equipo $(\sigma=0.66)$, el tiempo disponible con $3.09(\sigma=, 92)$ y 3.38 en objetividad $(\sigma=, 93)$.

Teniendo en cuenta el Coeficiente de correlación Pearson, se puede asegurar que la satisfacción con la ECOE correlaciona positivamente con el desarrollo del pensamiento reflexión y racionalidad ( $r=0.67)$, con la información previa suministrada $(r=0.46)$, con el ajuste a los contenidos de la asignatura $(r=0.40)$, con el trato recibido por parte de los profesores ( $r=0.34)$, con trabajar en equipo con los compañeros y compañeras $(r=0.38)$, con el tiempo del que disponen $(r=0.23)$ y con la objetividad del método $(r=0.43)$, pero en todos los casos con efecto no muy elevado.

En cuanto a la influencia del género en la satisfacción, se obtiene significación estadística con la prueba t de Student para todas las ocho preguntas de satisfacción evaluadas, siendo más elevada siempre la satisfacción en las mujeres que en los hombres.

En base a los resultados presentados, se afirma que la ECOE se presenta en la muestra como un método de evaluación bastante interesante para el alumnado, como así han demostrado otras investigaciones (Cuevas \& Timmerman, 2016). Se valora positivamente el trato de los profesores y el trabajo en equipo, de forma que son las variables interpersonales las que parecen tener más importancia en el grupo. El tiempo del que disponen para resolver cada estación es la variable peor puntuada, aspecto que 
suele repetirse también en otros tipos de evaluaciones y en otras ECOEs (MartínezMayoral, Sánchez-Ferrer, Ramos, Belinchón, Sempere \& Morales, 2019).

Al conocer las correlaciones entre variables, se puede aumentar la satisfacción con la prueba ECOE elaborando estaciones que impulsen la reflexión por medio de casos clínicos; dando mayor información previa a la ECOE sin que esta menoscabe el desarrollo de la evaluación, lo que en otros estudios se ha relacionado con una reducción de la ansiedad ante la prueba (Domínguez-González, \& Guzmán-Valdivia, 2018); ajustándose las estaciones al contenido teórico de la asignatura; fomentando el trato digno del profesorado al alumnado, por medio de programas de trato digno que actualmente se están desarrollando en la UVA; diseñando casos que requieran el trabajo en equipo, siempre que el equipo no sea muy numeroso para evitar la no participación de algún miembro; aumentando el tiempo disponible por estación, reduciendo al menos 2 horas de contenido teórico para poder adaptarse a las horas totales asignadas a la asignatura; y asegurando la objetividad por medio de un evaluador por estación que no sea además actor, solicitando la colaboración de profesores de otras asignaturas. Además, aunque se podría deducir que la mayor satisfacción con la prueba de evaluación en el caso de las mujeres podría ser beneficioso para ellas, se puede obtener otra lectura de este hallazgo, ya que el colectivo femenino con mayor frecuencia tiende al conformismo y se debería despertar en este grupo un espíritu crítico que empodere en sus evaluaciones de la asignatura. Este aspecto lo intuyeron ya los autores Trejo-Mejía, Blee-Sánchez, y Peña-Balderas (2014) en un estudio previo.

\section{CONCLUSIONES Y LIMITACIONES}

La ECOE se muestra cada vez más como un buen método de evaluación objetivo en los grados de Ciencias de la Salud y el nivel de satisfacción encontrado en este estudio así lo demuestra.

A pesar de los buenos resultados obtenidos en satisfacción por parte del alumnado, cabe destacar las mayores puntuaciones y por tanto mayor satisfacción del grupo femenino, que nos lleva a pensar en la necesidad de trabajar con ellas el espíritu crítico antes de la evaluación, para evitar el conformismo en las mujeres y el seguimiento de los roles de género establecidos que las llevan a consentir más frecuentemente que los varones.

Como toda investigación, ésta cuenta también con algunas limitaciones. La primera de ellas es emplear una encuesta ad hoc, que, a pesar de haberse empleado el curso académico anterior como prueba piloto, no se ha validado. Con los datos del curso previo y los del actual, se intentará validar la encuesta para futuras ediciones. La segunda de las limitaciones radica en la limitación en el número de participantes, ya que, aunque participa todo el alumnado, el número no es excesivamente grande. La tercera y última radica en el propio diseño cuantitativo que no permite conocer en profundidad los fenómenos que subyacen a la satisfacción. Para paliar este defecto, se pretende llevar a cabo un estudio cualitativo fenomenológico basado en entrevistas semiestructuradas, además de la observación participantes, para triangular datos y poder extraer conclusiones fenomenológicas desde la perspectiva hermenéutica. 


\section{REFERENCIAS BIBLIOGRÁFICAS}

Cuevas, H.E., y Timmerman, G.M. (2016). Use of an objective structured clinical examination in clinical nurse specialist education. Clinical Nurse Specialist, 30, 172-76. doi: 10.1097/NUR.0000000000000201

Domínguez-González, A., y Guzmán-Valdivia G. (2018). Cómo afrontar con éxito el examen clínico objetivo estructurado (ECOE). Educación Médica, 19(6), 369374. doi: 10.1016/j.edumed.2018.03.016

Facultad de Enfermería de Valladolid. (2020). Proyecto/Guía docente de la asignatura de Enfermería en Alteraciones de la Salud III. Recuperado de: https://albergueweb1.uva.es/guia_docente/uploads/2020/475/46186/1/Docume nto.pdf

Kronfly, E., Ricarte, J.I., Juncosa, S., y Martínez, J.M. (2007). Evaluation of the clinical competence of Catalonian medicine schools 1994-2006. Evolution of examination formats until the objective and structured clinical evaluation (ECOE). Medical Clinical 129, 777-784.

Martínez-Mayoral, M.A., Sánchez-Ferrer, F., Ramos, J.M., Belinchón, I., Sempere, T., y Morales, J. (2019). Análisis de la prueba de evaluación clínica objetiva estructurada (ECOE) de sexto curso en la Facultad de Medicina de la Universidad Miguel Hernández de Elche. Educación Médico, 20, 29-36. doi: 10.1016/j.edumed.2017.07.020

Trejo-Mejía, J.A., Blee-Sánchez, G., y Peña-Balderas, J. (2014). Elaboración de estaciones para el examen clínico objetivo estructurado (ECOE). Investigación Educativa Médica, 3, 56-59. doi: 10.1016/S2007-5057(14)72725-5 


\title{
3.2.5. Movimientos feministas y teoría jurídica feminista: Algunas propuestas innovadoras para el ámbito docente
}

\author{
Fernando Centenera Sánchez-Seco (Universidad de Alcalá, España)
}

\section{Resumen}

Este trabajo presenta dos experiencias docentes implementadas en el marco de la asignatura de Diversidad de género e igualdad de derechos, que se imparte en la Universidad de Alcalá desde el año 2009. Se trata de prácticas desarrolladas a propósito de los movimientos feministas y la teoría jurídica feminista, siguiendo un modelo de docencia semipresencial. En el primer caso el alumnado trabaja con textos, una imagen y un tema musical, que deben analizarse a partir de la teoría relativa a los tipos de feminismo. En el segundo caso se pretende que sea el propio alumnado el que conozca por medio de la práctica la perspectiva crítica de la teoría jurídica feminista, recurriendo para ello a análisis desarrollados mediante trabajo autónomo y en pequeños grupos. El uso de materiales y metodologías innovadoras suscitan la implicación del alumnado; algo que ha quedado constatado con el nivel de participación y las calificaciones obtenidas.

Palabras clave: crítica; docencia semipresencial; movimientos feministas; práctica; teoría jurídica feminista.

\section{INTRODUCCIÓN Y OBJETIVOS}

El artículo 4 de Ley Orgánica 1/2004, de 28 de diciembre, de Medidas de Protección Integral contra la Violencia de Género (2004) contempla los "Principios y valores del sistema educativo", y entre ellos cita la inclusión y fomento de la docencia en igualdad de género en las universidades. Hoy buen número de manifestaciones demuestran un interés indudable en dicha línea, y el contexto didáctico en el que se enmarcan las experiencias que presentamos, así como estas últimas, son muestras de ello. Se trata de actividades novedosas, pues al menos hasta donde conocemos, no se han implementado anteriormente ${ }^{14}$.

Los objetivos que hemos pretendido con las experiencias que presentamos son los siguientes:

1. Afianzar el conocimiento de los movimientos feministas por medio de la práctica.

2. Desarrollar actividades que contribuyan a formar un criterio propio a la hora de valorar los tipos de feminismo.

3. Proporcionar una mirada crítica sobre el Derecho, poniendo en práctica la teoría jurídica feminista.

4. Concienciar acerca de las desigualdades entre mujeres y hombres, históricas y actuales, así como de la necesidad de aportar soluciones.

5.Suscitar un aprendizaje duradero, recurriendo a metodologías y recursos sugerentes.

\footnotetext{
${ }^{14}$ No obstante, debemos decir que en nuestra experiencia docente precedente hemos recurrido a la metodología de identificación de textos, y también a algún recurso que nos ha ocupado en esta ocasión, aunque a propósito de temáticas diferentes.
} 


\section{CONTEXTUALIZACIÓN}

Las experiencias docentes que se presentan se han llevado a cabo en la asignatura transversal de Diversidad de género e igualdad de derechos, que se imparte en la Facultad de Derecho de la Universidad de Alcalá desde el año 2009. Su temática tiene un carácter interdisciplinar, que se especifica en lo docente con la participación de profesoras y profesores de diferentes áreas de conocimiento. Las profesoras M. ${ }^{a}$ Isabel Garrido Gómez, Encarnación Carmona Cuenca y María Macías Jara se han venido encargando de la coordinación de la asignatura.

Concretamente, en este trabajo se presentan las acciones desarrolladas a propósito de las siguientes temáticas, recogidas en una unidad del temario impartida por quien escribe estas páginas: los movimientos feministas y la teoría jurídica feminista. El carácter transversal de la asignatura conmina a plantear una docencia adaptada a un alumnado que puede estar cursando los estudios de Derecho, pero también otros ajenos al ámbito jurídico. Con vistas a lograr dicho objetivo, las actividades que presentamos se desarrollaron con metodologías centradas en la parcela práctica, para facilitar el entendimiento de contenidos, y recursos que, consideramos, podrían resultar sugerentes para el perfil de alumnado descrito.

\section{DISEÑO Y DESARROLLO}

Las cuestiones sobre las que hemos trabajado se han desarrollado en cuatro clases (dos por cada una de ellas) repartidas en dos semanas, siguiendo el modelo de docencia semipresencial establecido a consecuencia de la situación de pandemia en la que nos encontramos. Las sesiones primera y tercera se desarrollaron online, mediante la herramienta de videoconferencias Blackboard Collaborate, y la segunda y cuarta de forma presencial.

La actividad relativa a los movimientos feministas se implementó una vez impartida la teoría sobre la temática, expuesta en una sesión online, en la cual consideramos el feminismo de la igualdad, que comprende el feminismo liberal y el marxista y socialista; y el feminismo de la diferencia, que incluye el feminismo radical, el cultural y el postmoderno (en este desarrollo seguimos a Garrido Gómez, 2018, pp.61-63). A partir de los contenidos impartidos, ya en la clase práctica y de forma presencial trabajamos con textos breves que previamente habíamos proporcionado al alumnado por medio del aula virtual, para que los llevase a la sesión. Teniendo en cuenta el contenido de dichos textos, el alumnado debía determinar su autoría, la obra a la que pertenecían, y relacionar su contenido con alguno de los feminismos considerados desde el punto de vista teórico, razonando las respuestas. Concretamente, los extractos pertenecían a obras de Wollstonecraft (1998, p. 182), con reivindicaciones sobre la educación para las mujeres, previas al feminismo liberal; Gilligan (1994, pp. 165, 166), con desarrollos en la línea de la ética del cuidado, enmarcada en el feminismo cultural; y Engels (1891, s. p.), con el planteamiento que identifica al hombre con la burguesía y a la mujer con el proletariado, propio del autor citado que es representante del feminismo marxista.

También a propósito de la misma temática, solicitamos al alumnado que analizase dos recursos más. Por una parte, una fotografía en la que aparece Eleanor Roosevelt mostrando la Declaración Universal de Derechos Humanos (1948), en cuyo texto se reconoce la igualdad entre mujeres y hombres; una manifestación gráfica que preconiza el feminismo liberal. Según Lagarde $(2012$, pp. 15, 16, 189, 190) fue precisamente aquella quien reformuló el enunciado "Derechos del hombre" por "Derechos Humanos". Por otra parte, trabajamos con la letra del tema musical You Don't Own Me interpretado 
por Lesley Gore ([1965]), que recoge aspectos en los que tiempo después incidiría el feminismo radical. Se trata de un alegato contra la dominación masculina, característica del patriarcado, que podría contextualizarse en el ámbito privado de una relación de pareja, y que motiva el rechazo hacia la cosificación de las mujeres y las órdenes que reciben acerca de lo que deben hacer o decir, o con quién tienen que ir.

En el último punto de esta parte solicitamos una toma de postura justificada, a propósito del tipo de feminismo que se estimase más acorde al propio pensamiento.

Por otra parte, la experiencia desarrollada en torno a la teoría jurídica feminista transcurrió del ámbito práctico al teórico. En esta ocasión pretendimos que fuera el propio alumnado el que, por medio de su experiencia, llegase al cuestionamiento de la neutralidad y objetividad con la que se suele caracterizar al método jurídico, poniendo en práctica de este modo el carácter crítico de la Feminist Jurisprudence (sobre estos contenidos Garrido Gómez, 2018, pp. 69 y ss.).

Con tal fin, propusimos el análisis de varios recursos, con vistas a diagnosticar problemas en ellos. En esta ocasión la actividad se desarrolló en una sesión online y en parte de otra presencial. En ambas el alumnado trabajó autónomamente, pero también en pequeños grupos de 4-5 personas establecidos en parte de la sesión virtual, gracias a la opción que ofrece Blackboard Collaborate para crear grupos aleatoriamente. En este último caso, durante el transcurso de la actividad accedimos a cada uno de los grupos, con el fin de comprobar cómo se estaba desarrollando el trabajo y resolver posibles dudas. La opción es sugerente, pero nos fue imposible utilizarla para analizar todos los recursos, pues no disponíamos de tiempo para ello ${ }^{15}$.

El análisis de cada una de las referencias propuestas se fue combinado con varias puestas en común de los resultados obtenidos ${ }^{16}$, desarrolladas a partir de las intervenciones del alumnado ${ }^{17}$.

En esta ocasión comenzamos analizando algunos textos normativos de claro signo androcéntrico. Es el caso del extracto de una Ley sobre la regulación de la enseñanza media (1938), donde se ataca el afeminamiento y se ensalza la virilidad. Más allá de la constatación de estas discriminaciones -evidentes, pues la disposición formaría parte del ordenamiento jurídico de una dictadura que pretendió acabar con el feminismo-, nos interesaba que, aun reconociendo los importantes avances que trajo consigo el sistema democrático, también quedase constancia de que en nuestro tiempo todavía sigue teniendo sentido la mirada crítica de la Feminist Jurisprudence. Con tal objetivo, propusimos al alumnado que analizase textos normativos más actuales ${ }^{18}$, con vistas a detectar problemas en ellos. Así, por ejemplo, nos ocupamos del artículo 57.1 de la Constitución Española (1978), que establece la preferencia del hombre a la mujer en el acceso a la Corona. También reparamos en el Real Decreto 190/1996, de 9 de febrero, por el que se aprueba el Reglamento Penitenciario (1996), analizando, por ejemplo, su artículo 82.2, que considera como trabajo exterior "las labores de trabajo doméstico en su domicilio familiar", únicamente en el caso de las mujeres. La 'concesión' que se

\footnotetext{
15 Entre las dificultades constatadas encontramos la de que varias personas no tenían posibilidad de utilizar micrófono, y debieron participar escribiendo en el chat del grupo reducido en el que trabajaban.

${ }^{16}$ Cuando el trabajo se desarrolló en pequeños grupos desactivamos su configuración, para reconducir al alumnado a la sala principal de la sesión y así realizar la puesta en común.

${ }^{17}$ En el caso de la sesión online el alumnado solicitaba la palabra activando el icono disponible para ello en el entorno virtual. Las participaciones se desarrollaron por medio del micrófono, o bien, cuando no era posible dicha opción, escribiendo en el chat de la sesión.

${ }^{18}$ En lo que respecta a los mismos citamos legislación consolidada.
} 
observa en esta ocasión descubre la presencia de estereotipos de género (Larrauri Pijoan, 1998, p. 39) ${ }^{19}$.

De otro lado, también solicitamos diagnósticos de problemas en el ámbito de la interpretación y aplicación normativa. Para ello, consideramos breves escenas de la película Clara Campoamor. La mujer olvidada, en las cuales la sufragista aparece ejerciendo la abogacía en los juzgados, en un mundo jurídico entonces de hombres, donde estos hacían las leyes y las aplicaban (Mañá, 2011). De otro lado, reparamos también en algunas referencias de hemeroteca, en las que, por ejemplo, se informa de una sentencia en la que se afirma que una empleada podría haber provocado a un empresario con su ropa (EI País, 1990).

Finalmente, completamos los resultados a los que fuimos llegando con los contenidos relativos a la teoría jurídica feminista que pretendíamos impartir.

\section{EVALUACIÓN, CONCLUSIONES Y PROPUESTAS DE MEJORA}

La evaluación de las actividades expuestas en el apartado precedente se desarrolló del siguiente modo. Una vez concluidas las sesiones, y según habíamos informado desde el comienzo, el alumnado entregó de forma individual un documento con las respuestas a las cuestiones planteadas, por medio del correo de la plataforma virtual de la asignatura. Con ello pretendimos un feedback que diera cuenta de la atención prestada en las sesiones desarrolladas, así como de la adquisición y entendimiento de contenidos, convenientemente aplicados y argumentados.

Por otra parte, el alumnado tuvo la oportunidad de aumentar la nota obtenida en el trabajo anterior con la participación en las clases. Como resultado de todo ello, cada persona recibió una nota sobre 10 puntos, si bien posteriormente aplicamos el porcentaje correspondiente, teniendo en cuenta la puntuación asignada a la parte de la asignatura que impartimos, que es de 0,75 puntos.

A fecha de hoy todavía no disponemos de los datos de la encuesta docente, pero consideramos que, en términos generales, las experiencias realizadas arrojan un resultado bastante notable, dado que suscitan una implicación considerable del alumnado en las cuestiones tratadas. Tal circunstancia queda constatada con las intervenciones llevadas a cabo en clase, destacables cuantitativa y cualitativamente, y con las calificaciones obtenidas. El $20,5 \%$ de las personas que participaron en las experiencias obtuvieron sobresaliente, y el $55,8 \%$ notable.

Entre las propuestas de mejora para próximas ediciones quisiéramos citar las siguientes. En lo que respecta a la primera experiencia sería interesante recabar más recursos, con el fin de trabajar con todos los tipos de feminismo considerados en la teoría; y en lo concerniente a la segunda, sería enriquecedor desarrollarla totalmente mediante el trabajo en pequeños grupos. Por las razones apuntadas, dicha opción únicamente pudo implementarse parcialmente en el entorno virtual, pero entendemos que será factible cuando la esperada presencialidad esté totalmente de vuelta.

\footnotetext{
${ }^{19}$ Escogimos estos artículos teniendo en cuenta su consideración en los trabajos de Campos Rubio (2008, p. 180), sobre el primero, y Larrauri Pijoan (1998, p. 39), a propósito del segundo.
} 


\section{REFERENCIAS}

\section{Colaboraciones colectivas, libros y revistas}

Campos Rubio, A. (2008). Aportaciones iusfeministas a la revisión crítica del Derecho y a la experiencia jurídica. En Mujeres y Derecho: Pasado y presente I. Congreso multidisciplinar de la Sección de Bizkaia de la Facultad de Derecho (pp. 167226). Disponible en https://web-argitalpena.adm.ehu.es/pdf/UVWEB081572.pdf.

Engels, F. (1891). El origen de la familia, la propiedad privada y el Estado. En Marx, K. y Engels, F., Obras escogidas (sin paginar). Disponible en https://webs.ucm.es/info/bas/es/marx-eng/84of/84OF2.htm.

Garrido Gómez, Ma . I. (2018). Los movimientos feministas. En Carmona Cuenca, E., Garrido Gómez, $\mathrm{M}^{a}$. I. (coords.), Diversidad de género e igualdad de derechos (pp. 61-74). Valencia: Tirant lo Blanch.

Gilligan, C. (1994). La moral y la teoría. Psicología del desarrollo femenino (J. J. Utrilla, trad.). México: Fondo de Cultura Económica.

Lagarde y de los Ríos, M. (2012). El feminismo en mi vida. Hitos, claves y topías. México: Instituto de las Mujeres de la Ciudad de México. Disponible en https://www.legisver.gob.mx/equidadNotas/publicacionLXIII/EIFeminismoenmiVi da.pdf.

Larrauri Pijoan, E. (1998). Feminismo y multiculturalismo. En Análisis del Código Penal desde la perspectiva de género (pp. 32-44). Vitoria-Gasteiz: Instituto Vasco de la Mujer.

Disponible

en https://www.emakunde.euskadi.eus/contenidos/informacion/publicaciones_jorna das/es_emakunde/adjuntos/jornada.13.analisis.codigo.penal.perspectiva.gener o.cas.pdf.

Wollstonecraft, M. (1998). Vindicación de los derechos de la mujer (C. Martínez Gimeno, trad.). Asparkía. Investigació feminista, 9, 181-186. Disponible en https://www.raco.cat/index.php/Asparkia/article/view/108391/154822.

\section{Hemeroteca}

El País (1990). El Tribunal Supremo confirma la sentencia de Lérida del 'caso de la minifalda'. El País, 24 de mayo de 1990. Disponible en https://elpais.com/diario/1990/05/24/sociedad/643500002_850215.html.

\section{Normativa y otras disposiciones}

Constitución Española (1978). Boletín Oficial del Estado, 311, 29 de diciembre de 1978. Disponible en https://www.boe.es/buscar/pdf/1978/BOE-A-1978-31229consolidado.pdf.

Ley Orgánica 1/2004, de 28 de diciembre, de Medidas de Protección Integral contra la Violencia de Género (2004). Boletín Oficial del Estado, 313, 29 de diciembre de 
2004. Disponible en https://www.boe.es/buscar/pdf/2004/BOE-A-2004-21760consolidado.pdf.

Ley [sobre la regulación de la enseñanza media] (1938). Boletín Oficial del Estado, 85, 23 de septiembre de 1938 . Disponible en https://www.boe.es/datos/pdfs/BOE/1938/085/A01385-01395.pdf.

Naciones Unidas (1948). Declaración Universal de Derechos Humanos. Disponible en https://www.un.org/es/about-us/universal-declaration-of-human-rights.

Real Decreto 190/1996, de 9 de febrero, por el que se aprueba el Reglamento Penitenciario (1996). Boletín Oficial del Estado, 40, 15 de febrero de 1996. Disponible en https://www.boe.es/buscar/pdf/1996/BOE-A-1996-3307consolidado.pdf.

\section{Referencia cinematográfica}

Mañá, L. (2011). Clara Campoamor. La mujer olvidada. Cameo Media.

\section{Referencia musical}

Gore, L. ([1965]). You Don't Own Me. En The Golden Hits of Lesley Gore. LP. MG 21024. [USA]: Mercury. 


\subsubsection{Visibilización de la aportación de las mujeres al campo de la}

psicología mediante una metodología flipped learning

Cristina Díaz Berciano (C.E.S. Cardenal Cisneros, España); María Almudena Cabezas González (Universidad Complutense de Madrid, España); Susana Barón Vioque

(Universidad Complutense de Madrid, España).

\section{Resumen}

El sesgo de género está presente en las distintas áreas de la educación universitaria, y se transmite al alumnado de diversas formas, entre ellas, citando un menor número de autoras que de autores. Este proyecto ha pretendido dar visibilidad a una serie de autoras en el campo de la Psicología, utilizando la metodología Flipped Learning. Se ha aplicado en el curso 2019/2020 al Grado de Psicología, teniendo como resultado el aumento del porcentaje de mujeres (dentro de los autores relevantes para cada materia) recordados por el alumnado, al finalizar el cuatrimestre. Como conclusión se confirma la necesidad de introducir referencias a un mayor número de autoras y visibilizar su género (ya que a menudo se obvia, citando solamente su apellido) para que las alumnas interioricen su capacidad de aportaciones científicas valiosas y así romper con los estereotipos de género transmitidos por el profesorado.

Palabras clave: género; flipped learning; educación superior; ANOVA; psicología.

\section{INTRODUCCIÓN Y OBJETIVOS}

Al igual que en otras ciencias, numerosos estudios han informado de un sesgo de género en la psicología que abarca distintos aspectos de la vida académica, y que se refleja en una menor representación de las mujeres en los libros de texto (Furumoto \& Scarborough, 1986), en las comunicaciones orales de los congresos y en la presidencia de los simposios, siendo además su rango académico inferior al de los hombres (Johnson et al., 2017).

Asimismo, a pesar de superar a los hombres en número de tesis presentadas, dentro de la Psicología Cognitiva y Experimental, el número de mujeres que ocupan puestos como investigadoras remuneradas en Universidades e Institutos de investigación es inferior al de los hombres (Lazar \& Tuller, 2015).

Los indicadores de reconocimiento académico y profesional también muestran una importante diferencia en el porcentaje de varones y mujeres, como se observa en la composición de los consejos editoriales de las revistas ( $20 \%$ de mujeres), siendo las distintas figuras de editores principalmente hombres (Fouad et al., 2000). Incluso los premios más prestigiosos, poseen el nombre de reconocidos psicólogos varones (Vaid \& Geraci, 2016).

Nuestro proyecto tiene por objeto disminuir el sesgo de género en asignaturas del grado de psicología, a partir de la participación activa del alumnado, para visibilizar las aportaciones de las mujeres. Se busca de esta forma resolver a través de la metodología "Flipped Learning" la falta de conciencia sobre la invisibilidad de la contribución de las mujeres a la ciencia y proporcionar al alumnado modelos de reconocimiento académico de científicas/académicas (Donoso-Vázquez et al., 2014). 
Bergmann y Sams (2012) acuñaron el término Flipped Learning (FL) o "clase invertida", referido al método en el que el profesor conduce al alumno a revisar materiales (como textos o vídeos), antes de la clase presencial, aplicando este conocimiento a una actividad colaborativa.

EI FL es una metodología que transfiere determinados procesos fuera del aula y utiliza el tiempo de clase, junto a la experiencia docente, para facilitar y potenciar procesos de adquisición y práctica de conocimientos/destrezas en el aula (Alisherovna, 2020). Tiene como pilares fundamentales: el uso de las nuevas tecnologías al servicio de la docencia (Pozo Sánchez et al., 2020), la crucial trascendencia de la autonomía del alumnado (que pasa a estar en el centro del proceso) y el carácter inclusivo e integrador que proporciona (Prieto Martín, 2017; Sánchez et al., 2020).

\section{CONTEXTUALIZACIÓN}

La práctica docente ha sido parte de un proyecto de innovación educativa del que forma parte profesorado de la Universidad Complutense de Madrid de distintas facultades. En esta ocasión, nos hemos centrado en la experiencia y los datos recogidos del alumnado del grado de psicología, que ha sido parte activa del proceso y no un mero objeto de estudio.

El proyecto responde a la necesidad de introducir mejoras en nuestra práctica docente proporcionando modelos vicarios a nuestro alumnado (hombres y mujeres), presentando una perspectiva de género (Mora et al., 2009), mediante una implicación activa y participativa del mismo a través del uso de la metodología FL.

\section{DISEÑO Y DESARROLLO}

La metodología FL tiene como pilares fundamentales el uso de las nuevas tecnologías al servicio de la docencia, la crucial trascendencia de la autonomía del alumnado, que pasa a ser el centro del proceso, y su carácter inclusivo e integrador. Al invertirse las fases respecto al modelo tradicional (clase-estudio individual): 1) el profesorado diseña o selecciona las actividades y el material con el que el alumnado ha de estudiar individualmente antes de ir a clase; 2) el alumnado realiza las tareas diseñadas con el material propuesto e informa del producto de esa actividad; y 3) el profesorado prepara la clase en el grupo presencial/virtual, ajustada a las necesidades observadas para el alumnado.

De acuerdo con el primer objetivo, de dar mayor visibilidad a las mujeres, en el proyecto se plantean las siguientes acciones:

- Introducir modificaciones en la docencia tales como incluir fotos en las sesiones presenciales de las y los autores, para facilitar la identificación del género de las autoras y de sus aportaciones.

- Hacer explícito el género de las autoras cuyas aportaciones se estudian en clase.

- Proponer como actividad que, el propio alumnado, siguiendo la metodología FL preparase una exposición de las aportaciones más relevantes de las mujeres a nuestras disciplinas, compartidas a través del campus virtual.

Las actividades se estructuraron en tres fases: 
I. Fase inicial. Planificación y preparación previa al comienzo de la docencia (septiembre 2019)

II. Fase de intervención y difusión. Curso 2019/2020, primer cuatrimestre (segundo cancelado por pandemia)

III. Fase de evaluación del proyecto y de su impacto. Conclusiones. Finales 2020

\section{EVALUACIÓN, CONCLUSIONES Y PROPUESTAS DE MEJORA}

El análisis de los datos recogidos, en los tres grupos de la asignatura Psicología del Aprendizaje, son, presentados de forma resumida, los siguientes:

- Participaron un total de 226 alumnos y alumnas.

- Antes de la intervención el alumnado señalaba una media de 4,87 autores relevantes, de los que 4,75 eran varones, y 0,11 mujeres.

- Tras la finalización de la asignatura, con las intervenciones señaladas dentro del proyecto de innovación, el alumnado señalaba una media de 6,25 autores relevantes, de los que 4,39 eran varones, y 1,85 mujeres. (véase anexo II).

- Si realizamos un análisis de varianza de medidas repetidas $2 \times 2$, siendo el primer factor cuestionario (inicial vs final) y el segundo factor el género identificado por cada estudiante (hombre vs mujer) de los autores citados, obtendremos que hay diferencias estadísticamente significativas entre el número de autores relevantes identificados en el cuestionario inicial con respecto al final $F(1,225)=47,032$ $p<0.05$, al final de la asignatura recuerdan más autores relevantes.

- La variable género, también es relevante $F(1,225)=842,9 p<0.05$, se citan más hombres que mujeres; y es relevante la interacción entre ambos, ya que también resultó significativa $F(1,225)=98,3 p<0.05$, es decir que la diferencias no se reparten por igual, sino significativamente las diferencias se agrupan en el subgrupo de género mujer (véase anexo I).

- Por último, cabe señalar que se recuerdan un número muy similar de autores relevantes, aunque en el cuestionario final los autores citados son más específicos de la asignatura, mientras que en el cuestionario inicial los autores relevantes son bastantes más genéricos. Sería interesante para investigaciones posteriores incluir en el análisis este aspecto.

Conclusión: podemos afirmar que, con los datos obtenidos, sí se ha mejorado la visibilidad de los logros obtenidos por las autoras relevantes, empleando la metodología FL, que era el objetivo principal. La importancia de esta aportación radica en la posibilidad de que las alumnas interioricen su capacidad para hacer aportaciones científicas valiosas y romper con los estereotipos transmitidos. Sería conveniente confirmar con posterioridad estos resultados obtenidos.

Aspectos mejorables: Sería deseable en estudios posteriores, corregir el efecto de la relevancia de los autores para la materia, ya que, al comienzo del cuatrimestre los alumnos hacen referencia a un número similar de autores, pero la mayoría no han sido cruciales para el desarrollo de la materia. 
Figuras Anexo I
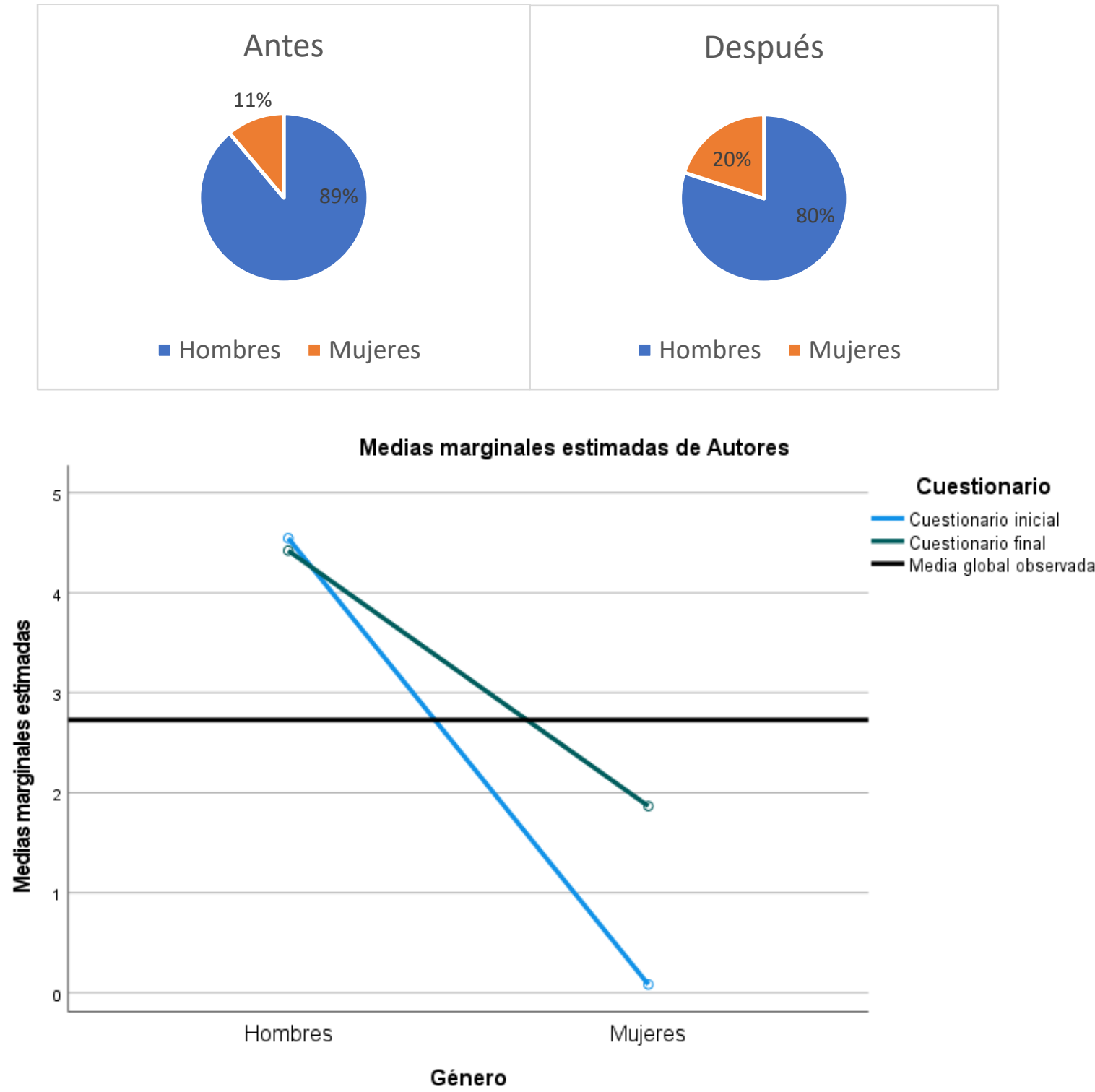

\section{REFERENCIAS BIBLIOGRÁFICAS}

Alisherovna, D. N. (2020). Flipped learning as the key to improving education in higher education. European Science, (1 (50)).

Bergmann, J., \& Sams, A. (2012). Flip your classroom, reach every student in every class every day. Eugene, OR: International Society for Technology in education (ISTE).

Donoso-Vázquez, T., Montané, A., \& de Carvalho, M. E. P. (2014). Género y calidad en Educación Superior. Revista Electrónica Interuniversitaria de Formación del Profesorado, 17(3), 157-171.

Fouad, N., Brehm, S., Hall, C. I., Kite, M. E., Hyde, J. S., Russo, N. F., Astin, H. S., Katz, P., Keita, G. P., \& Pion, G. (2000). BBAACCKK Task Force on Women in Academe. 65. 
Furumoto, L., \& Scarborough, E. (1986). Placing Women in the History of Psychology. American Psychologist, 8.

Johnson, C. S., Smith, P. K., \& Wang, C. (2017). Sage on the Stage: Women's Representation at an Academic Conference. Personality and Social Psychology Bulletin, 43(4), 493-507. https://doi.org/10.1177/0146167216688213

Lazar, V., \& Tuller, B. (2015). Is There a Gender Gap in the Perception, Action, and Cognition Program at NSF? APS Observer, 28(5).

Mora, E., \& Pujal Llombart, M. (2009). Introducción de la perspectiva de género en la docencia universitaria. Il Congreso Internacional Claves para la implicación de los estudiantes en la Universidad. Universitat de Girona. Recuperado de: http://hdl.handle.net/10256/2017

Pozo Sánchez, S., López Belmonte, J., Moreno Guerrero, A. J., \& Hinojo Lucena, F. J. (2020). Flipped learning y competencia digital: Una conexión docente necesaria para su desarrollo en la educación actual. Revista Electrónica Interuniversitaria de Formación del Profesorado, 23, 127-141.

Prieto Martín, A. (2017). Flipped Learning: aplicar el modelo de aprendizaje inverso (Vol. 45). Narcea Ediciones.

Sánchez, S. P., López-Belmonte, J., Moreno-Guerrero, A. J., Reche, J. M. S., \& Cabrera, A. F. (2020). Effect of Bring-Your-Own-Device Program on Flipped Learning in Higher Education Students. Sustainability, 12(9), 3729.

Vaid, J., \& Geraci, L. (2016). V. An examination of women's professional visibility in cognitive psychology. Feminism \& Psychology, 26(3), 292-319. https://doi.org/10.1177/0959353516641139 


\subsubsection{Experiencia educativa para estudiantes de enfermería de pregrado en la Patagonia chilena: Género, diversidad y disidencias sexuales en salud. Consideraciones para la gestión del cuidado.}

Renato Gómez Bascuñán (Enfermero. Académico Depto. Ciencias de la Salud. Universidad de Aysén, Chile); Dave Villafaña Sierra (Psicólogo. Docente colaborador Depto. Ciencias de la Salud. Universidad de Aysén, Chile).

\section{Resumen}

Estas reflexiones surgen de la implementación de un proceso educativo, que incorpora las perspectivas de la diversidad y disidencia afectivo, sexual, corporal y de género (DDSCG) para la gestión del cuidado, en estudiantes de enfermería de séptimo semestre en la Universidad de Aysén, Chile.

La experiencia educativa propuso una revisión de los principales conceptos de género, el aporte de los feminismos al debate sobre las identidades, las afectividades, sexualidades y corporalidades, y los efectos de los estereotipos del sistema sexo-género en el contexto de la salud y los cuidados de enfermería.

Lo anterior se implementó en coherencia con los profundos cambios que experimenta la educación chilena, orientada a la transversalización de las perspectivas de género en la formación de profesionales.

Palabras clave: género, perspectivas, educación; enfermería; gestión del cuidado.

\section{INTRODUCCIÓN Y OBJETIVOS}

En el 2018, la Universidad de Aysén crea la Unidad de Equidad de Género cuyo objetivo es proponer, coordinar y hacer seguimiento a las políticas $y$ acciones antidiscriminatorias en la casa de estudio. Orientados por tales propósitos, la unidad además de crear el primer Protocolo contra la violencia sexual y la discriminación arbitraria impulsa procedimientos institucionales que aceptan y reconocen el nombre social de toda persona trans al interior de la universidad. Al año siguiente, durante el 2019, la Unidad de Equidad de Género hace un llamamiento a los cuerpos académicos, para incorporar la perspectiva de género en las funciones de docencia, investigación, gestión y vinculación con el medio, a objeto de abordar las desigualdades entre hombre y mujeres en los campos profesionales, y al mismo tiempo, incorporar las perspectivas de las diversidades y disidencias afectivas, sexuales, corporales y de género en los procesos de formación de los estudiantes. Estas orientaciones surgen a propósito de los compromisos asumido por la Universidad de Aysén en el Consejo de Universidades del Estado de Chile (CRUCH, 2019), donde se insta a implementar una política de educación no sexista que erradique los estereotipos y sesgos que reproducen las desigualdades de género, tanto en las prácticas como en los contenidos educativos.

A raíz de lo anterior, en el primer proceso de revisión de malla curricular del 2018, y según las recomendaciones internacionales disponibles, la carrera de enfermería de la Universidad de Aysén se ha propuesto incorporar contenidos que promueva en el estudiantado, un marco compresivo para visualizar la variable de género como un constructo sociocultural y político, que controla y legitima el ordenamiento social basado en una jerarquía heteropatriarcal, donde la cúspide es la masculinidad hegemónica, caracterizada por un sistema binario que excluye cuerpos, sexualidades, expresiones o identidades de género que se alejan de las expectativas sociales relacionadas con el binomio hombre-mujer (Connell, 2012; Gasch-Gallén et al., 2020), dinámica que influye en los procesos de cuidado y atención en salud. 
Esta revisión y actualización se incorpora en el Módulo Integrado de Ética, Bioética y Género del Cuidado, espacio donde la presente experiencia educativa se implementa. Además del marco institucional que justifica la implementación, existen una serie de investigaciones que develan una importante desinformación y prejuicios por parte de los estudiante de enfermería y profesionales de la salud, respecto a las particularidades y necesidades de personas disidentes sexuales, afectivas, corporales y de género, recomendando la necesidad de sensibilizar y educar sobre esta población para reducir las brechas y desigualdades de atención en salud (Lim et al., 2013; Pratt-Chapman, 2020; Yingling et al., 2017).

Esta primera experiencia educativa tuvo como objetivo analizar los conceptos y principios de las perspectivas de la diversidad y disidencia afectivo, sexual, corporal y de género, integrándolo al quehacer de la gestión del cuidado desde la enfermería, donde se planteó que las y los estudiantes lograran:

- Identificar los conceptos de género, diversidad y disidencias, y los vínculos con su rol profesional en la gestión del cuidado.

- Analizar la enfermería desde la perspectiva de género y la importancia de ésta en el cuidado de las personas.

- Reflexionar sobre las perspectivas de género, diversidad y disidencia en el proceso de salud-enfermedad y del cuidado.

- Reflexionar las desigualdades en salud desde las perspectivas de género, la diversidad y disidencia.

\section{CONTEXTUALIZACIÓN}

Los procesos de atención a personas diversas y disidentes desde el punto de vista afectivo, sexual, corporal y de género en los servicios de salud, son un ejemplo de cómo las tradiciones socioculturales, y los poderes biomédicos reproducen estructuras binarias de la sexualidad y sus roles a través de un lenguaje, representaciones visuales y prácticas clínicas que dan cuenta de un modelo heterosexual y cis-normativo (GaschGallén et al., 2020).

Estos marcos de referencia se encuentran naturalizadas y hacen de los sistemas sanitarios, espacios que propician acciones de trato desigual, a través de mecanismos de exclusión e invisibilización de las necesidades de aquellos cuerpos e identidades no/normativos, aspecto que repercute en la salud, enfermedad y atención de esta población (Carpenter, 2016).

En este contexto, se vuelve cada vez más importante desarrollar competencias técnicas entre los profesionales de salud, y particularmente entre los estudiantes de enfermería, toda vez que esta disciplina se aboca a los cuidados directos en varios entornos de atención de salud. Un programa de formación para estudiantes y futuros profesionales, que promueva la comprensión de las necesidades de personas diversas y disidentes desde el punto de vista afectivo, sexual, corporal y de género, favorece el mejoramiento de prácticas de atención, y actualiza la gestión del cuidado, además de potenciar sensibilidad cultural en los estudiantes, según las actuales convenciones internacionales, y desafíos ético y bioéticos que propone esta población, para las ciencias de la salud y la enfermería (Kalenga et al., 2021; Lim et al., 2013; Strong \& Folse, 2015).

Según las últimas investigaciones, se plantea la necesidad de aumentar en los estudiantes de enfermería el conocimiento sobre terminologías, el aprendizaje respecto a derechos y desigualdades, reflexiones sobre la actitud profesional en la asistencia, y 
la participación activa de personas y comunidades LGBTIQ+ en sus procesos de atención y recuperación (Gasch-Gallén et al., 2020).

En este contexto, los planes de estudio de enfermería deben desafiar el binario de género para preparar mejor a las y los estudiantes y profesionales de enfermería, y así brindar una atención de calidad a pacientes en todos los espectros del género, incluyendo identidades no binarias, derribando barreras de desinformación (Carabez et al., 2016; Falck et al., 2020).

\section{DISEÑO Y DESARROLLO}

La experiencia educativa está inserta en la asignatura "Módulo integrado de ética, bioética y género del cuidado". La unidad se denomina "Genero, diversidad y disidencias sexuales en salud; consideraciones para la gestión del cuidado". Esta unidad se ofrece en el séptimo semestre de la carrera, y proporciona al estudiante herramientas para la integración de la ética, bioética y género en la gestión del cuidado, considerando los aspectos deontológicos que respaldan el quehacer profesional, con un enfoque de derechos humanos, a partir de la práctica crítica y reflexiva que orienten la toma de decisiones.

Las asignaturas de semestres anteriores incluyen fundamentos disciplinares, los cuidados de enfermería en todo el ciclo vital, considerando las diferentes complejidades y niveles de atención disponibles en los servicios sanitarios.

El objetivo de la unidad es analizar los conceptos y principios de la diversidad afectivo, sexual, corporal y de género, integrándolo al quehacer de la gestión del cuidado desde la enfermería. La unidad representó el $30 \%$ de las calificaciones de los y las estudiantes.

En la experiencia educativa se exploraron cuestiones relacionadas con la historia del concepto de género, sus bases ideológica y políticas asociada a los feminismos, análisis del patriarcado y sus expresiones de violencia/desigualdad en los servicios sanitarios, revisión de los conceptos de disidencia y diversidad sexual, afectivo, corporal y de género, debates de la biología feminista sobre los esencialismos biológicos y los estereotipos asociados al binarismos de género, y especificidades para la gestión del cuidado en salud de la población diversa/disidente.

Las metodologías para la enseñanza-aprendizaje de los y las estudiantes, incluyeron lectura y análisis de textos, clases expositivas/reflexivas, artículos teóricos sobre los conceptos e historia del género, recomendaciones del Ministerio de Salud chileno sobre la atención de personas trans en la red asistencial. Adicionalmente, se revisaron videos de entrevistas y discursos por parte de activistas y teóricas de disidencia sexual a nivel internacional, latinoamericano y chileno. Para favorecer la integración de los conocimientos, se realizaron talleres, revisión de casos y análisis de situaciones en salud, incorporando dimensiones de género, diversidad y disidencia. Respecto a esto último, a través de juego de roles, las y los estudiantes simularon virtualmente atenciones a personas diversas y disidentes, estrategia que fue guiada por los docentes, con el apoyo de material audiovisual.

La unidad del curso contempló dos evaluaciones, un ensayo para analizar, interpretar y aplicar los conceptos de machismo, sexismo, violencia, régimen heteropatriarcal, entre otros, a través del cortometraje "El Vestido Nuevo". Y una segunda evaluación de integración y aplicación de los conceptos revisados en el curso, enfocado en un proceso de atención de enfermería mediante simulación clínica virtual. 
Luego de finalizada la unidad, la experiencia educativa incluyó (a) una breve jornada de reflexión sobre el curso, que recogió la opinión de las y los estudiantes sobre los contenidos, las metodologías de evaluación y el impacto de estas perspectivas para sus vidas personales. Siete meses después, (b) se envió un cuestionario para conocer cómo la unidad ha contribuido en su ejercicio profesional, evaluar la utilidad y/o adecuación de contenidos, considerando que las y los estudiantes que cursaron el curso durante el año académico 2020, actualmente se encuentran en su práctica profesional.

De lo analizado, se puede concluir que la experiencia educativa contribuyó a desarrollar en los y las estudiantes, por una parte, conocimiento formal sobre las perspectivas de la diversidad y disidencias afectivo, sexual, corporal y de género, y por otro lado, el módulo promovió el desarrollo de una sensibilidad que hemos denominado, sensibilidad cuir, donde el aprendiz logra valorar el respeto a las distintas formas de vidas sexuales, afectivas, corporales y de género, pero al mismo tiempo logra considerar estas particularidades para la gestión del cuidado en enfermería, coherente con las convenciones internacionales sobre estas temáticas e investigaciones en el área (Kalenga et al., 2021; Lim et al., 2013; Strong \& Folse, 2015).

Al mismo tiempo, se puede concluir que las y los estudiantes toman conciencia y desarrollan una visión crítica sobre los sistemas de salud, en base a un análisis de las desigualdades de género que emergen frente a todo aquello que se escapa a la matriz patriarcal y heterosexual. A través de sus respuestas, las y los estudiantes se posicionan como sujetos políticos y éticamente responsables de las relaciones que establecen con las personas que atienden, cuidando el vínculo y la calidad de trato, resguardando, valorando y respetando la singularidad de las personas y su derecho de autodeterminación.

Se considera fundamental valorar y considerar la experiencia de las y los estudiantes, como primer recurso para deconstruir las identidades sexo-genéricas, e instalar el concepto de género como categoría de análisis en salud y enfermería. Desde nuestra experiencia, esto prepara condiciones de posibilidad para avanzar y teñir los aspectos profesionales, donde conceptos claves como régimen heterosexual, sexismo, machismo, violencia, entre otros, se introducen como una caja de herramientas o, mejor dicho, como anteojos para mirar las prácticas de enfermería, desde una actitud "ontoepistemológica cuir" o "fluid gender", que va mediando la gestión del cuidado desde un punto de vista relacional.

De la experiencia recogida durante el 2020, los aspectos a mejorar guardan relación con orientar los contenidos hacia una aplicabilidad cada vez mayor a los ámbitos de la salud. Por otra parte, adecuar modelos de evaluación de proceso que recojan de los estudiantes sus reflexiones y mejoras para la formación de enfermería en estas materias. Así mismo se visualiza la necesidad de levantar información pre y post implementación de la experiencia educativa, por medio de instrumentos que den cuenta de los progresos en términos de contenido formal sobre estas perspectivas, pero al mismo tiempo, revele aspectos subjetivos y actitudinales de los estudiantes sobre la gestión del cuidado de personas diversas y disidentes. Al mismo tiempo, y según el relato del las y los estudiantes, emerge la necesidad de ampliar la unidad a un curso de mayor crédito que tribute al perfil de egreso.

\section{REFERENCIAS BIBLIOGRÁFICAS}

Carabez, R. M., Eliason, M. J., \& Martinson, M. (2016). Nurses' knowledge about 
transgender patient care. Advances in Nursing Science, 39(3), 257-271. https://doi.org/10.1097/ANS.0000000000000128

Carpenter, M. (2016). The human rights of intersex people: addressing harmful practices and rhetoric of change. Reproductive Health Matters, 24(47), 74-84. https://doi.org/10.1016/j.rhm.2016.06.003

Connell, R. (2012). Gender, health and theory: Conceptualizing the issue, in local and world perspective. Social Science and Medicine, 74(11), 1675-1683. https://doi.org/10.1016/j.socscimed.2011.06.006

CRUCH. (2019). Documento Equidad de Género del CUECH. https://www.uestatales.cl/cue/?q=node/6224

Falck, F., Frisén, L., Dhejne, C., \& Armuand, G. (2020). Undergoing pregnancy and childbirth as trans masculine in Sweden: experiencing and dealing with structural discrimination, gender norms and microaggressions in antenatal care, delivery and gender clinics. International Journal of Transgender Health, 22(1-2), 42-53. https://doi.org/10.1080/26895269.2020.1845905

Gasch-Gallén, Á., Gregori-Flor, N., Hurtado-García, I., Suess-Schwend, A., \& RuizCantero, M. T. (2020). Affective-sexual, bodily and gender diversity beyond binarism in health sciences education. Gaceta Sanitaria, xx, 10-15. https://doi.org/10.1016/j.gaceta.2019.12.003

Kalenga, C. Z., Parsons Leigh, J., Griffith, J., Wolf, D. C., Dumanski, S. M., Desjarlais, A., Peterman, L., \& Ahmed, S. B. (2021). Trainee experiences with incorporation of sex and gender into health research: a multi-centre qualitative study. Canadian Journal of Cardiology, 37(2), e21. https://doi.org/https://doi.org/10.1016/j.cjca.2020.02.060

Lim, F. A., Brown, D. V., \& Jones, H. (2013). Lesbian, Gay, Bisexual, and Transgender health: Fundamentals for nursing education. Journal of Nursing Education, 52(4), 198-203. https://doi.org/10.3928/01484834-20130311-02

Pratt-Chapman, M. L. (2020). Implementation of sexual and gender minority health curricula in health care professional schools: A qualitative study. BMC Medical Education, 20(1), 1-14. https://doi.org/10.1186/s12909-020-02045-0

Strong, K. L., \& Folse, V. N. (2015). Assessing undergraduate nursing students'knowledge, attitudes, and cultural competence in caring for lesbian, gay, bisexual, andtransgender patients. Journal of Nursing Education, 54(1), 45-49. https://doi.org/10.3928/01484834-20141224-07

Yingling, C. T., Cotler, K., \& Hughes, T. L. (2017). Building nurses' capacity to address health inequities: incorporating lesbian, gay, bisexual and transgender health content in a family nurse practitioner programme. Journal of Clinical Nursing, 26(17-18), 2807-2817. https://doi.org/10.1111/jocn.13707 


\subsubsection{Géneros, Educación y Narrativa Transmedia: deconstruyendo mitos y estereotipos; construyendo relaciones afectivas en igualdad en la universidad}

Virginia Martagón Vázquez (Universidad de Málaga, España); Piedad Calvo León (Universidad de Málaga, España); Carmen Vaquero Cañestro (Universidad de Málaga, España); María Jesús Márquez García (Universidad de Málaga, España); Laura Triviño Cabrera (Universidad de Málaga, España); Analía Leite Méndez (Universidad de Málaga, España).

\section{Resumen}

El III Plan de igualdad de la Universidad de Málaga pone de relieve la necesidad de seguir avanzando en la universidad y desde la educación superior en el trabajo por la igualdad de género para el bienio (2019-2022). En concreto el plan visibiliza el trabajo que aún queda por hacer en prevención y sensibilización contra la violencia machista y en la participación de las estudiantes y profesoras en espacios, formación y diálogo en favor a la igualdad de género dentro de la universidad y en diálogo con otros espacios sociales y educativos. Para avanzar en esta finalidad del proyecto que llevamos a cabo se propone aumentar el grado de compromiso de la comunidad universitaria desde el principio de igualdad efectiva y con acciones participativas que impliquen un avance significativo en la eliminación de injusticias, prejuicios, estereotipos y mitos machistas entre hombres y mujeres. La propuesta la coordinamos un grupo interdisciplinar e interdepartamental de profesoras de la facultad de ciencias de la educación. En ella planteamos un seminario abierto como espacio de diálogo, análisis y debate a partir de los modelos de relación y sexualidad imperantes en los medios de comunicación y las instituciones educativas: vídeos, telenovelas, reality shows, campañas publicitarias, tiktok y otros recursos utilizados por jóvenes y adultos en la actualidad. La finalidad es generar un espacio vivo, de diálogo con el entorno y la creación de redes que den fuerza al activismo dentro y fuera de la universidad. Contamos con la participación de profesorado, alumnado y ciudadanía en general con el fin de abrir espacios de formación, información y participación en la facultad de Ciencias de la Educación de la Universidad de Málaga.

Palabras clave: feminismos; educación superior; género; narrativa transmedia.

\section{INTRODUCCIÓN Y OBJETIVOS}

El siglo XXI se caracteriza por grandes paradojas y discursos donde el papel de la mujer parece haber avanzado y haber roto muchos techos y prohibiciones en unos ámbitos, pero en otros aun seguimos en los márgenes, invisibilizadas e incluso en situaciones de vulnerabilidad. Los datos que encontramos en el diagnóstico realizado en el III Plan de Igualdad de la Universidad de Málaga ${ }^{20}$ pone de relieve en datos globales las brechas de desigualdad, mayores niveles de violencia y mayores cargas personales y laborales de las mujeres para "llegar", para equipararse o para ganar espacios. En este sentido y atendiendo a diversas investigaciones, artículos y referentes teóricos nacionales e internacionales como: Nancy Fraser, Ana de Miguel, Marina Subirat, Rosa Cobo, Subirat, Rita Segato, Judhit Butler, Lucas Platero, etc. la educación juega un papel vital en los procesos de visibilización y concienciación de las

20

https://www.uma.es/media/files/DIAGNOSTICO_Y_PLAN_IGUALDAD_DEFINITIVO_POSTAPROBACION_C G.pdf 
desigualdades de géneros, siempre y cuando se revisen los modelos patriarcales internalizados por hombres y mujeres, niños, niñas y jóvenes. Estos modelos, muchas veces sutiles e implícitos requieren un gran trabajo de deconstrucción y de generación de alternativas para poder construir otras formas de estar, ser y actuar en la sociedad y en los centros educativos desde la primaria a la educación superior (Rivas y Leite, 2009). Nuestra responsabilidad en la formación docente nos lleva a desarrollar otras estrategias de concienciación que puedan redundar en la creación de otros espacios de reflexión y posibilidades de cambio desde la Facultad de Ciencias de la Educación en diálogo con entidades sociales y educativas. La igualdad de género y la lucha contra la violencia machista en cualquiera de sus manifestaciones requiere de un activismo comprometido, creativo y solidario en el que sea amplíe en todas las direcciones, es decir, entre el profesorado, estudiantes, personal de administración y servicio de la universidad, así como en el trabajo colaborativo y dialógico con la sociedad local y global en el territorio y en las redes sociales.

En el compromiso por la sociedad igualitaria, feminista y anti patriarcal no basta con tener acciones puntuales, más bien debe de estar en los engranajes del sistema docente y social de la universidad. En la formación de profesionales de la educación resulta imprescindible formar desde esta mirada, visibilizar cómo la escuela al igual que otras instituciones socioeducativas han ido perpetuando estas desigualdades, así como las redes sociales y espacios de ciudadanía. Cómo la historia, el arte, la literatura o en cualquier otra disciplina han invisibilizado mujeres y siguen haciéndolo (Triviño y Vaquero, 2019; 2020). Nos preocupa continuar educando en roles cerrados estigmatizados y no valoramos las diferencias sea cual sea su naturaleza, ni la perspectiva interseccional y decolonial (Pons, 2019), ni la cultura y experiencias de las y los jóvenes de modo que se reproduzcan modelos sociales y relaciones machistas.

Objetivos

1.-Promover procesos de reflexión y reconocimiento de las desigualdades entre hombres y mujeres mediante la deconstrucción de mitos, estereotipos, historias, relatos, en el contexto de las nuevas tecnologías y la influencia de los medios de comunicación.

2.- Ofrecer propuestas alternativas de acción y reflexión sobre género y educación.

3.- Iniciar y consolidar un espacio interdisciplinar e interdepartamental (Facultad de Ciencias de la Educación) en diálogo con entidades sociales y centros educativos públicos para transformar las concepciones desiguales de géneros, prevenir la violencia machista, denunciar y destapar el patriarcado en educación y contribuir a la construcción de modelos de relaciones igualitarios y libres de violencia machista.

\section{METODOLOGÍA}

Se trabaja con la modalidad de tertulias dialógicas y seminarios (virtuales), donde se buscará el diálogo, la reflexión, el contraste con la realidad, la recuperación de relatos e historias de mujeres en los distintos ámbitos de la ciencia, el arte, la música y el campo de las ciencias sociales desde una perspectiva narrativa (Márquez, Leite y Calvo, 2017). Las tertulias tienen una continuidad temática, de ampliación y profundización de contenidos relevantes, por un lado y una continuidad colectiva en el sentido de la producción del grupo y la circulación y recuperación de diversos significados, prácticas y propuestas de cambio de mirada y actuación, por otro.

Se iniciará el proyecto, coincidiendo con el 8 de marzo, a través de una lectura transmedia online donde personas pertenecientes o cercanas a la comunidad universitaria aportarán de diversas maneras su propia "lectura" sobre el significado de este día. A partir de esta experiencia, decidimos continuar proponiendo actividades en 
relación con las diferentes líneas temáticas con la intervención de una especialista o referente en el tema de género y educación como: violencia machista, prevención; erotismo y sexualidad; sutilezas y evidencias en las redes sociales y medios de comunicación; currículum oculto en las instituciones educativas; modelos de relaciones y sexualidades, etc.

Se realizan tertulias dialógicas y seminarios con alumnado y profesorado de la Facultad y de centros educativos cada mes. La participación online tiene varias modalidades: con aportaciones en la tertulia a través de una plataforma virtual (Meet, Zoom, etc.), en una aplicación de elaboración colaborativa llamada Padlet (https://es.padlet.com/) o a partir del chat de YouTube, ya que las actividades serán retransmitidas en directo para las personas que no deseen realizar aportaciones (Fernandez, Gil e Hipolito, 2016). Esto también nos ofrece la oportunidad de compartir el enlace de la grabación de la actividad para que puedan verla quienes no han tenido la opción de estar en el horario propuesto. Iremos promocionando las actividades a través del perfil de Instagram del proyecto (gentuma8) a partir de diversos lenguajes como escrito, imágenes, videos, etc.

En el curso académico que dura el proyecto pretendemos la creación de espacios de visibilización igualitaria del papel de las mujeres en la historia y en la realidad cotidiana, libre de estereotipos machistas. Generar un espacio propio de la Universidad y sociedad de noticias de los distintos medios de comunicación sobre situaciones de desigualdad y violencia machista. Recopilación de relatos/historias que den cuenta de la situación de superación de las mujeres en todos los ámbitos en el pasado y en la actualidad.

\section{RESULTADOS Y DISCUSIÓN}

A través de la participación en el Padlet, anteriormente mencionado, hemos tenido la oportunidad de recoger aportaciones reflexivas que las y los participantes de esa actividad han querido compartir. A continuación, exponemos dos de esas aportaciones que siguen alimentando el debate y el encuentro entre personas con realidades diversas, pero con un enfoque cercano en relación al género y la educación.

Relato 1. Empieza y nunca acaba (Estudiante de Grado de educación)

Hoy empieza conmigo.

Escribo esto tumbada en la cama, en mi habitación. La puerta hace tiempo que la he cerrado. Este espacio es mío. Virginia me observa escribir y sabe que siempre tuvo razón. Dinero, estabilidad, independencia, arte.

Observó el lápiz bailar, a lo suyo, por la página, orquesto un ballet que me distrae de mi pierna derecha recién operada, del dolor, de la textura de tiza de los medicamentos que sigue en mi lengua por más que me empeñe en bajarla con agua, y mis palabras son un beso de Frida en la frente, el eco de su voz en mis oídos, ¿para qué los quieres?

Oigo otras voces en la televisión, discutiendo sobre una superviviente, sobre un juicio, una herida abierta. Hablan de largos de falda, de palabras intercambiadas, hablan de un miedo que no viven. Sor Juana suspira, exasperada. Hombres necios, que acusáis...

$Y$ hoy no me callo. Hoy me arranco el sombrero, que nada me oprima las ideas, y digo lo que tengo que decir. Por las que son excluidas de espacios que les pertenecen tanto o más que a quienes cierran las puertas, por aquella que pudo haber sido otro número en las estadísticas. Por las que están y las que echamos de menos.

Ayer fueron ellas. Hoy empieza conmigo. Empieza contigo. Y mañana, ¿quién sabe? Nosotras seremos las voces en el viento, los besos en la frente, las sonrisas que se saben vencedoras. Las que creen el mañana, crearán sobre el terreno que conquistemos para ellas, como otras lo hicieron por nosotras. 
Nuestras palabras, nuestros pinceles, nuestras voces serán suyas. Porque venimos de las que escaparon del fuego, nos toca empezar a apagarles hogueras a las que vendrán.

Hoy acaba conmigo.

Llegué bastante tarde anoche después de un largo día que fue rematado con la vida nocturna y el cansancio que arrastra. Demasiado dinero gastado en cosas banales. Quizás me podría haber ahorrado dinero en las tantas copas que consumí ya que una ola de invitaciones para comprarme el veneno de intoxicación llegaba a mis pies. Pero no accedía porque me aterraba la intención que había detrás de todo aquello. Ellos mirándome con sus ojos ebrios y perversos; yo bailando tratando de no sentirme incomoda, aunque claro que lo hacía. Incomodidad por todos lados y por más que luchara contra eso, más grande y más inquietantes se volvían sus miradas. Como animales casi primitivos. No me sentía segura ni cómoda ni tranquila.

Decidí volver a casa, donde de camino veía a muchas más compañeras asustadas y solas volviendo a sus respectivas casas. Nos mirábamos como buenas aliadas, sabiendo a lo que nos habíamos enfrentado esa noche y a lo que nos tocaría enfrentarnos las siguientes noches que decidiéramos salir. Presas de las miradas, de los comentarios fuera de lugar, de la presión que nos invade el pecho cuando vemos la hora y toca volverse sola, rezando a Dios o a quien sea que esté en el universo para que no nos ocurra nada y podamos mirar a nuestras madres a la cara y decirles con voz sincera y segura: "Mamá he disfrutado como nunca y sin peligro alguno." Pero la realidad es que no llevo la cuenta de todas las noches que le he mirado a la cara, diciéndole eso y mintiéndole. Así que esto va por ti mamá y por todas aquellas veces que te mentí cuando lo que quería era echarme a llorar en tus brazos.

Relato 2. Acerca del 8 de marzo (Estudiante de grado de educación)

Hoy no quiero felicitar.

Hoy no quiero felicitar a ninguna mujer ni quiero que lo hagan conmigo.

Porque pienso que no es un día para celebrar, sino que está para reivindicar.

Hoy solo quiero dar las gracias a todas las mujeres que un día lucharon y hoy siguen luchando por los derechos de todas. A todas aquellas que transmiten el mensaje del feminismo sea donde sea, aunque ni ellas mismas lo sepan.

Yo no me considero el mayor ni mejor exponente del feminismo, pero si pongo mi grano de arena cada día intentando reflexionar si lo que estoy diciendo o incluso pensando puede llegar a ser machista, cada día intento mejorar y así poco a poco aumentar mi respeto hacia todas las mujeres y aunque no lo crea también hacia mí misma. Con esto solo espero que nos dejen de felicitar en un día que no debería existir, o que espero que pronto deje de hacerlo, porque esto significara que esta lucha por fin acaba y que de verdad todos somos iguales sin importar sexo, raza o edad.

\section{CONCLUSIONES Y LIMITACIONES}

El proyecto se está iniciando por lo que hasta el momento no podemos sacar conclusiones. Si podemos mencionar la exitosa participación en el primer evento de Lectura Transmedia y preocupación por parte del profesorado y estudiantado asistente compartiendo algunos de los relatos de las estudiantes que compartieron e hicieron públicos. Todas las aportaciones de las diferentes actividades estarán recogidas en una página web del proyecto (en construcción) para poder hacer un análisis posterior de los resultados. 


\section{REFERENCIAS BIBLIOGRÁFICAS}

Fernández, Sergio; Gil, Nuria; Hipólito, Natalia. (2016). Las TIC para, cómo y con la Educación Social. La Gestión de la identidad digital como competencia desde la Educación Social. RES. Revista de Educación Social, (24), pp. 571-578.

Marquez García, Maria-Jesus.; Leite Méndez, Analia y Calvo León, Piedad. (2017) Pensarnos a Nosotras en el encuentro con los "otros/as". Investigación Narrativa y Transformación. Revista Digital, Año 8, № 10, pág. 100-112. ISSN 1853-1393. Resistencia (Chaco) Argentina.

Pons Bonals, Leticia. (2019) El "género" en el pensamiento decolonial, En Melo, Espinosa Torres, Pons Bonals, Rivas Flores (coords) Perspectivas decoloniales sobre la educación. UMA Editorial (España) - Editora Unicentro (Brasil).

Rivas Flores, José-Ignacio, Leite Méndez, Analía (2009) La Experiencia de género en la escuela: Espacio, éxito y relación, En SANTOS GUERRA, M.A. (Coord.): EI género como pasión. Homenaje a la profesora Gloria Arenas Fernández. Pp.195212. Servicio de Publicaciones de la Universidad de Málaga.

Triviño cabrera, Laura y Vaquero Cañestro, Carmen. (2020). Educación artística y ciudadana en la formación inicial de maestras/os en Educación Primaria. Desarrollo del pensamiento crítico-creativo-social a través de Malamente. Revista Complutense de Educación, 31 (3), 375-385 https://doi.org/10.5209/rced.63488

Triviño Cabrera, Laura y Vaquero Cañestro, Carmen (2019). Didáctica de la Eutopía. De la caverna global a las aldeas glocales. En Semova, Dimitrina J., Aladro Vico, Eva y Sosa Sánchez, Roxana Popelka (eds.). Entender el artivismo. Oxford: Peter Lang.

Triviño Cabrera, L. (2017). Feminismos, postmodernidad y cultura mediática en las aulas: el videoclip pop estadounidense como herramienta educativa para la discusión de temas controversiales. Investigaciones Feministas, 8(2), 493-514. https://doi.org/10.5209/INFE.54972

Vicerrectorado de Igualdad, Diversidad y Acción Social (2020) III Plan de Igualdad de la Universidad de Málaga 2019-2022. 


\subsubsection{La perspectiva feminista en historia de la ciencia y la tecnología. \\ Maria Medina-Vicent (Universitat Jaume I, España) ${ }^{21}$.}

\section{Resumen}

Al aproximarnos al estudio de la ciencia y la tecnología, encontramos diferentes problemáticas y limitaciones relacionadas con la desigualdad de género, como, por ejemplo, la limitada presencia de mujeres en dichas carreras, pero también la inexistencia de sus aportaciones en los libros de ciencias e Historia de la ciencia. En el marco de la asignatura de Historia de la ciencia y la tecnología (impartida en el primer curso de diversas ingenierías), se pretende formar al alumnado en la capacidad para comprender el funcionamiento del desarrollo científico y tecnológico y su necesaria vinculación con contextos históricos, sociales, culturales, políticos y económicos. Por esta razón, resulta de vital importancia incorporar la perspectiva feminista en una acepción plural del estudio de la ciencia y la tecnología, y de los retos y problemas que éstas plantean hoy en día. El objeto de este escrito es sintetizar la experiencia docente desarrollada en dicha asignatura desde el curso 2018/2019 hasta 2020/2021, así como proponer acciones de mejora para los próximos cursos.

Palabras clave: ciencia, tecnología, historia, feminismo, mujeres.

\section{INTRODUCCIÓN Y OBJETIVOS}

En el marco de la asignatura Historia de la ciencia y la tecnología se pretende desarrollar el estudio histórico y filosófico de ambos espacios, reflexionando entorno al aspecto social de las mismas. La ciencia aparece en los estudios de ingeniería como un cuerpo de conocimientos empíricos y teóricos producidos por una comunidad de investigadoras e investigadores que hacen uso de un método y unas técnicas específicas. Estos resultados se encuentran en constante revisión y desarrollo, y fruto de los mismos son la tecnología y sus aplicaciones en la sociedad en que vivimos. En este sentido, desde la historia de la ciencia y la filosofía de la ciencia, se pretende ampliar la visión normalizada de la ciencia, aportando o subrayando su componente humanista. $Y$ es que, la ciencia y la tecnología no son entes aislados de la sociedad, responden y adquieren su sentido en las necesidades y exigencias de la misma. Están sujetas a los devenires históricos y en gran medida son el eco de las imágenes sociales sobre diferentes temas. De hecho, pretender que la ciencia y la tecnología son espacios neutrales y objetivos puede resultar peligroso para el propio avance de ambos espacios y de la sociedad misma, ya que corremos el riesgo de perpetuar desigualdades de diferentes tipos, entre las que se encuentra también la desigualdad por razón de género (Medina-Vicent, 2013). En este contexto también resulta especialmente interesante poner entre interrogantes las grandes verdades de la ciencia, no solamente en cuanto se refiere al propio concepto de verdad y el establecimiento de teorías (Popper, 2008; Kuhn, 2013; Lakatos, 2011), sino también a sus métodos (Feyerabend, 2002) y a las "mentiras" sobre las mujeres que se han perpetuado en las mismas (García Dauder y Pérez Sedeño, 2017).

Así pues, el objetivo principal de esta experiencia educativa es incorporar la perspectiva feminista en la materia de Historia de la ciencia y la tecnología (conformada por tres

\footnotetext{
${ }^{21}$ Esta experiencia educativa se inscribe en el proyecto de mejora "Incorporació de la perspectiva de gènere en 12 graus de I'UJI. Avançament transversal per a la igualtat" financiado por la Unitat de Suport Educatiu de la Universitat Jaume I, con código 3980, Grupo PEPI (Pràctiques Educatives per a la Igualtat).
} 
bloques temáticos correspondientes a Historia de la ciencia, Filosofía de la ciencia y Retos actuales). Se trata de una asignatura que se imparte en primer curso de los grados en Ingeniería Química, Ingeniería en Tecnologías Industriales, Ingeniería Eléctrica e Ingeniería Mecánica. Este objetivo general se divide a su vez en dos objetivos específicos. El primero de ellos pone especial énfasis en aumentar la visibilización de las aportaciones de las mujeres en el desarrollo de la Historia de la Ciencia a lo largo de los cinco temas que componen el temario de la asignatura, a través de la incorporación de dichas figuras y sus aportaciones. El segundo objetivo específico pretende incentivar la reflexión crítica del alumnado realizada desde las bases que nos otorga la teoría feminista, a través del tratamiento de teorías y conceptos filosóficos sobre diferentes temáticas de interés para el ámbito científico y tecnológico.

\section{CONTEXTUALIZACIÓN}

Antes de avanzar en la experiencia educativa que aquí se narra, cabe señalar que la incorporación de la perspectiva feminista en carreras universitarias altamente masculinizadas resulta un tema urgente. En este sentido, a destacar que en la Universitat Jaume I en el curso 2019/2020 entre los grados en los que menos mujeres se matricularon, se encuentran el Grado en Ingeniería Eléctrica y el Grado en Ingeniería Mecánica 22 , ambos grados en los que se imparte esta asignatura. Por tanto, estas cifras muestran en cierta medida la necesidad real de incorporar las experiencias de las mujeres en el currículo de la asignatura, así como ir introduciendo poco a poco una perspectiva transversal feminista, crítica, filosófica e histórica en dicha materia.

De hecho, el marco general de esta asignatura busca ejercitar las siguientes competencias genéricas y específicas: CEA02 - Capacidad para comprender el funcionamiento del desarrollo científico y tecnológico y su necesaria vinculación con contextos históricos, sociales, culturales, políticos y económicos; CG01 - Capacidad de análisis y síntesis; y CG03 - Comunicación oral y escrita en lengua nativa; para ejercitar las dos primeras competencias se precisa incorporar, no solamente una visión histórica y filosófica de las aportaciones y los desarrollos científicos (Ordóñez, Navarro, y Sánchez Ron, 2013; Solís y Sellés, 2013), sino también del papel de la desigualdad de género en la misma.

En este sentido, de los resultados de aprendizaje perseguidos, consideramos que, al incorporar la perspectiva feminista, conseguimos obtener los siguientes:

CG01, CEA02 - Reconocer los principales retos a los que se enfrenta el desarrollo de la ciencia y la tecnología en la sociedad actual.

CG01, CEA02 - Ser capaz de analizar desde un punto de vista epistemológico y semántico el conjunto de cuestiones y desarrollos científicos y tecnológicos.

CG01, CEA02 - Ser capaz de analizar los impactos de la ciencia y la tecnología en la sociedad actual teniendo en cuenta las perspectivas de género.

CG01, CEA02 - Ser capaz de analizar los principales acontecimientos científicos y tecnológicos.

CG01, CEA02 - Ser capaz generar una actitud respetuosa hacia los valores humanos y de la naturaleza.

\footnotetext{
22 Ver Igualtat en xifres a I'UJI. Alumnat Curs 2019/2020:

https://ujiapps.uji.es/ade/rest/storage/82OV3MH0T7CG1AQIHGQMTA8GUVXFXLPQ
} 
Reiteramos pues, que, para poder trabajar las competencias especificadas en la guía docente de la asignatura, así como estar más cerca de conseguir los resultados de aprendizaje especificados, precisamos de una mirada transversal, no solamente histórica y/o filosófica que nos acerque a ampliar la visión de los fenómenos científicos y tecnológicos hoy, sino también feminista y de género.

\section{DISEÑO Y DESARROLLO}

A lo largo de los cursos 2018/2019, 2019/2020 y en el actual 2020/2021 se han ido incorporando nuevas acciones en la línea de cumplir con los dos objetivos específicos explicitados anteriormente. El primero de ellos pone especial énfasis en aumentar la visibilización de las aportaciones de las mujeres en el desarrollo de la historia de la ciencia a lo largo de los cinco temas que componen el temario de la asignatura, a través de la incorporación de dichas figuras y sus aportaciones. El segundo objetivo específico pretende incentivar la reflexión crítica del alumnado realizada desde las bases que nos otorga la teoría feminista, a través del tratamiento de teorías y conceptos filosóficos sobre diferentes temáticas de interés para el ámbito científico y tecnológico.

En primer lugar, para conseguir aumentar la visibilización de las aportaciones de mujeres científicas a la historia de la ciencia y la tecnología se han ido incorporando diferentes figuras y sus aportaciones a lo largo de las diferentes unidades temáticas. Algunos ejemplos de estas incorporaciones -que pretendemos ir aumentando con el paso de los cursos- son las siguientes: Hypatia, Marie Curie, Rosalind Franklin y Hedy Lamarr. En este sentido, encontramos materiales muy diversos que pueden contribuir a desarrollar esta tarea, como por ejemplo la página web Mujeres con ciencia ${ }^{23}$, donde podemos encontrar biografías de científicas e ingenieras, entre otras cuestiones de interés. En relación, consideramos importante ir incorporando también referencias bibliográficas a trabajos actuales que se encargan de recopilar estas aportaciones silenciadas (Casado, 2006; Santesmases, Cabré i Pairet, y Ortiz Gómez, 2017; LeviMontalcini, 2017; Gómez Rodríguez, 2019; VVAA, 2019; Harding, 2019; Navarro, 2019).

Cabe señalar también que en el curso 2020/2021 la Universitat Jaume I acogió la Exposición "Ellas tienen la fórmula", donde se elabora un recorrido cronológico a través de 3.000 años de historia de la química que protagonizan 17 mujeres y sus aportaciones científicas, desde la que está considerada como primera mujer química de la historia hasta investigadoras en activo de este siglo XXI. En el marco de la asignatura se consideró la posibilidad de visitar la exposición situada en la misma universidad (a escasos metros de la clase) para que el alumnado pudiese conocer de primera mano las diferentes biografías allí dispuestas. Además, se contactó con los responsables del programa Estudia e Investiga de dicha universidad (donde participa alumnado que se inicia en el mundo de la investigación durante sus estudios de grado) para invitar a alumnado de dicho programa a realizar una charla explicativa sobre la exposición en nuestra clase.

En segundo lugar, para incentivar la reflexión crítica y feminista del alumnado, tratamos de dar un espacio en el aula a la parte correspondiente a la teoría feminista de la ciencia y la tecnología. Para esto se realiza en el marco de la unidad temática cinco (La verdad y la racionalidad en la ciencia), una aproximación a las bases de la crítica feminista a la ciencia. Algunas de las propuestas teóricas que aquí se abordan son las de autoras como Judy Wajcman (2006), Sadie Plant (1998) y Donna Haraway (2016), que viaja entre el tecno feminismo, el ciberfeminismo y las propuestas ciborg en confluencia con

\footnotetext{
${ }^{23}$ Página web de la Cátedra de Cultura Científica de la Universidad del país Vasco. Ver: https://mujeresconciencia.com/mujeres-con-ciencia/
} 
las preocupaciones medioambientales. Así como otras propuestas más recientes como la del xeno feminismo (Hester, 2018) o el ciberfeminismo más actual (Zafra y LópezPellisa, 2020).

En esta misma línea, se ha creado un listado en la red social de cine Letterboxd donde se recopilan materiales audiovisuales (películas, series de televisión, cortometrajes, documentales, biopics, etc.) sobre ciencia, tecnología y mujeres. Esta lista se titula "History of Science, Philosophy of Science, Women in Science" ${ }^{24}$ y pretende aglutinar producciones que abordan las relaciones entre ciencia, tecnología y sociedad. A partir del tratamiento de estos materiales se pueden entablar diálogos con el alumnado, mediante el planteamiento de reflexiones críticas y conjuntas que incorporen la perspectiva feminista crítica, histórica y filosófica a las formas en las que entendemos la ciencia y la tecnología.

Las acciones que aquí se mencionan se han ido implementando poco a poco con el paso de dos cursos académicos, en la actualidad se siguen desarrollando con variaciones en función de las necesidades y respuestas del alumnado. La intención es seguir ampliando estas acciones y adaptándolas curso a curso. A continuación, reflexionamos sobre estas cuestiones.

\section{EVALUACIÓN, CONCLUSIONES Y PROPUESTAS DE MEJORA}

Una de las principales conclusiones a las que podemos llegar después de implementar las acciones expuestas en el apartado anterior es que existe un gran desconocimiento en las aulas sobre las aportaciones de las mujeres al mundo de la ciencia y la tecnología. Pero no solamente esto, sino que se vuelve necesario ejercitar la perspectiva crítica con la que el alumnado aborda las cuestiones relativas a la ciencia y la tecnología, si deseamos que aumente la conciencia del impacto social de ambos espacios. En este sentido, ampliar la perspectiva histórica y filosófica mediante el diálogo con la teoría feminista sobre la ciencia puede resultar muy fructífero en la edificación de miradas conscientes y más sensibles al impacto social, en dichos ámbitos. Después de superar las reticencias iniciales por parte del alumnado a la hora de abordar dicha perspectiva, se deben reforzar las aportaciones de las mujeres en dicho campo de forma fluida, incorporando poco a poco sus trabajos.

De cara a futuros cursos nos proponemos ampliar la bibliografía básica de la asignatura para incorporar las referencias más actualizadas sobre estudios feministas de la ciencia y la tecnología; así como ampliar el listado de producciones audiovisuales desde las que tratar dichas temáticas. A su vez, resulta interesante realizar un debate en el aula sobre las propuestas teóricas feministas en su relación con los problemas actuales de la ciencia. Por otro lado, también resultaría muy fructífera la realización de algún seminario relacionado con el trabajo actual de las mujeres en la ciencia, la ingeniería y la tecnología. Para esto nos proponemos invitar a científicas que puedan venir al aula a contar su experiencia y establecer un diálogo directo con el alumnado.

\footnotetext{
${ }^{24}$ Ver: https://letterboxd.com/marmed/list/history-of-science-philosophy-of-science/
} 


\section{REFERENCIAS BIBLIOGRÁFICAS}

Ballús, A., y Roqueta, M. (2018). Feminisme i ciencia. Conflictes, convergències i compatibilitats. Mètode, 97, 26-31.

Casado, M. J. (2006). Damas del laboratorio. Mujeres científicas en la historia. Madrid: Debate.

Feyerabend, P. (2002). Contra el método. Barcelona: Folio.

García Dauder, S., y Pérez Sedeño, E. (2017). Las "mentiras" científicas sobre las mujeres. Madrid: La Catarata.

Gómez Rodríguez, A. (2019). Escritos sobre ciencia y género. Madrid: La Catarata.

Haraway, D. (2016). Manifiesto para cyborgs. Ciencia, tecnología y feminismo socialista a finales del siglo XX. Buenos Aires: Puente Aéreo.

Harding, S. (2019). Ciencia y feminismo. Madrid: Morata.

Hester, H. (2018). Xenofeminismo. Tecnologías de género y políticas de reproducción. Buenos Aires: Caja Negra.

Kuhn, T. (2013). La estructura de las revoluciones científicas. México DF: Fondo de Cultura Económica.

Lakatos, I. (2011). Historia de la ciencia y sus reconstrucciones racionales. Madrid: Tecnos.

Levi-Montalcini, R. (2017). Las pioneras. Las mujeres que cambiaron la sociedad y la ciencia desde la Antigüedad hasta nuestros días. Madrid: Editorial Crítica.

Medina-Vicent, M. (2013). Desvelar la pretensión de neutralidad/objetividad de la ciencia moderna desde la óptica feminista: de la tecnofobia al desarrollo del Ciberfeminismo. Fòrum de Recerca, 18, 113-131.

Navarro, J. (2019). Mujeres matemáticas. Barcelona: RBA.

Ordóñez, J.; Navarro, V., y Sánchez Ron, J.M. (2013). Historia de la ciencia. Barcelona: Austral.

Plant, S. (1998). Ceros + Unos. Barcelona: Ciencias sociales-Destino.

Popper, K. (2008). La lógica de la investigación científica. Madrid: Tecnos.

Santesmases, M. J., Cabré i Pairet, M., y Ortiz Gómez, T. (2017). Feminismos biográficos: aportaciones desde la historia de la ciencia. ARENAL, 24(2), 379-404.

Solís, C., y Sellés, M. (2013). Historia de la ciencia. Barcelona: Espasa.

VVAA (2019). Mujeres de ciencia. Barcelona: RBA.

Wajcman, J. (2006). El tecnofeminismo. València: Ediciones Cátedra.

Zafra, R. y López-Pellisa, T. (2020). Ciberfeminismo. De VNS Matrix a Laboria Cuboniks. Barcelona: Holobionte Ediciones. 


\subsubsection{Campaña \#ViolenciaEs en la Ibero Ciudad de México: apelar a la experiencia \\ Alejandra Azucena Meza Uscanga (Universidad Iberoamericana, Ciudad de México)}

\section{Resumen}

Con el fin de dar a conocer a la comunidad de la Universidad Iberoamericana el Protocolo para la Prevención y Atención de la Violencia de Género en la Universidad Iberoamericana Ciudad de México, el Programa de Género e Inclusión lanzó la campaña \#ViolenciaEs de manera digital e impresa en las instalaciones. La estrategia consistió en una parodia de señaléticas que retomaban frases y conductas denunciadas en la universidad sobre comportamientos violentos, de modo que se exponía desde la visualidad el comportamiento y, en un segundo nivel de información, se explicaba cómo operaba la violencia en éste. El resultado además de promover el protocolo logró la conversación entre la comunidad, misma que se monitoreó en redes sociales y contactos directos con el área, sobre lo que implica normalizar estas conductas y, otras veces, cuestionarlas. El diálogo se generó, por coincidencia o por disidencia con la estrategia, entre docentes, administrativos y estudiantes.

Palabras clave: violencia de género; discriminación; campaña de sensibilización, campaña universitaria; difusión de protocolo.

\section{INTRODUCCIÓN Y OBJETIVOS}

Durante el periodo Primavera de 2019, era necesario dar a conocer el Protocolo para la Prevención y Atención de la Violencia de Género en la Universidad Iberoamericana Ciudad de México, como parte de una de las iniciativas entre distintas áreas de la casa de estudios para atender los casos de discriminación, acoso, hostigamiento y otras formas de violencia que pudieran tener cabida en la comunidad universitaria.

Como antecedente, durante 2018 se lanzaron algunas propuestas de difusión que señalaban el camino para denunciar ante la Procuraduría de los Derechos Universitarios estos abusos. Estas propuestas consistieron en separadores y banners impresos en distintas áreas, donde se anunciaba información como:

- Qué hacer en caso de ser víctima de violencia por género, clase, creencias u otra razón. Pasos que seguir para denunciar.

- Cómo promover buenas prácticas entre el personal administrativo y docente para evitar discriminación o violencia.

Sin embargo, cuando se sondeaban opiniones, sobre todo con el alumnado, el equipo del Programa de Género e Inclusión, a cargo de estas iniciativas de comunicación, llegó a una conclusión: existían conductas violentas naturalizadas. Es decir, no se entendía, para comenzar, porqué una actitud o frase podía ser violenta. De la misma manera, se comenzó a hacer visible durante las denuncias que la romantización de la violencia en los y las más jóvenes, también representa un obstáculo para la denuncia. Por ejemplo, 
algunas de las relaciones sentimentales que terminaban en conductas violentas, habían comenzado con gestos de control en cuanto al uso de contraseñas para redes sociales, correos y otras comunicaciones, bajo el entendido que "compartir contraseñas es un sinónimo de confianza".

Cuando llegó el momento, para el semestre Primavera 2019, de promover el Protocolo para la Prevención y Atención de la Violencia de Género en la Universidad Iberoamericana Ciudad de México, representaba un desafío en la parte creativa el cómo explicar el uso del protocolo, quiénes podían beneficiarse por esta iniciativa y, también, la traducción de términos técnicos a un lenguaje accesible para toda la comunidad. Fue así que surgió la idea de realizar una estrategia arriesgada para la lectura, pero que seguramente detonaría procesos apelando a la empatía de quien viera la campaña: usar las frases y comportamientos naturalizados como representación visual.

Los objetivos de la campaña serían:

- De manera general, dar a conocer el Protocolo para la Prevención y Atención de la Violencia de Género en la Universidad Iberoamericana.

De manera específica:

- Se realizaría una propuesta gráfica que utilizara los comportamientos denunciados como violentos, como ilustración de estos mecanismos, donde se explicaría cómo opera la violencia.

- Se difundiría la campaña a través de las redes sociales de la universidad, para generar conversación con los seguidores.

- La campaña se difundiría de manera impresa en las instalaciones, a través de espacios que aseguraran su visibilidad.

\section{CONTEXTUALIZACIÓN}

La desigualdad en las relaciones afectivas tiene como uno de sus principales componentes la romantización de la violencia. En México, esta romantización cuyo vehículo se encuentra en frecuentemente en narrativas de la producción cultural como el cine, la música o la literatura, ha ocasionado que se normalicen patrones de violencia que, en muchos casos, llegan al feminicidio.

Estos patrones son notables desde las primeras relaciones afectivas que se dan en la juventud. La Encuesta Nacional sobre Violencia en el Noviazgo 2007, señaló que el $76 \%$ de las y los jóvenes mexicanos entre los 15 y 24 años sufrió episodios de violencia al menos una vez durante su relación de noviazgo Estas conductas se perpetúan gracias a la complicidad de los entornos inmediatos de las y los jóvenes: la familia, la escuela, algunos círculos sociales. Según la ENDIREH 2016, 29.3\% considera que "si hay golpes o maltratos en la casa es un asunto de familia y ahí debe quedar".

Las conductas violentas, sin embargo, pueden detectarse a partir de gestos, razonamientos y frases que se visibilizan en el trato a los demás. En un entorno como la universidad, donde existen relaciones afectivas como la amistad, compañerismo, preparación profesional o relaciones sentimentales como el noviazgo o "free", es posible 
dar seguimiento a estas conductas y atenderlas. Sin embargo, durante 2018 el Programa de Género e Inclusión de la Universidad Iberoamericana Ciudad de México, a propósito de la difusión del protocolo que atendería a víctimas de estos casos, trató también de sensibilizar sobre estos comportamientos. La premisa inicial fue que, no es suficiente con señalar una conducta como violenta, sino explicar cómo opera la violencia en ella. Y quizá podría así incidirse en la percepción de estas conductas desde el inicio.

La manera de hacer este señalamiento sería vinculando la experiencia cotidiana de la misma comunidad como parte de la estructura visual en la campaña. De esta forma, la semiósfera (Lotman, 2000) en la que se desarrolla el mensaje vincula una situación presente y su reconocimiento desde la experiencia, en lugar de proponer mensajes verticales que se perciban como parte de una autoridad y no de acompañamiento. No se pretendía una campaña que tuviera como mensaje principal "no seas violento o violenta", sino una campaña que mostrara conductas diarias y explicara que esos comportamientos son violentos.

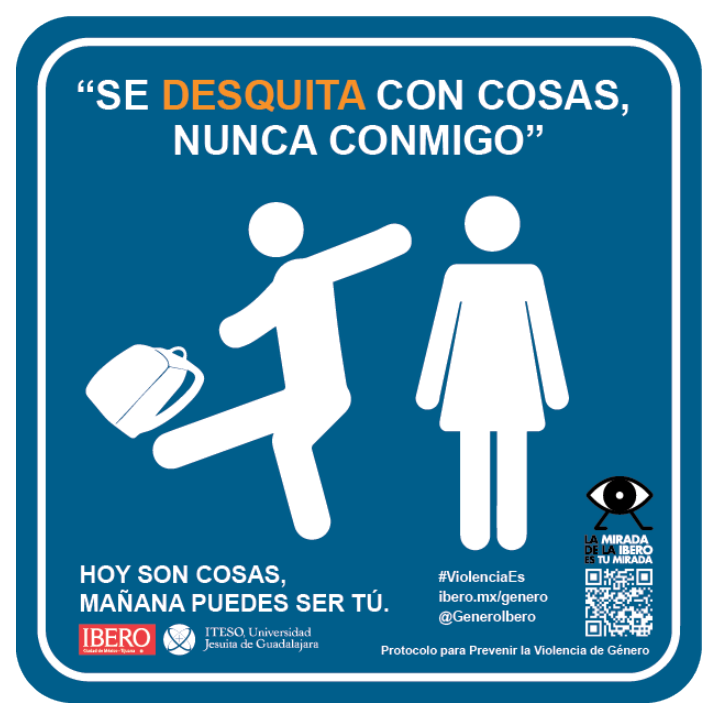

\section{DISEÑO Y DESARROLLO}

Para difundir el Protocolo para la Prevención y Atención de la Violencia de Género en la Universidad Iberoamericana, se realizaría una campaña que lo diera a conocer, pero que también, sensibilizara sobre la violencia en cuanto las formas en que opera detrás de conductas naturalizadas en la comunidad universitaria.

Como estrategia de comunicación, no se insertarían comportamientos o frases ficticias, sino que se haría uso de conductas denunciadas. Muchas de ellas, no han sido denunciadas formalmente, pero han sido parte de las quejas que escuchamos del alumnado o del personal docente y administrativo. La idea principal consistía en exponer estas frases de manera directa y, después, explicar cómo operan los patrones de violencia detrás de ellas.

Para el diseño visual, se usaría una representación gráfica de estas conductas como primer nivel de una arquitectura visual. Luego, como segundo nivel de construcción, se daría la explicación. En un tercer nivel de arquitectura visual, se daría la información 
sobre el protocolo, para quien fuera víctima de estos casos. La campaña llevaría el nombre de "Violencia Es", para enunciar el propósito de la sensibilización: visibilizar cómo opera la violencia en conductas diarias dentro del plantel. Se seleccionaron primero una serie de frases que se consideraron las más representativas de la diversidad de casos denunciados con mayor frecuencia, donde se visibilizaban conductas de violencia dentro de relaciones de amistad, noviazgo o "free", de docentes al alumnado o del personal administrativo.

Los canales para su difusión tratarían de provocar el diálogo en la comunidad. Por ello, se seleccionaron dos espacios en las instalaciones: los baños y las cafeterías. En el primer caso, se instalarían vinilos adhesivos impresos en el interior de las puertas de los baños y en los espejos. En el segundo caso, los vinilos adhesivos o stickers se pegarían en las mesas. Para dialogar con estos espacios, se aterrizó una propuesta gráfica que haría parodia de las señaléticas. Visualmente ubicado el azul y blanco como parte de la señalética de las instalaciones, y valiéndose de la gráfica común para mostrar personas u objetos de manera sintetizada, se desarrollaron 26 imágenes.

La explicación que acompañaba cada frase fue diseñada por la Dra. Elvia González Del Pliego Dorantes, coordinadora del Programa de Género e Inclusión y especialista en temas de género. La serie fue compartida entre algunos estudiantes cercanos al programa, docentes afines al tema y personal con interés en promover la campaña en la universidad. No se pretendía un mensaje complejo visualmente ni a nivel léxico, más bien, exponer cómo de manera cotidiana vemos o reproducimos comportamientos violentos que están naturalizados.

La serie de 26 imágenes fueron lanzadas en el periodo Primavera de 2019. Las imágenes podían verse en al menos 20 baños y 3 cafeterías de las instalaciones para una comunidad de 12 mil estudiantes, personal administrativo y docente. También se difundieron a través de las redes sociales del programa con la etiqueta \#ViolenciaEs. La campaña también fue replicada en el Instituto de Estudios Superiores de Occidente (ITESO) en la ciudad de Guadalajara.

Las conversaciones que comenzaron a generarse fueron, sobre todo, alrededor de los siguientes puntos:

- Que la universidad estaba prestando atención a estos temas, y que se incluyeron comportamientos de toda la comunidad: estudiantes, docentes y personal administrativo.

- Que los sitios donde se colocaba la información eran persuasivos.

- Reflexiones sobre si quienes leían la campaña, habían reproducido o visto de cerca estos comportamientos. Estas reflexiones tenían matices desde supuestos como "entiendo que este comportamiento es inadecuado", hasta otros del tipo "no es para tanto, esto no es violento". Los matices se dialogaron en la comunidad. 


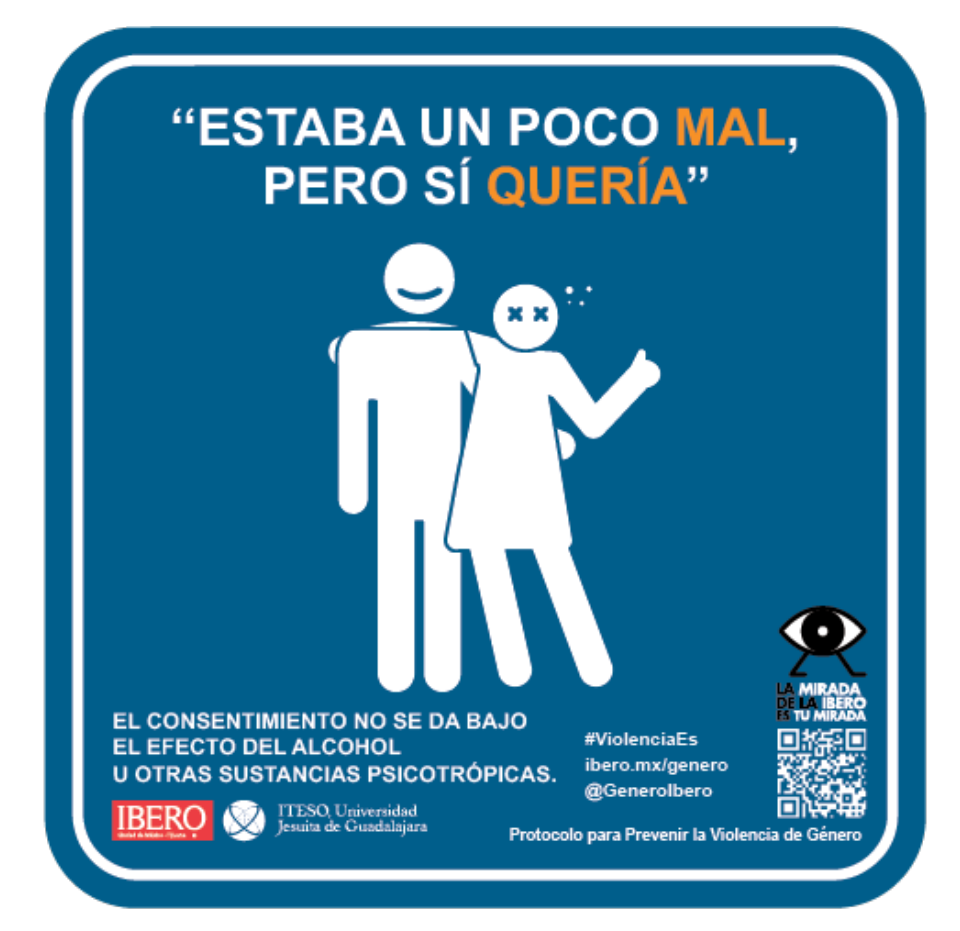

\section{EVALUACIÓN, CONCLUSIONES Y PROPUESTAS DE MEJORA}

Algunos de los resultados de la campaña \#ViolenciaEs durante la primavera de 2019 fueron:

- Se dio a conocer el Protocolo para la Prevención y Atención de la Violencia de Género en la comunidad universitaria, así como la Procuraduría de los Derechos Universitarios y el Programa de Género e Inclusión.

- Se generó conversación en torno a las conductas expuestas en las imágenes, que fueron posibles de seguir por redes sociales y escuchando a la comunidad universitaria.

Se recibió retroalimentación por distintos canales, en la que destacaron algunos puntos:

1. La campaña fue, en mayor medida, bien recibida por la comunidad. Se reconoció que tocó temas que han sido sensibles y que fueron representados de manera creativa. También, que fue una forma de dar voz a las quejas e incomodidades de quienes han sido víctimas de estas conductas en la comunidad y que, aunque no siempre se denuncian, agradecen que se señalen como incorrectas.

2. Parte de la comunidad de egresadas y egresados, así como quienes actualmente forman parte de la universidad, manifestaron un \#Orgullolbero, al considerar que la universidad atiende estos temas y trata de sensibilizar sobre ellos, a través de redes sociales.

3. Existieron quejas en cuanto a los espacios donde se difundieron los gráficos, pues algunas y algunos estudiantes consideraron estos lugares invasivos, sobre todo, los que se encontraban en el interior de las puertas del baño.

4. Quienes expresaron molestia por tocar estos temas, sobre todo en redes sociales, generaron diálogos sobre la manera en que naturalizaban sus conductas "machistas" o "clasistas".

5. Una de las conversaciones en redes que surgió fue la pertinencia de la arquitectura del mensaje. Se argumentó que afirmar la frase y luego explicarla, era una forma poco ética de llamar la atención y que se prestaba a confusiones 
para quienes leían. Ante esta conversación en Facebook y Twitter, algunas respuestas argumentaban que 1) esta campaña no se había hecho con un enfoque de género ni sensibilidad del tema desde su comunicación, 2) o bien que, esta queja era evidencia de lo poco desarrollado de la lectura en la comunidad universitaria, "si no leen las letras chiquitas y eres estudiante de una de las universidades más caras de México, estás tirando tu dinero" fue uno de los mensajes que se leían en las conversaciones.

Como parte del cierre de la campaña, en el Programa de Género e Inclusión notamos que podemos desarrollar herramientas para conocer el impacto de estas propuestas y su incidencia en la percepción de las conductas violentas naturalizadas por la comunidad. Estas herramientas deberían explorar: 1) los imaginarios sobre temas de violencia por razones de género o de clase, 2) la manera en que se leen los mensajes apelando a la experiencia, y si ello tiene connotaciones negativas al asociarse a momentos incómodos, 3) se debe explorar la relación entre estos mensajes y el uso del protocolo difundido. Sin embargo, por motivos de confidencialidad, este último punto es complicado.

Se comenzó a trabajar en el desarrollo de una segunda campaña. Esta vez, se involucraron a representantes de distintas comunidades estudiantiles, así como docentes y administrativos especializados en estos temas dentro de la universidad para recibir retroalimentación antes de su lanzamiento. El periodo previsto para la difusión de esta campaña sería la primavera de 2020 , pero debido al confinamiento, el lanzamiento de la misma se ha pospuesto.

\section{REFERENCIAS BIBLIOGRÁFICAS}

Instituto Nacional de Estadística y Geografía; Instituto Mexicano De La Juventud. (2008). Encuesta Nacional de Violencia en las Relaciones de Noviazgo 2007. México: Instituto Nacional de Estadística y Geografía.

Instituto Nacional de Estadística y Geografía. (2016). Encuesta Nacional sobre la Dinámica de las Relaciones en los Hogares 2016. México: Instituto Nacional de Estadística y Geografía.

Lotman, Yuri. (2000). Universe of the mind: a semiotic theory of culture. Bloomington, Ind.: Indiana University. 


\subsubsection{Estudio piloto sobre el uso de agentes físicos para reducir el dolor en la dismenorrea primaria, en estudiantes da Universidade da Coruña}

Naia Entonado, Zeltia; Quintela del Río, Alejandro; Martínez Bustelo, Sandra; Pérez Caramés, Antía; Ferrín Pereira, Mónica; Bello Rodríguez, Olalla (Universidade da Coruña)

\section{Resumen}

La dismenorrea primaria, dolor menstrual patológico y cíclico en ausencia de patología identificable, es la causa principal de consulta ginecológica en mujeres jóvenes. Las estrategias de autocuidado son las que más frecuentemente suelen utilizar, dentro de un ámbito privado (domiciliario). Los agentes físicos empleados en fisioterapia, con un fin terapéutico, pueden ser utilizados por ellas. Este uso, sin el consejo profesional del fisioterapeuta, puede distar de las recomendaciones científicas, resultando ineficaces o incluso perjudiciales. Se desarrolló un estudio transversal observacional, de cohorte de población adulta, mediante un cuestionario online autoadministrado para visibilizar el dolor menstrual entre las estudiantes universitarias e identificar el uso que realizan de los agentes físicos. Antes de su implementación, se llevó a cabo un estudio piloto, para identificar la viabilidad del estudio final. Los agentes físicos más conocidos son el calor, posturas, masaje, estiramientos, técnicas de relajación, el frío y las corrientes.

Palabras clave: Dysmenorrhea, menstrual pain, physical therapy, physical therapy modalities

\section{INTRODUCCIÓN Y OBJETIVOS}

La dismenorrea es el dolor menstrual patológico, pélvico y recurrente, asociado al ciclo menstrual; su característica principal es el dolor pélvico ${ }^{1-8}$.

La mayoría de las mujeres con DP tienden a normalizar su dolor; este aspecto se relaciona en la literatura con la normalización social del dolor menstrual y su identificación como algo "fisiológico" o relacionado con la fertilidad de la mujer. Los estudios indican que, ante el dolor menstrual, las mujeres no suelen consultar con un profesional sanitario, sino que se lo abordan en mayor medida desde el ámbito privado, domiciliario. Consecuentemente, la DP podría estar infraestimada e infradiagnosticada, desarrollándose menos medidas desde los sistemas sociosanitarios para tratarla ${ }^{7,9}$. Las mujeres que sí consultan su dolor menstrual suelen acudir en primer lugar a un profesional de la medicina, y en menor medida a un fisioterapeuta, aspecto que la literatura relaciona con el desconocimiento de su eficacia para abordar el dolor menstrual. La literatura científica justifica que se deben desarrollar tratamientos efectivos, asequibles, que mejoren la accesibilidad a los recursos sanitarios, y que supongan una alternativa al tratamiento farmacológico, por sus posibles riesgos y porque no todas las mujeres pueden consumir fármacos para la DP ${ }^{9-11}$. La fisioterapia está recomendada para el abordaje de la DP; puede utilizar estrategias de bajo coste y efectivas, que actúen sobre este dolor y sus consecuencias socioeconómicas. Las mujeres con DP suelen emplear estrategias de autocuidado relacionadas con agentes físico, propios de la fisioterapia, pero sin el conocimiento científico sobre su aplicación ${ }^{112,13,22-30,14-21 . ~}$

Este estudio pretende identificar el modo en que las mujeres con DP utilizan los agentes físicos de forma autónoma y visibilizar la dismenorrea como una entidad patológica. La 
información obtenida permitirá diseñar intervenciones terapéuticas más precisas, medidas de educación para la salud, hábitos comportamentales y de estilo de vida, con el fin de mejorar la calidad de vida y los costes socioeconómicos asociados. La literatura sugiere que es preciso que fisioterapeutas asesoren a las mujeres con DP para optimizar el uso de los agentes físicos. Este estudio es necesario para dar difusión al dolor menstrual como algo patológico y para identificar, en la franja de edad de mayor prevalencia y manifestaciones clínicas de mayor intensidad, el modo en que las mujeres jóvenes abordan esta patología. Permitirá definir sus estrategias de autocuidado y será la base sobre la que diseñar estrategias de intervención fisioterápica posteriores que redunden en un beneficio social y una mayor visibilidad del dolor menstrual, como entidad patológica.

Los objetivos de esta investigación son:

- Definir los agentes físicos más conocidos para reducir el dolor menstrual.

- Identificar las regiones de dolor durante la menstruación.

- Averiguar las molestias padecidas durante la menstruación

\section{METODOLOGÍA}

Se realizó un estudio piloto observacional entre las alumnas del grado de Sociología de la Universidade da Coruña, entre 18 y 25 años, mediante un cuestionario online autoadministrado, en la plataforma Microsoft Forms. Las mujeres debían ser nulíparas, tener ciclos menstruales regulares (entre 21 y 35 días), tener una duración del período menstrual máxima de 7 días, dolor menstrual de al menos 3 puntos en la escala Numeric Rating Scale de media en los tres últimos períodos menstruales. Los criterios de exclusión son: mujeres que utilicen anticonceptivos orales o un dispositivo intrauterino (DIU); con cirugía pélvica previa o con patología ginecológica.

Las variables analizadas fueron el conocimiento, uso y dosificación de los agentes físicos para reducir el dolor menstrual, las localizaciones anatómicas en las que se refirió dolor y las molestias durante el período menstrual.

\section{RESULTADOS Y DISCUSIÓN}

De un total de 48 estudiantes, divididos en tres grupos, se obtuvieron 40 respuestas. Los agentes físicos más conocidos, como recursos para reducir el dolor menstrual, fueron: el calor ( $45 \%$ de los estudiantes que respondieron lo conocían), las posturas (35\%), el masaje $(27,5 \%)$, los estiramientos $(17,5 \%)$, las técnicas de relajación $(12,5 \%)$, el frío $(12,5 \%)$ y las corrientes $(5 \%)$.

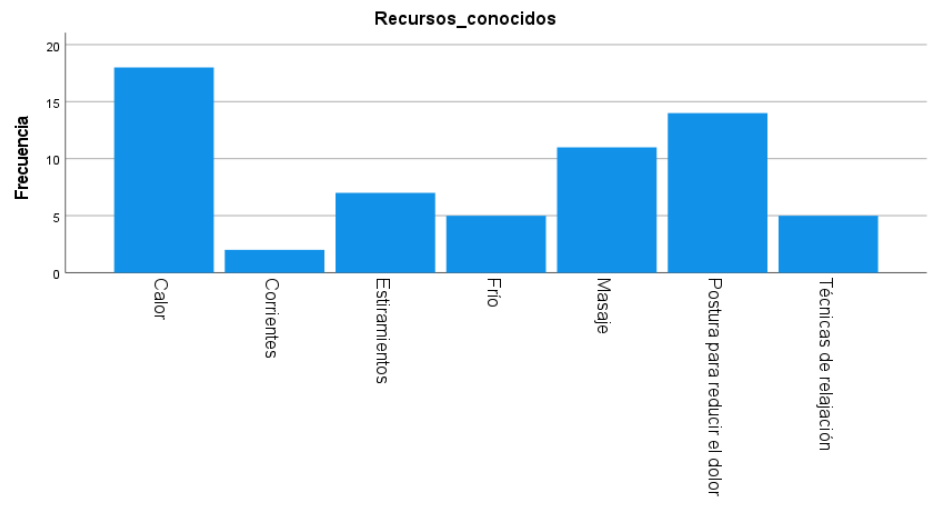


Figura 1: Frecuencia de las respuestas obtenidas para cada uno de los agentes físicos del cuestionario

Las molestias en la última menstruación indicadas fueron: dolor abdominal $(42,5 \%)$, sensibilidad del tejido mamario (35\%), hinchazón (30\%), malestar general (30\%), dolor de cabeza $(27,5 \%)$, dolor lumbar $(27,5 \%)$, diarrea $(17,5 \%)$, náuseas $(15 \%)$, mareos $(12,5 \%)$ y vómitos $(5 \%)$.

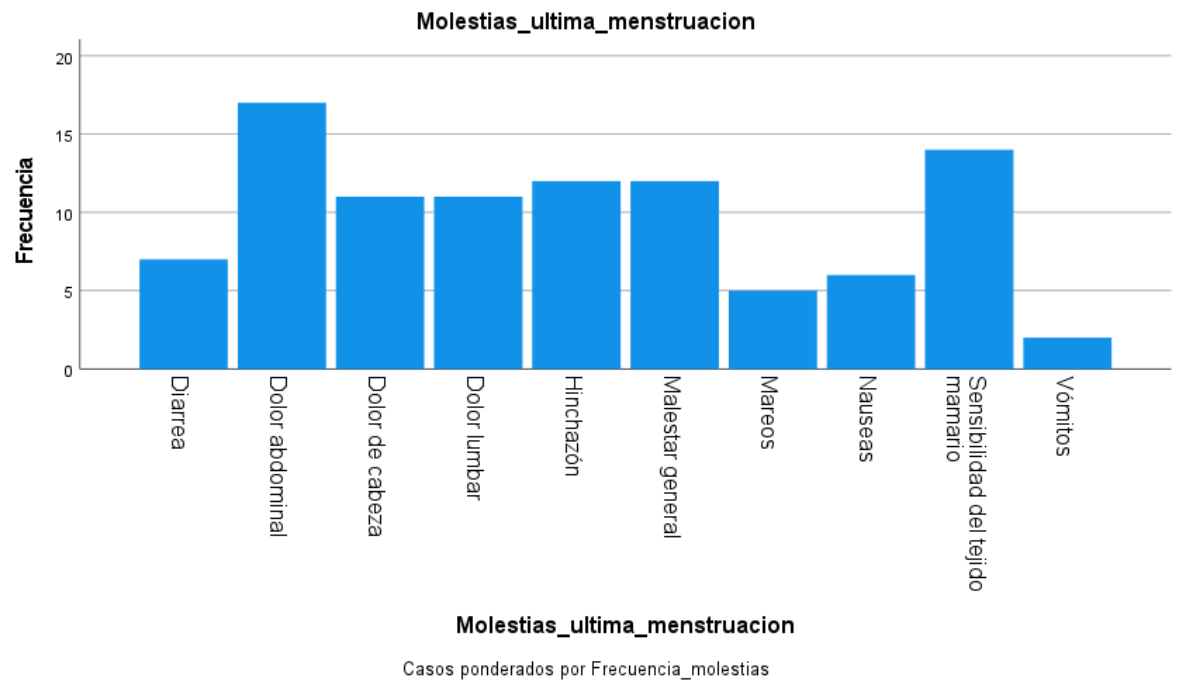

Figura 2: Frecuencia de las respuestas obtenidas para las molestias de la última menstruación

Las zonas de dolor durante la última menstruación identificadas son: abdomen, espalda y zona glútea $(40 \%)$, cráneo $(17,5 \%)$, pecho y hombros (15\%), zona media del brazo $(12,5 \%)$, muslo $(10 \%)$, antebrazo y mano $(5 \%)$, zona media de la pierna $(2,5 \%)$ y pantorrilla $(2,5 \%)$.

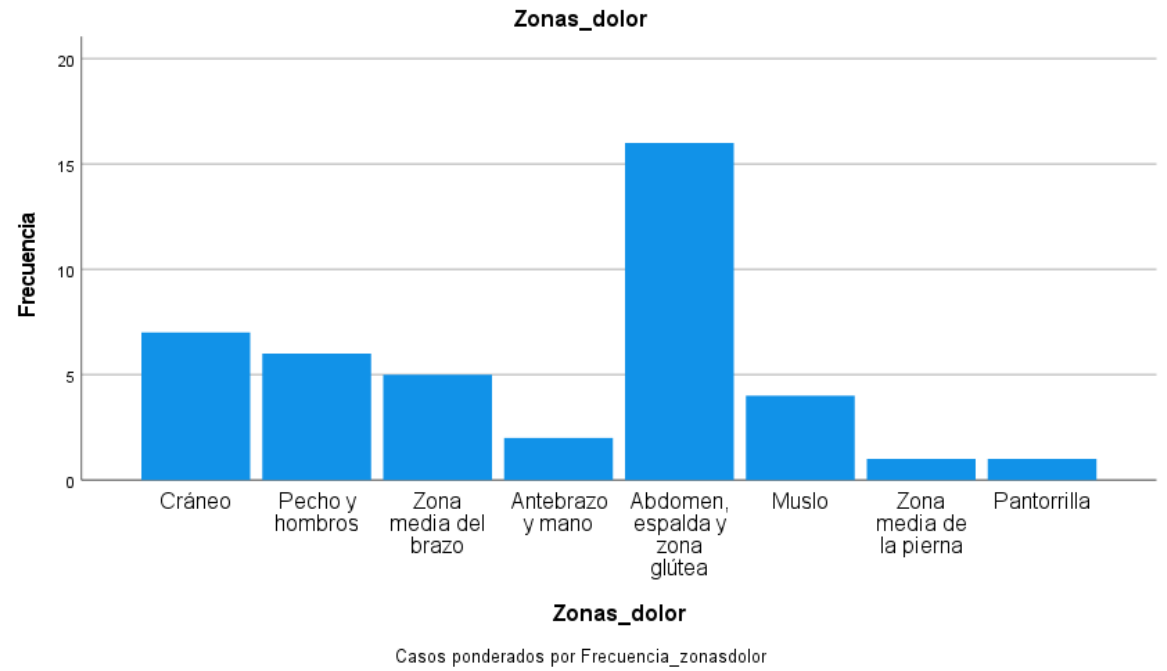

Figura 3: Frecuencia de las respuestas obtenidas para las zonas de dolor menstrual 
Según la literatura, la sintomatología dolorosa puede irradiarse a la espalda o los muslos, y presentarse junto con sensación de debilidad $(70 \%)$, lumbalgia $(56 \%)$, cervicalgia (59\%), náuseas (55\%), vómitos $(24 \%)$, mareos $(28 \%)$, diarrea, fatiga $(67 \%)$, hinchazón o malestar general ${ }^{8,31-37}$. En este estudio se identifica la sensibilidad del tejido mamario como el segundo síntoma más frecuente en el dolor menstrual.

\section{CONCLUSIONES Y LIMITACIONES}

Este estudio facilita la visibilización del dolor menstrual como una entidad patológica. También indica las posibilidades terapéuticas de la fisioterapia para reducirlo. La información obtenida, señala que es preciso seguir investigando para describir los patrones de dolor menstrual, e individualizar posibles abordajes fisioterápicos, adecuados a la población de estudio. En futuras investigaciones cabría difundir entre las mujeres con DP, los beneficios de técnicas fisioterápicas menos conocidas según este estudio, pero con respaldo científico, como el ejercicio terapéutico. Además, podrían establecerse líneas de colaboración con toda la comunidad universitaria, para facilitar la visibilización, la investigación e intervención fisioterápica sobre dolor menstrual, así como la sensibilización sobre el mismo, desde un ámbito multidisciplinar.

\section{REFERENCIAS BIBLIOGRÁFICAS}

[1] Lea RH, Ns GH, Levesque $P, Q c$ R, Lefebvre G, Pinsonneault O. Primary Dysmenhorrea Consensus Guideline. J Obstet Gynaecol Canada 2005:49-57.

[2] Potur DC, Kömürcü N. The effects of local low-dose heat application on dysmenorrhea. J Pediatr Adolesc Gynecol 2014;27:216-21. doi:10.1016/j.jpag.2013.11.003.

[3] Burnett M, Lemyre M. No. 345-Primary Dysmenorrhea Consensus Guideline. J Obstet Gynaecol Canada 2017;39:585-95. doi:10.1016/j.jogc.2016.12.023.

[4] Negrill S, LD Dorn, JB Hillman HB. The measurement of menstrual symtoms. Bone 2014;23:1-7. doi:10.1038/jid.2014.371.

[5] Böttcher B, Gizewski ER, Siedentopf C, Steiger R, Verius M, Riedl D, et al. Behavioural and neural responses to aversive visceral stimuli in women with primary dysmenorrhoea. Eur J Pain (United Kingdom) 2019;23:272-84. doi:10.1002/ejp.1302.

[6] Brinkert W, Dimcevski G, Arendt-Nielsen L, Drewes AM, Wilder-Smith OHG. Dysmenorrhoea is associated with hypersensitivity in the sigmoid colon and rectum. Pain 2007;132:46-51. doi:10.1016/j.pain.2006.12.011.

[7] lacovides S, Avidon I, Baker FC. What we know about primary dysmenorrhea today: A critical review. Hum Reprod Update 2015;21:762-78. doi:10.1093/humupd/dmv039.

[8] Dawood M. Primary Dysmenorrhea. Advances in pathogenesis and management. Obs Gynecol 2006;108:428-41.

[9] Han S, Park KS, Lee H, Zhu X, Lee JM, Suh HS. Transcutaneous electrical nerve stimulation (TENS) for pain control in women with primary dysmenorrhoea. 
Cochrane Database Syst Rev 2019;2019. doi:10.1002/14651858.CD013331.

[10] Latthe P, Latthe M, Say L, Gülmezoglu M, Khan KS. WHO systematic review of prevalence of chronic pelvic pain: A neglected reproductive health morbidity. BMC Public Health 2006;6:1-7. doi:10.1186/1471-2458-6-177.

[11] Akiyama S, Tanaka E, Cristeau O, Onishi Y, Osuga Y. Evaluation of the treatment patterns and economic burden of dysmenorrhea in japanese women, using a claims database. Clin Outcomes Res 2017;9:295-306. doi:10.2147/CEOR.S127760.

[12] Carroquino-Garcia $P$, Jiménez-Rejano JJ, Medrano-Sanchez E, De La CasaAlmeida M, Diaz-Mohedo E, Suarez-Serrano C. Therapeutic Exercise in the Treatment of Primary Dysmenorrhea: A Systematic Review and Meta-Analysis. Phys Ther 2019;99:1371-80. doi:10.1093/ptj/pzz101.

[13] Kannan P, Claydon LS. Some physiotherapy treatments may relieve menstrual pain in women with primary dysmenorrhea: A systematic review. J Physiother 2014;60:13-21. doi:10.1016/j.jphys.2013.12.003.

[14] Kannan P, Claydon LS, Miller D, Chapple CM. Vigorous exercises in the management of primary dysmenorrhea: A feasibility study. Disabil Rehabil 2015;37:1334-9. doi:10.3109/09638288.2014.962108.

[15] Armour M, Ee CC, Naidoo D, Ayati Z, Chalmers KJ, Steel KA, et al. Exercise for dysmenorrhoea. Cochrane Database Syst Rev 2019;2019. doi:10.1002/14651858.CD004142.pub4.

[16] Azima S, Bakhshayesh HR, Kaviani M, Abbasnia K, Sayadi M. Comparison of the Effect of Massage Therapy and Isometric Exercises on Primary Dysmenorrhea: A Randomized Controlled Clinical Trial. J Pediatr Adolesc Gynecol 2015;28:48691. doi:10.1016/j.jpag.2015.02.003.

[17] Matthewman G, Lee A, Kaur JG, Daley AJ. Physical activity for primary dysmenorrhea: a systematic review and meta-analysis of randomized controlled trials. Am J Obstet Gynecol 2018;219:255.e1-255.e20. doi:10.1016/j.ajog.2018.04.001.

[18] Ortiz MI, Cortés-Márquez SK, Romero-Quezada LC, Murguía-Cánovas G, Jaramillo-Díaz AP. Effect of a physiotherapy program in women with primary dysmenorrhea. Eur J Obstet Gynecol Reprod Biol 2015;194:24-9. doi:10.1016/j.ejogrb.2015.08.008.

[19] Rodríguez-Muñoz PM, Carmona-Torres JM, Rodríguez-Borrego MA. Influence of tobacco, alcohol consumption, eating habits and physical activity in nursing students. Rev Lat Am Enfermagem 2020;28. doi:10.1590/1518-8345.3198.3230.

[20] Heidarimoghadam R, Abdolmaleki E, Kazemi F, Masoumi SZ, Khodakarami B, Mohammadi Y. The effect of exercise plan based on FITT protocol on primary dysmenorrhea in medical students: A clinical trial study. J Res Health Sci 2019;19.

[21] Barcikowska Z, Rajkowska-Labon E, Grzybowska ME, Hansdorfer-Korzon R, Zorena K. Inflammatory markers in dysmenorrhea and therapeutic options. Int J Environ Res Public Health 2020;17:1-14. doi:10.3390/ijerph17041191.

[22] Lauretti GR, Oliveira R, Parada F, Mattos AL. The New Portable Transcutaneous Electrical Nerve Stimulation Device Was Efficacious in the Control of Primary Dysmenorrhea Cramp Pain. Neuromodulation 2015;18:522-6. doi:10.1111/ner.12269.

[23] Igwea SE, Tabansi-Ochuogu CS, Abaraogu UO. TENS and heat therapy for pain relief and quality of life improvement in individuals with primary dysmenorrhea: $A$ 
systematic review. Complement Ther Clin Pract 2016;24:86-91. doi:10.1016/j.ctcp.2016.05.001.

[24] Perez Machado AF, Perracini MR, Cruz Saraiva de Morais A da, da Silva BO, Driusso $P$, Liebano RE. Microwave diathermy and transcutaneous electrical nerve stimulation effects in primary dysmenorrhea: clinical trial protocol. Pain Manag 2017;7:359-66. doi:10.2217/pmt-2017-0021.

[25] Machado AFP, Perracini MR, Rampazo ÉP, Driusso P, Liebano RE. Effects of thermotherapy and transcutaneous electrical nerve stimulation on patients with primary dysmenorrhea: A randomized, placebo-controlled, double-blind clinical trial. Complement Ther Med 2019;47:102188. doi:10.1016/j.ctim.2019.08.022.

[26] Bai HY, Bai HY, Yang ZQ. Effect of transcutaneous electrical nerve stimulation therapy for the treatment of primary dysmenorrheal. Med (United States) 2017;96:2015-8. doi:10.1097/MD.0000000000007959.

[27] Ruffini N, D'Alessandro G, Cardinali L, Frondaroli F, Cerritelli F. Osteopathic manipulative treatment in gynecology and obstetrics: A systematic review. Complement Ther Med 2016;26:72-8. doi:10.1016/j.ctim.2016.03.005.

[28] Özgül S, Üzelpasaci E, Orhan C, Baran E, Beksaç MS, Akbayrak T. Short-term effects of connective tissue manipulation in women with primary dysmenorrhea: $A$ randomized controlled trial. Complement Ther Clin Pract 2018;33:1-6. doi:10.1016/j.ctcp.2018.07.007.

[29] Abaraogu UO, Igwe SE, Tabansi-Ochiogu CS, Duru DO. A Systematic Review and Meta-Analysis of the Efficacy of Manipulative Therapy in Women with Primary Dysmenorrhea. Explore 2017;13:386-92. doi:10.1016/j.explore.2017.08.001.

[30] Barassi G, Bellomo RG, Porreca A, Di Felice PA, Prosperi L SR. Somato-Visceral Effects in the Treatment of Dysmenorrhea: Neuromuscular Manual Therapy and Standard Pharmacological Treatment. J Altern Complement Med 2018;24:291-9. doi:10.1089/acm.2017.0182.

[31] Harlow SD, Campbell OMR. Epidemiology of menstrual disorders in developing countries: A systematic review. BJOG An Int J Obstet Gynaecol 2004;111:6-16. doi:10.1111/j.1471-0528.2004.00012.x.

[32] Proctor M, Murphy PA, Pattison HM, Suckling JA, Farquhar C. Behavioural interventions for dysmenorrhoea. Cochrane Database Syst Rev 2007. doi:10.1002/14651858.cd002248.pub3.

[33] Osayande, AS MS. Diagnosis and initial management of dysmenorrhea. Br J Hosp Med 2017;78:341-6. doi:10.12968/hmed.2017.78.8.C114.

[34] Ryan SA. The Treatment of Dysmenorrhea. Pediatr Clin North Am 2017;64:331-42. doi:10.1016/j.pcl.2016.11.004.

[35] Abu Helwa HA, Mitaeb AA, Al-Hamshri S, Sweileh WM. Prevalence of dysmenorrhea and predictors of its pain intensity among Palestinian female university students. BMC Womens Health 2018;18:1-11. doi:10.1186/s12905018-0516-1.

[36] Chen L, Tang L, Guo S, Kaminga AC, Xu H. Primary dysmenorrhea and self-care strategies among Chinese college girls: A cross-sectional study. BMJ Open 2019;9:1-9. doi:10.1136/bmjopen-2018-026813.

[37] Kamel DM, Tantawy SA, Abdelsamea GA. Experience of dysmenorrhea among a group of physical therapy students from Cairo University: An exploratory study. J Pain Res 2017;10:1079-85. doi:10.2147/JPR.S132544. 


\subsubsection{Evitemos la discriminación machista en el trabajo de}

campo

Zaida Ortega Diago (Universidad de Granada, España); Laura Contreras Peinado

(Universidade Federal de Mato Grosso do Sul, Brasil); Ana López Ballesteros (BC3Basque Centre of Climate Change, España); Marga L. Rivas (Universidad de Almería, España)

\section{Resumen}

Está demostrado que una ciencia más inclusiva produce mejores resultados en la participación y desarrollo de las mujeres en las carreras científicas y en la sociedad en general. En el ámbito universitario enfocado en el medio ambiente, las excursiones y salidas de campo son una parte esencial para el desarrollo y la puesta en práctica de las habilidades técnicas, y para una mejora notable de la empleabilidad del alumnado. No obstante, este desarrollo de habilidades prácticas que conlleva el trabajo de campo no es igual para hombres y mujeres. En esta ponencia identificamos y discutimos los tres tipos principales de conductas machistas que impregnan las salidas de campo: (1) el reparto desigual de tareas, (2) la socialización diferenciada y (3) los comentarios sexistas, el acoso y abuso sexual. Nuestro objetivo es fomentar la toma de conciencia del profesorado universitario responsable de salidas de campo, aportando algunas recomendaciones para eliminar la discriminación machista y continuar avanzando hacia la igualdad entre hombres y mujeres dentro de las carreras científicas STEM (Ciencia, Tecnología, Ingeniería y Matemáticas).

Palabras clave: trabajo de campo; excursiones; ecología; biología; medio ambiente.

\section{INTRODUCCIÓN Y OBJETIVOS}

El trabajo de campo es una parte fundamental de la educación en estudios universitarios relacionados con el medio ambiente, ya que allí se transmiten habilidades que serán cruciales para las y los estudiantes a la hora de encontrar empleo o trazar una carrera investigadora (Maskall y Strokes, 2008; Peasland et al., 2019). Además, en las salidas de campo se produce una convivencia cercana que promueve la colaboración y el networking, en un ambiente que no siempre está exento de los principales factores que resultan en relaciones desiguales de poder: sesgo inconsciente, discriminación, actitudes y comentarios sexistas, llegando al abuso sexual en los casos más extremos (Vila-Concejo et al., 2018).

Está demostrado que la calidad y la capacidad innovadora de la ciencia aumentan cuando ésta es más inclusiva (Hofstra, 2020). Para lograr una ciencia inclusiva, tenemos que continuar trabajando contra todas las formas - interrelacionadas - de discriminación a colectivos tradicionalmente poco representados en las carreras STEM (Ciencia, Tecnología, Ingeniería y Matemáticas, del inglés Science, Technology, Egeneering and Mathematics) entre las cuales la discriminación machista es una de las principales problemáticas (Diele-Viegas et al., 2021). Las principales manifestaciones de la discriminación machista en la ciencia son la falta de referentes, el sesgo inconsciente (por el cual las mujeres somos percibidas como menos competentes, mientras que a los hombres se les valora mejor en publicaciones científicas, consiguiendo más fondos y contratos de investigación), el abuso sexual y los problemas derivados de la maternidad 
y el reparto desigual del trabajo doméstico o trabajo de cuidados. A pesar del gran esfuerzo que se está realizando en los últimos años en pro de la igualdad de género, las cifras no son halagüeñas para las científicas en España, mostrando un progreso lento e incluso un estancamiento en varios indicadores (Ministerio de Ciencia e Innovación, 2021). Por ello, es necesario profundizar en la detección de los patrones de discriminación sexista y proponer mecanismos para evitarlos en todos los ámbitos de la carrera científica, ya sea como estudiante, investigador/a, profesor/a, jefe/a de departamento, decano/a, rector/a, etc.

En esta ponencia nos centraremos en aportar literatura, ejemplos propios y argumentos para ilustrar las discriminaciones machistas en las salidas de campo y elaboraremos una guía de recomendaciones para evitar que se produzcan. Con ello, pretendemos mejorar la concienciación sobre esta problemática por parte del profesorado y alumnado, con el objetivo de lograr unas experiencias de campo seguras e igualitarias en las que todas y todos salgamos ganando.

\section{CONTEXTUALIZACIÓN}

En primer lugar, basándonos en la literatura previa y en nuestras experiencias personales como alumnas y profesoras de diversas disciplinas con salidas de campo en numerosas universidades españolas y extranjeras (ej. Universidad de Salamanca, Universidad de Granada, Universidad Federal de Mato Grosso do Sul, Universidad de La Laguna, University of Venda), identificaremos y discutiremos los patrones generales de discriminación machista asociados a las salidas de campo. Después, realizaremos recomendaciones - destinadas principalmente al profesorado universitario que participa en salidas de campo - que ayuden a tomar consciencia de esas discriminaciones, lo que permita reducirlas o eliminarlas por completo.

\section{DISEÑO Y DESARROLLO}

Dentro del ambiente tan estimulante como socialmente complejo que se produce en las salidas de campo, es habitual que se refuercen los roles de género, de forma que se acaba produciendo una sutil - pero sustancial y constante - discriminación hacia las alumnas o colegas investigadoras por parte de profesores o compañeros. Esta discriminación suele manifestarse en algunos puntos clave: (1) el reparto desigual de tareas, (2) la socialización diferencial, (3) los comentarios sexistas y conductas sexuales inapropiadas.

En primer lugar, el reparto desigual de tareas se justifica habitualmente por supuestas diferencias en la fuerza física (ej. los alumnos cargan el material mientras que las alumnas lo organizan), en habilidades técnicas (ej. los alumnos conducen los coches; las alumnas toman nota; las alumnas limpian el material), o incluso de asignación de roles (ej. los alumnos capturan los animales o manejan instrumentación más compleja, ej. drones, porque es una actividad "más masculina"). La importancia que tiene este punto es que, aparte de la propia desigualdad y falta de libre elección en las tareas, el alumnado acaba entrenando siempre las mismas habilidades. Así, los alumnos entrenan más las actividades físicas, la manipulación de animales y/o instrumentos, o la conducción de vehículos, por ejemplo, mientras que las alumnas practican en mayor grado la anotación de datos, limpieza del material, etc. En el caso en el que esta 
discriminación sea fuertemente sesgada o constante, las alumnas no practicarían habilidades de campo de alto nivel de especialización necesarias para su desarrollo y futuro profesional. Esto forma una espiral en la que quien ha practicado menos una habilidad (ej. la manipulación de los animales de estudio, dispositivos, etc.) quedará relegada a otras actividades en futuras salidas, en favor de quien tiene más experiencia en tales habilidades técnicas (justificándose el nuevo reparto desigual de tareas por el ahorro de tiempo que conlleva la mayor experiencia en el desarrollo de la actividad).

En cuanto a la socialización diferenciada, es habitual que las alumnas sean excluidas de los momentos de socialización, tan importantes para el desarrollo de relaciones laborales futuras (networking), ya que las alumnas habitualmente quedan relegadas a la logística de la propia actividad (preparación de comida, limpieza, etc.); lo que supone un factor limitante en el desarrollo de una red de contactos que contribuya positivamente a las relaciones sociales y laborales futuras. La ausencia de las alumnas en estos momentos de asueto les aleja de colaboraciones, toma de decisiones y participación y/o liderazgo en futuros proyectos, lo que limita el aprendizaje de capacidades esenciales necesarias en el ámbito científico, y posibles futuras oportunidades laborales.

Estas dos formas sutiles pero continuas de discriminación machista, han sido identificadas y discutidas previamente en la literatura internacional (Vila-Concejo et al., 2018). Además, nuestra experiencia en más de 30 salidas de campo de diferentes asignaturas relacionadas con el medio ambiente corrobora estos patrones de discriminación, presentes, en mayor o menor grado, en absolutamente todas las salidas de campo mixtas a las que hemos asistido. Dado que se basa en el sesgo inconsciente, una posible solución es la toma de conciencia por parte del profesorado, acompañada de la elaboración de pautas explícitas de reparto de tareas.

Además, el sesgo inconsciente lleva asociado, como en todos los ámbitos, conductas continuas de mansplainning y manterrupting así como a actitudes paternalistas y condescendientes que invisibilizan las ideas y minan la autoestima y paciencia de las mujeres (Solnit, 2012).

Por último, en las prácticas de campo es habitual que se realicen comentarios sexistas sobre la vestimenta de las compañeras, su aspecto físico etc., incluso que se llegue a casos de acoso y/o abuso sexual. Obviamente, el efecto de esta faceta de discriminación machista es la intimidación de la alumna, haciéndola sentir que no forma parte por igual de la comunidad o llegando a traumatizarla en los casos más extremos (Giles et al., 2020; Schneider, 2020). Esta forma de violencia, desde los casos más leves, genera un ambiente hostil que perjudica a la salud mental de las mujeres, fomentando fenómenos como el síndrome de la impostora o el burnout, e incluso desencadenando ansiedad o enfermedades mentales más graves (Jaremka et al., 2020). Por todo lo anteriormente citado, una consecuencia directa de este patrón de discriminación machista sería la desmotivación o desinterés de esas alumnas por la carrera científica, llegando al abandono de la carrera en los casos más extremos.

\section{EVALUACIÓN, CONCLUSIONES Y PROPUESTAS DE MEJORA}

Como propuesta de mejora, hemos desarrollado una serie de recomendaciones para evitar la discriminación machista en las salidas de campo. Podemos establecer dos niveles de actuación complementarios para prevenir y atajar la discriminación machista en las salidas de campo: (1) nivel institucional (del centro o universidad en cuestión) y (2) nivel individual (del profesorado). Ambos son necesarios, y se potenciarían para 
generar y consolidar una cultura universitaria que promueva las relaciones de respeto e igualdad entre profesores/as y alumnos/as en el ámbito de las salidas de campo.

\section{Reparto de tareas}

El reparto desigual de tareas normalmente se produce debido al sesgo inconsciente. Por lo tanto, una forma simple y eficaz de evitarlo a nivel individual (del profesorado) es tomar consciencia del reparto de tareas, por ejemplo, elaborando ese reparto a priori, de forma que el profesor o profesora haga un trabajo previo para elaborar la lista de reparto de una manera aleatoria, evitando la influencia de estereotipos y roles de género en esa decisión. Otra alternativa, si se debe realizar el reparto en el momento, es hacerlo de manera aleatoria, alternando sexos.

A nivel institucional, se pueden realizar varias acciones para disminuir el sesgo inconsciente. Por un lado, se ha propuesto la creación de certificaciones de inclusión a la diversidad para programas de grado o postgrado que están diseñados atendiendo a una educación no sexista (y que disminuya también otras formas de discriminación; Diele-Viegas et al., 2021). Además, se sabe que la formación del profesorado en materia de igualdad es muy eficaz, de forma que un simple seminario de 2.5 horas es capaz de disminuir significativamente el sesgo inconsciente de profesores y profesoras (Carmes et al., 2015). Por último, incluir cuestiones relacionadas a la discriminación machista en evaluaciones de las actividades docentes, ayudaría a identificar los problemas específicos de cada actividad y, así, diseñar cómo eliminarlos.

\section{Socialización}

La socialización diferenciada se debe también a roles que se crean por el sesgo inconsciente. Por lo tanto, a nivel institucional, una solución es concienciar sobre la importancia de participación de las alumnas en los momentos de socialización, lo que garantice que todas las actividades de socialización que se realizan en las salidas de campo sean igualitarias. En primer lugar, es importante y necesario que exista igualdad de género en el profesorado, no sólo en participación equitativa de estas actividades sino también en formación en materia de igualdad. Si el profesorado tiene dicha formación, permitirá que sea más fácil que identifiquen sus sesgos y los minimicen. Además, proponemos diseñar las actividades de descanso y socialización con anterioridad a la salida de campo, pensando en crear experiencias lo más inclusivas posible.

\section{Comentarios sexistas y abuso sexual}

Para los casos más sutiles, proponemos, al igual que para un reparto igualitario de tareas y evitar la socialización diferenciada, formar al profesorado en materia de igualdad, para que tome conciencia de su sesgo y adapte su conducta de manera apropiada. En este caso, sería prioritario focalizar el esfuerzo en el profesorado y alumnado masculino, poniendo de manifiesto qué comentarios o conductas son inapropiadas, lo que genere empatía entre compañeros y compañeras, y les permita identificar los sesgos y evitarlos voluntariamente y conscientemente. Además, proponemos adoptar una política de tolerancia cero desde las instituciones, y promover que cualquier conducta de abuso sexual o acoso sea denunciada en el correspondiente departamento o institución competente. 


\section{REFERENCIAS BIBLIOGRÁFICAS}

Carnes, M., Devine, P. G., Manwell, L. B., Byars-Winston, A., Fine, E., Ford, C. E., ... \& Sheridan, J. (2015). Effect of an intervention to break the gender bias habit for faculty at one institution: a cluster randomized, controlled trial. Academic Medicine:Journal of the Association of American Medical Colleges, 90(2), 221. doi: 10.1097/ACM.0000000000000552

Diele-Viegas, L. M., Cordeiro, T. E. F., Emmerich, T., Hipólito, J., Queiroz-Souza, C., Sousa, E., ... \& Leite, L. (2021). Potential solutions for discrimination in STEM. Nature Human Behaviour, 1-3. https://doi.org/10.1038/s41562-021-01104-w

Giles, S., Jackson, C., \& Stephen, N. (2020). Barriers to fieldwork in undergraduate geoscience degrees. Nature Reviews Earth \& Environment, 1(2), 77-78. https://doi.org/10.1038/s43017-020-0022-5

Hofstra, B., Kulkarni, V. V., Galvez, S. M. N., He, B., Jurafsky, D., \& McFarland, D. A. (2020). The diversity-innovation paradox in science. Proceedings of the National Academy of Sciences, 117(17), 9284-9291. https://doi.org/10.1073/pnas.1915378117

Jaremka, L. M., Ackerman, J. M., Gawronski, B., Rule, N. O., Sweeny, K., Tropp, L. R., ... \& Vick, S. B. (2020). Common academic experiences no one talks about: Repeated rejection, impostor syndrome, and burnout. Perspectives on Psychological Science, 15(3), 519-543. https://doi.org/10.1177/1745691619898848

Maskall, J., \& Stokes, A. (2008). Designing effective fieldwork for the environmental and natural sciences. Plymouth, UK: Higher Education Academy Subject Centre for Geography, Earth and Environmental Sciences.

Ministerio de Ciencia e Innovación, Gobierno de España (2021). Científicas en Cifras. Observatorio Mujeres, Ciencia e Innovación. https://www.ciencia.gob.es/stfls/MICINN/Ministerio/FICHEROS/Cientificas_en_ Cifras_2021.pdf

Peasland, E. L., Henri, D. C., Morrell, L. J., \& Scott, G. W. (2019). The influence of fieldwork design on student perceptions of skills development during field courses. International Journal of Science Education, 41(17), 2369-2388. https://doi.org/10.1080/09500693.2019.1679906

Schneider, L. T. (2020). Sexual violence during research: How the unpredictability of fieldwork and the right to risk collide with academic bureaucracy and expectations. Critique of Anthropology, 40(2), 173-193. https://doi.org/10.1177/0308275X20917272

Solnit, R. (2012). Men still explain things to me. The Nation, 20. https://www.thenation.com/article/archive/men-still-explain-things-me/.

Vila-Concejo, A., Gallop, S. L., Hamylton, S. M., Esteves, L. S., Bryan, K. R., DelgadoFernandez, I., ... \& Splinter, K. (2018). Steps to improve gender diversity in coastal geoscience and engineering. Palgrave Communications, 4(1), 1-9.

https://doi.org/10.1057/s41599-018-0154-0 


\subsubsection{Contalles $i$ diàlegs, el storytelling y la tertulia para}

cuestionar la representación de las mujeres y otros colectivos sociales en los medios de comunicación

Laia Pitarch Centelles (IES Francesc Ribalta, España); Lucía García Pitarch (IES Francesc Ribalta, España); Begoña Marqués Ribés (IES Francesc Ribalta, España); María Tena Moya (IES Francesc Ribalta, España)

\section{Resumen}

Contalles i diàlegs se ha desarrollado en el módulo de Información y comunicación con perspectiva de género del CFGS de Promoción de la Igualdad de Género. Con ello, se propone el diseño, la implementación, dinamización y evaluación de un storytelling y una tertulia por parte del alumnado basándose en un artículo asignado. En el storytelling se presentan las ideas del texto a través de la exposición de una historia y en la tertulia se estimula un debate para ampliar los conocimientos. Por último, se realiza una evaluación participativa de la actividad. Los temas que abordan los escritos inciden en el cuestionamiento de la representación de las mujeres y otros colectivos sociales en los medios de comunicación desde una perspectiva feminista e interseccional. En consecuencia, se fomentan las competencias personales, profesionales y sociales de las futuras promotoras para la igualdad de género y se promueve su empoderamiento tanto individual como colectivo.

Palabras clave: storytelling; tertulia; comunicación; interseccionalidad; feminismos.

\section{INTRODUCCIÓN Y OBJETIVOS}

Si el lenguaje estructura el mundo, el mundo también estructura y da forma al lenguaje. Las historias orales han sido narradas y preservadas generación tras generación por las mujeres. En relación con las tertulias, desde el siglo XVI hay evidencias de salones literarios de mujeres en los que se leían textos, se debatía sobre política y se cuestionaban ideas filosóficas (Auffret, 2020). Hoy en día, estas dos técnicas están muy presentes en los medios de comunicación. Por un lado, se cuentan historias para transmitir ideas, representar unos valores o vender un producto mediante la publicidad, las películas o las series. Por otro, las tertulias y los debates sobre temas de actualidad son uno de los formatos más utilizados en televisión y radio.

El lenguaje tanto oral, escrito, corporal como simbólico, tiene un papel clave en la transmisión de creencias y pensamientos. Desde Contalles i diàlegs se han trabajado todos ellos a través del storytelling y las tertulias que diseña, implementa, dinamiza y evalúa el alumnado en el módulo de Información y comunicación con perspectiva de género del CFGS de Promoción de la Igualdad de Género. Con todo, se pretende dar herramientas al estudiantado para analizar la representación de las mujeres y otros colectivos sociales en los medios de comunicación a través del texto que se presenta en el storytelling y la tertulia.

\section{CONTEXTUALIZACIÓN}

Contalles i diàlegs se ha realizado en el IES Francesc Ribalta de Castelló en el CFGS de Promoción de la Igualdad de Género. Concretamente se ha llevado a cabo en el 
módulo de segundo curso, Información y comunicación con perspectiva de género. Tal y como se recoge en el Decreto 43/2017, este tiene una carga horaria de 180 horas, distribuidas en 2 trimestres, lo cual corresponde a 8 horas semanales.

Respecto a las características del alumnado, se compone de 15 personas [14 mujeres (93\%) y 1 hombre (7\%)], siendo un grupo muy feminizado. Las edades se comprenden entre los 20 y los 51 años, situándose la mayoría entre los 20 y 26 años. Algunas de ellas, compaginan los estudios con el trabajo remunerado y/o de cuidados. En relación con las diferentes nacionalidades presentes en el aula, encontramos una alumna venezolana.

Tal como se recoge en los resultados de aprendizaje del módulo de Información y comunicación con perspectiva de género establecidos en el Real Decreto 779/2013, el alumnado debe ser capaz de:

1. Caracterizar los procesos de comunicación desde la perspectiva de género, analizando las relaciones entre el pensamiento y el lenguaje y su papel en la discriminación por razón de sexo.

2. Detectar situaciones de discriminación por razón de género en los procesos de comunicación e información, analizando el contenido del mensaje, así como el lenguaje verbal e icónico utilizado.

3. Diseñar acciones de comunicación e información desde una perspectiva de género, seleccionando recursos expresivos y lingüísticos no sexistas ni discriminatorios y estrategias promotoras de cambios en los estilos comunicativos.

4. Implementar actuaciones de comunicación e información, seleccionando y elaborando materiales no sexistas ni discriminatorios.

5. Evaluar las actuaciones de comunicación e información desde la perspectiva de género, valorando la importancia de la misma para garantizar la calidad en los procesos de comunicación e información.

Para consolidar dichos resultados de aprendizaje, es imprescindible tener en cuenta las aportaciones que se hacen desde las pedagogías feministas y el aprendizaje dialógico.

Por lo que respecta a las pedagogías feministas, Martínez Marín (2016) considera que son sinónimo de multidimensionalidad, pluralidad, democracia y crítica social, pues implica la superación de una educación entendida como transmisora y reproductora de desigualdades. Para ello se recogen textos que promuevan una perspectiva feminista e interseccional, así como esta mirada debe estar presente en el desarrollo de la actividad de forma transversal.

En relación con el aprendizaje dialógico, mediante la realización del storytelling y la tertulia se fomentan valores positivos como la diversidad o la solidaridad entre el grupo. Además, se busca crear un diálogo igualitario entre el alumnado en el que se respeten todas las opiniones desde la convicción que todas las personas tienen inteligencia cultural. No menos importante es la contribución a la mejora de la expresión y comprensión oral y escrita del estudiantado. Por último, se insiste en que la lectura, el 
diálogo y la reflexión pueden contribuir a romper con los estereotipos de género y las normas sociales (Aubert, Flecha, García, Flecha y Racionero, 2008).

\section{DISEÑO Y DESARROLLO}

Contalles $i$ diàlegs se presenta en las primeras semanas del curso y se organiza el calendario según el número de alumnado, realizándose la actividad una vez por semana. El material que se utiliza son dos dosieres con indicaciones para desarrollar la actividad. Por un lado, "Pautas para la realización" en el que se indica: las tablas de los temas, en las cuales se incluye el título del artículo y referencias desde las artes, el activismo y los productos audiovisuales; la metodología de la actividad; y las recomendaciones para preparar el storytelling. Por otro lado, "Dosier de lecturas" en el que se incorporan todos los textos. Cabe señalar que cada escrito es un fragmento relevante de un artículo académico.

Cada tema busca analizar la representación de las mujeres y diversos colectivos sociales en los medios de comunicación para contribuir a un análisis feminista e interseccional. En consecuencia, los temas que se han planteado desde los artículos son: el feminismo mainstream, la violencia de género, las agresiones sexuales, la perspectiva decolonial, el ecofeminismo, mujeres y diversidad funcional, maternidades, mujeres rurales, mujeres deportistas, prostitución, pornografía, intersexualidad, lesbianismo, transexualidad, homosexualidad y masculinidades alternativas.

En los citados dosieres se recoge tanto el trabajo de intervención como el de documentación. Respecto a la intervención, cada alumna o alumno realiza la dinamización del storytelling y la tertulia basándose en el artículo escogido. Por lo que respecta a la documentación, el estudiantado realiza un dosier individual en el que se recoge todo lo expuesto en el aula, se amplía la información sobre el tema y se incorporan las reflexiones personales. En definitiva, el alumnado realiza el storytelling y dinamiza su tertulia en el aula y debe documentar e indagar sobre el resto de las tertulias en su propio dosier de la actividad.

La dinamización consiste en una tarea individual, por tanto, en la clase se establecen dos roles: la persona dinamizadora y el resto del alumnado. La persona dinamizadora se encarga de desarrollar el storytelling y la tertulia y llevar a cabo toda la sesión de manera individual y autónoma. El resto del estudiantado participa de las propuestas de la persona dinamizadora, coge apuntes, contribuye al debate en la tertulia y evalúa la actividad. El papel de la docente consiste en la observación y la documentación de todo lo que está sucediendo en el aula. Ayuda a preparar el aula, realiza una breve presentación, da indicaciones sobre los tiempos, pero interviene lo mínimo posible.

La dinamización en el aula se guía por la siguiente estructura: storytelling de 30 a 45 minutos; la tertulia, aproximadamente unos 45 minutos; y la evaluación, que consiste en unos 10 minutos. Los tiempos de las diversas acciones se alargan o acortan en función de la propuesta de la persona dinamizadora, el interés y la implicación del resto del alumnado.

En relación con el storytelling, se presentan las ideas, críticas y conceptos que se recogen en el artículo de una forma más creativa. Storytelling hace referencia al arte de 
diseñar, contar y adaptar historias. El alumnado se expone a narrar y teatralizar una historia en la que enlazar todo el argumentario. Para que el relato tenga contenido y se muestre de una manera interesante, se debe analizar muy bien el artículo e investigar sobre el tema. Desde esta idea tan abierta han surgido muchas formas de abordar el storytelling: con monólogos; juegos; exposiciones; dinámicas; viajes; historias de vida; programas de televisión; etc. Todos los relatos parten de un personaje con el que hilar todo el discurso y las historias siguen la clásica estructura de introducción, nudo y desenlace. Sin embargo, en muchas ocasiones el conflicto que presentan se deja en abierto para cuestionarlo en la tertulia posterior. Con todo, se pretende conocer con más profundidad el tema a través de una historia que emocione y/o sorprenda. De tal modo que estimula la formulación de preguntas e ideas para la tertulia, problematiza el tema desde otro punto de vista y amplía la información.

Tras esta primera parte, la segunda consiste en realizar la tertulia. Por ello, la persona dinamizadora se encarga de hacer preguntas para alentar el debate e incorporar técnicas para que todo el alumnado participe. En este caso, el peso recae en el resto del estudiantado, ya que la persona dinamizadora debe intervenir solo cuando sea necesario. Su función es plantear preguntas relevantes, dar turnos de palabras y garantizar que participen todas las personas.

En último lugar, se realiza la evaluación de la tertulia, en la cual se debe utilizar una herramienta de evaluación participativa. Se utilizan algunas técnicas como el felicitocritico-propongo; el termómetro; Kahoot! con preguntas; paletas con caras positivas o negativas, entre otras.

Respecto al trabajo de documentación, el dosier de la actividad, contempla los siguientes apartados por cada texto: reflexiones previas, en las cuales se realiza un breve resumen del artículo y se incorporan unas primeras reflexiones personales; el desarrollo del storytelling, en el que se recoge un esquema con el desarrollo del mismo; el visual thinking, incorpora de forma icónica contenidos e ideas que surgen en la tertulia; los conocimientos relacionados, donde se incorporan los conocimientos teóricos, conceptos e información que se hayan investigado sobre el tema; y la evaluación, en el cual se detalla en qué ha consistido y cómo se ha ejecutado la herramienta de evaluación utilizada por la persona dinamizadora.

\section{EVALUACIÓN, CONCLUSIONES Y PROPUESTAS DE MEJORA}

Respecto a la evaluación de Contalles i diàlegs, se realiza una heteroevaluación y una coevaluación para la dinamización. Para la primera herramienta se establece una guía de evaluación que recoge los siguientes criterios: storytelling, dinamización de la tertulia y evaluación. En relación con la coevaluación, es la persona dinamizadora la que propone una herramienta de evaluación que es cumplimentada por el resto de las compañeras y compañeros. El resultado de la coevaluación se añade en el apartado de la evaluación. Por lo que respecta al dosier individual de la actividad, en este se realiza la heteroevaluación en base a una guía de evaluación que alberga los siguientes criterios: estructura y formato del trabajo; expresión escrita, ortografía y lenguaje; contenido teórico, práctico y competencial; y la participación en el aula.

Como propuesta de mejora, se deberían modificar algunos apartados de la documentación. Por un lado, fusionar los conocimientos previos y los situados, ya que 
en ocasiones han generado confusión. Por otro lado, sería conveniente que el desarrollo del storytelling lo remitiese la persona dinamizadora para que el resto del alumnado disfrutase de la exposición sin la necesidad de estar cogiendo apuntes.

Para abordar la perspectiva del alumnado, se incorpora su propia visión:

Afrontar Contalles i diàlegs ha sido un reto. Ha despertado nuestro lado artístico, hemos sacado a la intérprete que llevamos dentro, nos hemos enfrentado al miedo escénico y a expresarnos en público. Con esta metodología, hemos sido especialistas en un tema, artistas por un día, tertulianas, investigadoras y/o redactoras... hemos compartido, discutido, llorado y reído (mucho) juntas. Nos hemos adentrado en temas en los que, de otra forma, quizá nunca hubiéramos podido profundizar tanto.

Como futuras promotoras de igualdad de género hemos visto reforzadas y afianzadas nuestras competencias profesionales, sociales y personales, así como se ha generado inquietud y motivación por aprender. En consecuencia, se ha ampliado nuestra mirada $y$ se ha sido consciente que el feminismo es plural, transversal y complementario.

Cuando realizas la tertulia, eres tú la que manejas, lideras al grupo y eres la especialista en ese tema. Por tanto, debes mostrar todas las habilidades que tienes y ese trayecto contribuye a tu propio empoderamiento. Sin embargo, también hay una parte colectiva. Como todas hemos buscado y analizado información sobre los distintos temas, hemos compartido libros, referentes, recursos, etc. Cada una lo ha hecho a su manera, pero la vivencia es la misma, tanto de forma individual como colectiva: nos hemos empoderado.

Como detalla Yolanda Domínguez (2021) las historias no solo llaman la atención del público, sino que les permiten empatizar con los personajes e incluso emocionarse. En consecuencia, contar historias en las aulas permite emocionar al alumnado. $Y$ si hay emoción, como señala Francisco Mora (2013), hay aprendizaje.

\section{REFERENCIAS BIBLIOGRÁFICAS}

Aubert, A., Flecha, A., García, C., Flecha, R., y Racionero, S. (2008). Aprendizaje dialógico en la sociedad de la información. Barcelona: Hipatia.

Auffret, S. (2020). La gran historia del feminismo. De la Antigüedad hasta nuestros días. Madrid: La Esfera de los Libros.

BOE. (2013). Real Decreto 779/2103, de 11 de octubre, por el que se establece el título de Técnico Superior en Promoción de lgualdad de Género y se dijan sus enseñanzas mínimas. Madrid: Boletín Oficial del Estado.

DOGV. (2017). Decreto 43/2017, de 24 de marzo, del Consell, por el que se establece el currículo del ciclo formativo de grado superior correspondiente al título de Técnico/a Superior en Promoción de Igualdad de Género. València: Diari oficial de la Generalitat Valenciana.

Domínguez, Y. (2021). Maldito estereotipo. ¡Así te manipulan los medios y las imágenes! Barcelona: Penguin random House. 
Martínez Marín, I. (2016). Construcción de una pedagogía feminista para una ciudadanía transformadora y contra-hegemónica. Revista Foro de Educación, 20, 129-151.

Mora, F. (2013). Neuroeducación. Madrid: Alianza editorial. 


\subsubsection{4. "Rompendo regras": proyecto curricular e}

interdisciplinar para una alfabetización menstrual crítica

Rodríguez Romero, Mar (Universidade da Coruña, España); Martínez Rodríguez, Alicia (Universidade da Coruña, España); Mosquera González, Ma José (Universidade da Coruña, España); Arza Arza, Neves (Universidade da Coruña, España); Rodríguez

Rodríguez, Carmen (Universidade da Coruña, España)

\section{Resumen}

Rompendo Regras es un proyecto colaborativo, curricular e interdisplinar que toma la menstruación como objeto de investigación y tema generador de experiencias formativas en seis materias de las Facultades de Ciencias de la Educación, Fisioterapia y Ciencias del Deporte y de la Educación Física. Desde la perspectiva de la alfabetización menstrual crítica, busca visibilizar la menstruación cuestionando su construcción sociocultural y económica y señalando su impacto en la salud y la sostenibilidad. Aplica metodologías participativas con enfoque feminista para cruzar vivencias personales con cuestiones de poder y de justicia social. Principalmente usa la producción de imágenes para elicitar temas controvertidos y vincular lo personal con lo político mediante la estrategia de fotovoz. En los primeros ciclos de análisis, los resultados muestran que se ha conseguido construir una visión más integral y reivindicativa de la menstruación y producir conocimiento compartido de modo significativo para las y los estudiantes y las profesoras.

Palabras clave: alfabetización menstrual crítica; investigación-acción; fotovoz; justicia social; educación superior;

\section{INTRODUCCIÓN Y OBJETIVOS}

La menstruación es un prisma muy potente para explorar las complicadas e interconectadas desigualdades que sufrimos las mujeres a nivel biológico, social, económico, cultural e histórico (Bobel, 2020). Su tratamiento convencional muestra el conjunto de injusticias de todo tipo que experimentamos las mujeres estructuralmente y que afianzamos de modo personal, ignorando los daños y la violencia que nos causamos a nosotras mismas (Reimóndez, 2021). En definitiva, todo lo referido a la menstruación es producto de la violencia misógina.

La alfabetización menstrual crítica supone una línea de reflexión y de actuación pedagógica, situada en los estudios críticos sobre la menstruación, que sobrepasa la cuestión de los productos menstruales. Entiende que ni su sustitución ni las medidas económicas, por importantes que sean para mitigar la pobreza menstrual que sufren millones de niñas y mujeres en todo el planeta, resolverán el estigma y el tabú. Asume la importancia de la gestión de la higiene menstrual, sin ignorar sus derivas neoliberales, pero considera que la menstruación tiene que tratarse desde una perspectiva educativa transformadora (Bobel, 2019). Situándola en el ámbito de la justicia reproductiva y trabajando por el control personal de nuestro periodo. También en el terreno de los derechos humanos, considerando no sólo aquellos que se ven afectados por menstruar en condiciones indignas como el derecho a la salud, a la educación y al trabajo, sino reivindicando derechos humanos y constitucionales específicos (Johnson, 2019).

Por alfabetización menstrual crítica nos referimos al conjunto de conocimientos, destrezas y actitudes que hacen a las personas dueñas de sus cuerpos en el ejercicio de una menstruación justa, saludable y sostenible. Esto implica actuar en cuatro ejes: 
1. Visibilizando y construyendo conocimiento colectivo, para acabar con el silencio y cuestionar el estigma creando discursos sobre la menstruación en los lugares que habitamos: el aula, la facultad, la Universidad.

2. Decidiendo sobre nuestro modo de vivir la menstruación, considerando cuestiones de salud, autocuidado y medio ambiente

3. Promoviendo alianzas sinérgicas entre múltiples sectores, agentes, mujeres y personas menstruantes.

4. Vinculando la menstruación con los derechos humanos y reclamando derechos específicos y normativas internacionales, nacionales y locales.

Desde esta perspectiva, los objetivos de nuestro proyecto son:

- Definir participativamente e implementar una alfabetización menstrual crítica desde materias específicas

- Construir una comunidad de práctica entre el profesorado de diversas facultades para incluir la menstruación en la investigación y en la formación

- Considerar posibles escenarios hacia una menstruación digna y eco saludable en la Universidad.

\section{CONTEXTUALIZACIÓN}

En la primavera de 2020, el Grupo de Traballo en Igualdade de Xénero de la Facultad de Ciencias de la Educación busca un tema generador que promueva una propuesta colectiva de indagación para la transformación social, a partir de cuestiones que relacionen mujeres y mundo en el escenario de la crisis ecosocial y de la pandemia. La respuesta es "Rompendo Regras", un proyecto con la menstruación como tema generador, que intenta neutralizar la violencia misógina cruzando vivencias y estructuras sociopolíticas y culturales con sostenibilidad. Estimulando sinergias empezó el trabajo interdisciplinar y colaborativo con profesoras de las Facultades de Fisioterapia y Ciencias del Deporte y de la Educación Física. Además, recibimos apoyos de la Oficina de Igualdade de Xénero (OIX) y estamos vinculadas a la Rede de Docencia, Investigación e Xénero (REDIX).

\section{DISEÑO Y DESARROLLO}

Se ha diseñado y realizado un proyecto de investigación-acción participativa utilizando la estrategia de Fotovoz, Este procedimiento cualitativo utiliza la producción de fotografías o imágenes representativas para desvelar temas sociales e individuales de un modo creativo (Werts, Brewer \& Mathews, 2012). Aplica el diálogo crítico para construir conocimiento colectivo y facilita humildes, pero prácticas transformaciones personales y sociales con perspectiva de género (Robinson-Keilig et al., 2014). Adoptando estos supuestos, se llevó a cabo un trabajo de Fotovoz adaptado a cada materia y título. En una de las materias, excepcionalmente, se optó por solicitar a las estudiantes el diseño de una unidad didáctica sobre la baja menstrual dentro de la programación del Módulo de FOL del máster de Profesorado de Secundaria, que tenían que realizar con el propósito de incorporar la menstruación en su práctica como futuros docentes. En otra han realizado una especie de metaanálisis, aplicando un proceso de foto voz con sus familiares.

En las clases, la secuencia general de tareas en pequeño grupo ha sido:

1. Lluvia de ideas, palabras previas

2. Relación de éstas con Objetivos de Desarrollo Sostenible y/o Necesidades Humanas Fundamentales para documentar 
3. Realización de imágenes, fotos, dibujos o composiciones y redacción de narrativas que explicaran sus significados.

4. Puesta en común para extraer los temas que afloraron y reflexión

5. Propuesta de acciones de cambio en varios escenarios

La secuencia seguida a partir de la realización de las fotos puede verse sintetizada en la Figura 1:

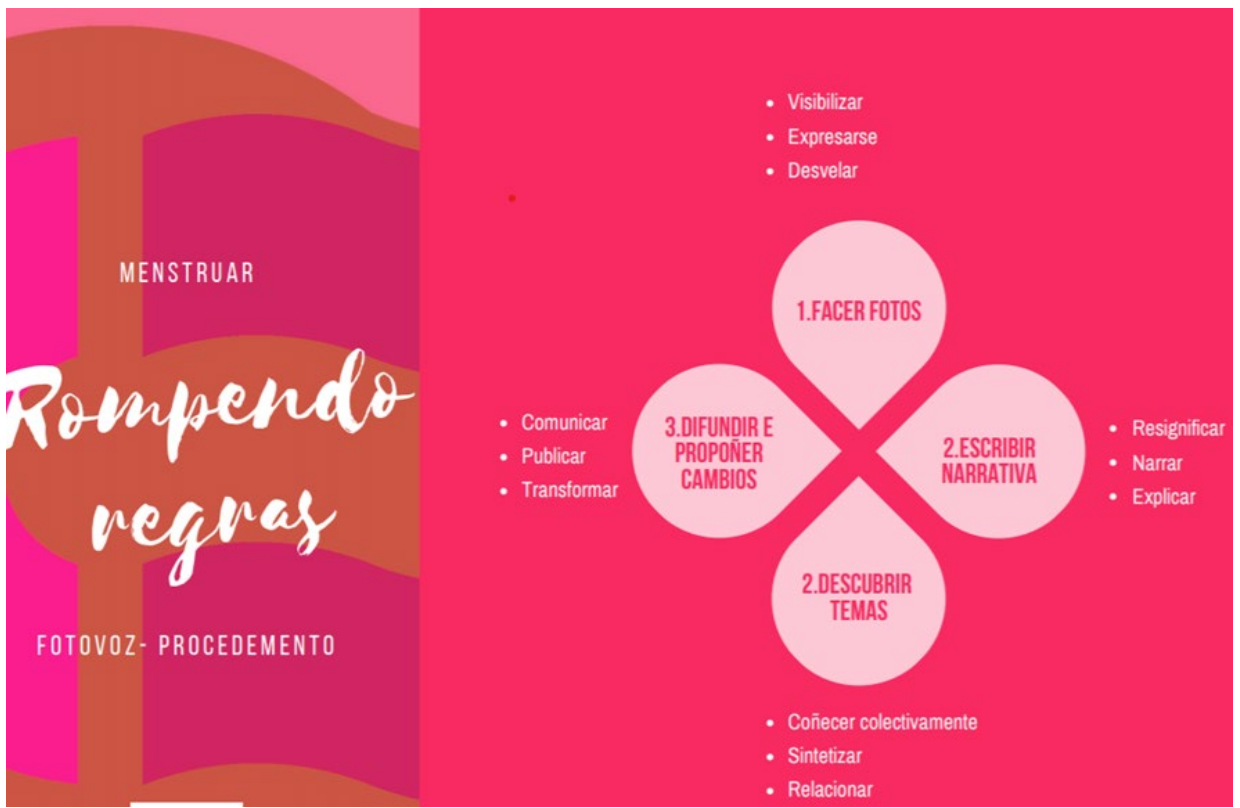

Participaron un total de 200 estudiantes (146 mujeres y 54 hombres). La distribución por materia y sexo puede verse en la Tabla 1.

\begin{tabular}{|c|c|c|c|c|c|}
\hline Facultad & Grado/máster & Materia & Alumnas & Alumnos & $\begin{array}{l}\text { Acción } \\
\text { educativa }\end{array}$ \\
\hline $\begin{array}{l}\text { CC de } \\
\text { Educación }\end{array}$ & $\begin{array}{l}\text { Educación } \\
\text { Social }\end{array}$ & $\begin{array}{l}\text { Deseño acción } \\
\text { socioeducativa }\end{array}$ & 54 & 12 & Fotovoz \\
\hline $\begin{array}{l}\text { CC de } \\
\text { Educación }\end{array}$ & $\begin{array}{l}\text { Educación } \\
\text { Social }\end{array}$ & Socioloxía & 29 & 5 & Fotovoz \\
\hline $\begin{array}{l}\text { CC de } \\
\text { Educación }\end{array}$ & $\begin{array}{l}\text { Profesorado de } \\
\text { Educación } \\
\text { Secundaria }\end{array}$ & $\begin{array}{l}\text { Inserción } \\
\text { orientación } \\
\text { laboral }\end{array}$ & 16 & 4 & $\begin{array}{l}\text { Propuesta } \\
\text { didáctica } \\
\text { baja } \\
\text { menstrual }\end{array}$ \\
\hline $\begin{array}{l}\text { CC de } \\
\text { Educación }\end{array}$ & $\begin{array}{l}\text { Dirección } \\
\text { centros } \\
\text { educativo }\end{array}$ & $\begin{array}{l}\text { Investigación } \\
\text { acción } \\
\text { innovación }\end{array}$ & 7 & 6 & Fotovoz \\
\hline $\begin{array}{l}\text { Ciencias } \\
\text { Deporte y } \\
\text { Educación } \\
\text { Física }\end{array}$ & $\begin{array}{l}\text { Educación } \\
\text { Física }\end{array}$ & $\begin{array}{l}\text { Muller Deporte } \\
\text { e Saude }\end{array}$ & 11 & 16 & Fotovoz \\
\hline Fisioterapia & Fisioterapia & $\begin{array}{l}\text { Fisioterapia } \\
\text { comunitaria e } \\
\text { saúde pública }\end{array}$ & 29 & 11 & Fotovoz \\
\hline
\end{tabular}


La recogida de datos de la evaluación se ha realizado mediante el análisis de documentos de los trabajos producidos por los grupos de estudiantes, la observación de las puestas en común en clase y entrevistas grupales. Se ha diseñado un cuestionario que está en proceso de aplicación.

La evaluación muestra cambios en la percepción de la menstruación por parte de las y los estudiantes en las materias. Estos cambios se refieren a:

1) La ampliación de perspectiva, de una biologicista y restringida a otra biopsicosocial, integral y diversa:

"Tras ahondar más durante este trabajo, podemos decir que tenemos una perspectiva mucho más rica a la par que amplia sobre las consecuencias que tiene la menstruación en el ámbito sociocultural, económico y laboral (...) En un primer momento todos teníamos una perspectiva similar, dentro del propio grupo la parte femenina se enfocaba más en el dolor y en los productos de higiene íntima; por otra parte, la parte masculina se centraba más en el embarazo y en el tema de las relaciones sexuales. Tras debatir el tema en la práctica e investigar por nuestra cuenta, nuestro punto de vista derivó más hacia la diferencia existente entre géneros fruto de la situación de inequidad y desigualdad que vive la mujer dentro de nuestra sociedad".

2) La revelación del tabú, incluso en nuestra sociedad, y en diversas facetas de las disciplinas:

"En estas imágenes se pueden ver las estanterías de la sección de higiene íntima de un supermercado, en las que no hay ningún producto que contenga el color rojo. Esto se debe a que la menstruación continúa siendo uno de los grandes tabúes de esta sociedad y existen una gran cantidad de eufemismos para hablar sobre ello..."

“(está) Invisibilizado el término en todo el mundo del deporte, no se habla del tema ni con entrenadores ni sale en los medios..."

3) La menstruación como fuente de inequidades de género de todo tipo:

"A pesar de que a menstruación é un proceso natural e biolóxico das mulleres, en moitos casos afecta na sua vida cotidiana e no seu rendemento académico. Nesta imaxe tentamos representar a comparativa na ausencia a clase entre rapaces e rapazas, como consecuencia da falta de recursos para poder levar a cabo a hixiene feminina".

"La dicomotomía en la normalización de la sangre cuando proviene de actos violentos, pero no de la relacionada con la menstruación".

4) La concienciación medioambiental:

"Es necesario concienciar a las mujeres de que existen alternativas a los tradicionales tampones y compresas desechables. Una de estas alternativas es la copa menstrual, que además de no ser perjudicial para el cuerpo de la mujer ni para el medioambiente, hace que ahorremos mucho dinero".

5) La conexión con las derivaciones para la propia profesión como:

"La menstruación no se considera ni en el entrenamiento ni de cara al rendimiento deportivo, se diseña todo en función del hombre..."

"En el siglo en que nos encontramos, debería de existir un mayor número de métodos ante esta problemática tan frecuente en la sociedad actual, que cada vez tiene un mayor desarrollo especialmente en nuestro ámbito de la fisioterapia. Por lo tanto, consideramos que es necesario fomentar las ayudas a la investigación sobre esta realidad que afecta a la mitad de la población". 
Podemos concluir que el proceso está siendo muy satisfactorio. Incluir la menstruación como contenido curricular en las materias, amplifica el tratamiento pedagógico de la igualdad de género y complejiza la imagen que tienen las y los estudiantes de la violencia misógina y el margen para la justicia social. La interdisciplinariedad enriquece el proceso de co-creación pedagógica haciéndolo más creativo y poliédrico y contribuyendo a construir una comunidad de práctica profesional sensible a la inclusión de la menstruación en la investigación y en la formación. La aplicación de una metodología creativa y participativa aumenta el compromiso del alumnado con lo que aprende; aprender haciendo y desde sus propias vivencias acrecienta su implicación y su reflexión. Hacerlo en equipo facilita la interacción, compartir experiencias y producir saberes propios colectivamente. Crear autonomía de pensamiento y acción son claves como ensayo para sus futuras prácticas profesionales. Aplicar la independencia de criterio y de acción a temas de género, es un objetivo esencial de las pedagogías feministas. Si además esto se hace poniendo el cuerpo y las vivencias propias como objeto de estudio y en relación con lo social, aumenta la coherencia entre el método de aprendizaje y los objetivos (Martínez Martín, 2016), como ha sucedido en nuestro caso.

\section{Por ejemplo:}

"La puesta en común de las fotografías y de los diversos temas, nos permitió ampliar nuestro conocimiento y los puntos de vista de nuestras compañeras. Fue un proceso muy enriquecedor que desembocó en una mejora de la calidad del trabajo y en una mayor consciencia por nuestra parte de acabar con todos estos tabús".

Aunque se han generado posicionamientos personales contra la pobreza menstrual, la ocultación de la menstruación, la desinformación y falta de control de los productos menstruales, la mala gestión en el desecho de estos y la escasez de productos eco saludables, la perspectiva de acción comunitaria y social se abordó más tímidamente. Esta faceta más comprometida requeriría de un mayor énfasis para la promoción de acciones comunitarias específicas.

Sobre los desafíos, el proyecto está en construcción y este primer abordaje fue prácticamente una intervención piloto que requiere de análisis más precisos que están en curso. En relación con los aprendizajes, hay que consolidar el tránsito desde la visibilización al cuestionamiento reforzando el compromiso con acciones personales más decisivas para alcanzar un control mayor sobre el ejercicio propio de la menstruación y aplicarlo en sus futuras prácticas profesionales. También reforzando el vínculo con prácticas de cambio entre iguales y en el contexto comunitario y social más amplio, como el activismo menstrual (Gómez Nicolau y Marco Arocas 2020). En relación con la pedagogía, habría que incidir en la dimensión curricular del proyecto, profundizando en metodologías y pedagogías feministas para aumentar la coherencia entre el tema generador y su traducción didáctica. Respecto al trabajo colaborativo e interdisciplinar, entre las profesoras, estamos afianzando relaciones y buscando apoyos y colaboraciones institucionales y entre colegas. Así como mejorando el cruce y la sistematización de la información entre áreas de conocimiento y materias, para unificar criterios sin perder la riqueza de las diferencias.

Sobre las futuras líneas de actuación, para profundizar sobre lo hecho y recabar más datos, en el próximo curso, estamos diseñando un diagnóstico participativo sobre prácticas y actitudes sobre la menstruación y posibles abordajes más comprometidos a nivel institucional, formativo y en la investigación. 


\section{REFERENCIAS BIBLIOGRÁFICAS}

Bobel, Chris. (2019) The Managed Body: Developing Girls \& Menstrual Health in the Global South, London, Palgrave Macmillan.

Bobel, Chris. (2020). Menstruation as Lens-Menstruation as Opportunity, en Chris Bobel, Inga T. Winkler, Breanne Fahs, Katie Ann Hasson, Elizabeth Arveda Kissling e Tomi-Ann Roberts, The Palgrave Handbook of Critical Menstruation Studies. Palgrave Macmillan

Gómez Nicolau, Emma., \& Marco Arocas, Elisabet. (2020). Desafiando las reglas: articulaciones políticas del activismo menstrual. Revista Española De Sociología, 29(3 - Sup1), 155-170. https://doi.org/10.22325/fes/res.2020.62

Reimóndez, María (2021) Bárbaras, Vigo, Xerais.

Martínez-Palacios, Jone. (2017). Exclusión, profundización democrática e interseccionalidad. Revista de Investigaciones Feministas 8 (1), 53-71. doi.org/10.5209/INFE.54827

Johnson, Margaret E. (2019) Menstrual Justice. U.C. Davis Law Review 1, 53. Recuperado: https://scholarworks.law.ubalt.edu/all_fac/1089

Robinson-Keilig, Rachael A., Hamill, Cynthia, Gwin-Vinsant, Annalisa e Dashner, Matthew. (2014). Feminist Pedagogy in Action: Photovoice as an Experiential Class Project. Psychology of Women Quarterly, 38, 292 - 297. 


\title{
4. EDUCACIÓN PARA LA IGUALDAD EN LA EDUCACIÓN NO FORMAL (OCIO Y TIEMPO LIBRE, ETC.).
}

\subsection{INVESTIGACIONES}

\author{
4.1.1. "Museo y género: el rol de la mujer en la antigüedad. \\ Propuesta de un nuevo recorrido de visita entre el Museo \\ Nazionale de Atestino y el área arqueológica de la ciudad de \\ Este." \\ Carolina Ahumada Pizarro (Profesora Paola Zanovello. Università degli Studi di \\ Padova, Italia)
}

\section{Resumen}

Esta investigación habla de la importancia de integrar la perspectiva de género en las exposiciones museales. Teniendo como objetivo principal la revalorización del rol de la mujer en la antigüedad, dando también una mayor visibilidad a la totalidad de miembros de una comunidad. Se llevó a cabo un análisis de la presencia femenina y de otres integrantes de la comunidad al interior de la exposición permanente de un museo italiano, para luego sugerir una propuesta con una metodología usada en España en diferentes exposiciones temporales. Iniciando con la elección del discurso expositivo, los materiales a exponer, el lenguaje e imágenes para crear la nueva narrativa. Los puntos mencionados se deben completar con la difusión y divulgación de las nuevas investigaciones en perspectiva de género.

En definitiva, la mayor dificultad para cumplir los objetivos son los escasos fondos y la poca disposición de algunos profesionales en abrir campos a nuevas investigaciones.

Palabras clave: museo y género; perspectiva de género; rol de la mujer en el pasado, didáctica museal igualitaria; nuevas interpretaciones históricas.

\section{INTRODUCCIÓN Y OBJETIVOS}

En este trabajo de investigación se expone principalmente la necesidad de integrar la perspectiva de género al interior de los museos, mediante la renovación del discurso expositivo.

La mayor parte de la constitución y fundación de los museos en Europa se dio durante el siglo XVII y XVIII, las personas que tenían esta labor fueron los hombres de la elite, seleccionando los discursos expositivos y el material que representa las memorias de toda la sociedad según sus intereses. Bajo esta situación nacieron los primeros museos, invisibilizando sobre todo a las mujeres y poniendo siempre como único ejemplo de agente social al hombre, blanco, heterosexual, fuerte y joven.

Paralelamente las mujeres con el sufragismo y el movimiento feminista inician a tomar fuerza, queriendo no solo recuperar los espacios en la comunidad. Los hombres temerosos de poder, buscaban justificar la discriminación y segregación con respuesta en el pasado "las mujeres siempre han estado en la casa" "en la prehistoria las mujeres se encargaban de los niños", dichas frases encontraban respaldo en las diferentes 
colecciones museales, donde el lenguaje androcentrista y sexista reforzaba el rol subordinado de la mujer respecto a los hombres.

La imagen de la mujer del pasado que hoy vemos en los diferentes museos con exposiciones tradicionales fue enormemente dañada, esto debido a que estas narraciones se crearon recurriendo a los prejuicios de género de la época y sin ninguna perspectiva.

Por ello el objetivo principal de esta investigación es la revalorización del rol de la mujer en el pasado, dando visibilidad a las mujeres en la construcción de las identidades de la comunidad. Además de evidenciar la importancia de estas en el progreso de las sociedades, se busca incluir a toda la comunidad en la narración expositiva. La difusión y divulgación de las nuevas investigaciones en temas de género es otro de los objetivos primordiales, asimismo la creación de una manual didáctico que sirva como ayuda en la comprensión de los nuevos contenidos tanto para docentes como para estudiantes.

Todo esto con el propósito de promover la educación de igualdad y paridad de género dentro de les visitadores.

\section{METODOLOGÍA}

La metodología de análisis utilizada en primera instancia fue la de identificar la presencia femenina y de otres integrantes de la comunidad, así como revisar los paneles informativos presentes en el recorrido e individualizar las imágenes que acompañan a estos.

Según las percepciones recabadas en diferentes visitas al museo y de la página web, se creó una propuesta usando como modelo la metodología establecida por el grupo de investigadoras "Pastwoman" para la creación de diferentes muestras temporales en España, esta consiste en primer lugar de la elección del discurso expositivo, que será el guion de lo que queremos contar y que representará la visión que daremos del pasado. En segundo lugar, está la selección de los materiales a exponer, los cuales deben favorecer la comprensión de la narración expositiva. El tercer aspecto a considerar es la elección del lenguaje con el que se comunica tal narración al público. Los tres aspectos nombrados anteriormente se complementan con la inclusión de imágenes, las cuales simplifican la lectura de les visitadores. La última parte de la metodología concierne a la difusión científica al interior del espacio museal, parte indispensable para la incorporación de la perspectiva de género.

La misma metodología debe estar presente en la creación del manual didáctico y del itinerario arqueológico de la ciudad, con la finalidad de difundir una concepción no sexista del rol de la mujer en la antigüedad, deconstruyendo los diferentes estereotipos aprendidos.

\section{RESULTADOS Y DISCUSIÓN}

El Museo Nazionale de Atestino de la Ciudad de Este en Italia fue el ejemplo territorial para llevar el análisis de esta investigación. El rol que tuvo la mujer en el territorio Véneto en época prerromana (del IX al II siglo a.C) es innegable, la presencia femenina en los restos arqueológicos de la exposición permanente de dicha institución es mayoritaria, por lo que facilita la visibilidad de la mujer. El material expuesto en el museo habla por sí solo, en él podemos observar la participación de la mujer en diferentes actividades cotidianas, ceremoniales, rituales y políticas. Es por esto que, en este museo, la elección 
del material con el que podemos narrar una nueva interpretación del pasado se simplifica.

El problema se presenta en el análisis del discurso expositivo, el lenguaje utilizado y las imágenes presentes en los paneles informativos, ya que no concuerdan con el material expuesto. En el recorrido del museo se hace muy poca referencia a la importancia de la mujer véneta en las diferentes actividades de su comunidad, sobre todo no se dan a conocer la relevancia de estas en los rituales de la comunidad, el acceso a fiestas y el conocimiento de la escritura, actividades que en otras civilizaciones (romana y griega) de la época eran reservadas solo para el género masculino.

En las pocas imágenes incluidas en el recorrido museal, vemos una división sexual del trabajo, las mujeres vénetas vienen puestas en segundo plano realizando tareas dentro del hogar, sentadas cosiendo o creando telares. Si bien sabemos que las mujeres en esta civilización se dedicaban a estas labores, no podemos reducir su participación solo a esto, ya que hoy con las nuevas tecnologías podemos comprobar que en realidad las mujeres en la antigüedad realizaban, al igual que los hombres, actividades que implican el uso de la fuerza, caza, pastoreo, etc.

Las interpretaciones históricas sin ninguna base científica otorgaron ciertas actividades "naturalmente" a los hombres, es por ello que en las imágenes presente en el museo de Este están siempre de pie, en primer plano y realizando las tareas que requieren un esfuerzo físico. Entregar este tipo de información solo fomenta los estereotipos en la sociedad, asociando a la mujer al sexo débil, segregándola a tareas que hoy consideramos menos importantes.

En el estudio del museo se observa también algunas omisiones de la presencia femenina. En la cerámica más importante de esta civilización, la "Situla Benvenuti" que muestra una iconografía trascendental para la cultura véneta, en la didascalia no se menciona que en realidad la sepultura pertenece a una niña de solo tres años, lo que cambia por completo las interpretaciones realizadas, donde se creía hasta hace muy poco que pertenecía a un hombre adulto.

Como último ejemplo de análisis, de los muchos que se pudieron observar, encontramos la tumba de una joven mujer la cual evidentemente murió en el parto. En la didascalia que narra la situación, se crean juicios innecesarios terminando el relato con preguntas como “¿por qué estaba pariendo sola?" “¿tenía algo que esconder?”, este mensaje inevitablemente llega a les visitadores que refuerzan la discriminación y prejuicios en contra de las mujeres. En realidad, según las nuevas investigaciones demuestran científicamente que la muerte en el parto durante la antigüedad era común, muy por el contrario de lo que transmite la información presente en el museo.

La propuesta realizada se focaliza en cambiar el discurso expositivo, mediante la inclusión de un lenguaje inclusivo e imágenes que integren a toda la comunidad, tomando como modelo algunos museos españoles que han realizado exposiciones temporales e itinerantes. Estos factores se deben complementar entre ellos con el fin de construir una nueva imagen del pasado con el apoyo de los paneles informativos.

Paralelamente a la renovación museográfica, en estos tiempos es indispensable también el uso de los canales sociales, que permiten llegar a una mayor cantidad de público proporcionando una rápida difusión que va más allá de la comunidad de Este. Esta nueva línea de educación museal con perspectiva de género la deben seguir también las muestras temporales y eventos los cuales deben ser acorde a la nueva visión que quiere entregar el museo. El conjunto de modificaciones son el punto clave para este nuevo enfoque, todo debe seguir una armonía con el objetivo de entregar en manera adecuada el mensaje al público.

Para las visitas didácticas es crucial la creación de un nuevo manual pedagógico, la difusión de esta guía a profesores y alumnes garantiza tratar la perspectiva de género 
de manera más completa. Las diferentes actividades propuestas se pueden moldear según la edad y etapa escolar de les estudiantes, en primer lugar, estas consienten organizar la visita al museo con anticipación, sugiriendo diversas actividades para trabajar en el aula de estudio. En segundo lugar, el manual debe otorgar actividades de realizar en cada sala del museo según la temática de estas, es importante que en este momento les estudiantes se encuentren bajo la guía de les docentes, les cuales son les encargados de aportar los nuevos conocimientos que permitirán que les alumnes al final del recorrido puedan realizar una crítica en autonomía los contenidos aprendidos.

La difusión de la transformación de la narración expositiva tiene que atravesar las murallas del museo, es de vital importancia difundir en la comunidad. Para esto es necesario renovar conjuntamente el recorrido arqueológico de la ciudad de Este, el cual viene propuesto en la página web del museo. las señaléticas de los puntos arqueológicos y la renovación de los paneles informativos que se encuentran en dieciséis puntos de la ciudad deben seguir el nuevo concepto del museo. Con la misma metodología de análisis, renovando el lenguaje e imágenes expuestas. Además de esto, es crucial integrar no solo datos arqueológicos tradicionales, sino que también es importante incorporar a toda la población en estas nuevas interpretaciones, que generan un mayor interés por visitar las memorias citadinas, ya que las personas de la comunidad se verán reflejadas en esta nueva forma de contar la historia, con un pasado mucho más realista e inclusivo.

\section{CONCLUSIONES Y LIMITACIONES}

En conclusión, la integración de la perspectiva de género es primordial para fomentar una educación más igualitaria entre la comunidad. No solo en el caso de los museos arqueológicos, sino que debe contemplar una renovación en la museografía en manera global, ósea aplicar la perspectiva de género en todas las tipologías museales.

La perspectiva de género se encuentra en la planificación cultural de diferentes países, pero la mayor dificultad para alcanzar el objetivo de incorporar esta nueva postura a las colecciones permanentes, son los altos costos que este procedimiento requiere. La mayor parte de los museos y universidades en las que existen distintas propuestas, estas no cuentan con los recursos necesarios para llevarlas a cabo. En algunos casos se encontró como solución la exposición de muestras temporáneas, son pocos los museos que hoy cuentan con pequeñas transformaciones en la colección permanente.

De cualquier modo, estas modificaciones aún si son pequeñas, son absolutamente necesarias debido a que uno de los roles en la sociedad del museo como institución es el de conservar y comunicar las testimonianzas de la sociedad a todos, todas y todes sin distinción alguna.

Otro punto importante que se enfrenta cuando al querer integrar la perspectiva de género en los museos es la poca disposición que tienen algunos profesionales e instituciones al incluir nuevas investigaciones, abrir campo a nuevas interpretaciones históricas es indispensable, puesto que la narrativa actualmente presente en la mayor parte de museos crea diferencias y discriminaciones que inconscientemente son transmitidas a la sociedad

El estudio y las investigaciones de otras actividades, tecnologías y conocimientos son necesarios para ahondar en las nuevas narraciones en perspectiva de género de las sociedades del pasado. Estas deben ser completadas con difusión y divulgación de las nuevas investigaciones científicas, para que de esta forma se pueda crear una opinión 
crítica en les visitadores, así de poder combatir contra los estereotipos actuales que han quedado en el imaginario colectivo.

En fin, abriendo nuevos espacios de reflexión a la comunidad a través del museo no solo ayuda a comprender con facilidad y de una manera realista las historias de las sociedades antiguas, sino que además se pueden integrar estos nuevos conocimientos en el presente para construir un futuro más igualitario.

\section{REFERENCIAS BIBLIOGRÁFICAS}

Albero Verdú, S., \& Arriaga, A. (2018, febrero). Educación con Perspectiva de Género en Museos Españoles. Enfoques y Discursos. GÉNEROS -Multidisciplinary Journal of Gender Studies Vol. 7 No. 1, 1531-1555.

Ángeles Querol, M. (2014). Museos y Mujeres: la desigualdad en Arqueología. (U. C. Madrid, A cura di) ArqueoWeb 15, 270-279.

Chieco Bianchi, R. S. (2002). 1902-2002: il Museo di Este: passato e futuro. Treviso: Canova.

Cuesta Davignon, L. (2018). Cómo introducir la perspectiva de género en los museos: marco legal y propuesta de modelo. XXXI Jornada de la Xarxa de Museus Locals, (p. 1-17). Valencia.

HORNOS, M. Á. (2011). LA REPRESENTACIÓN DE LAS MUJERES EN LOS MODERNOS MUSEOS ARQUEOLÓGICOS: ESTUDIO DE CINCO CASOS. Revista Atlántica-Mediterránea 13, 135-156.

NAVARRO, E. (2018). ANÁLISIS DE LOS DISCURSOS Y LAS IMÁGENES EN LOS MUSEOS ARQUEOLÓGICOS DESDE UNA PERSPECTIVA FEMINISTA: ESTUDIO DE TRES CASOS. Arqueología y Territorio, 139-151.

Rodríguez, L. B. (2016, aprile ). Asturias y el patrimonio arqueológico en femenino. Avances y permanecias. revista ph Instituto Andaluz del Patrimonio Histórico $n .^{\circ}$ 89,163 . Tratto da www.iaph.es/revistaph/index.php/revistaph/article/view/3742

Rueda, C., Rísquez, C., Herranz, A., Mata, F., \& García, A. (2016). Cuaderno profesorado, Exposición temporal: Las edades de las mujeres iberas. Jaén. Tratto da https://www.pastwomen.net/recursos-didacticos

Ruiz, L. P. (2017). Museo arqueológicos y género, educando en igualdad. servicio de publicaciones UAM.

Sánchez Romero, M. (20 de noviembre de 2020). Arqueología de género, los clichés prehistóricos. Podcast Noosfera 25. (Crespo Ignacio, Entrevistador) Obtenido de https://www.spreaker.com/user/12512368/noosfera-25

Soler, B., \& Alcantara, J. (2006). Las mujeres en la Prehistoria, Guía didáctica. Valencia: Museu de Prehistòria de València, Diputación de Valencia.

Torregrosa, M. (2019). Museos y género: una asignatura pendiente. Educación artística: revista de investigación. Valencia, 184-197. 


\subsubsection{La educación en los museos madrileños desde la perspectiva de género: retos y propuestas (investigación) Irene Barreno García (Universidad Complutense de Madrid, España).}

\section{Resumen}

En la presente propuesta se analizan inicialmente aquellas cuestiones a tener en cuenta al hablar de educación con perspectiva de género en los museos. Además de la inclusión de mujeres artistas en las actividades educativas, se contemplan muchos otros factores necesarios para lograr una reestructuración en clave feminista de los discursos educativos. Tras estas semblanzas iniciales, se examinan propuestas educativas con perspectiva de género puestas en práctica por museos madrileños entre 2019 y la actualidad. Se ha procedido a su sistematización y al estudio de sus mecanismos pedagógicos, detectándose asimismo algunos de los problemas de su implementación que habrán de ser solucionados en el futuro con la participación de educadoras artísticas feministas.

Palabras clave: género; educación; museos; arte; feminismo.

\section{INTRODUCCIÓN Y OBJETIVOS}

Para ahondar en la cuestión educativa desde la perspectiva de género en los museos, la primera pregunta que debemos hacernos es: ¿qué significan los museos a nivel cultural para la sociedad?

Estas instituciones son uno de los principales destinos en lo referente a visitas culturales. Según el Anuario de Estadísticas Culturales del Ministerio de Cultura y Deporte (2019), un $40,5 \%$ de la población asiste a museos anualmente. Esta actividad se sitúa solo por detrás de la asistencia a cines $(57,8 \%)$ y monumentos $(49,3 \%)$. Su papel como referente cultural para nuestra sociedad, así, es fundamental. El argumento de autoridad en este sentido ha de tenerse muy en cuenta: los discursos articulados desde las instituciones museísticas, como principales custodios del pasado, serán los que inconscientemente se vinculen con un relato de la historia más objetivo y veraz.

Esto nos sitúa en una problemática muy concreta: desde los museos no se está exponiendo ni difundiendo con equidad el legado histórico aportado por las mujeres (Pérez lbáñez, 2020). Desde la perspectiva de género está operando una especie de "educación por omisión": aquello que no está en el museo (las aportaciones femeninas) no se vincula con nuestra tradición histórica. Para educar en la desigualdad de género no hace falta que los museos favorezcan un relato manifiestamente discriminatorio contra la mujer. No incluirlas como artífices de la historia es suficiente para que los visitantes asimilen la creencia de que ninguna mujer ha sido suficientemente importante para estar ahí.

Existe además otra cuestión fundamental: la deconstrucción de las narrativas en los espacios museísticos. Desde la educación artística feminista no se aboga exclusivamente por introducir a las mujeres en las narrativas establecidas, porque los museos dediquen exposiciones y actividades educativas a mujeres artistas en los términos en que estas actividades existen actualmente. Lo realmente urgente es promover una reestructuración de los parámetros generales en los que se enseña aún el arte. Estos parámetros, no ya en su contenido, sino desde el mero continente, están impregnados de categorías patriarcales. Puede verse cuando se educa en arte con términos como "genios", "musas" o "Bellas Artes" (consideradas como las grandes creaciones producidas por la masculinidad occidental) versus "artes populares" 
(denostadas por vincularse tradicionalmente con las mujeres). Mientras la Historia del Arte siga enseñándose en estos términos, no habrá espacio en los museos para una digna educación en clave de género.

El estudio de las propuestas museísticas relacionadas con la educación y el género ha sido abordado por historiadoras y educadoras feministas desde múltiples perspectivas. Destacan como antecedentes a nuestra investigación las aportaciones de la educadora artística Marián López-Fernández Cao (2002). Asimismo, estructuralmente han resultado vitales los estudios de Sofía Ángela Albero Verdú (2017), especialista en educación en museos desde la perspectiva de género en España.

Frente a ese contexto estatal, proponemos un estudio concreto sobre los principales museos de Madrid. Las propuestas educativas recogidas son de rigurosa actualidad, realizadas entre 2019 y 2021 . Esto permitirá analizar los retos desde la perspectiva de género a los que nos enfrentamos hoy en una de las ciudades españolas con más oferta cultural. Los objetivos de esta investigación son:

- Analizar el papel que juegan los museos como espacios educativos desde la perspectiva de género

- Investigar las acciones educativas en clave de género que desde los museos madrileños se han realizado en los últimos años

- Sistematizar los tipos de actividades educativas más frecuentes en los museos madrileños desde el punto de vista del género, analizando sus principales mecanismos pedagógicos

\section{METODOLOGÍA}

Para esta propuesta se han rastreado las iniciativas de museos madrileños existentes desde 2019 hasta hoy. El criterio de selección de las actividades ha sido que en ellas operasen mecanismos relacionados con la mediación cultural, es decir, que en ellas se estableciera un diálogo directo entre público y objetos artístico. Así, conferencias, debates o mesas redondas han sido excluidas. Los cuatro tipos de propuestas educativas recogidas finalmente son visitas educativas, visitas autónomas mediadas por materiales educativos, cursos y actividades creativas. Según estos preceptos, y por motivos de extensión, se han registrado un total de dieciséis propuestas educativas de nueve instituciones museísticas.

\section{RESULTADOS Y DISCUSIÓN}

Desde hace tiempo venimos encontrando propuestas educativas que imbrican a las mujeres de alguna forma. Analizaremos ahora aquellas actividades desarrolladas en museos madrileños desde 2019 hasta hoy. Estas se han dividido en cinco grupos, atendiendo tanto a la clasificación que propone Marián López-Fernández Cao (2011, citado en Albero y Arriaga, 2018) como a necesidades particulares de esta investigación. Los ejes temáticos de estas actividades educativas son: visibilización de mujeres artistas, revisión del papel de la mujer, propuestas sobre el género como construcción social, revisión institucional en clave de género y la creación por parte del público femenino como motor de cambio social.

\section{La visibilización de mujeres artistas}

En este grupo de actividades resulta muy ilustrativo el Museo Nacional ThyssenBornemisza. En él son habituales las visitas educativas para cualquier franja de edad, tratando muchas de ellas la obra de mujeres artistas. Así sucede en la visita explicativa a la exposición Patriarcado (febrero-marzo 2019), donde se planteaba un diálogo entre 
obras de Cristina Lucas y Eulália Valldosera. El modus operandi consistió en plantear preguntas para reflexionar conjuntamente con las participantes: ¿cómo recibe el público estos diálogos? ¿Qué relaciones establecemos entre el título de la muestra y sus obras? ¿Cómo se pueden relacionar estas obras con la colección permanente?

Este modelo conversacional se evidencia también en la visita explicativa a la exposición Chechu Álava. Rebeldes (enero-marzo 2020), con retratos de mujeres históricas. Aquí se planteó al público los siguientes interrogantes: ¿cómo se representa a las mujeres destacables en la Historia del Arte? ¿Qué referentes tenemos del poder femenino? Esta dinamización a partir de preguntas aparece igualmente en la visita educativa online a la exposición Georgia O'Keeffe (abril-julio 2021).

El predominio de las visitas explicativas en este museo resulta muy interesante desde el punto de vista educativo. Nos estamos alejando del modelo pedagógico de los museos más tradicionales, donde era la institución quien proyectaba el discurso y esperaba que el público lo asumiese de forma pasiva. Las nuevas formas educativas incorporan aumentan la capacidad de interacción del público estableciendo un canal de doble comunicación recíproca que enriquece tanto a visitantes como a institución.

Otra propuesta destacable es el itinerario ¿Quién lo ha hecho? Una mujer por la colección permanente del Museo Nacional de Antropología (marzo-julio 2021). Este recorrido destaca piezas realizadas por mujeres de diversas culturas. La mediación cultural toma forma tanto de visitas guiadas como de material didáctico facilitado al público. No obstante, aquí no encontramos un modelo educativo interactivo como el anterior, sino una visita guiada entendida en parámetros más tradicionales donde se exponen los contenidos unidireccionalmente.

\section{La revisión del papel de las mujeres}

En este grupo destacan actividades como la visita guiada del Museo de América (marzo 2019) a la exposición La hija del Virrey. El mundo femenino novohispano en el siglo $X V I I$. El comisario de la exposición acompañaba al público por esta muestra que exponía los dos modos de vida de la América virreinal: el hispano (a través de la hija del virrey del lugar) y el indígena (mediante la vida de una mujer indígena).

Otro ejemplo es la visita guiada para adultos Feminismo. Una mirada feminista sobre las vanguardias del Museo Reina Sofía (2020-2021). Recorre las salas dedicadas a las vanguardias analizando el papel de la mujer en base a dos roles: tanto productora como receptora de obra, como sujeto y como objeto. Forma parte de una red de itinerarios sobre la colección del museo que cuestionan sus interpretaciones tradicionales. Esta visita también puede realizarse de forma autónoma, pues se proporcionan folletos y materiales educativos.

El Museo Arqueológico Nacional (marzo 2019) ofreció las visitas guiadas La mujer íbera y La mujer en la historia, que promovían el acercamiento al papel femenino en diferentes épocas históricas. En esta línea, encontramos la visita guiada El papel y los espacios de la mujer en el Museo Cerralbo (marzo 2019), donde se abordaron los principales personajes femeninos de la familia Cerralbo.

Estas actividades tampoco parten de una concepción interactiva y comunitaria, sino que se plantean partiendo del concepto educativo en el que el público es un mero receptor del discurso institucional.

\section{Propuestas sobre el género como construcción social}

Recientemente han tenido lugar los Itinerarios incómodos del Museo del Prado, visitas guiadas que "invitan a una revisión colaborativa de la colección desde una perspectiva 
contemporánea, generando espacios de conversación alejados de verdades únicas, desde el deseo de la construcción compartida de conocimiento con los participantes" (Museo del Prado, 2021). Existen tres itinerarios: Por definición (explora los prejuicios en torno a la figura de la mujer en distintos momentos históricos), Nuevas masculinidades (un recorrido por la visión trans-temporal del concepto de lo masculino que habla de identidad, emociones o violencia) y Diversidad y disidencia (parte de obras que permiten hablar de disidencias culturales, de género o conducta, reflexionando sobre el concepto de "la otredad" en la historia).

\section{Revisión institucional en clave de género}

El Museo Thyssen (2020-2021) presentó el curso online Más allá de las artistas. Género y públicos en el museo, con el que pretendía analizar cómo las instituciones museísticas están aplicando los discursos de género. Es por tanto una meta-reflexión, en tanto que estudia la propia institución y cómo cala en ella la perspectiva de género. Esta perspectiva autocrítica de la propia institución, a la par que necesaria, es increíblemente escasa, como muestra la ausencia de más actividades similares.

\section{La creación por parte del público femenino como motor del cambio social}

Esta categoría integra aquellas actividades de Educación artística basadas en la creación del público. El Museo Nacional de Artes Decorativas (marzo 2020) realizó el proyecto Lágrimas Negras, una muestra solidaria (organizada con varias asociaciones) basada en la utilización del arte como instrumento de transformación social. Se exhibió un tapiz de $2 \times 14$ metros realizado por mujeres que posteriormente se subastaría para colaborar con la lucha contra la explotación sexual.

Mediante esta iniciativa el museo apostó por valores educativos basados en la lucha contra la violencia machista y la colaboración comunitaria. Tradicionalmente, estos son valores que quedan excluidos de las políticas museísticas, en tanto que el foco de atención suele recaer en los grandes maestros (figuras individuales) y no en estas formas de creación colectiva.

Igualmente, el Museo del Traje (marzo 2019) realizó la actividad En-bola-atados. Partiendo de la palabra "embolatar" (engañar con mentiras), se transformaba su significado descomponiéndola por partes: en-bola-atar, que relataba la acción a realizar. Se ponía el punto de mira en la ropa personal, como símbolo de memoria e identidad, que se destruía y reconvertía, pretendiendo romper con las formas de discriminación hacia las mujeres.

\section{CONCLUSIONES Y LIMITACIONES}

Las actividades educativas con perspectiva de género en museos madrileños analizadas se vinculan esencialmente a dos temáticas: la visibilización de mujeres artistas y del papel de las mujeres en la historia. De las dieciséis actividades recopiladas, once se relacionan con estos dos ejes, existiendo una clara descompensación entre las diferentes temáticas. Aspectos como la revisión institucional en clave de género apenas se encuentran desarrollados aún.

Entre las actividades seleccionadas tampoco encontramos propuestas donde se abogue por una deconstrucción de las categorías conceptuales de tinte patriarcal a las que aludíamos en un inicio, lo que hace que la inclusión de la perspectiva de género en la educación en museos permanezca incompleta. 
Existe asimismo un problema fundamental: la concentración de estas actividades en el mes de marzo, perpetuándose su papel completamente secundario el resto del tiempo. La educación artística en clave de género no es una demanda que deba satisfacerse durante treinta días al año, sino un deber que los museos han de cumplir de manera integral a fin de que las generaciones venideras cuenten con referentes necesarios para desarrollarse plenamente. Deben hacerlo, además, contando para ello con educadoras artísticas especializadas en género, algo que tampoco sucede a nivel general.

Algo destacable en los datos recogidos es que existe cierta tendencia de los nuevos modelos educativos a proyectar la voz del público planteando interrogantes sobre las obras, en lugar de facilitar información unidireccionalmente. Esto es algo especialmente observable en el Museo Thyssen. Sin embargo, la ingente mayoría de las propuestas recogidas abogan aún por parámetros comunicativos y pedagógicos tradicionales. Esa brecha en la jerarquía estructural del museo que contempla la intervención y construcción del conocimiento de manera colectiva ha de continuar trabajándose, pues permite introducir nuevas voces y discursos y puede actuar como puerta de entrada de la perspectiva de género reclamada cada vez por más público para desquebrajar el ideario patriarcal institucional.

\section{REFERENCIAS BIBLIOGRÁFICAS}

Albero Verdú, S. (2017). La perspectiva de género en el ámbito educativo de los museos y centros de arte españoles [Tesis doctoral, Universidad Pública de Navarra]. https://academica-e.unavarra.es/xmlui/handle/2454/27573

Albero Verdú, S.; Arriaga, A. (2018). Educación con perspectiva de género en museos españoles. Enfoques y discursos. Géneros-Multidisciplinary Journal of Gender Studies 7(1), 1531-1555.

López-Fernández Cao, M. (2002). La educación artística y la equidad de géneros: un asunto pendiente. Arte, individuo y sociedad, 1, 145-171.

Ministerio de Cultura y Deporte (2019). Anuario de Estadísticas Culturales. https://www.culturaydeporte.gob.es/dam/jcr:3bdcb17c-050c-4807-b4f461e3714cbc15/anuario-de-estadisticas-culturales-2019.pdf

Museo Arqueológico Nacional (2019). Día Internacional de la Mujer. http://www.man.es/man/actividades/actividades-extraordinarias/202103-diamujer.html

Museo Cerralbo (2019). El papel y los espacios de la mujer en el Museo Cerralbo. https://www.culturaydeporte.gob.es/cultura/mc/espacio-deigualdad/actividades/dia-internacional-mujer-2019/actividades-museosestatales/museo-cerralbo.html

Museo de América (2019). La hija del Virrey. El mundo femenino novohispano en el siglo XVII.

http://www.culturaydeporte.gob.es/museodeamerica/actividades2/exposicionestemporales/la-hija-del-virrey.html

Museo del Prado (2021). Itinerarios incómodos. https://www.museodelprado.es/recurso/itinerarios-incomodos/c4461cef-03064d58-a370-f567175b4439

Museo del Traje (2020). En-bola-atados. http://www.culturaydeporte.gob.es/mtraje/actividades/celebraciones/diamujer/historico/2019.html 
Museo Nacional de Antropología (2021). ¿Quién lo ha hecho? Una mujer. https://www.culturaydeporte.gob.es/dam/jcr:f0a80a54-d30c-483e-8bb6ab546580524c/qui-n-lo-ha-hecho-una-mujer-ampliado.pdf

Museo Nacional de Artes Decorativas (2020). Lágrimas negras. http://www.culturaydeporte.gob.es/actualidad/2020/03/200304-artesdecorativas.html

Museo Nacional Thyssen-Bornemisza (2019). Explicación: Patriarcado. https://www.educathyssen.org/programas-publicos/explicacion-patriarcado

Museo Nacional Thyssen-Bornemisza (2020). Explicación: Chechu Álava: Rebeldes. https://www.educathyssen.org/programas-publicos/explicacion-chechu-alavarebeldes?_ga $=2.152038777 .1180555823 .1620817889$ 1654444714.1605100578

Museo Nacional Thyssen-Bornemisza (2020). Más allá de las artistas: Género y públicos en el museo. https://www.educathyssen.org/centro-estudios/educacionmuseos/curso-online-mas-alla-artistas-genero-publicos-museo

Museo Nacional Thyssen-Bornemisza (2021). Visitas educativas online para adultos: Georgia O'Keeffe. https://www.educathyssen.org/programas-publicos/visitaseducativas-online-adultos-georgia-okeeffe

Museo Reina Sofía (2020). Feminismo. Una mirada feminista sobre las vanguardias. https://www.museoreinasofia.es/visita/tipos-visita/visita-comentada/feminismo

Nochlin, L. (1988). Why have there been no great women artists? Women, Art and Power and Other Essays, 145-178.

Pérez Ibáñez, M. (ed.) (2020). Estudio sobre desigualdad de género en el sistema del arte en España. Ecosistema del Arte.

Woolf, V. (2008). Una habitación propia. Seix Barral. 


\title{
4.2. EXPERIENCIAS
}

\author{
4.2.1. Igualdad de Género y Tiempo Libre en el Campus Hondarribia \\ Azkarate-Morales, Ander (UPV/EHU, España); Santamaría-Marcian, Estibaliz (Sedena \\ $S L$, España)
}

\section{Resumen}

El Campus Hondarribia no es un campamento de verano cualquiera: un entorno incomparable, una gran diversidad de actividades y una clara intención educativa son sólo algunas de sus principales características. En la edición del año 2018, participaron un total de 2389 menores que se convirtieron en protagonistas de un conjunto de actividades desarrolladas dentro de una temática común: la igualdad de género. Cuentacuentos, Las Comisiones, La Historia de Amaia, El Diario de ... o El Cuaderno de la lgualdad son algunas de las dinámicas diseñadas con el objetivo de fomentar la toma de conciencia del citado valor. La propuesta obtuvo los resultados esperados, se constató un cambio en el discurso de las y los participantes y se confirmó la utilidad de emplear el ámbito de la educación no formal para tratar estos temas.

Palabras clave: Igualdad, Educación, Tiempo libre, Buenas prácticas.

\section{INTRODUCCIÓN Y OBJETIVOS}

La educación no formal es un ámbito de intervención que ha existido desde siempre, pero no es hasta finales de la década de los años 60 cuando se empieza a reconocer de manera oficial la existencia de este "sistema indefinido" (Colom, 2005; Coombs, 1971). Un contexto que permite que niñas y niños aprendan y desarrollen tanto la identidad propia como la social, construyendo valores de igualdad y fomentando vivencias de reconocimiento positivo ante la diversidad y la diferencia. Novella et al. (2014) afirman que la participación en estas actividades influye en múltiples aspectos, entre los que destaca la ciudadanía, la tendencia asociativa y el compromiso social.

Smitter (2006) define los siguientes principios de la educación no formal:

- Intercomplementariedad: permite la existencia de diferentes sistemas cooperativos.

- Descentralización: responde a una realidad concreta.

- Flexibilidad: proporciona una alta capacidad de adaptación a los cambios sociales.

- Inmediatez: facilita la pronta toma de decisión ante cualquier problemática.

- Practicidad: relacionado con aprendizajes prácticos que mejoran la calidad de vida de las personas.

- Cobertura amplia: gran diversidad de programas, contextos, contenidos, etc.

Así pues, la educación no formal comprende: "todo proceso educativo diferenciado de otros procesos, organizado, sistemático, planificado específicamente en función de unos objetivos educativos determinados, llevado a cabo por grupos, personas o entidades identificables y reconocidos, que no forme parte integrante del sistema educativo legalmente establecido" (Pastor, 2001, p.184).

En este marco se sitúa el Camus Hondarribia, un campamento de verano con una clara intención de educar a cada participante en áreas del desarrollo como son la educación 
en valores, las habilidades sociales, la realización personal, hábitos saludables, etc. Su finalidad general es promover, a través de la educación del tiempo libre, la transmisión de valores personales, colectivos y sociales que ayuden a desarrollar personas plenas, felices, responsables y solidarias. Como objetivos específicos, se plantean cinco grandes bloques: experiencia lúdica, crecimiento y desarrollo personal, actividad física y hábitos saludables, creatividad y la responsabilidad.

Teniendo en cuenta este marco, desde la organización del Campus Hondarribia, se decidió que durante la edición del año 2018 la igualdad de género fuera la temática a trabajar: un reto urgente de la sociedad que requiere medidas concretas en todo tipo de instituciones, universidades, asociaciones o entidades.

En relación a esta propuesta, se plantearon los siguientes objetivos:

- Introducir la igualdad de género en las diferentes áreas que componen la programación, aplicando esta perspectiva en cualquier actividad propuesta.

- Fomentar la toma de conciencia del valor de la igualdad de género.

- Generar actitudes integradoras de cooperación y respeto entre niñas y niños.

- Fomentar la conciencia sobre la desigualdad actual entre mujeres y hombres, tanto en roles, como en actitudes, valores, etc. favoreciendo un mayor grado de sensibilización al respecto.

- Utilizar un lenguaje inclusivo (ni sexista, ni discriminatorio).

- Ofrecer referentes que sirvan de apoyo y orientación, para tratar de que cada niña y niño puedan dar un sentido libre a su identidad

\section{CONTEXTUALIZACIÓN}

El Camus Hondarribia es un proyecto de Fundación Caja Navarra, una entidad privada, sin ánimo de lucro, que tiene como finalidad promover el progreso social, económico y cultural de Navarra. Sedena SL es la empresa encargada de la gestión de este campus, ofreciendo una propuesta profesional e integral en la gestión de las instalaciones y programación de las actividades.

El Campus Hondarribia se desarrolla en La Colonia Blanca de Navarra (Hondarribia, Gipuzkoa), un lugar privilegiado para disfrutar de unos días de verano, a los pies de Jaizkibel y a tan sólo 200 metros de la playa. Este servicio ofrece una respuesta eficaz y de calidad a las familias que confían en este campamento para que las y los menores pasen una semana diferente en la que, además de disfrutar y pasárselo bien, incorporen nuevos aprendizajes y desarrollen ciertas competencias. Las actividades que se programan tienen una clara intención de promover el trabajo de valores, habilidades sociales e inteligencia emocional.

Cada verano, las y los participantes se agrupan por edades en los siguientes campus:

- Campus Alevín: entre los 7 y 9 años de edad.

- Campus Infantil: entre los 10 y 12 años de edad.

- Campus Eolo: entre los 13 y 15 años de edad.

Pese a que conviven en las mismas instalaciones, cada campus tiene sus propios espacios y una programación de actividades adaptada a su edad y a sus características. Las actividades que se proponen se caracterizan por seguir una línea metodológica flexible, activa, participativa, colaborativa, motivadora y basada en el juego como herramienta principal.

En el caso del equipo de monitoras y monitores, se dividen en tres grupos, uno por campus. Hay una monitora o un monitor responsable por cada 10 participantes, y una 
persona coordinadora por campus, encargada de organizar y gestionar las diferentes actividades programadas a lo largo de toda la semana.

En la edición del Campus Hondarribia del año 2018 se llevaron a cabo 10 tandas, con una duración de 7 días cada una de ellas. El número total de participantes fue de 2389 menores, distribuidos de la siguiente forma: 366 en el Campus Alevín, 1189 en el Campus Infantil y 834 en el Campus Eolo.

\section{DISEÑO Y DESARROLLO}

El desarrollo de la presente propuesta se resume en las siguientes intervenciones:

1. Diseño de la propuesta. Para el diseño y desarrollo de las actividades se generó un equipo de trabajo multidisciplinar formado por: personal de Fundación Caja Navarra, personal de Sedena SL y asesorías externas (Universidad del País Vasco, Medicus Mundi).

2. Formación al equipo de monitoras y monitores. Se llevó a cabo un fin de semana de formación específico para las personas que iban a encargarse de poner en marcha el presente plan. La finalidad principal de estas jornadas fue desarrollar el conocimiento práctico del equipo de profesionales del ocio y tiempo libre en relación al concepto de la Igualdad. En concreto:

- Ofrecer un espacio de reflexión sobre el concepto de la igualdad de género en el tiempo libre.

- Presentar el Proyecto Educativo y el Plan de Convivencia.

- Aprender dinámicas, juegos y veladas que se llevan a cabo en verano.

- Conocer el contexto en el que se desarrollan los campamentos: localización, recursos y recorridos.

- Fomentar la interrelación entre el monitorado.

3. Desarrollo. A continuación, se presentan, de forma resumida, las actividades diseñadas para trabajar la temática con las y los participantes de cada campus:

- Campus Alevín:

- Historia de Amaia. Durante toda la semana, como hilo conductor, se presenta la historia ficticia de Amaia Mugarrieta: la única mujer que participó en la caza de la ballena blanca. Se aprenderán los orígenes de esta práctica, curiosidades de la época y, sobre todo, la importancia del papel de la mujer. El primer día de estancia en Hondarribi las niñas y los niños recibirán la visita de Ane, la nieta de Amaia, para que les hable de cómo era la vida de su abuela en el pueblo. Ane traerá consigo 5 libros que recogen la vida de mujeres que han hecho mucho por la sociedad y que en su momento no tuvieron el reconocimiento que merecían (relacionado con la siguiente actividad).

- Cuentacuentos. Las niñas y los niños dispondrán durante toda la semana de una cuidada selección de libros que narran historias relacionadas con la igualdad de género. Además, cada noche, una monitora o un monitor será la persona encargada de leer uno de los cuentos protagonizado por mujeres que cambiaron el mundo: Marie Curie, Dian Fossey, Amelia Earhart, etc.

- Camus Infantil:

- "Diario de...". El objetivo de esta actividad es escribir el desarrollo vital de una persona recién nacida basándose únicamente en una fotografía en la que, para algunos grupos, aparecerá vestida de rosa y, para otros, de azul. Para ayudarles a construir las historias 
se les pueden lanzar preguntas, como, por ejemplo: ¿a qué le gustará jugar cuando tenga vuestra edad?, ¿cómo le gustará vestirse cuando tenga vuestra edad?, ¿en qué creéis que trabajará?, ¿cómo pensáis que será cuando sea mayor?, ¿cómo pensáis que será su vida? Al finalizar la semana se pondrán en común las historias creadas y se analizarán las diferencias.

- Campus Eolo:

- El cuaderno de la lgualdad. Un cuaderno en blanco que irá pasando de grupo en grupo con la finalidad de que en él se plasmen textos, historias, citas, dibujos... un cuaderno muy especial que tiene como objetivo recopilar aportaciones relacionadas con la temática de la igualdad que las y los participantes irán haciendo durante su estancia Un ejercicio de creatividad que culmina con una puesta en común el último día de la semana.

- Actividades intercampus. Con el objetivo de fomentar las relaciones entre las y los integrantes de los diferentes campus, todos los veranos se proponen actividades intercampus. Mediante estas dinámicas se consigue que haya un momento de encuentro entre los tres grupos y los resultados de la experiencia siempre son muy positivos.

- Comisión de lgualdad. Comisión encargada de garantizar el trato igualitario entre niñas y niños y por parte del equipo de monitoras y monitores. Será la encargada de atender situaciones en las que se favorezca a uno de los dos sexos o se menosprecie por este motivo. Después de la cena, la comisión de reunirá con el objetivo de valorar el día y de decidir si ese día cada campus merece una bandera verde, amarilla o roja (según la valoración).

- Murales. Gracias a la colaboración con Medicus Mundi, se elaboraron una serie de murales que fueron colocados por las instalaciones. En ellos, se describen las vidas y las aportaciones de mujeres como Gloria Fuertes o Frida Kahlo, entre otras.

\section{EVALUACIÓN, CONCLUSIONES Y PROPUESTAS DE MEJORA}

Cada año se evalúa la intervención desde tres perspectivas: participantes, familias y el equipo de monitoras y monitores. Esta evaluación se lleva a cabo mediante una encuesta, adaptada a cada agente, compuesta por diferentes ítems en relación a aspectos tales como la temática (en este caso la igualdad), las actividades externas que se llevan a cabo durante la semana, etc.

En este caso, los datos recopilados en la edición del año 2018 fueron muy satisfactorios. Las y los participantes evaluaron muy bien el campamento, al igual que el monitorado, quien hizo un especial hincapié en la temática trabajada y los valores transmitidos cada semana.

El feedback recibido por parte de las familias mediante los diferentes canales de comunicación fue en su gran mayoría positivo y con numerosas felicitaciones por el trabajo elaborado.

Como conclusión general, he de destacar que el trabajo elaborado durante este año fue muy enriquecedor, tanto en aspectos relacionados con la organización como en la actividad diaria y momentos vividos cada día por las personas participantes en el Campus Hondarribia. 
Vídeo resumen de la experiencia:

https://www.gandere.eus/contexto/campus-hondarribia-la-igualdad-de-genero-en-eltiempo-libre/

Para más información sobre el Campus Hondarribia:

https://www.fundacioncajanavarra.es/es/educacioncultura/colonias-hondarribia

\section{REFERENCIAS BIBLIOGRÁFICAS}

Colom A. J. (2005). Continuidad y completariedad entre la educación formal y no formal. Revista de Educación, (338), 9-22.

Coombs, Ph. H. (1971). La crisis mundial de la educación. Barcelona: Península.

Novella, A. et al. (2014). Participación infantil y construcción de la ciudadanía. Barcelona: Graó.

Pastor, M. I, (2001). Orígenes y evolución del concepto de educación no formal. Revista española de pedagogía, (220), 525-544.

Smitter, Y. (2006). Hacia una perspectiva sistémica de la educación no formal. Laurus, 12(22), 241-256. 


\title{
4.2.2. Campaña TOCA IGUALDAD: Coeducar para prevenir las violencias machistas. Clara Urbano Molina (ONGD InteRed, España)
}

\begin{abstract}
Resumen
Presentamos la Campaña TOCA IGUALDAD de la ONGD InteRed (2018), una organización experta en educación y género, como una apuesta por reforzar el papel de la educación y en concreto la coeducación en la construcción de mundos libres de violencias machistas desde la educación formal y no formal. La propuesta parte de situar en el centro el papel de la comunidad educativa y para ello consideramos necesario un trabajo a diferentes niveles, que sitúe como protagonistas del cambio a las generaciones jóvenes, dado el contexto actual de inestabilidad y precariedad social y económica, agravado en España a raíz de la pandemia por el Covid19.
\end{abstract}

Palabras clave: violencias machistas, desigualdad de género, coeducación, igualdad, toca igualdad.

\section{INTRODUCCIÓN Y OBJETIVOS}

Actualmente InteRed trabaja en 12 países con más de 120 proyectos y acciones distribuidas por América Latina, África, Asia y Europa. En España tiene en activo 44 proyectos de educación, con la participación de más de $\mathbf{3 0}$ centros educativos, 27.000 escolares y 4.500 docentes $^{25}$. Esta organización sin ánimo de lucro coordina su trabajo educativo a través de campañas que posibilitan hacer proceso durante varios años, pudiendo promover así el cambio hacia fuera de la organización iniciándolo, primero, al interno de sus equipos.

En este marco, la anterior campaña de Actúa con Cuidados (2012-2017) permitió permear el saber hacer y conocimientos de la organización, teniendo entre sus objetivos "la promoción de una ciudadanía global en la medida que favorecía espacios de reflexión sobre en qué sociedad vivimos cuando lo más básico, la generación y el sostenimiento de la vida, ha quedado relegado a un último nivel de valoración y reconocimiento" (Ortega y de Arriba, 2019, p. 7). De esta forma, Actúa con Cuidados apostaba por "procesos de empoderamiento y generación de capacidades en la ciudadanía, encaminados a la transformación personal y colectiva" (ídem) ${ }^{26}$.

Fue en este proceso de concienciación interna y de praxis en la ejecución con la comunidad educativa desde la Pedagogía de los Cuidados, cuando InteRed pudo constatar cómo, a medida que se avanza en el trabajo por los cuidados es necesario trabajar la prevención de las violencias machistas. Esta conclusión a la que se llegó coincidía con las peticiones que los equipos internacionales, que llevaban trabajando el abordaje de las violencias machistas, en coherencia con el trabajo desarrollado y las necesidades detectadas en los distintos países donde InteRed interviene a través de la cooperación al desarrollo. Una conclusión que coincide también con el corazón de toda intervención con enfoque de cuidados: el objetivo no es otro que situar la vida en el centro, frente a nuestro actual modelo capitalista de desarrollo. Dicho de otra forma, la Pedagogía de los Cuidados y una mirada feminista permitieron dar el primer paso para aprender a identificar las violencias machistas. $Y$ es que, tal y como nos lo enseña la

25 InteRed (2021) Memoria 2021. Disponible en: https://www.intered.org/es/recursos/memoriade-actividades-2020 [consultada el 13 de junio de 2021].

${ }^{26}$ Para consultar el contenido y poder descargar los materiales de la campaña de Actúa con Cuidados, visitar la web: https://www.intered.org/es/que-hacemos/campanas/actua-concuidados [consultada el 12 de mayo de 2021]. 
historia de los feminismos, identificar no es fácil, aprender a ver distinto es, quizás, el paso más complicado cuando hablamos de intervenir en violencias, por distintas razones.

De esta forma, InteRed dio el salto en 2018 a la campaña TOCA IGUALDAD por la prevención de las violencias machistas a través de la coeducación, que tiene tres objetivos a nivel pedagógico (los tres pasos de la Hoja de ruta coeducativa):

\section{El primer objetivo de TOCA IGUALDAD es aprender a ver diferente: aprender a IDENTIFICAR las violencias machistas.}

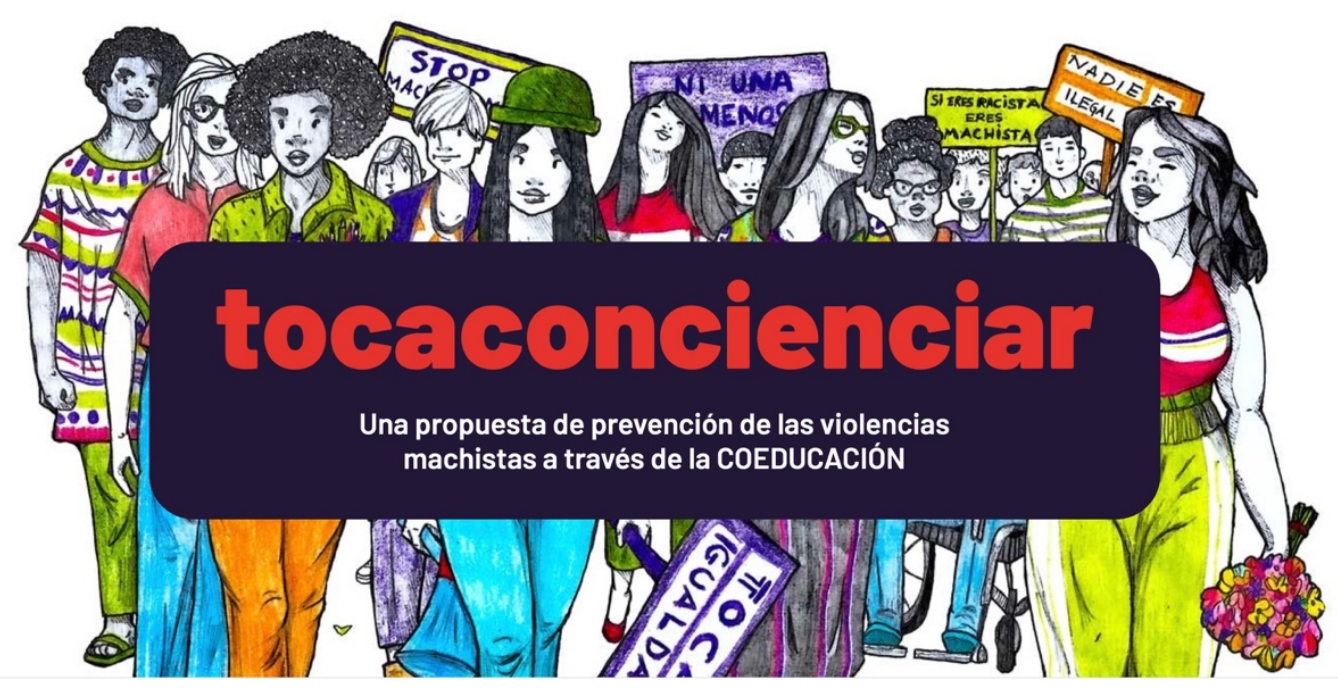

Ilustración de la web de la campaña www.tocaigualdad.org

Pero, ¿y luego?, una vez que ya sé ver "distinto" ... ¿qué puedo hacer yo para no quedar congelada/o o impotente frente a todas las violencias que he aprendido a percibir y que antes no veía? Porque inicialmente puede suponer una cierta sorpresa o un cierto shock esta toma de conciencia... Es esta "sorpresa" (entre otras razones) lo que hace que sea necesario que pensemos en colectivo, que reflexionemos y creemos consciencia con otras y con otros. Si no, es demasiado difícil, desde la nada, poder avanzar a solas, desde el cuestionamiento de nuestros afectos y nuestras formas de vida. Así, el segundo de los pasos o de los objetivos de la propuesta pedagógica de TOCA IGUALDAD es DESMONTAR, tanto individual como colectivamente, las causas que hacen posibles las violencias machistas y el actual modelo global de desarrollo.

Para poder andar este camino desde la educación, consideramos clave hacerlo a través de la COEDUCACIÓN. Entendiendo como tal, una educación transformadora que se desarrolla en igualdad y que promueve y trabaja por la igualdad. El papel de una mirada coeducativa con enfoque de ciudadanía global será la llave que permita pasar del Identificar al Desmontar, aprendiendo, paso a paso, a deconstruir nuestros aprendizajes machistas y violentos para, a continuación, construir en comunidad otros nuevos, más justos, conscientes y respetuosos con una misma y uno mismo, con todas las personas y con el planeta.

Y aún nos queda un paso más para poder formar parte de la solución: el tercer objetivo es ACTUAR. Porque sabemos que no vale con aprender a ver y a pensar ( $j a u n q u e ~ y a$ sea mucho y gran parte del camino!): necesitamos entrar en acción, individualmente y con otras y con otros. 
Como sabemos, lo que justifica la intervención de las ONGD es la realidad que creemos necesario cambiar. En este sentido, la pandemia ha puesto de relieve lo urgente que es atajar las causas de las desigualdades que reproduce nuestro actual sistema de desarrollo. El Covid19 no nos ha mostrado nada nuevo, pero sí nos ha hecho conscientes (y lamentablemente sigue haciéndolo) de cómo el mundo en que vivimos sigue estando atravesado por una realidad desigual entre hombres y mujeres y cómo esta desigualdad utiliza la violencia para poder seguir existiendo (Urbano, 2020).

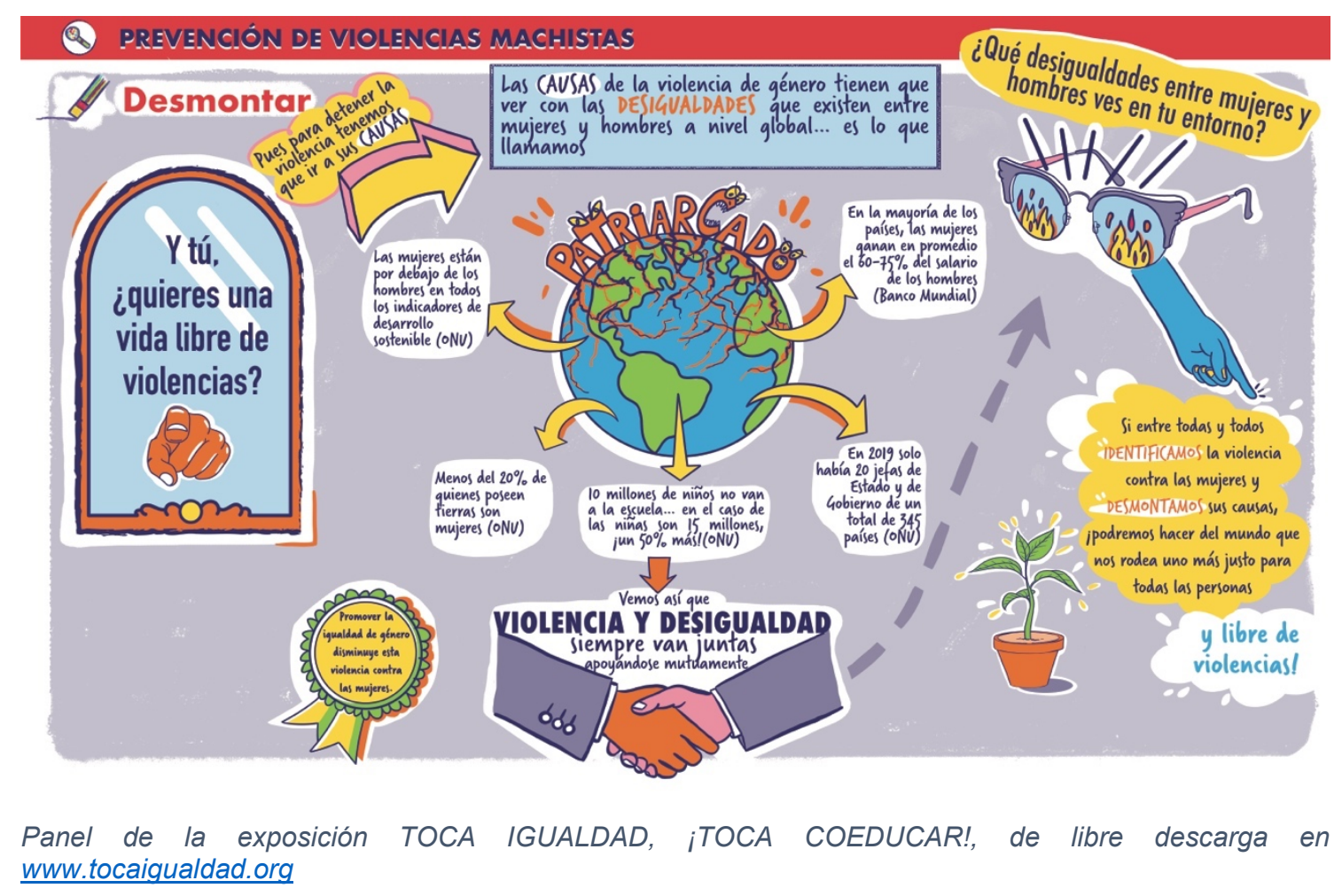

No hace falta buscar mucho a día de hoy para encontrar declaraciones de diversos expertas/os y organismos nacionales e internacionales (Ministerio de Igualdad, ONU, PNUD, etc.) que nos alertan sobre cómo, en épocas de crisis y de pandemia, el enfoque de género es uno de los puntos que los estados eliminan de su agenda más rápidamente, cuando es en estas crisis cuando debemos reforzar nuestra mirada sensible a las violencias machistas y al enfoque de género para poder activar un cambio real. Es más, ya antes del Covid19 estos mismos organismos internacionales nos avisaban de cómo estábamos retrocediendo en relación al ODS 5 de la Agenda 2030 relativo a la Igualdad de Género, debido, precisamente, al auge de los fundamentalismos y los discursos de odio a nivel global.

\section{DISEÑO Y DESARROLLO}

De cara a fomentar la construcción de mundos libres de violencias machistas, TOCA IGUALDAD plantea una intervención múltiple, propiciando así la dimensión comunitaria de la organización o centro educativo:

- con la infancia y la juventud

- con el profesorado y las y los educadores

- con la creación de grupos motores de jóvenes activistas por la igualdad

- con las familias 


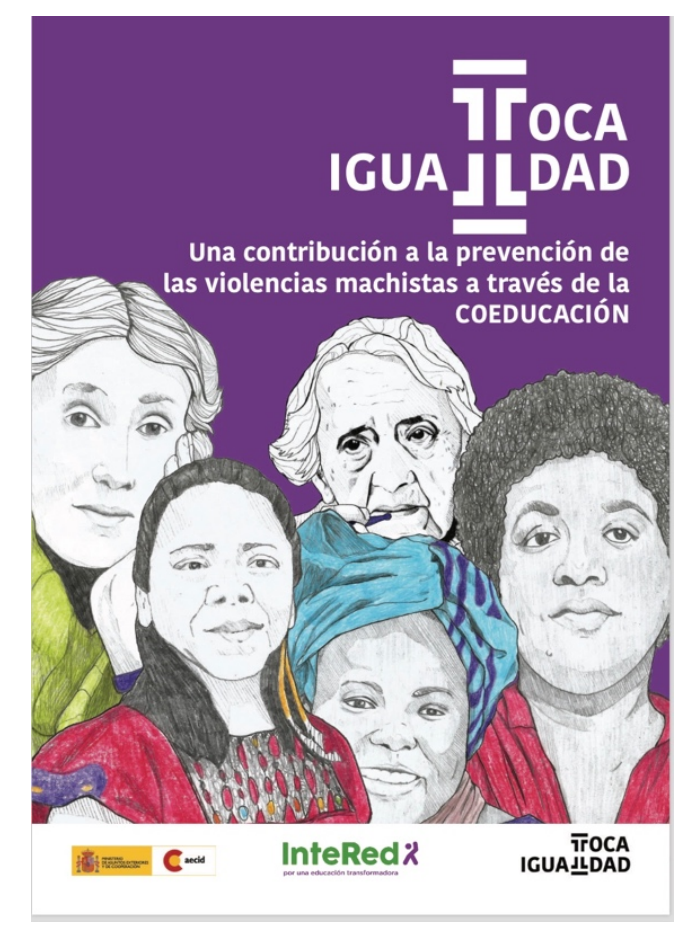

Documento de presentación de TOCA IGUALDAD.

Por otra parte, se entiende necesaria la intervención tanto en el sector de la educación formal como en la educación no formal, con una visión amplia de lo que entendemos como "comunidad educativa". En este viaje, será central el papel de los llamados grupos motores de activistas, formados por jóvenes del centro que desempañarán un papel de "faro" para la comunidad, así como poder contar con la voluntad política de la dirección o presidencia del centro u organización.

Además, tal y como recoge el documento de presentación de la campaña ${ }^{27}$, otro de los elementos clave de TOCA IGUALDAD es su propuesta coeducativa de trabajo simultáneo en cuatro ejes o áreas de reflexión-acción:

EJE 1: Poner en el centro el cuidado de las personas y del planeta favoreciendo aprendizajes que reconozcan la interdependencia entre las personas y su eco dependencia.

EJE 2: Reconocer y celebrar la riqueza de la diversidad de identidades como un valor en positivo y una fuente de transformación, repensando las identidades hegemónicas impuestas por el heteropatriarcado.

EJE 3: Promover una educación afectivo sexual respetuosa y de calidad. Entendiendo que las emociones, los afectos y la sexualidad son centrales para el desarrollo de las personas.

EJE 4: En relación directa con los ejes anteriores, consideramos la prevención de las violencias machistas como dimensión imprescindible de la Coeducación, mostrando tolerancia cero ante cualquier violencia.

Finalmente, y a nivel metodológico, InteRed entiende que "las metodologías han de ser coherentes con los fines y enfoques propuestos ${ }^{28}$. Así, las metodologías para la

\footnotetext{
${ }^{27}$ Disponible para su descarga en www.tocaigualdad.org

${ }^{28}$ Para más información sobre el Posicionamiento de Educación de InteRed y en concreto sobre sus fines y enfoques, consultar:

https://www.intered.org/sites/default/files/intered_posicionamientode_educacion_2019.pdf
} 
transformación han de atender a los enfoques de derechos, género, interculturalidad, sostenibilidad, etc. Han de ser metodologías humanistas, holísticas e integrativas, que impliquen a toda la persona, incluyendo sus dimensiones: corporal, emocional, mental y espiritual" (InteRed, 2019, p. 31).

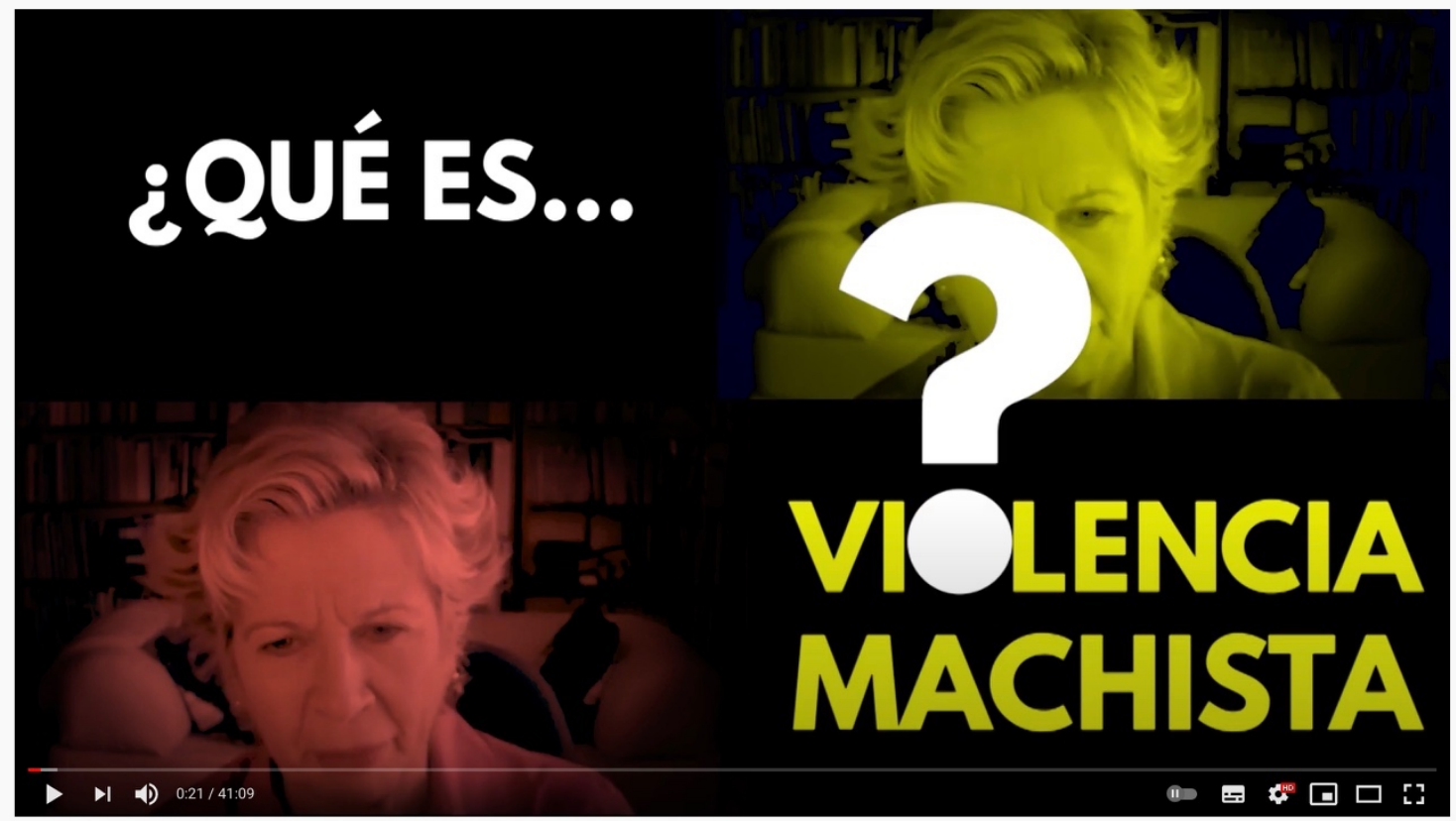

Documental: Toca Igualdad Toca Coeducar

Fotograma del Documental Toca Igualdad, Toca Coeducar, disponible en dos formatos según se necesite en la intervención educativa: descargable según la trilogía de videos breves de acuerdo a los tres pasos de la Hoja de Ruta Coeducativa (Identificar, Desmontar y Actuar): https://www.youtube.com/watch?v=ImYRuVWk2s0\&t=182s), o bien de forma completa (duración 41 minutos) en: https://www.youtube.com/watch? $v=L s r X I Z 00 a 4 U$

Hemos de decir que, durante la pandemia, el aspecto metodológico de TOCA IGUALDAD (al igual que en el del resto de intervenciones educativas de la organización) ha supuesto un reto -como bien por haberlo vivido todo el sector educativo-. Y para su abordaje hemos tenido que adaptar nuestros métodos y herramientas a la circunstancia del Covid19. Pero no sólo ha sido y sigue siendo un reto para el "cómo", sino también para el "qué", pues sabemos que la educación en formato digital ha llegado para quedarse y a día de hoy nos hacemos preguntas como éstas: ¿cómo hacer una educación digital que sea transformadora sin la presencia física que sostiene los lazos afectivos que hacen posible que el aprendizaje sea realmente transformador y nutritivo para la persona y, por ende, para la sociedad? ¿cómo dar el salto a la educación digital sin que ésta suponga "dejar a nadie atrás", sin acentuar las desigualdades que evidencia la "brecha digital"? 29

\section{EVALUACIÓN, CONCLUSIONES Y PROPUESTAS DE MEJORA}

InteRed creó desde el inicio de la campaña una herramienta de medición del impacto, a través de una web realizada en Wordpress. El procedimiento fue complejo y arrancó a

29 "No Dejar a Nadie Atrás es la promesa central y transformadora de la Agenda 2030 para el Desarrollo Sostenible y sus Objetivos de Desarrollo Sostenible (ODS). Ella representa el compromiso inequívoco de todos los Estados miembros de la ONU de erradicar la pobreza en todas sus formas, poner fin a la discriminación y la exclusión, y reducir las desigualdades y vulnerabilidades que dejan a las personas atrás y socavan el potencial de las personas y de la humanidad en su conjunto" (ONU), más información en: https://unsdg.un.org/es/2030agenda/universal-values/leave-no-one-behind [consultada el 13 de mayo de 2021]. 
partir de la creación de una serie de matrices que pretendían medir cualitativa y cuantitativamente algunos de los cambios generados en las poblaciones participantes. Con este fin, la herramienta ofrece cuestionarios y registros de grupos focales para cada colectivo, diferenciando por franjas de edad para la juventud: jóvenes de 12-14 años, jóvenes de 15-25 años, profesorado/educadores/as y familias. De esta forma, la herramienta ofrece la posibilidad de recoger datos que alimenten una línea de base inicial, previa a la intervención educativa enfocada a conocer el punto del que partimos, para posibilitar una recogida posterior a nuestra intervención educativa, de cara a conocer mejor el impacto de nuestras acciones y su mejora en fases futuras.

Como conclusiones, podemos decir que hoy más que nunca se hace necesario un trabajo en red y coordinado a nivel local y global para reforzar y defender el derecho humano a una educación de calidad para la infancia y juventud de todo el planeta. $Y$, si bien ésta es una de las conclusiones (quizás la más importante) que obtenemos del camino hasta aquí con TOCA IGUALDAD, ésta es, también, uno de nuestros mayores retos: reforzar el trabajo en red a todos los niveles en coordinación con los objetivos de la Agenda 2030 desde un enfoque transversal y real en Derechos Humanos, y que se alimente constantemente de la realidad que nos sostiene y que precisamente justifica nuestra intervención.

\section{REFERENCIAS BIBLIOGRÁFICAS}

López, L. y Aguado, G. (2019): Un currículo orientado a la ciudadanía global: aportes para su construcción. Madrid. InteRed. Disponible en: https://www.intered.org/es/recursos/un-curriculo-orientado-la-ciudadania-globalaportes-para-su-construccion

Monjas, M. y Urbano, C. (2020): Toca Igualdad. Una contribución a la prevención de las violencias machistas a través de la coeducación. InteRed. Madrid. Disponible en: https://www.intered.org/es/recursos/toca-igualdad-una-contribucion-la-prevencion-delas-violencias-machistas-traves-de-la

Ortega, M. y de Arriba, C. (2019). El valor de los cuidados en los procesos de empoderamiento de las mujeres. El caso de la Campaña "Actúa con cuidados. Transforma la Realidad". Revista de Fomento Social (74/1), 725. doi.org/10.32418/rfs.2019.293.1534

Urbano, C. (29 de julio de 2020). El impacto de la COVID-19 en la violencia de género. eldiario.es, Recuperado de: https://www.eldiario.es/opinion/tribuna-abierta/impactocovid-19-violencia-genero_129_6132839.html [consultada el 12 de mayo de 2021]. 


\subsubsection{La perspectiva coeducativa en la intervención con menores infractores \\ Julia Martínez Del Valle (Educación Pública, España)}

\section{Resumen}

El cumplimiento de una orden judicial no puede suponer una desventaja en el pleno desarrollo de los menores infractores. El Derecho a la Educación es básico y clave para la reeducación de estos jóvenes, motivo por el cual la Ley Orgánica 5/2000, de 12 de enero, reguladora de la responsabilidad penal de los menores marca como uno de sus objetivos prioritarios "disponer de un ambiente que provea de las condiciones educativas adecuadas para que el menor pueda reorientar aquellas disposiciones o deficiencias que han caracterizado su comportamiento antisocial, [...]".

La tipología de delitos más frecuentes entre estos menores, así como su alto riesgo de exclusión social, hacen necesario el desarrollo de un programa de intervención desde la coeducación, que tendrá como fin último la sensibilización y concienciación del alumnado sobre los diferentes tipos de violencias patriarcales y cómo nos deshumanizan las mismas.

Palabras clave: Derecho a la Educación; menores infractores; reeducación; reorientar, coeducación.

\section{INTRODUCCIÓN Y OBJETIVOS}

El alto riesgo de exclusión social de los menores infractores les lleva a cometer delitos contra la intimidad y libertad sexual, violencia familiar, robos, etc., mientras la criminalización de los jóvenes agresores ha demostrado ser una solución inadecuada. Por ello, una respuesta educativa adecuada en un entorno tan complejo requiere de la implicación de toda la comunidad, siendo prioridad poder trabajar con los menores en medio abierto/semiabierto, pues entendemos que el fin último de la intervención es superar los factores que propiciaron la infracción y lograr la plena inserción social.

La Ley Orgánica 3/2020, de 29 de diciembre, por la que se modifica la Ley Orgánica $2 / 2006$, de 3 de mayo, de Educación, establece que el alumnado con Necesidades Educativas Especiales (N.E.E.) es:

Aquel que afronta barreras que limitan su acceso, presencia, participación o aprendizaje, derivadas de discapacidad o de trastornos graves de conducta, de la comunicación y del lenguaje, por un periodo de su escolarización o a lo largo de toda ella, y que requiere determinados apoyos y atenciones educativas específicas para la consecución de los objetivos de aprendizaje adecuados a su desarrollo.

En la Comunidad Autónoma de Andalucía, las Instrucciones de 8 de marzo de 2017, de la Dirección General de Participación y Equidad, por las que se actualiza el protocolo de detección, identificación del alumnado con necesidades específicas de apoyo educativo y organización de la respuesta educativa, en su Anexo II, considera que este alumnado presenta Necesidades Específicas de Apoyo Educativo (N.E.A.E.) por precisar de actuaciones de carácter compensatorio.

Conforme a la legislación vigente a nivel estatal y autonómico, uno de los principales objetivos de la intervención será mejorar el nivel educativo y cultural de los menores. Para tal fin, será necesaria la toma de conciencia de las propias emociones, conductas y hechos delictivos cometidos. Este programa requiere de una escucha activa, una 
reflexión profunda y un autocontrol sobre los niveles de ansiedad/frustración de los participantes.

Siguiendo los estudios realizados por Isabel Germán y Estefanía Ocáriz (2009), si bien es cierto que los menores bajo sanciones judiciales han cometido delitos de diversa índole y gravedad, también han sufrido muchas violencias previas a los actos delictivos cometidos (violencia vicaria, abusos de autoridad, maltrato infantil, maltrato familiar, etc.), a lo que se une las carencias de un sistema educativo que les rechaza y del que ellos se terminan desvinculando. Esta realidad les marca de por vida y terminan reproduciendo el único repertorio de conductas exitosas que conocen: la violencia. Por ello será necesario analizar las diferentes relaciones familiares y de amistad desde una filosofía coeducativa, integral e integradora, que les haga identificar, analizar y parar los ciclos de violencia.

En definitiva, la intervención educativa busca garantizar la igualdad, teniendo en cuenta no sólo lo socialmente considerado masculino (fuerza, seguridad, independencia, etc.), sino poniendo en valor lo socialmente considerado femenino (la sensibilidad, la cooperación, el cuidado de los demás...), entendiendo la educación como un acto de justicia social. Por tanto, los objetivos generales de la intervención son:

- Favorecer el pleno desarrollo del individuo, desde el conocimiento de sus derechos y deberes, individuales y colectivos.

- Establecer relaciones basadas en el respeto y la igualdad real, desmontando estereotipos y prejuicios fuertemente arraigados.

- Analizar las posibles interpretaciones erróneas de la realidad que llevan al individuo a percibir el mundo de manera disfuncional.

- Favorecer el diálogo, la escucha activa, el respeto y la reflexión, en pos de la empatía y unas relaciones sociales dignas e igualitarias.

- Promover valores y actitudes contra las violencias machistas (física, psicológica, sexual, económica, patrimonial, social y vicaria).

- Sensibilizar y orientar a las familias ante estas violencias, impulsando su participación en los talleres y grupos organizados desde el centro de menores.

- Hacer partícipe a todo el equipo socioeducativo del centro y del centro ordinario de referencia, cambiando la mirada docente sobre este alumnado.

\section{CONTEXTUALIZACIÓN}

El Centro de Internamiento de Menores Infractores (C.I.M.I.) abrió sus puertas en 2016, bajo los términos establecidos en la LORPM y al Decreto 98/2015, de 3 de marzo, por el que se regula la organización, el funcionamiento y las características de los CIMI en Andalucía. Se trata de un centro que acoge a varones menores de entre 14 y 21 años que cumplen medidas de régimen cerrado, semiabierto, abierto y de fin de semana. Su cercanía a la ciudad permite el acceso al transporte público y el aprovechamiento de los recursos. Esto facilita la inserción social y comunitaria de los menores y a la vez, facilita la incorporación de la familia al proyecto educativo.

Los menores que cumplen medidas en este CIMI presentan una serie de necesidades como: identificar, analizar y eliminar las conductas disruptivas, los prejuicios y disonancias cognitivas; la necesidad de adquirir estrategias de autorregulación y autocontrol de la frustración, la ira o la ansiedad; este alumnado necesita también adquirir habilidades socioemocionales, de interacción, planificación, flexibilidad, empatía, comunicación, expresión y autocontrol emocional, etc. En definitiva, como 
señalan Herrera Pastor y Del Pozo Serrano (2018): "en este contexto es fundamental proyectar principios fundamentales de la Pedagogía Social, como son la libertad, la educación como derecho y la construcción de posibilidades a partir de la relación".

Debemos señalar la menor influencia de las familias en el comportamiento de los menores, cediendo protagonismo a las redes sociales, amistades, medios de comunicación y escuela. Además, existe un incremento de jóvenes de clases altas que cometen delitos, vinculados a grupos cuyos estilos de vida promueven el consumo de drogas, el acoso a iguales, el consumo de pornografía y prostitución, etc. Por ello se hace necesario recurrir a variables individuales y sociales para la explicación de las conductas violentas.

Los instrumentos para la recogida de esta información fueron los propios informes de los menores, donde se recogen datos relativos a la situación social y familiar, actividad laboral, datos de los expedientes judiciales, historia escolar, consumo de drogas e historial clínico, así como los datos obtenidos en el IGI-J (Inventario de Gestión e Intervención para Jóvenes) y la Escala de Desarrollo Antisocial, realizados por el equipo de especialistas en psicología del centro.

\section{DISEÑO Y DESARROLLO}

Dadas las necesidades anteriormente mencionadas, los objetivos específicos del programa son:

- Analizar y modificar pensamientos, emociones y comportamientos que conducen a cometer infracciones y justifican la violencia.

- Facilitar estrategias que permitan interiorizar la responsabilidad personal de los hechos delictivos.

- Modificar hábitos agresivos que conducen a la comisión del acto delictivo.

- Favorecer la empatía con las víctimas, así como potenciar la construcción de una vida alternativa a la agresión y violencia.

- Identificar situaciones de riesgo que incrementan la probabilidad de una recaída.

- Generar en los padres capacidad para reconocer los tipos de violencia psicológica que utilizan los hijos.

- Transmitir estrategias y técnicas de refuerzo, disciplina y comunicación.

- Hacer entender la necesidad de la presencia educativa parental, tanto psicológica como física, en la vida del hijo.

- Trabajar en la reducción de los sentimientos de culpa, fracaso y soledad, tanto en los menores como en sus familias.

- Ayudar a los menores y sus familias a reconocer las consecuencias de las violencias.

- Asesorar de forma individualizada a cada menor y familia con el objetivo de dar respuestas más precisas y adecuadas en cada caso.

El programa de intervención propuesto consta de tres fases: evaluación inicial de menores y familias, desarrollo del programa y consolidación. La fase de desarrollo consta de cuatro módulos con diez sesiones cada uno, centrados en:

- Tomar conciencia de nuestras emociones y nuestras conductas, para conocer nuestros pensamientos erróneos y buscar alternativas.

-Dinámicas de grupo (autoconocimiento).

-La autoestima y el autoconcepto. Mejora de habilidades personales y sociales.

-Relación entre ira, enfado y violencia. Estrategias para su control.

-Resolución pacífica de conflictos. 
-Técnicas de relajación.

- Hablar no sólo de los hechos delictivos/violentos cometidos, si no de los que ha visto o vivido ellos, de la experiencia de las víctimas y de su experiencia como víctimas.

-Comunicación asertiva.

-Expresión de emociones y habilidades de interacción social.

-Consecuencias del uso de la fuerza y agresiones. Víctimas directas e indirectas.

-Diferencias entre culpa, responsabilidad y justificación de la violencia.

-Solidaridad y empatía.

-Relación entre haber sido víctima y ser agresor en el futuro.

- Entender que vivimos en una sociedad que promueve la violencia de la que ellos han sido parte, pero también pueden serlo de la solución.

-La sociedad de consumo: individualismo y violencia.

-Necesidades individuales y colectivas.

-Pornografía, drogas, prostitución, robo y otras formas de violencia. Análisis y alternativas.

- Reforzar los aprendizajes y tener en cuenta las posibles recaídas/errores, sus razones y alternativas.

-Análisis de creencias sobre la familia, el amor, el sexo, la amistad, el consumo de drogas y la justificación de los abusos.

-Análisis de factores facilitadores de la conducta antisocial. Prevención de los abusos.

-Participación de la familia a través de la Escuela de Padres e intervenciones individuales.

-Generalización de resultados durante las salidas programadas en coordinación con el equipo de medio abierto.

Las sesiones serán de dos horas de duración, dos días a la semana. En la experiencia educativa participarán las familias mediante talleres formativos, así como el equipo técnico y socioeducativo. La formación a las familias será realizada por los especialistas en psicología del centro y trabajadores sociales.

Los menores deberán reconocer sus infracciones para poder acceder al programa, a fin de no entorpecer el ritmo del grupo. El programa está pensado para aplicarse en grupos de 10 miembros como máximo.

No deberá pasarse a la siguiente sesión hasta que la anterior no se haya completado de forma adecuada, considerando el ritmo de cada menor. Además, se reforzarán los contenidos trabajados en sesiones individuales de intervención a través de la acción tutorial. Las actividades se realizarán coordinadamente con otros profesionales y programas de intervención psicosocial del CIMI y estarán enfocados a despertar una actitud crítica y reflexiva mediante debates, análisis de noticias, películas, libros, charlas y entrevistas, historias de vida, análisis de los propios contextos sociales, etc.

\section{EVALUACIÓN, CONCLUSIONES Y PROPUESTAS DE MEJORA}

Además de la participación y los cambios globales en los menores, se contará con otras técnicas de evaluación como apoyos visuales, el uso de un lenguaje sencillo, la presentación y secuenciación de las preguntas según las necesidades que puedan 
surgir, el uso de aplicaciones y programas informáticos, la flexibilidad de las sesiones y la generalización de los aprendizajes.

La evaluación de los progresos del alumnado se realizará teniendo en cuenta los indicadores de evaluación vinculados a los objetivos generales y específicos de la intervención coeducativa, estableciendo el grado de consecución de los mismos (NI. No iniciado - EP. En proceso - C. Conseguido).

Se realizará una evaluación inicial, continua y final, de manera que se tengan en cuenta cada pequeño avance del menor, desde una perspectiva comprensiva y utilizando instrumentos de evaluación como:

- Observación sistemática y registro de las sesiones.

- Diario de aula. Valoración del trabajo diario.

- Generalización y consolidación de los aprendizajes.

- Rúbricas.

Se llevarán a cabo reuniones periódicas entre los profesionales con intervención directa con los menores para el adecuado seguimiento del programa. En cuanto a la mejora de la práctica docente, utilizaremos rúbricas del proyecto, donde tendremos presente los objetivos establecidos en la programación de la intervención educativa, la consecución de las competencias clave y la participación de todos los agentes implicados en el proceso de enseñanza-aprendizaje del menor que cumple medidas judiciales.

\section{REFERENCIAS BIBLIOGRÁFICAS}

Consejería de Justicia e Interior, (2018). Guía de Centros y Servicios de Justicia Juvenil. Junta de Andalucía.

Decreto 98/2015, de 3 de marzo, por el que se regula la organización, funcionamiento y características de los Centros de Internamiento de Menores Infractores de Andalucía y se crea la Comisión Andaluza de Centros de Internamiento de Menores Infractores. Boletín Oficial de la Junta de Andalucía, número 44.

Defensor del menor de Andalucía (2014). Informe especial. La atención a menores infractores en centros de internamiento de Andalucía. Defensor del Pueblo Andaluz.

Garay, B., Lasarte, G., Tresserras, A., López de Arana E., Martinez, J. y Corres, I. (2019, junio). Cambiemos la Mirada Docente ante el Alumnado que Nadie Quiere: De un Problema de Conducta a un Tema de Justicia Social. Actas del XIX Congreso Internacional de Investigación Educativa (Vol. I) (351-356). AIDIPE. Madrid. España.

Germán, I. y Ocáriz, E. (Diciembre 2009). Menores Infractores/menores víctimas: hacia la ruptura del círculo victimal. EGUZKILORE, (23), 287 - 300. 23-GermanOcar.indd (ehu.eus)

Herrera Pastor, D. y Del Pozo Serrano, F. (2018). Educar entre muros, el reto de educar desde la privación de libertad. Desafíos para la Educación Social en tiempos de cambio. Propuestas de trabajo para la intervención socioeducativa. (165-186). Aljibe.

Herrera Pastor, D. y Del Pozo Serrano, F. (2019, junio). La Educación Social entre Muros: Retos para Educar en Contextos de Privación de Libertad. En Actas del XIX Congreso Internacional de Investigación Educativa (Vol. I) (883-888). AIDIPE. Madrid. España. 
Instrucciones de 8 de marzo de 2017, de la Dirección General de Participación y Equidad, por las que se actualiza el protocolo de detección, identificación del alumnado con necesidades específicas de apoyo educativo y organización de la respuesta educativa. Instrucciones de 8 de marzo de 2017 (juntadeandalucia.es)

Ley Orgánica 5/2000, de 12 de enero, reguladora de la responsabilidad penal de los menores. BOE-A-2000-641. https://www.boe.es/eli/es/lo/2000/01/12/5/con

Ley Orgánica 3/2020, de 29 de diciembre, por la que se modifica la Ley Orgánica 2/2006, de 3 de mayo, de Educación. BOE-A-2020-17264. https://www.boe.es/eli/es/lo/2020/12/29/3

López Sánchez, F. (1994) Agresores y agredidos. Los abusos sexuales de adolescentes. Estudios de Juventud. $\mathrm{n}^{\circ}$ 4298, 27-33. https://www.bienestaryproteccioninfantil.es/imagenes/tablaContenidos03SubSe c/Revista42-4.pdf

Nevado, F. C. (2007). La intervención psicoterapéutica, social y familiar con menores infractores-víctimas. Fundación márgenes y vínculos, (1-16).

Ortega, C.E., García, G.J., De La Fuente, S.L. \& Zaldívar, B.F. (Noviembre, 2012). Metaanálisis de la reincidencia de la conducta antisocial penada en adolescentes españoles. EduPsykhé, (2), 171-189.

Redondo, S., Martínez, A. y Pueyo, A. (2011). Factores de éxito asociados a los programas de intervención con menores infractores. Ministerio de Sanidad, Política Social e Igualdad. 


\subsubsection{Memoria e investigación de la educación en relación: Igualdad, Justicia y Cultura de Paz en las relaciones \\ interpersonales y con la naturaleza. El poder de la imagen. Concha Gaudó Gaudó (WILPF España, España); Carmen Durán Martínez (WILPF España/FIBGAR), España y otras}

\section{Resumen}

Proponemos la recuperación y el análisis de la imagen de la igualdad y de la paz en cualquiera de los medios del mundo circundante. El punto de partida es el análisis de la imagen, histórica y actual en algunos elementos visuales:

1- La exposición temática "100 Años de WILPF (Liga Internacional de Mujeres por la Paz y la Libertad)".

2- Audiovisual "Cómo viven actualmente la igualdad/desigualdad las mujeres en distintos trabajos". FIGBAR. Análisis comparativo del cumplimiento de los DDHH.

3- Audiovisual "Un viaje hacia la voz, el trabajo y el voto de las Mujeres". Instituto Aragonés de la Mujer-Gobierno de Aragón. 2001.

La metodología tiene como base propiciar el diálogo y el debate. Invitando al alumnado a intervenir, participar sobre alguno de los ejemplos propuestos, tanto de forma individual como en grupos.

Palabras clave: igualdad; pacifismo; justicia; DDHH; visibilidad.

\section{INTRODUCCIÓN Y OBJETIVOS}

Las autoras de este trabajo somos todas profesoras de Educción Secundaria (Inglés, Matemáticas, Filosofía e Historia) con experiencia en proyectos educativos centrados en los $\mathrm{DDHH}$, en educación para la Paz, en cooperación, activismo social, por los DDHH, la Justicia Humanitaria y Justicia Universal, y la cultura de paz, y hemos colaborado con distintas instituciones como Escuela Instrumento de Paz, y el Centre International de Formation à l'Enseignement des Droits de l'Homme et de la Paix (CEFIDOP), AIPAZ, FIBGAR (Fundación Internacional Baltasar Garzón) y otras.

La refundación de WILPF en España en 2011, organización a la que pertenecemos, y la celebración del centenario de la organización en La Haya en el año 2015, nos animó a preparar la exposición "100 años de WILPF" para dar a conocer la organización y difundirla, especialmente en el ámbito de la Cultura de Paz.

Las distintas problemáticas que afectan de forma global a la humanidad, los conflictos que surgen por múltiples alteraciones entre Estados o instituciones hacen de imperiosa necesidad un mínimo conocimiento de la actuación de la justicia tanto a nivel próximo como a nivel transaccional hacia la aplicación global y de la Justicia Universal.

Los objetivos principales de la actividad son:

- Difundir los DDHH, los Derechos de las niñas y niños y los Derechos de los Pueblos como base CIVICA y relación con la Naturaleza.

- Promover el conocimiento de los DDHH, DDNN, DDPP en todo espectro educativo como base de la Educación y Cultura de Paz.

- Estimular a la participación crítica constructiva en el proceso educativo personal y de mejora interrelacional y con la naturaleza. 
- Adecuar los centros escolares a las inquietudes e intereses propios y de la actualidad en la búsqueda de soluciones creativas y pacíficas

- Valorar la Educación y Cultura de Paz como estímulo personal y mejora social.

- Propiciar la formación continua como mejora de vida, del entorno social y medioambiental.

- Presentar la organización WILPF y otras organizaciones pacifistas y el trabajo de importantes mujeres por la paz en el mundo

Proponer la mediación y la no violencia como forma de resolución de conflictos a escala personal, social y mundial.

- Mostrar la determinación de la igualdad entre los seres humanos, en el ámbito personal, social y mundial.

- Valorar la importancia de la justicia, su proximidad a la ciudadanía, lenguaje y sus ámbitos de aplicación.

- Conocer los objetivos de la Liga Internacional de Mujeres por la Paz y la Libertad-

- Diferenciar la finalidad de otras organizaciones que promueven el entendimiento cívico, la mediación y la resolución pacífica de conflictos.

\section{CONTEXTUALIZACIÓN}

La Declaración Universal de los Derechos Humanos, fue proclamada en la Asamblea de Naciones Unidas el 10 de diciembre de 1948. Pero estos derechos, inalterables e iguales para todos los pueblos, para todos los miembros de la familia humana, han tardado mucho tiempo impregnar el ámbito escolar y social y sigue siendo necesario el trabajo pedagógico para su cumplimiento, desarrollo y ampliación.

El compromiso como docentes con la Educación en Valores nos ha llevado a trabajar en las aulas la Declaración Universal de los Derechos Humanos, los DDNN y DDPP, como base y horizonte principal, desde el que combinamos nuestro objetivo con los objetivos de la Liga Internacional de Mujeres por la Paz y la Libertad, una organización que desde hace más de 100 años trabaja por la igualdad, la paz y la libertad, principios incluidos en la Declaración Universal y que nos permiten incidir también en nuestros objetivos educativos de las distintas materias y actividades transversales propias del ámbito escolar y del entorno familiar y social e institucional.

En los programas oficiales y los currículos escolares oficiales apenas se nombra el trabajo realizado desde las organizaciones pacifistas y las organizaciones de mujeres por la conquista y desarrollo de los Derechos Humanos ni de las instituciones supranacionales como el Tribunal Internacional de Arbitraje, Corte Penal Internacional, la Sociedad de Naciones o las Naciones Unidas, o de los programas internacionales de desarme, abolición de armamento químico y nuclear, etc. Esta presentación transversal de la incidencia política desde la sociedad civil nos permite recuperar estas lagunas curriculares y ampliar el horizonte educativo.

\section{DISEÑO Y DESARROLLO}

Nuestro punto de partida como motivación en igualdad y por los derechos individuales y colectivos y la participación en acuerdos y tomas de decisión conjunta es la presentación de la exposición "100 años de WILPF". Se trata de una muestra gráfica 
compuesta de 46 paneles que recorren los principales momentos y acciones que la Liga Internacional de Mujeres por la Paz y la Libertad ha realizado en todo el mundo a lo largo de sus 100 años de historia. (La exposición está disponible en castellano, euskera (a iniciativa del Gobierno de Navarra), catalán e inglés. También existe une versión online disponible en la web de WILPF España).

Y, además, el material audiovisual aportado y visibilizado en web FIBGAR Fundación Internacional Baltasar Garzón, como actividad en "el mes de las mujeres" en donde distintas mujeres cuentan cómo "viven la igualdad" en sus respectivos trabajos, las deficiencias y propuestas de necesaria actualidad para una "igualdad digna".

\section{Contenido temático.}

En una segunda fase, y según la demanda del profesorado que apoya esta actividad, realizamos una charla introductoria, una explicación guiada por la exposición o combinamos ambas cosas. La finalidad es llegar a la reflexión personal y colectiva sobre los tres ejes en los que gira la actividad actual de la organización:

- Alcanzando una Voluntad Crítica (Reaching Critical Will). Partiendo de la lectura/recordatorio DDHH, aprobados en 1948, comparar si se conocen, se cumplen en 2021, tratamos de vivenciar aspectos de la cultura de paz y de igualdad, en que situaciones se cumplen y en que otros aspectos sería preciso ampliar para una mejor conciliación, formación y participación profesional/social de las mujeres.

- Paremos la carrera armamentística (Stop The Arms Race. STAR), para alcanzar la abolición total y universal de todo tipo de armamento. Ampliar conocimientos sobre fábricas de armas, a que países se venden, inversión anual de los estados en material armamentístico y militar.

- Mujeres por la paz (Peace Women), para incrementar la presencia de las mujeres en las negociaciones de paz, en cumplimiento de la Resolución 1325 de las Naciones Unidas sobre Mujeres Paz y Seguridad (2000). Más presencia y participación de mujeres en órganos de decisión. Más formación e inclusión.

Estos ejes se pueden trabajar desde distintas perspectivas, de investigación históricas o enfocadas al momento actual (nos adaptamos a la demanda del profesorado responsable). La exposición siempre permite tener una visión de conjunto y relacionar los temas y los procesos. El audiovisual, parte de la actualidad y exigencias sin cumplir.

\section{Metodología.}

Participativa. Individual. En equipos. En gran grupo.

La metodología esencial se orienta a provocar el interrogante, ante lo visibilizado/escuchado, a través del dialogo y del debate. Partimos de las reflexiones, preguntas o comentarios del alumnado.

Esta metodología se adapta, en función de las personas destinatarias, edad, intereses, etc., de forma oral o escrita, promoviendo la reflexión personal y en equipos, con conclusiones comparativas de otros grupos y opiniones diferentes.

Todos nuestros proyectos están encaminados a conocer los derechos históricos (ddhh, ddnn, ddpp) cómo se cumplen a nivel personal en los distintos entornos que vivimos, escolares, profesionales, locales e interrelación con las distintas administraciones, organismos e instituciones. Abordamos la necesidad de la "ampliación" de estos derechos a las circunstancias actuales: con la inclusión de derechos como el derecho al 
cuidado de la Naturaleza, el derecho a la Paz, al bienestar, el derecho al cuidado, .... Y la resolución pacífica de los conflictos como forma de articular la convivencia entre los seres humanos, con todo lo que esto conlleva: justicia, igualdad, desarrollo económico, trabajo y vida en sostenibilidad y dignidad.

"Porque la violencia es evitable, nosotras elegimos la no violencia, como medio y como fin" (WILPF. Manifiesto. La Haya, 2015). Queremos generar un pensamiento crítico entre mujeres y hombres, basado en la colaboración, el respeto a los DDHH, el desarrollo de nuevas masculinidades, para lograr la igualdad, la justicia y la paz, derechos humanos básicos.

\section{EVALUACIÓN, CONCLUSIONES Y PROPUESTAS DE MEJORA}

En la o las sesiones, tanto en círculos sociales como escolares, hacemos siempre una reflexión/valoración final con las personas participantes sobre el contenido, forma y aportación del material y desarrollo de la misma, de forma oral y/o escrita.

Solicitamos a las personas responsables que nos aporten una evaluación externa y nos indiquen los posibles cambios y puntos de mejora, previa entrega de un mínimo cuestionario, flexible y adaptado a la situación concreta.

Nos interesa evaluar, esencialmente, el clima de "vivencia de los Derechos" a nivel personal, en los distintos ámbitos: comunidad escolar, grupo social, etc., con el fin de potenciar la interiorización y análisis crítico sobre estos temas.

Es importante que en la valoración participen todas las personas implicadas y que conozcan los resultados, para promover una reflexión crítica y poder así ofrecer una mejora del cumplimiento de los Derechos Humanos.

\section{REFERENCIAS BIBLIOGRÁFICAS}

Sandra Blasco Lisa y Carmen Magallón Portolés. 2020. Feministas por la paz. La Liga Internacional de Mujeres por la Paz y la Libertad en América Latina y España. Barcelona. Icaria.

Gertrude Bussey y Margaret Tims. 1980. Pioneers for Peace. Women's International League for Peace and Freedom 1915-1965. Oxford, Alden Press.

Victoria Camps. 2021. Tiempo de Cuidados. Barcelona. Editorial Arpa.

David Cortright. 2008, $8^{a}$ ed. 2014. Peace. A History of Movements and Ideas. Cambridge. Cambridge University Press.

Declaración Universal de los Derechos Humanos. 1948.

Declaración de los Derechos del Niño. 1959.

Declaración Universal de los Derechos de los Pueblos. 1976.

Baltasar Garzón. 2020. La encrucijada. Ideas y valores frente a la indiferencia. Barcelona. Ediciones Carena.

Manuel Rivas. 2020. Zona a Defender. Madrid. Alfaguara 
Bertha von Suttner. 1889-2014. Abajo las Armas. Madrid. Editorial Cátedra.

Irene Vallejo. 2020. Manifiesto por la lectura. Madrid. Siruela.

vv.aa. 2012. ACTÚA: 12 llamadas a la acción frente a la crisis económica, política y social. Barcelona. Editorial Debate.

También pueden verse:

Fundación Internacional Baltasar Garzón (FIBGAR): https://fibgar.es

Women's International League for Peace and Freedom

(WILPF Internacional): https://www.wilpf.org/

Liga Internacional de Mujeres por la Paz y la Libertad

(WILPF España): https://wilpf.es/ 


\subsubsection{En los caminos del poder: el caso de las mujeres Morales Arencibia Julita (Universidad de Pinar del Río Hermanos Saíz Montes de Oca, Cuba).}

\section{Resumen}

La presente investigación teniendo en cuenta los cambios acontecidos en la economía cubana desde el 2011 hasta la actualidad, se propuso reflexionar críticamente sobre el poder de las mujeres en el contexto cubano, es decir, si es que se puede definir de esta manera, así como abordar algunas experiencias de emprendimientos de titulares féminas en el sector cuentapropista y los impactos generados en tiempos de pandemia. Asimismo, se utilizaron como herramientas metodológicas necesarias la revisión bibliográfica en función de un posicionamiento teórico y la entrevista personalizada para ahondar en las experiencias práctica del estudio. Donde se obtuvo que aún las féminas estudiadas necesitan trabajar en la creación de alianzas entre y para las mujeres emprendedoras en tiempos de pandemia y otros procesos, potenciando la sororidad como una cualidad para desarrollar el empoderamiento femenino, proceso crítico de transformación social de la sociedad en su conjunto y emancipador de las relaciones sociales.

Palabras clave: Género; Poder; Emprendimientos Femeninos, Mujer; Cuentapropismo.

\section{INTRODUCCIÓN Y OBJETIVOS}

¿Qué es el poder y cómo utilizarlo? Constituyen las interrogantes en torno al acceso de las mujeres al poder y su inserción en el mundo laboral, que históricamente ha sido diferente con respecto a los hombres. En este campo resulta interesante apostar por la reivindicación de los derechos de la mujer en las sociedades industriales, bajo el principio de la equidad social.

Sería interesante entonces, partir de un análisis de las teorías que de forma general han abordado la temática, tales como: las Teorías Neoclásicas del Capital Humano, Teorías de Parcelación del Mercado de Trabajo, la Teoría Dialéctica de Anthony Guiddens de Estructura-Acción, Teoría de la Desigualdad de Género, Teoría del Techo de Cristal o Efecto Matilde, Teoría del Empoderamiento Femenino para encontrar en ellas las premisas básicas en las que profundizará la investigación en el contexto cubano acorde a lo que se proyecta en el mercado laboral.

Es por eso, que a la corriente académica Gender and Development (GAD) se le reconoció como resultado importante sus avances en la formulación de estrategias que trataron de invertir las relaciones de poder en el campo de los proyectos de desarrollo partiendo de los conceptos y estudios de autoras como Kate Young y Maxine Molyneux. ${ }^{30}$

Por lo que se asume por empoderamiento de las mujeres o femenino: "aumento de la participación de las mujeres en los procesos de toma de decisiones y acceso al poder, así como la toma de conciencia del poder que individual y colectivamente ostentan las

\footnotetext{
${ }^{30}$ La corriente teórica Género en el Desarrollo (GED), desde los movimientos sociales analiza la construcción social de roles y relaciones de género, la división sexual del trabajo en sociedades específicas, aspectos invisibles del trabajo productivo y reproductivo de la mujer, las desigualdades de género; así como el poder y su relación con el género para empoderar a las mujeres.
} 
mujeres y que tiene que ver con la recuperación de la propia dignidad de las mujeres, y el fortalecimiento de sus propias potencialidades y capacidades" (Rojas, 2017). Es decir, implica deconstruir las construcciones socioculturales negativas en torno a la etimología del concepto y posicionarse en el principio de la autonomía como expresión de la tenencia de capacidades, el derecho de actuar y a tener influencia las mujeres con ellas mismas y su entorno social.

Asimismo, la presente investigación tiene como objetivo: reflexionar críticamente sobre el poder de las mujeres en el contexto cubano, es decir, si es que se puede definir de esta manera, así como abordar algunas experiencias de emprendimientos de titulares féminas en el sector cuentapropista y los impactos generados en tiempos de pandemia.

\section{CONTEXTUALIZACIÓN}

La presente investigación tendrá como punto de partida las transformaciones en el diseño de la política de empleo desde el (2016-2019), específicamente el auge del trabajo por cuenta propia en la sociedad cubana, así como la emancipación y participación de la mujer en la vida pública, en dicho espacio laboral con el propósito de analizar y valorar el empoderamiento de la misma en la sociedad y cómo ha tributado a su desarrollo comunitario, teniendo en cuenta que para que se produzca habrá que partir: de la deconstrucción de la falsa conciencia del empoderamiento de la mujer que ocurre desde lo teórico-práctico en torno al desempeño en un cargo político, sino que se construye en una relación bidireccional que se produce en dos niveles: individual y colectivo, desde una dimensión económica, cultural, social y psicológica que se expresa en un análisis de crítico de la conciencia de poder y la toma de decisiones que tienen que ver directamente con las capacidades que desarrolla la persona y cómo estas capacidades contribuyen a transformar el entorno.

Igualmente, resultó interesante señalar que el 8 de marzo de 2021 se aprobó el Programa Nacional de Adelanto de la Mujer, el cual tiene entre sus prioridades visibilizar, respaldar el empleo femenino y sus modificaciones, así como el empoderamiento de la mujer en el contexto cubano.

No obstante, a pesar de que la provincia de Pinar del Río no es de las que más crece en el país en términos de la gestión de la política de empleo, específicamente en el Sector No Estatal de la Economía (SNE) o Sector Privado (SP), se tomó una muestra de 15 mujeres inscritas como dueñas de negocios en el sector cuentapropista (SCP) en el municipio de Pinar del Río pertenecientes Consejo Popular Capitán San Luis, donde se concentra la mayor cantidad de actividades económicas en el sector cuentapropista en el municipio.

\section{DISEÑO Y DESARROLLO}

La experiencia educativa que se socializa es parte de una investigación en proceso de formación doctoral en Ciencias Sociológicas en el contexto cubano, donde precisamente para este tipo de socialización de experiencias se inscribe en la educación no formal, teniendo en cuenta que la lucha por la emancipación de la mujer en el ámbito público continúa siendo un espacio en cual minimizar brechas por concepto de género. Partiendo de la situación que a nivel mundial ha generado la pandemia del Covid-19 y sus impactos, los resultados que aquí se presentan forman parte de un análisis de las 
autoras con un grupo de la muestra de estudio debido a que la mayoría de las mujeres titulares de emprendimientos femeninos tuvieron que cerrarlos producto a la situación epidemiológica que se ha evidenciado en el país. Para ello, se recurrió a la revisión bibliográfica en función de un posicionamiento teórico y la entrevista personalizada para ahondar en las experiencias prácticas del estudio. Válido acotar que, aunque no se emplearon técnicas de evaluación, si se utilizó la lluvia de ideas para llegar al consenso de lo que significó en su dinámica de vida esta actividad.

En la aplicación de la entrevista personalizada se obtuvo los siguientes resultados:

La totalidad de las mujeres entrevistadas tiene una edad promedio de 38.5 años de edad, con estado civil casada o en unión consensual excepto una que es divorciada, todas con un alto nivel instrucción universitarias. Por otra parte, excepto una todas tienen hijos (as) y su lugar de residencia es en el centro de la ciudad de Pinar del Río.

En cuanto al puesto que desempeñan actualmente se describe cómo titulares de: Servicios gastronómicos en cafetería, artesano, florista, gimnasio y salón de belleza, donde la inscripción de estas patentes estuvo dada en el período de 2013-2017. No obstante, resulta válido aclarar que en su generalidad las mujeres estudiadas de la muestra tienen como años de experiencias patentada alrededor de 10 años aproximadamente, pero como titulares de su propio negocio en el período que se mencionó anteriormente.

En su generalidad, todas se desempeñaron en la realización de su actividad laboral en el sector estatal acorde a la carrera universitaria que estudiaron, pero paralelamente cuando el país dio apertura en sus readecuaciones de la economía y el empleo a partir del año 2011 las mujeres del presente estudio encontraron una vía para cumplir sus aspiraciones en el sector privado, resulta interesante en este sentido traer a colación una frase que se repite en casi todas: "Siempre me gustó ser mi propio jefe" y "tener mi negocio propio".

La decisión de trabajar del sector estatal al privado estuvo dada por: condicionantes económicas, de tenencia de una vivienda, de cambios acontecidos en el sector educacional en la enseñanza media superior, por aspiraciones personales, así como con la oportunidad de ayudarse a sí mismas sino a otras mujeres y hombres al igual que ellas.

En el ejercicio de este trabajo por cuenta propia las mujeres estudiadas han expresado haber afrontado varias dificultades relacionadas con: la preparación y/o educación para llevar adelante un actividad de este tipo, la confianza a desarrollar con las personas que te rodean, la obtención de materiales, insumos y recursos necesarios para el desarrollo de la actividad, la implementación de la tarea de ordenamiento monetario que ha implicado un aumento de los precios en el mercado minorista y un acceso a los recursos en una moneda que no es la que circula en dinero físico en el país, así como, un cambio en las ofertas que se les realiza a los clientes y consumidores a partir los cambios generados en las tarifas de precios en los servicios que se ofertan.

Ahora bien, en cuanto a las facilidades percibidas está dado por: la construcción de un negocio familiar, el cumplimiento de un sueño personal que ha conllevado mucho esfuerzo, las utilidades económicas que genera no solo para ellas sino para sus trabajadores (as) contratados (as), la flexibilidad de horario en cuanto a que soy mi propia jefa lo que exige de mí compromiso y responsabilidad en el trabajo, así como la realización de una actividad con la cual me siento satisfecha y los que me rodean también. 
Las mujeres entrevistadas sostienen que la cuestión relacionada en cómo articulan la vida familiar con la laboral es una relación que se construye diariamente debido a las dinámicas propias que impone la vida cotidiana, pero que han contado con un total apoyo de sus familias, hijos (as), relaciones de pareja, amigos (as), vecinos en fin que se ha construido toda una red de apoyo a la mujer trabajadora que se multiplica en diversos roles, donde se sienten orgullo por la actividad que desempeñan y cómo lo hacen.

Por su parte, la pandemia ha impuesto retos importantes, en este sentido, las titulares de negocios sostienen que las estrategias o soluciones que han tenido que implementar para mantener la estabilidad de su negocio ha estado vinculado a lo siguiente:

- Cambios en la oferta de los servicios.

- La introducción de los servicios en las redes sociales.

- Implementación adecuada de los requerimientos de salud.

- Cierre del negocio en algunos momentos.

- Reducción de la plantilla de trabajadores producto a que no todos viven en el municipio de Pinar del Río y está paralizado el transporte local, intermunicipal y provincial.

En este sentido, resulta interesante señalar que todas las titulares de negocios de la investigación tienen trabajadores (as) contratados (as) donde refieren haber cumplido con las demandas y protección de los derechos laborales de sus trabajadores según los establecido en la Ley No. 116/2013 Código de Trabajo. Gaceta Oficial No. 29 Extraordinaria de 17 de junio de 2014. ISSN 1682-75, no obstante, se cuestionan y plantean la idea de ¿por qué tienen que ser ellas las que paguen las prestaciones sociales si sus trabajadores le pagan el tributo al Ministerio de Trabajo y Seguridad Social? Independientemente, de que lo han hecho tienen ideas contradictorias y falta de conocimiento con lo establecido por la ley en un sentido general.

Desde el punto de vista económico, para la realización de esta actividad desde sus inicios las mujeres han contado con la ayuda de familiares, amistades, relaciones de pareja anteriores, acumulación de un pequeño capital antes de ser titulares de negocios, así como, la solicitud de un crédito en el banco lo que les posibilitó emprender en este nuevo cambio en términos de empleo. En la actualidad, debido a las transformaciones que ha generado la pandemia para la estabilidad del negocio han introducido nuevos cambios en cuanto a los servicios, en algunas ocasiones han cerrado de manera temporal 2 o 3 días y en otras ha habido reducción de plantillas laborales producto a temas como el transporte debido a que en estos momentos está interrupto.

Y, por último las mujeres de la investigación plantearon respecto a las mejoras que propondría para las personas en este sector, no sólo para las mujeres, sino también para los hombres, tales como: adquisición de una mayor cultura jurídica en torno a la actividad que realiza, revisión por parte del Estado del establecimiento de una cuenta única en una moneda que no circula en físico en el país para la compra de productos y materiales para ofertar los servicios y su correspondencia con la tarifa de precio en el mercado minorista, es decir, los usuarios o clientes, las utilidades y ganancias, así como la diversificación de otras áreas de servicios al interior del mismo negocio sin que medien tantos trámites burocráticos.

\section{EVALUACIÓN, CONCLUSIONES Y PROPUESTAS DE MEJORA}

En el desarrollo de la experiencia en principio no se han utilizado técnicas de evaluación, pero indistintamente en el encuentro con las entrevistadas del estudio en una 
conversación coloquial se ha empleado la lluvia de ideas como una técnica participativa o de consenso en cuanto a la temática abordada, en las que han hecho énfasis en las palabras para definir la actividad que realizan como: reto, desafío, perseverancia, ruptura y equidad.

Por otra parte, un plan de mejoras en el trabajo de la temática deber estar encaminado a: adquisición de una mayor cultura jurídica en torno a la actividad que realiza, una educación mínima en torno al emprendimiento de un negocio, al fortalecimiento del movimiento asociativo de mujeres con la finalidad de exigir la defensa de sus derechos y cumplimiento de las leyes y la estimulación de medidas enfocadas a la sensibilización sobre la importancia de la participación más equilibrada de mujeres y hombres en los distintos ámbitos y niveles de toma de decisión.

\section{REFERENCIAS BIBLIOGRÁFICAS}

Ley No. 116/2013 Código del Trabajo. Gaceta Oficial No. 29 Extraordinaria de 17 de junio de 2014. ISSN 1682-7511

Molyneux, M. (1985). Mobilization without Emancipation? Women 's Interests, the State and Revolution in Nicaragua. Feminist Studies, 11(2), 227-253.

Rojas Hernández, Belkis. (2017). El empoderamiento femenino de la mujer rural como vía para el desarrollo de las comunidades rurales. Revista Rumbos TS, año XII, № 16. ISSN ED. Impresa 0718- 4182 / ED. En Línea 0719-7721, pp. 77-92

Young, K. (1993). Planning Development with Women. Making a World of Difference.Londres: MacMillan. 15p. 


\subsubsection{La desigualdad es real \\ Centro de Formación Océano Atlántico \\ Meritxell Laborda Montalbán y Fernando Cabeza Garrido (directores generales) \\ Zaragoza, España}

\section{Resumen}

El pasado 2019, en nuestro trabajo diario de intervención directa con colectivos de infancia y juventud, a partir del desarrollo de gestión y organización de diferentes servicios de ocio y tiempo libre, detectamos la necesidad de trasladar la igualdad de género desde una perspectiva diferente, novedosa y atractiva para la población.

A raíz de ello, elaboramos una exposición diseñada para transmitir de una manera diferente que la desigualdad entre hombres y mujeres existe; que no es algo del pasado, sino que es algo real. Así, por medio de diferentes elementos como la realidad aumentada y la realidad virtual, trasladamos al participante a situaciones lamentablemente demasiado cotidianas en las que las mujeres podemos sentirnos acosadas, perseguidas o en peligro en nuestro día a día. Por medio de estas experiencias y de diferentes juegos y propuestas de que cuenta la exposición, el participante conoce diferentes aspectos de las desigualdades, educando a través de la empatía, la mejor manera de entender las desigualdades existentes en el día a día de las mujeres y haciendo un análisis de la historia, así como de las relaciones afectuosas en la actualidad.

Desde su creación, nuestra exposición itinerante se ha trasladado a más de 50 municipios de la Comunidad Autónoma de Aragón, trabajando con diferentes perfiles y edades, obteniendo siempre resultados positivos dando lugar a una mayor concienciación, combinando la educación con la innovación tecnológica, consiguiendo así llamar la atención de los/as asistentes, aspecto difícil de conseguir en la actualidad, sobre todo de las personas más jóvenes.

Palabras clave: Desigualdad, innovación, inmersión, prevención en violencia de género, género.

\section{INTRODUCCIÓN Y OBJETIVOS}

Desde nuestra entidad trabajamos de forma permanente la sensibilización en violencia de género con los colectivos con los que intervenimos habitualmente, desde los centros educativos con infancia y juventud hasta otros espacios con población adulta o tercera edad, tanto educación formal como no formal, de tal manera que se detecta que sobre todo con la población joven lo que más funciona es la tecnología para educar y llamar su atención, además de percibir una gran problemática en la actualidad sobre las relaciones sentimentales y la manera de afrontarlas.

Los objetivos generales que se plantean son los siguientes:

1. Trabajar la violencia de género con toda la población en general.

2. Trabajar la prevención de violencia de género de una manera dinámica y llamativa.

3. Llegar al máximo número de personas posibles para trabajar la sensibilización y prevención de violencia de género.

4. Fomentar la empatía a través de vivencias en primera persona.

Los objetivos específicos que se plantean son los siguientes: 
1. Trabajar con la población joven y más adulta en prevención y sensibilización de violencia de género.

2. Trabajar la temática a través de realidad virtual llamando la atención así de los y las más jóvenes.

3. Llevar el proyecto por diferentes localidades y municipios.

4. Hacer vivir a las personas situaciones reales de desigualdad que las mujeres viven en su día a día para poder entender mejor según qué situaciones que se pueden producir.

5. Hacer entender a los/las participantes que la desigualdad no es algo del pasado, sino que es algo real.

6. Aprender que la desigualdad está presente en muchos ámbitos como cultura, deporte, publicidad, educación...

7. Aprender cuales son las señales de alerta dentro de una relación.

8. Trabajar la problemática a través de la innovación.

9. Aprender partes teóricas y prácticas a su vez sobre la violencia de género y las desigualdades.

10. Percibir y vivir una realidad existente.

\section{CONTEXTUALIZACIÓN}

Hemos querido crear un proyecto basado en la innovación, la diferenciación y la tecnología actual para crear algo llamativo y atractivo para toda la población, pero más concretamente a la juventud. A veces es difícil trabajar a fondo una temática como la problemática de la violencia de género de manera transversal y preventiva a la vez que divertida, por eso esta propuesta de proyecto creemos que se adecua a lo que queremos conseguir.

En la actualidad se viven muchas relaciones de las que llamamos "tóxicas", sobre todo entre la juventud, aunque también existen entre los más adultos, relaciones basadas en el control y en los celos, en los que está muy presente el papel de las nuevas tecnologías y de las redes sociales; algo que creemos que es fundamental abordar y trabajar haciendo hincapié en las relaciones sanas y los nuevos modelos de violencia de género.

Para justificar la necesidad vamos a presentar datos recogidos relacionados con la problemática.

Según el INE (Instituto Nacional de Estadística) el número de mujeres víctimas de violencia de género aumentó un $2,0 \%$ en el año 2019, hasta 31.911. La tasa de víctimas de violencia de género fue de 1,5 por cada 1.000 mujeres de 14 y más años. El número de víctimas de violencia doméstica creció un 3,6\%.

Los juzgados españoles recibieron un total de 40.491 denuncias por violencia de género en trimestre 4 de 2020.

Como podemos observar los datos son muy altos, por eso creemos en la necesidad real de trabajar en la prevención y sensibilización de la violencia de género, desde las edades adolescentes para no llegar a dichas cifras y conseguir erradicar la problemática, para eso hay que hacer un fuerte trabajo en la prevención de ésta. 
Se trata de una experiencia en la que vivir en primera persona desigualdades existentes en nuestra sociedad actual entre hombres y mujeres en todos los aspectos de la vida, así como las nuevas formas de control y violencia de género que han traído las redes y las nuevas tecnologías y un pequeño paso por la historia.

Esta exposición constará de trabajar a través de las diferentes zonas que nombramos a continuación:

-Zona de carteles + realidad aumentada: una serie de carteles aportan información acerca de los ámbitos en los que la desigualdad está más presente como el deporte, arte, publicidad, educación... Para complementarlos, basta descargar una sencilla aplicación y enfocar unas imágenes para que aparezca contenido extra en Realidad Aumentada. También se puede jugar a descubrir inventos e inventoras con nuestras Tablets a través de otra aplicación de Realidad Aumentada, así como otros logros en la posta EMPAREJADAS.

-Zona de "señales de alerta en $360^{\circ}$ ": el/la visitante podrá descubrir cuáles son las señales de alerta dentro de una relación a través de una imagen en $360^{\circ}$ interactiva. Desde las señales más sutiles como el control en las redes sociales, hasta las más evidentes, como la violencia verbal o las consecuencias en la víctima.

-Zona de realidad virtual: el/la visitante puede elegir entre 3 escenas grabadas en cámara de $360^{\circ}$ en las que se dan situaciones de desigualdad. La inmersión es total gracias a las gafas de realidad virtual, haciendo creer que se está viviendo esa situación realmente. Un ejercicio de empatía que no deja indiferente.

-Zona Kahoot: Es una divertida aplicación que permite competir con tu Smartphone en un test de preguntas sobre la violencia de género y desigualdades contra las personas que tienes a tu lado. No es necesaria ninguna aplicación. Los/as visitantes podrán competir entre ellos acerca de su conocimiento sobre la temática.

-Zona Photocall: Los/as visitantes podrán realizarse divertidas fotos en el photocall como recuerdo de la visita de la exposición.

\section{EVALUACIÓN, CONCLUSIONES Y PROPUESTAS DE MEJORA}

Para evaluar la experiencia de "la desigualdad es real" utilizamos diferentes técnicas métodos de evaluación, combinando cuantitativa y cualitativa. Por un lado, una encuesta online a través de códigos QR en los que las personas participantes puedan valorar la experiencia y aportar propuestas de mejora, y por otro lado la propia posta de Kahoot, que sirve para evaluar lo que han aprendido mediante la exposición. En el caso concreto de la experiencia de realidad virtual, al quitarse las gafas, un educador/a hablará con la persona para saber cara a cara como ha sido su experiencia, que ha aprendido etc. Además, al finalizar la actividad se emitirá un informe sobre lo observado y resultados obtenidos.

Los resultados son positivos en todas las evaluaciones planteadas, aunque comprobamos a través del Kahoot que los conceptos más teóricos es lo que más se les escapa. Como aspectos a mejorar, planteamos incorporar un apartado de conceptos clave de manera divertida y visual con tecnología, así como es el resto de la actividad. 


\section{REFERENCIAS BIBLIOGRÁFICAS}

Instituto Nacional de Estadística. (1 de mayo de 2020). Estadística de violencia doméstica y violencia de género. Año 2020. https://www.ine.es/dyngs/INEbase/es/operacion.htm?c=Estadistica_C\&cid=125 $4736176866 \&$ menu=ultiDatos\&idp $=1254735573206$

EpData. (20 de mayo de 2021) Violencia de género - datos y estadísticas. https://www.epdata.es/datos/violencia-genero-estadisticas-ultimavictima/109/espana/106\#: :text=Los\%20juzgados\%20espa\%C3\%B1oles\%20re cibieron\%20un,del\%20Consejo\%20General\%20del\%20Poder 


\title{
5. EDUCACIÓN PARA LA IGUALDAD EN LAS FAMILIAS.
}

\subsection{INVESTIGACIONES}

\author{
5.1.1. La Narrativa Autobiográfica y las Relaciones Interpersonales \\ en la Perspectiva del Desarrollo y de Género \\ Flavia Arantes Hime (Pontifícia Universidade Católica de São Paulo, Brasil); Vivian \\ Holovaty Suhorebri (Pontifícia Universidade Católica de São Paulo, Brasil)
}

\section{Resumen}

El objetivo del presente estudio fue comprender las intersecciones entre la construcción de la identidad de los jóvenes y la historia de sus relaciones familiares e íntimas (amorosas, sexuales y de amistades). El método empleado fue el de la investigación descriptiva y cualitativa. La participante fue una joven negra de 23 años, con nivel superior universitario completo, que se define como transexual y pansexual. El instrumento de investigación fue el de la narrativa autobiográfica. Se ha constatado la importancia de la familia como base para la construcción de la identidad. El rechazo por parte de la familia materna tuvo efectos negativos en la infancia de la joven, algo compensado en cierta medida por el apoyo paterno. Los amigos, a su vez, se constituyeron como parte de la familia de elección, promoviendo una base de contención, soporte y acogida, necesarios para un desarrollo saludable. La joven tuvo diferentes experiencias amorosas y sexuales y se deparó con una gran necesidad afectiva. Las concepciones de género y de interseccionalidad fueron útiles para la comprensión de la articulación entre las desigualdades y sus repercusiones a lo largo de la vida de la participante. Es necesario que la Psicología produzca más investigaciones en ese ámbito, contribuyendo así, para la transformación de las desigualdades que impactan en el desarrollo de las personas no blancas, situadas fuera de la heteronormatividad cisgénero.

Palabras clave: juventud; género; transexualidad; familia; relaciones interpersonales.

\section{INTRODUCCIÓN Y OBJETIVOS}

La Psicología en general y la Psicología del Desarrollo en particular han sufrido diversas críticas por mantener, en algunas de sus producciones, una mirada binaria y heteronormativa respecto a los temas ligados al género, perpetuando, de este modo, las desigualdades (Oliveira \& Madureira, 2014). Esperamos que la presente investigación pueda constituirse en un pequeño aporte desde la perspectiva combinada del desarrollo y de género. La primera hace referencia a un campo de estudios cuyo foco son los procesos de cambio.

La concepción de género ha venido sufriendo transformaciones desde que Robert Stoller la propuso en 1968, utilizando el término "identidad de género". Diversos aportes fueron hechos por autoras de la llamada segunda y tercera ola del feminismo, como 
Scott (2012), Rubin (2007) y más recientemente Butler (2018). Entre las teóricas e investigadoras que han empleado la noción de interseccionalidad y se han ocupado de los temas de género en relación con las problemáticas étnico-raciales, de clase, sexualidad, entre otras, podemos mencionar a Patricia Hill Collins y Sirma Bilge (2021).

El presente estudio tuvo por objetivo comprender las intersecciones entre la construcción de la identidad de los jóvenes y la historia de sus relaciones familiares e íntimas (amorosas, sexuales y de amistades). Será presentado el proceso de construcción de si de una mujer de 23 años, transexual y pansexual. Como marco teórico utilizamos las concepciones de sexualidad y género, además de una conceptualización acerca de las juventudes y observaciones sobre el amor en la contemporaneidad.

Preferimos hablar de juventudes, basándonos en Abramovay \& Esteves (2007) y Groppo (2010), por la multiplicidad de formas en las que estas se presentan, sea por las singularidades relativas a la construcción de las subjetividades, como también por las intersecciones con las variables de raza, etnia, clase, religión y género.

En ese proceso de búsqueda y afirmación de si, se destacan como referencias importantes, además de la familia (Sampaio, 2016), las relaciones amorosas (Costa, 1999). Los diferentes procesos de subjetivación para hombres y mujeres (Zanello, 2018), aunados a la superposición de valores y patrones arcaicos y modernos, característicos de la sociedad brasileña contemporánea (Figueira, 1987) pueden llevar a relaciones jerárquicas en la experiencia amorosa heterosexual (Hime, 2014). Las relaciones homoafectivas, por el contrario, tienden a ser más simétricas (Carter \& Mc Goldrick, 2001).

Con la posmodernidad, las relaciones se han tornado más fluidas. El amor confluente (Giddens, 1993) es contingente y hay primacía de la satisfacción, y ya no más de la duración. La sexualidad se desvincula de la obligatoriedad de ejercerse desde modelos monogámicos y heterosexuales.

La monogamia es ampliamente instituida - y trasgredida- en la cultura brasileña, aunque la fluidez de la posmodernidad haya abierto otras posibilidades amorosas y sexuales (Lins, 2017).

\section{METODOLOGÍA}

Realizamos una investigación descriptivo-cualitativa (Ludke \& André, 1983). La participante, seleccionada a través del método "bola de nieve", se identifica como mujer transexual, pansexual, negra de 23 años con formación superior universitaria en Geografía. Su actividad actual es como profesional del sexo. Para preservar su identidad la Ilamaremos Kika. El instrumento de investigación fue la narrativa autobiográfica (Levinson (1976). Luego, le solicitamos a la joven que nos contase la historia de su vida, del modo que mejor le pareciera. El procedimiento de análisis y discusión de los resultados consistió en una reflexión sobre el proceso de construcción de la identidad de la joven, haciendo hincapié en las relaciones amorosas, familiares y de amistad. El proyecto fue aprobado en 2019 por el Comité de Ética en Investigación de la Pontificia Universidad Católica de São Paulo (PUC-SP). 


\section{RESULTADOS Y DISCUSIÓN}

Para el análisis y la discusión de los resultados consideramos la cronología del relato de Kika, en el sentido de poder comprender el proceso de construcción de su identidad. Subrayaremos, sobre todo, aspectos relativos a su experiencia familiar, amistades y relaciones amorosas, es decir, hicimos una delimitación a partir de sus relaciones interpersonales significativas a lo largo del tiempo en relación con el tema género.

Kika empezó su relato partiendo de la niñez: el padre es africano y tras haber vivido en Brasil regresó a Sudáfrica. Ella siempre estudió en colegios privados, mensualidades que su padre abonaba. La madre es brasileña. Observamos la importancia dada por ella a su familia como base y el énfasis al "mestizaje" [sic], que le ofreció una diversidad de costumbres, valores, creencias religiosas y modelos de relación. Es importante atender al hecho de que Brasil es un país que presenta un racismo estructural (Almeida, 2020) velado por una supuesta tolerancia y aceptación, además de la "naturalización" de las desigualdades a partir del color de la piel: cuanto más oscura es una persona, más ella será objeto de prejuicios y opresiones (Zanello, 2018). Destacó su primera experiencia de enamoramiento, un niño de quién estuvo enamorada de los cinco años hasta el primer grado. La amistad de ellos era considerada por la madre, evangélica, como siendo pecado. De este modo, Kika fue desarrollándose con un sentimiento de inadecuación, vergüenza y culpa por la reprobación que sentía por parte de su familia materna. Sabemos de la importancia de los niños desarrollaren un sentido de autonomía, iniciativa y autoconfianza proporcionadas por la primera matriz del proceso de desarrollo del ciclo vital, la familia (Erikson, 1976). A medida que fue creciendo, Kika empezó a percibirse como un joven gay, ya consciente de la homofobia presente en su seno familiar. Oraba para salvarse, pues sentía miedo de ir al infierno por estar pecando. Rogaba, "Dios mío, si usted me quita la Pomba-Gira del cuerpo, me quedaré tres días en ayuno orando y haciendo vigilia" [sic]. Observamos aquí la fuerte presión ejercida por una institución religiosa, avalando así, la heteronormatividad cisgénero.

Esto sumado al tema racial y la diferencia de clase social: "Yo, no era considerado un muchacho bonito, era negro y pelado en aquel lugar lleno de burgueses blanquitos..." [sic]. Aunque su padre pudiera pagarle un colegio privado, se sentía como diferente e inferior a los demás colegas. Percibimos aquí la importancia de considerar a la interseccionalidad para comprender dicha experiencia (COLLINS \& BILGE, 2021): es una articulación de las desigualdades, que han colocado a Kika en una posición inferior, como si ella no tuviera derecho a los mismos bienes y oportunidades que los otros niños.

Cuando tenía catorce años, su padre fue a visitarle en Brasil. Fue un momento importante ya que, además de conocerle, asumió públicamente su relación gay con otro adolescente con quien estuvo en pareja hasta ingresar a la universidad. Desde entonces pasó a convivir con nuevos valores, creencias, pasando a verse no más como alguien inadecuado y merecedor de puniciones como antes.

Al término de su carrera de grado, Kika se mudó para un gran centro urbano. Conoció a una muchacha transexual y, desde allí, comenzó a tener nuevas dudas en cuanto a su orientación sexual e identidad de género. Desde entonces, cambió su nombre para el femenino y se puso en pareja con un muchacho transexual. Fue un período de muchas experiencias, lo que Erikson (1976) llamó de 'moratoria psicosocial'.

Al consultar un psiquiatra a razón de su estado depresivo, él le sugirió que ella podría ser una mujer transexual que se estaba descubriendo y no un muchacho gay cisgénero. Observamos su transfobia internalizada cuando se resistió a reconocer e identificarse como trans, por vergüenza y miedo de la reacción que despertaría en su familia. Sin 
embargo, dice: "Noté que yo era una persona pansexual, que no me interesaba solo por hombres y mujeres cis y transgéneros, sino que me interesaba también por personas no binarias, fluidas, y así las cosas se fueron dando" [sic]. Este discurso nos remite a las concepciones de Butler (2018) acerca de la teoría queer y al no binarismo, que proponen una ruptura con categorías fijas de género que encasillan a las personas en normatizaciones y jerarquías. Para la autora, la sexualidad es fluida y las normas se cristalizan en los individuos en definiciones que pueden no corresponder con lo que verdaderamente sienten.

Kika inició la transición de género a través del tratamiento hormonal. Fue profesora en una célebre escuela, pero le echaron tras ser descubierta como mujer trans por los colegas del trabajo. Desde entonces no pudo conseguir trabajo en ese ámbito, excepto dar clases particulares esporádicamente. Después de hacer diversos intentos en diferentes tipos de trabajos, no le quedó otra sino la prostitución. Queda patente, en su relato, toda la opresión sufrida por las personas que se desvían de la heteronormatividad cisgénero. Vistas como personas abyectas (Butler, 2018), muchas veces son excluidas de sus familias y de la sociedad, quedándose sin posibilidades de elección en el ámbito personal y profesional.

Kika relató prejuicios y dificultades para tener relaciones afectivas incluso dentro del universo LGBTQIA+. Además, hay prejuicios respecto al color de su piel: Kika dice que para las mujeres trans blancas es más fácil haber oportunidades, sumado al hecho de que ellas tienen una mayor expectativa de vida en relación a las negras, que en Brasil es de 35 años.

Sus amigas y amigos son su familia de elección. Ella destaca que tres de ellas, la aceptan incondicionalmente y la apoyan en los momentos difíciles desde la adolescencia. Es nítida la necesidad de tener una base segura, un soporte, principalmente en los momentos de crisis, de inestabilidad emocional, de transición. Las amigas han cumplido ese rol, compensando de ese modo, la ausencia por parte de la familia materna: "No nos dejan vivir, porque la tasa de la mortandad de personas trans es muy alta, las chicas mueren precozmente. Tampoco tenemos afecto de nuestras familias...son muy pocas las que aceptan nuestros cuerpos diferenciados" [sic].

Kika es una persona consciente de la opresión y desigualdades que experimenta en diversos ámbitos de su vida, fenómenos que reflejan una sociedad racista y cis heteronormativa como es la brasileña, en la que las relaciones de poder están presentes, excluyendo e invisibilizando personas que escapan a la norma, perpetuando así las desigualdades sociales y económicas.

\section{CONCLUSIONES Y LIMITACIONES}

El objetivo de este estudio fue comprender las intersecciones entre la construcción de la identidad de una mujer transexual de orientación pansexual y la historia de sus relaciones familiares e íntimas (amorosas, sexuales y de amistad).

Hicimos hincapié en nuestro análisis, en la importancia de considerar la noción de interseccionalidad. Percibimos en el caso estudiado, la escasez de oportunidades profesionales, aun teniendo suficiente formación y cualificación. En nuestra sociedad cis heteronormativa y racista, las personas no blancas, no cis género, y no heterosexuales sufren con la exclusión, la invisibilización e incluso con la muerte.

La familia tiene un rol central como base de la construcción de la identidad, entendido por nosotras como un proyecto en abierto, siempre sujeto a sucesivas revisiones. No 
obstante, es común que personas transexuales, homosexuales, bisexuales o pansexuales recurran a su familia de elección, sus amigos, lo que les da respaldo para que la persona pueda transformarse y ser quien ella siente que verdaderamente es.

Nuevos estudios podrán completar las brechas del corpus de conocimiento de la Psicología a partir de la perspectiva de género. Por ejemplo, comparando las relaciones y dinámicas familiares entre hombres y mujeres transexuales en diferentes momentos del ciclo vital.

La Psicología debe posicionarse en relación a las desigualdades, contribuyendo para transformarlas al dar voz y visibilidad a las personas consideradas desviantes por su género u orientación sexual, color de piel, etnia y clase social.

\section{REFERENCIAS BIBLIOGRÁFICAS}

Almeida, S. (2020). Racismo estrutural. Ed. Jandaira.

Butler, J. (2018). Problemas de gênero: Feminino e subversão da identidade. Civilização brasileira.

Carter, B. \& Mc Goldrick, M. (2001). As mudanças no ciclo vital de vida familiar: Uma estrutura para a terapia familiar. Artmed.

Collins, P. H. (2021) \& Bilge, S. (2021). Interseccionalidade. Boitempo.

Costa, J. F. (1999). Sem fraude nem favor: Estudos sobre o amor romântico. Rocco

Esteves, L. C. G., \& Abramovay, M. (2007). Juventude, Juventudes: Pelos outros e por elas mesmas. In M. Abramovay, E. R. Andrade, L. C. Esteves (Orgs.), Juventudes: Outros olhares sobre a diversidade (pp. 19-50). Organização para as Nações Unidas para a Educação, a Ciência e a Cultura.

Figueira, S. A. (1987). O "moderno" e o "arcaico" na nova família brasileira. In S. A. Figueira (Org.), Uma nova família? (pp. 11-30). Zahar.

Giddens, A. (1993). A transformação da intimidade. Ed. Universidade Estadual Paulista.

Groppo (2010). Condição juvenil e modelos contemporâneos de análise sociológica das juventudes. Última década, 33, 11-26.

Hime, F.A. (2014). A narrativa autobiográfica e a história das relações amorosas a dança entre o "eu" e o "nós". IV Congresso Nacional de Psicologia Ciência e Profissão - Il Congresso Brasileiro de Pesquisa do Relacionamento Interpessoal. São Paulo.

Levinson, D.J. et. al. (1979). The seasons of a man's life. Ballantine Books.

Lins, R. N. (2017). Novas formas de amar. Ed. Planeta.

Ludke, M. \& André, M. (1986) Pesquisa em educação: Abordagens qualitativas. E.P.U.

Oliveira, M. C. S. L. \& Madureira, A. F. A. (2014). Gênero e Psicologia do Desenvolvimento: quando a Ciência é utilizada como força normatizadora das identidades de gênero. Estudos feministas. Julho-dezembro

Recuperado de https://www.labrys.net.br/labrys26/psy/maria\%20claudia.htm

Rubin, G. (1975/2007). Políticas do sexo. Ubu.

Sampaio, C.M. R. (2016). Identidade na vida adulta: A singularização da experiência. [Tese de Doutorado, Pontifícia Universidade Católica de São Paulo]. 
Scott, J. W. (2012). Os usos e abusos do gênero. Projeto História. São Paulo, 45, 327351.

Zanello, V. (2018). Saúde mental, gênero e dispositivos: Cultura e processos de subjetivação. Ed. Appris. 


\subsubsection{Manejo de Redes Sociales en la Adolescencia y Juventud LGTB+ durante el Confinamiento \\ Lucas Platero (Universidad Rey Juan Carlos, España); Miguel Ángel López-Sáez \\ (Universidad Rey Juan Carlos, España).}

\section{Resumen}

Durante el Estado de Alarma por pandemia de COVID-19, la adolescencia y juventud con sexualidades e identidades de género no normativas han experimentado una situación particularmente estresante, por pertenecer a una minoría social y tratar de dar sentido a sus identidades. Este contexto fue especialmente complicado, donde el sistema educativo se vio desbordado con el paso a la educación a distancia, dejando de lado muchos otros aspectos relacionados con el desarrollo sexual y afectivo de su alumnado. Este estudio evalúa las correlaciones entre usos de redes sociales online, las percepciones de apoyo recibido, sentirse en soledad y como carga para otras personas, y la convivencia. Usamos una muestra de 445 participantes, con edades entre 13 a 21 años. Realizamos un análisis descriptivo, multivariable de la varianza y correlaciones bivariadas. Encontramos que, la identidad de género (cis o trans/género no binario) y el ciclo vital (adolescencia y juventud) influyen en cómo se usan las redes sociales, con quién se convive y la percepción de ser una carga. En general, las personas trans y género no binarias hacen menos uso de las redes para el contacto con sus círculos, también se sienten con menos apoyos y se auto perciben como carga. En conclusión, son datos relevantes que sugieren que el sistema educativo ha de incluir la atención a la juventud LGTB+, teniendo en cuenta la frecuente falta de apoyo social, su comportamiento en redes y la posibilidad de recibir violencia.

Palabras clave: redes sociales; autopercepción de carga; apoyo social; LGBT+; juventud y adolescencia.

\section{INTRODUCCIÓN Y OBJETIVOS}

Durante el período de estado de alarma dictado por el Gobierno español (RD 463/2020, de 14 de marzo) debido a la pandemia por COVID-19, la adolescencia y juventud con sexualidades e identidades de género no normativas se han enfrentado a una situación particularmente estresante. Para esta adolescencia (entre 13 y 17 años) y juventud (18 a 21 años) con sexualidades e identidades de género no normativas, que ha tenido que seguir sus clases online y convivir intensivamente con sus familias (a menudo en hogares con dificultades de aceptación), tratar de mantener sus vínculos con iguales sin contacto físico ha sido un gran reto. Diversos estudios han alertado de "la tormenta perfecta" que ha supuesto el confinamiento, con un aumento y un agravamiento de casos de violencia de género y violencia vicaria, y la infancia y adolescencia LGBT+. El personal docente y los equipos de orientación se han visto desbordados, mostrando un sistema poco preparado para ayudar en el desarrollo de estrategias para superar esas situaciones de violencia (Usher et al., 2021).

La pandemia por COVID-19 tuvo implicaciones en la vida cotidiana escolar. El sistema educativo tuvo que adaptar bruscamente sus clases a formatos a distancia, ya que desde el 13 de marzo hasta el 26 de abril se impuso un confinamiento obligado. Los 
centros educativos intentaron programar actividades curriculares para continuar con los procesos de aprendizaje de contenidos, sin embargo, otros ámbitos referidos a los afectos, los sentimientos y las relaciones sociales apenas fueron considerados y la falta de apoyo en ese sentido fue frecuente (Hervalejo et al., 2020). Carentes de estos apoyos educativos específicos, Internet supuso un espacio para explorar esos aspectos y dar sentido a sus identidades, así como para afrontar la discriminación LGTBQA+ fóbica en su vida cotidiana. Además, este tiempo "en pausa" facilitó que muchas personas jóvenes explorasen aspectos de su identidad sexual, como así reportan entidades como la Línea Arco Iris de la Federación Estatal de personas LGTB+.

Con nuestro estudio nos proponemos explorar la relación existente entre usos de redes, apoyo percibido y convivencia, así como la autopercepción de ser una carga, en jóvenes lesbianas, gays, bisexuales, transexuales y no binarios (LGBT+) durante las medidas del estado de alarma, dictadas por el gobierno en España en 2020. Todo ello, fijándonos en las diferencias según la edad (comparando entre adolescencia y juventud), así como nos fijamos en la situación diferencial entre ser cis lesbiana, gay o bisexual, frente a las identidades trans y no binarias. Aspectos que son relevantes para la intervención educativa con jóvenes.

\section{METODOLOGÍA}

Las personas participantes se reclutaron a través de convocatorias en diferentes redes sociales y correos electrónicos enviados a asociaciones y entidades durante el mes de abril de 2020. En las convocatorias se proporcionaba un enlace a la investigación. Al acceder, se les explicaba que la recopilación de datos sería anónima y confidencial.

Un total de 445 personas, con edades comprendidas entre los 13 y 21 años $(M=1.8$, $D E=0.40$ ), y que viven en el estado español, completaron el cuestionario en el que se basa este estudio. En total, el $51.5 \%$ de las personas que participaron fueron cismujeres, el $4.9 \%$ mujeres trans, el $17.1 \%$ cishombres, el $13.9 \%$ hombres trans y el $12.6 \%$ género no binario. En este grupo de edad la gran mayoría son estudiantes, de manera que un $17.1 \%$ se encontraba dentro de las etapas de educación obligatoria (primaria o secundaria), un $55,1 \%$ se encontraba en bachillerato o FP y un $27.9 \%$ cursaba estudios universitarios.

\section{Instrumentos}

- Cuestionario socio-demográfico

- Ítems sobre uso de redes sociales

- Cuestionario de Frecuencia y Satisfacción con el Apoyo Social percibido (QFSSS)

- Cuestionario de Necesidades Interpersonales (INQ-PB)

\section{RESULTADOS Y DISCUSIÓN}

Análisis multivariable de la varianza

Las diferencias por grupos de edad e identidad de género fueron analizadas a través de un análisis multivariable de la varianza (MANOVA). Se consideraron como variables dependientes las escalas, las diferentes convivencias y el cambio del lugar de residencia, y los ítems relacionados con redes sociales. Mientras que como variables independientes estaban los grupos de edad y la identidad de género.

Los resultados del MANOVA indicaron significaciones en la interacción (grupo de edad $x$ identidad de género), $F(14,427)=1.78, p<.05, n p 2=.05$ Esta se produjo en los ítems referido al apoyo percibido de las amistades, QFSSS-Fr, $F(1,440)=5.70, p<.05$, np2= 
.01. Este tipo de interacción necesita del análisis de los efectos simples para poder ser interpretada sin error. Los análisis de los efectos simples de los grupos de edad mostraron que existían diferencias significativas entre la adolescencia cis y trans-no binaria $(F(1,87)=8.53, p=.005, n p 2=.09)$, pero no así entre la juventud. Así, la adolescencia cis puntuaba más alto en el apoyo percibido por amistades, QFSSS-Fr, que la adolescencia trans y no binaria. Los análisis de los efectos simples de la identidad de género mostraron que existían diferencias significativas entre la adolescencia y juventud trans-no binaria $(F(1,138)=9.50, p<.005, n p 2=.06)$, donde la juventud puntuaba más alta en el apoyo percibido por amistades. No aparecieron esas diferencias entre la juventud y adolescencia cis.

También, aparecieron diferencias en la percepción de agresiones en las redes sociales, $F(1,440)=7.01, p<.05, n p 2=.01$. Los análisis de los efectos simples de los grupos de edad mostraron que existían diferencias significativas entre la juventud cis y trans-no binaria $(F(1,354)=7.23, p=.05, n p 2=.02)$, pero no entre la adolescencia. Es decir, la juventud trans-no binaria puntuaban más alto en percepción de agresión que la juventud cis. Los análisis de los efectos simples de la identidad de género mostraron que existían diferencias significativas entre la adolescencia y juventud trans-no binaria $(F(1,138)=$ $6.07, \mathrm{p}<.05, \mathrm{np} 2=.04)$, donde la juventud puntuaba más alta. No aparecieron esas diferencias entre la juventud y adolescencia cis.

Por último, en el uso de las redes para ligar encontramos $(F(1,440)=5.62, p<.05$, np2= .01). Los análisis de los efectos simples de los grupos de edad mostraron que existían diferencias significativas entre la adolescencia cis y trans-no binarios $(F(1,87)=4.74, p<$ $.05, n p 2=.05)$, pero no entre la juventud. Así, la adolescencia cis puntuaban más alto en el uso de las redes sociales y aplicaciones para ligar que la adolescencia trans-no binaria. Los análisis de los efectos simples de la identidad de género mostraron que existían diferencias significativas entre la adolescencia y la juventud trans-no binaria $(F(1,138)=6.58, p<.05, n p 2=.04)$, donde la juventud puntuaba más alta. No aparecieron esas diferencias entre la juventud y adolescencia cis.

En la convivencia con familia, el análisis de efectos principales del ciclo vital mostraron la existencia diferencias significativas entre adolescencia y juventud $(F(1,440)=6.41, p<$ .05 , np2 $=.01$ ), puntuando la adolescencia de todos los grupos más alta en la convivencia familiar. De igual manera, los análisis de efectos principales en la convivencia con amistades, mostraron la existencia diferencias significativas entre adolescencia y juventud $(F(1,440)=5.37, p<.05, n p 2=.01)$, puntuando la juventud de todos los grupos más alta en la convivencia con amistades.

En cuanto al uso de las redes sociales y aplicaciones para cibersexo, los análisis de efectos principales mostraron la existencia de diferencias cercanas a la significación entre adolescencia y juventud $(F(1,440)=2.92, p=.08, n p 2=.01)$. Lo que indica que la juventud de todos los grupos puntuó más alto en el uso de redes para cibersexo.

En el apoyo social recibido de la familia, QFSSS-F, los análisis de efectos principales de la identidad de género $F(1,440)=13.22, p<.001, n p 2=.03)$, mostraron la existencia diferencias significativas entre personas cis, trans-género no binario, puntuando la adolescencia y juventud cis más alto. Por tanto, estos datos revelan que las personas cis perciben que tienen más apoyo de sus familias, que las personas trans y no binarias. Sobre la autopercepción negativa de ser una carga para el resto y tener sentimientos de soledad, INQ-PB $(\mathrm{F}(1,440)=14.90, \mathrm{p}<.001, \mathrm{np} 2=.03)$ e INQ-TB $(F(1,440)=11.23, \mathrm{p}<$ $.05, \mathrm{np} 2=.02$ ), los análisis de efectos principales de la identidad de género mostraron la existencia diferencias significativas entre personas cis y trans-género no binario, puntuando la adolescencia y juventud trans-no binarios más alto. Es decir, tanto la 
adolescencia como la juventud trans y no binaria tienen más autopercepción de ser una carga para el resto y tienen más sentimientos de soledad.

Por último, en uso de las redes sociales y otras aplicaciones para hablar con la familia, los análisis de efectos principales de la identidad de género $(F(1,440)=7.91, p<.05$, $\eta p 2=.02)$ mostraron la existencia diferencias significativas entre personas cis y transgénero no binario, puntuando la adolescencia y juventud cis más alto. De manera homóloga aunque rozando la significación $(F(1,440)=2.92, p=.08, n p 2=.01)$, también encontramos esta relación en el uso de las redes sociales y otras aplicaciones para hablar con amistades. Así las personas cis de todas las edades usan más las redes para hablar con familiares y amistades.

\section{Correlaciones}

En la Tabla aparecen las correlaciones para toda la muestra con respecto a las siguientes variables: identidad de género, ciclo vital, QFSSS, INQ, personas de convivencia, cambio de residencia, usos de redes y aplicaciones y percepción de agresión. Las correlaciones se estimaron mediante el coeficiente $\rho$ de Spearman, debido a la ruptura de los supuestos de continuidad o normalidad en todos los pares de variables.

\begin{tabular}{|l|l|l|l|l|l|}
\multicolumn{5}{|c|}{ Correlaciones de toda la muestra con usos de redes actuales. } \\
\hline & $\begin{array}{l}\text { Agresión } \\
\text { percibida }\end{array}$ & Ligar & Cibersexo & $\begin{array}{l}\text { Hablar } \\
\text { familia }\end{array}$ & $\begin{array}{l}\text { Hablar } \\
\text { amistades }\end{array}$ \\
\hline Identidad de género & .075 & -.033 & .013 & -.036 & $-.125^{\star *}$ \\
\hline Ciclo vital & .016 & .072 & .058 & -.012 & -.053 \\
\hline Cambio residencia & .055 & .018 & .012 & .041 & .015 \\
\hline Vivir con familia & -.014 & -.009 & -.041 & .071 & -.062 \\
\hline Vivir con amistades & -.071 & -.011 & .024 & .001 & .049 \\
\hline Vivir con pareja & $.129^{* *}$ & -.018 & .017 & $-.094^{*}$ & .065 \\
\hline $\begin{array}{l}\text { Vivir sólo } \\
\text { (QFSSS-Fr) }\end{array}$ & -.022 & .046 & .027 & -.032 & -.013 \\
\hline (QFSSS-F) & -.009 & .088 & -.006 & $.248^{* *}$ & $.385^{* *}$ \\
\hline
\end{tabular}




\begin{tabular}{|c|c|c|c|c|c|}
\hline $\begin{array}{l}\text { Apoyo de pareja } \\
\text { (QFSSS-P) }\end{array}$ & $.115^{\star}$ & .086 & $.160^{* *}$ & $.255^{\star *}$ & $.212^{* *}$ \\
\hline $\begin{array}{l}\text { Carga percibida (INQ- } \\
\text { PB) }\end{array}$ & $.100^{*}$ & -.067 & $.095^{\star}$ & $-.149^{* *}$ & $-.154^{* *}$ \\
\hline $\begin{array}{l}\text { Pertenencia frustrada } \\
\text { (INQ-TB) }\end{array}$ & .001 & $-201^{* *}$ & -.029 & $-.297^{\star *}$ & $-.200^{* *}$ \\
\hline \multicolumn{6}{|c|}{ Nota ${ }^{*} p<.05 ;{ }^{* *} p<.01 ;{ }^{* * *}$. } \\
\hline
\end{tabular}

\section{CONCLUSIONES Y LIMITACIONES}

El ciclo vital y ser una persona trans o no binaria son clave a la hora de percibir más agresiones en las redes durante el confinamiento. Esta percepción está ligada a que de hecho reciben una violencia aún mayor que la experimentada por sus iguales cis, que dicha violencia es cada vez más frecuente en las redes sociales, aunque no siempre se denuncie.

Asimismo, el ciclo vital por sí mismo parece influir en poder convivir con unas personas u otras durante el confinamiento. Como cabía esperar, a menor edad, mayor convivencia con familiares y menor convivencia con amistades o parejas. Esta convivencia intensiva con familiares, en un momento de crisis como el vivido, hace que los adolescentes tengan que valorar si mostrar su identidad en hogares en los que no siempre reciben apoyo, señalando la vulnerabilidad a una violencia en el hogar de la que no pueden escapar (Gorman-Murray et al, 2018; Borraz, 2020; Momoitio 2020).

El ciclo vital influye también en el uso de las redes sociales. En general, en la adolescencia aparece la necesidad de explorar la sexualidad y para quienes tienen identidades no normativas, supone enfrentarse a rechazo potencial (Mustanski et al., 2011) que les invita a acudir a las redes en búsqueda de los apoyos, encontrar iguales y parejas potenciales que no tienen en la vida offline (DeHaan et al., 2013). De hecho, encontramos que en la adolescencia tienen más interés en usarlas para ligar, mientras que en la juventud es más frecuente usar las redes sociales para practicar cibersexo. Estas interacciones entre su comportamiento online y offline son las que moldean sus identidades emergentes, sus relaciones románticas, comportamientos sexuales y su salud (DeHaan et al., 2013).

Por otro lado, la identidad de género determina la percepción de apoyo de amistades, de manera que las personas cis de la muestra perciben que tienen más apoyo que las personas trans y no binarias. Aparece además una mayor autopercepción de sentirse como una carga para el resto, tener sentimientos de frustración y soledad, que es más frecuente en las personas trans y no binarias, lo cual es consistente con los resultados de otros estudios (Pullen Sansfaçon et al., 2019). Por último, la identidad de género determina el tipo de uso de las redes sociales y aplicaciones para conversar con familiares, donde las personas cis de la muestra las usan con más frecuencia, dato que puede estar ligado a que tienen más apoyo y comunicación con las familias que las personas trans y no binarias que participan en este estudio.

Las correlaciones de la muestra en su totalidad permiten afirmar algunos aspectos de la literatura previa y de las alertas que aparecen en prensa estos días (Borraz, 2020; Momoitio, 2020). Aunque estos datos encontrados han de matizarse con más estudios 
específicos, sin duda señalan la necesidad de atender a una población que está viviendo una violencia particular, y que carece de apoyos necesarios de sus entornos educativos y de las instituciones que atienden a adolescentes y jóvenes. Dichas instituciones educativas y de atención a la infancia a su vez han de prestar atención al uso de redes y aplicaciones que hacen adolescentes y jóvenes con sexualidades e identidades no normativas, ofreciendo más apoyos dentro y fuera de estas redes, que acompañen sus procesos identitarios, y en particular, de la adolescencia trans y no binaria. En ese sentido, nuestro estudio viene a ratificar otros trabajos que señalan la necesidad de una educación sexual integral y el papel destacado de las instituciones educativas para esta labor.

\section{REFERENCIAS BIBLIOGRÁFICAS}

Borraz, M. (2020, mayo 1). El doble encierro de vivir con una familia que rechaza al colectivo LGTBI: «Es triste que solo pueda ser yo misma a través de la pantalla». Eldiario.es.https://www.eldiario.es/sociedad/doble-encierro-salido-armariofamilia 1 1466142.html

DeHaan, S., Kuper L.E., Magee, J.C., Bigelow L. \& Mustanski, B. (2013). The Interplay between online and offline explorations of identity, relationships, and sex: A mixed-methods study with LGBT youth. Journal of Sex Research, 50:5, 421-434, DOI: $10.1080 / 00224499.2012 .661489$

Gorman-Murray, A., McKinnon, S., Dominey-Howes, D., Nash, C.J. \& Bolton, R. (2018). Listening and learning: giving voice to trans experiences of disasters. Gender, Place \& Culture, 25(2), 166-187, doi:10.1080/0966369X.2017.1334632

Hervalejo, D., Carcedo, R. J., \& Fernández-Rouco, N. (2020). Family and Mental Health During the Confinement Due to the COVID-19 Pandemic in Spain: The Perspective of the Counselors Participating in Psychological Helpline Services. Journal of Comparative Family Studies, 51(3-4), 399-416.

Momoitio, A. (2020, abril 29). Armarios y miedos que sellan el encierro. Pikara Magazine. https://bit.ly/33Ulzcr

Mustanski, B., Newcomb, M. E., \& Clerkin, E. M. (2011). Relationship characteristics and sexual risk-taking in young men who have sex with men. Health Psychology, 30(5), 597-605. doi: 10.1037=a0023858

Pullen Sansfaçon, A., Temple-Newhook, J., Suerich-Gulick, F., Feder, S., Lawson, M.L., Ducharme, J., Ghosh, S., Holmes C. \& On behalf of the Stories of GenderAffirming Care Team (2019). The experiences of gender diverse and trans children and youth considering and initiating medical interventions in Canadian gender-affirming speciality clinics, International Journal of Transgenderism, 20(4), 371-387. doi: 10.1080/15532739.2019.1652129

Usher, K., Bradbury Jones, C., Bhullar, N., Durkin, D. J., Gyamfi, N., Fatema, S. R., \& Jackson, D. (2021). COVID-19 and family violence: Is this a perfect storm?. International journal of mental health nursing. 


\title{
5.2. EXPERIENCIAS
}

\author{
5.2.1. Mapa de la Diversidad (Experiencia Educativa) \\ Víctor Luqui Plumed (grana psicología \& musicoterapia, España)
}

\section{Resumen}

En esta comunicación oral se presenta el trabajo realizado con familias de menores trans con las que se ha realizado formación sobre aspectos relacionados con diversidad afectivo-sexual y de género para favorecer el acompañamiento de sus familiares en el núcleo familiar y al mismo tiempo ser agentes de igualdad y de espacios seguros para las personas trans. Analizando el papel del género que tiene en las áreas de identidad, orientación y expresión y de cómo esto se inserta en la sociedad.

Palabras clave: género; familias; diversidad; formación; transpositivo.

\section{INTRODUCCIÓN Y OBJETIVOS}

Dentro del espectro de diversidad sexo-afectiva y de género, la perspectiva de educación transpositiva, supone un marco de referencia profundo y amplio de comprensión de la diversidad para garantizar la igualdad de oportunidades

Partiendo del currículo que se imparte en los centros docentes que materializan el sistema educativo español. En cuestión de género, aparecen los temas tratados desde una visión que perpetúa el sistema sexo-género tradicional, lo que supone una invisibilización sistémica de procesos personales que se producen en el crecimiento de las personas en cuanto a identidad, orientación y expresión de género.

Siendo la familia el núcleo fundamental para favorecer el desarrollo de cada persona en todas sus áreas, la formación para las familias va dirigida a ampliar los parámetros prestablecidos del sistema sexo-género tradicional, para favorecer el acompañamiento de la infancia, adolescencia y juventud de cada persona en su seno familiar y desde este lugar, potenciarlo a todos los sistemas de educación bien formal, bien no formal.

Los objetivos planteados:

- Trabajar la visión de género de la que parte la familia desde el análisis del sistema sexo-género para paliar su perpetuación en el núcleo familiar.

- Introducir terminología en relación a la diversidad afectivo-sexual y de género que garantice la visibilización de todas las realidades personales.

- Favorecer la deconstrucción de género.

\section{CONTEXTUALIZACIÓN}

La fuerte discriminación en ámbito educacional desde la propia estructura del mismo, más allá de los propios casos aislados de discriminación que pueden sufrir las personas trans en los entornos educativos. Esta discriminación se observa en el ostracismo y la invisibilización de las personas trans y de la diversidad las personas en todas sus áreas de los diferentes sistemas a los que pertenecen. 
El poner palabras y delimitar términos, supone dar herramientas a las personas para poder desarrollarse en base a sus narrativas personales. De ahí que sea fundamental favorecer la formación en aspectos transpositivos.

Además, el apoyo familiar en el acompañamiento en la transición en todos los entornos de la persona trans; bien sea a nivel familiar, social, escolar y jurídico, disminuye los niveles de psicopatologías internalizadas en menores respecto a aquellas personas menores que cuya identidad no había sido previamente reconocida (Olson et al., 2016).

\section{DISEÑO Y DESARROLLO}

Se llevó a cabo mediante sesiones de 90 minutos. De grupos de 10-12 personas de familiares de personas trans. Se partió de las inquietudes de las propias familias, quienes demandaron la necesidad de plasmar en un espacio sus dudas sobre los diferentes discursos en torno a la diversidad y al cuestionamiento del sistema sexogénero para poder acompañar mejor a sus hijas/os/es.

Para ello se solicita mediante cuestionario, las inquietudes o necesidades por parte de las familias para poder ajustar el plan de formación. A posteriori se programó una fecha y se realizó la formación.

En ella se incluyó un recorrido en las tres dimensiones que atraviesa la diversidad afectivo-sexual y de género de una persona; la identidad, la orientación y la expresión. La identidad se aborda desde una perspectiva antropológica haciendo referencia a las referencias históricas que expresan la presencia de personas trans integradas en las sociedades de diferentes culturas, en distintos momentos temporales de la historia de la humanidad. La orientación; se aborda desde un paraguas plural que visibiliza el espectro que denota las variables asexual y alosexual; se hablan de distintos tipos de atracciones y se introduce el espectro plurisexual/romántico y monosexual/romántico. $Y$ en la expresión de género; se habla del binarismo y se rompe esta realidad estadística de lo femenino, masculino, para recorrer mitos, juicios y expectativas en referencia a la expresión de género y la asociación automática que se perpetúa entorno a ello.

Todo ello tratado desde una metodología participativa y vivencial, que permite a la audiencia, en este caso las familias, de la formación, poder adherirse más a la tarea y a los contenidos sobre los que se debaten a modo de asamblea.

\section{EVALUACIÓN, CONCLUSIONES Y PROPUESTAS DE MEJORA}

Se realiza un cuestionario al finalizar la sesión que recoge los aspectos del contenido, aspectos a mejorar, aspectos que han resultado útiles para las familias, y evalúa instalaciones y medios audiovisuales, así como materiales y dinámica de grupo.

En referencia a todo ello, las familias atribuyen como positiva la experiencia por permitirles ampliar su vocabulario en términos de género y de diversidad afectivo-sexual y de género. Algo que les permite acercarse a sus hij ${ }^{*}$, y les da herramientas para enfrentarse a la perpetuación del sistema sexo-género, así como detectar más situaciones no seguras para las personas independientemente de que sean cis o trans. También evidencia que las exigencias de género están muy marcadas en torno a la expresión de género, y al conjunto binarista de la realidad asumida desde un punto de vista educacional, económico, organizacional, etc. En cuanto a la orientación, se desmitifican mitos y se genera un paraguas que hasta la fecha dicen no haber sido conscientes de percibirlo; al tratar el término alosexual y situar la asexualidad dentro del área de la orientación. Y en general, para las familias supone una forma de cuestionarse sus propios procesos vitales como personas que tienen una identidad, una orientación y una expresión de género. 
Como propuesta de mejora, seguir ahondando en el tema, dado a lo cambiante de la realidad discursiva del ámbito de diversidad afectivo-sexual y de género. Ampliar el número de referentes. Y sin duda, abrir este espacio para padres que no tengan por qué tener familiares trans, sino para todo el plural de la población, algo que garantiza la sensibilización hacia la igualdad de género y de las personas.

\section{REFERENCIAS BIBLIOGRÁFICAS}

Berne, E. (1961). Transactional Analysis in Psychotherapy. New York: Ballantine Books.

Bowlby, J. (1989). Una base segura: aplicaciones clínicas de la teoría del apego. Barcelona: Paidós.

Cerezo, F., y Méndez, I. (2012). Conductas de riesgo social y de salud en adolescentes. Propuesta de intervención contextualizada para un caso de bullying. Anales De Psicología, 28(3), 705-719.

Moreno-Cabrera, O. y Punche-Cabezas, L. (2017) Transexualidad, adolescencias y educación: miradas multidisciplinares. Barcelona-Madrid: Egales

Platero, L.R. (2015) TRANS*EXUALIDADES: Acompañamiento, factores de salud y recursos educativos. Barcelona: Bellaterra

Olson, KR, Durwood, L., DeMeules, M. y McLaughlin, KA (2016). Salud mental de niños transgénero que son apoyados en su identidad. Revista de Pediatría, 137 (3).

The Ryan, C., Russell, ST, Huebner, D., Díaz, R. y Sánchez, J. (2010). Aceptación familiar en la adolescencia y salud de jóvenes LGBT. Revista de enfermería psiquiátrica infantil y adolescente, 23 (4), 205-213. 


\subsubsection{Prevención de la violencia de género con el Plan Director para la convivencia y mejora de la seguridad en los centros educativos y sus entornos}

Sánchez Hernández, David (Unidad de Violencia sobre la Mujer en Soria, España); Barreda del Olmo, María Luisa (Unidad de Coordinación de Violencia sobre la Mujer en Murcia, España)

\section{Resumen}

Se presenta la prevención de la Violencia de Género en el marco del Plan Director, articulada mediante actividades presenciales en formato 'charla-coloquio' por profesionales dedicados al seguimiento de casos de violencia de género.

El objetivo es el cuestionamiento de los estereotipos sobre las relaciones de pareja hombre-mujer, que se reconocen en cierta medida como externamente impuestas, para comprender el significado real de la igualdad y la incorporación de la perspectiva de género a la protección pública frente a la violencia y la discriminación.

A través de la experiencia educativa, alumnado y profesorado redescubren el papel de la mujer en el progreso social y su trascendental implicación en el desarrollo de la siguiente generación.

La experiencia reconecta al alumnado con la idea de Justicia: La violencia se interioriza a edades tempranas, pero el sentido de la justicia, que nos posiciona contra la violencia y la discriminación, es innato y prevalece.

Palabras clave: plan director; violencia de género; convivencia; protección; justicia social

\section{INTRODUCCIÓN Y OBJETIVOS}

El Plan Director para la Convivencia y Mejora de la Seguridad en los Centros Educativos y sus Entornos (Instrucción 7/2013 de la Secretaría de Estado de Seguridad) tiene como objetivo ayudar a la comunidad educativa en la identificación de conductas que puede dañar a alumnas y alumnos, con el fin de evitar que se conviertan en víctimas o en instigadores de la violencia. Convirtiendo al grupo social en adalid de los valores de responsabilidad, igualdad y respeto, frente a aquellos actores que perturban y amenazan la convivencia en el entorno educativo.

El Plan Director en su conjunto atiende al mandato constitucional del artículo 27 de la Constitución Española de 1978, que establece que "la educación tendrá por objeto el pleno desarrollo de la personalidad humana en el respeto a los principios democráticos de convivencia y a los derechos y libertades fundamentales".

La colaboración interinstitucional en el Plan Director es fundamental para conseguir sus ambiciosos objetivos en las siguientes materias: acoso escolar, consumo y tráfico de estupefacientes, consumo de alcohol, violencia contra la comunidad escolar y los centros (hurtos, robos, vandalismo, etc.), actividad de bandas, acoso, abusos y agresiones sexuales, maltrato en el ámbito familiar, violencia sobre la mujer y discriminación por razón de sexo u orientación sexual, riesgos asociados al uso de internet y las nuevas tecnologías, y comportamientos racistas y xenófobos.

Centrándonos en violencia de género, la práctica refleja que cuanto menor es la edad de la víctima y del agresor, menos recursos intelectuales y vitales tienen para salir de la 
situación de violencia y discriminación. De ahí que la prevención deba realizarse a edades tempranas, antes de que se establezcan las relaciones de pareja.

No obstante, en cualquier experiencia educativa con menores hay que tener presente que la prioridad es su protección, de manera que debe anteponerse la protección individual de las/los alumnas/os a la prevención del colectivo, acotando la información que se facilita en función de la madurez y prestando especial atención a las reacciones del alumnado, ya que puede haber menores que convivan con situaciones de violencia de género en el momento de la actividad.

\section{CONTEXTUALIZACIÓN}

El mandato constitucional no contó con un impulso público que proporcionara a los centros educativos herramientas profesionales para trabajar el respeto a los principios democráticos de convivencia y a los derechos y libertades fundamentales. De modo que, en la práctica, la implantación ha dependido de la implicación personal de cada docente.

Hoy día es habitual encontrar personas dentro y fuera de la comunidad educativa que entienden la igualdad en sentido literal ('hombres y mujeres son iguales'), desconociendo la trascendental diferencia biológica que ha justificado históricamente un estatuto jurídico diferenciado en las relaciones de pareja entre hombres y mujeres. Especialmente, tras la legalización de los métodos anticonceptivos y del aborto la diferencia ha dejado de ser considerada como algo relevante.

De esta manera, existen jóvenes que no entienden justificada la protección integral frente a la violencia de género, cuestionando la intervención pública al considerar que coloca a los hombres en su conjunto en una posición de vulnerabilidad frente a la actuación arbitraria del Estado.

Por ello, resulta imprescindible impulsar en los centros educativos el cumplimiento del mandato constitucional, desarrollado con perspectiva de género por el artículo 4 de la Ley Orgánica 1/2004, de 28 de diciembre, de Medidas de Protección Integral contra la Violencia de Género, que regula los "Principios y valores del sistema educativo", en el que se requiere a la administración educativa a no ser mera espectadora del desarrollo individual de alumnas y alumnos respecto a la igualdad efectiva entre hombres y mujeres, y a la prevención de conflictos y la resolución pacífica de los mismos, animando a una intervención contundente.

En base a estos principios y valores establecidos en el artículo 4 de la Ley Orgánica $1 / 2004$, y de acuerdo a lo dispuesto en el Plan Director, se crea la experiencia educativa que a continuación se describe.

\section{DISEÑO Y DESARROLLO}

La 'Prevención de la Violencia de Género' en el marco del Plan Director en la Comunidad Autónoma de la Región de Murcia se promueve por la Unidad de Coordinación de Violencia sobre la Mujer (depende funcionalmente de la Delegación del Gobierno contra la Violencia de Género). Se desarrolla de manera presencial, mediante 'charlascoloquio' en las que se intercalan exposición y debate.

En el diseño de la experiencia educativa se han volcado las conclusiones obtenidas del seguimiento de los casos de violencia de género, de manera que sean conocidos con una finalidad preventiva. 


\section{Descripción de la actividad}

Consiste en facilitar a alumnado y profesorado información 'técnica' (objetiva), sencilla y fácilmente comprensible, pero expuesta de manera que invite a la participación y al cuestionamiento. A partir del análisis individual compartido, se propicia la reflexión colectiva que nos conecta con los vínculos sociales naturales al ser humano.

El aspecto fundamental es fomentar la participación. Para ello la actividad se desarrolla preferentemente con grupos reducidos y en el aula habitual, de modo que las personas se encuentren en una 'zona segura' para expresar y debatir ideas, y formular preguntas.

\section{Estructura temática}

El contenido de la charla se estructura en una presentación y cuatro temas que se desarrollan en mayor o menor medida en función del ciclo educativo, la madurez del alumnado, el grado de participación, así como de las circunstancias relevantes comunicadas por el propio centro educativo. Los dos primeros temas relativos a 'Las normas' y a 'La Violencia de Género', en los que se intercalan pinceladas sobre los temas 'Relaciones de Pareja' y 'Nuevas Formas de Violencia'.

\section{Presentación}

La presentación, marcadamente institucional, comprende la identificación de la ponente con expresión de su formación, tanto académica como laboral, así como su motivación, que conecta con el conocimiento profesional de los casos de violencia de género, y con la propia experiencia vital. Las reglas para participar son respetar las opiniones ajenas y expresar las propias (primer mecanismo protector).

\section{'Las normas'}

Se abordan dos cuestiones fundamentales:

1. Las normas como mecanismo de protección colectiva frente a la violencia: la inteligencia y el lenguaje posibilitan la alianza social para una convivencia pacífica que garantiza la protección y subsistencia de las personas vulnerables.

2. La consagración del principio de igualdad como valor superior del Estado: Conocer el cambio radical que supuso en la relación de pareja y en el trabajo, y re-conocer la diferencia biológica.

Al hilo de estas dos cuestiones, se destaca la importancia de la protección pública para el desarrollo de las personas, y se aborda la modificación del marco legal de la relación hombre-mujer ocurrida en España entre los años 1975-1981, que definió un nuevo orden basado en el reconocimiento de derechos fundamentales con independencia del sexo 0 estado civil.

El debate se promueve en relación con la idea de la igualdad como valor superior del Estado, y con la diferencia entre la igualdad en sentido literal y en sentido real.

Este tema es el más propiamente técnico-jurídico y, sin embargo, es el que conecta más directamente con la esencia del ser humano, cualquiera que sea la edad del auditorio.

\section{'La Violencia de Género'}

El concepto de 'violencia de género' exige explicar cómo esa transformación legal no llevó aparejada una inmediata transformación de la sociedad, invitándoles a ser parte de ese proceso en el que nos encontramos actualmente.

La realidad social se transmite mediante el visionado de anuncios de la época que reflejan, de manera estereotipada, el papel que hombre y mujer tenían atribuido en la relación de pareja. 
Fijado este contexto se introduce la intervención de los poderes públicos, garantes de la igualdad real, para eliminar los obstáculos que dificultan su plenitud: El acceso de la mujer al trabajo y la violencia de género.

Por lo que se refiere al trabajo, se visibiliza el diferente esfuerzo que la biología impone a hombres y mujeres a la hora de gestar una nueva vida, y que ha marcado el acceso de la mujer al mercado laboral, colocándola en una posición de vulnerabilidad económica frente a su pareja-hombre, especialmente, si quiere ser madre.

En cuanto a la violencia de género, se expone previamente la evolución de la intervención estatal frente a la violencia ejercida en la pareja, desde la consideración como cuestión privada excluida de la intervención pública, pasando por la intervención penal posterior para castigar al agresor, hasta la creación del concepto de 'violencia de género', con el que se introduce la perspectiva de género, de manera que la prioridad del Estado no es tanto castigar al agresor, sino prevenir las agresiones y proteger a las víctimas, mujeres y menores dependientes.

Fijada la justificación y finalidad de la intervención pública, se explica el concepto y los elementos que lo integran, detallando las formas de violencia y desigualdades detectadas en parejas jóvenes, así como los mecanismos de protección, destacando el papel de la educación.

\section{'Relaciones de pareja'}

La configuración de las relaciones de pareja como un nuevo ámbito de actuación, sumamente enriquecedor, que precisa de cierto grado de madurez y de la interiorización de mecanismos protectores o herramientas vitales. En concreto:

1. Los Derechos Fundamentales y las libertades públicas, en su doble vertiente positiva y negativa.

2. Reglas para la resolución pacífica de los conflictos entre personas: Autoestima, empatía y asertividad.

3. Igualdad de derechos y de oportunidades para hombres y mujeres.

Se destacan en la exposición los principales peligros que condicionan la relación de pareja y pueden conducirla hacia la violencia de género (estereotipos, establecimiento de roles y normalización de la violencia), así como las señales de alarma que nos alertan de la situación de violencia de género.

\section{'Nuevas formas de violencia'}

Finalmente, el último tema aborda las nuevas formas de violencia que se han incorporado a la legislación penal, en buena medida por la evolución de medios tecnológicos y la introducción de la perspectiva de género.

El contenido comprende las figuras de acoso, 'sexting' y 'grooming child'.

La exposición se desarrolla con el apoyo de vídeos explicativos, en función de la madurez del alumnado, en los que se identifican las conductas realizadas por el agresor y el temor/sufrimiento de la víctima.

Están detectándose, especialmente, entre adolescentes. Se destaca la vinculación de estas nuevas formas con la 'violencia de género'.

\section{EVALUACIÓN, CONCLUSIONES Y PROPUESTAS DE MEJORA}

La experiencia es sumamente enriquecedora para alumnado y profesorado; les permite entender y verbalizar ideas que sentían que eran así, pero no disponían de argumentos 
'técnicos' para poder expresarlas y defenderlas. La experiencia conecta con los vínculos naturales que nos conforman y nos protegen frente a la violencia y la discriminación.

La actitud inicial del alumnado difiere según la edad y, en cierto modo, según la actitud del profesorado presente en el aula; en Primaria la atención inicial suele ser máxima y la participación alta, especialmente entre los chicos, que manifiestan un claro conocimiento y posicionamiento en contra de la violencia y comprenden las diferencias biológicas entre hombre y mujer; por el contrario, las chicas son más reacias a participar y a expresar su opinión en voz alta.

A partir de Secundaria, se detecta cierta resistencia a participar en la actividad que, en algún caso, ha sido cuestionada por el profesorado. En este ciclo, se advierte que el alumnado empieza a desarrollar ciertas habilidades individuales que le lleva a considerar que ha abandonado la zona de vulnerabilidad y, por tanto, no precisan del apoyo social para su protección.

Conforme avanza la exposición la actitud cambia, y comprenden el sentido de la protección social; la importancia de defender los derechos fundamentales; los límites en el ejercicio de mis derechos; las consecuencias de la violencia en las relaciones personales; la perspectiva de género; ... En definitiva, recuperan el sentido innato de la Justicia Social.

El objetivo de la experiencia educativa es conseguir el análisis 'vital' individual del alumnado, que propicie la reflexión colectiva en el aula, y potencie la participación activa del centro educativo en contra de la violencia y la discriminación, promoviendo la difusión de las iniciativas en la comunidad local.

\section{Conclusiones y propuestas de mejora:}

- Es necesario formar al profesorado y a los equipos directivos en perspectiva de género, de manera que dispongan de herramientas y argumentos para contrarrestar la influencia negativa de la violencia en la vida del alumnado. Es decir, asumir el papel de líderes desde una posición adulta, no desde un plano de igualdad ('colegas').

- Déficit de trabajo previo sobre aspectos esenciales como son los derechos fundamentales, la dignidad de la persona como presupuesto de la sociedad, los valores superiores y límites del Estado.

- Incidir en la dicotomía agresor-sociedad: La actuación del Estado frente al agresor no se produce porque sea hombre, sino porque es una persona violenta que vulnera nuestra convivencia pacífica establecida para la protección de las personas más vulnerables, y esa agresión nos daña como sociedad.

- Enfoque de prevención y protección: Uno de los aspectos más complicados de la experiencia es encontrar el equilibrio entre la prevención y la protección: Que la información que se facilita no provoque el 'derrumbe emocional' de alguna persona que esté viviendo una situación de violencia de género.

- Trabajar la prevención más allá de la actividad presencial, implicando a los centros a un trabajo transversal integrando la perspectiva de género en el temario de las asignaturas.

- Potenciar la implicación de las Asociaciones de Madres y Padres de Alumnos (AMPAS) y de las instituciones locales. 


\section{REFERENCIAS BIBLIOGRÁFICAS}

Constitución Española. BOE 311, de 29/12/1978.

Ley Orgánica 1/2004, de 28 de diciembre, de Medidas de Protección Integral contra la Violencia de Género. BOE 313, de 29/12/2004. España.

Instrucción 7 de 2013 [Secretaría de Estado de Seguridad de España]. Plan Director para la convivencia y mejora de la seguridad en los centros educativos y sus entornos. 12 de julio de 2013. http://www.interior.gob.es/web/servicios-alciudadano/planes-de-prevencion/plan-director-para-la-convivencia-y-mejoraescolar 


\title{
6. EDUCACIÓN PARA LA IGUALDAD DESDE LOS MEDIOS DE COMUNICACIÓN.
}

\author{
6.1. INVESTIGACIONES
}

\author{
6.1.1. Tertulias dialógicas literarias y podcasting \\ María del Pilar Gómez Mondino (UNED-Cantabria, España)
}

\begin{abstract}
Resumen
El proyecto de tertulias dialógicas literarias y podcasting en Merindades nació como un trabajo de investigación, en 2018/2019, en un área rural, en espacios virtuales y reales con el objetivo de vincular la literatura y el podcasting como la mejor manera de crear un espacio de encuentro entre mujeres rurales. Mediante la visita a tertulias literarias de mujeres en otros entornos, organización de tertulias dialógicas en el medio rural, dinamización y monitorización de redes sociales y blogs y la creación de podcasts entorno a las experiencias realizadas.
\end{abstract}

Acercando algunas de las conclusiones que se desarrollan en esta investigación puedo destacar que los espacios virtuales creados están condicionados por las relaciones de convivencia en el entorno rural, coinciden las estructuras mediáticas con las estructuras sociológicas, las posibilidades que tiene el podcasting en entornos educativos y de cohesión social generan oportunidades de escucha y la presencia de la linealidad en las interacciones.

Palabras clave: podcasting; aprendizaje dialógico; redes sociales; educación mediática; mujeres rurales.

\section{INTRODUCCIÓN Y OBJETIVOS}

El trabajo con las tertulias dialógicas literarias está documentado en números estudios, podemos encontrar mucha literatura científica sobre experiencias en esta dinámica participativa pero el primer gran estudio sobre las tertulias dialógicas (Valls, R, Soler, M. \& Flecha, R. (2008) en contextos escolares en Europa lo podemos encontrar en el proyecto INCLUD-ED, el cuál analiza qué estrategias educativas contribuyen a superar las desigualdades y a fomentar la cohesión social y cuáles generan exclusión social, prestando especial atención a grupos vulnerables o desfavorecidos, publicado en 2011 por el Ministerio de Educación.

Puigvert Mallart, L., Melgar, P. (2007) también se interesan en esta temática y realizan una revisión documental de las teorías más relevantes sobre la formación de las mujeres desde una orientación dialógica, para ello exponen los elementos que deben guiar las prácticas educativas en los centros de educación de personas adultas para lograr la inclusión de todas las mujeres. Dentro del apartado de conclusiones destacan que para posibilitar esta transformación y la inclusión se hace necesario que en los centros de educación de personas adultas las prácticas educativas estén basadas en un diálogo igualitario entre todos y todas, profesorado y personas participantes. 
En esta investigación ya se recogen experiencias anteriores en las cuales a través de la participación en centros educativos muchas mujeres sin titulación académica están reivindicando que su voz sea escuchada (Puigvert, 2001).

También se incluyen experiencias y movimientos en la línea del trabajo de investigación que presento, dónde de visibilizan la realidad de mujeres que se organizan en grupos concretos o bien para realizar diferentes actividades, como tertulias literarias. Algunos ejemplos concretos que cita el trabajo de Puigvert Mallart, L., Melgar, P. (2007) son las acciones desarrolladas por la CONFAPEA (Confederación de asociaciones de participantes en educación y cultura democrática a nivel estatal), como el Grupo de Mujeres de FACEPA. Aquí recoge la experiencia de mujeres, miembros de este grupo, creado en 1999, las cuáles se reunían mensualmente para trabajar a través del diálogo y el consenso, sobre los temas que les preocupan, y con el objetivo de luchar desde su cotidianeidad para construir un feminismo inclusor en el cual puedan participar todas las mujeres de forma igualitaria.

En 2008, el profesor Ramón Flecha publica resultados de estudios sobre la mejora en la adquisición de la lectura y la escritura en contextos educativos en los cuáles participan personas diferentes a los que asumían el rol en la escuela industrial mediante tertulias literarias dialógicas, incluyen la participación de otras personas de la comunidad escolar, desde una concepción del aprendizaje tomada de autores como Freire, Habermas o Searle.

En 2017, también se publica el trabajo de García-Yeste, Carme; Gairal, Regina; Ríos, Oriol en el cual se analiza cómo las tertulias literarias dialógicas están permitiendo empoderar a las mujeres inmigrantes y disminuir su situación de vulnerabilidad respondiendo a los retos de diferentes organismos internacionales como la Comisión Europea o las Naciones Unidas en relación a las injusticias de género, en el mismo concluyen que las mujeres que participan en ésta actuación educativa de éxito (las tertulias dialógicas literarias) mejoran el aprendizaje del idioma, dotando de seguridad a las mujeres, fortaleciendo su autoestima y reforzando sus relaciones familiares y de amistad.

En el ámbito español y en relación directa con el feminismo podemos encontrar la propuesta de latribu.info "un cuarto propio compartido" por el cual se desarrolla un proyecto de club de lectura para mujeres en los cuales se trabajan temáticas de género directamente relacionadas con la mujer en diferentes espacios. En la actualidad existen más de 20 centros en toda España, que mediante las redes sociales y el blog del proyecto comparten iniciativa y sus lecturas.

Los objetivos de la investigación que se pretende describir son:

Objetivos generales:

- Generar sinergias entre el grupo de mujeres que participan en las actividades de la asamblea feminista de las Merindades de Burgos mediante tertulias dialógicas literarias como espacios de encuentro físico y en las redes sociales.

- Desarrollar un trabajo de investigación para iniciar nuevos proyectos en Las Merindades, relacionados con la mujer, la comunicación y la cultura.

- Integrar a mujeres en la dinámica de las tertulias dialógicas literarias y el podcasting.

Objetivos específicos:

- Difundir iniciativas literarias desde una perspectiva de empoderamiento de las mujeres en el entorno rural de carácter síncronas y asíncronas, a través de redes sociales, utilizando el podcast como herramienta de encuentro.

- Desarrollar nuevos proyectos transmedia de participación de las mujeres en los entornos rurales, con la literatura como herramienta de encuentro. 
- Crear espacios de encuentro para desarrollar nuevos proyectos con carácter educativo para alumnos y alumnas de educación secundaria, mediante el uso de la literatura, el podcast y las redes sociales.

\section{METODOLOGÍA}

El modelo de investigación se enmarca desde una perspectiva cualitativa, a través del análisis documental, la etnografía virtual, el análisis descriptivo del blog y el uso del podcasting como instrumento de investigación con el fin de generar sinergias que despierten nuevos proyectos en torno a la mujer, la educación y la comunicación en el entorno rural.

Los datos de esta propuesta se recogen mediante las anotaciones de campo, la fotografía y las observaciones participantes en las sesiones, pero también en la red, en los diferentes instrumentos utilizado para compartir la experiencia, a través del uso de las analíticas de los espacios virtuales creados.

La muestra para el análisis de los datos obtenidos en campo está compuesta por el diario de la investigadora, las conclusiones del análisis documental, el blog, redes sociales y archivos sonoros, así como el feed (Aparici, R., \& Silva, M., 2012) recibido en las sesiones presenciales o a través de la red en torno al proyecto.

Esta propuesta se enmarca como un estudio de caso, en el cual se interviene en el entorno con una propuesta bien definida, estructurada como sesión de tertulia dialógica literaria y podcasting. Se invita a participar a personas que vivan en el entorno rural de las Merindades de Burgos, principalmente a mujeres.

\section{RESULTADOS Y DISCUSIÓN}

Este trabajo describe las acciones y sus incidencias en relación con las sesiones de tertulias dialógicas literarias realizadas y los podcasts creados en formato spin-off de éstas.

De esta manera se describe la intervención tanto en el espacio físico como en el espacio virtual en cual se comparte, como es el blog y las redes sociales, así como el tráfico que genera en los entornos virtuales (Elboj, C., Pulido, M. \& Welikala, T., 2013).

Desde la experiencia realizada considero que los espacios virtuales creados están condicionados por los espacios reales de convivencia. Coinciden las estructuras mediáticas con las estructuras sociológicas y la comunicación se ve determinada por los espacios de encuentro. La arquitectura del medio y de las acciones participativas se contaminan de las jerarquías sociales existentes del entorno dónde nacen.

La linealidad de las comunicaciones en el entorno tanto físico como virtual es claro, si bien el modelo de blog facilita otra comunicación, el trabajo con redes sociales también comparte esta característica. Se busca a la persona y no al proyecto, la identidad de las participantes genera más feedback que una identidad común. La mensajería instantánea facilita la interacción más personalizada, en grupos pequeños y face to face.

La arquitectura del medio sea blog o redes sociales, ejercen ciertos condicionantes a la hora de participar, los más importantes son las competencias digitales reales y la accesibilidad, traducida en acceso a internet.

La temática de las sesiones condicionan la participación, el feminismo entendido como movimiento social y político que se inicia formalmente a finales del siglo XVIII y que supone la toma de conciencia de las mujeres como grupo o colectivo humano, de la opresión, dominación, y explotación de que han sido y son objeto por parte del colectivo de varones en el seno del patriarcado a lo largo de la historia condicionado por las 
transformaciones de la sociedad y los cambios vertiginosos de los últimos años, sobre todo en relación a las tecnologías de la comunicación generan grandes espacios de incomprensión y falta de sentimiento compartido de esta perspectiva, naciendo términos similares e incluso contradictorios que no facilita al movimiento los consensos sociales ni entre las propias mujeres.

\section{CONCLUSIONES Y LIMITACIONES}

Considero que la propuesta de tertulias literarias dialógicas y el uso del podcast como herramienta para crear diálogos transmedia pueden ser una propuesta interesante en diferentes ámbitos socioeducativos y de la comunicación. Además de la disponibilidad de herramientas y plataformas para construir proyectos en torno al diálogo, las posibilidades de trasladarlo a otros espacios como la prevención de la violencia, en diferentes espacios tanto virtuales como en contextos naturales de socialización (familia, escuela, comunidad) pueden ofrecer la posibilidad de construir sinergias que trabajen en pro de la igualdad.

Se inician nuevas líneas de trabajo y colaboración tras la participación en este proyecto que generan nuevas semillas de futuras acciones en torno a la formación y el uso del podcasting como elemento metodológico y didáctico en experiencias de aprendizaje no formal de docentes y mujeres que participan en una asociación feminista. En cuanto a las sinergias se realizan actividades de sororidad internacional facilitadas por la web hacialahuelgafeminista.org y los grupos de activismo que se coordinan a través de esta, como una participación en una radio de Ginebra, con el objetivo de compartir la organización de la jornada del 8 de marzo en Las Merindades (junto a las mujeres a algunas mujeres que participaban en las tertulias dialógicas) con las mujeres que organizaban la jornada en Suiza y la colaboración en la organización de las actividades de las jornadas Transfeministas en Ginebra.

Además, resaltar las posibilidades que tiene el podcasting en entornos educativos y de cohesión social, generando oportunidades de escucha. Se inician contactos para crear actividades de formación mediante MOOCs u otros recursos digitales.

Si bien las tertulias literarias en estos momentos no están siendo impartidas fuera de la temporalización del proyecto inicial, las redes sociales y el blog son elementos vivos que pueden continuar moviéndose y generando tráfico, además de propuestas que surgen en torno al proyecto de tertulias literarias dialógicas, algunos de ellos relaciones con propuestas para la mujer y el feminismo y otros desde las posibilidades del podcast como herramienta de investigación.

Se recogen diferentes propuestas de mejora en la temporalización, en el entorno, en la colaboración e incorporación al proyecto de otras asociaciones, así como la ampliación de las temáticas de las tertulias propuestas. Así como nuevos proyectos relacionados con el entorno rural, los cuentos y la oralidad, desde propuestas de creación de audiolibros y creación literaria en el entorno rural, como nuevos grupos de tertulias literarias. Muchas de las actividades han sido interrumpidas por la situación sanitaria derivada del covid-19. Se pretenden reanudar en breve.

La principal barrera que nos podemos encontrar es la falta de alfabetización mediática y desarrollo del pensamiento crítico, básicos para afrontar proyectos de estas características, pero aun así la tertulia dialógica puede ofrecer canales de formación en contextos formales y no formales que minimicen las limitaciones. 


\section{REFERENCIAS BIBLIOGRÁFICAS}

Aparici, R., \& Silva, M. (2012). Pedagogía de la interactividad. Comunicar, 38, 51-58 https://doi.org/10.3916/C38-2012-02-05

Elboj, C., Pulido, M. \& Welikala, T. (2013). Las Tecnologías de la Información y la Comunicación en la salida del aislamiento rural. El caso de Ariño. Scripta Nova, Vol. XVII, núm. 427. http://www.ub.edu/geocrit/sn/sn-427/sn-427-2.htm

García-Yeste, C., Gairal, R., \& Ríos, O. (2017). Empoderamiento e inclusión social de mujeres inmigrantes a través de las tertulias literarias dialógicas. Revista Internacional de Educación para la Justicia Social (RIEJS). DOI: 10.15366/riejs2017.6.2.006

Puigvert Mallart, L., \& Melgar, P. (2007). Aportaciones desde la educación de personas adultas al género y al feminismo.

Soler, Marta, \& Flecha, Ramón. (2010). From Austin's speech acts to communicative acts: Perspectives from Searle, Habermas and CREA. Revista signos, 43(Supl. 2), 363-375. https://dx.doi.org/10.4067/S0718-09342010000400007

Valls, R, Soler, M. \& Flecha, R. (2008). Lectura dialógica: interacciones que mejoran y aceleran la lectura. Revista Iberoamericana de Educación (OEI), (46), 71-87.

http://www.rieoei.org/rie46a04.htm 


\title{
6.2. EXPERIENCIAS
}

\author{
6.2.1. Taller de sensibilización: "Dale la vuelta al Meme" \\ María Isabel Abril Bernal (UNED-Centro asociado Alzira-Valencia, España) \\ María del Pilar Gómez Mondino (UNED-Centro asociado Cantabria, España)
}

\section{Resumen}

Esta experiencia surge a partir de la participación en formación universitaria superior en materia de género. La propuesta nace desde la colaboración y gestión de planes de sensibilización para la igualdad, con jóvenes en el ámbito local y comarcal.

Se pretende desarrollar acciones de sensibilización a través del uso de las nuevas tecnologías, tomando el fenómeno de los "memes" y favoreciendo la co-creación de estos nuevos elementos culturales digitales de participación que se comparten en internet. Teniendo en cuenta las ODS 2030, principalmente el Objetivo 4; 5; 9 y 16.

- Objetivo 4: garantizar una educación inclusiva, equitativa y de calidad y promover oportunidades de aprendizaje durante toda la vida para todos.

- Objetivo 5: lograr la igualdad entre los géneros y empoderar a las mujeres y las niñas.

- Objetivo 9: construir infraestructuras resilientes, promover la industrialización inclusiva y sostenible y fomentar la innovación.

- Objetivo 16: promover sociedades justas, pacíficas e inclusivas.

Para ello desarrollaremos una acción real, con niñas y niños de entre 10 y 16 años, en el entorno local, con la intención de valorar si a partir de estas prácticas se puede fomentar el pensamiento crítico con perspectiva de género, además de empoderar a los más jóvenes en el uso de los espacios virtuales y sus producciones.

Esta acción forma parte de una propuesta de activismo mediado que inicia su andadura en el contexto valenciano, pero tiene intención de continuar expandiéndose en forma de proyecto de investigación, en torno a la sensibilización en materia de igualdad de género y a alfabetización mediática.

Palabras clave: igualdad, adolescentes, memes, educomunicación, co-creación.

\section{INTRODUCCIÓN Y OBJETIVOS}

El uso de los elementos culturales digitales que se distribuyen por internet conocidos como "memes" ya han sido analizados en diferentes contextos. Así podemos destacar los estudios de Martínez Pérez, S. (2017) en educación secundaria obligatoria, en el cual recoge la necesidad de realizar acciones de sensibilización en materia de violencia de género con la población joven, por otro lado, Rodríguez Lozano, A. (2018) sobre el uso de los memes en las redes sociales, donde recoge la importancia que tienen los "memes" para distribuir y expresarse de forma rápida y abierta por las redes sociales.

También es muy interesante recoger la propuesta de la Universidad de Barcelona, a través del trabajo de Prado Soto, M. N. (2015), en cual se trabaja desde el "meme" feminista para desarrollar talleres de sensibilización contra la violencia de género. 
Por todo ello, nos planteamos desarrollar una acción de sensibilización en igualdad a través del uso de los "memes", en la cual los participantes puedan dar la vuelta al mensaje que inicialmente transmitían y eliminar los sesgos de género. Teniendo en cuenta las Objetivos de Desarrollo Sostenible 2030, principalmente el Objetivo 4; 5; 9 y 16.

- Objetivo 4: garantizar una educación inclusiva, equitativa y de calidad y promover oportunidades de aprendizaje durante toda la vida para todos. $Y$ metas como: que de aquí a 2030, se asegure que todos los alumnos adquieran los conocimientos teóricos y prácticos necesarios para promover el desarrollo sostenible, entre otras cosas mediante la educación para el desarrollo sostenible y los estilos de vida sostenibles, los derechos humanos, la igualdad de género, la promoción de una cultura de paz y no violencia, la ciudadanía mundial y la valoración de la diversidad cultural y la contribución de la cultura al desarrollo sostenible.

- Objetivo 5: lograr la igualdad entre los géneros y empoderar a las mujeres y las niñas. $Y$ metas como: poner fin a todas las formas de discriminación contra todas las mujeres y las niñas en todo el mundo, así como; mejorar el uso de la tecnología instrumental, en particular la tecnología de la información y las comunicaciones, para promover el empoderamiento de las mujeres.

- Objetivo 9: construir infraestructuras resilientes, promover la industrialización inclusiva y sostenible y fomentar la innovación. $Y$ metas tales como: aumentar significativamente el acceso a la tecnología de la información y las comunicaciones y esforzarse por proporcionar acceso universal y asequible a Internet en los países menos adelantados de aquí a 2020.

- Objetivo 16: promover sociedades justas, pacíficas e inclusivas. Y metas como: garantizar el acceso público a la información y proteger las libertades fundamentales, de conformidad con las leyes nacionales y los acuerdos internacionales.

\section{CONTEXTUALIZACIÓN}

Dada las diversas actividades que se han desarrollado en contextos marcados por la pandemia sanitaria declarada en marzo de 2020, se hace necesario realizar y diseñar propuestas con planes de contingencia en espacios virtuales. De esta manera surge la idea de plantear una actividad uniendo la educomunicación, el pensamiento crítico y la igualdad.

Según la normativa vigente y el esfuerzo de las administraciones locales en la prevención de la violencia de género y la promoción de la igualdad, se desarrollan planes de igualdad en el ámbito local, lo que abre la posibilidad de trabajar con la población del municipio.

El proyecto se desarrolla en Soneja, un municipio de la Comunidad Valenciana perteneciente a la provincia de Castellón y la comarca del Alto Palancia. Soneja está situada en el camino natural que une Aragón con la Comunidad Valenciana. No es de los pueblos más pequeños de la zona (tiene sobre 1500 habitantes. Por otro lado, los procesos participados está previsto desarrollarlos en el colegio y/o en instalaciones del ayuntamiento.

Esta acción responde a la necesidad de implementar el plan municipal de igualdad del municipio con adolescentes y jóvenes. Es decir, se corresponde con la acción indicada en el plan de acción del plan de igualdad municipal con el objetivo de sensibilizar a la población joven sobre la presencia de sesgos de género en los objetos digitales "memes", tan comunes en las redes sociales de los jóvenes en la actualidad. 
Desde estos intereses planteamos la posibilidad de responder a dos necesidades e intereses de manera complementaria, la promoción de la igualdad y la educación mediática.

\section{DISEÑO Y DESARROLLO}

Se plantea realizar la acción en el contexto de desarrollo de acciones de intervención de un plan de igualdad, en el ámbito local.

Para ello, en las primeras fases, se pretende iniciar el contacto con todos los sectores de la población. En el caso de las personas adolescentes se pretende desarrollar una acción de sensibilización en forma de taller de análisis y deconstrucción de memes desde una perspectiva de género. La primera toma de contacto con los jóvenes tiene la colaboración de la entidad local.

Se desarrolla la elaboración de las diversas actividades con la población, en materia de igualdad, de manera paralela a la concreción de un plan integral e integrado de igualdad.

A través de cuestionarios se valorará la participación en dicha actividad, así como también del registro de observación sistematizada de espacios virtuales y de sesiones presenciales (siempre que la situación sanitaria lo permita).

Posteriormente se ponen en común los datos recopilados y se triangulan con las líneas de los ODS 2030, en especial de los objetivos:

* Objetivo 4: Garantizar una educación inclusiva, equitativa y de calidad y promover oportunidades de aprendizaje durante toda la vida para todos.

* Objetivo 5: Lograr la igualdad entre los géneros y empoderar a todas las mujeres y las niñas.

* Objetivo 9: Construir infraestructuras resilientes, promover la industrialización sostenible y fomentar la innovación.

* Objetivo 16: Promover sociedades justas, pacíficas e inclusivas.

Se pretende desarrollar y describir las interacciones que se realizan durante las sesiones del taller, la satisfacción de los participantes directos (jóvenes) e indirectos (administraciones públicas), intentando favorecer nuevas sinergias tras la participación en los talleres.

\section{EVALUACIÓN, CONCLUSIONES Y PROPUESTAS DE MEJORA}

En la actualidad las acciones se encuentran en fase de planificación e intervención. La idea de compartir los resultados y buscar nuevas sinergias que enriquezcan el proyecto en el contexto del congreso de educación y género es uno de los objetivos principales de esta comunicación.

Esta actividad pretende desarrollar actividades de sensibilización de género, pero a su vez, actuar con y en las redes sociales, para iniciar a los jóvenes en el pensamiento crítico, dando las herramientas de análisis crítico necesarias para evitar la propagación de mensajes de odio y discriminación por razones de género. Estas acciones permiten generalizar el activismo mediático con diferentes movimientos que alimentan la desinformación y los sesgos mediáticos, los cuáles aprovechar la viralidad de las redes sociales para extender mensajes de odio y discriminación.

Por otro lado, consideramos que las propuestas que se describen pueden generar nuevos espacios colaborativos que favorezcan los objetivos de la propuesta general y aporten nuevos antecedentes en relación con los objetivos de desarrollo sostenible (ODS) 2030, en nuestro país. 
Los ODS 2030 deberían marcar las hojas de ruta de las administraciones públicas, incorporando estos objetivos en la organización y gestión de los presupuestos municipales y facilitando acciones de colaboración y participación de las ciudadanas y ciudadanos en su confección.

\section{REFERENCIAS BIBLIOGRÁFICAS}

Asociación Española para la Digitalización (2019). Digitales. El desafío de las vocaciones S TEM. Por qué los jóvenes españoles descartan los estudios de ciencia y tecnología. DigitalES

Giraldo-Gil, E. (2014). Revisando las prácticas educativas: Una mirada posmoderna a la relación género-currículo. Revista Latinoamericana de Ciencias Sociales, Niñez y Juventud, 12(1), pp. 211-223. Doi: 10.11600/1692715x.12112071713

Martínez Pérez, S. (2017). El uso del internet y la violencia de género: las percepciones del estudiantado de educación secundaria obligatoria (eso). Revista Caribeña de Investigación Educativa (RECIE),1(1), 70-82. doi: https://doi.org/10.32541/recie.2017.v1i1.pp70-82

Naciones Unidas (2015) La Agenda 2030 y los Objetivos de Desarrollo Sostenible. Naciones Unidas.

Rodríguez Lozano, A. (2018) Memes de Internet y comunicación en las redes sociales digitales. Una mirada desde el diseño. Universidad Nacional de Colombia Sede Bogotá Facultad de Artes Escuela de Diseño Gráfico https://repositorio.unal.edu.co/handle/unal/69159

Prado Soto, M. N. (2015). Taller sobre Violencias de Género 2.0.Universidad de Barcelona http://diposit.ub.edu/dspace/bitstream/2445/67141/1/Taller\%20VG\%202.0\%20 mostra\%20recerca.pdf

Vázquez-Cano, E. (2020). Medios, Recursos y Tecnología Educativa. UNED. 


\author{
6.2.2. Documental, videoactivismo y perspectiva de género \\ Daniel Aparicio González (Universidad Complutense de Madrid, España); Valeria \\ Levratto (Universidad Rey Juan Carlos, España).
}

\begin{abstract}
Resumen
La experiencia docente consiste en empoderar la imagen de la mujer a través del documental audiovisual, y se aplica a diversas asignaturas del grado de Periodismo de la Facultad de Ciencias de la Información de la Universidad Complutense de Madrid. Se explica el trabajo docente realizado con tres documentales donde la mujer se hace protagonista y en los que se apunta activamente al cambio social: Made in La (Almudena Carracedo, 2007), El precio del perdón. Una mujer en el río (Sharmeen Obaid-Chinoy, 2015), y Para Sama (Waad al-Kateab, Edward Watts, 2019). Los tres son documentales dirigidos por mujeres. En las dinámicas de aula con los estudiantes se consolidan algunas reflexiones: la potencialidad del documental para denunciar y promover cambios sociales, la potencialidad de las mujeres para liderarlo, y algunas cuestiones de fondo: ¿qué diversos sentidos adquieren el término "igualdad de género" según los contextos donde se esgrime?
\end{abstract}

Palabras clave: Medios de comunicación y género, documental audiovisual y mujer, educación mediática, videoactivismo.

\title{
1. INTRODUCCIÓN Y OBJETIVOS
}

$1^{\circ}$. La presente comunicación pretende dar visibilidad a una experiencia educativa llevada a cabo durante más de una década, con estudiantes de Periodismo, en diversas asignaturas que tienen como objetivos la capacitación de los estudiantes en la realización de sus propios trabajos audiovisuales, principalmente reportajes y documentales. Las asignaturas son Medios audiovisuales y educación (tercer curso de grado), Información en televisión (cuarto curso de grado), y Videoperiodismo (asignatura de postgrado), vinculadas al grado de Periodismo de la Facultad de Ciencias de la información de la Universidad Complutense de Madrid.

La experiencia educativa gira en torno a tres documentales donde la mujer se hace protagonista y en los que se apunta activamente al cambio social: Made in LA (Almudena Carracedo, 2007), El precio del perdón. Una mujer en el río (Sharmeen Obaid-Chinoy, 2015), y Para Sama (Waad al-Kateab, Edward Watts, 2019). Los tres son documentales dirigidos por mujeres. A través de un análisis sintomático de su contenido, se intenta demostrar que los documentales, además de mantener una interesante factura técnica, son capaces de promover cambios en su contexto social, en la línea de lo que Zunzunegui (2007: 97) denomina documental transicional, "aquel diseñado con "decidida voluntad de inserción en una realidad que no sólo documentan, sino que buscan modificar".

$2^{\circ}$. Por otro lado, se pretende visibilizar la potencialidad de los documentales dirigidos por mujeres para promover la defensa de los derechos de la mujer, y, a un mismo nivel, dar a conocer estos tres documentales, que son buenas muestras de trabajos que activaron cambios concretos. Por límites en la extensión del trabajo, dejamos fuera el desarrollo de otros documentales con los que hemos trabajado, igualmente productivos: Womanhood (Beryl Magoko, 2018), sobre la mutilación genital femenina; Period. End of Sentence (Rayka Zehtabchi, 2018), sobre la estigmatización de la menstruación; La eminencia (Carlota Coronado y Clara Roca, 2019), sobre la invisibilización de la mujer científica, Ucrania no es un burdel (Kitty Green, 2013), sobre la lucha contra el patriarcado, etc. Aceptando que los medios de comunicación han contribuido históricamente al mantenimiento de roles sexistas (Rivas, 2020), se pretende con este 
tipo de dinámicas y de documentales contribuir a un imaginario colectivo realista y más igualitario.

\section{CONTEXTUALIZACIÓN}

Las asignaturas citadas, que lógicamente responden a resultados de aprendizaje diversos, sí comparten algunos objetivos comunes. Destacamos aquí los que tienen que ver con la experiencia que venimos desarrollando:

- Dar a conocer la historia del documental social y del videoactivismo, a través de sus ejemplos más destacados

- Capacitar a los estudiantes en la creación de guiones de reportajes y documentales, así como en la grabación y edición de estos.

- Analizar el estilo audiovisual de los documentales visionados a través del análisis de su narrativa y de la utilización de los recursos estilísticos.

Siendo estos sus objetivos curriculares básicos, determinamos que la dinámica se concretase en ejemplos de documental que tienen como objetivo la denuncia de la vulneración de los derechos fundamentales, y más en concreto, de los derechos de la mujer. De esta forma, la perspectiva de género se conforma en objetivo transversal en las respectivas asignaturas.

Por otro lado, y aunque las asignaturas ya de por sí tienen lo mediático como aspecto curricular, encuadramos esta experiencia en un marco de educación mediática (Mastermann, 1993; Ferrés 1994; Buckingham, 2003), es decir, enseñar con y a través de los medios con una metodología que fomente la reflexión y el pensamiento crítico, de modo que el uso de los recursos audiovisuales no se reduzca a un mero instrumento operativo, sino que sea un activo motivador en el proceso de enseñanza-aprendizaje.

\section{DISEÑO Y DESARROLLO}

La dinámica docente se desarrolla en las siguientes etapas:

1. Introducción a la actividad

2. Visionado del documental

3. Análisis y reflexión sobre el visionado

4. Realización de trabajos propios por parte del estudiante (ensayos, críticas audiovisuales, etc.)

5. Puesta en común y análisis de los trabajos de los estudiantes

A continuación, se desarrollan con más detalle cada una de estas fases, aunque, para una mejor comprensión de estas, debemos ofrecer antes una pequeña sinopsis de cada uno de los documentales:

Made in LA (70 minutos): cuenta el largo proceso de demandas laborales que un grupo de trabajadoras latinas en EEUU emprende contra una multinacional textil (Forever 21). Desde su condición de mujeres explotadas laboralmente reclaman, entre otras, jornadas laborales ajustadas a la ley, salarios dignos, contratos directos con la empresa, etc. A lo largo de un tortuoso camino de sentencias y de recursos, unos ganados y otros perdidos, queda espacio para ofrecer ciertas claves sobre la realidad migratoria: 
desmembramiento familiar, frustraciones personales, fragilidad individual frente al sistema administrativo y judicial, etc. El documental culmina con la consecución de un acuerdo beneficioso para las trabajadoras.

Más allá de la demanda, las líneas de fuerza del documental abordan sin tapujos otros muchos frentes que afectan a estas mujeres, que pasan de ser víctimas (de machismo, sumisas a sus parejas, solas en la crianza etc.) a defensoras de sus derechos.

Una mujer en el río: El precio del perdón (38 minutos): El documental abre con un texto informativo:

"Más de mil mujeres son asesinadas cada año en Pakistán por parientes masculinos que creen que las víctimas han deshonrado a sus familias. Esta es la historia de una joven paquistaní que sufrió uno de esos crímenes de honor"

Efectivamente, el documental sigue paso a paso el proceso de Saba, una joven de 18 años a la que su padre y tío paterno intentan asesinar, al considerar que ella, al elegir libremente su pareja en detrimento de la recomendada por la familia, había deshonrado al clan familiar. La película documenta el proceso judicial del frustrado intento de asesinato, y el espectador asiste impotente a una resolución que absuelve a los acusados, al ampararse en el perdón, obligadamente forzado, de Saba.

Para Sama (93 minutos): Está narrado en primera persona por su directora, Waad alKateab, una joven estudiante siria que, en mitad del conflicto bélico que atraviesa su país, se queda embarazada. Una vez superada la difícil decisión de vivir un embarazo en una zona asediada por los bombardeos, Waad al.Kateab decide grabar imágenes de todo lo que va ocurriendo, con la idea de contarle en un futuro a su hija Sama lo que significó luchar y sufrir por ella. El documental, montado posteriormente por al Kaetab en colaboración con Edward Watts, ofrece esas imágenes tomadas desde la dura trinchera que constituye el hospital donde esta madre valiente vive sus días, atendiendo heridos y moribundos que llegan a cada momento. Su locución en off recoge el miedo, frustración e impotencia de una mujer que no entiende por qué ella y su futuro bebé deben de sufrir esas circunstancias en un Planeta que las ignora, mirando hacia otro lado. Pero también deja patente una personalidad luchadora, rebelde, capaz de hacer todo lo necesario para que su voz sea escuchada y su fuerza tenida en cuenta.

A continuación, explicamos lo más sobresaliente de la dinámica:

\section{Introducción a la actividad}

Presentamos la ficha técnica del documental a visionar, y planteamos algunas preguntas y consejos previos al visionado que active la reflexión de los estudiantes. Por ejemplo:

\section{- Sobre la narración audiovisual:}

Intenta detectar las claves de guion y de realización: estructura narrativa, lenguaje audiovisual, etc.

Intenta medir las claves de producción: dificultades de grabación, estimación de tiempos de grabación/edición, etc.

- Sobre el contenido: 
¿Te parece que el tema es interesante? ¿Qué valor le das? ¿Cuáles son las secuencias que consideras claves o representativas?

- Sobre la enunciación y con el contexto social

¿Qué te parece el documental audiovisual como motor de cambio?

¿En qué medida crees que este documental ha podido ayudar a resolver los problemas que plantea?

¿Qué te parece que el documental esté narrado por mujeres? ¿Lo consideras un documental activista? ¿Lo consideras feminista? ¿Por qué?

\section{Visionado del documental}

Para nosotros, es un momento crucial. Intentamos crear las condiciones para un visionado activo, haciendo que el alumnado tome anotaciones durante la proyección. Y dedicamos al visionado todo lo que el documental dure. Es decir, no activamos la opción de que lo visionen en clase y traigan sus cuestiones ya trabajadas, a modo de flippedclassroom. Si bien aprovechamos esta técnica para otras dinámicas, en el caso de los visionados preferimos respetar el acto "litúrgico" del visionado conjunto, desde la fe en que la química colectiva que se genera ayuda al análisis posterior. Después de muchos años trabajando con este tipo de actividades, hemos comprobado que cuando los visionados son encargados como tareas para casa, los debates posteriores son más pobres, entre otras razones porque las experiencias de visionado individual no han sido suficientemente serias (en ocasiones, directamente no se producen).

\section{Análisis y reflexión sobre el visionado}

Visto el documental, pasamos a escuchar las impresiones de los estudiantes, mientras vamos añadiendo datos clave de contexto.

Para hacerlo, nos apoyamos en algunas teorías que los alumnos ya conocen, porque han sido previamente trabajadas en clase. Así, hemos estudiado los autores clásicos que han utilizado el documental como motor de cambio: Grierson, Cavalcanti, Resnais, Wiseman, Varda, Herzog, León de Aranoa, etc.). Por su lado, para el análisis audiovisual nos basamos en lo aprendido durante el curso sobre gramática y narración fílmicas. Para valorar la imagen que estos documentales ofrecen de la mujer, les planteamos la importancia que tiene el que sean retratadas como sujetos proactivos para el cambio, y no solo como víctimas pasivas. Nos parece fundamental salir del marco mediático habitual donde la mujer solo es retratada como objeto de la vulneración de sus derechos, en los que casi nunca se habla de ella "más allá de su condición de víctima" (Gámez, Gómez y Maseda, 2016). Para entender el alcance de cambio social que tienen los documentales, trabajamos sobre el análisis sintomático propuesto por Bordwell y Thompson (2002: pp. 49-52): se trata de un nivel de interpretación abstracto y general, que conecta lo que la película cuenta con la tendencia de pensamiento que se supone característica de la sociedad en la que se inscribe. Este análisis sintomático nos permite contextualizar los documentales en sus sociedades y ayudar a que el estudiante valore el alcance que tienen. Por ejemplo:

- Made in LA: El documental se fue grabando en un periodo de cuatro años. Participante en más de 80 festivales por todo el mundo, ganadora de innumerables premios (incluido un premio Emmy en 2008), lo mejor del documental viene en ese proceso de difusión 
local, nacional e internacional, donde cada proyección se convierte en un pequeño foro de progreso y empoderamiento social para otros ciudadanos y ciudadanas, que ven en los esfuerzos de superación y desarrollo de estas mujeres un espejo en el que mirarse. Toda una experiencia de videoactivismo al servicio de los derechos laborales de la ciudadanía. Y aunque el epicentro de esta iniciativa la constituye el documental, su página web oficial ${ }^{31}$ terminó constituyéndose en otro gran foro activo de difusión y motor, en definitiva, de acciones sociales vinculadas a los derechos laborales del colectivo inmigrante.

- Una mujer en el río: El precio del perdón": La película fue galardonada con el Premio Oscar en la categoría mejor corto documental en 2016. Según afirmó la propia directora al recoger el premio "el primer ministro de Pakistán declaró que va a cambiar la ley sobre crímenes de honor después de ver esta película. Ese es el poder del cine".

- Para Sama: Son innumerables los galardones que recibió en 2019 (entre ellos el BAFTA británico y una nominación al Oscar al mejor documental). Tras muchos meses grabando en Siria en modo independiente, la directora consiguió el apoyo de Channel 4 News, y a partir de ahí el documental cogió un sonoro alcance. Como en el caso de Made in LA, crearon una web de apoyo ${ }^{32}$ que ayudara a conseguir los cambios que el documental promovía, como el de proteger a la infancia o pedir que se paren los bombardeos de los hospitales de la resistencia siria por parte del bando del régimen, todas circunstancias contrarias a las resoluciones de Naciones Unidas. Al recoger el premio $\mathrm{Bafta}^{33}$, la directora, ante una audiencia muy célebre y con una gala retransmitida para todo el Plantea, pudo pedir ayuda para los ciudadanos sirios que seguían siendo bombardeados, y alude directamente al pueblo británico a que no permitan que los abusos se sigan produciendo.

Destacar que los documentales elegidos han sido nominados y/o premiados en festivales de prestigio en todo el mundo. Es un modo de asegurarnos de que han tenido cierta repercusión social.

4. Realización de trabajos propios por parte del estudiante (ensayos, críticas audiovisuales, etc.)

Intentamos que la experiencia formativa no concluya sin que los estudiantes aporten producción propia vinculada al documental visto. A veces basta con un ensayo escrito, aunque lo normal es que solicitemos una pequeña pieza audiovisual, con las propias imágenes del documental y/o otras grabadas por ellos ${ }^{34}$.

\section{Puesta en común y análisis de los trabajos de los estudiantes}

Aunque no hay espacio en esta comunicación para compartir los resultados, es aquí, en sus trabajos reflexivos, donde podemos testar el nivel de sensibilización que los estudiantes alcanzan respecto a los temas tratados. Además, al poner en común estas reflexiones, se produce una retroalimentación colectiva muy interesante.

\footnotetext{
${ }^{31}$ http://madeinla.com/toolkit\%3Flang=spanish.html

32 https://www.actionforsama.com/

${ }^{33}$ https://www.youtube.com/watch?v=H3xwJnAvVWk

${ }^{34}$ No se incluyen aquí por falta de espacio y porque, en su mayoría, son piezas audiovisuales
} 
1. La dinámica cumple con los objetivos docentes con los que se plantea: los estudiantes se adentran en el mundo del videoactivismo, y entrenan en las competencias de diseño de guiones y de realización de documentales propios. No profundizamos en esta conclusión por no ser de especial interés a efectos de Género y Comunicación

2. A efectos de representación de la mujer en medios de comunicación, sí que la dinámica destila ciertos puntos de interés, compartidos por alumnos y alumnas, que destacamos aquí:

2.1. La importancia de dedicar documentales de reconocida trayectoria a visibilizar la situación de desigualdad, indefensión o violencia que sufren muchos colectivos de mujeres en el mundo.

2.2. El valor de que los documentales denuncien estas vulneraciones de derechos desde la realidad de personas concretas, lo que permite, según admiten la inmensa mayoría de los estudiantes, un mayor proceso de identificación con las protagonistas, y por tanto, de implicación con sus circunstancias. Los estudiantes reconocen que tiene mucho más impacto en sus actitudes y formas de pensar un documental personalizado en una mujer concreta que sufre un crimen de honor, por ejemplo, que los "fríos" datos que llegan en un informativo diario sobre la globalidad de las mujeres en el mundo que los sufren.

2.3. En línea con lo anterior, los estudiantes valoran la importancia de que en estos documentales se dediquen muchos meses, y hasta años, en documentar a fondo los casos que relatan. Es otra ventaja que ponen en valor respecto a los informativos convencionales, donde los periodistas cuentan con los tiempos muy limitados para retratar estas injusticias con la profundidad merecida.

2.4. Llama la atención que, tras el visionado de los documentales, a los estudiantes les varía el epicentro sobre el que pivotar el concepto de igualdad de género y de feminismo, al contrastar sus realidades con el concepto de globalidad. Así, manifiestan su frustración al comprobar que, a pesar de todo lo que aún hay por alcanzar en Europa, en otras zonas del Planeta la igualdad de género se disputa en terrenos muchos más duros: crímenes de honor, derecho a la maternidad, mutilación genital, explotación sexual, acceso a servicios de higiene básica, explotación laboral severa, etc.

3. A nivel evaluativo, y a pesar de la satisfacción alcanzada, queremos seguir ampliando el repertorio de documentales pro-derechos de la mujer, y, en otro orden de cosas, reforzar la dinámica aquí contada con la inclusión de cuestionarios formales que midan la percepción del estudiante sobre el concepto de igualdad antes y el después de los visionados.

\section{REFERENCIAS BIBLIOGRÁFICAS}

Aparicio, Daniel (2019): “Ochenta ideas sobre el documental audiovisual”; en Arquero, Isabel: "Algo que ver. 8 ensayos sobre la imagen fotográfica y cinematográfica". Editorial Fragua, Madrid, 2020.

Buckingham, David (2003): Media Education: Literacy, Learning, and Contemporary Culture. Londres: Polity Press 
Bordwell, D. y Thompson, K. (2002). El arte cinematográfico: una introducción. Barcelona: Paidós.

Ferrés, J. (1994). Vídeo y educación. Barcelona: Paidós.

Gámez Fuentes, M. J.; Gómez Nicolau, E. y Maseda García, R. (2016): "Celebrities, violencia de género y derechos de las mujeres: ¿hacia una transformación del marco de reconocimiento?", en Revista Latina de Comunicación Social.

Mastermann, L. (1993) La enseñanza de los medios. Madrid: Ediciones La Torre.

Rivas De Roca, R. (2020). Ética periodística para una información con perspectiva de género. Revista Internacional de Investigación en Comunicación.

Zunzunegui, S. (1994): Paisajes de la forma. Ejercicios de análisis de la imagen. Madrid: Cátedra. 


\subsubsection{El observatorio ciudadano de la comunicación en Ecuador: un espacio de encuentro para la igualdad de género y para aprender otras formas de ver \\ Marcela Samudio Granados (Universidad de Málaga, España); Sandra López Astudillo (Fundación GAMMA, Ecuador)}

\section{Resumen}

El Observatorio Ciudadano de la Comunicación (OCC) trabaja desde hace más de 15 años para visibilizar, denunciar y transformar el sexismo en los medios de comunicación de Ecuador. Su estrategia de gestión tiene cuatro elementos: investigación, formación, participación e incidencia. A lo largo de la experiencia, se ha dado una correlación directa entre resultados de investigaciones sobre el sexismo, la formación en equidad y las premiaciones y sanciones a medios de comunicación. Al ser un colectivo de organizaciones con un equipo técnico consolidado y unido a la participación ciudadana, el OCC realiza diferentes acciones que tienen peso e incidencia en la comunidad. Asimismo, la participación le da legitimidad a todo el proceso transformador del OCC hacia la creación de oportunidades de desarrollo y de aportes a la equidad social en el Ecuador.

Palabras clave: Comunicación; Publicidad; Sexismo, Educación; Inclusión.

\section{INTRODUCCIÓN Y OBJETIVOS}

El Observatorio Ciudadano de la Comunicación (OCC) nace en el año 2004 en Ecuador y trabaja para aportar elementos que visibilicen y transformen el sexismo en los medios de comunicación del país. En la actualidad, el Comité Permanente del OCC está constituido por 11 instituciones tanto gubernamentales como de la sociedad civil. Su equipo técnico ha sido la Fundación Grupo de Apoyo al Movimiento de Mujeres del Azuay (GAMMA), que define al OCC como un espacio de encuentro para poner en común las ideas y percepciones sobre lo que se ve en los medios y en las calles. Las publicidades se ponen en el centro del análisis para observar y analizar el mensaje, lo que dicen y lo que no y las oportunidades perdidas para construir una sociedad mejor (López, 2012).

El objetivo de la presentación de esta experiencia es reflexionar más profundamente sobre los elementos impulsores de transformación social en igualdad de género en cada una de las áreas de actuación del OCC.

\section{CONTEXTUALIZACIÓN}

El OCC nace como resultado del I Plan de Igualdad de Oportunidades entre Mujeres y Hombres de Cuenca (Ecuador) de 2001, como parte del eje de prevención de violencia y seguridad; el objetivo fue constituir un foro para el análisis y la difusión de estudios sobre mensajes publicitarios en los medios de comunicación, que luego serían ampliados a otro tipo de ángulos temáticos, con el objetivo de aportar al cambio de imaginarios sociales que sostienen la discriminación, el abuso y la exclusión de las mujeres. Luego de un primer estudio, en 2003, sobre la programación de los medios, y dada la relevancia, la repetición constante y el porcentaje de contenidos publicitarios frente al total del contenido de los medios, se definió que sería prioritario focalizar el análisis en las publicidades. Luego, con los primeros resultados del estudio técnico, se vio la potencialidad de poner en consideración directa de la ciudadanía, a través de un 
evento llamado Salón de la Comunicación (cuya primera edición tuvo lugar en 2005), la votación para definir cuál es el mensaje publicitario más sexista y el menos sexista; en años posteriores se hablaría ya de mensajes inclusivos (Grupo de Apoyo al Movimiento de Mujeres del Azuay, 2006).

En esta presentación de experiencia educativa se pretende identificar qué es lo que ha hecho el OCC, en sus diferentes áreas de actuación, para que los diferentes actores puedan visualizar lo que antes no veían con respecto a la representación del género y al sexismo de los mensajes publicitarios, lo que antes estaba normalizado y ahora es posible cuestionarse.

\section{DISEÑO Y DESARROLLO}

EI OCC tiene una estrategia integral de gestión que incluye cuatro áreas de actuación: investigación, formación, participación e incidencia.

- Para investigar, el OCC toma anualmente y desde su creación una muestra representativa de publicidades de los medios de comunicación a nivel nacional (radio, prensa, televisión y vallas), para evaluarla por medio de cuatro unidades analíticas, cada una con sus diferentes criterios de evaluación plasmados en resultados anuales y diferentes publicaciones.

- La formación se realiza, a partir de los hallazgos de la investigación, en talleres de capacitación a instituciones educativas y universidades, así como en jornadas de profesionalización para periodistas. Adicionalmente, la formación se da durante el evento anual del Salón de la Comunicación.

- El factor que consolida la estrategia integral del OCC es la participación ciudadana en los Salones de la Comunicación. Este es el tronco fundamental que enriquece la construcción colectiva hacia una ciudadanía más activa tanto en la denuncia de mensajes sexistas como en el reconocimiento de la labor de los diseñadores de las publicidades. Los resultados del salón provocan, asimismo, incidencia para el cambio en la producción publicitaria, pero también fortalecen la capacidad de autorregulación con base en la lectura crítica de las publicidades desde una perspectiva de género y derechos humanos.

- La incidencia es la consecuencia de toda la estrategia integral de investigación, formación y participación. Las sinergias de todo este proceso organizado desde un colectivo hacen posible ejercer presión política y social.

Para realizar esta recopilación de experiencia, se revisó todo el material documental con el que contaba el OCC y que incluía:

- Sistematizaciones de 16 Salones de Comunicación y de los talleres anuales de lectura crítica y de capacitación.

- Resultados anuales desde 2005 y sus publicaciones.

- Cartas de felicitación y llamados de atención para las agencias de publicidad.

- Acciones legales que han involucrado al OCC.

\section{EVALUACIÓN, CONCLUSIONES Y PROPUESTAS DE MEJORA}

Entre los principales hallazgos de esta búsqueda de los elementos impulsores están:

\section{Organización e institucionalización del proceso}

- Equipo técnico consolidado: Se ha mantenido un mismo equipo técnico a lo largo de toda la experiencia, no un equipo rotativo. 
- Cooperación interinstitucional: El ser un grupo de instituciones visto como un colectivo que, además, estimula y promueve la participación ciudadana en su conjunto hace muy fuerte la incidencia del OCC.

- Esto puede sugerir que el hecho de que sea un colectivo de organizaciones unido a la participación ciudadana hace que el OCC, en sus diferentes acciones y decisiones, tenga un mayor peso e incidencia.

\section{Investigación}

- No ha habido muchos cambios en relación a los estereotipos de género tal y como son representados en las publicidades ecuatorianas; las investigaciones muestran que las mujeres predominantemente mantienen el rol de amas de casa, mientras que los hombres son diversos y tienen otras actividades. Sin embargo, es importante notar que, desde 2013, los hombres han comenzado a ocupar espacios privados en las publicidades, cosa que llevó a que la categoría analítica "ama de casa" sea cambiada a "cuidados".

- Estos cambios podrían estar relacionados tanto con una aceptación cultural incipiente como también con la acción directa del OCC. Así, si miramos las premiaciones y sanciones del OCC a través de los años, se puede apreciar que cada vez es más evidente que por un lado se sanciona a una publicidad no solo por colocar a la mujer en función de objeto decorativo o de objeto sexual, sino también por colocarla exclusivamente en roles de madre y en actividades ligadas al hogar y a la reproducción; del mismo modo, en esta experiencia se ha premiado a publicidades que presentan a hombres que están en el espacio privado y en actividades de cuidado de sus hijas e hijos, así como en labores domésticas.

\section{Formación}

- En las jornadas de profesionalización con periodistas se han tenido en cuenta temas de coyuntura y de debate político como, por ejemplo, la Ley de Comunicación, la libertad de expresión, la igualdad de género, la sociología mediática y la psicología del comportamiento, entre otros.

- En la formación en escuelas, organizaciones y universidades se trabajan diferentes temáticas para reflexionar sobre los sistemas de subordinación, los roles, los atributos y los espacios para mujeres y hombres, es decir sobre los imaginarios sexistas, tomando siempre en cuenta los resultados de los Salones de la Comunicación. A través de la sanción "Ultraje", por ejemplo, que es la más fuerte y que generalmente se da a publicidades con imágenes fuertes de cosificación de la mujer o de violencia de género, se ha podido contribuir a generar un mayor rechazo ciudadano y, por ende, a una disminución de este tipo de publicidad en el transcurso de la experiencia.

- Es importante mencionar que, a pesar de los esfuerzos de capacitación y formación, los cambios también se dan de acuerdo al desarrollo histórico y las bases ideológicas y culturales ecuatorianas. Por tanto, en el caso de la función de servicio, es difícil romper este estereotipo dada la idiosincrasia y la realidad ecuatoriana, donde el $71 \%$ de los hombres son jefes de hogar y el $66 \%$ de las mujeres trabajan de manera no remunerada en el hogar (Mujeres y hombres del Ecuador en cifras III, INEC 2014).

\section{Participación}

- El hecho de que el premio sea otorgado sobre la base de la votación ciudadana directa, y no por nominación de colectivos de activistas o de personas 
involucradas en la militancia, hace también que tenga un mayor peso y más incidencia y legitimidad, así como que su valorización por parte de las empresas premiadas sea mayor.

- En el análisis de los discursos de los representantes de las empresas ganadoras en los diferentes Salones de la Comunicación se encontró que una de las palabras que más se destaca, luego de "publicidad", "medio" y "producto", es "responsabilidad". Se evidencia, incluso a nivel discursivo, una toma de conciencia frente a la influencia del mensaje en la creación de imaginarios, del ser y deber ser de las personas y aunque esa responsabilidad es asumida, a veces, como resultado de un proceso que se percibe como coercitivo, también aparece la motivación de querer obtener el reconocimiento por el bien hacer.

- El hecho de que se evidencie, a través de los premios del OCC, que la participación ciudadana está valorando las transgresiones de estereotipos sexistas hacia una representación más equitativa hace que las empresas, cada vez más, se animen a deconstruir sus marcas y a crear nuevas estrategias más inclusivas.

\section{Incidencia}

- La gestión del OCC ha permitido eliminar reinados infantiles, solicitar cambios en las estrategias de campañas de las empresas, influenciar decisiones de cofinanciamiento de contrapartes, etc., para así poder, por un lado, sancionar moralmente a quienes producen mensajes discriminatorios, así como, por otro lado, crear estímulos para impulsar una nueva forma de hacer comunicación en el marco de los derechos humanos en general y de los derechos de las mujeres en particular.

- Es importante recalcar que el OCC ha alcanzado conquistas como, por ejemplo, la de que se haya logrado bajar vallas sexistas concretas y se haya llegado a una disminución notable de los mensajes publicitarios sexistas en ese medio de comunicación específico.

\section{Conclusiones y propuestas de mejora}

Luego de analizar el documento del estudio comparativo y de la experiencia del OCC, se encuentra que los principales elementos impulsores para el cambio son los siguientes:

- En relación a la organización, cuentan con un equipo técnico consolidado, con una alta cooperación interinstitucional.

- Existe una correlación directa entre resultados de investigación, procesos de formación y premiaciones y sanciones.

- Hay una alta participación ciudadana que le da la legitimidad a todo el proceso y es un reflejo de la vara cambiante de aceptación o rechazo de estereotipos.

- Los Salones de la Comunicación son espacios directos de expresión de la opinión pública sensibilizada y formada para evaluar el sexismo en las publicidades.

- El equipo técnico del OCC ha tenido mayor incidencia en vallas y prensa de la ciudad en la que se encuentra, Cuenca (Ecuador).

- A raíz de la pandemia se genera la oportunidad de ampliar el impacto; de hecho, en el XVII Salón de la Comunicación se ha llegado a más de 4.000 personas de América Latina.

Entre las propuestas de mejora se apuntan: 
- Poner a disposición las bases de datos de los estudios técnicos de la experiencia, de manera que quienes se interesen en profundizar y analizar las variables desde diferentes cruces y perspectivas cuenten con la información y se enriquezca el debate, lo que permitirá nuevos campos para la incidencia.

- Reforzar los talleres de lectura crítica hacia la necesidad de cambiar roles estereotípicos de la mujer como ama de casa o como persona al servicio de otras. Es necesario visibilizar la relación entre este estereotipo y situaciones como la sobrecarga de trabajo o la falta de acceso a oportunidades laborales para las mujeres.

- Fortalecer el trabajo en nivel directo con medios de comunicación, periodistas y demás personas relacionadas, para incidir en otro tipo de géneros comunicacionales como, por ejemplo, las noticias, en donde también persisten muchos estereotipos (el último informe del GMMP [Monitoreo Mundial de Medios] da cuenta de una presencia de las mujeres en tan solo un $26 \%$ de la representación total de personas en las noticias [Observatorio Veracruzano de Medios, 2021]).

Si bien es prioritario reforzar todas las áreas de actuación del OCC, dado su nivel de incidencia y por ser un proyecto con mucho potencial por su integralidad, se podría poner énfasis en ampliar la participación ciudadana, puesto que es a través de ella que se legitima el proceso y es, además, la presión que surge de ella la que hace que las diferentes personas y organizaciones de la comunicación asuman la responsabilidad de ser conscientes y consecuentes con sus acciones. Por otro lado, es crucial priorizar también el elemento de formación, ya que estos actores pueden sinceramente creer que están obrando responsablemente y, al mismo tiempo, estar normalizando actitudes y comportamientos sexistas porque, sin la formación adecuada, no han aprendido otras formas de ver.

Si a esto añadimos la investigación seria y rigurosa como paso previo a la formación masiva, así como un énfasis aún mayor en comunicar todo lo relacionado con la estrategia integral del OCC, se podrá trabajar para incrementar el impacto del OCC, de tal forma que este pueda continuar contribuyendo al cumplimiento de los objetivos para los que fue creado.

\section{REFERENCIAS BIBLIOGRÁFICAS}

Grupo de Apoyo al Movimiento de Mujeres del Azuay, 2006. Gamma - Ecuador. Cómo nació el OCC, cómo funciona. Recuperado de https://gammaecuador.org/comonacio-el-occ-como-funciona

Instituto Nacional de Estadísticas del Ecuador, 2014. Mujeres y hombres del Ecuador en cifras III. Recuperado de https://www.ecuadorencifras.gob.ec/wpcontent/descargas/Libros/Socioeconomico/Mujeres_Y_Hombres_del_Ecuador_en_Cifr as_III.pdf

López, S. (2012). Gamma - Ecuador. Estudio de Caso: Observatorio Ciudadano de la Comunicación - Cuenca. Recuperado de https://gammaecuador.org/estu- diode-casol

Observatorio Veracruzano de Medios, 2021. Informe Preliminar - Proyecto Mundial De Monitoreo Global De Medios (GMMP) 2020. Recuperado de https://www.uv.mx/blogs/obvio/files/2021/03/INFORME-PRELIMINAR-GMMP2020.pdf 